\title{
The Bishop Tuff, California: New Insights into Magmatic Timescales and Processes from Micro-Analytical Approaches
}

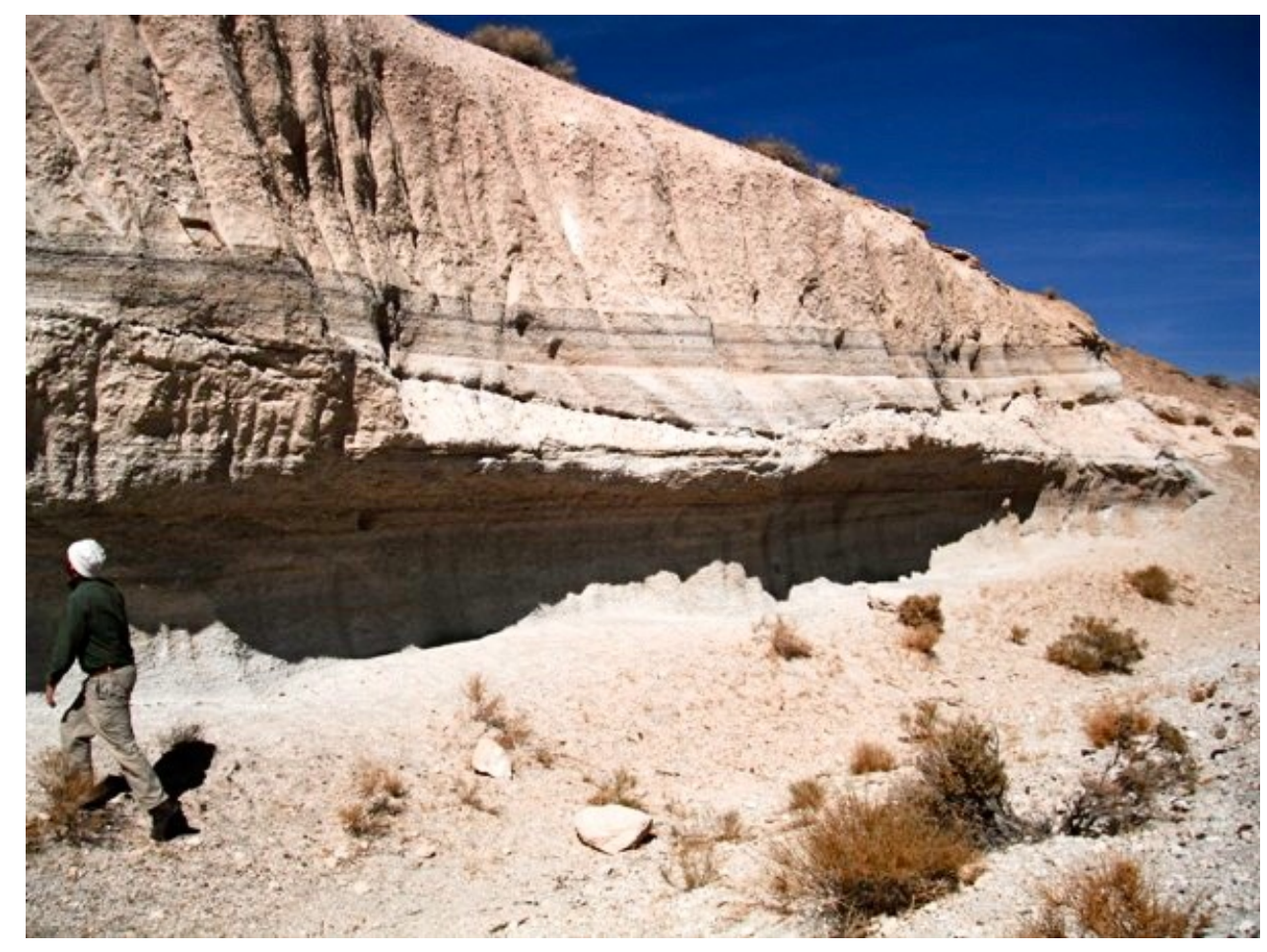

\section{By \\ Katy Jane Chamberlain}

A thesis submitted to the Victoria University of Wellington in fulfilment of the requirements for the degree of Doctor of Philosophy

Victoria University of Wellington 
\#supervolcano 


\section{Abstract}

The Bishop Tuff is the product of one of the largest eruptions on Earth in the last 1 Myr. This thesis studies the Bishop Tuff in order to better understand the nature of the preeruptive magma body, with an emphasis on the processes that occurred within it and the timescales over which they operated. In situ geochemical analyses of crystals and glass from samples collected throughout the Bishop Tuff stratigraphic succession yields insights into the nature of zoning and mixing within this supervolcanic system.

Timescales for zircon growth (inferred to represent longevity of the magma chamber) are investigated using U-Pb dating of zircons. Zircon textural and trace element data obtained by SIMS (SHRIMP-RG) are presented from 15 stratigraphically controlled Bishop Tuff samples and two older Glass Mountain (GM) lava samples. The resulting eruption age estimate derived from the weighted mean of 166 rim ages of $766.6 \pm 3.1 \mathrm{ka}(95 \%$ confidence) is identical within uncertainty to published values from ID-TIMS and ${ }^{40} \mathrm{Ar} /{ }^{39} \mathrm{Ar}$ techniques. An eruption age is also derived for GM dome YA (the youngest GM dome) of $862 \pm 23 \mathrm{ka}$ (95\% confidence), significantly older than the widely used $790 \pm 20 \mathrm{ka} \mathrm{K-Ar}$ age. The oldest zircon cores from late-erupted Bishop material (including those with GM-type textures) have a weighted mean of $838.5 \pm 8.8 \mathrm{ka}$ ( $95 \%$ confidence), implying that the Bishop Tuff system was only active for $\sim 80 \mathrm{kyr}$, and had effectively no temporal overlap with the GM system. Bishop zircon textures are divided into four suites whose proportions change systematically through the eruptive sequence. Trace element variations in Bishop zircons are influenced strongly by sector zoning for many elements, and thus restrict the value of trace element variations in discerning compositional stratification within the magma chamber. In later-erupted units, bright-rim overgrowths are common, and are inferred to have crystallized from the same 'bright-rim' magma as generated the contrasting rims seen in CL or BSE imaging on quartz, feldspar and orthopyroxene. From zircon zonation patterns, this less-evolved, slightly hotter magma invaded deeper parts of the chamber represented in the late-erupted northern units possibly up to $\sim 10 \mathrm{kyr}$ prior to eruption.

In order to better quantify the timescales of interaction with the 'bright-rim' magma, twofeldspar thermometry data are presented on multiple Bishop Tuff samples to constrain temperature variations within the pre-eruptive magma body and yield values for diffusion modelling. Two-feldspar thermometry agrees well with published Fe-Ti-oxide thermometry and reveals a $\sim 80{ }^{\circ} \mathrm{C}$ uniform thermal gradient between the upper and lower 
regions of the magma chamber. Using this thermometry, diffusion of Ti in quartz, $\mathrm{Ba}$ in sanidine, $\mathrm{Sr}$ in sanidine and $\mathrm{Fe}-\mathrm{Mg}$ interdiffusion in orthopyroxene are modelled to estimate timescales for the formation of overgrowth rims on crystals. Ti in quartz and Fe$\mathrm{Mg}$ in orthopyroxene diffusion both yield timescales of $<150$ years for the formation of overgrowth rims, although differing by about an order of magnitude in their timing. However, Ba and Sr diffusion modelling in sanidine yields disparate timescales 1-2 orders of magnitude longer than for Ti in quartz. The main cause for this discrepancy is inferred to be an incorrect assumption for the initial profile shape for $\mathrm{Ba}$ and $\mathrm{Sr}$ diffusion modelling (i.e. the profile is influenced by growth zoning). Using the comparison with Sr, constraints are placed on the initial width of the core-rim interface and the initial conditions can be refined, bringing $\mathrm{Ba}$ and $\mathrm{Sr}$ diffusion timescales into mutual alignment and closer to the values from $\mathrm{Ti}$ in quartz. This modelling shows that piecemeal rejuvenation of lower Bishop Tuff magma chamber occurred over a period of $\sim 500$ years leading up to eruption.

In situ major and trace element analyses of sanidine, plagioclase, biotite, orthopyroxene, clinopyroxene, zircon and matrix glass from the Bishop Tuff and two GM lavas are presented to investigate the pre-eruptive stratification of the Bishop magma chamber and its chemical relationship to the GM system. Analyses of samples from the entire Bishop stratigraphy confirm that the magma chamber was thermally and compositionally zoned prior to growth of crystals and the intrusion of the 'bright-rim' forming magma. Study of rare mixed swirly and dacitic pumice samples shows enrichments in $\mathrm{Ba}$, Sr and $\mathrm{Ti}$ (the elements responsible for bright-rim overgrowths in phenocryst phases) and identifies these pumices as possible representatives of the 'bright-rim' magma. This integrated study of phenocrysts and glass from the Bishop Tuff leads to development of a revised magma chamber model, in which there is a unitary chamber with a stepped or sloping roof. The chamber has an upper, volumetrically dominant $(\sim 2 / 3)$ part showing no evidence for convection and with unzoned crystals, and a lower part which had experienced mixing of crystals and interaction with the 'bright-rim' magma. Intrusion of the 'bright-rim' magma introduced orthopyroxene and dominantly bright zircon crystals, and caused overgrowth of bright rims enriched in $\mathrm{Ti}, \mathrm{Sr}$ and $\mathrm{Ba}$ on sanidine and quartz phenocrysts. Chemical compositions of GM and Bishop Tuff materials show a shared consanguinity, implying common modes of magma generation, yet the generation of GM and Bishop eruptible magma bodies were physically and temporally separate events. 


\section{Acknowledgements}

Firstly the biggest thanks have to go to my PhD 'Dad' Colin Wilson, you have made this past 3 (and a bit) years so special. I have been truly lucky to have you as my supervisor, always fighting my corner. Your passion and dedication to this project has been truly inspiring. I cannot thank you enough. To Dan Morgan at the University of Leeds: thank you for believing in me and giving me the courage to pursue a $\mathrm{PhD}$ - I am especially grateful for all your diffusional expertise. Thanks also to the academic staff at VUW for all your help during lab work, when I was stuck on a tricky question, and for all the fun I have had tutoring for you including Joel Baker, Monica Handler, Marc-Alban Millet, Joe Hiess, John Gamble, Tim Little, Diane Seward, Ian Schipper and Julie Vry, I have learnt so much from you all. Thanks to my examiners- John Gamble, Patrick Browne and John Wolff for their time and effort spent reviewing this thesis. This study was made possible by funding from the Marsden Fund of the Royal Society of New Zealand and a New Zealand International Doctoral Research Scholarship.

To my PhD 'big brothers' George, Simon, Chris \& Aidan - without you I would not have known how to crush a pumice let alone do anything with it afterwards - it's been mean guys, real mean. I am so lucky to have worked and played with so many awesome people at Vic including my patient office mates: Jiao, Jess, Connie, Sophie; the VGP group students: Jenni, Denise, Alexa, Melissa, Sarah; and Ash (my lab and running buddy), Loretta, Matt Ryan, Ben ( $G$ \& H), Rich, Molly, Jess, Shaun, Mona, John, Kim, and everyone else in SGEES, thank you so much for all the great times.

Megan, for always being there (no matter the time difference) and letting me distract you with gossip sessions and trips to get diet coke - you are amazing. Gina, you've kept me exercising during this $\mathrm{PhD}$, and have motivated and listened to me as I rambled about volcano stuff on long runs: I owe you so much. My wonderful flatmates of 148A Raroa, Kate, Stu \& Amy especially, have made my 'down time' so fun, thank you for always being there for a rant or self-saucing pudding! Overloaders and everyone on the various social sports teams I've been privileged enough to be a part of, thanks for providing a release from the $\mathrm{PhD}$. To all the girls at $\mathrm{OBU}$ Women thanks for letting me take my frustrations out with you on the field during the day and at the Cambridge during the night (Georgia) I owe you my sanity (what's left of it).

Finally, thanks to my family, for their unerring support, belief, hugs and (sometimes unintentional) chocolate. Mum, Dad, you are my inspiration, without all our walking holidays (and my tantrums) I wouldn't have discovered my love of geology. Calum, for all the times you listened to me whinge, let me cry on your shoulder, and bought me treats; you are the best little brother in the world. 


\section{Contents}

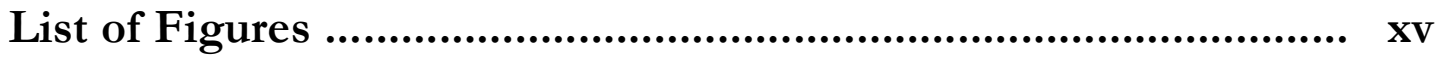

List of Tables ................................................................ xvii

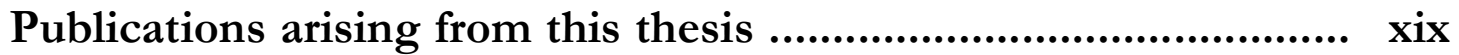

\section{1. - Introduction}

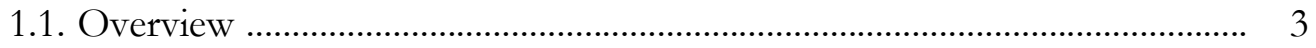

1.2. Thesis objectives and structure ………………………………………......... 4

1.3. Introduction to supervolcanic systems …………............................................ 7

1.3.1. Constituents of a supervolcano ……………............................................. 8

1.3.1.1. The magma chamber...................................................................... 9

1.3.1.2. A ‘mushy' system? ........................................................................ $\quad 10$

1.3.2. What can crystals tell us? ........................................................................... 12

1.3.3. Supervolcanic timescales ................................................................... 15

1.4. Setting of the Bishop Tuff: Long Valley volcanism ..................................... 17

1.4.1. Plate tectonic setting ............................................................................... 17

1.4.1.1. Regional tectonics and lithospheric structure ............................... 17

1.4.1.2. Faulting in the Long Valley area ...................................................... 18

1.4.2. Eruptive history of Long Valley region .................................................... 19

1.4.2.1. Precaldera eruptive history ............................................................. 19

1.4.2.2. The Bishop Tuff eruption ............................................................... 21

1.4.2.3. Postcaldera eruptive history ............................................................... 21

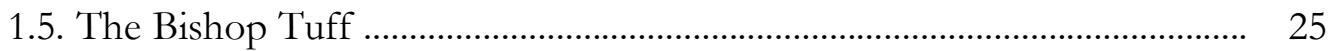

1.5.1. Physical volcanology ................................................................................. 25

1.5.2. Geochemistry of the Bishop Tuff .......................................................... 26

\section{2. - Fieldwork \& analytical techniques}

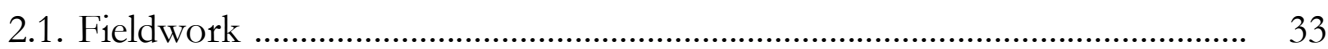

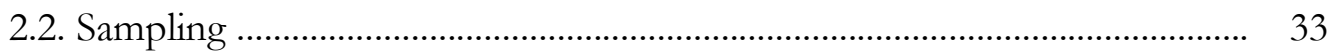

2.2.1. Sampling methods ................................................................................. 33

2.2.2. Key sample locations ............................................................................... 35

2.2.3. Pumice types ........................................................................................... 39

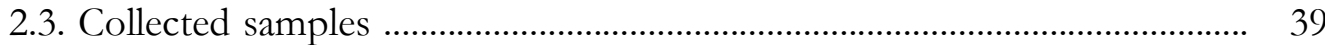

2.4. Sample preparation .................................................................................... 42 
2.4.1. Cleaning and crushing ........................................................................ 42

2.4.2. Sieving and separation .......................................................................... 42

2.5. EPMA major element microanalysis of mineral and glass separates ......... 42

2.5.1. Mounting, polishing and coating samples ............................................ 42

2.5.2. Analysing conditions ............................................................................ 43

2.5.3. Standard analyses ..................................................................................... 44

2.6. LA-ICPMS trace element analysis of mineral and glass separates.............. 46

2.6.1. Analysing conditions ........................................................................... 46

2.6.2. Data processing ................................................................................ 47

2.6.3. Standard analyses ............................................................................ 48

2.7. Ion probe analysis of zircons ........................................................................... 48

2.7.1. Zircon separation .................................................................................. 52

2.7.2. Analysing conditions ............................................................................ 53

\section{3. - New perspectives on the Bishop Tuff from zircon textures,} ages and trace elements

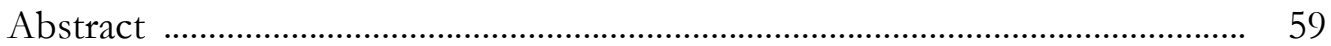

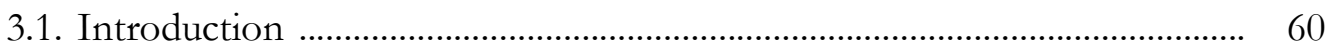

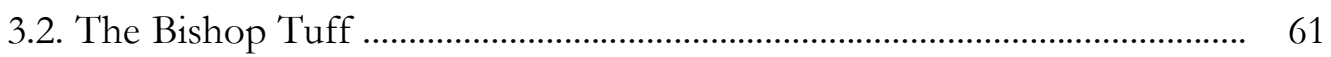

3.2.1. Geological background ......................................................................... 61

3.2.2. Eruption age estimates ..................................................................... 63

3.2.3. Magma accumulation timescales .......................................................... 65

3.2.4. Trace element patterns ........................................................................ 66

3.2.5. Sample suites for this study .................................................................... 67

3.3. Analytical techniques ...................................................................................... 69

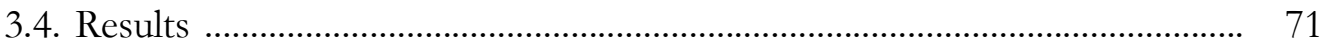

3.4.1. Zircon textures .............................................................................. 71

3.4.1.1. Sector zoning ............................................................................ 74

3.4.1.2. Bright overgrowths .................................................................... $\quad 75$

3.4.1.3. Zircons from swirly pumices ………………………………..... $\quad 75$

3.4.2. U-Pb age determinations ................................................................... 75

3.4.2.1. Bishop Tuff: general age data ....................................................... 76

3.4.2.2. Bishop Tuff: details in age data .................................................. 78

3.4.2.2.1. Sector-zoned ages ............................................................... 78 
3.4.2.2.2. Early- versus late-erupted units .............................................. 78

3.4.2.2.3. Cores versus rims ................................................................... 78

3.4.2.2.4. Bright rimmed grains ............................................................... 83

3.4.2.3. Glass Mountain samples .......................................................... 84

3.4.3. Trace elements in Bishop zircons ......................................................... 84

3.4.3.1. Bishop Tuff: general trace element data ........................................ 85

3.4.3.2. Sector zoning contrasts .................................................................... 87

3.4.3.3. Core/bright-rim contrasts ........................................................... 91

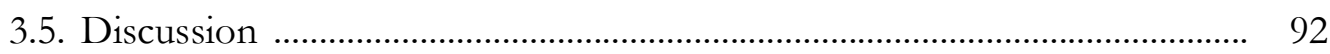

3.5.1. Zircon chronological information in the Bishop Tuff ........................ 92

3.5.1.1. Eruption age of the Bishop Tuff .................................................... 92

3.5.1.2. Temporal relationships between Glass Mountain and the

Bishop Tuff ............................................................................................... 95

3.5.1.3. Assembly of the Bishop magma body .......................................... 96

3.5.2. Zircon compositional information in the Bishop Tuff ........................ 97

3.5.2.1. Implications of sector zoning variations ......................................... 97

3.5.2.2. Ti concentrations and Ti-in-zircon thermometry ........................ 98

3.5.2.3. Contributing components to the zircon population in the

Bishop Tuff magma .............................................................................. 100

3.5.3. Origin of the 'bright-rim' magma ......................................................... 102

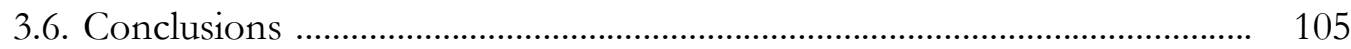

\section{4. - Timescales of magma mixing and mobilisation in the}

\section{Bishop Tuff: perspectives from diffusion chronometry}

Abstract ........................................................................................................ 111

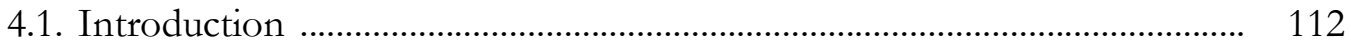

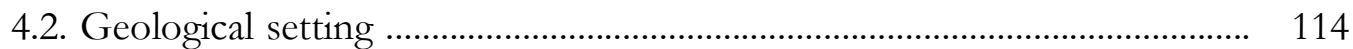

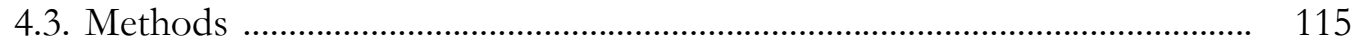

4.3.1. Sample preparation ………………………………………………….. 115

4.3.2. BSE imaging ..................................................................................... 115

4.3.3. CL imaging ………………………………......................................... 116

4.3.4. Quantitative analyses .......................................................................... 116

4.3.5. Modelling parameters ........................................................................... 117

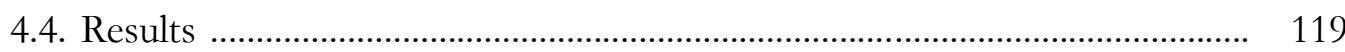


4.4.1. Two-feldspar thermometry

4.4.2. Ti-in-quartz

4.4.3. $\mathrm{Fe}-\mathrm{Mg}$ in orthopyroxene

4.4.4. Ba-in-sanidine

4.4.5. Sr-in-sanidine

4.5. Discussion

4.5.1. Temperature stratification within the Bishop magma body

4.5.2. Uncertainties in diffusion chronometry

4.5.3. Trends in diffusion profiles

4.5.4. Contrasts in modelled timescales between crystal phases

4.5.4.1. Modelling diffusion in sanidine

4.5.4.2. Removing the "growth" effect

4.5.4.3. Comparisons of modelled timescales between crystal phases ....

4.5.5. Pyroxenes and their textural implications

4.5.6. Rejuvenation of the Bishop magma body

\section{5. - New perspectives on the Bishop Tuff magma chamber from}

\section{crystal and glass chemistries}

Abstract

5.1. Introduction

5.2. The Bishop Tuff

5.3. Sampling and analytical techniques

5.4. Results

5.4.1. Sanidine 160

5.4.2. Plagioclase 165

5.4.3. Biotite 167

5.4.4. Orthopyroxene 169

5.4.5. Clinopyroxene 172

5.4.6. Glass host material

5.4.6.1. Glass chemistry from 'normal' early- and intermediate-erupted pumices

5.4.6.2. Glass chemistry from 'normal' late-erupted pumices 
5.4.6.4. Glass from dacite juvenile clasts

5.4.6.5. Glasses from Glass Mountain domes YA and OD

5.5. Discussion

5.5.1. Origin of Bishop crystals

5.5.1.1. Phenocrysts in the Bishop magma

5.5.1.2. 'Bright-rim' crystals 183

5.5.1.3. Pyroxenes and Fe-Ti-oxides - disequilibrium or not? 185

5.5.2. Zonation within the Bishop magma chamber 190

5.5.2.1. Vertical zonation 190

5.5.2.2. Lateral heterogeneity 193

5.5.2.3. Role of mixing and the 'bright-rim' magma 194

5.5.3. Origin of minor ignimbrite packages 196

5.5.4. Compositional relationships between Glass Mountain and the Bishop Tuff 197

5.5.5. The Bishop magma chamber 198

5.5.5.1. One chamber or two? 198

5.5.5.2. Model for the Bishop magma chamber 201

5.6. Conclusions 205

\section{6. - Synthesis and conclusions}

6.1. Key findings

6.1.1. Can eruption age estimates from ID-TIMS be replicated using SIMS techniques in the Bishop Tuff?

6.1.2. What are the timescales for assembly of the Bishop Tuff magma chamber?

6.1.3. The Bishop Tuff and Glass Mountain: two separate entities? 213

6.1.4. Bishop: One magma chamber or two? 214

6.1.5. What was the nature of the Bishop magma body? 214

6.1.6. What was the role of the 'bright-rim' magma in establishing the stratification of the Bishop Tuff?

6.1.7. For how long did the 'bright-rim' magma interact with the Bishop Tuff?

6.1.8. Diffusion modelling in the Bishop Tuff: limitations and implications 
6.2. Addressing the controversies of the Bishop Tuff

6.3. Comparisons and contrasts ......................................................................... 222

6.4. Suggestions for further work …………………….................................... 225

6.4.1. Within the Long Valley region .......................................................... 225

6.4.2. Possibilities for wider study ................................................................... 228

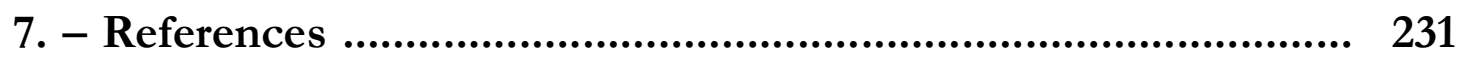

8. - Appendix 1: Enlarged Key Figures.......................................... 253

9. - Appendix 2: Sample Listing................................................... 255

10. - Appendix 3: Conference Abstracts .................................... 267

\section{1. - Electronic Appendices - DVD}

Electronic Appendix 1- Zircon U-Pb age compilation

Electronic Appendix 2- Zircon textures

Electronic Appendix 3- Zircon trace element compositions

Electronic Appendix 4- Samples studied for diffusion

Electronic Appendix 5- Fe-Mg in orthopyroxene diffusion profiles

Electronic Appendix 6- Quartz zoning patterns

Electronic Appendix 7- Ti in quartz diffusion profiles

Electronic Appendix 8- Ba in sanidine diffusion profiles

Electronic Appendix 9- Sr in sanidine diffusion profiles

Electronic Appendix 10- Compiled diffusion results

Electronic Appendix 11- Mineral and glass EPMA

Electronic Appendix 12- Mineral and glass LA-ICPMS 


\section{List of Figures}

Figure 1.1. Location map of young $(<2.6 \mathrm{Myr})$ global supereruptions ........................ 8

Figure 1.2. Schematic model of a magma chamber ............................................................ 9

Figure 1.3. Crystal-specific geochemical techniques utilised in this study ................... 14

Figure 1.4. Techniques which can be used to determine volcanic timescales ............. 16

Figure 1.5. Tectonic setting of Long Valley caldera .................................................... 18

Figure 1.6. Location map of the Bishop Tuff .................................................................. 19

Figure 1.7. Stratigraphy and inferred vent locations for all units of the Bishop Tuff 22

Figure 1.8. Postcaldera vent locations at Long Valley .................................................... 24

Figure 1.9. Contrasting models for the pre-eruptive Bishop Tuff magma chamber... 28

Figure 2.1. Stratigraphic variations in pumice types within the Bishop Tuff ............. 34

Figure 2.2. Stratigraphic log through the basal deposits of the Bishop Tuff at

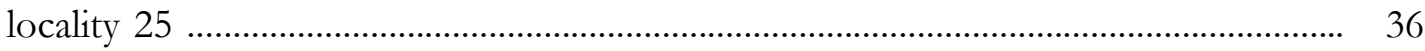

Figure 2.3. Location map of collection sites for pumices from the Bishop

Tuff

Figure 2.4. Photograph of the stratigraphic relationship between NW ignimbrite units

Figure 2.5. 'Normal' pumice textures of the Bishop Tuff 40

Figure 2.6. 'Variant' pumice textures of the Bishop Tuff 41

Figure 2.7. Matrix glass textures from the Bishop Tuff 41

Figure 2.8. Accuracy and precision of LA-ICPMS standards 49

Figure 2.9. Separation technique using lithium polytungstate ..................................... 52

Figure 2.10. Analytical variability of the MAD zircon standard ................................... 54

Figure 3.1. Location map of the Bishop Tuff ................................................................. 61

Figure 3.2. Stratigraphy of the Bishop Tuff, labelled with zircon sample locations.. $\quad 62$

Figure 3.3. Range of zircon textures observed ……………………………................... 72

Figure 3.4. Variation in zircon zoning arranged by stratigraphic unit .......................... 74

Figure 3.5. U concentration versus age for all Bishop zircons analysed ...................... 76

Figure 3.6. Histograms and PDF curves for all Bishop and Glass Mountain U-Pb ages

Figure 3.7. Histograms and PDF curves for different sectors of zircons from the Bishop Tuff

Figure 3.8. Histograms and PDF curves for cores and rims from early and late samples of the Bishop Tuff 
Figure 3.9. Terra-Wasserburg diagram for low-U grains 83

Figure 3.10. Trace element data from all Bishop Tuff zircon grains 86

Figure 3.11. Trace element data from sector-zoned zircons 90

Figure 3.12. Trace element data from cores and bright rims in zircons 92

Figure 3.13. Ti-in-zircon temperatures from different sectors and cores/rims of Bishop zircons 99

Figure 3.14. Histograms and PDF curves for zircons with varying widths of rim overgrowths 104

Figure 4.1. Location map and stratigraphy of the Bishop Tuff 114

Figure 4.2. Temperature stratification of the Bishop Tuff 122

Figure 4.3. Examples of zonation and diffusion profiles from Ti in quartz 124

Figure 4.4. Combined diffusion timescales from Ti in quartz, Fe-Mg in orthopyroxene, $\mathrm{Ba}$ in sanidine and $\mathrm{Sr}$ in sanidine

Figure 4.5. Examples of zonation and diffusion profiles from $\mathrm{Mg} \#$ in orthopyroxene

Figure 4.6. Examples of zonation and diffusion profiles from $\mathrm{Ba}$ and $\mathrm{Sr}$ in sanidine...

Figure 4.7. Correlation between $\mathrm{Ba}$ and $\mathrm{Sr}$ from EPMA and LA-ICPMS measurements

Figure 4.8. Three classes of diffusion profiles observed in all investigated Bishop Tuff crystal phases

Figure 4.9. Cumulative frequency plot of timescales from combined modelling of $\mathrm{Ba}$ and $\mathrm{Sr}$ diffusion in sanidine

Figure 4.10. Cumulative frequency plot of all modelled diffusion timescales

Figure 4.11. Possible origins for variable zoning within orthopyroxene

Figure 5.1. Location map of the Bishop Tuff 156

Figure 5.2. Summary stratigraphy of the Bishop Tuff 157

Figure 5.3. Types of zoning observed in Bishop Tuff crystals 161

Figure 5.4. Sanidine major and trace element variations 162

Figure 5.5. Plagioclase major and trace element variations 168

Figure 5.6. Biotite major element variations 170

Figure 5.7. Pyroxene major and trace element variations 171

Figure 5.8. 'Normal' glass major and trace element variations 175 
Figure 5.9. 'Variant' and Glass Mountain glass major and trace element variations

Figure 5.10. Core-rim variations between eastern and northern samples of the

Bishop Tuff ..... 182

Figure 5.11. Cartoon for crystal sources in the Bishop Tuff magma chamber 184

Figure 5.12. Modelled melt compositions from clinopyroxene, orthopyroxene and high-Ca plagioclase

Figure 5.13. Averages and ranges in glass compositions with stratigraphic unit 192

Figure 5.14. Glass and sanidine chemical variations based on crystallinity of pumice sampled 202

Figure 5.15. A revised magma chamber model for the Bishop Tuff ..... 204

Figure 6.1. Magma chamber model for the Bishop Tuff (repeated from Chapter 5)

\section{List of Tables}

Table 2.1. Pumice types in the Bishop Tuff ................................................................. 35

Table 2.2. EPMA calibrating standards .......................................................................... 43

Table 2.3. EPMA operating conditions ............................................................................. 44

Table 2.4. Precision and accuracy of VG-568 rhyolite glass .......................................... 45

Table 2.5. Precision and accuracy of Orthoclase Or_1A ................................................. 45

Table 2.6. Precision and accuracy of Plagioclase NMNH 115900 ............................... 45

Table 2.7. Precision and accuracy of Hypersthene USNM 746..................................... 45

Table 2.8. Precision and accuracy of Kakanui Augite ................................................... 45

Table 2.9. Precision and accuracy of Biotite PSU 5-110 .................................................. 46

Table 2.10. Precision and accuracy of Orthoclase Or_1A for Sr diffusion ................. 46

Table 2.11. Summary of LA-ICPMS measurement conditions .................................... 47

Table 2.12. Precision and accuracy of ATHO-G analyses ......................................... 50

Table 2.13. Precision and accuracy of BCR-2G analyses .............................................. 51

Table 2.14. Analytical variability of the MAD zircon standard .................................... 55

Table 3.1. Samples from which zircon was separated ................................................... 68

Table 3.2. Summary of textural features in Bishop Tuff and Glass Mountain

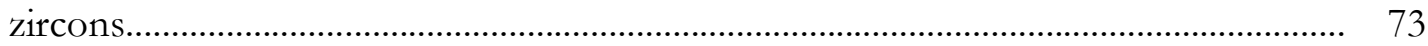

Table 3.3. Average U-Pb ages for individual samples from the Bishop Tuff and Glass Mountain 
Table 3.4. Average and ranges in trace element data from zircons

Table 3.5. Enrichment factors between dark and light sectors in sector-zoned zircons

Table 4.1. Diffusion parameters used in this study

Table 4.2. Major element analyses and two-feldspar thermometry results from sanidine and plagioclase

Table 4.3. Temperatures used for diffusion modelling

Table 4.4. Timescales from combined $\mathrm{Ba}$ and $\mathrm{Sr}$ diffusion modelling in sanidine phenocrysts

Table 5.1. Samples used for phenocryst and glass investigation

Table 5.2. Representative sanidine major and trace element analyses 164

Table 5.3. Representative plagioclase major and trace element analyses 166

Table 5.4. Representative biotite major and trace element analyses 169

Table 5.5. Representative pyroxene major and trace element analyses 172

Table 5.6. Representative glass major and trace element analyses 176

Table 6.1. Comparisons and contrasts between the Bishop Tuff and other large silicic eruptions 


\title{
Publications arising from this thesis
}

\author{
Journal Articles
}

Chamberlain, K.J., Wilson, C.J.N., Wooden, J.L., Charlier, B.L.A. \& Ireland, T.R. (2014). New perspectives on the Bishop Tuff from zircon textures, ages and trace elements. Journal of Petrology 55, 395-426.

Chamberlain, K.J., Morgan, D.J. \& Wilson, C.J.N. (accepted). Timescales of magma mobilisation in the Bishop Tuff: perspectives from diffusion chronometry. Contributions to Mineralogy and Petrology.

Chamberlain, K.J., Wilson, C.J.N., Wallace P. J. \& Millet, M.-A. (in prep). New perspectives on the Bishop Tuff from crystal compositions and textures.

\section{Conference Abstracts}

Chamberlain, K.J., Morgan, D.J. \& Wilson, C.J.N. (2013). Diffusion profiles in sanidine, orthopyroxene and quartz: Timescales for priming of the Bishop Tuff eruption, California. Oral presentation; In: Reid C. M., Wandres, A. (eds.). Abstract Volume, GeoNZ 2013 Conference, Christchurch, New Zealand. Geoscience Society of New Zealand Miscellaneous Publication 136A, 16.

Chamberlain, K.J. \& Wilson, C.J.N. (2013). The Bishop Tuff: Product of one or two magma chambers? Poster presentation; In: Reid C. M., Wandres, A. (eds.). Abstract Volume, GeoNZ 2013 Conference, Christchurch, New Zealand. Geoscience Society of New Zealand Miscellaneous Publication 136A, 16.

Chamberlain, K.J., Morgan, D.J. \& Wilson, C.J.N. (2013). Combined diffusion studies in sanidine, quartz and orthopyroxene: Timescales of magma mixing in the Bishop Tuff. Poster presentation; Goldschmidt Conference Abstracts, Mineralogical Magazine 77 (5), 850.

Chamberlain, K.J., Wilson, C.J.N., Wooden, J. L., Baker, J. A. \& Charlier, B.L.A. (2012). Fifty Shades of Grey: Zircon perspectives on the timing and chemistry of magma interactions reflected in the Bishop Tuff. Poster presentation; Abstract V31C-2794 presented at 2012 Fall Meeting, AGU, San Francisco, Calif., 3-7 Dec.

Chamberlain, K.J., Wilson, C.J.N. \& Baker, J.A. (2011). The Bishop Tuff, California: Deposit of a horizontally variable super-sized magma chamber? Oral presentation; In: Litchfield, N.J., Clark, K. (eds.). Abstract Volume, GeoNZ 2011 Conference, Nelson, New Zealand. Geoscience Society of New Zealand Miscellaneous Publication 130A, 23. 
Chapter 1 


\section{Introduction}

\subsection{Overview}

Supereruptions (defined as those resulting in the eruption of more than $10^{15} \mathrm{~kg}$ or $\sim 450$ $\mathrm{km}^{3}$ of magma: Sparks et al., 2005; Self, 2006; Miller \& Wark, 2008) are the largest explosive volcanic eruptions on Earth. These supereruptions have not only catastrophic immediate impacts due to widespread pyroclastic flows and even wider dispersed ash-fall, they also are postulated to result in significant climate change associated with the dispersal of fine particulates and gases into the atmosphere. Were a supereruption to occur in modern society, it would also have devastating impacts on global trade and communications (Rampino \& Self, 1993; Sparks et al., 2005; Self, 2006; Self \& Blake, 2008). Although little can be done to mitigate the vicious effects of a supereruption, the more that can be understood about the processes which occur within these giant-sized systems, and specifically the timescales over which these processes operate, the better we can hope to monitor these supervolcanoes and their future eruptions, large and small. Another important feature of supervolcanoes (volcanoes which have produced these supereruptions) is that they also have the potential to generate smaller-sized eruptions, as well as those which classify as supereruptions. For example, the Yellowstone Plateau Volcanic Field has produced multiple supereruptions as well as smaller eruptions throughout its $\sim 2.2$ Myr history (Christiansen \& Blank, 1972; Christiansen, 2001). Therefore, understanding whether the next eruption from a supervolcano will indeed be super-eruptive, adds further complexity to understanding these systems.

This thesis presents a study of the Bishop Tuff, the product of one of the largest volcanic eruptions in the last $1 \mathrm{Myr}$ (Wilson \& Hildreth, 1997). The eruption, in eastern California, resulted in the expulsion of more than $600 \mathrm{~km}^{3}$ of magma in a period estimated to have been $\sim 6$ days (Wilson \& Hildreth, 1997). Extensive physical volcanology has been undertaken on the Bishop Tuff deposit which has led to the establishment of a well characterised stratigraphy and identification of a range of pumice textures and chemical compositions (Wilson \& Hildreth, 1997; Hildreth \& Wilson, 2007). This stratigraphy, combined with abundant X-Ray Fluorescence (XRF) data on single-pumice samples (Hildreth \& Wilson, 2007) provides a solid framework on which further work can be based. Use of micro-analytical techniques offers the chance to develop new perspectives on the characteristics of the Bishop Tuff eruption products, and forms the core of this thesis. 


\subsection{Thesis objectives and structure}

Although much previous study has been undertaken on the Bishop Tuff, questions still remain regarding the longevity, nature and stratification of the parental magma system. By applying a variety of micro-analytical techniques in mineral and glass separates from the Bishop Tuff, any lateral and vertical stratification with the pre-eruptive Bishop Tuff magma body can be investigated. More specific questions relating to the Bishop Tuff magma body that are investigated in this thesis include:

* What are the limitations of U-Pb dating of zircons from the Bishop Tuff, and in particular can the data set used to make an eruption age estimate from Isotope Dilution - Thermal Ionisation Mass Spectrometry (ID-TIMS) work (Crowley et al., 2007) be matched using Secondary Ion Mass Spectrometry (SIMS) techniques? Can SIMS U-Pb dating of zircon contribute to assessment of the Bishop Tuff eruption age, and with it the ongoing debate surrounding the ${ }^{40} \mathrm{~K}$ decay constant used in ${ }^{40} \mathrm{Ar} /{ }^{39} \mathrm{Ar}$ dating of volcanic eruptions (e.g. Renne et al., 2010, 2011; Rivera et al., 2011; Phillips \& Matchan, 2013)? This is investigated by collecting SIMS U-Pb ages from the Bishop Tuff.

* What are the timescales for assembly of the erupted Bishop Tuff magma body, given that previous workers have suggested timescales from $\sim 1.3 \mathrm{Myr}$ to $<10 \mathrm{kyr}$ (e.g. Christensen \& Halliday, 1996; Davies \& Halliday, 1998; Simon \& Reid, 2005; Crowley et al., 2007; Reid \& Schmitt, 2012)? How does the Bishop Tuff magma body relate temporally and compositionally to the precursory Glass Mountain system, given the continuity in bulk chemistry and isotopic characteristics (Halliday et al., 1984, 1989; Metz \& Mahood, 1991)? SIMS U-Pb dating of zircons from samples collected throughout the entire Bishop Tuff is used to trace the temporal evolution of the Bishop Tuff magma system, and address the debate over the longevity of the magma body. Glass chemistry and $\mathrm{U}-\mathrm{Pb}$ ages from two representative eruptive units of Glass Mountain are then compared with those of the Bishop Tuff.

* What was the nature of the Bishop Tuff magma chamber and, in particular what stratification existed in it prior to eruption? Addressing this question includes investigating two aspects. First, whether the crystal phases present in the Bishop 
pumices are all in equilibrium and hence are true phenocrysts (e.g. Hildreth, 1977, 1979; Hildreth \& Wilson, 2007; Evans \& Bachmann, 2013; Ghiorso \& Gualda, 2013). Second, establishing the role of the magma(s) represented by the variant pumice types of Hildreth \& Wilson (2007) in establishing the overall stratification. These aspects are explored using major and trace element analyses of glass and crystals to look at the chemical evolution of the Bishop magma body from all stratigraphic levels. Two-feldspar thermometry is used to supplement evidence for or against thermal stratification in the Bishop magma body (cf. Hildreth \& Wilson, 2007 vs. Gualda et al., 2012a). As an extreme viewpoint, the mineralogical and chemical variations in the Bishop Tuff have been used to propose the existence of two separate magma chambers (Gualda et al., 2012a; Gualda \& Ghiorso, 2013a) and I address this hypothesis as part of this thesis.

* The presence of crystal rims with sharply contrasting trace-element composition from their cores and notable for their brighter tones in Back-Scattered Electron (BSE) or cathodo-luminescence (CL) images have been recorded on Bishop quartz, feldspar and zircon (Anderson et al., 2000; Peppard et al., 2001; Simon \& Reid, 2005; Wark et al., 2007). These bright rims are attributed to growth following the late-stage introduction into the magma chamber of another magma of contrasting composition. In this thesis I address the role of this magma ('bright-rim' magma hereafter) in establishing the stratification of the Bishop Tuff and the duration of its interaction with the pre-existing volumetrically dominant Bishop Tuff magma system. The possible origins for this 'bright-rim' magma (especially compared with variant pumice types: Hildreth \& Wilson, 2007) are considered.

* How comparable are the different timescales measured or modelled from the Bishop Tuff and how do they relate to the overall evolution of the magma system? Diffusion chronometries from orthopyroxene, quartz and sanidine and $\mathrm{U}-\mathrm{Pb}$ age dating of texturally defined zones in zircon crystals are used to both compare the diffusive timescales from different phases and to determine the timing of interaction with the 'bright-rim' magma.

* What are the limitations of diffusion modelling in rhyolitic systems? By comparing the timescales modelled from $\mathrm{Ti}$ diffusion in quartz, $\mathrm{Fe}-\mathrm{Mg}$ interdiffusion in 
orthopyroxene, $\mathrm{Ba}$ diffusion in sanidine and $\mathrm{Sr}$ diffusion in sanidine, possible causes of differences in model timescales are addressed.

These specific questions (and others) are addressed within six interrelated chapters with the main aim of better understanding the nature of the pre-eruptive Bishop magma body. Chapter 3 has been published as Chamberlain et al. (2014a), Chapter 4 has been accepted for publication and Chapter 5 (in combination with Chapter 6) is in preparation for publication. Although each of these chapters ( 3 to 5) can be read independently, they successively build upon each other to lead to a coherent thesis. The only changes made to published or submitted chapters has been to impose a uniform style.

Chapter 1 introduces general concepts regarding silicic volcanism, and the way in which these systems can be investigated. The regional and local setting of Long Valley and the Bishop Tuff are then described and the previous work from various lines of study is discussed.

Chapter 2 describes the key stratigraphic and textural variations within the Bishop Tuff, and the key sample sites from which samples were collected. The techniques used to investigate the Bishop Tuff samples are then detailed.

Chapter 3 details the investigation into the Bishop Tuff magma chamber using zircons. Textural study, U-Pb dating and trace element analyses are used to determine the longevity of the Bishop Tuff system, and its relationship to the earlier Glass Mountain system. Textural quantification is also used to understand the role of compositional diversity within the Bishop magma chamber, and the role of the 'bright-rim' magma in establishing this diversity and possible chamber stratification.

Chapter 4 focuses on the relatively short $\left(10^{0}\right.$ to $10^{3}$ years) timescales associated with priming and evacuation of the Bishop Tuff magma body, using two-feldspar thermometry combined with diffusion chronometry from sanidine, quartz and orthopyroxene crystals. The comparability between four different diffusion schemes is investigated, with particular implications for the application of sanidine geospeedometry. The relationships between the three crystal phases and their respective origins within the Bishop magma body is then discussed. 
Chapter 5 documents the compositions of phenocrysts and glass in samples from the Bishop Tuff and two representative precursory Glass Mountain lavas, using in situ techniques. The results are then discussed with respect to addressing the nature and origin of the vertical and lateral stratification within the Bishop magma chamber. Using analytical data and inferred timescales from Chapters 3 and 4, the origin of the 'bright-rim' magma is then addressed, and its roles in stratifying and conditioning for eruption of the Bishop magma chamber are discussed. A new model for the pre-eruptive Bishop magma chamber is then proposed and compared with pre-existing models for one or two chambers (Wallace et al., 1999; Hildreth \& Wilson, 2007; Gualda \& Ghiorso, 2013a).

Chapter 6 synthesises the primary findings of this research, and discusses the wider implications of this work through comparisons with other large silicic volcanic systems. Suggestions for areas of further work are then made to build on the outcomes of this study.

\subsection{Introduction to supervolcanic systems}

A supereruption is defined as the eruption of more than $1 \times 10^{15} \mathrm{~kg}$ of magma, equivalent to $\sim 1000 \mathrm{~km}^{3}$ of ejecta, or $\sim 450 \mathrm{~km}^{3}$ of magma during a single eruptive sequence, which may occupy a period of days, months or years (Sparks et al., 2005; Self, 2006). The fact that supervolcanoes can produce both 'normal'-sized eruptions and supereruptions, and the lack of predictability of the size and repose period of eruptions from these supervolcanoes (e.g. Wilson, 1993) means that reactivation of a supervolcano has potentially catastrophic implications for society, regardless of whether an eruption occurs and of what size. The most recent supereruption on Earth (Oruanui) occurred at Taupo volcano, New Zealand 25,400 years ago with $\sim 530 \mathrm{~km}^{3}$ of magma being erupted (Wilson, 2001; Vandergoes et al., 2013). Yet since the Oruanui event, 28 eruptions of a wide range of volumes and eruptive styles have occurred from Taupo volcano (Wilson, 1993; Sutton et al., 2000). Similarly, in the Long Valley region, the most recent eruption $\sim 650$ years ago was of small volume ( $\sim 0.5 \mathrm{~km}^{3}$ : Miller, 1985; Mastin, 1991), even though it is known that this region has or had the potential to produce devastating supereruptions, as evidenced by the Bishop Tuff. Since the dawn of civilised man no supereruptions have occurred and yet even (apparently) small volume eruptions in the last 2000 years have had significant impacts. For example, the catastrophic Krakatau eruption in 1883 was the product of the evacuation of only 12.5 
$\mathrm{km}^{3}$ of magma and yet was directly responsible for the death of more than 36,000 people (Mandeville et al., 1996; Tanguy et al., 1998).

Globally, 10 supereruptions have occurred in the Quaternary (Fig. 1.1) with the Taupo Volcanic Zone (TVZ) responsible for four of these. Of note is the fact that of the six centres which have produced supereruptions, Long Valley and Cerro Galan have produced a single caldera-forming eruption, whereas the TVZ, Yellowstone, Valles Caldera and Toba have a longer history of super-sized volcanism (Fig. 1.1). The comparisons between these systems, given their different tectonic settings, can yield important insights into the processes that allow such massive accumulations (and subsequent eruptions) of magma to occur.

\subsubsection{Constituents of a supervolcano}

Although supervolcanoes produce exceptionally large eruptions, the components of the magma system are still comparable with 'non-super' eruptions. One feature which distinguishes supereruptions from significantly smaller events is the formation of caldera structure which all supereruptions produce (Sparks et al., 2005) whereas only a minority of 'non-super' eruptions result in caldera formation (and those which produce calderas involve the eruption of least $5 \mathrm{~km}^{3}$ of magma and are explosive). Calderas form from collapse of the crust during the eruption, due to evacuation of the magma chamber, although the dynamics of caldera collapse can vary significantly (Lipman, 1997).

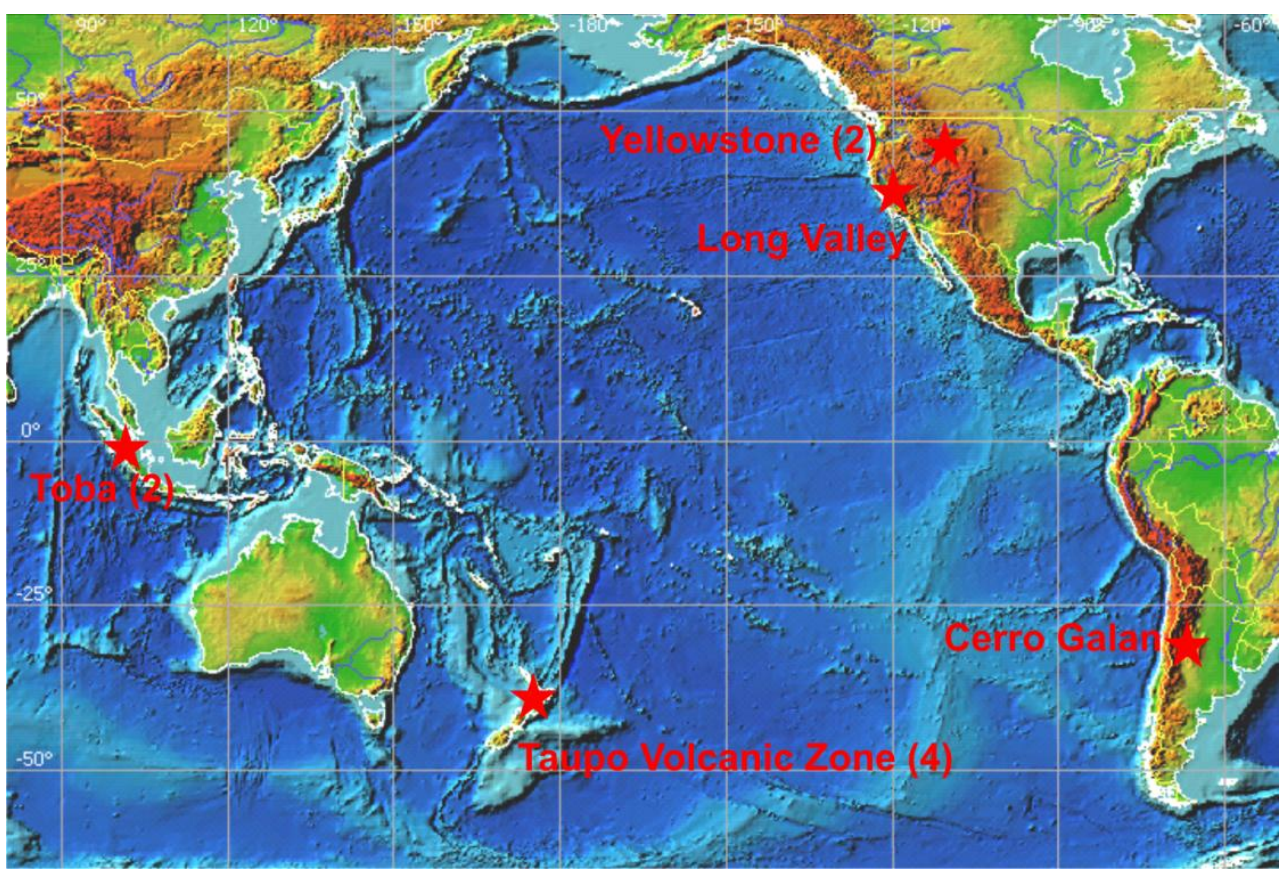

Fig. 1.1. Map of the locations of all supereruptions in the last 2.6 Myr. The number in brackets indicates the number of supereruptions in the $2.6 \mathrm{Myr}$ time period, where more than one has occurred. 


\subsubsection{The magma chamber}

Eruptions of caldera-forming size are universally inferred to be associated with extensive magmatic roots, which contain varying degrees of melt (Smith, 1979; Hildreth, 1981; Marsh, 2000; Bachmann \& Bergantz, 2008a; Quick et al., 2009; Fig. 1.2). When considering these large-scale systems it is important to clearly define what is meant by the term 'magma chamber' as opposed to the whole magmatic system. Although magma alone can be thought of as molten material in the Earth, which is a combination of liquid melt, gases and crystals in varying proportions (Hildreth \& Wilson, 2007), the term magma chamber is more difficult to define. For consistency with other works, the term 'magma chamber' is used here to discuss only the part of the magma system which is comprised dominantly of melt (<50 vol.\% crystals, Bachmann \& Bergantz, 2008a) and does not include the regions of the magma system which contain lesser proportions of magma (Fig. 1.2: Hildreth \& Wilson, 2007).

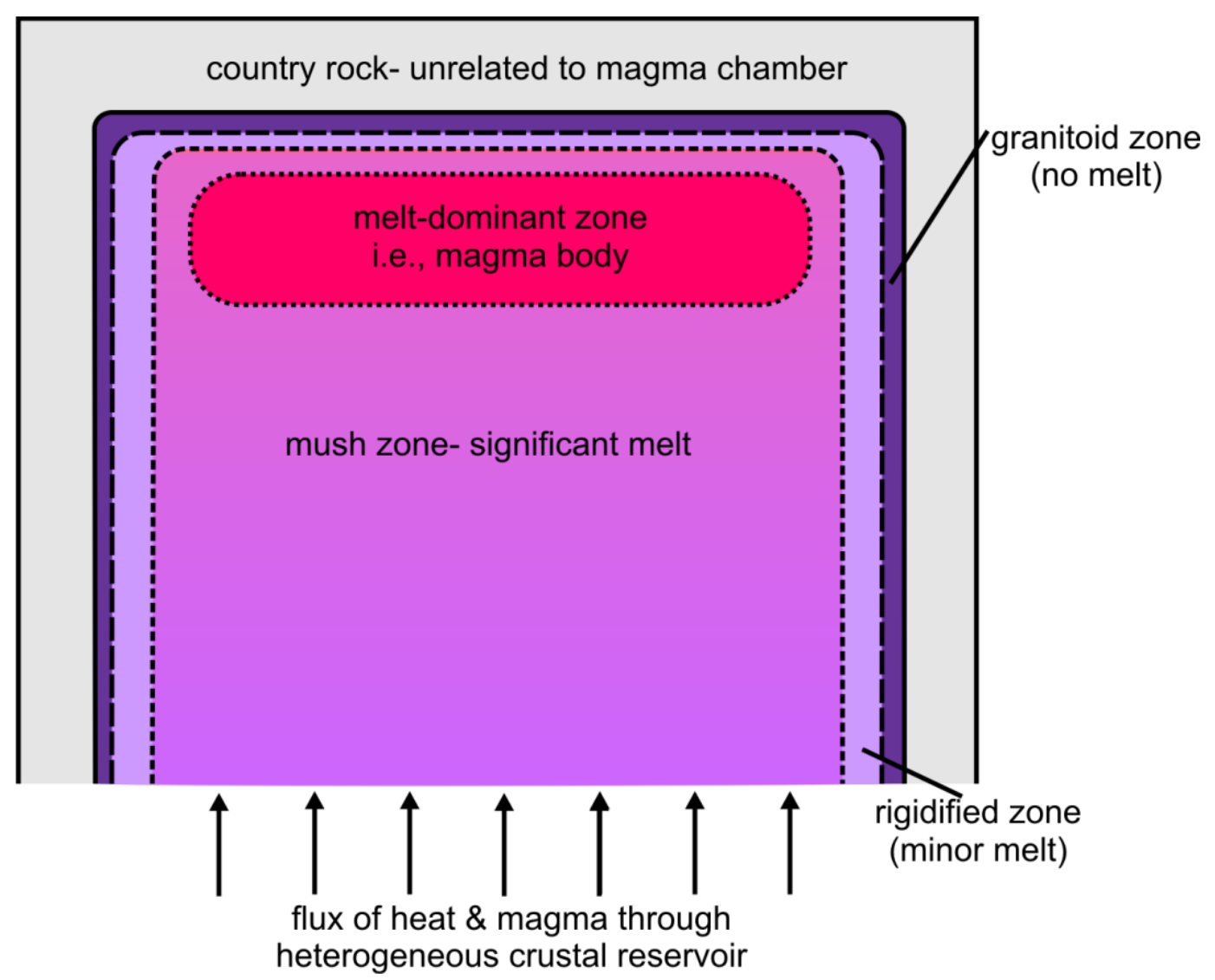

Fig. 1.2. Definition sketch of a magma chamber model (adapted from Hildreth \& Wilson, 2007) showing the relationship between the melt-dominant crystal poor magma chamber, the gradation to the surrounding mush zone with $50-60$ vol. $\%$ crystals, and the rigidified zone and finally the granitoid zone before coming into contact with the surrounding country rock. The rigidified zone, although solid, still maintains a physical and thermal link to the mush and magma chamber. 
When crystals begin to make up $50 \%$ to $60 \%$ of the magma they increasingly become in sustained contact with each other, and models suggest that they begin to form a rigid skeleton where the melt-crystal mixture can no longer flow or erupt: the 'mush' zone (Marsh, 1989; Hildreth, 2004; Hildreth \& Wilson, 2007; Bachmann \& Bergantz, 2008a). At even greater crystal concentrations the magma can be technically considered a solid, with only small portions of melt present (the rigidified zone on Fig. 1.2). Although this region cannot flow, it still maintains a physical and thermal link with the magmatic system, and can potentially contribute portions of melt and crystals to the mushy zone or magma chamber (Hildreth \& Wilson, 2007). Although this model framework is useful to begin to visualise a magmatic plumbing system, it is important to note that the boundaries between identified regions of the magmatic system are often diffuse and not sharp, stepped changes, and that in reality the interactions and 'eruptible-nature' of the mush are much more complex. For example, it is known that some lava domes have been extruded at $>60$ vol.\% crystallinity (e.g. Murphy et al., 2000) and that crystal-crystal interactions can be of significance at much less than $50 \%$ crystallinity.

\subsubsection{A 'mushy' system?}

As mentioned above, the mush region comprises at least $\sim 50-60$ vol. $\%$ crystals and is inferred to be a volumetrically dominant component within the magmatic systems of all supervolcanic and smaller-scale rhyolite systems (Fig 1.2; Bachmann \& Bergantz, 2004, 2008a,b; Hildreth \& Wilson, 2007). In fact it is thought that all high-silica rhyolites $(>70$ wt. $\% \mathrm{SiO}_{2}$ ), regardless of their tectonic setting, are products of underlying crystal mush systems (Hildreth, 2004; Bachmann \& Bergantz, 2004, 2008b). In the case of supereruptions, this implies that a volumetrically huge mush zone must exist within the crust (although the size of the mushy zone only limits the maximum eruptible size: small volumes of rhyolite can be erupted from large mush systems e.g. Taupo volcano, New Zealand: Sutton et al., 2000). In order to generate the large volumes of rhyolite erupted in supereruptions, two-end member scenarios are plausible. 1) Partial melting of crustal material by less-evolved melts, or 2) melt separation from a crystallising mush system, which releases high-silica rhyolite due to extensive fractionation and evolution having already occurred at lower depths (e.g. Michael, 1983; Cameron, 1984; Bachmann \& Bergantz, 2004; Hildreth, 2004). 
In reality, it is unlikely for high-silica rhyolite magma to be a pure product of either partial melting of the crust or extraction from a crystal mush. There are however, many advocates for accumulation of rhyolitic magma from a volumetrically dominant mush system, described futher here. These crystal mush systems are envisaged to still have a high enough permeability to allow for relatively efficient melt-segregation (McKenzie, 1985; Wickham, 1987; Bachmann \& Bergantz, 2004). In fact this extraction of melt is modelled to occur over relatively short timescales, with up to $500 \mathrm{~km}^{3}$ of rhyolite being theoretically extractable over time periods of $10^{3}-10^{6}$ years (Bachmann \& Bergantz, 2004). This thousand year to million year time frame is comparable with the timescales from $\mathrm{U}-\mathrm{Pb}$ and U-Th dating of zircon crystals in systems such as the Bishop Tuff (Long Valley: Reid \& Coath, 2000; Simon \& Reid, 2005; although see Chamberlain et al., 2014a [Chapter 3]) and the Oruanui (TVZ, Charlier et al., 2005; Wilson \& Charlier, 2009). In the case of the Bishop Tuff, the three orders of magnitude variation in proposed accumulation timescales from magma mush models in fact spans all proposed timescales (e.g. 1.3 Myr from Davies \& Halliday, 1998, to <10 kyr from Crowley et al., 2007), making this model extremely appealing for all authors arguing for long or short residence timescales of the Bishop Tuff. One aim of this thesis is thus to more precisely constrain the magma accumulation and residence time prior to the Bishop Tuff eruption, by collecting new $\mathrm{U}-\mathrm{Pb}$ age data from zircons.

The eventual state of these crystal mush systems is thought to be represented by granitic intrusions, where the mush finally freezes once thermal and physical inputs into the system cease (Lipman, 1984, 2007; Bachmann et al., 2007; Hildreth \& Wilson, 2007). However in some cases it is thought that, whilst still melt-bearing and capable of remobilisation, this crystal mush body can (at least partially) erupt to form the so-called monotonous intermediate (or rhyolitic) ignimbrites, such as the Fish Canyon Tuff (Lipman et al., 1997; Bachmann et al., 2002; Charlier et al., 2007; Bachmann \& Bergantz, 2008b) the Whakamaru ignimbrite (Brown et al., 1998; Matthews et al., 2012 a,b), or the Ongatiti ignimbrite (Cooper, 2014). These large-scale, crystal-rich ignimbrites have been proposed to represent one of three hypothetical categories of ignimbrites, the compositions of which reflect the end-product of different degrees of interaction with the underlying crystal mush (Bachmann \& Bergantz, 2008c). However, it is likely that a continuum exists between all three end-members for any single eruption. The first, abruptly-zoned (in composition and crystallinity, \pm temperature) ignimbrites, typified by the Valley of Ten Thousand Smokes 
(1912 CE: Hildreth, 1983), Aniakchak ( 3.4 ka: Dreher et al., 2005) or Crater Lake (6.8 ka: Bacon \& Druitt, 1988; Druitt \& Bacon, 1989) ignimbrites is the product of eruption of the extracted rhyolite melt and a compositionally different underlying magma type (suggested to either represent the mush, or allow mobilisation of the mush: Bachmann \& Bergantz, 2008c). The second, already discussed, 'monotonous' homogenous ignimbrites, represents a system with a highly dominant convection scheme which allows rapid homogenisation of extracted melt with the 'un-locked' crystal mush prior to eruption (Bachmann \& Bergantz, 2008c). Finally, there are eruptions with deposits that have linear gradients in composition, temperature and crystallinity, of which the Bishop Tuff is a type-example (Hildreth \& Wilson, 2007). These gradients are inferred to be generated by piecemeal extraction of melt from the underlying crystal mush, which then also differentiates in situ. Convective mixing between different zones of the magma chamber is slow enough to not eradicate the zonation, but rapid enough to 'smear' the transition from different units (Bachmann \& Bergantz, 2008c). In reality, many high-silica rhyolites do not fall into one of these neatly defined categories. The Oruanui eruption products show compositional diversity coupled with no gradients, but are crystal poor (Wilson et al., 2006) and does not fit into one of the three categories outlined by Bachmann \& Bergantz (2008c). Also, both the Oruanui and the Bishop Tuff preserve evidence for shortly pre-eruptive mixing with a less-evolved magma, and yet the Oruanui was comprehensively mixed, and the Bishop Tuff magma chamber preserved its stratification (Hildreth, 1977, 1979; Wilson et al., 2006; Wark et al., 2007; Allan et al., 2012). Therefore the processes which control melt-extraction from an underlying feeder zone must be inherently more complex than apparent in these three endmember models. By examining eruptions of high-silica rhyolites independently of this model, a better understanding of the role of an underlying mush zone, and the processes resulting in stratification (or lack thereof) of the magma chamber can be garnered.

\subsubsection{What can crystals tell us?}

This study focuses on in situ analyses of crystal phases (in combination with matrix glasses) to yield insights into the Bishop Tuff magma chamber, in a similar approach to those studies carried out by workers on New Zealand supereruptive systems (Allan et al., 2012; 2013; Cooper et al., 2012; Allan, 2013; Cooper, 2014: for full methods detail see Chapter 2). Crystals sampled from a volcanic product can have 3 typical end-member origins. 1) Phenocrystic crystals, which means that the crystals are 'native' to the melt-dominant magma body, and grew in the melt in which they were erupted (i.e. in the relatively crystal 
poor magma chamber). 2) Crystals can be sourced from disaggregation from surrounding country rocks of diverse origins, and therefore are xenocrystic in origin. 3) Another possibility is that crystals are 'antecrystic' which considers that the crystals are sourced from within the overall magmatic system, but grew under contrasting conditions in the underlying, longer-lived crystal-mush zone, rather than in the melt-dominant magma chamber itself (Bacon \& Lowenstern, 2005; Charlier et al., 2005).

By measuring changes in chemical composition in different zones within crystals, changes in intensive variables of the magma system can be traced. The preservation of zones allows for the relative timings for changes of these intensive variables to be deduced (in relation to other events). This time constraint yields insights not possible from measurements of matrix glass, which will by nature record only an average of the chemical changes experienced in the magma system, due to mixing and partial or complete homogenisation of the melt. Depending on the stability relations of various crystal phases, crystals can (in principle) be used to record variations in intensive variables in the melt-dominant magma chamber from the beginning of assembly of the magma system, right through to processes occurring immediately prior to eruption (e.g. Streck, 2008), although no crystal phase is guaranteed to have been stable for the entire magma chamber lifetime. Changes in pressure $(\mathrm{P})$, temperature $(\mathrm{T})$ and composition $(\mathrm{X})$ can be inferred when crystals change composition from core to rim, sometimes identified in BSE or CL images (Fig. 1.3; e.g. Marshall, 1988; Corfu et al., 2003; Reed, 2005). By analysing in situ the major and trace element compositional changes from cores to rims of crystals, the effects of different growth regimes (and/or different magma compositions) can be inferred. These inferences of changing growth regimes are strengthened when similar changes are observed across a majority or all of the crystals of a particular phase, or are common to multiple crystal phases. Other information can be obtained (see section 1.3.3, below), such as crystallisation ages from radiometric isotopic measurements (especially $\mathrm{U}-\mathrm{Pb}$ in zircon, Fig. 1.3) and timescales for magmatic mixing events can be estimated from diffusion modelling across compositional boundaries within crystals (Fig 1.3; e.g. Morgan \& Blake, 2006; Costa et al., 2008).

Compositions of crystals, especially those demonstrably growing together in close proximity, can be used to estimate the intensive variables $\left(\mathrm{T}, \mathrm{P}, f \mathrm{O}_{2}\right)$ of the magmas from which they grew based on mineral-mineral or mineral-melt equilibria (for a comprehensive 


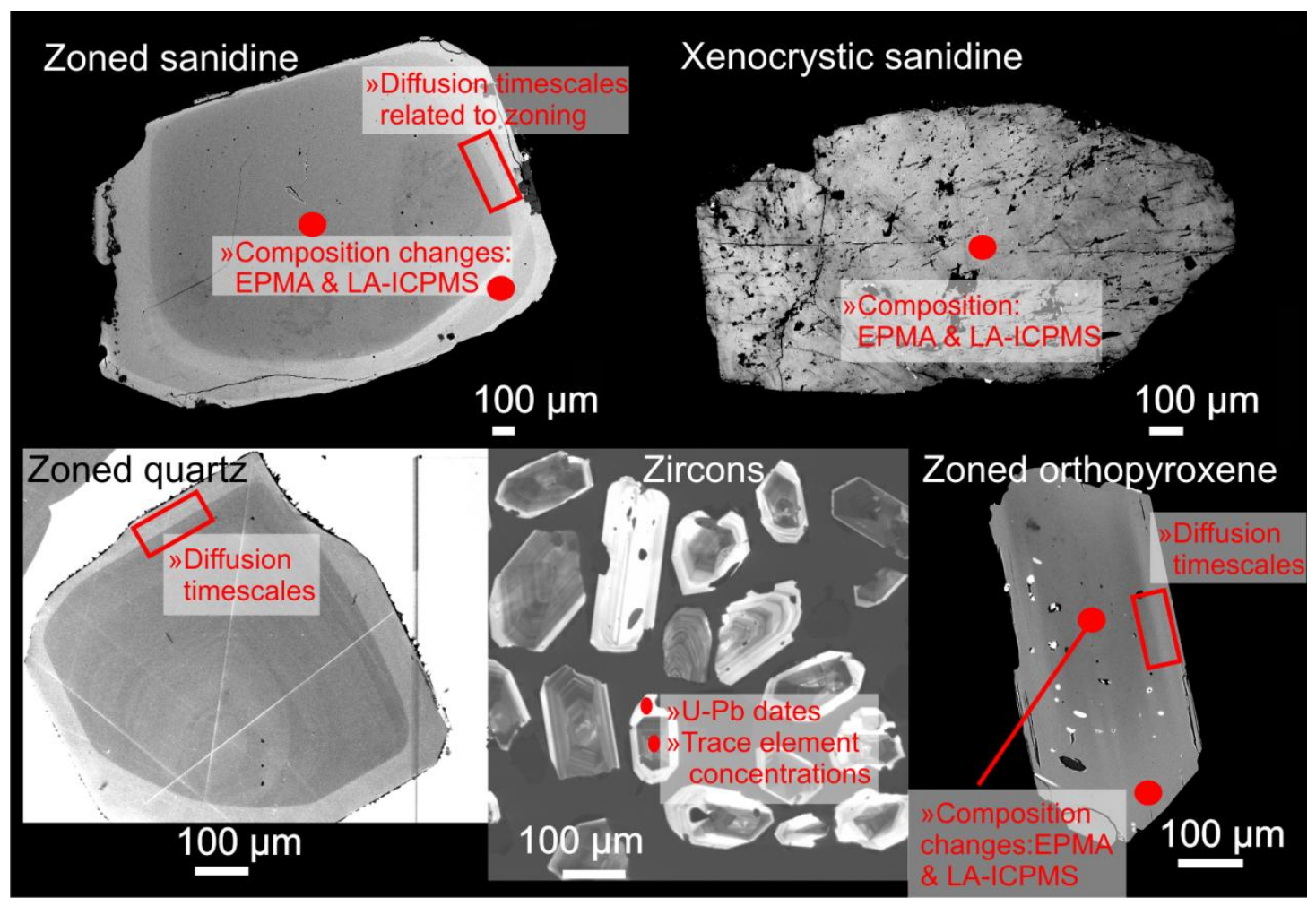

Fig. 1.3. Representative crystals in the Bishop Tuff showing the range of zoning textures visible, and the analyses that can be carried out on respective phases to yield information about the pre-eruptive magma system. Panels show backscattered electron (BSE) images for sanidine and orthopyroxene, and cathodoluminescence (CL) images for zircon and quartz.

review see Putirka, 2008). One of the most common techniques to establish magmatic temperatures is to use touching pairs of Fe-Ti-oxides, the compositions of which record the magmatic temperature (Ghiorso \& Sack, 1991; Ghiorso \& Evans, 2008). It has been shown that these Fe-Ti-oxide pairs re-equilibrate relatively rapidly at magmatic temperatures and therefore the modelled temperatures are only representative of temperatures in the days to weeks prior to eruption (Freer \& Hauptman, 1978; Hammond \& Taylor, 1982; Venezky \& Rutherford, 1999), and do not reflect the longer-term history of the magma. However, many other thermobarometers are available. In this study in particular (Chamberlain et al., 2014b [Chapter 4]), I utilise the two-feldspar thermometry of Elkins \& Grove (1990) on sanidine inclusions within plagioclase (or vice versa), to establish magmatic temperatures. Given the slow nature of $\mathrm{Ca}, \mathrm{Na}$ and $\mathrm{K}$ diffusion within plagioclase and sanidine (Cherniak, 2010), these temperatures are less likely to be affected by late thermal perturbations within the magma chamber, unlike Fe-Ti-oxides. Therefore by comparing and contrasting Fe-Ti-oxides and two-feldspar thermometry, temporal 
constraints on temperature variation can be constrained and compared to the other longterm thermometry carried out on the Bishop Tuff by Bindeman \& Valley (2002).

\subsubsection{Supervolcanic timescales}

Key questions in the study of supervolcanic systems include what processes operate within the magma chamber? Why do some large-scale magmatic systems produce both smallvolume eruptions and supereruptions (e.g. Taupo volcano: Sutton et al., 2000; Wilson et al., 2006; Wilson \& Charlier, 2009)? And, over what timescales do these processes operate? These questions have driven many investigations into supervolcanic systems, with similar processes (magma body assembly, crystal fractionation, magma mixing) occurring within the melt-dominant magma bodies, but on much larger scales. The timescales over which these processes operate can be investigated using a range of techniques which can probe processes operating from only a few seconds to minutes prior to eruption, up to hundreds of millions of years (Fig. 1.4; Turner \& Costa, 2007).

At one extreme, given its highly robust nature, zircon is often used to date the initiation, evolution and eruptive ages of rhyolitic magma systems (e.g. Reid et al., 1997; Reid \& Coath, 2000; Charlier et al., 2005; Crowley et al., 2007) and can be used to quantify the proportions of crystals (at least in the zircon population) which are xenocrysts, antecrysts or phenocrysts (Bacon \& Lowenstern, 2005; Charlier et al., 2005; Wilson \& Charlier, 2009). Zircon is a very useful mineral as radiometric dating can be carried out in situ (due to the highly compatible nature of $\mathrm{U}$, and highly incompatible nature of $\mathrm{Pb}$ in zircon) on single zones within single grains, to not only investigate the age of crystallisation but also the length of time over which this crystallisation has occurred (Bindeman et al., 2001; Simon \& Reid, 2005; Bindeman et al., 2006). Depending on the age of volcanic rocks either U-Pb dating, or U-series dating (for eruption ages of $<150-200 \mathrm{ka}$ ) can be carried out to investigate the magma system (e.g. Reid et al., 1997; Reid \& Coath, 2000; Charlier et al., 2005). Other radiogenic techniques can be utilised to investigate the timescales for magmatic residence (e.g. Rb-Sr: Christensen \& Halliday, 1996), magma transport from the mantle (although this is less relevant for silicic systems) and even magmatic degassing (using short-lived U-series isotopes, Hawkesworth et al., 2004; Turner \& Costa, 2007). Presented in this thesis work are zircon $\mathrm{U}-\mathrm{Pb}$ age data from the Bishop Tuff, which allow investigation into the longevity of the magma system, and its relationship to forerunner Glass Mountain activity (Metz \& Mahood, 1985, 1991). 


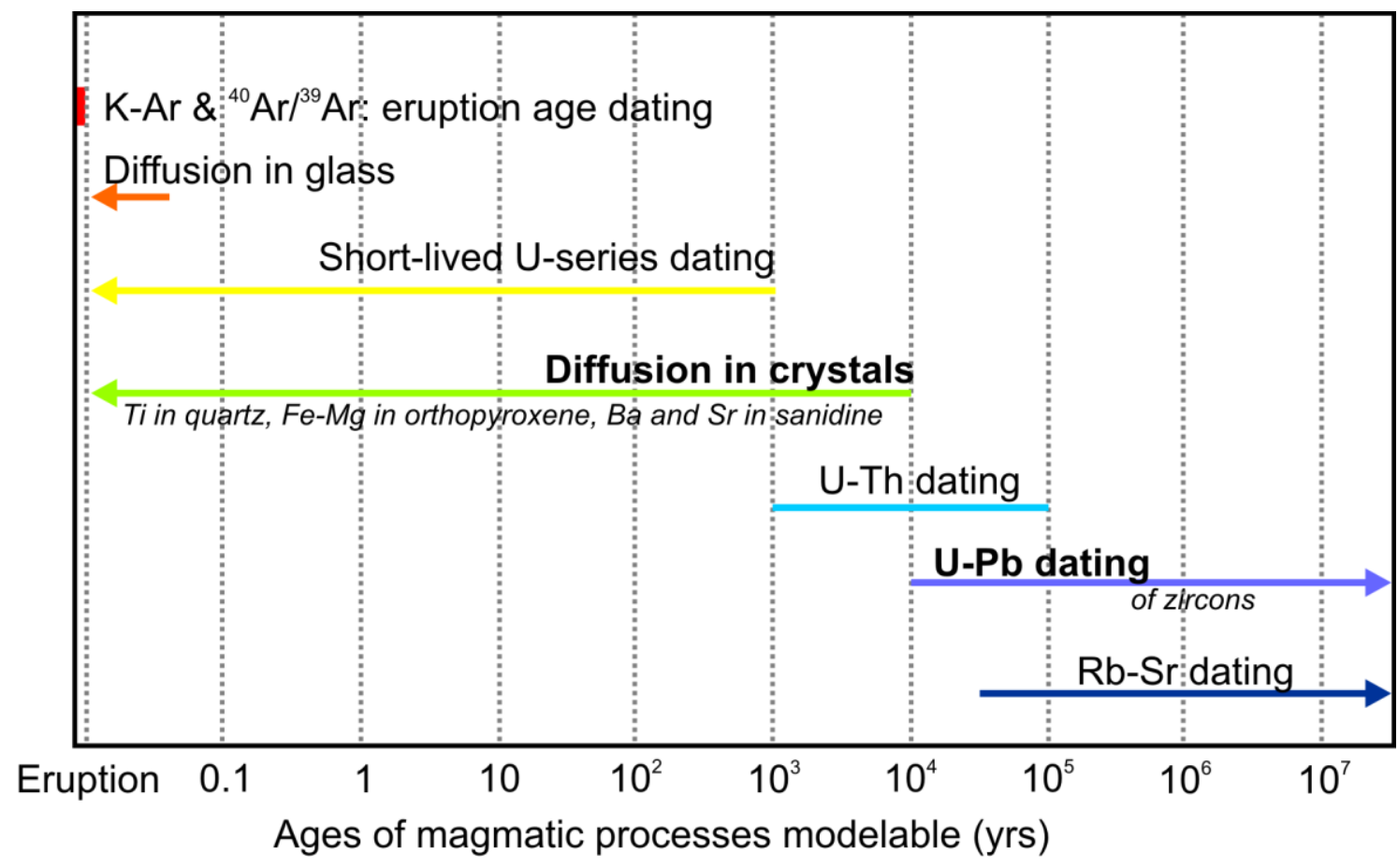

Fig. 1.4. The range in timescales resolvable using different radiogenic and diffusion techniques, adapted from Turner \& Costa (2007). Techniques used in this study are highlighted in bold, with the specific mineral phases investigated using these methods detailed in italics.

Another key tool used to investigate the timescales of magmatic processes is elemental diffusion modelling between zones of high- and low-concentrations of various elements within crystals (e.g. Costa et al., 2008). Unlike radiogenic dating, the timescales generated from diffusion chronometry are relative timescales, rather than absolute ages. In volcanic systems these timescales are relative to eruption age, as crystals pass through their closure temperatures for diffusion at this time. Diffusion chronometry (or geospeedometry to which it is sometimes referred) has been used in volcanoes in a variety of tectonic settings and compositions, from small-scale, less-evolved magma eruptions at Etna (e.g. Kahl et al., 2013) or Mt. St. Helens (Saunders et al., 2012a) to rhyolitic supereruptions (e.g. Wark et al., 2007; Gualda et al., 2012b; Matthews et al., 2012a; Allan et al., 2013). Diffusion chronometry can span a huge range of timescales (Fig. 1.4) as different diffusion regimes, with different diffusive speeds, can be chosen to investigate different processes. In practise though, applications are limited by what crystals are found in the eruptive products, and their petrogenetic relationships with the magma system, and other mineral phases within it. It is important to remember that all timescales from diffusion chronometry are all model timescales, and therefore are only as reliable as the assumptions and coefficients used. Timescales can therefore be greatly influenced by what value for the diffusion coefficient is 
used (e.g. Cherniak, 1996; Morse \& Allaz, 2013). In this study I utilise Ti diffusion in quartz, Ba and Sr diffusion in sanidine and $\mathrm{Fe}-\mathrm{Mg}$ interdiffusion in orthopyroxene crystals, to investigate the timescales of pre-eruptive mixing in the Bishop Tuff magma chamber. Each of these techniques has been applied separately to studies of various supereruptions (Ti-in-quartz: Wark et al., 2007; Matthews et al., 2012a; Fe-Mg in orthopyroxene: Saunders et al., 2012a; Allan et al., 2013: Ba in sanidine: Morgan \& Blake, 2006), but are for the first time in this thesis compared and contrasted in studies of crystals from the same single pumices.

\subsection{Setting of the Bishop Tuff: Long Valley volcanism}

\subsubsection{Plate tectonic setting}

Long Valley caldera, formed during the Bishop Tuff eruption, is located just east of the Sierra Nevada in California, USA (Fig. 1.5: Bailey et al., 1976; Hill et al., 1985). The caldera is situated in the North American plate, at the junction of the Sierra Nevada microplate (which is intermediate in the contact zone between the North American and Pacific plates: Fig. 1.5) with the extensional Basin and Range province (Fig. 1.5; Wakabayashi \& Sawyer, 2001). At the latitude of Long Valley the North American and Pacific plates currently move past each other in a transform motion (although the Long Valley caldera region is also in extension, see section 1.4.1.2; Fig. 1.5). The Pacific plate is currently moving northwest past the North American plate at $\sim 38-40 \mathrm{~mm} / \mathrm{yr}$, with $\sim 24-30 \mathrm{~mm} / \mathrm{yr}$ of dextral motion being accommodated in the Sierra Nevada microplate (Fig. 1.5; Wakabayashi \& Sawyer, 2001).

\subsubsection{Regional tectonics and lithospheric structure}

Long Valley caldera lies within the Walker Lane Belt-East Californian Shear Zone (WLECSZ) which currently accommodates $20-25 \%$ of the far-field plate motion between the Pacific and North American plates (Bennett et al., 1999; Dixon et al., 2000; Oldow et al., 2001). The WL-ECSZ is one of the most active fault belts in the USA (Rundle \& Hill, 1988) with faults evident all around the Long Valley caldera, which often align with volcanic edifices (Rundle \& Hill, 1988; Hildreth, 2004). The Long Valley/Owens Valley region (Fig. 1.5) is in a transtensional stress state, with many active faults present in the region (Bailey, 1989; Wakabayashi \& Sawyer, 2001; Taylor \& Dewey, 2009). The crust in the WL-ECSZ has been previously thickened during the convergence of the Pacific and North American plates $(80-45 \mathrm{Ma})$, but is now being thinned by the extension associated 
with the Basin and Range province (Wakabayashi \& Sawyer, 2001; Unruh et al., 2003). In the Long Valley area the crust is generally $35-40 \mathrm{~km}$ thick, as interpreted from receiver function analysis (Zandt et al., 2004). Local country rocks to the Long Valley area consist of Mesozoic metavolcanics, felsic intrusive rocks of the Sierra Nevada batholith, and Palaeozoic metasediments (Hildreth \& Mahood, 1986; Bailey, 1989).

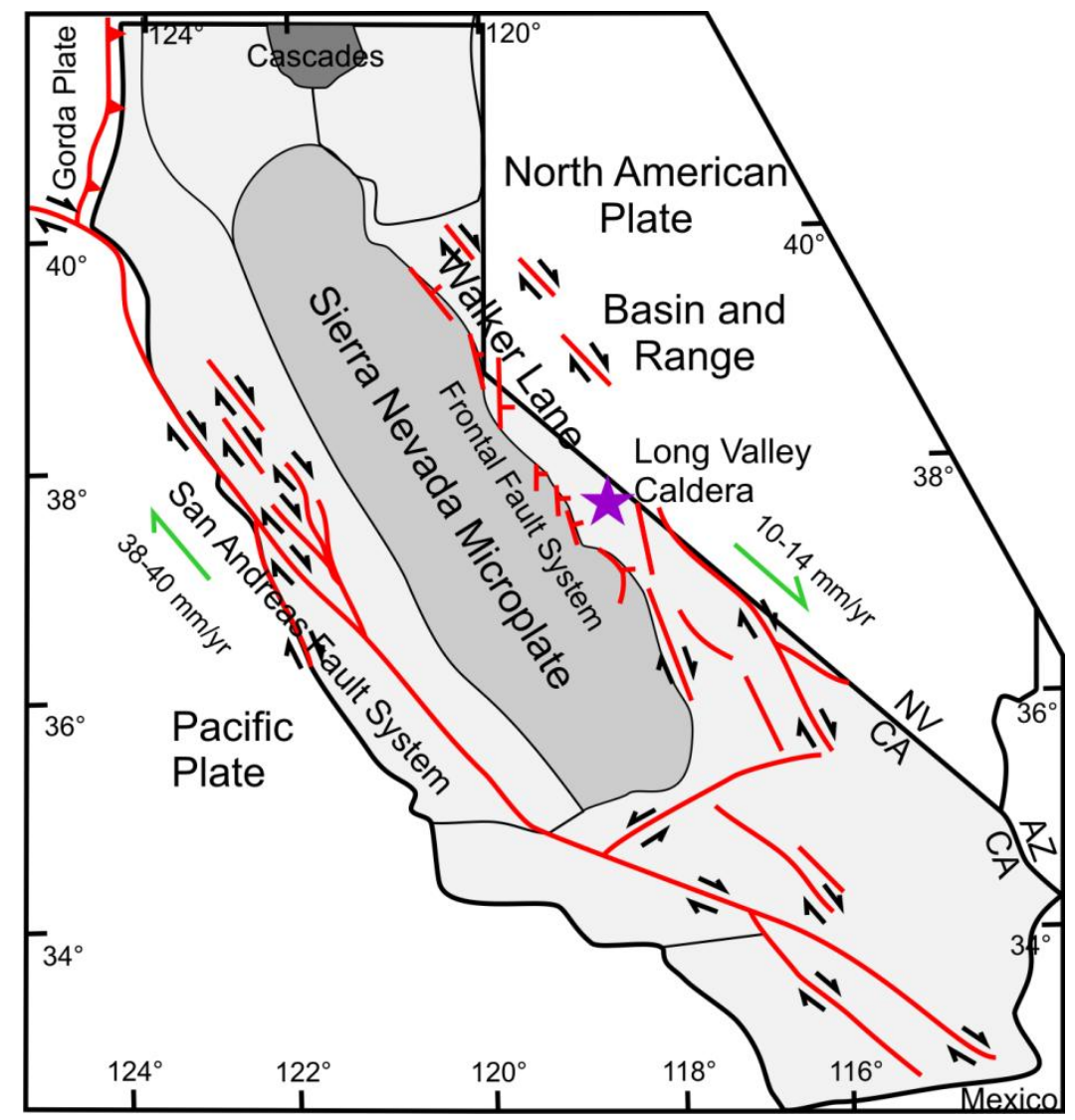

Fig. 1.5. Map of California showing the active faults in the region (in red) with relative motions on the faults indicated by black arrows. Relative plate motions are shown by green arrows. The location of Long Valley caldera is shown by a purple star. Adapted from Wakabayashi \& Sawyer (2000).

\subsubsection{Faulting in the Long Valley area}

In the Owens Valley/Long Valley region the faults have a general NNW/SSE orientation (Fig. 1.6; Strand, 1967; Bailey, 1989) and there are both normal and strike-slip faults in the area (Bailey et al., 1976). The Mono craters lie northeast of the Long Valley caldera, and lie approximately along the line of the Hartley Springs Fault (Rundle \& Hill, 1988) showing the complex interplay of volcanism and tectonics (e.g. Bursik et al., 2003). It has been postulated that movement on local faults could have triggered the Bishop Tuff eruption (as well as other eruptions from the area) due to the presence of many faults in the vicinity (Bindeman \& Valley, 2002; Hildreth 2004). This proposal is not unreasonable as other eruptions have been shown to be triggered (and halted) due to local faulting (e.g. Bursik et 


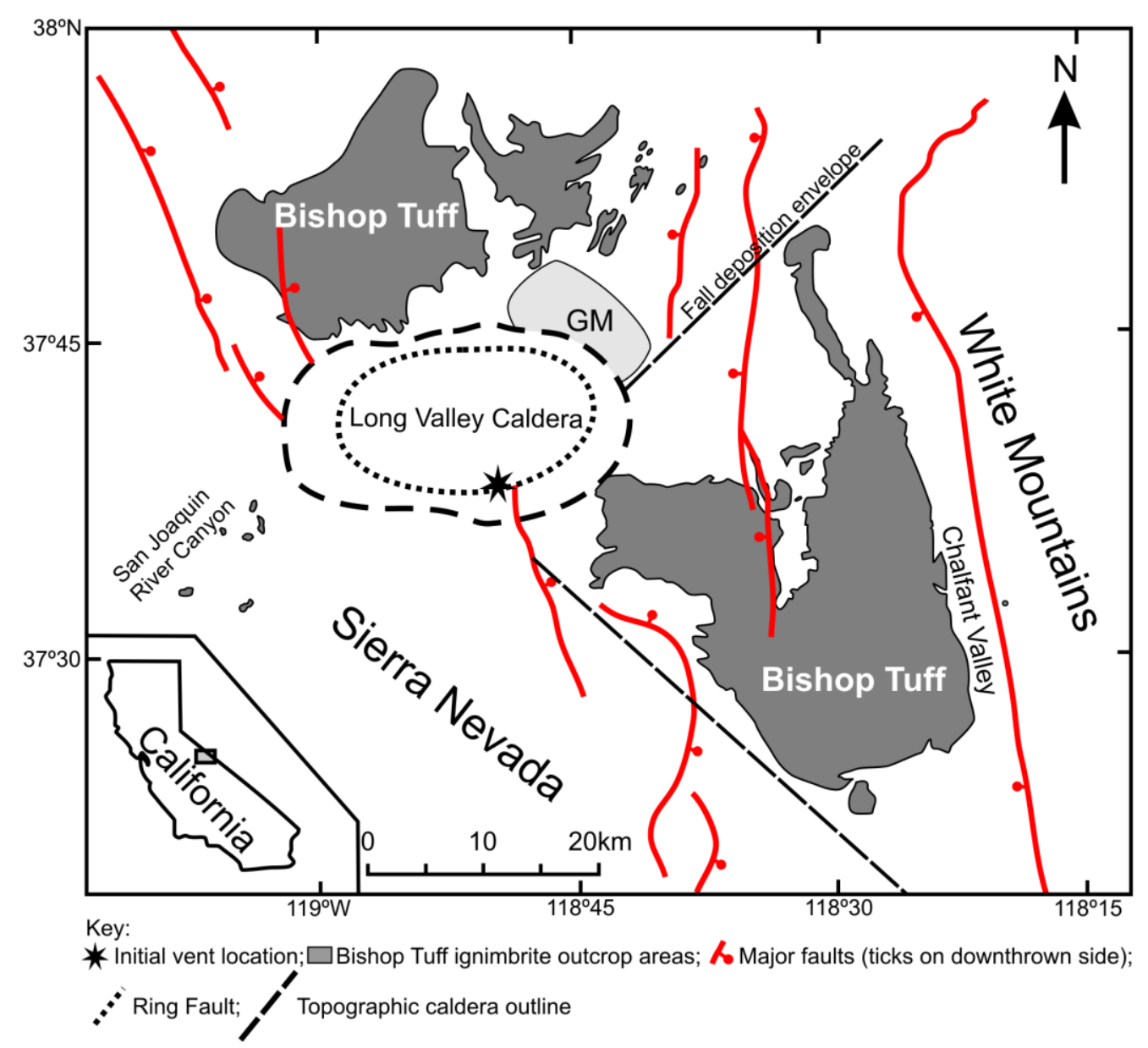

Fig. 1.6. Location map of Long Valley caldera and the Bishop Tuff. Areas of ignimbrite deposition are highlighted in dark grey, and the area of proximal fall deposition is delineated by the lines in the NE - SE region. Faults are shown in red with the tick on the downthrown side. The area of precursory Glass Mountain lava and pyroclastic material is shown in light grey. Adapted from Hildreth \& Wilson (2007).

al., 2003; Allan et al., 2012). However a much better understanding of the interplay between magma chambers and active faults in the eastern Sierra Nevada is needed.

\subsubsection{Eruptive bistory of the Long V alley region}

\subsubsection{Precaldera eruptive history}

Magmatism began in the Long Valley region at $\sim 4.5 \mathrm{Ma}$ with the eruption of basaltic and then progressively more evolved lavas (Van Kooten, 1980, 1981; Lange et al., 1993; Lange \& Carmichael, 1996; Bailey, 2004). Within these precaldera eruptives three major units have been described by Bailey (2004), that appear to have variable lithospheric-mantle, or asthenospheric-mantle sources, which differs across an E-W transect from the Sierra Nevada to the Basin and Range regions. Initial basalts, originating from partial melting of lithospheric mantle sources which retain an arc-signature from previous subduction-related 
volcanism (Van Kooten, 1980; Lange et al., 1993) and accompanied the extension of the lithosphere (Van Kooten, 1980, 1981; Bailey, 2004), evolved to a precaldera dacite field which was active between 3.5 and $2.5 \mathrm{Ma}$ northwest of the future location of Long Valley caldera (Hildreth, 2004). The majority of these precaldera lavas show little geochemical (based on isotopic measurements) or physical evidence (due to the lack of crustal xenoliths) for contamination by upper crustal rocks (Bailey, 2004).

Dacitic magmatism in the Long Valley region then evolved to rhyolites which fed a series of explosive and extrusive eruptions termed the Glass Mountain eruptive sequence (GM on Fig. 1.6; Bailey et al., 1976; Metz \& Bailey, 1993; Hildreth, 2004). This period of rhyolitic volcanism lasted nominally from 2.2 to $0.79 \mathrm{Ma}$ (though see Chapter 3 and Davies et al., 1994), with more than 60 vents preserved outside the northeastern rim of the future Long Valley caldera, erupting $100 \pm 20 \mathrm{~km}^{3}$ of magma in this time (Metz \& Mahood, 1985, 1991; Hildreth, 2004). Other vents may have been active within the area engulfed by the collapse of Long Valley caldera. The Glass Mountain eruptives are highly evolved high-silica rhyolites $\left(76.7\right.$ - 77.7 wt. $\left.\% \mathrm{SiO}_{2}\right)$ with $\mathrm{Fe}-$ Ti-oxide temperatures of $695-718{ }^{\circ} \mathrm{C}$, (Metz \& Mahood, 1991; Hildreth, 2004) defining a range which extends to lower temperatures than those estimated by Hildreth \& Wilson (2007) for the Bishop Tuff.

The Glass Mountain rhyolites are easily distinguished from the Bishop Tuff rhyolites, as they are only sparsely porphyritic (Metz \& Mahood, 1991). This Glass Mountain activity can be split into two discrete periods of Older Glass Mountain and Younger Glass Mountain (e.g. Metz \& Mahood, 1985, 1991). Older Glass Mountain eruptives (2.1 - 1.2 $\mathrm{Ma})$ have variable crystallinities generally between 1 and $8 \mathrm{wt} . \%$, whereas the younger Glass Mountain eruptives $(1.2-0.79 \mathrm{Ma})$ have $<5$ wt.\% crystals (Metz \& Mahood, 1991). The Older Glass Mountain activity produced magmas which were chemically heterogeneous, which Metz \& Mahood (1991) interpret to reflect eruption from more than one magma chamber (see Fig. 16 in Hildreth \& Wilson, 2007). The Younger Glass Mountain eruptives have a smaller range in trace element compositions, and are interpreted to reflect a progression towards a large integrated single magma chamber, where trace element variations are a product of fractional crystallisation (Metz \& Mahood, 1991). Although the Younger Glass Mountain eruptives are more geochemically similar to the Bishop Tuff (Hildreth, 2004), the early Bishop Tuff is more evolved than the youngest Glass Mountain products. This compositional contrast suggests that at least part of the compositional 
gradient seen in the Bishop eruption products was developed within the nominal 20-30 kyr hiatus between the youngest Glass Mountain eruption and the Bishop Tuff eruption (Metz \& Mahood, 1991), although the longevity and significance of this time break is addressed here in Chapter 3.

\subsubsection{The Bishop Tuff eruption}

The Bishop Tuff eruption at $767 \mathrm{ka}$ (van den Bogaard \& Schirnick, 1995; Sarna-Wojcicki et al., 2000; Rivera et al., 2011) involved $>600 \mathrm{~km}^{3}$ of magma which is inferred to have been discharged over a period of about 6 days (Wilson \& Hildreth, 1997; Hildreth \& Wilson, 2007). The Bishop eruption produced both fall deposits (covering $>2.5 \times 10^{6} \mathrm{~km}^{2}$ : Izett $e t$ al., 1988) and ignimbrite (extending at least $70 \mathrm{~km}$ from vent: Wilson \& Hildreth, 1997, Figs. 1.6 and 1.7).

The Bishop Tuff is overwhelmingly rhyolitic, with whole-rock silica contents generally ranging from 71 to $77.5 \mathrm{wt} \%$ across the whole eruptive spectrum (Hildreth \& Wilson, 2007). The majority of pumices erupted fall within a 'normal' textural suite (see Chapter 2) with a sequential change in crystallinity of the dominant pumice type from crystal poor $(<6$ wt.\%) early in the eruption, to crystal rich $(12-25 \mathrm{wt} . \%)$ later in the eruption (Hildreth \& Wilson, 2007). Of the crystals present in the Bishop Tuff, quartz and sanidine are the most dominant phases, making up $\sim 40 \%$ of the crystal population, although this does vary between pumice samples (Hildreth \& Wilson, 2007). The third most abundant crystal species is plagioclase at $10-15 \%$ of the crystal content. The most common mafic phases are biotite and titanomagnetite, found throughout the entire eruptive stratigraphy, but never being more than $2 \%$ of the crystal content (Hildreth, 1977). Similarly, but in significantly smaller proportions, zircon (and in even lesser amounts) apatite are found in all units of the Bishop Tuff. Allanite is only found in earlier, lower temperature units of the Bishop Tuff, whereas orthopyroxene and clinopyroxene are only present in later Ig2 units (and some F9 pumices; Hildreth \& Wilson, 2007).

\subsubsection{Postcaldera eruptive history}

Following the Bishop Tuff eruption and caldera collapse, a series of extrusive eruptions associated with the formation of a resurgent dome within the caldera occurred from $760 \mathrm{ka}$ to 650 ka (Fig. 1.8; Bailey, 1989; McConnell et al., 1995; Hildreth, 2004). This phase of activity erupted approximately $100 \mathrm{~km}^{3}$ of uniform, phenocryst poor $(0-3 \mathrm{wt} . \%)$ high 
(a) Northern section through Bishop Tuff, Azimuth (degrees)

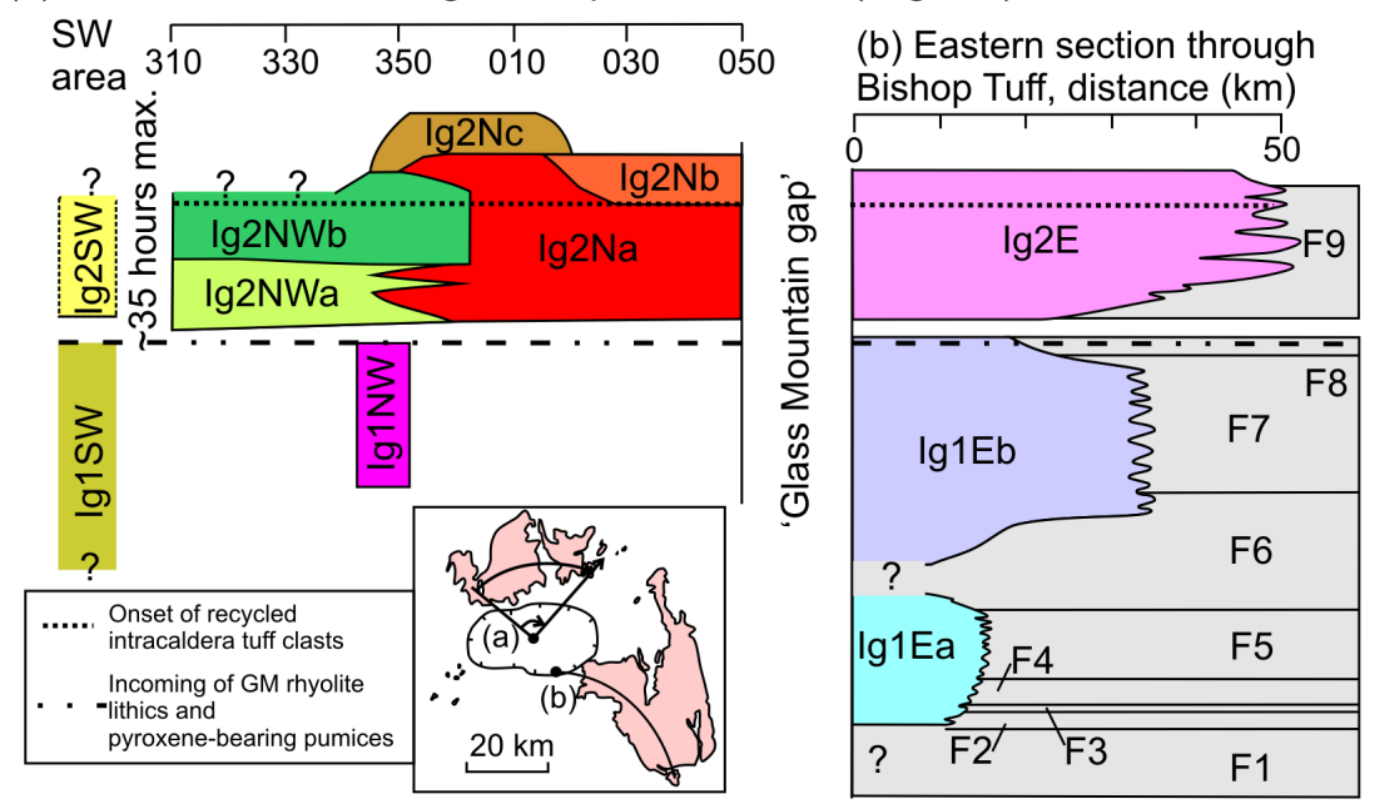

(c) Vent locations of the various units of the Bishop Tuff

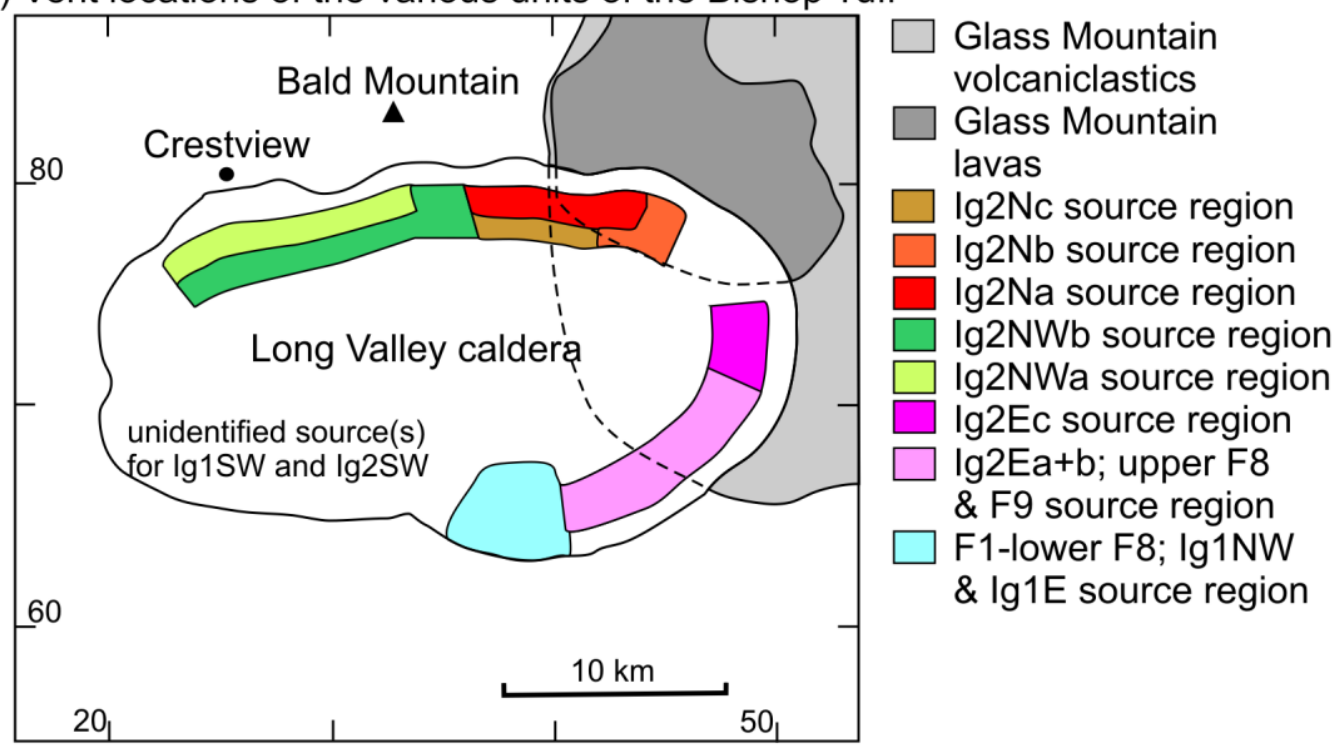

Fig. 1.7. Stratigraphy of the Bishop Tuff eruption deposits. (a, b) Ignimbrite packages shown in colour, fall units in grey, adapted from Hildreth \& Wilson (2007). (c) Approximate vent areas for various units of the Bishop Tuff (adapted from Wilson \& Hildreth, 1997).

silica (74 - 75 wt.\% $\mathrm{SiO}_{2}$ ) magma (Bailey et al., 1976, Hildreth, 2004). In these lavas, although the glass composition is similar to the later erupted Bishop Tuff, no sanidine or quartz is present in the small percentage of crystals (Hildreth, 2004). Unlike the Bishop Tuff, the resurgent dome units are bimodal with respect to trace element concentrations, showing a difference in source(s) of the postcaldera magmas to the precaldera and caldera magmas (Bailey, 2004). 
The resurgent domes were followed by the Central Long Valley episode from 527 - $100 \mathrm{ka}$ which consisted of 3 distinct clusters of eruptive activity. The eruptions during this period were small-volume, dome-forming eruptions of (dominantly) crystal rich, high silica rhyolite (termed the 'Moat rhyolites'; Hildreth, 2004). In addition, there is one isolated, volumetrically minor, undated dome (Dome 7403) extruded along the northern caldera ring fracture. This dome is unusual in its dacite composition and mineralogy (hornblendebearing) and as such is anomalous in the history of post-caldera eruptions from the Long Valley magma reservoir (Hildreth, 2004). This Central Long Valley episode of activity is interpreted to represent crystallisation of the Bishop Tuff magma chamber, and the cessation of melt withdrawal from the crystal mush (Hildreth, 2004). Geophysical investigations into the Long Valley region have identified a region of $\sim 30 \%$ partial melt at $7-11 \mathrm{~km}$ depth, which is interpreted to be a relic of the Bishop Tuff magma systempossibly the crystallising mush zone (Seccia et al., 2011); however, no large volume midcrustal magma reservoir can be identified (Kissling, 1988). The episodic uplift and earthquakes observed in historic times at Long Valley caldera are interpreted to reflect small scale diapiric upwelling of material with $\sim 2-3 \%$ partial melt from the relict Bishop magma system, and not large replenishments of melt-dominant material into the nowderelict chamber (Hill et al., 2003; Hill \& Prejean, 2005; Seccia et al., 2011). Therefore this modern partial melt identified from geophysical studies is not a rejuvenation of the moribund Bishop magma chamber, which is not thought to currently contain any significant proportions of molten material (Hildreth, 2004).

The Mammoth Mountain activity followed the Central Long Valley episode from 120 ka to $57 \mathrm{ka}$ and erupted $4 \pm 1 \mathrm{~km}^{3}$ of magma (Hildreth, 2004; Mahood et al., 2010). The Mammoth Mountain edifice lies west of the caldera ring fault and consists of $25-30$ overlapping domes of trachydacite and alkali rhyodacite $\left(65-71\right.$ wt. $\left.\% \mathrm{SiO}_{2}\right)$ defining a compositional continuum (Hildreth, 2004), and yet coeval mafic units which have overlapping ${ }^{40} \mathrm{Ar} /{ }^{39} \mathrm{Ar}$ ages are also recognised to originate from this region (Mahood et al., 2010). This activity is very different to the precaldera activity, and represents a change in volcanism from large scale silicic magma chambers, to smaller and less silicic magma chambers distinct from the Long Valley caldera-related magma system. Magmatic unrest, with high levels of $\mathrm{CO}_{2}$ fluxing and earthquake swarms, have been present in the region from $\sim 1989$ to present day, but this is not thought to reflect rejuvenation of this magma 


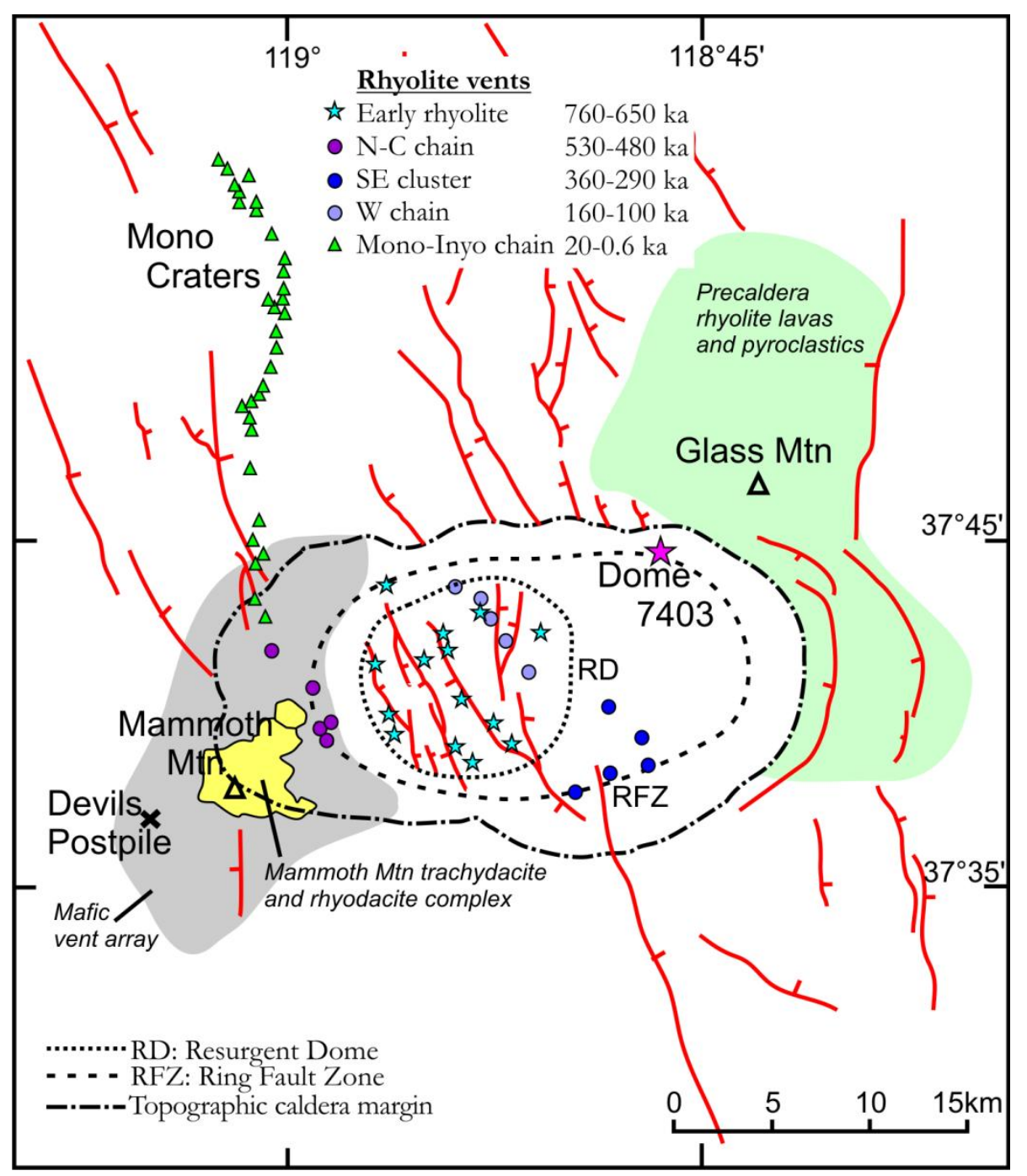

Fig. 1.8. Post-caldera volcanism in the Long Valley region. The Bishop Tuff caldera topographic outline is shown by the dashed-dotted line, with the ring fault zone (RFZ) in dashes. Post-caldera rhyolite vents are shown as coloured circles, triangles or stars. The post-caldera rhyodacite dome (Dome 7403) is highlighted in pink. Adapted from Hildreth (2004).

system, but instead to be the result of a crustal mafic intrusion (Hill \& Prejean, 2005; Browne et al., 2010).

The most recent activity in the Long Valley region is from the Mono Craters and Inyo chains of vents. The Mono Craters chain has been sporadically active from $50-55$ ka until 660 years ago, producing approximately 30 dike fed domes aligned N-S to Mono Lake, northwest of the caldera (Fig. 1.8; Bailey, 1989; Bursik \& Sieh, 1989; Chen et al., 1996; Kent et al., 2002; Bursik et al., 2003). The lavas of Mono Craters are all (bar one) high-silica rhyolites with 75.4 - 77 wt. $\% \mathrm{SiO}_{2}$, with phenocryst contents ranging from $<1 \%$ to $8 \%$ (Wood, 1983; Kelleher \& Cameron, 1990). The magmas feeding the Mono Craters vents 
are thought to originate from extensive crystal fractionation of a local, more-mafic source, which also experienced variable amounts of mixing with crustal melts, and MORB-type mantle inputs (Kelleher \& Cameron, 1990; Bailey, 2004). This genesis is different from the Bishop Tuff, as there is no inferred single mush system which is being sporadically tapped to produce the magmas of Mono Craters chain (Hildreth, 2004; Hildreth \& Wilson, 2007). A recently identified Northwest Caldera sequence operating from $40-29$ ka (previously thought to be part of the Mammoth Mountain sequence) consists of a series of trachydacite domes and trachybasalt lava flows (Mahood et al., 2010). The presence of these units suggest a greater degree of temporal continuity between the northern erupted Mono Craters chain and the southern Inyo chain, and highlights the continuing presence of mafic eruptions in the Long Valley region during the eruptions of the Mono-Inyo chain. The younger Inyo chain has been sporadically active from $\sim 9$ ka until $650-550$ years ago. It is represented by an $11 \mathrm{~km}$ long chain of six magmatic and more than 15 phreatic centres aligned along a north-trending fracture (Miller, 1985; Mahood et al., 2010). The Inyo vents lie on the western side of the Long Valley caldera (Mastin, 1991) and, in similar fashion to the Mono Craters chain, are likely to be underlain by a dike-like feeder system (Miller, 1985). Contrastingly, the products of the Inyo chain are much more variable in composition (Sampson \& Cameron, 1987; Vogel et al., 1989; Reid et al., 1997). This variation in composition is thought to represent interaction between two end-member rhyolites, one of which may represent the thermally rejuvenated Long Valley magmatic mush system (Sampson \& Cameron, 1987; Reid et al., 1997).

\subsection{The Bishop Tuff}

\subsubsection{Physical volcanology}

The first record of the pyroclastic origin of the Bishop Tuff came from Gilbert (1938) who mapped the extent of the pyroclastic flows, and also identified welding within the ignimbrite units. The fall material (units F1 - F9: Fig 1.7) was only recognised to be a part of the Bishop Tuff eruption much later (Bateman, 1965). The work of Bateman (1965) also identified localities where near-complete sequences of the fall deposits occur. The associated regional fall deposits across the USA were subsequently identified by Izett et al. (1970). Initial identification of the multi-lobate nature of the Bishop Tuff flow units (and study of the mineralogy and fossil fumaroles of the Bishop Tuff) came with the work of Sheridan $(1965,1968,1970)$. 
Long Valley caldera (universally interpreted to have formed as a consequence of the Bishop Tuff eruption) was mapped by Bailey et al. (1976). The location for the initial vent of the Bishop Tuff eruption has been placed in the south central part of the caldera (Figs. 1.7; Hildreth \& Mahood, 1986) based on studies of lithic lithologies in the early-erupted Bishop deposits. Detailed field studies have established an internal stratigraphy of the Bishop Tuff (Fig. 1.7; Hildreth, 1979; Wilson \& Hildreth, 1997; Hildreth \& Wilson, 2007). Ignimbrite packages of the Bishop Tuff are dominantly separated into two outcrop areas, to the east in which packages often have interbedded fall units, and to the north with no intercalated fall deposits (Fig. 1.7). The lack of fall deposits associated with the northern ignimbrite units is probably due to the plinian plume being driven eastward by dominant westerly winds (Fig. 1.6). Two minor ignimbrite packages emplaced to the southwest are thought to represent overflow of material into the San Joaquin Canyon (Wilson \& Hildreth, 1997), but the origin of these units and role these units played in the stratification of the Bishop Tuff, including that of Ig1NW, are investigated further in this thesis.

\subsubsection{Geochemistry of the Bishop Tuff}

Detailed petrographic and geochemical studies through all units of the Bishop Tuff by Hildreth $(1977,1979)$ were used to infer the presence of a systematic stratification within the melt-dominant magma body that generated the Bishop Tuff (Fig. 1.9a). Given the stratigraphy within the Bishop Tuff fall deposits and ignimbrite, the earliest erupted material (fall unit F1) is inferred to represent tapping of the uppermost part of the meltdominant magma body. With increasing stratigraphic height, proportions of pumices with less-evolved compositions increase, this is mirrored by higher proportions of crystal rich pumice (Fig. 2.1) and increases in inferred magmatic temperatures (Hildreth, 1977, 1979; Hildreth \& Wilson, 2007). Studies of melt inclusions within quartz and feldspar crystals also show increased $\mathrm{CO}_{2}$ and decreasing $\mathrm{H}_{2} \mathrm{O}$ contents with increasing inferred depth within the magma body (Dunbar \& Hervig, 1992a; Lu et al., 1992; Wallace et al., 1999; Anderson et al., 2000). Trace element analyses of glass, melt inclusions and phenocrysts show increases in $\mathrm{Ba}, \mathrm{Sr}$ and $\mathrm{Ti}$, as well as decreases in incompatible elements with increasing inferred depth within the magma chamber (Hildreth, 1977, 1979; Anderson et al., 2000; Roberge et al., 2013), again showing its less-evolved nature, and supporting the theory of systematic tapping of a compositionally zoned magma chamber (Fig. 1.9a). In contrast, it has been argued that an apparent bimodality of sanidine and plagioclase major element compositions shows that the late-erupted Bishop Tuff came from a separate magma 
chamber to that which produced the early, eastern units (Fig. 1.9b; Gualda et al., 2012a; Gualda \& Ghiorso, 2013a). By undertaking a detailed study of phenocryst and glass compositions from throughout the entire eruptive sequence these contrasting hypotheses are tested in this thesis (Chapter 5).

The stratification within the Bishop Tuff magma body is proposed to have been established prior to crystallisation of the major mineral phases due to the crystals being in equilibrium with the remaining melt (Hildreth, 1977, 1979; Hildreth \& Wilson, 2007). Various models have been proposed as to how to generate this stratification in crystal content and chemistry within the melt dominant magma chamber including Soret diffusion at chamber walls (Hildreth, 1979), crystal sinking (e.g. Anderson et al., 2000; Peppard et al., 2001) or extraction from an underlying crystal mush (Hildreth \& Wilson, 2007). The last option is now the favoured model. However, given the ranges in crystal compositions documented in this thesis, there is scope for further consideration of where the phenocrysts in the Bishop Tuff grew. For example, the discovery in the Oruanui eruption products that various crystal phases crystallised in distinctly different parts of the magma system (Allan, 2013; Allan et al., 2013) suggest that there is scope for re-examining the origins of the crystal cargo in the Bishop Tuff.

The thermal stratification of the Bishop magma body has been investigated using a range of thermometers including Fe-Ti-oxides, $\Delta^{18} \mathrm{O}$ in quartz and magnetite and Ti-in-quartz, as well as thermodynamic modelling (Hildreth 1977, 1979; Bindeman \& Valley, 2002; Wark et al., 2007; Ghiorso \& Evans, 2008; Thomas et al., 2010; Gualda et al., 2012a,b; Wilson et al., 2012; Evans \& Bachmann, 2013; Ghiorso \& Gualda 2013). These techniques yield temperature estimates of between $\sim 700{ }^{\circ} \mathrm{C}$ and $\sim 820{ }^{\circ} \mathrm{C}$, however the maximum and minimum values of temperatures within the Bishop magma chamber is still vigorously debated, and is considered as part of this thesis.

The eruption age of the Bishop Tuff has been investigated by many workers, in large part due to its proximity in time to the Matuyama (reversed) to Brunhes (normal) palaeomagnetic chrons. Early K-Ar age dating of sanidine gave an estimate of $\sim 700 \mathrm{ka}$ (Dalrymple et al., 1965). The most recent investigation, using ${ }^{40} \mathrm{Ar} /{ }^{39} \mathrm{Ar}$ dating in sanidines, has yielded an eruption age estimate of $767.4 \pm 2.2 \mathrm{ka}$ (Rivera et al., 2011). This result is closely matched by ID-TIMS determinations on zircons from early Bishop Tuff which 
yielded a mean U-Pb date of $767.1 \pm 0.9 \mathrm{ka}$ (Crowley et al., 2007). However, some debate still remains as to the correct calibration to use for the ${ }^{40} \mathrm{~K}$ decay constant which has resulted in eruption age estimates varying by $\sim 20 \mathrm{kyr}$ between $758 \mathrm{ka}$ (Sarna-Wojcicki et al., 2000), $767 \mathrm{ka}$ (Rivera et al., 2011) and $780 \mathrm{ka}$ (following Renne et al., 2010; Simon et al., 2014).

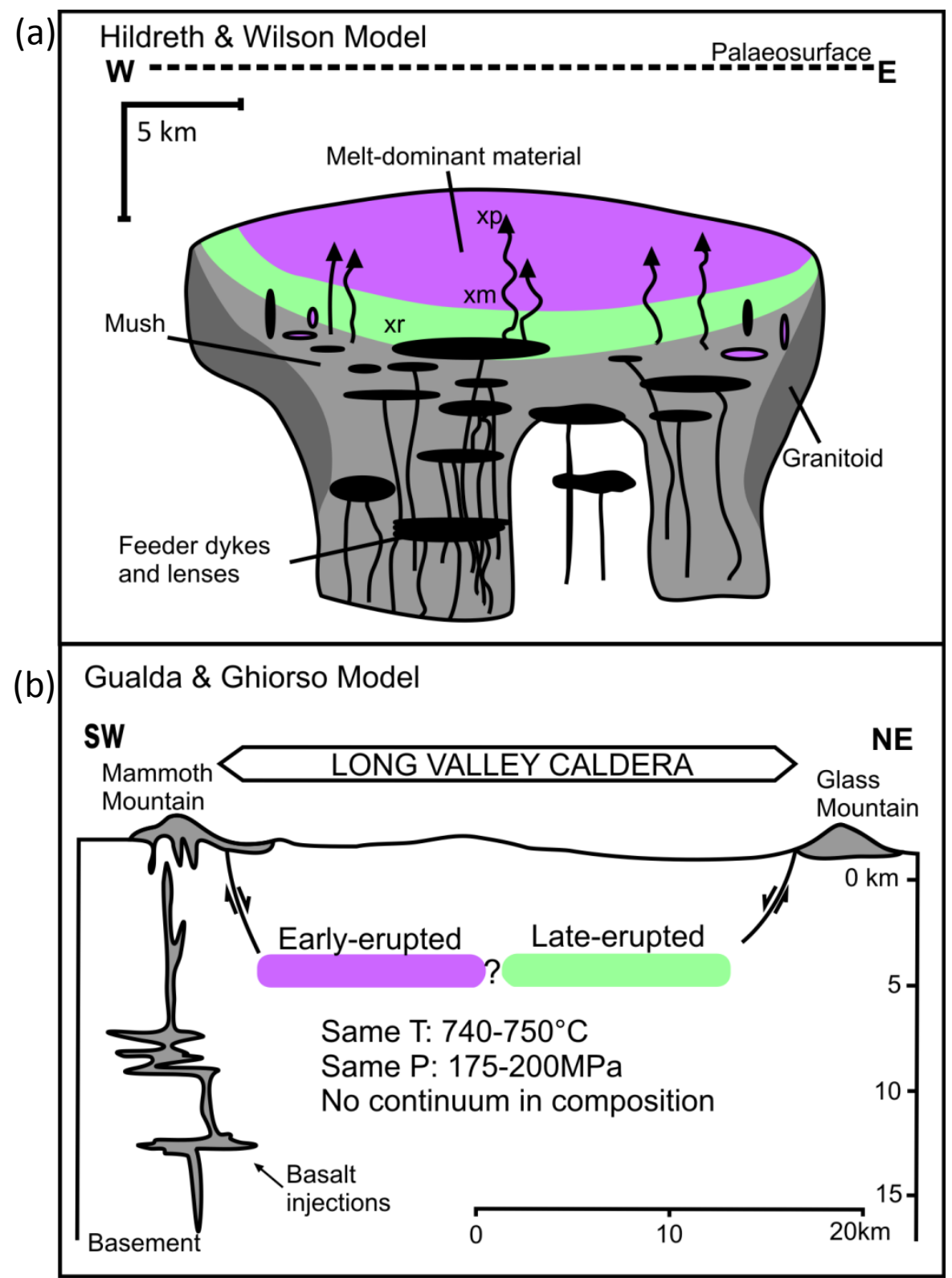

Fig. 1.9. Two contrasting models for the pre-eruptive Bishop Tuff magma system. The upper diagram [(a): adapted from Hildreth \& Wilson, 2007] shows a single, compositionally zoned magma body fed from below by rejuvenation of the underlying crystal mush zone. The magma chamber is stratified with respect to crystal content too, with upper regions containing crystal poor (xp) magma, grading through crystal medium (xm) magma to crystal rich (xr) magma at the base. The lower diagram [(b): adapted from Gualda \& Ghiorso, 2013a] has the Bishop Tuff being fed from two separate magma chambers erupting largely sequentially. 
Long residence time estimates of the parental Bishop magma body have been proposed from Rb-Sr and Sm-Nd model ages of crystals and glass within the Bishop Tuff. Such studies suggest ages for differentiation of the Bishop Tuff magma between 2.1 and 1.0 Ma, yielding inferences of $1.3-0.3 \mathrm{Myr}$ of crystal residence in the melt dominant magma chamber (Christensen \& Halliday, 1996; Davies \& Halliday, 1998). Similarly, ${ }^{40} \mathrm{Ar} /{ }^{39} \mathrm{Ar}$ dates of melt inclusions within quartz yielded a weighted mean age estimate of $1.89 \pm 0.03$ Ma (van den Bogaard \& Schirnick, 1995), but these have been shown to not represent a crystallisation age, as quartz-hosted melt inclusions contain excess ${ }^{40} \mathrm{Ar}$ (Winick et al., 2001). Phase equilibria calculations (MELTS) have been used to estimate timescales of evolution if fractional crystallisation produced the high silica magma of the Bishop Tuff, yielding timescales of $>1$ Myr (Fowler \& Spera, 2010), but these calculations have been criticised on the basis of unrealistic assumptions about heat fluxes into and out of the chamber (Gualda \& Ghiorso, 2011). Previous studies involving U-Pb dating of zircon crystals (inferred to be the earliest crystallising phase: Hildreth, 1977) from Bishop pumices have yielded ages which range from 890 ka to within uncertainty of eruption age (Reid \& Coath, 2000; Simon et al., 2005; Crowley et al., 2007; Reid et al., 2011; Reid \& Schmitt, 2012), significantly shorter than the residence times modelled from radiogenic isotopes in glass and thermodynamic modelling. Shorter still are the timescales proposed from models for crystal growth using crystal size distributions (CSD, Pamukcu et al., 2012) and diffusion of Ti in quartz (Gualda et al., 2012b), both of which propose millennial scale timescales for crystallisation of the major felsic phases, an order of magnitude shorter than those suggested from single-crystal zircon ages. Debate is still vigorously continuing as to which timescales are 'correct' and whether the crystal species investigated are 'true' phenocrysts (instead of antecrysts: Bacon \& Lowenstern, 2005; Charlier et al., 2005) and raises questions which I address within this thesis. 
Chapter 2 


\section{Fieldwork \& analytical techniques}

\subsection{Fieldwork}

An intensive fieldwork programme was carried out in the Long Valley region, utilising the extensive physical volcanological studies already completed in the area (e.g. Bailey et al., 1976; Hildreth \& Mahood, 1986; Wilson \& Hildreth, 1997, 2003; Hildreth \& Wilson, 2007), which have led to the establishment of a widely accepted stratigraphic framework (see Fig 1.7; Section 1.5.1). The focus of the fieldwork conducted for this study was thus not to reexamine any inferences from deposit characteristics, but to obtain a comprehensive suite of samples spanning the temporal and spatial distribution of the Bishop eruption products for geochemical investigation. Over a three year period (2009 - 2011), 249 samples of Bishop Tuff pumice and fall material were collected (see Appendix 2). Colin Wilson collected 25 samples (BP001 -BP025) in 2009 for a preliminary investigation into Ba-zoning in sanidine. The bulk of the samples (BP026 - BP198) were collected in October 2010, from every known stratigraphic unit of the Bishop Tuff. In June 2011, a small number of samples (BP199 - BP203) were collected to increase the number of variant pumices sampled. A final sampling campaign was undertaken in October 2011 to increase the number of crystal-poor and swirly pumices in the sample suite, and also to make sure a complete geographic distribution of material had been sampled (BP204 - BP249). All ignimbrite or fall unit names used for the remainder of this thesis relate to those specified by Wilson \& Hildreth (1997) and Hildreth \& Wilson (2007; Fig. 1.7).

\subsection{Sampling}

\subsubsection{Sampling methods}

Pumices from ignimbrite units were sampled where the deposits were unwelded, which was typically in the lower parts or lateral fringes of the ignimbrite where it rested on or lapped onto underlying paleotopography. Fall deposits are all non-welded and so could be sampled in multiple locations (as no welded samples were collected for this study). The collected pumices were generally glassy, fresh and unweathered. Where available, unoxidised samples were collected; however, this was not always possible, particularly in the Sherwin lobe of Ig1Eb. Biotite was a key mineral indicator of weathering, and therefore when present, samples with fresh black biotite were collected in preference to those containing weathered, golden brown biotite. Samples were collected from proximal locations (i.e. within $30 \mathrm{~km}$ of 
the source) in order to sample large pumices that would yield enough material for geochemical study, even in the crystal-poor samples.

Representative pumices and bulk samples were collected from the Bishop Tuff so that every stratigraphic unit was sampled (Fig. 1.7) from the earliest fall unit (F1) through to the latest ignimbrite unit $(\mathrm{Ig} 2 \mathrm{Nc})$. As discussed in Chapter 1, pumices in the 'normal' (Hildreth \& Wilson, 2007) spectrum vary from crystal-poor (<6\%) to crystal-rich $(>12 \%$; Table 2.1; Fig 2.1). To address this diversity, the entire pumice range within each eruptive unit was sampled to examine differences between crystal-poor and crystal-rich samples within a unit. A range of variant pumices was also sampled to cover the full range of textures and compositions present (Table 2.1). Each ignimbrite stratigraphic unit was sampled at multiple locations, in order that any geographic variations in glass or crystal chemistry could be investigated. For some units (e.g. Ig1SW and Ig2SW) this was not possible. Fall unit F1 was specifically targeted so that enough material was collected for zircon extraction. Two exposures in Owens River Gorge, to the southeast of the caldera rim, (Figs. 2.2, 2.3) were visited, where the F1 unit is $18 \mathrm{~cm}$ (loc. 25) and $29 \mathrm{~cm}$ (loc. 495) thick.

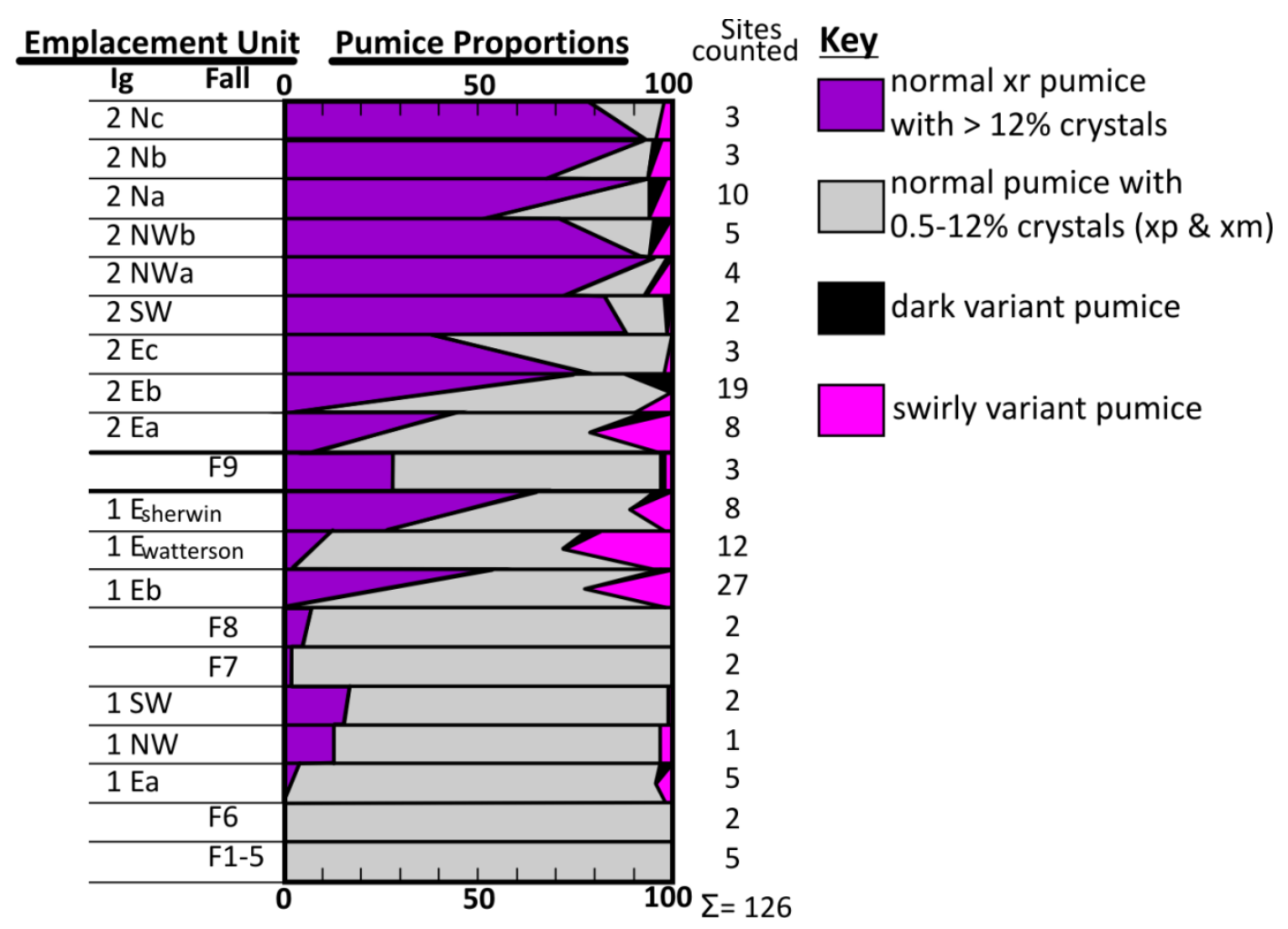

Fig. 2.1. Pumice clast proportions for various Bishop Tuff emplacement units, in approximate stratigraphic order, from F1 to Ig2Nc. Note the systematic increase in the proportion of crystal rich (xr) pumice clasts from early- to late-erupted units. Figure modified after Hildreth \& Wilson (2007). 
Table 2.1. Pumice types in the Bishop Tuff (from Hildreth \& Wilson, 2007)

\begin{tabular}{|c|c|c|c|}
\hline Pumice type & Abbreviation & $\begin{array}{l}\text { Crystallinity } \\
\text { (modal percent) }\end{array}$ & Identifying Features \\
\hline Crystal poor & $x p$ & $<6 \%$ & $\begin{array}{l}\text { Normal Bishop pumices which can vary in } \\
\text { oxidisation and vesicularity (typically }<0.1 \text { to }\end{array}$ \\
\hline Crystal medium & $\mathrm{xm}$ & $6-12 \%$ & $\begin{array}{l}1 \mathrm{~mm} \text { in diameter). Only separated based on } \\
\text { the crystal content of the individual }\end{array}$ \\
\hline Crystal rich & $\mathrm{xr}$ & $12-25 \%$ & $\begin{array}{l}\text { samples. } \mathrm{SiO}_{2} \text { ranges between } 73.4 \text { wt.\% } \\
\text { and } 77.9 \mathrm{wt} \% \text {. }\end{array}$ \\
\hline Adobe & $\mathrm{Ad}$ & $12-25 \%$ & $\begin{array}{l}\text { Coarsely fibrous linear pumiceous fabric. } \\
\text { Can contain schlieren and clustered, broken } \\
\text { crystals. Grades through 'Adobe-lite' texture } \\
\text { to normal xr pumice. } \mathrm{SiO}_{2} \text { ranges between } \\
73.4 \text { wt. } \% \text { and } 77.6 \text { wt.\%. }\end{array}$ \\
\hline Swirly & sw & $0.7-9.1 \%$ & $\begin{array}{l}\text { Generally dark to pale grey, often variably } \\
\text { oxidised. Micro-vesicular fabrics which can } \\
\text { be wavy or distorted. Cores of pumice clasts } \\
\text { can display late inflation of coarse vesicles } \\
\text { to } 10-30 \mathrm{~mm} \text { in size. Lowest density sub- } \\
\text { type within the Bishop Tuff. Swirly pumices } \\
\text { are more abundant within later units of the } \\
\text { Bishop Tuff (Fig } 2.1 \text { ). } \mathrm{SiO}_{2} \text { ranges between } \\
71.5 \text { wt.\% and } 76.8 \mathrm{wt} . \% \text {. }\end{array}$ \\
\hline Dark & $\mathrm{dk}$ & $0.4-6.6 \%$ & $\begin{array}{l}\text { Comparable densities and fabrics to the } \\
\text { normal Bishop Tuff spectrum, but are dark } \\
\text { grey or black. These are often intermingled } \\
\text { with white normal pumice, which carry the } \\
\text { majority of the crystal cargo (Fig. } 2.6 \text { ). } \mathrm{SiO}_{2} \\
\text { ranges between } 67.0 \text { wt.\% and } 76.1 \text { wt.\%. }\end{array}$ \\
\hline Glistening & gt & $1.4-6.4 \%$ & $\begin{array}{l}\text { Pale grey to white in colour with distinctive } \\
\text { tubular shaped vesicles }(0.1-1 \mathrm{~mm} \text { in } \\
\text { diameter). Thick vesicle walls (Fig. } 2.7 \text { ) cause } \\
\text { pumice samples to shimmer in reflected } \\
\text { light. } \mathrm{SiO}_{2} \text { ranges between } 77.0 \text { wt. } \% \text { and } \\
78.2 \mathrm{wt} \% \text {. }\end{array}$ \\
\hline Dacite & dc & --- & $\begin{array}{l}\text { Only found in unit Ig2NWb. Rich in large (up } \\
\text { to } 13 \mathrm{~mm} \text { ) felsic crystals. }\end{array}$ \\
\hline
\end{tabular}

\subsubsection{Key sample locations}

Among the localities sampled (Fig 2.3) pumice clasts were collected from five key localities, where a wide number of samples could be taken and/or the units show key stratigraphic relationships, and/or are type locations for the stratigraphic identification of fall units. 

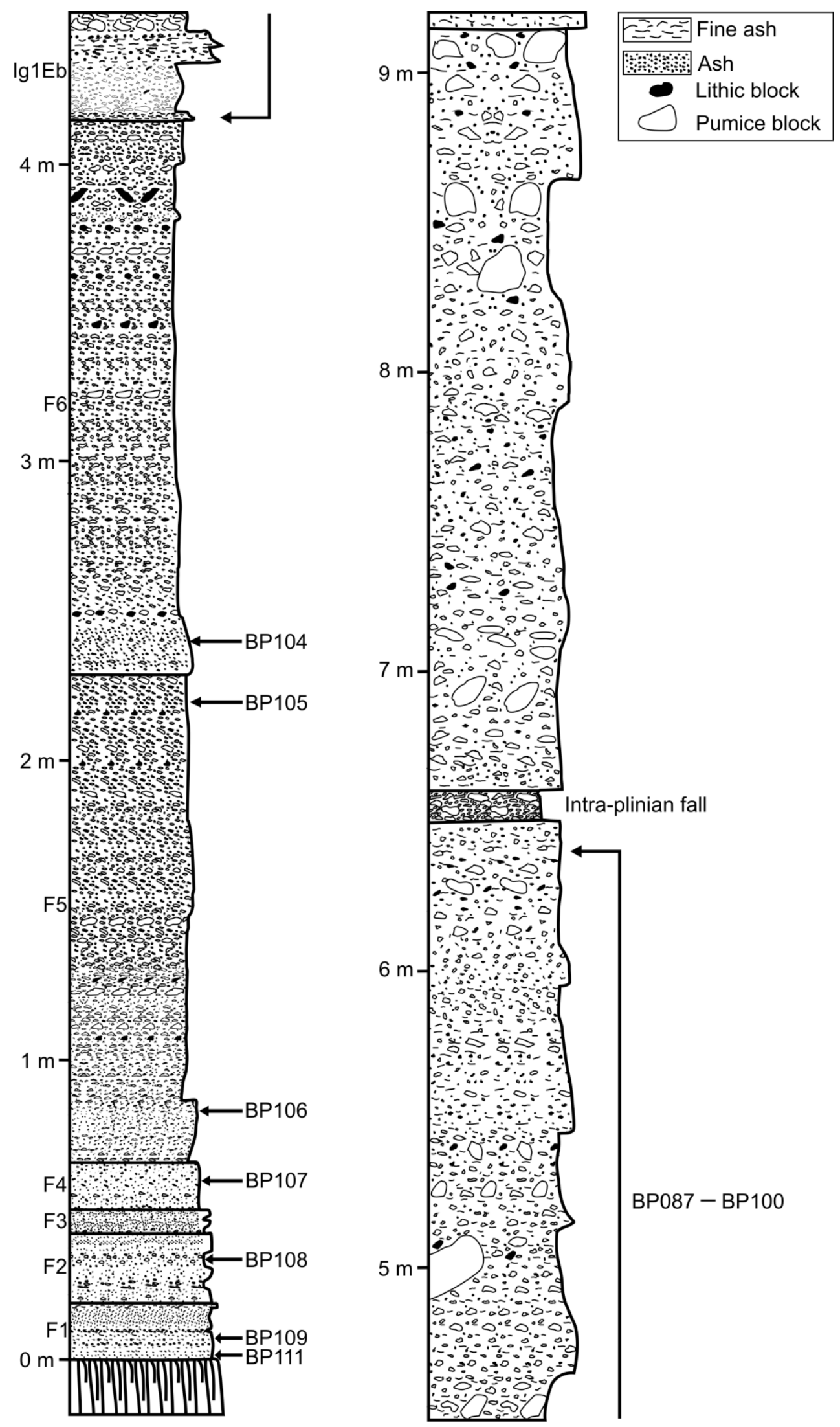

Fig. 2.2. Stratigraphic log through the earliest fall units of the Bishop Tuff at locality 25 (Fig. 2.3). Locations of samples of fall material are labelled. Samples BP087-BP100 were collected from basal few metres of Ig1Eb at this locality but were not specifically located within the logged section. 
a) Locality 25: Upper Owens River Gorge

At this locality in a gully on the west side of the gorge, units F1 - F6 are exposed, overlain by Ig1Eb including its basal contact (Fig. 2.2). This location is approximately $20 \mathrm{~km}$ from the coeval early vent (Hildreth \& Mahood, 1986). All of these deposits are non-welded at the level of this site, and show little to no oxidation. Samples BP087 - BP111 were collected from this locality, either as individual pumice clasts or as bulk samples of the finer fall units (Fig. 2.2).

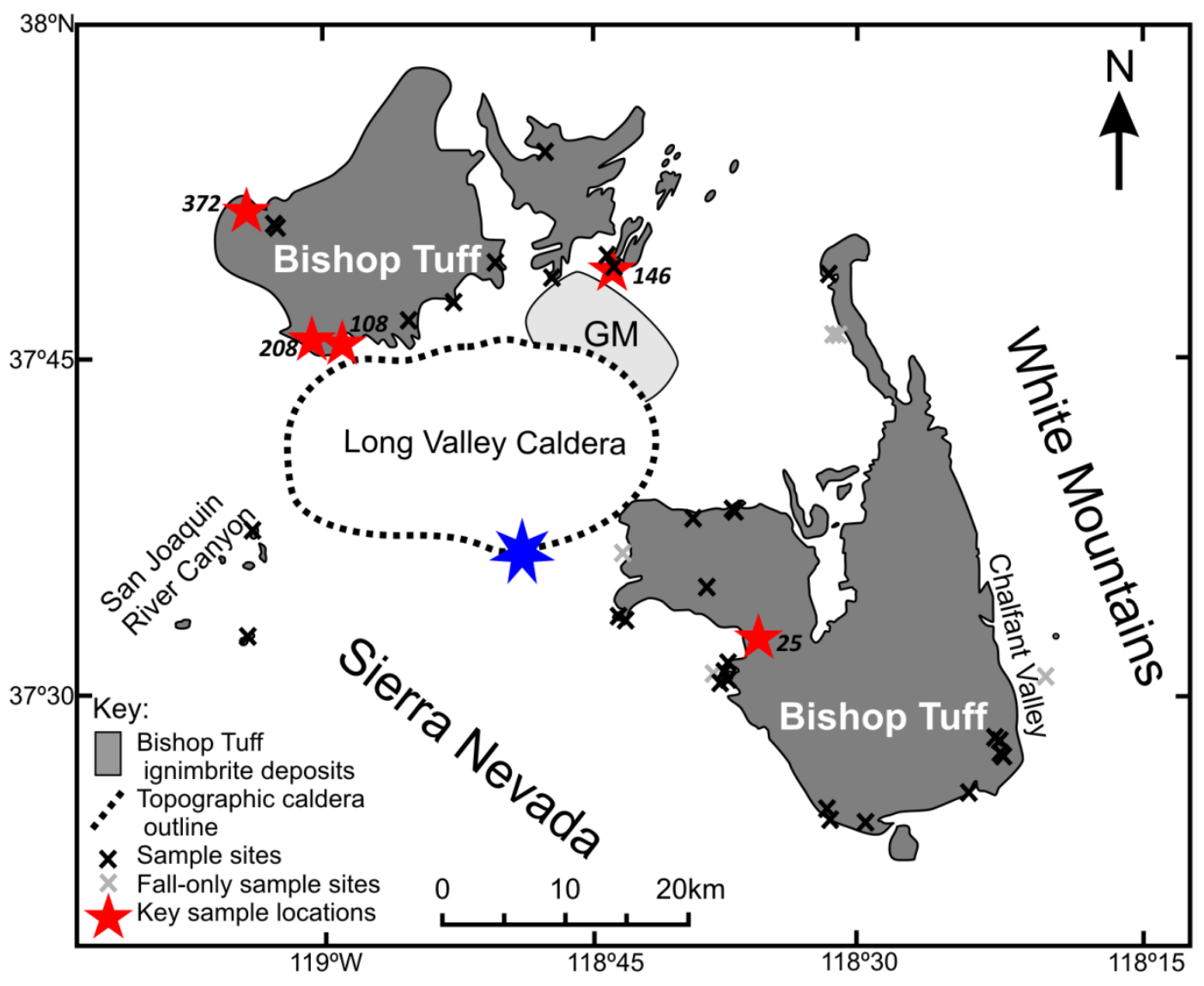

Fig. 2.3. Map showing all sites where Bishop Tuff samples were collected for this study (crosses). Key sample sites discussed in the text are shown as red stars and numbered. The approximate location of the initial vent is shown as a blue star after Hildreth \& Mahood, 1986.

b) Locality 108: Clark Canyon

At this locality, the contact between Ig1NW and Ig2NWa occurs (Fig. 2.4). Ig1NW can be distinguished from the later Ig2NW by the absence of crystal-rich, pyroxene-bearing clasts and the presence of lithics of metasediments from the Mount Morrison pendant, which are characteristic of ignimbrite erupted from the early vent and absent from the Ig2 deposits (Hildreth \& Mahood, 1986). Ig1NW is exposed as a slope forming unit with a greyish-white colour. Pumice clasts range in 
size up to $5-10 \mathrm{~cm}$ in diameter. Lithics present in Ig1NW are either granites or metasediments.

c) Locality 208: Crestview

This Crestview road cut exposes the earliest northern-sourced erupted material in the NW ignimbrite lobes (Ig2NWa and its basal contact on palaeosol). This locality has been commonly sampled by other authors investigating the Bishop Tuff, and is the locality for samples BP025 - BP028 and BP113 - BP121 in this study.

d) Locality 372: Aeolian Buttes

Ig2NWb is consistently welded across most of its depositional area but at this, and other localities in this area, it laps onto underlying highs in the granite basement and is less welded, allowing for easy extraction of pumice. The outer $2-10 \mathrm{~cm}$ of pumice clasts are generally oxidised, but the large size of pumices at this site allows for removal of the oxidised material to yield unoxidised cores. Samples BP122 BP129 and BP211 - BP222 were collected from this area. Variant pumice types were specifically targeted for sampling on a second visit to this site, as swirly and dacite clasts are more abundant here than in Ig2NWa.

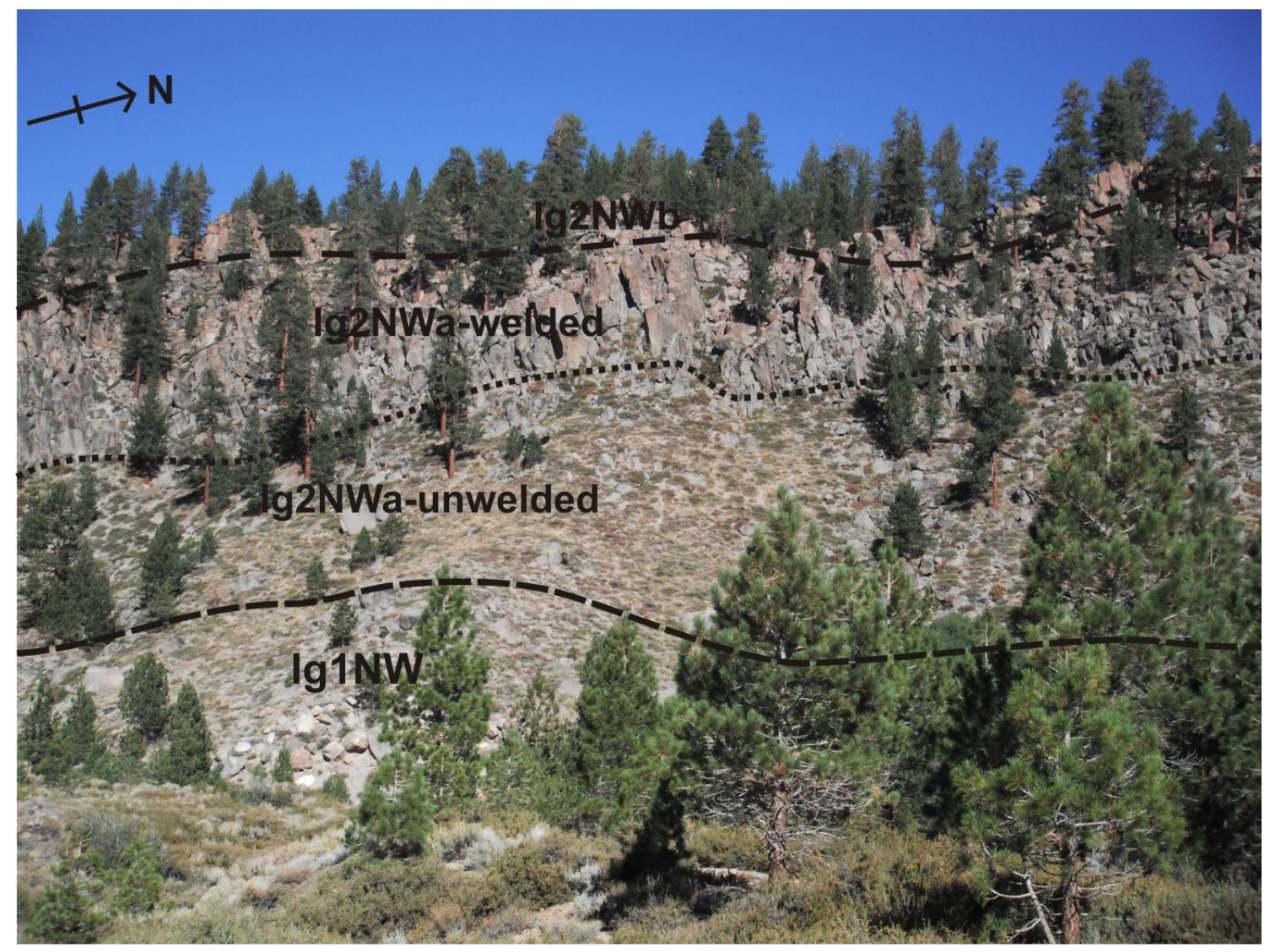

Fig. 2.4. Contacts between Ig1NW, Ig2NWa and Ig2NWb shown at locality 108. Scarp is $170 \mathrm{~m}$ high for scale. 
e) Locality 146: McGee Canyon

$\operatorname{Ig} 2 \mathrm{Nb}$ is exposed in this area as non-welded to sintered ignimbrite. In general, Ig2Nb material is pervasively oxidised, but at some localities (e.g. 372), pumice clasts are large enough to allow removal of the oxidised material. Ig2Nb pumices are dominantly crystal-rich varieties, although a range of crystallinities is present at this locality. Crystal-poor and swirly pumices were specifically collected from this locality. Samples collected from McGee Canyon are numbered BP166 - BP173 and BP223 - BP232.

\subsubsection{Pumice types}

Pumices of the Bishop Tuff can be categorised based on their crystal content and texture (Hildreth \& Wilson, 2007). The majority (70 - 100\% depending on eruptive unit) of all pumices from the Bishop Tuff fall into the 'normal' pumice spectrum as defined by Hildreth \& Wilson (2007; Fig. 2.1). This normal spectrum of pumices is then further subdivided based on crystallinity and crystal fragmentation (Appendix 2; Fig. 2.5). Normal pumice types have $\mathrm{SiO}_{2}=73.4-77.9$ wt.\%, with more crystal-rich pumices having lower $\mathrm{SiO}_{2}$ (Fig. 2.5; Hildreth \& Wilson, 2007). Variant pumice types can constitute up to $30 \%$ of a single unit, but commonly represent only $5-10 \%$ of the pumice clasts in Bishop Tuff deposits (Fig. 2.1). These variant pumice types have three dominant sub-types, with further rare sub-types (Appendix 2; Fig. 2.6). Vesicle textures, evidenced by images of glass shards, change significantly based on pumice type, as can be seen in BSE images of glass shards (Fig. 2.7).

\subsection{Collected samples}

A total of 249 samples of Bishop Tuff were collected during this study, comprising all the normal and the three main variant pumice types. In addition, two samples of representative Glass Mountain lavas (domes OD and YA: Metz \& Bailey, 1993) were collected to explore their compositional relationships (particularly zircon textures, ages and trace elements) with respect to the Bishop samples. All details for the collected samples are listed in Appendix 2. 

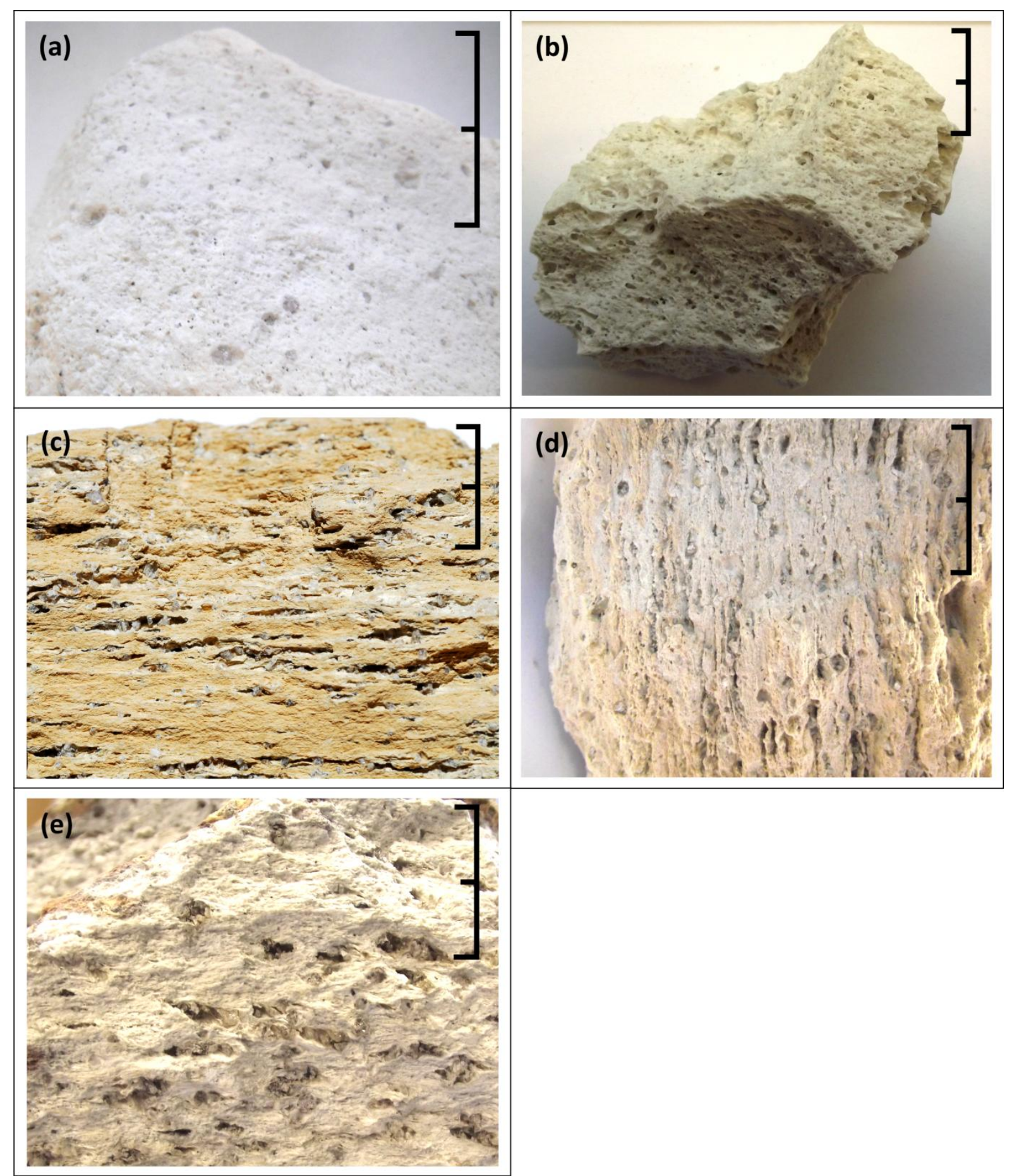

Fig. 2.5. A selection of normal pumices showing the range in textures from crystal medium (a) and crystal poor (b) to the more crystalline Adobe (c), Adobe lite (d) and normal type crystal rich (e). See Table 2.1 for full descriptions of these textures. Scale bar is $20 \mathrm{~mm}$ in length for all images. 


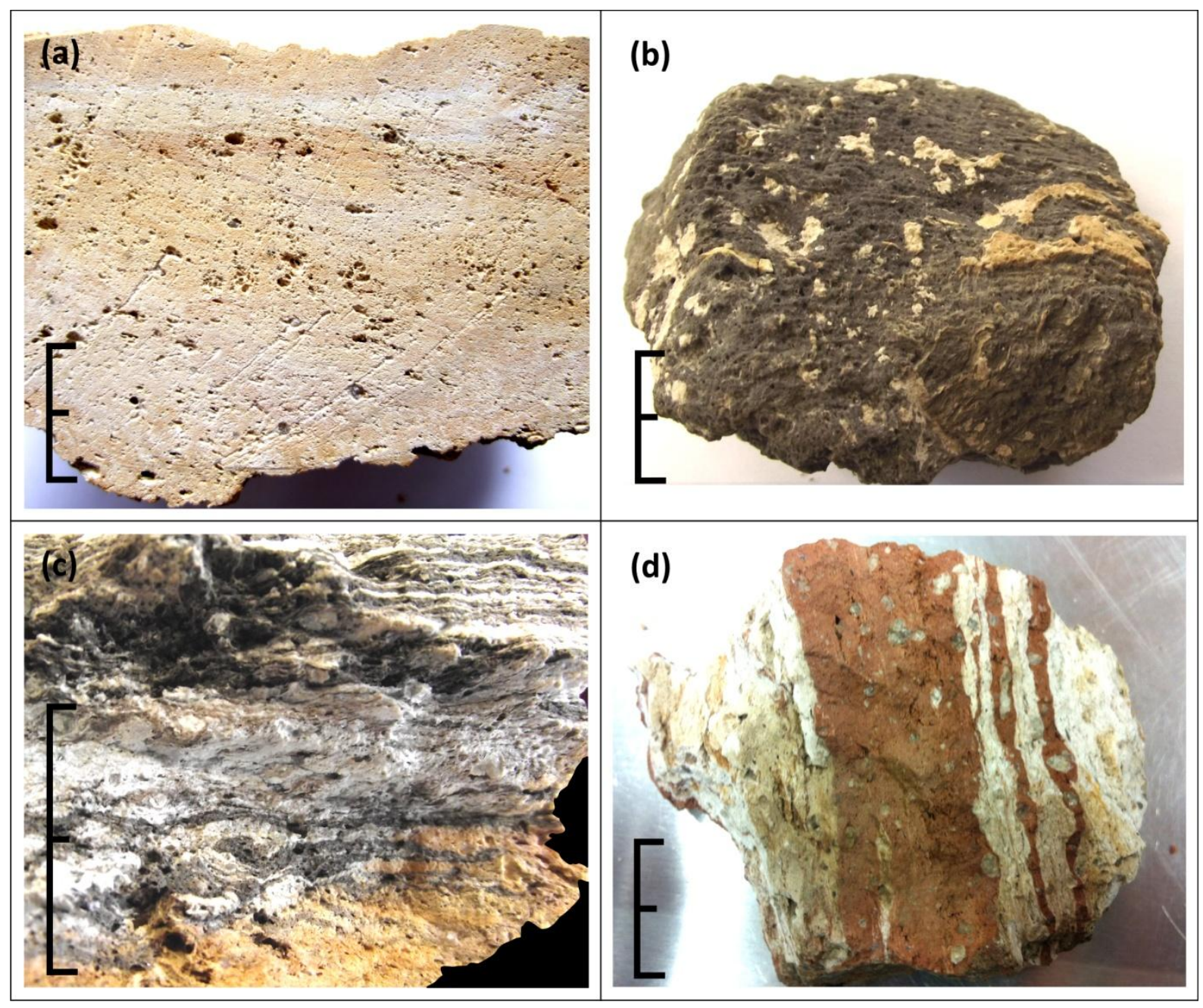

Fig. 2.6. The range in Bishop variant pumice types from swirly to chocolate types. (a) Watterson subunit swirly pumice with varying degrees of oxidation; (b) a small chocolatecoloured pumice clast, crystal poor, from unit Ig1Eb. Typically, evidence of magma mixing is present in dark (c), swirly and dacitic (d) clasts where a white more-evolved magma mixes with a darker, less-evolved magma. Scale bar is $20 \mathrm{~mm}$ in length for all images.

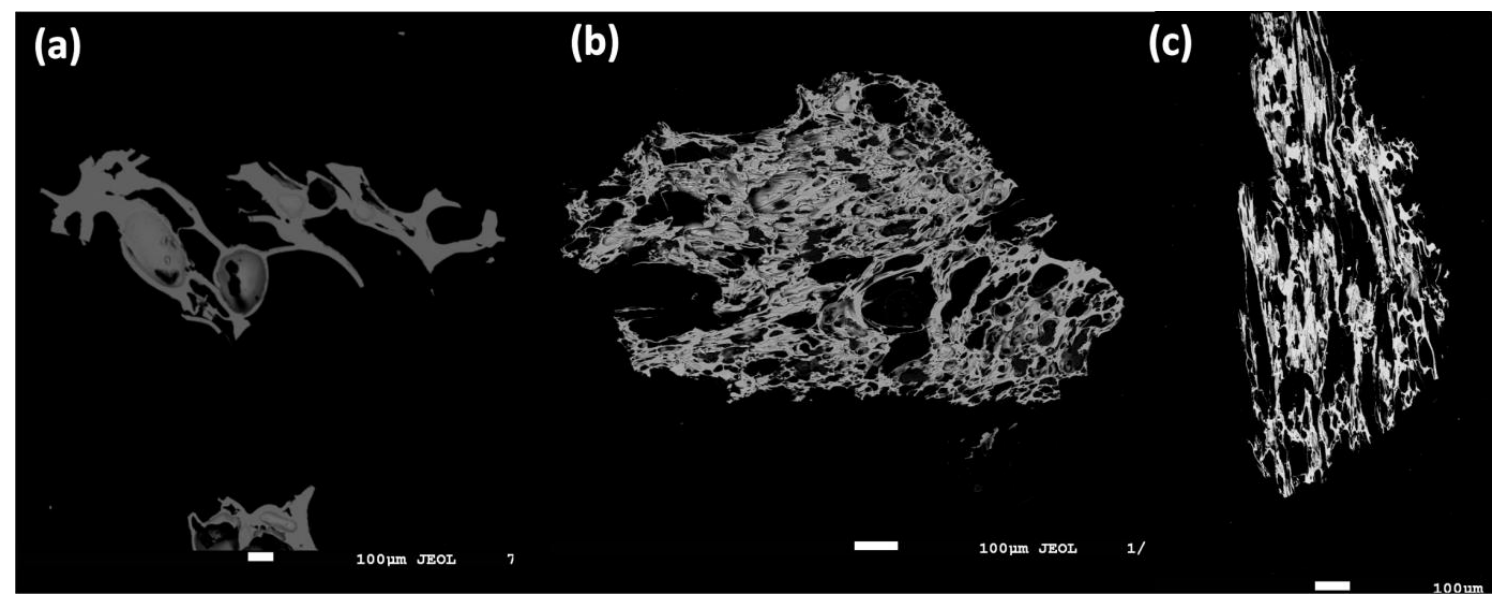

Fig. 2.7. Compilation of BSE images of glass shards $(0.5-1 \mathrm{~mm})$. The thick glass walls of the glistener type pumice (a) are evident when compared to that of typical eastern (b) and northern (c) glass shards. Scale bars are $100 \mu \mathrm{m}$ in length. 


\subsection{Sample preparation}

\subsubsection{Cleaning and crushing}

On return from the field, samples were scrubbed under tap water to remove any adhering ash or biological material. Samples were then soaked for a minimum of $12 \mathrm{~h}$ in milli-RO water and lightly scrubbed again, before being dried for at least $24 \mathrm{~h}$ at $100{ }^{\circ} \mathrm{C}$. Large samples that were $>20 \mathrm{~cm}$ diameter were cut into smaller fragments using a diamond saw. The cut pieces were then scrubbed and soaked in milli-RO water to remove any contamination from the sawing process. Finally, the samples were dried again at $100{ }^{\circ} \mathrm{C}$. The dried samples were crushed using either a Boyd crusher at $4 \mathrm{~mm}$ plate width or a hydraulic press to roughly crush the pumice to $<15 \mathrm{~mm}$ pieces. Where samples were being crushed to extract zircons, roughly crushed material was then milled to $<250 \mu \mathrm{m}$ in grainsize using a tungsten carbide Tema swing mill.

\subsubsection{Sieving and separation}

Crushed samples were dry sieved into $4 \mathrm{~mm}, 2 \mathrm{~mm}, 1 \mathrm{~mm}, 500 \mu \mathrm{m}, 250 \mu \mathrm{m}$ and $125 \mu \mathrm{m}$ size fractions. The $1-2 \mathrm{~mm}, 0.5-1 \mathrm{~mm}$ and $250-500 \mu \mathrm{m}$ size fractions were then roughly separated into crystal and glass fractions by water-panning in tap water. These separates were dried at $100{ }^{\circ} \mathrm{C}$ for a minimum of $12 \mathrm{~h}$. Samples for zircon extraction were subjected to the same procedures described above before being wet sieved at $60 \mu \mathrm{m}$ using a fresh piece of sieve cloth for each sample. The zircon-bearing fraction $(250-60 \mu \mathrm{m})$ was retained and dried at $100{ }^{\circ} \mathrm{C}$, as was the $<60 \mu \mathrm{m}$ pan fraction.

\subsection{EPMA major element analysis of minerals and glass separates}

\subsubsection{Mounting, polishing and coating samples}

Crystals were hand-picked under a binocular microscope from the sieved size fractions of crushed material after water panning. Quartz and feldspar grains were hand-picked from the 1-2 mm fraction; biotite crystals and glass shards from the $0.5-1 \mathrm{~mm}$ fraction and pyroxene crystals from the $250-500 \mu \mathrm{m}$ fractions. The picked material was mounted on double sided sticky tape on a glass slide. Where crystal axes could be distinguished from the crystal morphologies, the grains were mounted parallel to the $c$-axis to ensure a perpendicular section through the crystal was obtained. The crystals were then mounted in either Epotech or Epofix epoxy resin, which was left to harden into a $25 \mathrm{~mm}$ disc for at least $12 \mathrm{~h}$. The disc was removed from the mould before being ground down to expose the crystals. The mounts were then polished using diamond paper and finely polished using a 3 
$\mu \mathrm{m}$ and $1 \mu \mathrm{m}$ diamond lap. Once polished the mounts were imaged under a binocular microscope, and then coated with carbon before electron probe microanalysis (EPMA).

\subsubsection{Analysing conditions}

Major element analyses were undertaken on a JEOL JXA 8230 SuperProbe at Victoria University of Wellington (VUW). Quantitative analyses were made using wavelength dispersive spectrometry (WDS) relative to international mineral and glass standards with similar matrix compositions to the crystals or glass being analysed (Table 2.2). Measurement conditions were varied depending on the material being analysed (Table 2.3). For all material, apart from when undertaking $\mathrm{Sr}$ analyses on sanidine, an accelerating voltage of $15 \mathrm{kV}$ was used for analyses. For all major element analyses on-peak counts were $30 \mathrm{~s}$, with backgrounds measured for a total of $15 \mathrm{~s}$ apart from when measuring $\mathrm{Na}$ in glass, where the peak was accurately located using multiple accumulations during standardisation. The $\mathrm{Na}$ peak was only measured for $12 \mathrm{~s}$, with $12 \mathrm{~s}$ of background measurement, in order to reduce the effects of $\mathrm{Na}$ volatilisation by the electron beam. For $\mathrm{Sr}$ and $\mathrm{Ba}$ analyses in sanidine, in order to increase the precision of the analyses, on-peak count times were $240 \mathrm{~s}$ (with $120 \mathrm{~s}$ background times) and $120 \mathrm{~s}$ (with $60 \mathrm{~s}$ background times) respectively. When more than one element was analysed on one channel, the element with the lower atomic number was always measured first.

Table 2.2. EPMA calibrating standards

\begin{tabular}{|c|c|c|c|c|c|c|}
\hline \multirow[t]{2}{*}{ Material } & Standard & Standard & Standard & Standard & Standard & Standard \\
\hline & Elements & Elements & Elements & Elements & Elements & Elements \\
\hline \multirow[t]{2}{*}{ Glass } & $\begin{array}{l}\text { VG-568 } \\
\text { Rhyolitic Glass }\end{array}$ & $\begin{array}{l}\text { VG-A99 } \\
\text { Basaltic Glass }\end{array}$ & $\begin{array}{l}\text { ATHO Rhyolitic } \\
\text { Glass }\end{array}$ & $\begin{array}{l}\text { Manganese } \\
\text { Oxide* }\end{array}$ & Benitoite & \\
\hline & $\mathrm{Si}, \mathrm{Al}, \mathrm{K}, \mathrm{Na}$ & $\mathrm{Mg}, \mathrm{Ca}, \mathrm{Ti}$ & $\mathrm{Fe}$ & $M n$ & $B a$ & \\
\hline \multirow[t]{2}{*}{ Feldspar } & Orthoclase & Plagioclase & Iron Oxide* & $\begin{array}{l}\text { Manganese } \\
\text { Oxide* }\end{array}$ & $\begin{array}{l}\text { Titanium } \\
\text { Oxide* }\end{array}$ & Benitoite \\
\hline & $S i, A l, K$ & $\mathrm{Na}, \mathrm{Ca}$ & $\mathrm{Fe}$ & $M n$ & $\mathrm{Ti}$ & $B a$ \\
\hline \multirow[t]{2}{*}{ Biotite } & $\begin{array}{l}\text { Biotite PSU 5- } \\
110\end{array}$ & Kakanui Augite & $\begin{array}{l}\text { Titanium } \\
\text { Oxide* }\end{array}$ & $\begin{array}{l}\text { Chromium } \\
\text { Oxide* }\end{array}$ & & \\
\hline & $\mathrm{Si}, \mathrm{Al}, \mathrm{Mg}, \mathrm{Fe}, \mathrm{K}$ & $\mathrm{Na}, \mathrm{Ca}$ & $T i$ & $\mathrm{Cr}$ & & \\
\hline \multirow[t]{2}{*}{ Clinopyroxene } & Kakanui Augite & Hornblende & $\begin{array}{l}\text { Chromium } \\
\text { Oxide* }\end{array}$ & $\begin{array}{l}\text { Manganese } \\
\text { Oxide* }\end{array}$ & & \\
\hline & $\begin{array}{l}\mathrm{Si}, \mathrm{Al}, \mathrm{Na}, \mathrm{Mg} \\
\mathrm{Ca}, \mathrm{Fe}, \mathrm{Ti}\end{array}$ & $K$ & $\mathrm{Cr}$ & $M n$ & & \\
\hline \multirow[t]{2}{*}{ Orthopyroxene } & Hypersthene & Kakanui Augite & Hornblende & $\begin{array}{l}\text { Chromium } \\
\text { Oxide* } \\
\end{array}$ & $\begin{array}{l}\text { Titanium } \\
\text { Oxide* }\end{array}$ & $\begin{array}{l}\text { Manganese } \\
\text { Oxide* }\end{array}$ \\
\hline & $\begin{array}{l}\mathrm{Si}, \mathrm{Al}, \mathrm{Mg}, \mathrm{Ca} \text {, } \\
\mathrm{Fe}\end{array}$ & $\mathrm{Na}$ & $K$ & $\mathrm{Cr}$ & $\mathrm{Ti}$ & $M n$ \\
\hline
\end{tabular}

* identifies synthetic rather than natural standards 
Table 2.3. EPMA operating conditions

\begin{tabular}{lll} 
Material & Analysing current $(\mathbf{n A})$ & Beam diameter $(\boldsymbol{\mu m})$ \\
\hline \hline Glass and melt inclusions & 8 & 15 \\
Feldspar & 12 & Spot $-\sim 1 \mu \mathrm{m}$ \\
Biotite & 12 & Spot $-\sim 1 \mu \mathrm{m}$ \\
Clinopyroxene & 12 & Spot $-\sim 1 \mu \mathrm{m}$ \\
Orthopyroxene & 12 & Spot $-\sim 1 \mu \mathrm{m}$ \\
Sanidine (for Sr) & 40 & 5 \\
\hline
\end{tabular}

Major element concentrations were all calculated using the standard ZAF correction method (as part of the JEOL PC-SEM software version 3.0.1.6), and results are presented as the weight percent (wt.\%) oxide concentration, with all Fe calculated as FeO. Grains were imaged in back-scattered electron (BSE) mode before or after analysis so that analysis points could be accurately recorded, and any chemical zoning imaged and analysed. Trace elements in sanidine ( $\mathrm{Sr}, \mathrm{Ba}$ ) were analysed using a $40 \mathrm{nA}$ current, $20 \mathrm{kV}$ accelerating voltage, and a defocused beam of $5 \mu \mathrm{m}$. Peaks were accurately located each time, and background measurements were made within $2 \mathrm{~mm}$ of the peak location, rather than the standard $5 \mathrm{~mm}$, to avoid overlap with nearby peaks.

\subsubsection{Standard analyses}

Calibrated standards were run as unknowns throughout EPMA analyses, interspersed between every 4-10 true unknowns, to monitor instrumental drift and the precision and accuracy of the output data. Where instrumental measurements produced oxide totals with more than $\sim 10 \%$ variation from the reference value data acquisition was halted and new calibrating standards were run to improve precision. Tables 2.4 to 2.10 show that the accuracy of standard analyses of major elements ( $>5 \mathrm{wt} . \%$ concentration) is nearly always within $5 \%(2 \sigma)$, and always within $1 \mathrm{wt} . \%$ for minor elements (1-5 wt. $\%)$. Trace and minor elements have a lower accuracy due to the reduced difference in counts between the peak and background measurements from the lower concentrations. When Sr was measured in sanidine the uncertainties are much higher due to the overlap between the Si and Sr peaks. This was mitigated by increasing the analysing current, and narrowing the window for background measurements and the precision of the measurements is $\pm 75 \mathrm{ppm}$ ( 2 s.d.) comparable to that obtained in Ginibre et al. (2002). 
Table 2.4. Precision and accuracy of EPMA analyses of VG-568 rhyolitic glass; $n=420$

\begin{tabular}{ccccccccccc} 
& $\mathbf{S i O}_{\mathbf{2}}$ & $\mathrm{Al}_{\mathbf{2}} \mathbf{O}_{\mathbf{3}}$ & $\mathrm{TiO}_{\mathbf{2}}$ & $\mathrm{FeO}$ & $\mathrm{MnO}$ & $\mathbf{M g O}$ & $\mathbf{C a O}$ & $\mathbf{N a}_{\mathbf{2}} \mathbf{O}$ & $\mathbf{K}_{\mathbf{2}} \mathrm{O}$ & $\mathrm{BaO}$ \\
\hline \hline Average & 76.19 & 11.95 & 0.07 & 1.08 & 0.02 & 0.02 & 0.46 & 3.37 & 4.96 & 0.01 \\
Maximum & 78.74 & 12.21 & 0.10 & 2.05 & 0.12 & 0.50 & 0.59 & 3.87 & 5.16 & 0.05 \\
Minimum & 72.87 & 11.22 & 0.01 & 0.54 & 0.00 & 0.00 & 0.31 & 1.43 & 4.72 & 0.00 \\
$2 \sigma($ wt.\%) & 2.00 & 0.37 & 0.03 & 0.31 & 0.04 & 0.02 & 0.08 & 0.67 & 0.18 & 0.02 \\
$2 \sigma(\%)$ & 2.6 & 3.1 & 45 & 29 & 165 & 93 & 18 & 20 & 3.6 & 319 \\
Ref Value & 76.96 & 12.17 & 0.08 & 1.08 & 0.02 & 0.03 & 0.45 & 3.52 & 4.93 & 0.00 \\
Offset(wt.\%) & 0.77 & 0.22 & $<0.05$ & $<0.05$ & $<0.05$ & $<0.05$ & $<0.05$ & 0.15 & $<0.05$ & $<0.05$ \\
\hline
\end{tabular}

Reference values from: Jarosewich et al. (1980).

Table 2.5. Precision and accuracy of EPMA analyses of orthoclase Or_1A used for sanidine analyses; $\mathrm{n}=310$

\begin{tabular}{cccccccccc} 
& $\mathbf{S i O}_{\mathbf{2}}$ & $\mathbf{A l}_{\mathbf{2}} \mathbf{O}_{\mathbf{3}}$ & $\mathrm{TiO}_{\mathbf{2}}$ & $\mathbf{F e O}$ & $\mathbf{M g O}$ & $\mathbf{C a O}$ & $\mathbf{N a}_{2} \mathbf{O}$ & $\mathbf{K}_{\mathbf{2}} \mathbf{O}$ & $\mathbf{B a O}$ \\
\hline \hline Average & 64.51 & 18.27 & 0.00 & 0.01 & 0.00 & 0.04 & 0.98 & 14.93 & 0.81 \\
Maximum & 68.49 & 19.91 & 0.03 & 0.13 & 0.05 & 0.37 & 3.06 & 16.15 & 1.06 \\
Minimum & 61.84 & 17.37 & 0.00 & 0.00 & 0.00 & 0.00 & 0.46 & 10.91 & 0.00 \\
$2 \sigma($ wt.\%) & 2.13 & 0.92 & 0.01 & 0.03 & 0.01 & 0.06 & 0.31 & 0.87 & 0.28 \\
$2 \sigma(\%)$ & 3.3 & 5.0 & 570 & 300 & 990 & 160 & 31 & 5.8 & 35 \\
Ref Value & 64.39 & 18.19 & 0.00 & 0.03 & 0.00 & 0.00 & 1.14 & 14.92 & 0.82 \\
Offset (wt.\%) & 0.12 & 0.08 & $<0.05$ & $<0.05$ & $<0.05$ & $<0.05$ & 0.16 & $<0.05$ & $<0.05$ \\
\hline
\end{tabular}

Reference values from: Ingamells (1980) and Goldich et al. (1967).

Table 2.6.Precision and accuracy of EPMA analyses of plagioclase NMNH 115900; $\mathrm{n}=167$

\begin{tabular}{llllllllll} 
& $\mathbf{S i O}_{2}$ & $\mathbf{A l}_{2} \mathbf{O}_{\mathbf{3}}$ & $\mathrm{TiO}_{2}$ & $\mathbf{F e O}$ & $\mathbf{M g O}$ & $\mathbf{C a O}$ & $\mathbf{N a}_{2} \mathbf{O}$ & $\mathbf{K}_{\mathbf{2}} \mathbf{O}$ & $\mathbf{B a O}$ \\
\hline \hline Average & 51.65 & 29.59 & 0.03 & 0.46 & 0.14 & 13.70 & 3.50 & 0.13 & 0.01 \\
Maximum & 54.25 & 31.33 & 0.05 & 0.54 & 0.21 & 14.46 & 4.35 & 0.16 & 0.08 \\
Minimum & 49.62 & 27.74 & 0.00 & 0.39 & 0.10 & 12.25 & 2.59 & 0.11 & 0.00 \\
$2 \sigma($ wt.\%) & 1.33 & 1.78 & 0.03 & 0.06 & 0.03 & 0.69 & 0.38 & 0.02 & 0.04 \\
$2 \sigma(\%)$ & 2.6 & 6.0 & 100 & 13 & 24 & 5.0 & 11 & 15 & 280 \\
Ref Value & 51.25 & 30.91 & 0.05 & 0.46 & 0.14 & 13.64 & 3.45 & 0.18 & 0.05 \\
Offset (wt.\%) & 0.40 & 1.32 & $<0.05$ & $<0.05$ & $<0.05$ & 0.06 & 0.05 & 0.05 & $<0.05$ \\
\hline
\end{tabular}

Reference values from: Jarosewich et al. (1980).

Table 2.7. Precision and accuracy of EPMA analyses of hypersthene USNM 746; $n=102$

\begin{tabular}{lllllllllll} 
& $\mathrm{SiO}_{2}$ & $\mathrm{Al}_{2} \mathrm{O}_{3}$ & $\mathrm{TiO}_{2}$ & $\mathrm{FeO}$ & $\mathrm{MnO}$ & $\mathrm{MgO}$ & $\mathrm{CaO}$ & $\mathrm{Na}_{2} \mathrm{O}$ & $\mathrm{K}_{2} \mathrm{O}$ & $\mathrm{Cr}_{2} \mathrm{O}_{3}$ \\
\hline \hline Average & 54.45 & 1.14 & 0.07 & 15.21 & 0.49 & 27.30 & 1.44 & 0.02 & 0.01 & 0.67 \\
Maximum & 55.65 & 1.29 & 0.11 & 15.70 & 0.53 & 28.42 & 1.62 & 0.04 & 0.02 & 0.87 \\
Minimum & 54.17 & 0.98 & 0.06 & 15.23 & 0.43 & 26.85 & 1.26 & 0.00 & 0.00 & 0.53 \\
$2 \sigma($ wt.\%) & 1.36 & 0.26 & 0.03 & 0.68 & 0.05 & 1.38 & 0.24 & 0.02 & 0.01 & 0.16 \\
$2 \sigma(\%)$ & 2.5 & 23 & 51 & 4.5 & 10 & 5.0 & 17 & 130 & 130 & 24 \\
Ref Value & 54.09 & 1.23 & 0.16 & 15.22 & 0.49 & 26.79 & 1.52 & 0.00 & 0.00 & 0.75 \\
Offset(wt.\%) & 0.36 & 0.09 & 0.09 & $<0.05$ & $<0.05$ & 0.51 & 0.08 & $<0.05$ & $<0.05$ & 0.08 \\
\hline
\end{tabular}

Reference values from: Jarosewich et al. (1980).

Table 2.8. Precision and accuracy of EPMA analyses of Kakanui augite; $\mathrm{n}=34$

\begin{tabular}{lllllllllll} 
& $\mathrm{SiO}_{2}$ & $\mathrm{Al}_{2} \mathrm{O}_{\mathbf{3}}$ & $\mathrm{TiO}_{2}$ & $\mathrm{FeO}$ & $\mathrm{MnO}$ & $\mathrm{MgO}$ & $\mathrm{CaO}$ & $\mathrm{Na}_{2} \mathrm{O}$ & $\mathrm{K}_{2} \mathrm{O}$ & $\mathrm{Cr}_{2} \mathrm{O}_{3}$ \\
\hline \hline Average & 50.88 & 8.80 & 0.76 & 6.40 & 0.14 & 17.09 & 15.92 & 1.28 & 0.01 & 0.14 \\
Maximum & 51.19 & 8.99 & 0.79 & 6.55 & 0.18 & 17.26 & 16.09 & 1.35 & 0.02 & 0.21 \\
Minimum & 50.50 & 8.62 & 0.73 & 6.27 & 0.09 & 16.89 & 15.78 & 1.21 & 0.00 & 0.07 \\
$2 \sigma($ wt.\%) & 0.38 & 0.15 & 0.03 & 0.15 & 0.04 & 0.17 & 0.17 & 0.07 & 0.01 & 0.08 \\
$2 \sigma(\%)$ & 0.76 & 1.7 & 4.2 & 2.4 & 26 & 1.0 & 1.1 & 5.1 & 150 & 57 \\
Ref Value & 50.73 & 8.73 & 0.74 & 6.34 & 0.13 & 16.65 & 15.82 & 1.27 & 0.00 & 0.15 \\
Offset(wt.\%) & 0.15 & 0.07 & $<0.05$ & 0.06 & $<0.05$ & 0.44 & 0.10 & $<0.05$ & $<0.05$ & $<0.05$ \\
\hline
\end{tabular}

Reference values from: Jarosewich et al. (1980) and Klügel et al. (2005) 
Table 2.9. Precision and accuracy of EPMA analyses of biotite PSU 5-110; $\mathrm{n}=121$

\begin{tabular}{lllllllllll} 
& $\mathrm{SiO}_{\mathbf{2}}$ & $\mathrm{Al}_{\mathbf{2}} \mathbf{O}_{\mathbf{3}}$ & $\mathrm{TiO}_{\mathbf{2}}$ & $\mathrm{FeO}$ & $\mathrm{MgO}$ & $\mathrm{CaO}$ & $\mathrm{Na}_{\mathbf{2}} \mathbf{O}$ & $\mathbf{K}_{\mathbf{2}} \mathbf{O}$ & $\mathrm{Cr}_{\mathbf{2}} \mathrm{O}_{\mathbf{3}}$ & $\mathrm{BaO}$ \\
\hline \hline Average & 37.44 & 12.59 & 1.72 & 10.53 & 19.75 & 0.01 & 0.26 & 10.14 & 0.25 & 0.50 \\
Maximum & 40.20 & 13.68 & 2.25 & 11.63 & 21.20 & 0.09 & 0.31 & 10.50 & 0.41 & 0.77 \\
Minimum & 33.02 & 11.21 & 1.13 & 9.31 & 17.66 & 0.00 & 0.18 & 8.65 & 0.12 & 0.20 \\
$2 \sigma($ wt.\%) & 2.32 & 1.06 & 0.38 & 0.80 & 1.13 & 0.03 & 0.04 & 0.64 & 0.13 & 0.26 \\
$2 \sigma(\%)$ & 6.2 & 8.4 & 22 & 7.6 & 5.7 & 260 & 18 & 6.3 & 52 & 51 \\
Ref Value & 38.63 & 13.08 & 1.55 & 11.00 & 19.94 & 0.18 & 0.26 & 10.00 & 0.23 & 0.45 \\
Offset(wt.\%) & 1.19 & 0.49 & 0.17 & 0.47 & 0.19 & 0.17 & $<0.05$ & 0.14 & $<0.05$ & 0.05 \\
\hline
\end{tabular}

Reference values from: Ingamells (1979).

Table 2.10. Precision and accuracy of EPMA analyses of orthoclase Or_1A for Sr diffusion analyses in sanidine; $\mathrm{n}=357$

\begin{tabular}{lccccccc} 
& $\mathbf{S i O}_{\mathbf{2}}$ & $\mathbf{A l}_{\mathbf{2}} \mathbf{O}_{\mathbf{3}}$ & $\mathbf{N a}_{\mathbf{2}} \mathbf{O}$ & $\mathbf{K}_{\mathbf{2}} \mathbf{O}$ & $\mathbf{B a O}$ & $\mathbf{S r O}$ & $\mathrm{Sr}(\mathbf{p p m})$ \\
\hline \hline Average & 64.28 & 18.69 & 1.65 & 14.66 & 0.80 & 0.045 & 377 \\
Maximum & 67.99 & 19.97 & 2.53 & 15.59 & 0.83 & 0.057 & 482 \\
Minimum & 62.53 & 18.08 & 1.08 & 10.35 & 0.76 & 0.032 & 271 \\
$2 \sigma($ wt.\%) & 1.55 & 0.53 & 1.21 & 1.10 & 0.03 & 0.009 & 73 \\
$2 \sigma(\%)$ & 2.4 & 2.8 & 73 & 7.5 & 3.9 & 20 & 20 \\
Ref Value & 64.39 & 18.19 & 1.14 & 14.92 & 0.82 & 0.034 & 288 \\
Offset (wt.\%) & 0.11 & -0.50 & -0.51 & 0.26 & $<0.05$ & $<0.05$ & -89
\end{tabular}

Reference values from: Ingamells, 1980, and Goldlich et al., 1967.

\subsection{LA-ICPMS trace element analysis of minerals and glass separates}

Mineral and glass trace element compositions were measured in situ using a New Wave deep UV laser (193 $\mathrm{nm}$ solid state) coupled to an Agilent $7500 \mathrm{cs}$ inductively coupled plasma mass spectrometer (ICP-MS) in the geochemical analytical laboratory of VUW. Sample mounts from EPMA analysis were cleaned using methanol to remove the carbon coating, and then sawn in half so that mounts would fit in the laser ablation chamber along with a standard mount.

\subsubsection{Analysing conditions}

After loading the sample and standard into the ablation chamber, the ICP-MS was tuned by ablating the standards NIST 612 (for feldspars and glass) or BCR-2G (for mafic minerals). Prior to analysis, pulse/analog (P/A) factors were measured on all high concentration elements to ensure that the ICP-MS was correctly performing the switch from pulse counting mode (use for low concentrations) to analog counting mode (for high concentrations, i.e. more than $1 \times 10^{6}$ counts per second). Instrumental tuning conditions were adjusted to achieve the lowest relative standard deviation (RSD) on the ablation signal and also to optimise the sensitivity of the ICP-MS. This was largely accomplished by changing the optional gas (helium) flow and torch position. ThO/Th ratios were monitored to ensure that oxide production was $<2 \%$, and to minimise potential polyatomic isobaric interferences. Samples were analysed in runs of $\leq 20$ unknowns, with a bracketing 
standard being analysed every 5 unknowns. Both unknown samples and standards were ablated for $60 \mathrm{~s}$, followed by a $60 \mathrm{~s}$ washout of the ablation cell. Laser ablation operating conditions, including spot size and laser power, were varied depending on the type of material being analysed (Table 2.11).

Table 2.11. Summary of LA-ICPMS measurement conditions

\begin{tabular}{|c|c|c|c|}
\hline Material & Laser Spot Diameter & Laser Power & Elements Analysed \\
\hline Sanidine & $50 \mu \mathrm{m}$ & $85 \%$ & $\begin{array}{l}{ }^{7} \mathrm{Li},{ }^{11} \mathrm{~B},{ }^{25} \mathrm{Mg},{ }^{29} \mathrm{Si},{ }^{43} \mathrm{Ca},{ }^{55} \mathrm{Mn},{ }^{71} \mathrm{Ga},{ }^{85} \mathrm{Rb},{ }^{86} \mathrm{Sr}, \\
{ }^{88} \mathrm{Sr},{ }^{137} \mathrm{Ba},{ }_{138}{ }^{8 a},{ }^{139} \mathrm{La},{ }^{140} \mathrm{Ce},{ }^{141} \mathrm{Pr},{ }^{146} \mathrm{Nd},{ }^{147} \mathrm{Sm}, \\
{ }^{151} \mathrm{Eu},{ }^{153} \mathrm{Eu},{ }^{208} \mathrm{~Pb} .\end{array}$ \\
\hline Plagioclase & $50 \mu \mathrm{m}$ & $85 \%$ & $\begin{array}{l}{ }^{7} \mathrm{Li},{ }^{25} \mathrm{Mg},{ }^{29} \mathrm{Si},{ }^{44} \mathrm{Ca},{ }^{45} \mathrm{Sc},{ }^{47} \mathrm{Ti},{ }^{51} \mathrm{~V},{ }^{53} \mathrm{Cr},{ }^{55} \mathrm{Mn}, \\
{ }^{59} \mathrm{Co},{ }^{60} \mathrm{Ni},{ }^{63} \mathrm{Cu},{ }^{66} \mathrm{Zn},{ }^{71} \mathrm{Ga},{ }^{85} \mathrm{Rb},{ }^{86} \mathrm{Sr},{ }^{88} \mathrm{Sr},{ }^{89} \mathrm{Y}, \\
{ }^{90} \mathrm{Zr},{ }^{91} \mathrm{Zr},{ }^{93} \mathrm{Nb},{ }^{95} \mathrm{Mo},{ }^{133} \mathrm{Cs},{ }^{138} \mathrm{Ba},{ }^{139} \mathrm{La},{ }^{140} \mathrm{Ce}, \\
{ }^{141} \mathrm{Pr},{ }^{146} \mathrm{Nd},{ }^{147} \mathrm{Sm},{ }^{151} \mathrm{Eu},{ }^{153} \mathrm{Eu},{ }^{157} \mathrm{Gd},{ }^{159} \mathrm{~Tb}, \\
{ }^{163} \mathrm{Dy},{ }^{165}{ }^{165},{ }^{166} \mathrm{Er},{ }^{169} \mathrm{Tm},{ }^{172} \mathrm{Yb},{ }^{175} \mathrm{Lu},{ }^{178} \mathrm{Hf}, \\
{ }^{181} \mathrm{Ta},{ }^{182} \mathrm{~W},{ }^{208} \mathrm{~Pb},{ }^{232} \mathrm{Th},{ }^{238} \mathrm{U} .\end{array}$ \\
\hline Glass & $35 \mu \mathrm{m}$ & $85 \%$ & $\begin{array}{l}{ }^{7} \mathrm{Li},{ }^{11} \mathrm{~B},{ }^{23} \mathrm{Na},{ }^{24} \mathrm{Mg},{ }^{29} \mathrm{Si},{ }^{43} \mathrm{Ca},{ }^{45} \mathrm{Sc},{ }^{47} \mathrm{Ti},{ }^{51} \mathrm{~V},{ }^{53} \mathrm{Cr}, \\
{ }^{55} \mathrm{Mn},{ }^{59} \mathrm{Co},{ }^{60} \mathrm{Ni},{ }^{63} \mathrm{Cu},{ }^{66} \mathrm{Zn},{ }^{71} \mathrm{Ga},{ }^{85} \mathrm{Rb},{ }^{86} \mathrm{Sr},{ }^{88} \mathrm{Sr}, \\
{ }^{89} \mathrm{Y},{ }^{91} \mathrm{Zr},{ }^{92} \mathrm{Zr},{ }^{93} \mathrm{Nb},{ }^{95} \mathrm{Mo},{ }^{133} \mathrm{Cs},{ }^{138} \mathrm{Ba},{ }^{139} \mathrm{La}, \\
{ }^{140} \mathrm{Ce},{ }^{141} \mathrm{Pr},{ }^{146} \mathrm{Nd},{ }^{147} \mathrm{Sm},{ }^{151} \mathrm{Eu},{ }^{153} \mathrm{Eu},{ }^{157} \mathrm{Gd}, \\
{ }^{159} \mathrm{~Tb},{ }^{163} \mathrm{Dy},{ }^{165} \mathrm{Ho},{ }^{166} \mathrm{Er},{ }^{169}{ }^{16 m},{ }^{172} \mathrm{Yb},{ }^{175} \mathrm{Lu}, \\
{ }^{178} \mathrm{Hf},{ }^{181} \mathrm{Ta},{ }^{182} \mathrm{~W},{ }^{208} \mathrm{~Pb},{ }^{232} \mathrm{Th},{ }^{238} \mathrm{U} .\end{array}$ \\
\hline Pyroxene & $35 \mu \mathrm{m}$ & $85 \%$ & $\begin{array}{l}{ }^{7} \mathrm{Li},{ }^{25} \mathrm{Mg},{ }^{29} \mathrm{Si},{ }^{44} \mathrm{Ca},{ }^{45} \mathrm{Sc},{ }^{47} \mathrm{Ti},{ }^{51} \mathrm{~V},{ }^{53} \mathrm{Cr},{ }^{55} \mathrm{Mn}, \\
{ }^{59} \mathrm{Co},{ }^{60} \mathrm{Ni},{ }^{63} \mathrm{Cu},{ }^{66} \mathrm{Zn},{ }^{69} \mathrm{Ga},{ }^{85} \mathrm{Rb},{ }^{86} \mathrm{Sr},{ }^{88} \mathrm{Sr},{ }^{89} \mathrm{Y}, \\
{ }^{90} \mathrm{Zr},{ }^{93} \mathrm{Nb},{ }^{95} \mathrm{Mo},{ }^{133}{ }^{13 s},{ }^{137} \mathrm{Ba},{ }^{139}{ }^{2} \mathrm{La},{ }^{140} \mathrm{Ce},{ }^{141} \mathrm{Pr}, \\
{ }^{146} \mathrm{Nd},{ }^{147} \mathrm{Sm},{ }^{153} \mathrm{Eu},{ }^{157} \mathrm{Gd},{ }^{159} \mathrm{~Tb},{ }^{163} \mathrm{Dy},{ }^{165} \mathrm{Ho}, \\
{ }^{166} \mathrm{Er},{ }^{169} \mathrm{Tm},{ }^{172} \mathrm{Yb},{ }^{175} \mathrm{Lu},{ }^{178} \mathrm{Hf},{ }^{181} \mathrm{Ta},{ }^{182} \mathrm{~W}, \\
{ }^{208} \mathrm{~Pb},{ }^{232} \mathrm{Th},{ }^{238} \mathrm{U} .\end{array}$ \\
\hline
\end{tabular}

\subsubsection{Data processing}

Raw data in counts per second (cps) were extracted from the ICPMS software in a .csv format. This file was then processed in Iolite ${ }^{\mathrm{TM}}$ using either ${ }^{29} \mathrm{Si}$ or ${ }^{43} \mathrm{Ca}$ to internally normalise data. The value for $\mathrm{Si}$ (or $\mathrm{Ca}$ ) was calculated using the formula (from $\mathrm{SiO}_{2}$ or $\mathrm{CaO}$ concentrations from EPMA analyses):

$$
\mathrm{Si}=\mathrm{SiO}_{2} \text { measured }(w t \%) \times\left[\frac{\text { Si atomic weight }}{\mathrm{SiO}_{2} \text { atomic weight }}\right]
$$


Firstly, the 60 second backgrounds were selected to give a baseline to remove from measured peaks. Then, the NIST-612 or BCR-2G analyses were highlighted to measure the change in the response of the machine to a known standard. Finally peaks in the unknowns were selected and labelled to correct using the measurements from EPMA. When selecting the peaks it was important to ensure that no contamination (from ablating anything other than the targeted species, such as small mineral/melt inclusions) was included in the peaks. Count traces from multiple elements were therefore scrutinised to ensure that ablation had occurred of the pure target species. For example, had an oxide inclusion been partly ablated with glass, one would expect to see a peak in such elements as V, Fe, Ti and other transition metals. Similarly, if a sanidine inclusion was accidentally ablated whilst analysing a pyroxene crystal, abnormal peaks in Ba, Sr and LREE could reveal this as an unusable data point.

\subsubsection{Standard analyses}

Secondary standards were not run as bracketing standards during LA-ICPMS analytical sessions. Instead, complete runs of ATHO-G and BCR-2G were carried out throughout the time of LA-ICPMS measurements to track the long term reproducibility of the standard data. Nearly all elements have $2 \sigma$ uncertainty of $<20 \%$ although this is commonly $<15 \%$ for ATHO-G (see Tables 2.12 and 2.13). BCR-2G yielded results that are more precise (possible due to mafic phases analyses being carried out over a period of $\sim 9$ months, compared with $\sim 27$ months for felsic phases and glass) with $2 \sigma$ generally $<10 \%$. BCR-2G is accurate to within $10 \%$ of the published values, however ATHO is generally within $20 \%$ of the published values (Fig. 2.8). Where concentrations of elements in the standard and unknown are comparable the $2 \sigma$ (ppm) is used as the uncertainty on the unknown, however, where concentrations in the unknown are an order of magnitude (or more) different, the $2 \sigma$ (in \%) is applied to measured values, so that a $2 \sigma$ in ppm can be calculated.

\subsection{Ion probe analysis of zircons}

Secondary ionisation mass spectrometry (SIMS) was used to analyse zircon crystals. The Sensitive High-Resolution Ion MicroProbe- Reverse Geometry (SHRIMP-RG) instruments at the joint USGS-Stanford University (SUMAC) and the Australian National University (ANU) facilities, were used for U-Pb dating (SUMAC, ANU) and trace element analysis (SUMAC only). 

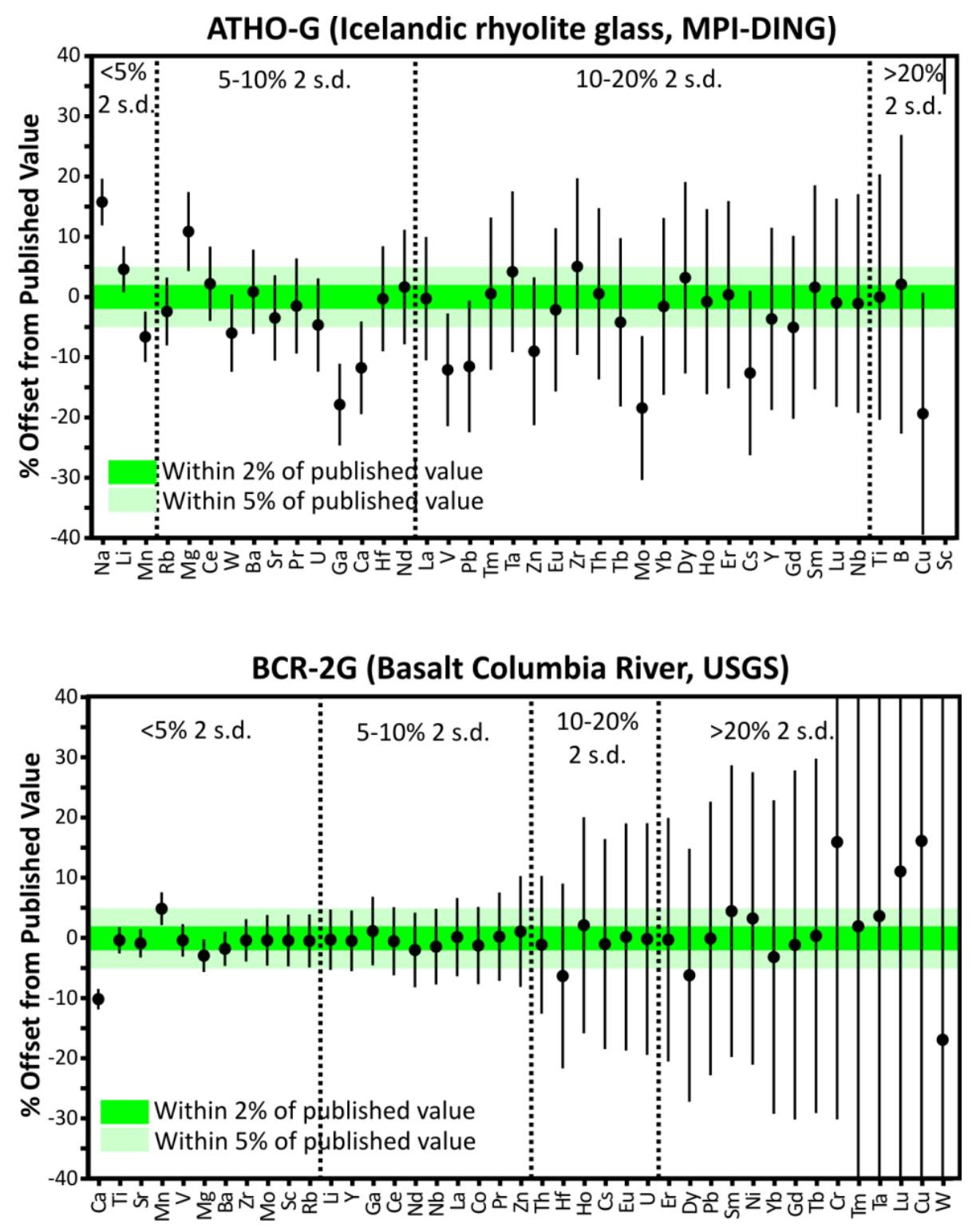

Fig. 2.8: Accuracy and precision of trace element data obtained by LA-ICPMS from both ATHO-G (for glass and feldspars) and BCR-2G (for pyroxenes). Elements arranged in order of increasing 2 s.d. (\%). Reference values using current (2013) values from GeoReM database (Jochum et al., 2005). 
Table 2.12: Precision and accuracy of LA-ICPMS analyses of ATHO-G standard; $n=34$

\begin{tabular}{|c|c|c|c|c|c|}
\hline Element & Average & $2 \sigma(p p m)$ & $2 \sigma(\%)$ & Published Value & Offset (\%) \\
\hline $\mathrm{Li}$ & 29.9 & 1.09 & 3.7 & 28.6 & 4.6 \\
\hline B & 5.82 & 1.41 & 24 & 5.70 & 2.1 \\
\hline $\mathrm{Na}$ & 32200 & 1080 & 3.4 & 27800 & 16 \\
\hline $\mathrm{Mg}$ & 708 & 42.0 & 5.9 & 639 & 11 \\
\hline $\mathrm{Ca}$ & 11800 & 1030 & 8.7 & 13300 & -12 \\
\hline Sc & 11.2 & 4.54 & 41 & 5.00 & 120 \\
\hline $\mathrm{Ti}$ & 1530 & 311 & 20 & 1530 & -0.02 \\
\hline V & 3.44 & 0.37 & 11 & 3.91 & -12 \\
\hline $\mathrm{Cr}$ & 3.76 & 3.50 & 93 & 6.10 & -28 \\
\hline $\mathrm{Mn}$ & 767 & 34.4 & 4.5 & 821 & -6.6 \\
\hline $\mathrm{Ni}$ & 15.6 & 13.8 & 88 & 13.0 & 20 \\
\hline $\mathrm{Cu}$ & 15.0 & 43.7 & 25 & 18.6 & -19 \\
\hline $\mathrm{Zn}$ & 128 & 17.3 & 14 & 141 & -9.0 \\
\hline $\mathrm{Ga}$ & 20.8 & 1.72 & 8.3 & 25.3 & -18 \\
\hline $\mathrm{Rb}$ & 63.7 & 3.68 & 5.8 & 65.3 & -2.4 \\
\hline $\mathrm{Sr}$ & 90.8 & 6.67 & 7.4 & 94.1 & -3.5 \\
\hline Y & 91.1 & 14.3 & 16 & 94.5 & -3.6 \\
\hline $\mathrm{Zr}$ & 538 & 75.1 & 14 & 512 & -5.1 \\
\hline Mo & 3.92 & 0.57 & 15 & 4.80 & -18 \\
\hline $\mathrm{Nb}$ & 61.7 & 11.3 & 18 & 62.4 & -1.1 \\
\hline Cs & 0.94 & 0.15 & 16 & 1.08 & -13 \\
\hline $\mathrm{Ba}$ & 552 & 38.3 & 7.0 & 547 & 0.86 \\
\hline La & 55.5 & 5.70 & 10 & 55.6 & -0.28 \\
\hline $\mathrm{Ce}$ & 124 & 7.48 & 6.1 & 121 & 2.2 \\
\hline $\operatorname{Pr}$ & 14.4 & 1.15 & 8.0 & 14.6 & -1.5 \\
\hline $\mathrm{Nd}$ & 61.9 & 5.80 & 9.4 & 60.9 & 1.7 \\
\hline Sm & 14.4 & 2.41 & 17 & 14.2 & 1.6 \\
\hline Eu & 2.70 & 0.37 & 14 & 2.76 & -2.1 \\
\hline $\mathrm{Gd}$ & 14.5 & 2.33 & 16 & 15.3 & -5.1 \\
\hline $\mathrm{Tb}$ & 2.40 & 0.35 & 15 & 2.51 & -4.2 \\
\hline Dy & 16.7 & 2.58 & 15 & 16.2 & 3.2 \\
\hline Ho & 3.40 & 0.53 & 15 & 3.43 & -0.78 \\
\hline $\mathrm{Er}$ & 10.3 & 1.60 & 16 & 10.3 & 0.37 \\
\hline $\mathrm{Tm}$ & 1.53 & 0.19 & 13 & 1.52 & 0.54 \\
\hline $\mathrm{Yb}$ & 10.3 & 1.54 & 15 & 10.5 & -1.6 \\
\hline Lu & 1.53 & 0.27 & 17 & 1.54 & -0.97 \\
\hline $\mathrm{Hf}$ & 13.7 & 1.20 & 8.8 & 13.7 & -0.30 \\
\hline $\mathrm{Ta}$ & 4.06 & 0.52 & 13 & 3.90 & 4.1 \\
\hline W & 8.74 & 0.60 & 6.8 & 9.30 & -6.0 \\
\hline $\mathrm{Pb}$ & 5.02 & 0.62 & 13 & 5.67 & -12 \\
\hline Th & 7.44 & 1.05 & 14 & 7.40 & 0.5 \\
\hline $\mathrm{U}$ & 2.26 & 0.18 & 8.1 & 2.37 & -4.7 \\
\hline
\end{tabular}

Reference values using current (2013) values from GeoReM database (Jochum et al., 2005). 
Table 2.13: Precision and accuracy of LA-ICPMS analyses of BCR-2G standard; $n=30$

\begin{tabular}{|c|c|c|c|c|c|}
\hline Element & Average & $2 \sigma(p p m)$ & $2 \sigma(\%)$ & Published Value & Offset (\%) \\
\hline $\mathrm{Li}$ & 8.97 & 0.45 & 5.0 & 9.00 & -0.31 \\
\hline $\mathrm{Mg}$ & 21400 & 600 & 2.8 & 22100 & -3.0 \\
\hline $\mathrm{Ca}$ & 49700 & 948 & 1.9 & 55400 & -10 \\
\hline Sc & 32.8 & 1.42 & 4.3 & 33.0 & -0.44 \\
\hline $\mathrm{Ti}$ & 14000 & 310 & 2.2 & 14100 & -0.39 \\
\hline v & 424 & 11.5 & 2.7 & 425 & -0.41 \\
\hline $\mathrm{Cr}$ & 19.7 & 7.83 & 40 & 17.0 & 16 \\
\hline $\mathrm{Mn}$ & 1540 & 40.0 & 2.6 & 1470 & 4.9 \\
\hline Co & 37.5 & 2.44 & 6.5 & 38.0 & -1.3 \\
\hline $\mathrm{Ni}$ & 13.4 & 3.16 & 24 & 13.0 & 3.2 \\
\hline $\mathrm{Cu}$ & 24.4 & 21.1 & 86 & 21.0 & -16 \\
\hline $\mathrm{Zn}$ & 126 & 11.5 & 9.1 & 125 & 1.1 \\
\hline $\mathrm{Ga}$ & 23.3 & 1.31 & 5.6 & 23.0 & 1.1 \\
\hline $\mathrm{Rb}$ & 46.8 & 2.07 & 4.4 & 47.0 & -0.51 \\
\hline $\mathrm{Sr}$ & 339 & 8.10 & 2.4 & 342 & -0.90 \\
\hline Y & 34.8 & 1.77 & 5.1 & 35.0 & -0.50 \\
\hline $\mathrm{Zr}$ & 183 & 6.50 & 3.5 & 184 & -0.41 \\
\hline $\mathrm{Nb}$ & 12.3 & 0.79 & 6.4 & 12.5 & -1.5 \\
\hline Mo & 269 & 11.4 & 4.2 & 270 & -0.40 \\
\hline Cs & 1.15 & 0.20 & 18 & 1.16 & -1.0 \\
\hline $\mathrm{Ba}$ & 671 & 19.5 & 2.9 & 683 & -1.2 \\
\hline La & 24.7 & 1.61 & 6.5 & 24.7 & 0.13 \\
\hline $\mathrm{Ce}$ & 53.0 & 3.02 & 5.7 & 53.3 & -0.55 \\
\hline $\operatorname{Pr}$ & 6.71 & 0.49 & 7.3 & 6.70 & 0.20 \\
\hline $\mathrm{Nd}$ & 28.3 & 1.79 & 6.3 & 28.9 & -2.0 \\
\hline $\mathrm{Sm}$ & 6.88 & 1.60 & 23 & 6.59 & 4.4 \\
\hline $\mathrm{Eu}$ & 1.97 & 0.37 & 19 & 1.97 & 0.15 \\
\hline $\mathrm{Gd}$ & 6.63 & 1.95 & 29 & 6.71 & -1.2 \\
\hline $\mathrm{Tb}$ & 1.30 & 0.30 & 29 & 1.02 & 0.33 \\
\hline Dy & 6.04 & 1.35 & 22 & 6.44 & -6.2 \\
\hline Ho & 1.30 & 0.23 & 18 & 1.27 & 2.1 \\
\hline $\mathrm{Er}$ & 3.69 & 0.75 & 20 & 3.70 & -0.31 \\
\hline $\mathrm{Tm}$ & 0.52 & 0.26 & 50 & 0.51 & 1.9 \\
\hline $\mathrm{Yb}$ & 3.28 & 0.88 & 27 & 3.39 & -3.2 \\
\hline Lu & 0.56 & 0.30 & 54 & 0.50 & 11 \\
\hline $\mathrm{Hf}$ & 4.59 & 0.74 & 16 & 4.84 & -6.3 \\
\hline $\mathrm{Ta}$ & 0.81 & 0.42 & 53 & 0.78 & 3.6 \\
\hline w & 0.42 & 1.64 & 400 & 0.50 & -17 \\
\hline $\mathrm{Pb}$ & 11.0 & 2.50 & 23 & 11.0 & -0.10 \\
\hline Th & 5.83 & 0.68 & 12 & 5.90 & -1.2 \\
\hline U & 1.69 & 0.33 & 20 & 1.69 & -0.19 \\
\hline
\end{tabular}

Reference values using current (2013) values from GeoReM database (Jochum et al., 2005). 


\subsubsection{Zircon separation}

15 samples of the Bishop Tuff were selected for zircon extraction, with 2 samples of Glass Mountain lavas also investigated (Table 3.1 for list of samples). Zircons were separated from the $60-250 \mu \mathrm{m}$ size fraction, following crushing and brief swing milling. After drying this fraction, most of the glass was removed from the crystal concentrate using waterpanning. The resulting crystal concentrate was then dried thoroughly before being put into lithium polytungstate (LST) liquid (Fig. 2.9) with a density of $2.8 \mathrm{~g} / \mathrm{cm}^{3}$. All material with a density $>2.8 \mathrm{~g} / \mathrm{cm}^{3}$ sank to the base of the separating funnel where it was collected.

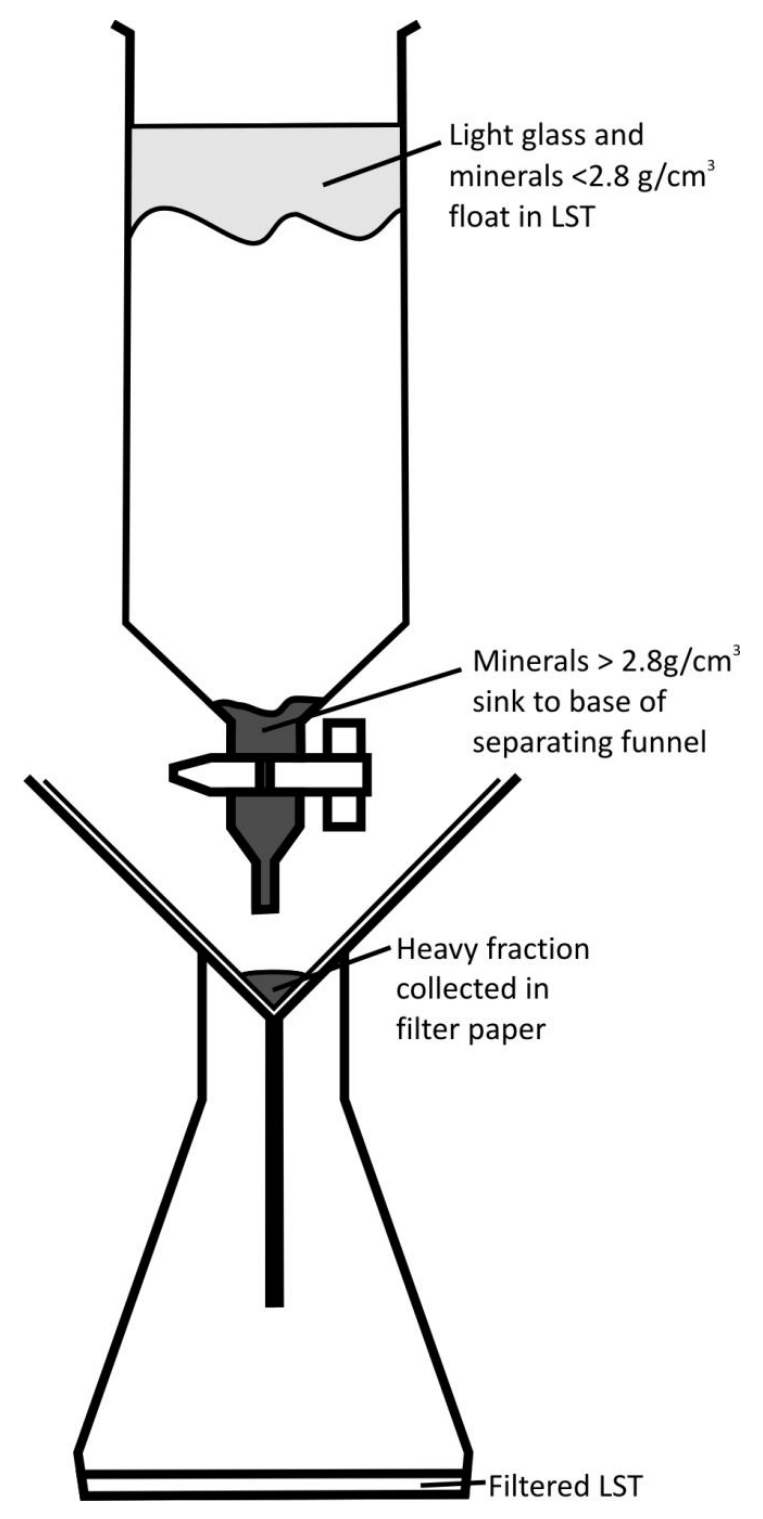

Fig. 2.9: Schematic diagram for zircon and heavy mineral separation using lithium polytungstate. 
The heavy fraction was then washed thoroughly in water to remove all traces of LST, before being dried at $60^{\circ} \mathrm{C}$ for at least $24 \mathrm{~h}$. Fe-Ti oxides were then removed from this fraction using a hand magnet. The heavy fraction was then further separated in methylene iodide with a density of $3.3 \mathrm{~g} / \mathrm{cm}^{3}$. In this liquid, only allanite, pyroxene, apatite and zircon crystals sank to the base of the separating funnel. The heavy fraction was then siphoned off and washed repeatedly with acetone to remove any remaining traces of methylene iodide. This heavy separate was then further separated using magnetic separation in a Frantz isodynamic separator. This allowed removal of weakly magnetic phases (such as pyroxenes) from the heavy separate. Zircon crystals were then hand-picked from the remaining crystal fraction. Mounts for zircons were made as detailed in section 2.5.1, but further details are given in section 3.3.

\subsubsection{Analysing conditions}

Full details of analytical procedures for both $\mathrm{U}-\mathrm{Pb}$ age determinations and trace element analyses are given in Chapter 3: section 3.3. During trace element analyses (at SUMAC) the MAD zircon was run as the concentration standard. The analytical variability of the MAD standard is shown in Table 2.14 and Fig. 2.10. Compiled data from October 2011 and October 2012 (2 analytical sessions) are presented which demonstrate that for almost all elements (concentrations $\geq 10 \mathrm{ppm}$ ) the data have 2 standard deviation (s.d.) of $<10 \%$.

The standards deviations are only greater than $10 \%$ when concentrations of elements are less than $20 \mathrm{ppm}$. This is part due to the method by which trace element data are collected using SIMS techniques. Unlike LA-ICPMS, where trace element concentrations are calculated from silica contents measured on the microprobe, all trace element concentrations are calculated as:

$$
\text { concentration }(p p m)=\left[\frac{c p s(M A D)}{c p s(\text { unknown })}\right] x \text { concentration in } M A D
$$

where the concentration of all elements in MAD are measured by solution ICPMS, and cps refers to counts per second. As this calibration is also carried out on all MAD analyses, the uncertainties calculated actually represent the reproducibility of the standard values, and offsets from the "measured" values and published values are irrelevant. 


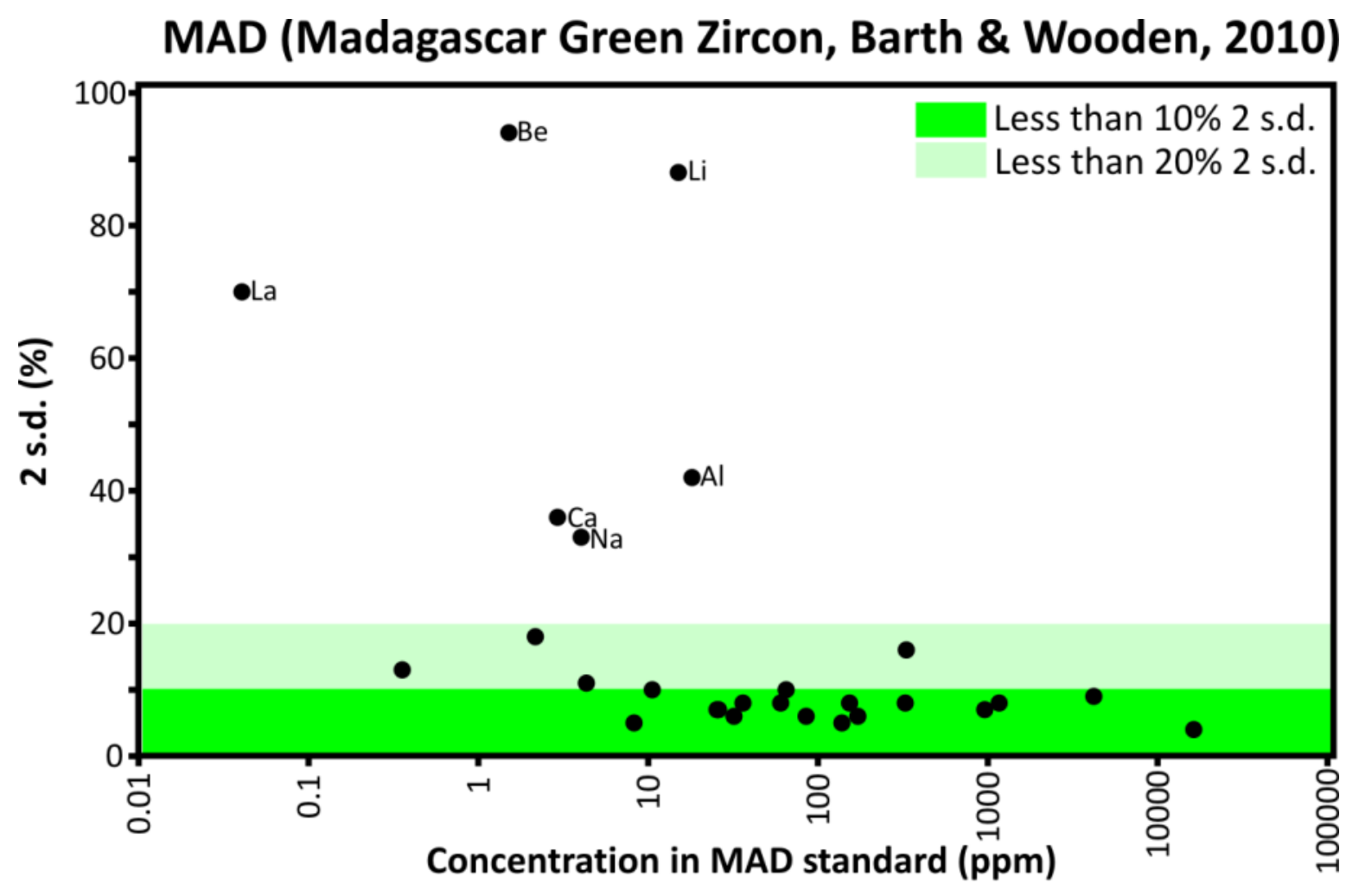

Fig. 2.10. Analytical variability of trace element analyses on the MAD zircon standard (Barth \& Wooden, 2010) arranged by their increasing concentration in MAD measured from solution ICPMS. Those elements with 2 s.d. greater than $20 \%$ are labelled. The full analytical variability per element is listed in Table 2.14 . 
Table 2.14. Analytical variability of ion probe analyses of the MAD zircon standard; $\mathrm{n}=21$

\begin{tabular}{|c|c|c|c|}
\hline Element & $\begin{array}{l}\text { Mean } \\
\text { (2 s.f.) } \\
\end{array}$ & $\begin{array}{c}2 \sigma \\
\text { (ppm; 2.s.f.) }\end{array}$ & $\begin{array}{c}2 \sigma \\
(\% ; 2 \text { s.f. }) \\
\end{array}$ \\
\hline 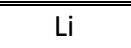 & 15 & 13 & 88 \\
\hline $\mathrm{Be}$ & 1.5 & 1.4 & 94 \\
\hline B & 2.1 & 1.8 & 86 \\
\hline $\mathrm{F}$ & 32 & 24 & 74 \\
\hline $\mathrm{Na}$ & 4 & 1.3 & 33 \\
\hline $\mathrm{Al}$ & 18 & 7.6 & 42 \\
\hline$P$ & 170 & 10 & 6 \\
\hline $\mathrm{K}$ & 1.0 & 0.3 & 31 \\
\hline $\mathrm{Ca}$ & 2.9 & 1.0 & 36 \\
\hline Sc & 11 & 1.1 & 10 \\
\hline $\mathrm{Ti}(49)$ & 25 & 1.8 & 7 \\
\hline $\mathrm{Fe}$ & 4.6 & 3.4 & 73 \\
\hline$Y$ & 960 & 66 & 7 \\
\hline $\mathrm{Nb}$ & 65 & 6.8 & 10 \\
\hline La & 0.0 & 0.0 & 70 \\
\hline $\mathrm{Ce}$ & 140 & 6.9 & 5 \\
\hline $\mathrm{Nd}$ & 2.2 & 0.4 & 18 \\
\hline $\mathrm{Sm}$ & 4.3 & 0.5 & 11 \\
\hline $\mathrm{Eu}$ & 0.40 & 0.0 & 13 \\
\hline $\mathrm{Gd}$ & 26 & 1.9 & 7 \\
\hline $\mathrm{Ho}$ & 32 & 1.9 & 6 \\
\hline $\mathrm{Tb}$ & 8.3 & 0.4 & 5 \\
\hline Dy & 85 & 5.0 & 6 \\
\hline $\mathrm{Er}$ & 150 & 12 & 8 \\
\hline $\mathrm{Tm}$ & 36.3 & 2.9 & 8 \\
\hline $\mathrm{Yb}$ & 330 & 27 & 8 \\
\hline Lu & 60 & 4.8 & 8 \\
\hline $\mathrm{Hf}$ & 16300 & 600 & 4 \\
\hline $\mathrm{Pb}(206)$ & 330 & 52 & 16 \\
\hline$U$ & 4200 & 400 & 9 \\
\hline Th & 1170 & 89 & 8 \\
\hline
\end{tabular}

Reference values from Barth \& Wooden (2010). 


\section{Chapter 3}

Published as: Chamberlain, K. J., Wilson, C. J. N., Wooden, J. L., Charlier, B. L. A. \& Ireland, T. R. (2014): New perspectives on the Bishop Tuff from zircon textures, ages and trace elements. Journal of Petrology 55, 395-426. 


\title{
3. New perspectives on the Bishop Tuff from zircon textures, ages and trace elements
}

\begin{abstract}
We present zircon textural, trace element and $\mathrm{U}-\mathrm{Pb}$ age data obtained by secondary ion mass spectrometry (SIMS) (SHRIMP-RG: sensitive high resolution ion microprobereverse geometry) from 15 stratigraphically controlled Bishop Tuff samples and 2 Glass Mountain (GM) lava samples (domes OD and YA). Bishop zircon textures divide into four suites, (a) dominant sector-zoned grains, with (b) subordinate grains showing bright rims (lower U, Th, rare earth elements [REE]) in CL imaging, and sparse (c) GM-type grains (texturally similar to zircons from GM dome YA) and (d) Mesozoic xenocrysts from Sierran granitoid country rocks. All Bishop zircons from suites (a) - (c) combined have a weighted mean age of $777.9 \pm 2.2 \mathrm{ka}(95 \%$ confidence) and a tail back to $\sim 845 \mathrm{ka}$. Our eruption age estimate using the weighted mean of $166 \mathrm{rim}$ ages of $766.6 \pm 3.1 \mathrm{ka}(95 \%$ confidence) is identical within uncertainty to published estimates from isotope-dilution thermal ionization mass spectrometry (ID-TIMS) (767.1 $\pm 0.9 \mathrm{ka}, 2 \sigma)$ and ${ }^{40} \mathrm{Ar} /{ }^{39} \mathrm{Ar}(767.4$ $\pm 2.2 \mathrm{ka}, 2 \sigma$ ) techniques, the latter using the $28.172 \mathrm{Ma}$ age for the Fish Canyon sanidine standard. We estimate also an eruption age for GM dome YA of $862 \pm 23 \mathrm{ka}(95 \%$ confidence), significantly older than the currently accepted $790 \pm 20 \mathrm{ka} \mathrm{K}$-Ar age. The oldest zircon cores from late-erupted Bishop material (including those with GM-type textures) have a weighted mean of $838.5 \pm 8.8 \mathrm{ka}$ (95\% confidence), implying that the Bishop Tuff system was only active for $\sim 80 \mathrm{kyr}$, and had effectively no temporal overlap with the GM system. Trace element variations in Bishop zircons are influenced strongly for many elements by sector zoning, producing up to $3 \mathrm{x}$ concentration differences between sides and tips within the same growth zones. Contrasting trends in molar $\left(\mathrm{S} c+\mathrm{Y}+\mathrm{REE}^{3+}\right) / \mathrm{P}$ ratios between sides and tips indicate contrasting mechanisms of substitution in different sectors of the same crystal. Concentrations of Ti in tips are double those in the sides of crystals, hindering applicability of the Ti-in-zircon thermometer, in addition to variations inherent to the $0.15-0.67$ range in values proposed for $a \mathrm{TiO}_{2}$. The bright-rim portions of grains are inferred to have crystallized from the same magma as generated the bright rims seen under cathodoluminescence or back-scattered electron imaging on quartz and feldspar, respectively. This less evolved, slightly hotter magma
\end{abstract}


invaded the deeper parts of the chamber represented in the late-erupted northern units possibly up to $\sim 10 \mathrm{kyr}$ prior to eruption, but only invaded shallower levels very shortly before eruption as shown by our textural information and previously proposed from the sharp delineation of quartz bright rims. By obtaining a large number of analyses from zircon separates which systematically cover the entire Bishop Tuff eruption sequence we can produce an eruption age estimate using SIMS to the same precision and accuracy as ID-TIMS and ${ }^{40} \mathrm{Ar} /{ }^{39} \mathrm{Ar}$ techniques.

\subsection{Introduction}

The Bishop Tuff has become an iconic representative of the largest group of felsic explosive volcanic eruptions ('supereruptions') and a central focus of debates on the origin, assembly and compositional zonation of large silicic magma bodies. In particular, following the seminal studies of Hildreth $(1977,1979)$ and their setting into regional and global perspectives (Hildreth, 1981, 2004), several key areas have remained controversial. The central inference of Hildreth $(1977,1979)$ of a pre-eruptive, vertically and laterally continuous $>600 \mathrm{~km}^{3}$ body of moderate- to high-silica rhyolite, vertically zoned with respect to composition (particularly trace elements), crystal and volatile contents, and temperature has remained (Dunbar \& Hervig, 1992a; Wallace et al., 1999; Anderson et al., 2000; Bindeman \& Valley, 2002; Hildreth \& Wilson, 2007; Roberge et al., 2013, but see also Gualda et al., 2012a).

There remains vigorous debate, however, about two aspects of this picture which we consider here from the zircon perspective. The first concerns inconsistencies between estimates of the eruption age derived from ${ }^{40} \mathrm{Ar} /{ }^{39} \mathrm{Ar}$ experiments on sanidine, and between those estimates and values derived from U-Pb dating of zircons using high-precision IDTIMS methods. The second concerns the longevity of the Bishop magma chamber, the timing of its assembly and the magmatic regime, derived from various lines of evidence and modelling. To address these issues, we present a comprehensive suite of zircon age determinations and associated trace element data obtained by secondary ion mass spectrometry (SIMS). We have analyzed zircons from fifteen stratigraphic horizons in the Bishop Tuff in order to trace the geochronological and trace-element development of the magma chamber as recorded in discrete zones of single crystals. Although single SIMS age determinations are less precise than those derived from single-zircon ID-TIMS techniques, the ability to create large data sets from discrete zones in single zircons from different 
pumice types and different eruptive units within the Bishop Tuff places powerful constraints on the pre-eruptive history of the magma body. Additionally, collection of trace-element data and the linkage to zircon textures as shown in cathodoluminescence (CL) imaging allow the overall petrogenetic context and broad timings of interaction of the zircon crystals with different magma compositions to be assessed.

\subsection{The Bishop Tuff}

\subsubsection{Geological backeground}

The $>600 \mathrm{~km}^{3}$ Bishop Tuff was erupted in association with formation of Long Valley caldera in eastern California (Fig. 3.1; Bailey et al., 1976; Hildreth, 1979, 2004; Wilson \& Hildreth, 1997; Hildreth \& Wilson, 2007). The eruption represented the culmination of $\sim 4.5 \mathrm{Myr}$ of magmatism and the rhyolite erupted in the Bishop Tuff event is greater in volume than all other felsic eruptions combined in the Long Valley area before or since (Hildreth, 2004).

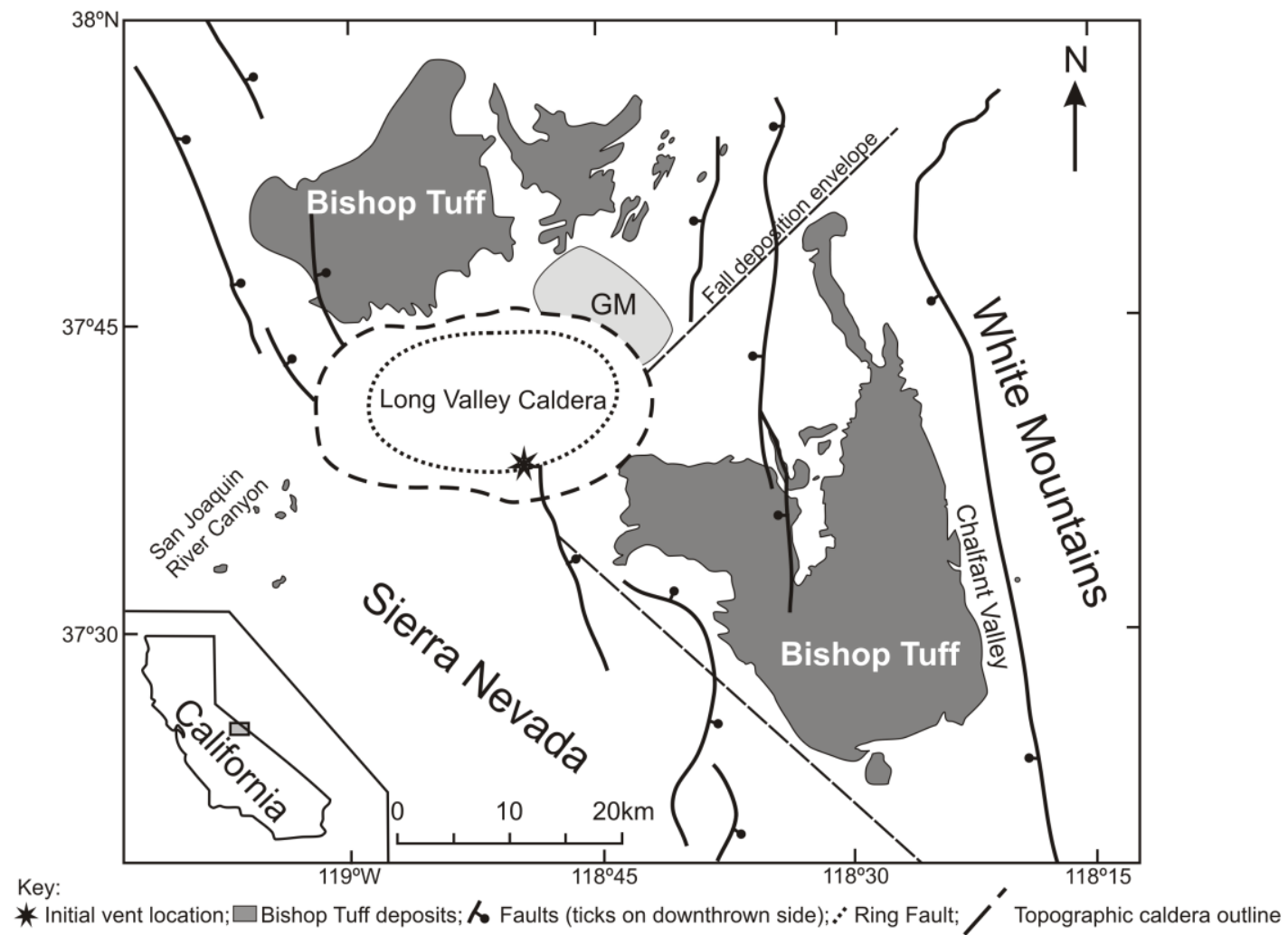

Fig. 3.1. Map of the Long Valley area, eastern California, USA, after Hildreth \& Wilson (2007). The topographic outline of the caldera is shown as a dashed line, with the ringfault zone shown as a dotted ellipse inside the topographic margin. Regions of Bishop pyroclastic-flow deposition are shaded grey. The envelope enclosing precursory Glass Mountain (GM) lava domes is highlighted in light grey. The line marked 'Fall deposition envelope' marks the westerly limits of where Bishop fall deposits are found in this area. 
The Bishop Tuff in its proximal outcrop area between the Sierra Nevada and White Mountains (Fig. 3.1) consists of a sequence of plinian pumice fall deposits generated before, and coevally with, lobes of ignimbrite, together with voluminous co-eruptive caldera fill (Wilson \& Hildreth, 1997). In these proximal areas where we (and all other workers concerned with pumice in the Bishop Tuff) have sampled, the fall deposits are found only in an $\sim 90^{\circ}$ sector east of source; however the overall blanket of fall deposits (plinian and co-ignimbrite) covers much of the western USA to $>2000 \mathrm{~km}$ from source (Izett et al., 1988). Marker horizons in the proximal fall deposits were used to divide them into nine units (F1 to F9). In turn, interbedding relationships and recognition of other marker horizons were used to correlate between the fall and flow deposits and estimate that the eruption occurred (with only one possible very short hiatus between F8 and F9) over a period of the order of 6 days (Wilson \& Hildreth, 1997).

(a) Azimuth, degrees

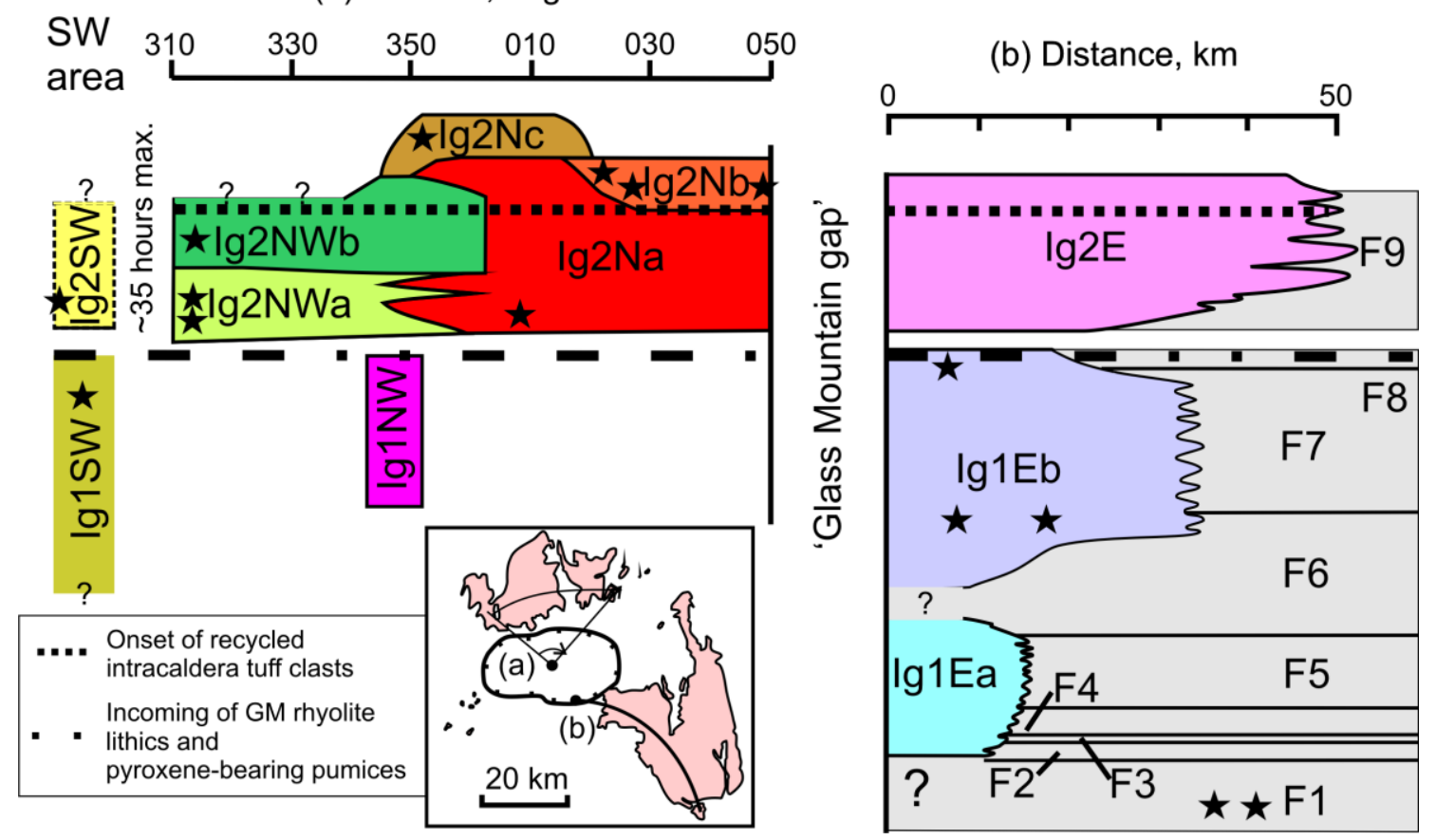

Fig. 3.2. Summary stratigraphy of the Bishop Tuff, after Hildreth \& Wilson (2007). Locations for samples in this study are starred (see Table 3.1 for sample numbers and sites). (a) Hypothetical cross section from NW to NE across the northern ignimbrite lobes as viewed from the centre of Long Valley caldera. (b) Schematic proximal to distal cross-section approximately along the line of Owens River Gorge, where the horizontal axis represents distance from the initial vent site of Hildreth \& Mahood (1986). Enlarged stratigraphy figure is also repeated in Appendix 1. 
Lithic assemblages in the fall deposits and ignimbrite serve to locate the initial vent in the southeastern sector of what became the caldera and then follow the subsequent concurrent development of venting along the northern and eastern portions of the ring fracture (Figs. 3.1, 3.2: Hildreth \& Mahood, 1986; Wilson \& Hildreth, 1997).

Prior to the Bishop Tuff eruption the Glass Mountain rhyolitic system was active from 2.2 Ma to $790 \mathrm{ka}$, producing more than 60 effusive and explosive eruptions, and building a lava dome complex with a surrounding fan of primary and reworked volcaniclastic material (Metz \& Mahood, 1985, 1991; Metz \& Bailey, 1993; Hildreth, 2004). This system has two sub-groups: a 2.2 - 1.3 Ma sequence of chemically variable, exceedingly evolved high-silica rhyolites, and a younger group (1.2 Ma to $790 \mathrm{ka}$ ) of chemically more uniform, highly evolved high-silica rhyolites, the latter similar in bulk composition to the early Bishop eruption products (Metz \& Mahood, 1991; Hildreth, 2004). Glass Mountain rhyolites are dominantly crystal poor ( $<8 \%$ crystals), with similar mineral assemblages to the Bishop Tuff (Metz \& Mahood, 1991). Earlier rhyolitic volcanism is represented by plinian pumice fall deposits, best exposed in the Blind Spring Valley area east of Glass Mountain but which also extend for hundreds of kilometres farther east (Sarna-Wojcicki et al., 2005). Younger parts of this sequence were correlated with Glass Mountain activity, but older lapilli-bearing (hence probably within tens of kilometres of vent) fall deposits returned ${ }^{40} \mathrm{Ar} /{ }^{39} \mathrm{Ar}$ single-crystal sanidine ages of between c. 2.2 and $2.8 \mathrm{Ma}$ (Sarna-Wojcicki et al., 2005). As such, these deposits apparently pre-date activity at the Glass Mountain system and came from sources as yet undefined within the Long Valley area.

\subsubsection{Eruption age estimates}

The age of the Bishop Tuff has long been of interest globally because of its proximity in time to the Matuyama Reversed to Brunhes Normal (M-B) paleomagnetic transition (e.g. Sarna-Wojcicki et al., 2000; Mark et al., 2012; Singer et al., 2012). Two contrasting approaches have been used to assess the Bishop Tuff eruption age: U-Pb geochronology, both by ID-TIMS and SIMS techniques, and Ar-Ar geochronology.

Crowley et al. (2007) reported high-precision ID-TIMS U-Pb age determinations on a suite of zircons from a densely welded zone of Bishop Tuff in the Owens River gorge. From their description we infer their sample to be from the dense-welded portion of $\operatorname{Ig} 1 \mathrm{~Eb}$ (welding zone c of Wilson \& Hildreth, 2003; Fig 3.2b). The zircons illustrated in Crowley 
et al. (2007) are dominated by a sector-zoned structure, often with an apparent central domain and $U$ concentrations ranging from under $1000 \mathrm{ppm}$ to $2000 \mathrm{ppm}$ in the central domain to over $5000 \mathrm{ppm}$ in pyramidal tips. These zircons yielded a weighted mean estimate of $767.1 \pm 0.9 \mathrm{ka}[2 \sigma$, mean square of weighted deviates $(\mathrm{MSWD})=1.3]$ from 17 of 19 grains analysed.

U-Pb age determinations by SIMS have been reported by Reid \& Coath (2000), Simon \& Reid (2005) and Reid \& Schmitt (2012). The ion microprobe uses a focused ion beam to sputter the target with the advantage of allowing selection of particular domains in the zircon. However, the fine sampling scale of the ion microprobe greatly diminishes the sample size and there is a commensurate loss of precision. However, the issue of ion microprobe analysis is not simply the final determination of a bulk age, but rather the association of that age with discrete structures in the zircon. Reid \& Coath (2000) and Simon \& Reid (2005) determined that zones in the zircons showed a significant preeruptive history extending back hundreds of thousands of years. Although such prehistory should have also been apparent in the bulk ID-TIMS analyses, the samples analyzed were not the same and the possibility arises that there could be stratigraphic variations in the zircon age characteristics. Simon \& Reid (2005) reported weighted mean crystallisation ages (uncertainties reported as $1 \sigma_{\mathrm{m}}$ ) of $811 \pm 7 \mathrm{ka}$ (MSWD $=3.4,20$ analyses on 14 grains) for interiors of grains from $\operatorname{Ig} 2 \mathrm{NW}[\mathrm{b}], 841 \pm 8 \mathrm{ka}(\mathrm{MSWD}=0.9, n=29)$ from rims of grains from Ig1Eb, and $823 \pm 14 \mathrm{ka}$ (MSWD = 0.8, 22 analyses on 20 grains) from Ig1Eb [also reported by Reid \& Coath (2000)]. Pooled minimum ages (i.e. first-order estimates of eruption age) from the first two of these data sets were given as $753 \pm 11 \mathrm{ka}(n=7)$ and $767 \pm 30 \mathrm{ka}(n=4)$, respectively.

Closely similar eruption-age estimates to those from $\mathrm{U}-\mathrm{Pb}$ experiments were obtained from 20-25 grain multi-crystal total fusion ${ }^{40} \mathrm{Ar} /{ }^{39} \mathrm{Ar}$ experiments on Bishop sanidines by Rivera et al. (2011) from the same sample (79G94) as used by Sarna-Wojcicki et al. (2000). From their descriptions, we infer this sample to be from ignimbrite packages $\operatorname{Ig} 2 \mathrm{Na}$ or Ig2Nb of Wilson \& Hildreth (1997). Rivera et al. (2011) derived a weighted mean for the Bishop sanidines of $767.4 \pm 2.2 \mathrm{ka}(2 \sigma$, external errors), along with an equivalent astronomically intercalibrated ${ }^{40} \mathrm{Ar} /{ }^{39} \mathrm{Ar}$ age for the Fish Canyon Tuff (FCT) sanidine standard (FCT) of $28.172 \pm 0.028 \mathrm{Ma}(2 \sigma$, external errors). 
The apparently excellent agreement between $\mathrm{U}-\mathrm{Pb}$ age determinations and ${ }^{40} \mathrm{Ar} /{ }^{39} \mathrm{Ar}$ experiments conflicts, however, with proposals for contrasting values for the ${ }^{40} \mathrm{~K}$ decay constant and consequent FCT standard age values that would have the Bishop Tuff eruption age being significantly older (Renne et al., 2010, 2011; Mark et al., 2012). The eruption age estimate derived from the experiments of Sarna-Wojcicki et al. (2000) would shift to $778.4 \pm 3.7 \mathrm{ka}[2 \sigma$, using the $28.305 \pm 0.036 \mathrm{Ma}$ FCT age from Renne et al. (2010)] or $778.1 \pm 3.7 \mathrm{ka}[2 \sigma$, after Renne et al. (2011): FCT age of $28.294 \pm 0.036 \mathrm{Ma}$ ]. Further age determinations by Mark et al. (2012) on the same feldspar sample as used by SarnaWojcicki et al. (2000) and Rivera et al. (2011) were reported as $776.4 \pm 0.9 \mathrm{ka}$ (inferred by us to be $1 \sigma$ ), on the basis of the Renne et al. (2011) FCT value.

\subsubsection{Magma accumulation timescales}

A range of methods have been used to investigate timescales of magma accumulation and residence in silicic systems [for reviews see Hawkesworth et al. (2000, 2004)]. It should be noted, however, that the term 'residence time' may be interpreted in different ways. A distinction is drawn by us between the lifetimes of crystals (reflecting complex, possibly prolonged patterns of growth, stasis or dissolution) and the lifetime of the melt-dominant body in which they were suspended when quenched on eruption. Hildreth (1979) proposed that the crystal population in Bishop pumices grew in situ and that the species present reflected the overall zonation in bulk-compositional characteristics. On this basis, the age range of the crystals and the lifetime of the melt-dominant body should be effectively the same. In contrast, studies of comparably-sized systems (Bindeman et al., 2001; Charlier et al., 2005, 2008, 2010) show that crystal populations in deposits pre- and post-dating the climactic events are influenced by inheritance and recycling of antecrysts (from earlier crystallization events in the system) and xenocrysts (from local basement rocks). The age spectra of zircons within the Oruanui (New Zealand) pumices demonstrably bear no resemblance to the much shorter timescale for growth of the final melt-dominant body that was evacuated in the Oruanui eruption (Wilson \& Charlier, 2009; Allan et al., 2013).

For the Bishop Tuff, at one extreme, timescales of the order of hundreds of thousands to a million years have been proposed for development of the parental magma body. Glassfeldspar Rb/Sr isochrons from Glass Mountain lavas (particularly those from $\sim 1.1 \mathrm{Ma}$ onwards), and pumices from the Bishop Tuff itself, yield model ages 300 to $1300 \mathrm{kyr}$ older than notional eruption ages (Halliday et al., 1989; Christensen \& DePaolo, 1993; 
Christensen \& Halliday, 1996; Davies \& Halliday, 1998). This protracted timescale was apparently supported by ${ }^{40} \mathrm{Ar} /{ }^{39} \mathrm{Ar}$ ages from melt inclusions in quartz $(2.0-2.3 \mathrm{Ma}$; van den Bogaard \& Schirnick, 1995), but these ages were subsequently attributed to excess Ar (Winick et al., 2001). Theoretical models of felsic magma genesis have also been used to estimate a million year timescale for development of the Bishop magma (Fowler \& Spera, 2010), but this approach has been suggested to be unrealistic on the grounds of thermal constraints (Gualda \& Ghiorso, 2011; Fowler \& Spera, 2011).

Studies focusing on the chronological information from zircons have, however, yielded shorter and contrasting timescales. Zircon in the Bishop Tuff is considered to be one of the earliest crystallising phases (Hildreth, 1979) on the basis of its presence as inclusions within all other crystal species. It would thus be expected that the zircon age spectra should date the timescales of crystallization during generation of the Bishop magma in the overall crystal-dominated roots of the magmatic system (the mush zone: Bachmann \& Bergantz, 2004; Hildreth, 2004). There is, however, a distinct contrast between zircon mean ages of 811 - 841 ka plus the $\sim 160$ kyr range of pre-eruptive ages from SIMS (Reid \& Coath, 2000; Simon \& Reid, 2005; Reid et al., 2011) and the $\sim 12$ kyr maximum range proposed from IDTIMS (Crowley et al., 2007). This contrast has been further highlighted by proposals (Gualda et al., 2012a,b; Pamukcu et al., 2012) that crystallisation histories of the major mineral phases in the Bishop magma occurred over a much smaller range in magmatic temperatures $\left(757-762{ }^{\circ} \mathrm{C}\right.$ : Gualda et al., 2012a) than those inferred from Fe-Ti oxide equilibria $\left(714-818^{\circ} \mathrm{C}\right.$ : Hildreth \& Wilson, 2007) and over associated shorter timescales, more consistent with those implied by the results of Crowley et al. (2007).

\subsubsection{Trace element patterns}

The great variations in trace-element abundances within the Bishop pumices were first highlighted by Hildreth $(1977,1979)$ and attributed to liquid-state fractionation (Soret diffusion). This specific mechanism has since been demonstrated to be inappropriate (Lesher, 1986), and the variations are now considered to result from crystal fractionation processes (Michael, 1983; Cameron, 1984) in the mush zone, with extraction of variably fractionated liquids to form the melt-dominant body (Hildreth, 2004; Hildreth \& Wilson, 2007) although debate still remains. The crystal-specific record shows, however, further complexities. The outer zones of crystals (together with their melt inclusions) from pumices in ignimbrite lobes north and northwest of the caldera rim show contrasting 
textures that correlate with trace-element patterns. Many quartz, sanidine and zircon crystals from these inferred later-erupted materials have outer zones that are brighter under cathodoluminescence (CL) (quartz, zircon) or back-scattered electron (BSE) imaging (sanidine), and have volatile abundances and trace-element patterns indicative of crystallisation from a less-evolved, inferred hotter melt (Dunbar \& Hervig, 1992a; Wallace et al., 1999; Anderson et al., 2000; Peppard et al., 2001; Wark et al., 2007; Reid et al., 2011). Originally interpreted to reflect sinking of the crystals from the 'normal' Bishop magma (represented by the earlier-erupted plinian fall deposits and eastern-side ignimbrite lobes) into the contrasting magma (Wallace et al., 1999; Anderson et al., 2000; Peppard et al., 2001), these features are now interpreted to reflect ingress into the Bishop chamber of the contrasting magma type (e.g. Wark et al., 2007; Reid et al., 2011). The boundaries between the 'normal' (i.e., crystals typical of earlier-erupted plinian fall deposits and eastern-side ignimbrite) cores and contrasting rims in the crystals are often sharp to $<10 \mu \mathrm{m}$. Such abrupt changes have been linked to introduction of a contrasting magma that may have triggered the onset of the eruption itself (e.g. Wark et al., 2007; Reid et al., 2011), and/or accompanied rapid rise of the host magma to shallow depths (Thomas et al., 2010; cf. Wilson et al., 2012).

Trace-element patterns within Bishop zircons from 'early' versus 'late'-erupted material show wide variations (Hildreth, 1979; Mahood \& Hildreth, 1983 from bulk crystal aliquots; Reid et al., 2011 from single crystals) that match closely the variations seen in the quartz and feldspar. As shown by Reid et al. (2011) and amplified in this study, however, most of the trace element contrasts arise from variations within the individual crystals. Outer rims, brighter under CL imaging, occur on virtually no grains in the early erupted material, but are frequent and up to tens of microns thick on grains from the late-erupted material. Melt compositions indicated by the bright-rim material or represented by melt inclusions in these rims, were inferred or demonstrated to represent less-evolved and/or hotter melts (Wallace et al., 1999; Anderson et al., 2000; Wark et al., 2007). However, our work shows that this picture is neither as simple, nor as uniform as implied by these earlier studies.

\subsubsection{Sample suites for this study}

Fifteen samples of the Bishop Tuff were selected for zircon extraction (Table 3.1; Fig. 3.2), plus two samples from Glass Mountain domes OD (K-Ar age of $1.33 \pm 0.01 \mathrm{Ma}$ ) and YA $(0.79 \pm 0.01 \mathrm{Ma})$ (ages from Metz \& Mahood, 1985). The tuff was systematically sampled 
by us from the earliest fall unit (F1) through to the latest ignimbrite unit (Ig2Nc) to track any vertical and lateral variations present within the single zoned magma body. A range of pumice types was selected, from crystal-poor to crystal-rich in the 'normal' pumice spectrum as well as some of the 'variant' very crystal-poor pumices (Hildreth \& Wilson, 2007; see Table 3.1 for brief sample descriptions).

Table 3.1. Samples used in this study

\begin{tabular}{|c|c|c|c|c|c|}
\hline $\begin{array}{l}\text { Sample } \\
\text { Number }\end{array}$ & Unit & Type & Location & Grid Ref & Brief Description \\
\hline BP109 & F1 & multi & Owens River Gorge & $\begin{array}{l}03594, \\
41564\end{array}$ & $\begin{array}{l}\text { Bottom } 12 \mathrm{~cm} \text { bulk sample of F1 } \\
\text { (pumices sieved to }>1 \mathrm{~mm} \text { ). }\end{array}$ \\
\hline BP178 & $\mathrm{F} 1$ & multi & Owens River Gorge & $\begin{array}{l}03550, \\
41607\end{array}$ & $\begin{array}{l}\text { Bulk pumice sample of } 2.8-8 \mathrm{~mm} \text { fraction } \\
\text { from F1. }\end{array}$ \\
\hline BP087 & $\lg 1 \mathrm{~Eb}$ & $x p$ & Owens River Gorge & $\begin{array}{l}03594, \\
41564\end{array}$ & $\begin{array}{l}\text { Very fresh, large }(26 \mathrm{~cm}) \text { pumice crystal - } \\
\text { poor to -moderate. }\end{array}$ \\
\hline BP098 & $\lg 1 \mathrm{~Eb}$ & vxp-sw & Owens River Gorge & $\begin{array}{l}03594, \\
41564\end{array}$ & $\begin{array}{l}\text { Moderately vesicular vxp pumice with a } \\
\text { sugary texture- swirly type. }\end{array}$ \\
\hline BP130 & $\lg 1 S W$ & multi & Sotcher Lake & $\begin{array}{l}03174, \\
41661\end{array}$ & $\begin{array}{l}\text { Bulk sample of the largest single } \\
\text { unoxidised pumices. }\end{array}$ \\
\hline BP040 & $\begin{array}{l}\text { Ig1Eb } \\
\text { (Sherwin) }\end{array}$ & $\mathrm{xr}$ & Sherwin Grade & $\begin{array}{l}03483, \\
41578\end{array}$ & $\begin{array}{l}\text { Oxidised, crystal rich, 'Adobe' type single } \\
\text { pumice. }\end{array}$ \\
\hline BP216 & $\lg 2 \mathrm{SW}$ & multi & Pumice Butte & $\begin{array}{l}03169, \\
41572\end{array}$ & $\begin{array}{l}\text { Bulk sample of largest single pumice } \\
\text { clasts from the upper parts of Ig } 2 \mathrm{SW} \text {. }\end{array}$ \\
\hline BP118 & Ig2NWa & $\mathrm{xr}$ & Crestview & $\begin{array}{l}03241 \\
41812\end{array}$ & $\begin{array}{l}\text { Moderately vesicular crystal-rich pumice } \\
\text { with a uniaxial fibrous texture. }\end{array}$ \\
\hline BP115 & $\lg 2 \mathrm{NWa}$ & vxr & Crestview & $\begin{array}{l}03241 \\
41812\end{array}$ & $\begin{array}{l}\text { Moderately vesicular very crystal-rich } \\
\text { pumice with a planar fabric. }\end{array}$ \\
\hline BP059 & $\lg 2 \mathrm{Na}$ & $\mathrm{xr}$ & Bald Mountain Spring & $\begin{array}{l}03381 \\
41879\end{array}$ & $\begin{array}{l}\text { Fresh, moderately vesicular, very crystal- } \\
\text { rich single pumice. }\end{array}$ \\
\hline BP124 & $\lg 2 \mathrm{NWb}$ & $\mathrm{xr}$ & Aeolian Buttes & $\begin{array}{l}03175, \\
41925\end{array}$ & $\begin{array}{l}\text { Moderately vesicular crystal-rich single } \\
\text { clast with a fibrous texture. }\end{array}$ \\
\hline BP170 & $\lg 2 \mathrm{Nb}$ & $\mathrm{xr}$ & McGee Lobe & $\begin{array}{l}03477, \\
41871\end{array}$ & $\begin{array}{l}\text { Core of a very fresh crystal-rich pumice } \\
\text { with a crimped-fibrous texture. }\end{array}$ \\
\hline BP172 & $\lg 2 \mathrm{Nb}$ & $x p-s w$ & McGee Lobe & $\begin{array}{l}03477 \\
41871\end{array}$ & $\begin{array}{l}\text { Very crystal-poor, moderately vesicular } \\
\text { light grey swirly pumice. }\end{array}$ \\
\hline BP232 & $\lg 2 \mathrm{Nb}$ & xp-sw & McGee Lobe & $\begin{array}{l}03476, \\
41872\end{array}$ & $\begin{array}{l}\text { Pale grey, finely vesicular pumice with a } \\
\text { foamy texture- swirly. }\end{array}$ \\
\hline BP206 & $\lg 2 \mathrm{Nc}$ & $\mathrm{xr}$ & Granite Mountain & $\begin{array}{l}03422, \\
41971\end{array}$ & $\begin{array}{l}\text { Crystal-rich single clast with an Adobe- } \\
\text { like texture. }\end{array}$ \\
\hline BR228 & Dome YA & xp lava & $\begin{array}{l}\text { Dome YA-Glass } \\
\text { Mountain }\end{array}$ & $\begin{array}{l}03409, \\
41846\end{array}$ & Very crystal-poor obsidian. \\
\hline BR226 & Dome OD & $\mathrm{xm}$ & $\begin{array}{l}\text { Dome OD-Glass } \\
\text { Mountain }\end{array}$ & $\begin{array}{l}03449, \\
41877\end{array}$ & Crystal-moderate to -rich lava. \\
\hline
\end{tabular}

Erupted units and types are from Hildreth \& Wilson (2007). For pumice type descriptions see Table 2.1 in Chapter 2. 
Fourteen samples are from single pumice clasts (Bishop) or obsidian dome carapace material (Glass Mountain). For Bishop Ig1SW and Ig2SW samples, due to a lack of pumices of adequate size, zircons were extracted from multiple lapilli-sized pumices. For the samples from fall F1, bulk samples were taken, sieved (to exclude free crystals) and a pumice fraction separated by water panning and hand-picked (to remove lithic fragments) before crushing for zircon extraction.

\subsection{Analytical techniques}

Zircon crystals for analysis were handpicked from a $60-250 \mu \mathrm{m}$ sieve fraction pumice crush, which had been concentrated using standard density and magnetic separation techniques. Age determinations were made by SIMS techniques on the SHRIMP-RG instruments at the joint USGS-Stanford University facility (SUMAC) and at the Research School of Earth Sciences, Australian National University (ANU). Zircons were mounted in epoxy resin, polished to expose the cores of the grains, and imaged in reflected light, transmitted light, as well as by CL on a scanning electron microprobe (SEM) at SUMAC and ANU. To minimise contamination by common $\mathrm{Pb}$, the mounts were cleaned in detergent, petroleum spirits or dilute EDTA, and $1 \mathrm{M} \mathrm{HCl}$, with intervening rinses in distilled water, then gold coated.

During analysis, the primary beam was rastered for 180 seconds over an area of $35 \times 45 \mu \mathrm{m}$ prior to data acquisition to remove the gold coat and any possible surface contamination. Secondary ions were then sputtered with a 5-6 nA primary $\mathrm{O}_{2}^{-}$beam focused to a $\sim 25 \mathrm{x} 35$ $\mu \mathrm{m}$ spot. The mass spectrometer was cycled through peaks corresponding to (bracketed species run at SUMAC only) $\left({ }^{172} \mathrm{Yb}^{16} \mathrm{O}\right),{ }^{90} \mathrm{Zr}_{2}{ }^{16} \mathrm{O},\left({ }^{180} \mathrm{Hf}{ }^{16} \mathrm{O}\right),{ }^{204} \mathrm{~Pb}$, background, ${ }^{206} \mathrm{~Pb}$, $\left.{ }^{207} \mathrm{~Pb},{ }^{208} \mathrm{~Pb},{ }^{232} \mathrm{Th}\right),{ }^{238} \mathrm{U},{ }^{232} \mathrm{Th}^{16} \mathrm{O}$ and ${ }^{238} \mathrm{U}^{16} \mathrm{O}$, with a total analysis time of $750-900 \mathrm{~s}$. Extended count times were used for ${ }^{206} \mathrm{~Pb}(20$ or $30 \mathrm{~s})$ and ${ }^{207} \mathrm{~Pb}(20 \mathrm{~s})$ and six scans were run through the mass sequence. The concentration standard was MAD (Madagascar green: Barth \& Wooden, 2010; 4196 ppm U) at SUMAC and SL13 (238 ppm U) at ANU. The U$\mathrm{Pb}$ age standard throughout was R33 (420 Ma: ID-TIMS age from: http://earth.boisestate.edu/isotope/analytical-capabilities/id-tims-u-pb). Data reduction used SQUID 2 (Version 1.51: Ludwig, 2009), and data were plotted using Isoplot 3.76 (Ludwig, 2008). For single analyses uncertainties given by SQUID2 are reported here at $2 \sigma$, whereas for our grouped data sets uncertainties are given at the $95 \%$ confidence interval as 
generated in Isoplot. In these grouped data sets weighted means are calculated using the 'reject OK?' option engaged in Isoplot.

The ${ }^{230}$ Th correction for initial disequilibrium was calculated using the measured Th and $\mathrm{U}$ concentrations in the zircons from the SIMS measurements, together with melt $\mathrm{Th} / \mathrm{U}$ values derived from laser ICP-MS data from glass separates for the Bishop Tuff samples (see Electronic Appendix 12) and published instrumental neutron activation analysis (INAA) data for the two Glass Mountain samples (Metz \& Mahood, 1991). For comparison, Crowley et al. (2007) used a single value of 2.81 from the mean of 12 melt inclusion analyses published by Anderson et al. (2000). A correction factor was then applied using $\mathrm{f}=\left(\mathrm{Th} / \mathrm{U}_{\text {zir }}\right) /\left(\mathrm{Th} / \mathrm{U}_{\mathrm{wr}}\right)$, following Schärer (1984). The presence of common $\mathrm{Pb}$ was evaluated by monitoring ${ }^{204} \mathrm{~Pb}$ and ${ }^{207} \mathrm{~Pb} /{ }^{206} \mathrm{~Pb}$, and a correction was then applied using the recorded ${ }^{207} \mathrm{~Pb} /{ }^{206} \mathrm{~Pb}$ values and a common- $\mathrm{Pb}$ isotopic composition for the sample age from the average crust model of Stacey \& Kramers (1975). This approach was tested using a regression of ${ }^{238} \mathrm{U} /{ }^{206} \mathrm{~Pb}$ vs. ${ }^{207} \mathrm{~Pb} /{ }^{206} \mathrm{~Pb}$ for twenty spots with $>20 \%$ of the ${ }^{206} \mathrm{~Pb}$ attributable to common- $\mathrm{Pb}$. This plot yielded a ${ }^{207} \mathrm{~Pb} /{ }^{206} \mathrm{~Pb}$ intercept of $0.82 \pm 0.03$, consistent with use of the Stacey \& Kramers (1975) value for the sample age (see Electronic Appendix 1). Analyses of grains with $>10 \%$ common $\mathrm{Pb}$ at $\mathrm{U}>500 \mathrm{ppm}$ were excluded from the data set. However, some zircons from later-erupted pumices showed CL-bright zones which had $<500 \mathrm{ppm} U$ and accompanying higher proportions of common- $\mathrm{Pb}$. For these 31 analyses a cut-off of $30 \%$ common- $\mathrm{Pb}$ was used and these data were handled separately.

SIMS analyses for trace elements were performed on the SHRIMP-RG at SUMAC using a 1.5-3 nA primary beam current and a focused $15 \times 12 \mu \mathrm{m}$ spot. Analytical sites were selected in order to avoid inclusions visible in reflected light images and to representatively sample different CL zones, as well as crystal cores and rims. Trace element analytical spots were not superimposed on the $\mathrm{U}-\mathrm{Pb}$ age dating spots (and vice versa), but care was taken to locate trace element analyses within the same growth zones of the zircon crystals as those that were age dated. The MAD zircon standard was used to calibrate trace element concentrations (Electronic Appendix 1). 


\subsection{Results}

Our data suite consists of three quantifiable aspects of zircons: the textures as shown under CL imaging, the age data, and the trace-element data, which we first consider as separate entities.

\subsubsection{Zircon textures}

A total of $\sim 3300$ zircon crystals from the Bishop Tuff and Glass Mountain samples were characterised for their respective CL zoning patterns. When mounting the crystals, care was taken to lay prismatic crystals flat so that when they were ground down and polished, a representative cross section was made of textures in the plane of the $a$ - and $c$ - or $b$ - and $c$ axes. The patterns observed are grouped into four main suites (Figs. 3.3, 3.4; Table 3.2) as follows:

(a) The 'typical' Bishop suite (referred to hereafter as 'normal Bishop') of euhedral prismatic grains, almost always with a strongly developed sector-zonation but lacking bright rims (Fig. 3.3a-c). This type overwhelmingly dominates the zircon populations from the fall deposit and easterly-distributed ignimbrite, and is still present in all samples from the northern ignimbrite lobes. All the grains illustrated by Crowley et al. (2007) belong to this type.

(b) A subordinate suite having some proportion of the crystal that displays distinctly bright CL shades when compared to the normal Bishop type, and labelled 'bright rim' type (Fig. 3.3c-e). The bright material most often forms discrete, sharply defined rims on grains, the cores of which have morphologies and CL patterns similar to the normal Bishop grains (above), but also comprises whole grains or continuously CL-zoned grains in samples from some of the northern lobes. The zircons with bright rims were further separated into four categories: $<10 \mu \mathrm{m}$ rim; $10-30 \mu \mathrm{m}$ rim; rim $>30 \mu \mathrm{m}$ wide overgrowing a core of contrasting composition; $>80 \%$ of the crystal showing bright CL shades and inferred to have largely or wholly crystallised from the 'bright-rim magma'.

(c) A sparsely developed suite of oscillatory zoned, poorly shaped crystals with little or no visible indications of sector zoning (Fig. 3.3f). This type comprises virtually all of the grains for the YA dome sample (Fig. 3.4) and is thus termed 'Glass Mountain type'. Grains with similar characteristics are a sparse $(0-6 \%)$ component of the zircon suites in pumices from northern and northwestern Bishop ignimbrite lobes. 


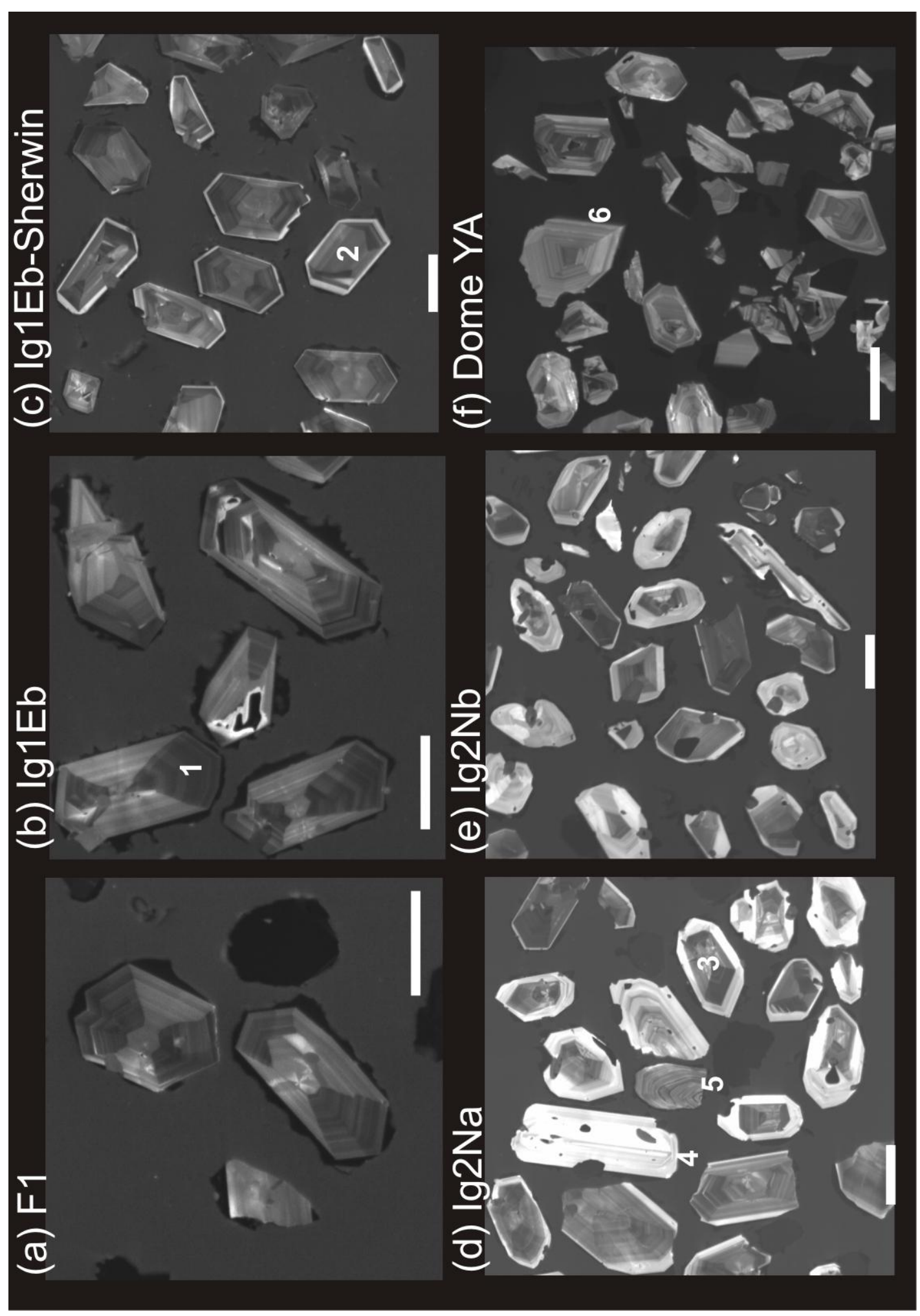

Fig. 3.3. Zircon CL textures shown in samples from the Bishop Tuff (a-e) compared with those of the youngest Glass Mountain (GM) dome [YA (f): see text for details]. (a) BP178-F1; (b) BP087-Ig1Eb; (c) BP040-Ig1Eb- Sherwin; (d) BP059-Ig2Na; (e) BP170Ig2Nb (See Table 3.1 for sample descriptions). Types of zircons described in the text are as follows: 1, dominantly sector-zoned 'normal Bishop' zircons showing the characteristic oscillatory zoning; 2, 'normal Bishop'-type zircon with a narrow $(<10 \mu \mathrm{m})$ bright rim; 3, a wide bright rim overgrowing a 'normal Bishop'-type zircon; 4, a completely CL-bright zircon; 5, Triassic zircon showing oscillatory zoning with no sector-zoning or bright rim: the crystal is fractured but still glass coated; 6, Glass Mountain-type oscillatory zoned crystal. Scale bar represents $100 \mu \mathrm{m}$ in each image. 
(d) A sparsely developed suite of concentrically zoned irregularly shaped to euhedral grains which are commonly fractured, oscillatory zoned, and darker in CL than the Glass Mountain type (Fig. 3.3d, labelled as grain 5). Trace-element analyses, incorporating short counts for ${ }^{206} \mathrm{~Pb}$ (10 seconds) and ${ }^{238} \mathrm{U}^{16} \mathrm{O}$ (5 seconds) for $\mathrm{Pb}$ and $\mathrm{U}$ concentrations, respectively, showed that such grains are xenocrystic (although glass coated, showing that they are not accidental), returning Mesozoic, overwhelmingly Triassic, ages inferred to reflect a source in the local Sierra Nevada granites (Barth et al., 2011). These grains are labelled as 'basement type' hereafter.

Systematic changes in zircon textures are observed in pumices collected through the Bishop Tuff eruptive sequence (Fig. 3.4; Electronic Appendix 2).

Table 3.2. Summary of textural features observed in zircons from Bishop Tuff samples examined in this study

\begin{tabular}{|c|c|c|c|c|c|c|c|c|c|c|}
\hline Sample & $\begin{array}{c}\text { Eruptive } \\
\text { unit }\end{array}$ & $\begin{array}{l}\text { Number } \\
\text { of grains }\end{array}$ & $\begin{array}{c}\text { Sector } \\
\text { zoned, } \\
\%\end{array}$ & $\begin{array}{c}\text { No } \\
\text { bright } \\
\text { rim, \% }\end{array}$ & $\begin{array}{c}<10 \mu \mathrm{m} \\
\text { bright } \\
\text { rim, \% }\end{array}$ & $\begin{array}{c}10-30 \mu \mathrm{m} \\
\text { bright } \\
\text { rim, \% }\end{array}$ & $\begin{array}{c}>30 \mu \mathrm{m} \\
\text { bright } \\
\text { rim, \% }\end{array}$ & $\begin{array}{c}\text { All } \\
\text { bright } \\
\%\end{array}$ & $\begin{array}{c}\text { Mesozoic, } \\
\%\end{array}$ & $\begin{array}{c}\text { Glass } \\
\text { Mtn, } \\
\%\end{array}$ \\
\hline BP206 & $\lg 2 \mathrm{Nc}$ & 688 & 24 & 5 & 32 & 27 & 8 & 22 & 3 & 3 \\
\hline BP124 & Ig2NWb & 257 & 23 & 1 & 31 & 33 & 14 & 16 & 2 & 3 \\
\hline BP172 & $\lg 2 \mathrm{Nb}$ & 67 & 42 & 43 & 9 & 9 & 6 & 15 & 18 & 0 \\
\hline BP232 & $\lg 2 \mathrm{Nb}$ & 190 & 44 & 41 & 13 & 7 & 5 & 7 & 21 & 6 \\
\hline BP170 & $\lg 2 \mathrm{Nb}$ & 53 & 15 & 0 & 11 & 51 & 21 & 13 & 0 & 4 \\
\hline ВР059 & $\lg 2 \mathrm{Na}$ & 257 & 61 & 3 & 32 & 30 & 16 & 14 & 3 & 4 \\
\hline BP115 & Ig2NWa & 624 & 32 & 1 & 30 & 33 & 14 & 20 & 2 & 1 \\
\hline BP118 & Ig2NWa & 98 & 89 & 4 & 67 & 22 & 3 & 3 & 0 & 0 \\
\hline BP216 & Ig2SW & 306 & 67 & 42 & 54 & 2 & 0 & 1 & 1 & 0 \\
\hline ВР040 & $\begin{array}{c}\text { Ig1Eb } \\
\text { (Sherwin) }\end{array}$ & 239 & 86 & 31 & 58 & 10 & 0 & 1 & 0 & 0 \\
\hline BP130 & Ig1SW & 64 & 66 & 100 & 0 & 0 & 0 & 0 & 0 & 0 \\
\hline ВР087 & Ig1Eb & 79 & 99 & 100 & 0 & 0 & 0 & 0 & 0 & 0 \\
\hline BР098 & Ig1Eb & 58 & 79 & 97 & 2 & 0 & 0 & 0 & 2 & 0 \\
\hline BP178 & $\mathrm{F} 1$ & 284 & 83 & 100 & 0 & 0 & 0 & 0 & 0 & 0 \\
\hline BP109 & F1 & 34 & 82 & 94 & 3 & 0 & 0 & 0 & 3 & 0 \\
\hline BR228 & DomeYA & 451 & 3 & 2 & 0 & 0 & 0 & 0 & 0 & 97 \\
\hline BR226 & Dome OD & 127 & 7 & 2 & 4 & 1 & 0 & 0 & 1 & 88 \\
\hline
\end{tabular}

Eruptive units are from Hildreth \& Wilson (2007). 


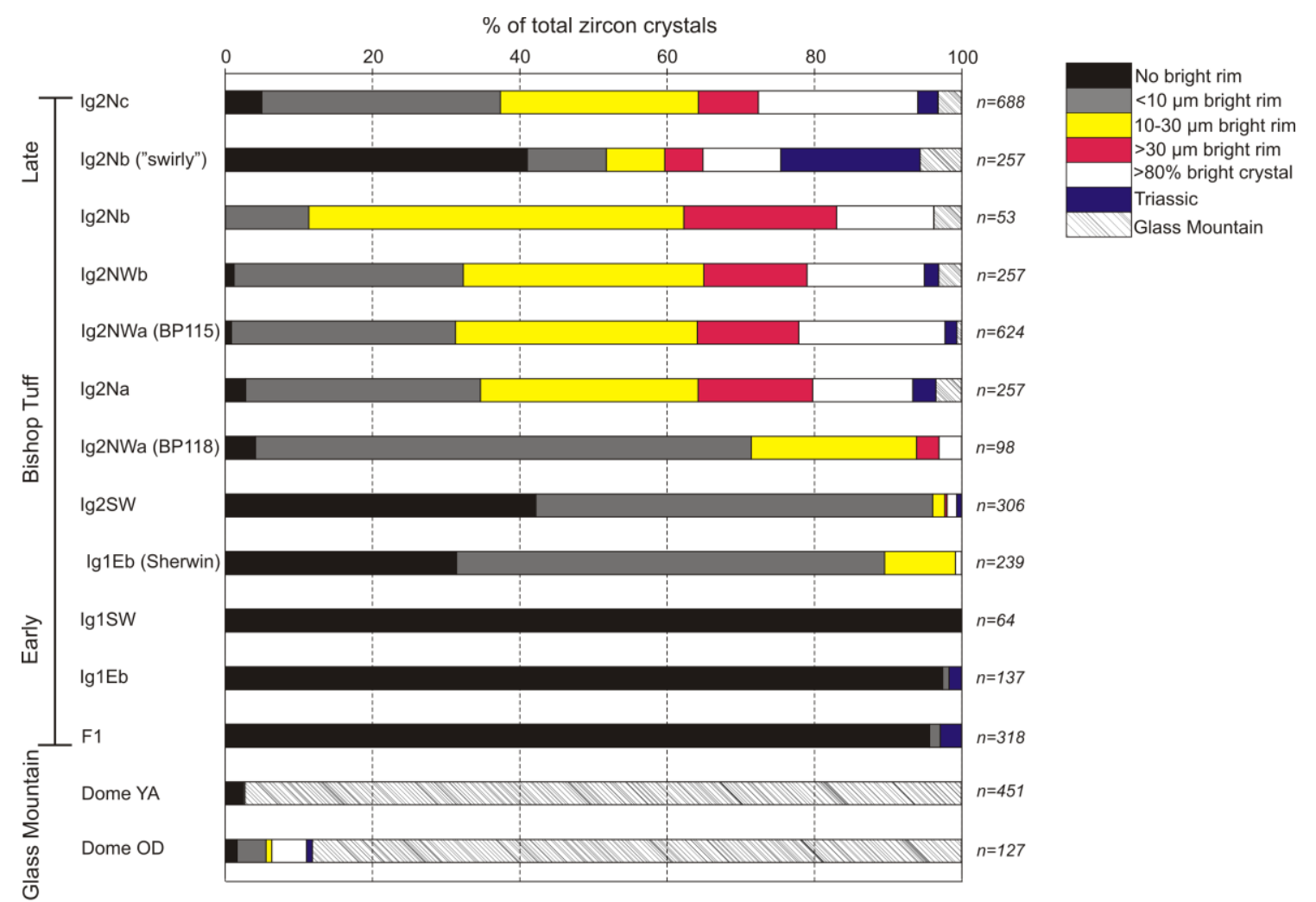

Fig. 3.4. Zircon CL zoning patterns (Fig. 3.3) correlated to stratigraphic position (from Wilson \& Hildreth, 1997) within the deposits studied here. (Note the systematic changes through the Bishop eruption sequence from a dominance of 'normal Bishop'-type zircons with no bright rim to a dominance of zircons that have various degrees of development of the CL-bright rims.)

\subsubsection{Sector Zoning}

Sector zoning occurs both in non-rimmed grains and the cores of many bright-rimmed grains. Variable grey-scale intensities in the sector zoning dominate the CL images, whether oscillatory zoning is present or not (Fig. 3.3). Zircons from the fall units and early eastern ignimbrite lobes are dominantly $(\sim 85 \%)$ sector zoned, whereas the abundance of sector zoning diminishes to $24 \%$ in the latest unit $(\operatorname{Ig} 2 \mathrm{Nc})$. This diminution is gradual, with no sharp definable change corresponding to changes in eruption vent locations (Hildreth $\&$ Mahood, 1986; Wilson \& Hildreth, 1997). Sector zoning is also common in zircons from the Ig1SW and Ig2SW units, previously been suggested to be from a source similar to (but not necessarily co-vented from) the early-erupted fall deposits and ignimbrite (Hildreth \& Wilson, 2007). 


\subsubsection{Bright Overgrowths}

Bright overgrowths on zircons become the dominant feature in northern-erupted units, where $<5 \%$ of the crystals show no bright overgrowth, and $\sim 65 \%$ of all crystals have $>10$ $\mu \mathrm{m}$ wide bright rims. The core-rim contact shows no evidence for dissolution of the crystal core (Fig. 3.3, Electronic Appendix 2), implying that ingress of the contrasting magma composition or any changes in physical conditions did not cause significant dissolution of pre-existing grains. The width of the bright rim generally increases in zircons from pumices later in the eruption sequence, with some crystals showing purely bright-CL characteristics (Fig. 3.4). Sector zoning is greatly subdued in the bright zones. The bright CL rims in zircons are inferred to be the counterparts to the bright rims reported from CL and BSE images on quartz and sanidine crystals, respectively (Peppard et al., 2001; Morgan \& Blake, 2006; Wark et al., 2007; Pamukcu et al., 2012). Bright rims on quartz and sanidine are generally reported only in the later units erupted from the northern caldera rim, although Gualda (2007) reported sparse bright-rimmed quartz and feldspar grains from the early-erupted sequences. Our observation that $<10 \mu \mathrm{m}$ bright rims are present in late Ig1Eb (Sherwin subunit of Hildreth \& Wilson, 2007) and Ig2SW is in agreement with glass and melt inclusion chemistry (Roberge et al., 2013) showing some degree of mixing in 'middle-erupted' units of the Bishop Tuff. Bright rims are not found in zircons from Glass Mountain dome YA, yet are sparsely present on crystals from dome OD. We infer that the magma from which the bright zones crystallised in zircon (and other minerals) is not simply a short-lived feature associated only with the Bishop Tuff magma body, but represents a recurrent feature.

\subsubsection{Zircons from swirly pumices}

Two pumices sampled were of the crystal poor, highly vesicular swirly type (Hildreth \& Wilson, 2007), collected from Ig2Nb. Particularly high proportions (18 and 21\%) of basement-derived zircons occur in these clasts; the grains wholly lack any overgrowths ('normal' or 'bright rim'), and are commonly fractured but always glass coated.

\subsection{2 $\mathrm{U}-\mathrm{Pb}$ age determinations}

A total of 616 acceptable $\mathrm{U}-\mathrm{Pb}$ ages were obtained on 12 samples of the Bishop Tuff, as well as 38 ages from Glass Mountain dome YA and 18 from dome OD. 'Acceptable' for the purpose of this study means analyses with $<10 \%$ of the ${ }^{206} \mathrm{~Pb}$ attributable to common $\mathrm{Pb}$, regardless of the $\mathrm{U}$ concentration at the spot point. Single age determinations on grains 
with $U>500$ ppm have $2 \sigma$ uncertainties between 14 and $179 \mathrm{kyr}$, with an average of \pm 48 kyr; however, when the analyses are combined in weighted mean estimates the uncertainties are greatly reduced.

\subsubsection{Bishop Tuff: general age data}

Age determinations, together with values for ${ }^{206} \mathrm{~Pb} /{ }^{238} \mathrm{U}$ ratios, concentrations of $\mathrm{U}$ and $\mathrm{Th}$, and the proportions of ${ }^{206} \mathrm{~Pb}$ attributable to common $\mathrm{Pb}$ for all zircons analysed are given in Electronic Appendix 1. These data are annotated also for cores versus rims, sides versus tips of sector zoned grains, and binned for the bright rim widths. Zircons with a wide range of $\mathrm{U}$ concentrations were analysed (Fig. 3.5) although at lower $\mathrm{U}$ concentrations the analytical uncertainties increase and the proportions of ${ }^{206} \mathrm{~Pb}$ attributable to common $\mathrm{Pb}$ often are beyond our 10\% cut-off for acceptable analyses (see Methods section). Age determinations do not, within analytical uncertainties, increase at high uranium concentrations (Fig. 3.5) as has been reported elsewhere and attributed to the effects of metamictization or high trace element concentrations resulting in analyses of unknowns no

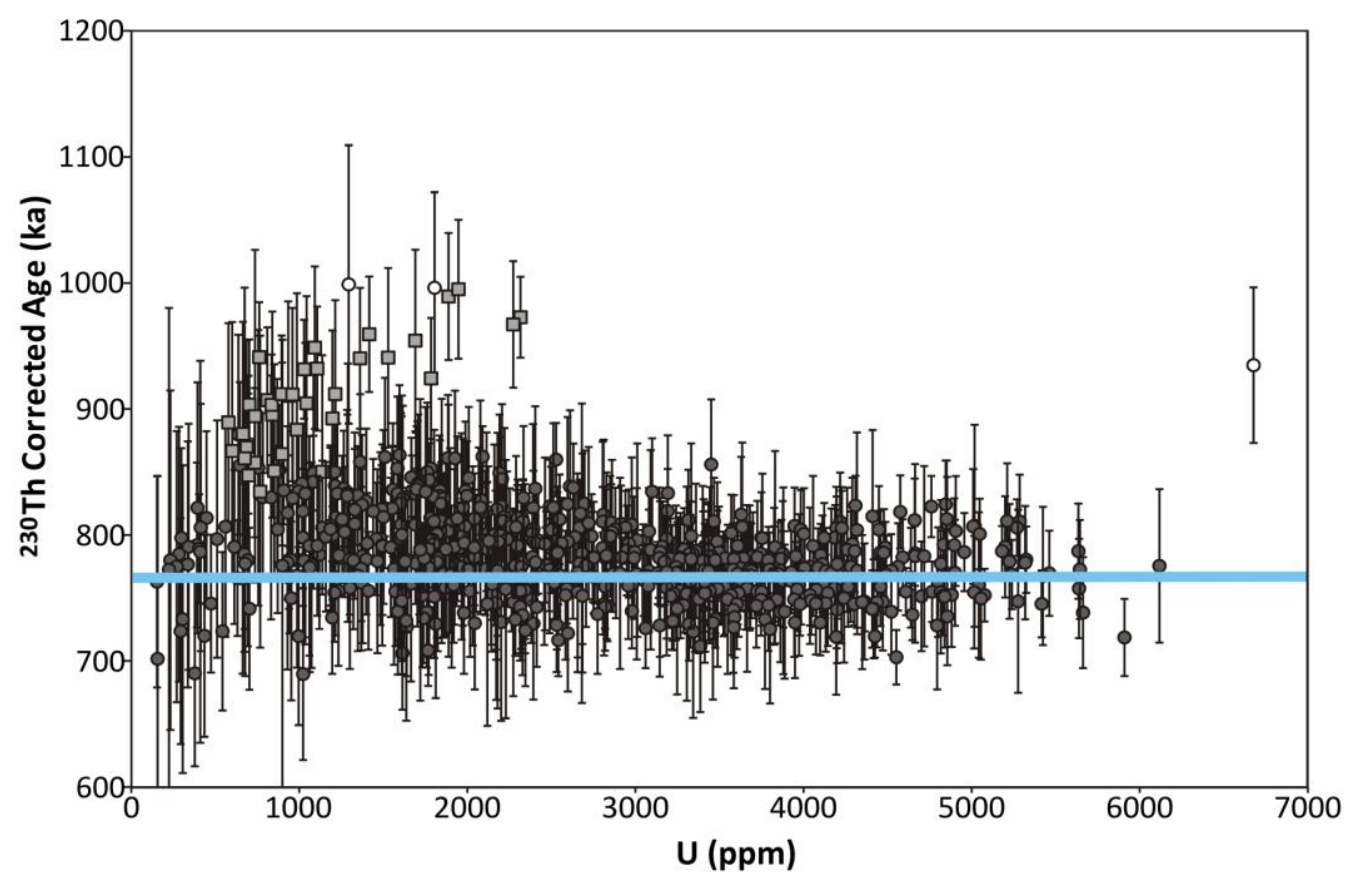

Fig. 3.5. U concentrations (ppm) versus ${ }^{230} \mathrm{Th}$-corrected ${ }^{206} \mathrm{~Pb} /{ }^{208} \mathrm{U}$ ages (ka) for all Bishop Tuff (circles) and Glass Mountain dome YA (squares) data points. The 3 open circles represent data points which fall outside of the bulk range of Bishop Tuff data and may be erroneous. The thick line indicates eruption age estimates from ${ }^{40} \mathrm{Ar} /{ }^{39} \mathrm{Ar}$ experiments on feldspar and ID-TIMS experiments on zircon $(767 \mathrm{ka}$; see text for details and references). Error bars represent $2 \sigma$ uncertainties. 
longer being matrix-matched by the zircon standard (e.g. Gagnevin et al., 2011; White \& Ireland, 2012). Variations in U concentrations are not systematic with sample or eruptive timing (Electronic Appendix 1). Our age determinations for all Bishop eruptive units and all locations within crystals range from $\sim 700 \mathrm{ka}$ to $\sim 880 \mathrm{ka}$. A probability density function (PDF) curve generated in Isoplot (Ludwig, 2008) for all acceptable Bishop age determinations shows a unimodal peak (Fig. 3.6), with an associated weighted mean value of $777.9 \pm 2.2 \mathrm{ka}(95 \%$ confidence limits), where 26 of 616 analyses were rejected (MSWD $=2.1$, probability $=0.00)$.

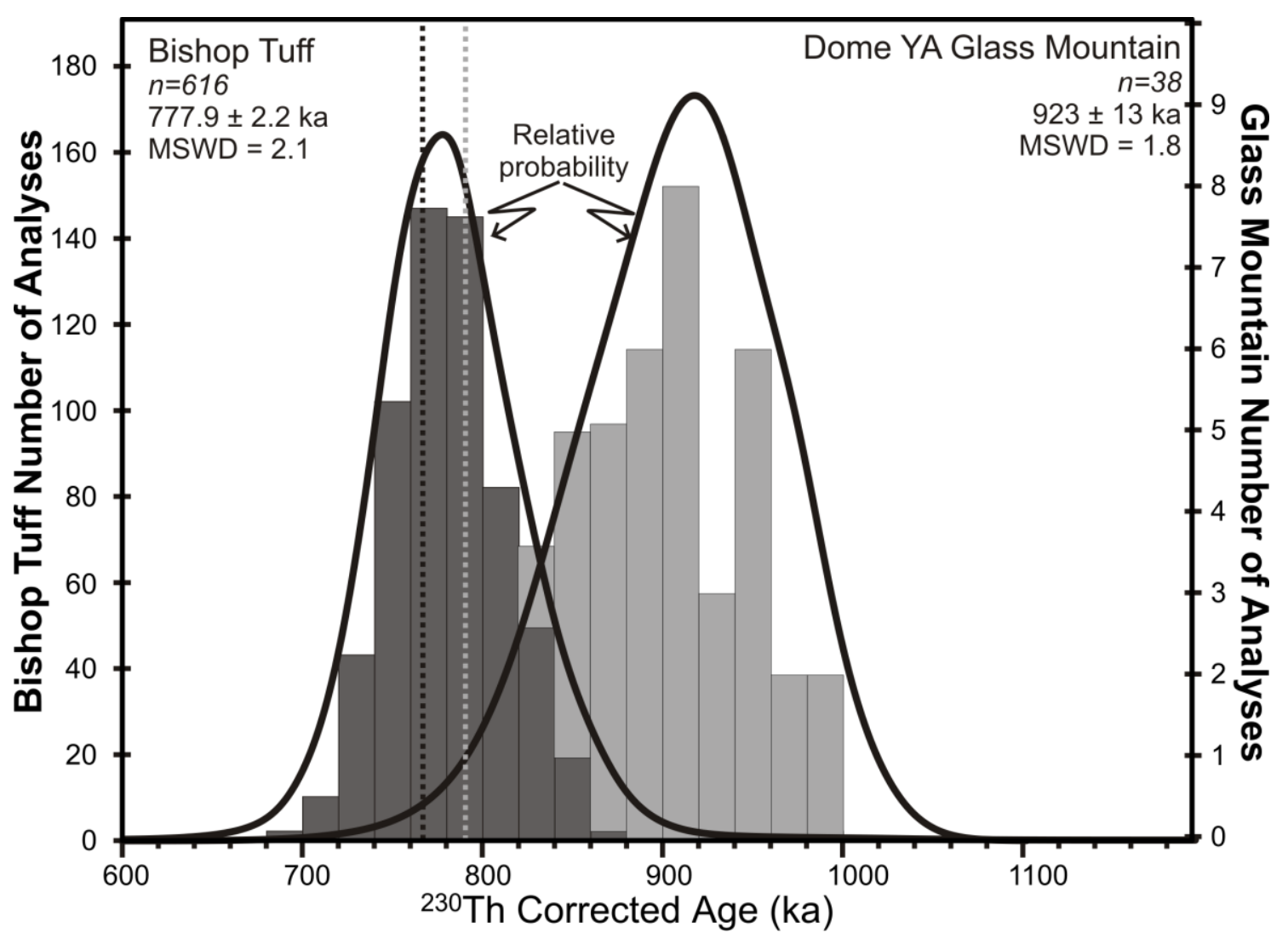

Fig. 3.6. Zircon ${ }^{230} \mathrm{Th}$-corrected ${ }^{206} \mathrm{~Pb} /{ }^{208} \mathrm{U}$ age data for the entire Bishop Tuff (dark grey), and for dome YA (Glass Mountain, light grey). The dashed lines are published eruption ages of the Bishop Tuff (767 ka; see text) and dome YA (790 $\pm 20 \mathrm{ka}$ : Metz \& Mahood, 1985). The probability density function (PDF) curve (from Isoplot: Ludwig, 2008) and histograms demonstrate the clear temporal separation between the youngest precursory Glass Mountain eruption and the Bishop Tuff. Values for the two data sets represent the number of spots used, and the weighted means, uncertainties at $95 \%$ confidence and mean squares of weighted deviates (MSWD) values for each population. For full data set see Electronic Appendix 1. 


\subsubsection{Bishop Tuff: details in age data}

3.4.2.2.1. Sector-zoned ages. Given the dominance of sector zoning in zircons from early-erupted samples, we investigated whether the different sectors yielded the same ages for the same growth zones, as indicated by the 'growth rings' of oscillatory zoning. When sides and tips were compared there is no systematic age difference between sectors (Fig. 3.7): the CL darker tips yield a weighted mean of $773.5 \pm 2.8 \mathrm{ka}$ (nine of 267 rejected, MSWD=1.8) whereas the lighter sides have a weighted mean of $776.1 \pm 7.2 \mathrm{ka}$ (three of 60 rejected, MSWD=1.7). Side and tip ages within single crystals from samples BP098 and BP178, differ between the two sectors by $<20 \mathrm{kyr}$ for 13 of 22 crystals, but by $20-70 \mathrm{kyr}$ for the others (Fig. 3.7; Electronic Appendix 1). When viewed together as part of a large sample suite it is apparent that there are no resolvable age differences between sides and tips.

3.4.2.2.2. Early- versus late-erupted units. Table 3.3 summarises weighted means for each of the 12 samples analysed for age. Four samples from F1 and lowest Ig1Eb representing 'early-erupted' material have age spectra with weighted-mean values ranging between $752.3 \pm 5.7 \mathrm{ka}$ and $776.1 \pm 5.1 \mathrm{ka}$. In later-erupted samples the weighted means are somewhat older, ranging from $790.8 \pm 8.5 \mathrm{ka}$ to $825 \pm 13 \mathrm{ka}$. When plotting single sample PDF curves through the eruption sequence, older ages are represented more in the later erupted material (see Electronic Appendix 1). However some bias has been introduced to analyses from zircons in the later-erupted samples owing to our specific targeting of cores within the bright-rimmed grains to ascertain whether they showed a longer crystallisation history (Simon \& Reid, 2005). By separating core and rim analyses prior to calculating weighted means, we account for this bias.

3.4.2.2.3. Cores versus rims. In the four 'early-erupted' samples there is no significant difference in core versus rim ages, both yielding age-equivalent unimodal peaks (Fig. 3.8). Cores give a weighted mean of $774 \pm 10 \mathrm{ka}$ (one of 22 rejected, MSWD=1.6) and rims a weighted mean of $766.6 \pm 3.1 \mathrm{ka}$ (six of 172 rejected, MSWD=1.3). Three samples from the late-erupted $\operatorname{Ig} 2 \mathrm{Nb}$ and $\mathrm{Ig} 2 \mathrm{Nc}$ have rims that yield a slightly older weighted mean of $787.3 \pm 5.2 \mathrm{ka}$ (two of 62 rejected, MSWD=1.7). However, the cores of these late-erupted samples yield a bimodal PDF curve with a weighted mean of $807.5 \pm 7.7 \mathrm{ka}$ (three of 55 rejected, MSWD=1.4), which can be split into two age groups ( $<808 \mathrm{ka}$ and $>808 \mathrm{ka})$. The younger age group gives a weighted mean of $784.1 \pm 8.7 \mathrm{ka}$ (none of 27 rejected, 


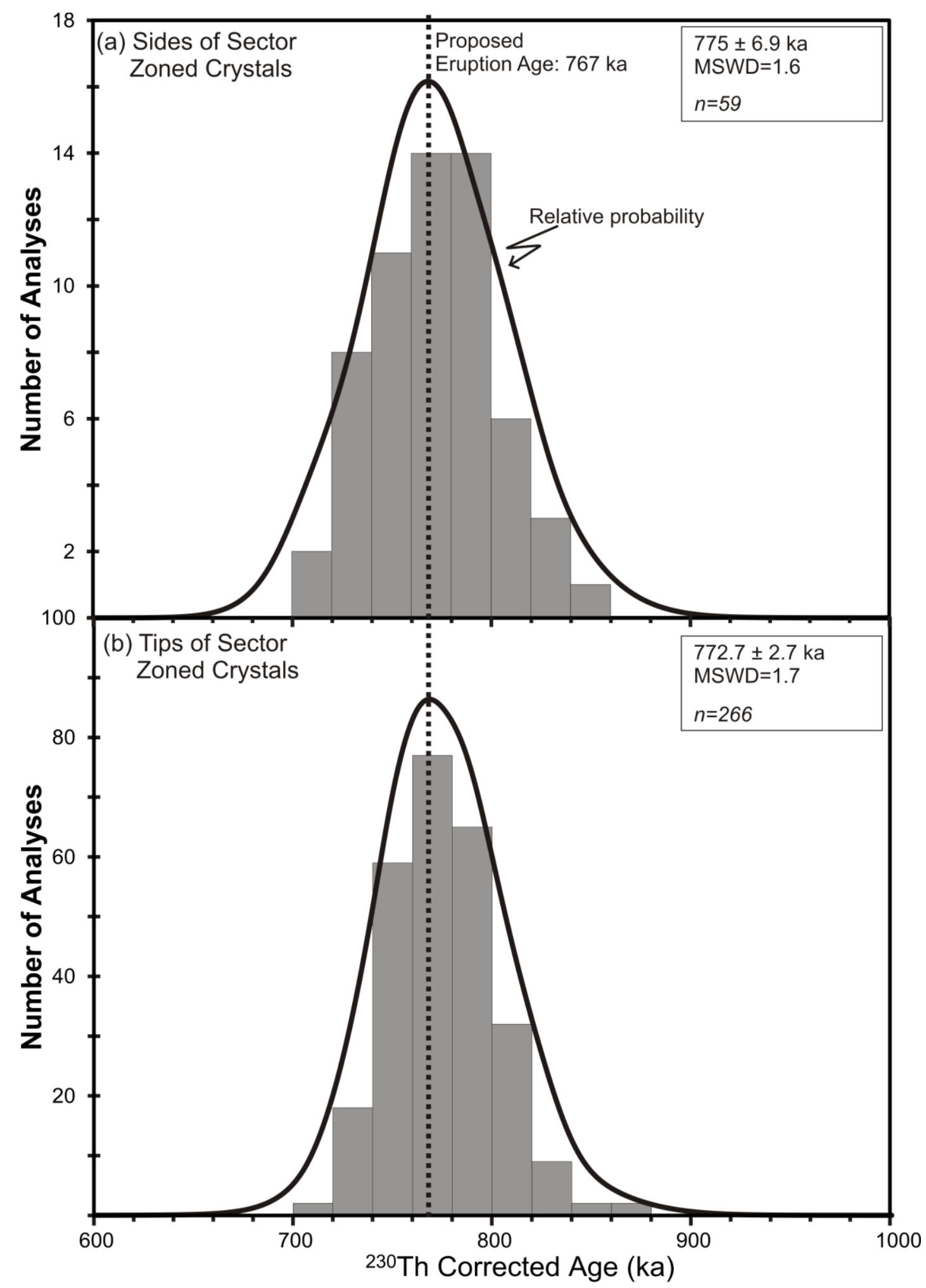

Fig. 3.7. Zircon ${ }^{230} \mathrm{Th}$-corrected ${ }^{206} \mathrm{~Pb} /{ }^{208} \mathrm{U}$ age data for all sector zoned zircons, to compare age determinations from the tips vs sides of the same crystals. Dashed line represents the proposed eruption age from ${ }^{40} \mathrm{Ar} /{ }^{39} \mathrm{Ar}$ experiments on feldspar and IDTIMS experiments on zircon (767 ka; see text for details and references). Probability density function (PDF) curves from Isoplot. Values for the data sets represent the number of spots used $(n)$, and the weighted means, uncertainties at $95 \%$ confidence and MSWD values for the respective populations. (For full data set see Electronic Appendix 1.) 


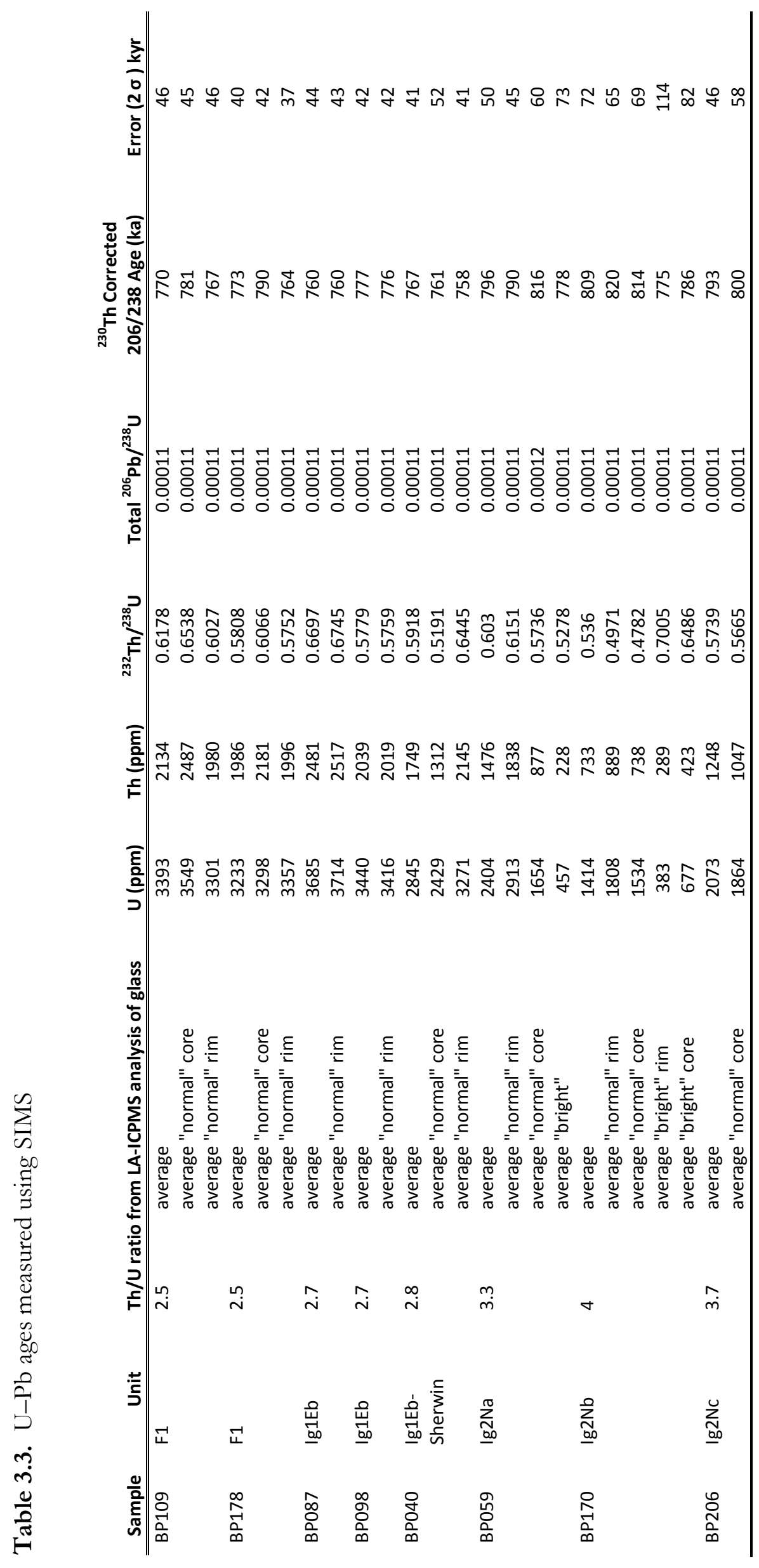




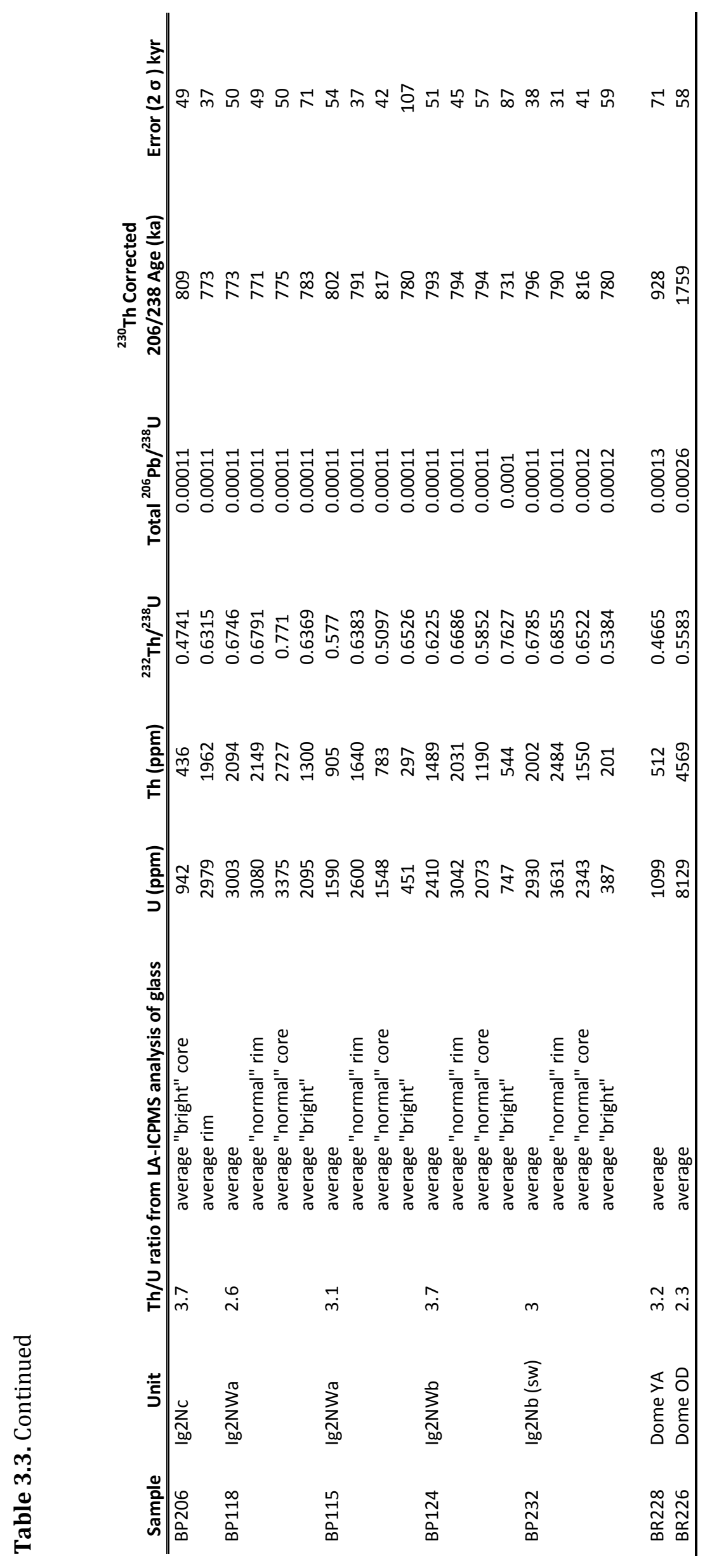




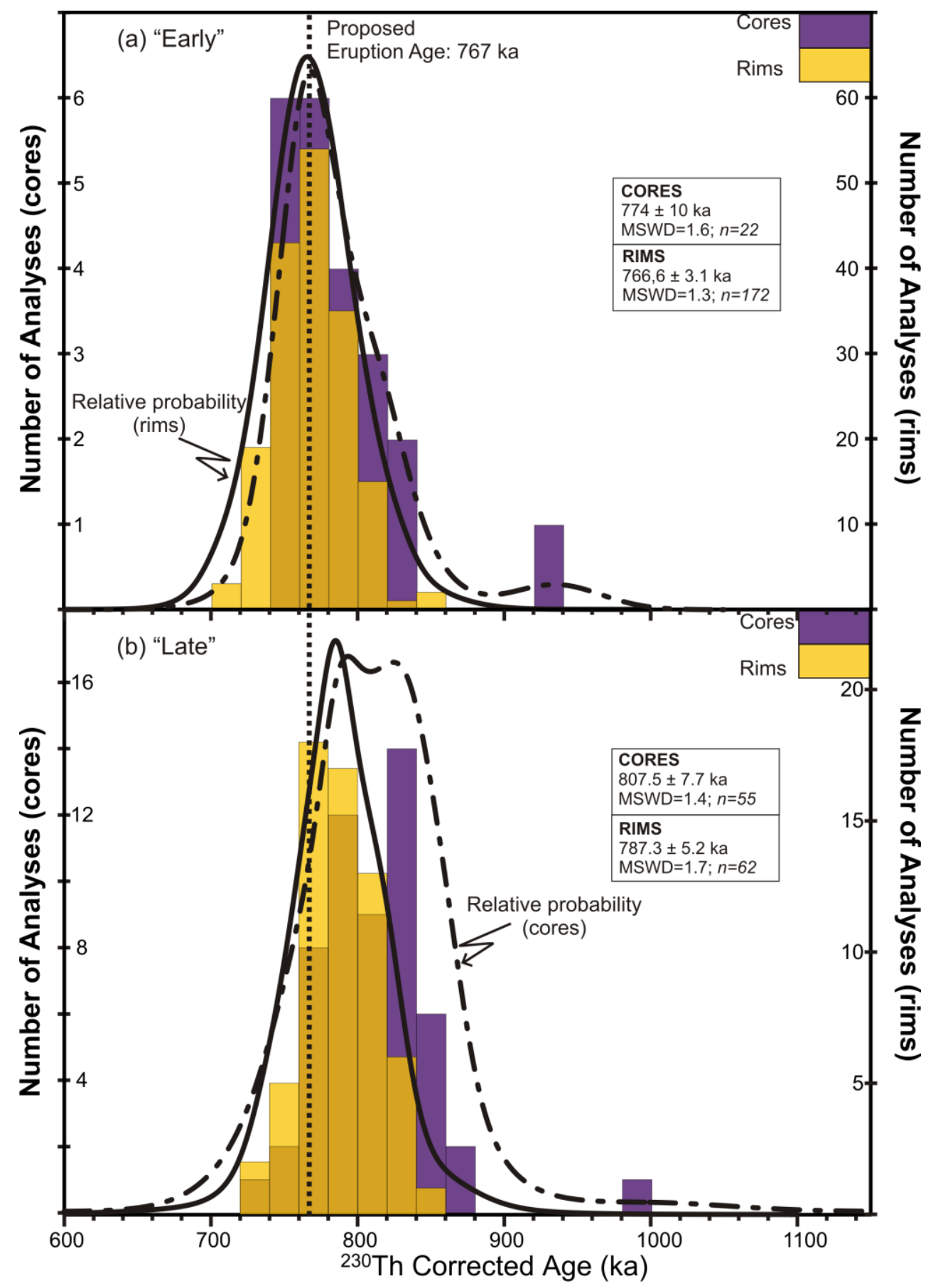

Fig. 3.8. Zircon ${ }^{230} \mathrm{Th}$-corrected ${ }^{206} \mathrm{~Pb} /{ }^{208} \mathrm{U}$ age data compared for spots in cores and rims from typical early and late-erupted samples. Dashed line represents the proposed eruption age from ${ }^{40} \mathrm{Ar} /{ }^{39} \mathrm{Ar}$ experiments on feldspar and ID-TIMS experiments on zircon (767 ka; see text for details and references). (a) Early erupted samples (F1-BP109 and BP178; Ig1Eb-BP087, see Table 3.1) have cores with a mean age that is closely similar to the rims from these samples. Both are within uncertainty of the independently determined eruption age estimates (see text). (b) Late-erupted rims from $\operatorname{Ig} 2 \mathrm{Nb} / \mathrm{c}$ (BP170, BP206 and BP232: see Table 3.1) samples are slightly older than eruption age, whereas cores show a marked tail-off to older ages. Probability density function (PDF) curve from Isoplot. Values for the data sets represent the number of spots used $(n)$, and the weighted means, uncertainties at 95\% confidence and MSWD values for the respective populations. For full data set see Electronic Appendix 1. 
MSWD=0.42), whereas as the older age group yields a weighted mean of $838.5 \pm 8.7 \mathrm{ka}$ (none of 28 rejected, MSWD=0.75). When the 'unmix' option in Isoplot is applied to the data sets, two weighted means are obtained of $790.6 \pm 10.0 \mathrm{ka}$ and $836.9 \pm 11.0 \mathrm{ka}$. Both of these approaches imply that there are two populations of grains, both distinctly older than those in the early-erupted samples, but which are indistinguishable on a textural basis.

3.4.2.2.4. Bright rimmed grains. Age determinations from the bright rims (Table 3.2) have greater uncertainties commensurate with the lower $\mathrm{U}$ and Th concentrations (sometimes <200 ppm: see Electronic Appendix 2). When plotted on a Tera-Wasserburg diagram, the collection of all low- $\mathrm{U}$ analyses with $<30 \%$ of the ${ }^{206} \mathrm{~Pb}$ attributable to common $\mathrm{Pb}$ yield a lower age intercept with a disequilibrium-corrected concordia value of $772 \pm 28 \mathrm{ka}$ (Fig. 3.9), matching the data from the higher-U grains or domains. Ages from the higher- $\mathrm{U}$ cores, but from spots sited just inside narrow $(<10 \mu \mathrm{m})$ bright rims have a weighted mean of $777.5 \pm 5.4 \mathrm{ka}$ (five of 90 rejected, MSWD=2.3).

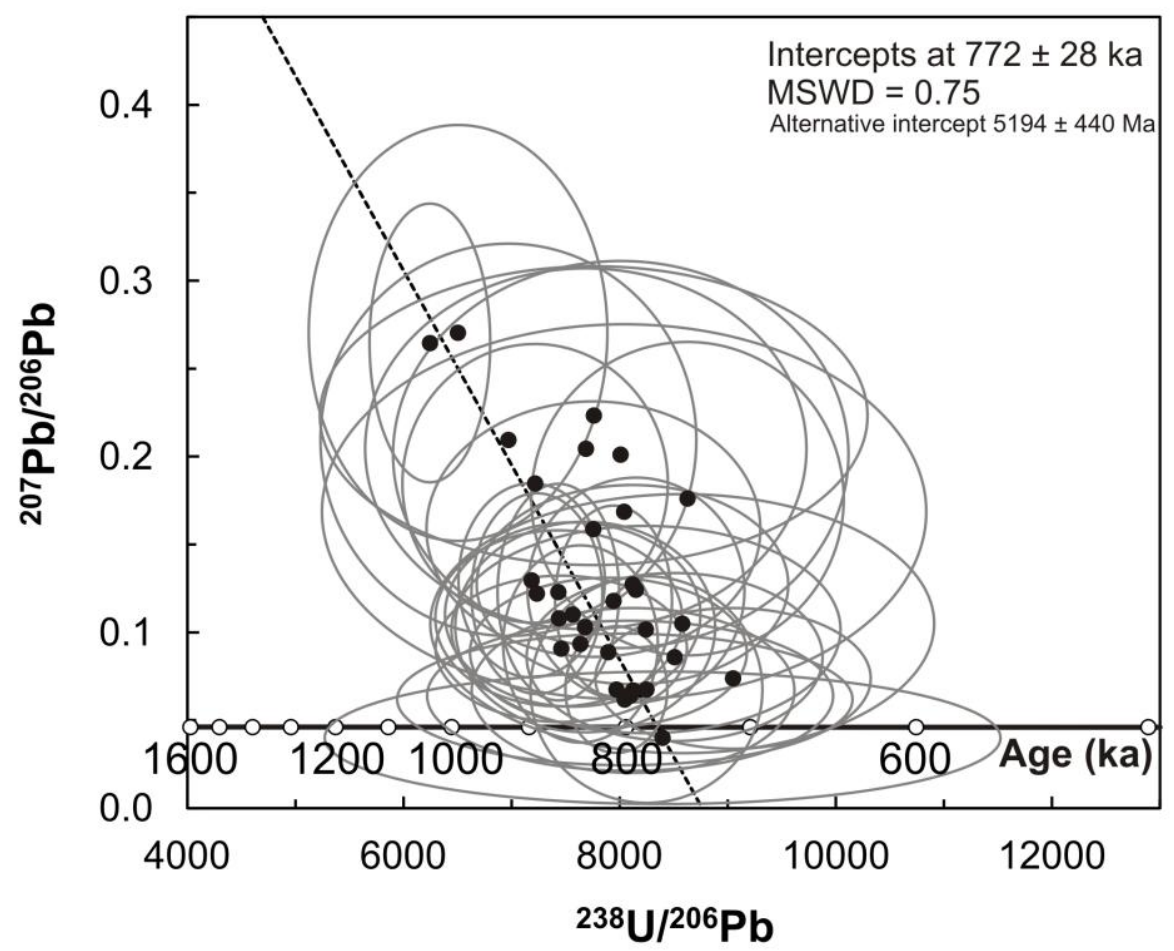

Fig. 3.9. Inverse isochron (Tera-Wasserburg) diagram generated in Isoplot of all analyses from grains with $\mathrm{U}<500 \mathrm{ppm}$ and up to $30 \%$ of the ${ }^{206} \mathrm{~Pb}$ attributable to common $\mathrm{Pb}$, using the common- $\mathrm{Pb}$ composition for this age from the crustal evolution model of Stacey \& Kramers (1975) (see text for discussion). The best-fit line is not pinned to any intercept value. Ellipses represent $2 \sigma$ uncertainty on individual analyses. (For data set see Electronic Appendix 1.) 


\subsubsection{Glass Mountain samples}

Eighteen ages for dome OD have a weighted mean of $1.750 \pm 0.021 \mathrm{Ma}$ (one of 18 rejected, $M S W D=2.8$ : Table 3.3), similar to the 'minimum age' average of $1.728 \pm 0.043$ $\mathrm{Ma}(1 \sigma, n=4)$ from Simon \& Reid (2005). Both figures are significantly older than the KAr eruption age of $1.35 \pm 0.10 \mathrm{Ma}$ (Metz \& Mahood, 1985), but consistent with the ${ }^{40} \mathrm{Ar} /{ }^{39} \mathrm{Ar}$ age determination from step-heating experiments on sanidine of $1.702 \pm 0.011$ Ma (1б) in Davies et al. (1994). [Note that Davies et al. (1994) report a value of $1.686 \pm$ $0.011 \mathrm{Ma}$ relative to a value of $1071 \mathrm{Ma}$ for standard Hb3gr, for which Renne et al. (2011) give an age of $1081 \pm 1.2 \mathrm{Ma}$.]. Zircons from dome YA yield 38 acceptable ages, one of which $(1.682 \pm 0.079 \mathrm{Ma})$ is inferred to be xenocrystic, despite having identical textural characteristics to the others. The 37 remaining ages range from $1000 \mathrm{ka}$ to $820 \mathrm{ka}$ and yield a unimodal PDF peak with a weighted mean of $923 \pm 13 \mathrm{ka}$ (none rejected; MSWD=1.8), somewhat younger than the average reported by Simon \& Reid (2005) of $995 \pm 19 \mathrm{ka}(n=9$, MSWD=2.2). A positive correlation of age versus $U$ concentration is observed in the dome YA data (Fig. 3.5), in contrast to Bishop zircons, but we attribute this correlation to secular changes in the uptake of $U$ into the grains, not to metamictisation or excessive trace element concentrations. The weighted mean for the youngest $30 \%$ of our age data yields a value of $862 \pm 23 \mathrm{ka}(n=12$, MSWD $=0.096)$. We infer, based on previous work with New Zealand examples where eruption ages have been independently determined (e.g. Milicich et al., 2013), that this value represents an accurate estimate for the eruption age of dome YA. This age is in contrast to the $790 \pm 20 \mathrm{ka} \mathrm{K}-$ Ar determination by Metz \& Mahood (1985).

\subsubsection{Trace elements in Bishop zircons}

Trace element analyses of zircons from seven Bishop Tuff samples were undertaken to characterise the trace element variation across the range of ages and CL characteristics, taking account of variations between sectors within single crystals as well as those between normal cores and the bright rims. Additionally, we collected trace-element data from the Mesozoic grains in sample BP232 (Ig2Nb: Table 3.1) to see if the compositional patterns differed significantly from those for the young grains. As in all microanalytical approaches to mineral chemistry, there is the risk of analyses reflecting contamination by melt or crystal inclusions. Although analytical spots were placed away from any visible inclusions, whether in CL images or in reflected light, in some cases it became apparent that inclusions 
were intersected. We used common elements that are normally found at very low concentrations in zircon compared to the contaminant phase to monitor such contamination: $\mathrm{Ca}, \mathrm{Al}, \mathrm{Na}$ and $\mathrm{K}$ for feldspar and glass; $\mathrm{Ca}, \mathrm{P}$ and $\mathrm{F}$ for apatite; Fe for $\mathrm{Fe}-$ $\mathrm{Ti}$ oxides; and $\mathrm{Ca}$ and $\mathrm{Fe}$ for allanite. Analyses showing significant degrees of contamination were culled accordingly. The full data are given in Electronic Appendix 3; spots with severe contamination are omitted, while others with minor contamination are highlighted and have suspect concentrations of affected elements struck through.

\subsubsection{Bishop Tuff: general trace element data}

When plotted all together, the trace element data form two contrasting end-member patterns (Fig. 3.10), between a single coherent array where intra-grain variations (see section below on sector zoning) fall within the overall trend of the array, or two separated but sub-parallel arrays. The overall trends in Fig. 3.10 reflect fractionation driven changes in the melt from which the zircons are growing (Reid et al., 2011; Fig. 3.10a,b). It is typical for $\mathrm{Ti}$ and $\mathrm{Th} / \mathrm{U}$ and $\mathrm{Nd} / \mathrm{Yb}$ ratios to decrease and $\mathrm{Yb} / \mathrm{Gd}$ to increase with increasing melt fractionation as measured by higher $\mathrm{Hf}$ concentrations or lower $\mathrm{Eu} / \mathrm{Eu}^{*}$ ratios. $\mathrm{U}$ typically covaries with $\mathrm{Yb}$ and the molar $\left(\mathrm{Y}+\mathrm{Sc}+\mathrm{REE}^{3+}\right) / \mathrm{P}$ ratio (Belousova et al., 2002; Claiborne et al., 2006, 2010; Barth \& Wooden, 2010; Barth et al., 2012). Zircons from the earlier-erupted samples tend to have $\mathrm{Eu} / \mathrm{Eu}^{*}$ ratios around or lower than 0.01 , whereas those from later-erupted samples have higher values due to crystallisation from a (still veryevolved) melt which has experienced slightly less feldspar fractionation (Reid et al., 2011). The xenocrystic Triassic-age zircons follow the same general trends, but differ in values of $\mathrm{Eu} / \mathrm{Eu}^{*}, \mathrm{Yb} / \mathrm{Gd}$ and Th/U (Fig. 3.10e,f).

In contrast to the general fractionation-driven trends in Fig. 3.10, some elements or elemental ratios clearly plot as two parallel arrays. When subdivided into distinct groups the data reflect the overarching influence of sector zoning (Fig. 3.10). Two sub-parallel trends are apparent when $\mathrm{Yb}$ or another heavy REE (HREE), or the molar $\left(\mathrm{Y}+\mathrm{Sc}+\mathrm{REE}^{3+}\right) / \mathrm{P}$ (Fig. 3.10c,d), is plotted against $\mathrm{U}$; these elements require careful consideration if magmatic trends are to be interpreted from these parameters. 

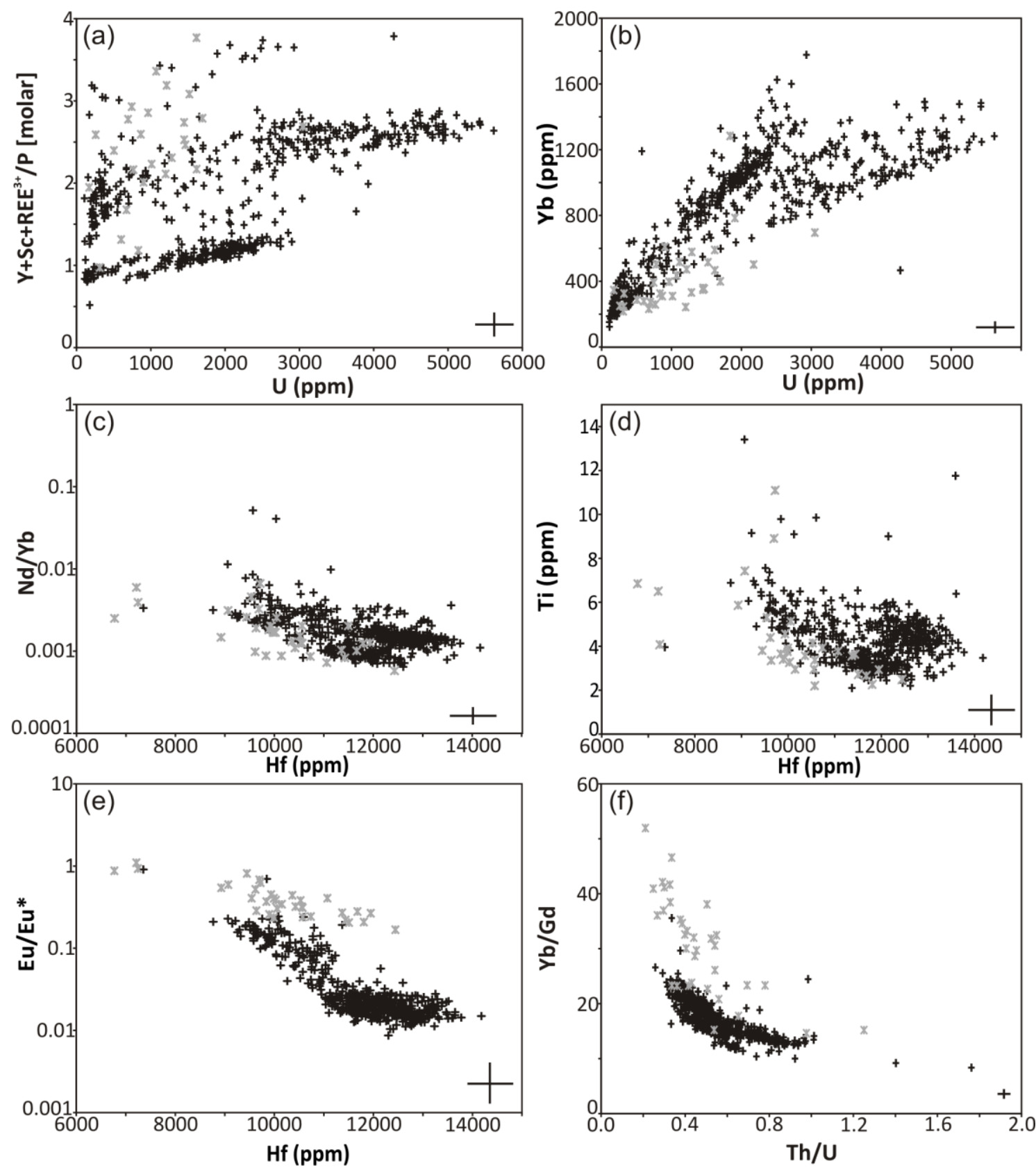

Fig. 3.10. Summary plots of zircon trace-element data from samples from the full range of the Bishop eruptive sequence. With certain trace elements or elemental ratios, sector zoning is clearly represented by the presence of split arrays $(a, b)$, whereas its effect is subdued in other cases $(\mathrm{c}-\mathrm{f})$. Cross in bottom right of each panel represents $2 \sigma$ uncertainties based on repeat analyses of the MAD green zircon (Barth \& Wooden, 2010). Triassic-age grains are marked in grey, all Bishop data are in black. (For full data set see Electronic Appendix 3.) 


\subsubsection{Sector zoning contrasts}

Whenever present, sector zoning strongly influences the distributions and abundances of many trace elements (Table 3.4; Figs. 3.10, 3.11). We have thus differentiated the data into those from crystal sides (growth along the $a$ - and $b$-axes; lighter shades under CL) and from tips (growth along the c-axis; darker under CL) (Fig. 3.11). CL emission in zircons is primarily thought to be generated by $\mathrm{Dy}, \mathrm{Sm}, \mathrm{Eu}, \mathrm{Tb}, \mathrm{Gd}, \mathrm{Er}$ and $\mathrm{Nb}$, and can be suppressed by U, Y, Ca, P and Fe (Nasdala et al., 2003). For the Bishop zircons that exhibit sector zoning, plots of many trace elements or their ratios against an element or ratio that can be used as an index of fractionation (e.g. Hf, Yb/Gd: Grimes et al., 2009; Claiborne et al., 2010; Carley et al., 2011) define two arrays that might, in the absence of textural context, be interpreted as reflecting separate compositional suites. When compared with the lighter sides, the darker tips are enriched in Ti by $\sim 45 \%$, in the $\left(\mathrm{Sc}_{\mathrm{c}}+\mathrm{Y}+\mathrm{REE}^{3+}\right) / \mathrm{P}$ molar ratio by $\sim 100 \%$ (Fig. 3.11a,b), in U and Th by up to about three times, and in Nb, U, Sm, Nd, Gd and Dy by 1.3 - 2 times (see Table 3.5 and Electronic Appendix 3). The lighter sides more closely follow the 'xenotime substitution' mechanism, where the molar ratio $\left(\mathrm{Y}+\mathrm{Sc}+\mathrm{REE}^{3+} / \mathrm{P}\right)$ is unity (Hoskin \& Schaltegger, 2003; Reid et al., 2011), whereas the darker tips show values of this ratio between 2.1 and 3.0, increasing with $\mathrm{U}$, Th or Yb. This contrast between the different sectors appears to mostly reflect a relative depletion of $\mathrm{P}$ in the darker tips (Table 3.5, Fig. 3.11d).

Lighter sides have lower concentrations of trace elements in general, when compared with the dark tips. However, the separate data arrays for the two sectors are roughly sub-parallel in elongation and show similar evolutionary patterns. Some elements, such as HREE and $\mathrm{Yb}$ (Fig. 3.11e,f), are apparently less influenced by the sector zoning. 
Table 3.4. Average and range in trace element concentrations for all samples analysed in the Bishop Tuff.

\begin{tabular}{|c|c|c|c|c|c|c|c|c|c|c|c|}
\hline Sample & Unit & Location & $\mathbf{P}$ & $\mathrm{Ti}$ & $Y$ & La & $\mathrm{Ce}$ & Nd & Sm & Eu & Gd \\
\hline \multirow[t]{8}{*}{ BP109 } & F1 & lighter sides & & & & & & & & & \\
\hline & & average & 1356 & 3.23 & 3224 & 0.013 & 44.6 & 1.27 & 5.08 & 0.096 & 58.7 \\
\hline & & maximum & 1529 & 3.71 & 4383 & 0.06 & 67 & 2.89 & 9 & 0.193 & 92 \\
\hline & & minimum & 1067 & 2.62 & 2120 & 0 & 25.7 & 0.67 & 3.23 & 0.041 & 33.6 \\
\hline & & darker tips & & & & & & & & & \\
\hline & & average & 743 & 4.73 & 3583 & 0.015 & 90.6 & 1.6 & 6.44 & 0.123 & 77 \\
\hline & & maximum & 944 & 5.92 & 4619 & 0.064 & 115.7 & 2.45 & 9.36 & 0.181 & 101.7 \\
\hline & & minimum & 630 & 4.05 & 2760 & 0.003 & 71.7 & 1.12 & 4.8 & 0.082 & 60.1 \\
\hline \multirow[t]{8}{*}{ BP087 } & Ig1Eb & lighter sides & & & & & & & & & \\
\hline & & average & 1309 & 3.1 & 3033 & 0.011 & 45.2 & 1.13 & 4.63 & 0.102 & 60.4 \\
\hline & & maximum & 1609 & 3.74 & 4924 & 0.021 & 94 & 4.17 & 12.92 & 0.281 & 156.1 \\
\hline & & minimum & 981 & 2.34 & 1864 & 0.003 & 23.7 & 0.54 & 2.47 & 0.054 & 30.3 \\
\hline & & darker tips & & & & & & & & & \\
\hline & & average & 714 & 4.63 & 3617 & 0.012 & 94.7 & 1.63 & 6.69 & 0.129 & 80.2 \\
\hline & & maximum & 838 & 5.4 & 4465 & 0.025 & 117.3 & 2 & 7.99 & 0.209 & 98.3 \\
\hline & & minimum & 471 & 3.69 & 2026 & 0.003 & 49.9 & 1.02 & 3.6 & 0.083 & 42.8 \\
\hline \multirow[t]{8}{*}{ BP040 } & Ig1Eb & lighter sides & & & & & & & & & \\
\hline & (Sherwin) & average & 1077 & 2.99 & 2964 & 0.012 & 40.1 & 0.95 & 4.07 & 0.089 & 51.7 \\
\hline & & maximum & 1688 & 3.6 & 3535 & 0.029 & 52.5 & 1.29 & 5.16 & 0.122 & 64.1 \\
\hline & & minimum & 448 & 2.44 & 2125 & 0.001 & 25.2 & 0.55 & 2.67 & 0.048 & 35 \\
\hline & & darker tips & & & & & & & & & \\
\hline & & average & 721 & 4.49 & 3577 & 0.012 & 90 & 1.55 & 6.63 & 0.115 & 79.1 \\
\hline & & maximum & 838 & 5.32 & 4522 & 0.03 & 114.2 & 1.96 & 8.39 & 0.148 & 98.3 \\
\hline & & minimum & 521 & 3.61 & 2257 & 0.002 & 52.2 & 0.83 & 4.09 & 0.084 & 49.8 \\
\hline \multirow[t]{8}{*}{ BP059 } & $\lg 2 \mathrm{Na}$ & lighter sides & & & & & & & & & \\
\hline & & average & 1227 & 3 & 2827 & 0.045 & 39.4 & 0.95 & 3.94 & 0.093 & 48.1 \\
\hline & & maximum & 1463 & 3.48 & 3676 & 0.137 & 52.1 & 1.6 & 6.37 & 0.13 & 65.7 \\
\hline & & minimum & 1021 & 2.49 & 1995 & 0.02 & 29.2 & 0.62 & 2.63 & 0.068 & 32.4 \\
\hline & & darker tips & & & & & & & & & \\
\hline & & average & 626 & 4.35 & 3147 & 0.038 & 85.4 & 1.52 & 5.71 & 0.13 & 67.2 \\
\hline & & maximum & 758 & 5.5 & 4104 & 0.09 & 121.8 & 2.14 & 7.79 & 0.17 & 92.5 \\
\hline & & minimum & 448 & 3.64 & 2152 & 0.016 & 57.6 & 1.17 & 3.47 & 0.074 & 42.6 \\
\hline \multirow[t]{8}{*}{ BP170 } & $\lg 2 \mathrm{Nb}$ & cores & & & & & & & & & \\
\hline & & average & 714 & 3.94 & 2377 & 0.026 & 58.1 & 1.46 & 4.72 & 0.135 & 50.2 \\
\hline & & maximum & 1245 & 6.09 & 4613 & 0.118 & 134.9 & 3.31 & 9.49 & 0.284 & 108.2 \\
\hline & & minimum & 359 & 2.71 & 1400 & 0.005 & 20 & 0.51 & 1.82 & 0.02 & 23.1 \\
\hline & & bright rims & & & & & & & & & \\
\hline & & average & 303 & 4.99 & 819 & 0.023 & 34.7 & 0.74 & 1.91 & 0.187 & 17.5 \\
\hline & & maximum & 684 & 6.8 & 1488 & 0.173 & 57.7 & 1.39 & 3.67 & 0.581 & 34 \\
\hline & & minimum & 146 & 3.13 & 327 & 0.004 & 20.3 & 0.27 & 0.79 & 0.05 & 7 \\
\hline \multirow[t]{16}{*}{ BP118 } & Ig2NWa & lighter sides & & & & & & & & & \\
\hline & & average & 1331 & 3.24 & 2936 & 0.014 & 42.1 & 0.95 & 3.96 & 0.092 & 49.4 \\
\hline & & maximum & 1688 & 3.73 & 4401 & 0.04 & 53.7 & 1.25 & 5.21 & 0.128 & 68.6 \\
\hline & & minimum & 1075 & 2.7 & 2126 & 0.003 & 33.9 & 0.67 & 3.03 & 0.073 & 39.6 \\
\hline & & darker tips & & & & & & & & & \\
\hline & & average & 686 & 4.75 & 3273 & 0.015 & 91.6 & 1.57 & 6.12 & 0.132 & 72.3 \\
\hline & & maximum & 872 & 5.37 & 4555 & 0.052 & 125.2 & 1.99 & 8.53 & 0.234 & 104.2 \\
\hline & & minimum & 489 & 4.1 & 1910 & 0.001 & 50.5 & 0.89 & 3.52 & 0.085 & 41 \\
\hline & & cores & & & & & & & & & \\
\hline & & average & 1043 & 4.16 & 2773 & 0.031 & 60.7 & 1.21 & 4.73 & 0.122 & 54.2 \\
\hline & & maximum & 1567 & 5.79 & 4049 & 0.153 & 108.1 & 1.8 & 8.07 & 0.172 & 91 \\
\hline & & minimum & 573 & 2.76 & 1871 & 0.004 & 28.9 & 0.57 & 2.51 & 0.076 & 33.1 \\
\hline & & bright rims & & & & & & & & & \\
\hline & & average & 459 & 5.2 & 1093 & 0.304 & 38.6 & 1.25 & 2.46 & 0.161 & 22.1 \\
\hline & & maximum & 1092 & 7.56 & 2230 & 1.896 & 53.8 & 3.17 & 3.95 & 0.324 & 40.7 \\
\hline & & minimum & 188 & 3.17 & 570 & 0.007 & 21.3 & 0.53 & 1.35 & 0.065 & 12.7 \\
\hline \multirow[t]{8}{*}{ BP232 } & $\lg 2 \mathrm{Nb}$ & cores & & & & & & & & & \\
\hline & & average & 1037 & 4.17 & 3369 & 0.037 & 70.2 & 1.52 & 5.47 & 0.149 & 66.6 \\
\hline & & maximum & 1583 & 5.59 & 4415 & 0.106 & 121.4 & 2.52 & 7.93 & 0.544 & 98.5 \\
\hline & & minimum & 368 & 2.9 & 1199 & 0.009 & 34.5 & 0.92 & 3.18 & 0.071 & 32.9 \\
\hline & & bright rims & & & & & & & & & \\
\hline & & average & 795 & 4.43 & 2559 & 0.055 & 48.2 & 1.51 & 4.63 & 0.197 & 51.1 \\
\hline & & maximum & 1618 & 7.84 & 4488 & 0.297 & 84.4 & 4.08 & 10.98 & 1.068 & 110 \\
\hline & & minimum & 110 & 2.67 & 636 & 0.013 & 23.7 & 0.62 & 1.64 & 0.063 & 14.8 \\
\hline
\end{tabular}


Table 3.4. continued

\begin{tabular}{|c|c|c|c|c|c|c|c|c|c|c|c|}
\hline Sample & $\mathrm{Tb}$ & Dy & Ho & Er & $\mathrm{Tm}$ & $\mathrm{Yb}$ & Lu & Hf & $\mathrm{Pb}$ & $\mathbf{U}$ & Th \\
\hline BP109 & \multicolumn{11}{|c|}{ lighter sides } \\
\hline It-av & 127.1 & 23.7 & 297.7 & 591 & 129.2 & 1076 & 195.6 & 11817 & 0.189 & 2060 & 1010 \\
\hline It-max & 172 & 34.9 & 419.1 & 789.1 & 167.3 & 1393 & 245.9 & 12454 & 0.259 & 2671 & 1451 \\
\hline \multirow[t]{2}{*}{ It-min } & 83.3 & 14.8 & 191.2 & 410.9 & 92.9 & 801.2 & 146.2 & 11209 & 0.103 & 1415 & 534 \\
\hline & \multicolumn{11}{|c|}{ darker tips } \\
\hline dk-av & 144 & 29.7 & 353.8 & 646.7 & 138.3 & 1136 & 201.6 & 12577 & 0.363 & 3548 & 2232 \\
\hline $\mathrm{dk}-\max$ & 185.8 & 38.5 & 452.7 & 820.4 & 172.5 & 1397 & 249 & 13029 & 0.604 & 4547 & 3628 \\
\hline $\mathrm{dk}-\mathrm{min}$ & 111.8 & 23.7 & 281.5 & 501.8 & 107.4 & 867.9 & 152.6 & 11969 & 0.264 & 2733 & 1229 \\
\hline BP087 & \multicolumn{11}{|c|}{ lighter sides } \\
\hline It-av & 127.1 & 23.9 & 297.2 & 557.9 & 127.1 & 1054 & 191.9 & 11898 & 0.189 & 2013 & 983 \\
\hline It-max & 253.7 & 55.6 & 640.7 & 883.1 & 225.1 & 1777 & 308.9 & 12647 & 0.283 & 2927 & 1977 \\
\hline \multirow[t]{2}{*}{ It-min } & 73.3 & 12.5 & 159.5 & 341.4 & 77.3 & 654.7 & 124.1 & 11327 & 0.124 & 1197 & 384 \\
\hline & \multicolumn{11}{|c|}{ darker tips } \\
\hline dk-av & 145.7 & 30.5 & 360.2 & 644.4 & 135.7 & 1103 & 193.5 & 12692 & 0.388 & 4165 & 3190 \\
\hline dk-max & 180.9 & 37.8 & 447.8 & 829.2 & 179.2 & 1491 & 262.6 & 13239 & 0.534 & 5434 & 4806 \\
\hline $\mathrm{dk}-\mathrm{min}$ & 82 & 16.3 & 195.6 & 373.7 & 79.5 & 662.5 & 119.7 & 12087 & 0.237 & 2144 & 957 \\
\hline ВР040 & \multicolumn{11}{|c|}{ lighter sides } \\
\hline It-av & 20.8 & 266.6 & 116.7 & 541.1 & 119.6 & 1005 & 184.8 & 11945 & 0.183 & 1970 & 880 \\
\hline It-max & 24.9 & 320 & 139.2 & 639.2 & 139.9 & 1175 & 215.4 & 12552 & 0.274 & 2354 & 1130 \\
\hline \multirow[t]{2}{*}{ It-min } & 14.4 & 188.3 & 83.8 & 396.9 & 89.6 & 756.3 & 141.6 & 11591 & 0.122 & 1418 & 507 \\
\hline & \multicolumn{11}{|c|}{ darker tips } \\
\hline dk-av & 30.3 & 359.5 & 144.5 & 646.3 & 135.9 & 1112 & 196 & 12823 & 0.398 & 4170 & 3041 \\
\hline dk-max & 37.6 & 449.6 & 186.5 & 836.1 & 178.5 & 1475 & 266.8 & 13094 & 0.492 & 5256 & 4534 \\
\hline $\mathrm{dk}-\mathrm{min}$ & 20 & 241.7 & 95.9 & 448.9 & 93.9 & 807.2 & 143.2 & 12580 & 0.308 & 2976 & 1982 \\
\hline BP059 & \multicolumn{11}{|c|}{ lighter sides } \\
\hline It-av & 111.6 & 20.7 & 266.2 & 544.8 & 120.9 & 1033 & 188 & 12241 & 0.188 & 1859 & 797 \\
\hline It-max & 145 & 28 & 359 & 720.2 & 157.9 & 1351 & 241.9 & 12805 & 0.304 & 2562 & 1214 \\
\hline \multirow[t]{2}{*}{ It-min } & 76.9 & 13.7 & 178.6 & 371.4 & 84.6 & 735.8 & 137.5 & 11719 & 0.089 & 1141 & 422 \\
\hline & darker & & & & & & & & & & \\
\hline dk-av & 127.5 & 26.9 & 327.9 & 595 & 127.5 & 1060 & 185.6 & 13150 & 0.374 & 3463 & 2370 \\
\hline dk-max & 168.4 & 36.8 & 444.4 & 778.2 & 167.5 & 1393 & 241.1 & 13774 & 0.538 & 4883 & 4235 \\
\hline $\mathrm{dk}-\mathrm{min}$ & 86.9 & 17.3 & 218 & 420.8 & 93.2 & 783.1 & 143.7 & 12563 & 0.15 & 1448 & 582 \\
\hline BP170 & cores & & & & & & & & & & \\
\hline c-av & 94.4 & 19.1 & 228.4 & 432.2 & 93.3 & 773 & 140.4 & 11739 & 0.16 & 1536 & 972 \\
\hline$c-\max$ & 180.9 & 41.2 & 475.9 & 822.1 & 173.1 & 1385 & 238.8 & 12302 & 0.53 & 5148 & 4988 \\
\hline$c-\min$ & 52.3 & 9.3 & 119.6 & 251.5 & 57.1 & 487.1 & 90.1 & 10428 & 0.041 & 655 & 249 \\
\hline & bright & & & & & & & & & & \\
\hline br-av & 32.7 & 6.5 & 77.4 & 156.1 & 35.2 & 304.9 & 58.8 & 10309 & 0.053 & 362 & 184 \\
\hline br-max & 65.4 & 13.8 & 165.5 & 320.6 & 70.7 & 598.1 & 110 & 12228 & 0.182 & 1185 & 638 \\
\hline br-min & 12.6 & 2.3 & 30 & 61.5 & 13.7 & 123.6 & 25.1 & 9296 & 0.008 & 110 & 49 \\
\hline BP118 & lighter & & & & & & & & & & \\
\hline It-av & 110.1 & 20.1 & 254.6 & 517.6 & 114.3 & 956.3 & 175.5 & 11588 & 0.182 & 1757 & 859 \\
\hline It-max & 155 & 28.4 & 357.8 & 723.3 & 160 & 1312 & 236 & 12284 & 0.288 & 2747 & 1400 \\
\hline It-min & 82.6 & 15.3 & 189.8 & 379.9 & 82.9 & 712.7 & 133.3 & 10771 & 0.109 & 1234 & 585 \\
\hline & darker & & & & & & & & & & \\
\hline dk-av & 132.4 & 27.7 & 329.8 & 594.4 & 125.9 & 1027 & 181 & 12429 & 0.351 & 3500 & 2612 \\
\hline dk-max & 185 & 40.1 & 471.2 & 842 & 176.7 & 1463 & 252.5 & 12908 & 0.503 & 5423 & 4479 \\
\hline $\mathrm{dk}-\mathrm{min}$ & 77.4 & 15.8 & 188.1 & 352.9 & 76.2 & 636.9 & 115.8 & 11438 & 0.213 & 1918 & 1060 \\
\hline & cores & & & & & & & & & & \\
\hline c-av & 108.9 & 21.3 & 259.7 & 501.6 & 109.1 & 912.1 & 166 & 11621 & 0.19 & 2029 & 1235 \\
\hline$c-\max$ & 164 & 34.7 & 405.8 & 735.6 & 155.4 & 1289 & 225.9 & 12239 & 0.306 & 3789 & 2697 \\
\hline c-min & 71.2 & 13.4 & 165.7 & 326.6 & 72.5 & 606 & 114.5 & 10939 & 0.101 & 838 & 386 \\
\hline & bright & & & & & & & & & & \\
\hline br-av & 43 & 8.4 & 101.3 & 202.9 & 45.2 & 385.7 & 72.5 & 10608 & 0.069 & 522 & 262 \\
\hline br-max & 86.4 & 15.9 & 197.4 & 400.4 & 88.4 & 756.5 & 139.2 & 11179 & 0.105 & 945 & 489 \\
\hline br-min & 22.2 & 4.6 & 52.5 & 105.3 & 24.1 & 210.7 & 39.6 & 9514 & 0.037 & 196 & 111 \\
\hline BP232 & cores & & & & & & & & & & \\
\hline c-av & 131.2 & 25.9 & 316.7 & 601.8 & 128.3 & 1077 & 190.2 & 11876 & 0.314 & 2716 & 1739 \\
\hline c-max & 171.7 & 37.5 & 438.1 & 770.9 & 165 & 1350 & 237.1 & 13035 & 0.653 & 5320 & 5015 \\
\hline$c-\min$ & 47.6 & 10.6 & 120.3 & 225.2 & 48.3 & 422.5 & 78.4 & 9651 & 0.045 & 265 & 172 \\
\hline & bright & & & & & & & & & & \\
\hline br-av & 100.9 & 19.8 & 242 & 471 & 101.6 & 863.5 & 154.9 & 11309 & 0.203 & 1751 & 915 \\
\hline br-max & 182.1 & 40.5 & 467.4 & 836.6 & 172.7 & 1407 & 241.2 & 13605 & 0.49 & 4113 & 2900 \\
\hline br-min & 25 & 5.1 & 62.4 & 119.8 & 26.7 & 241.4 & 45 & 7354 & 0.018 & 156 & 100 \\
\hline
\end{tabular}



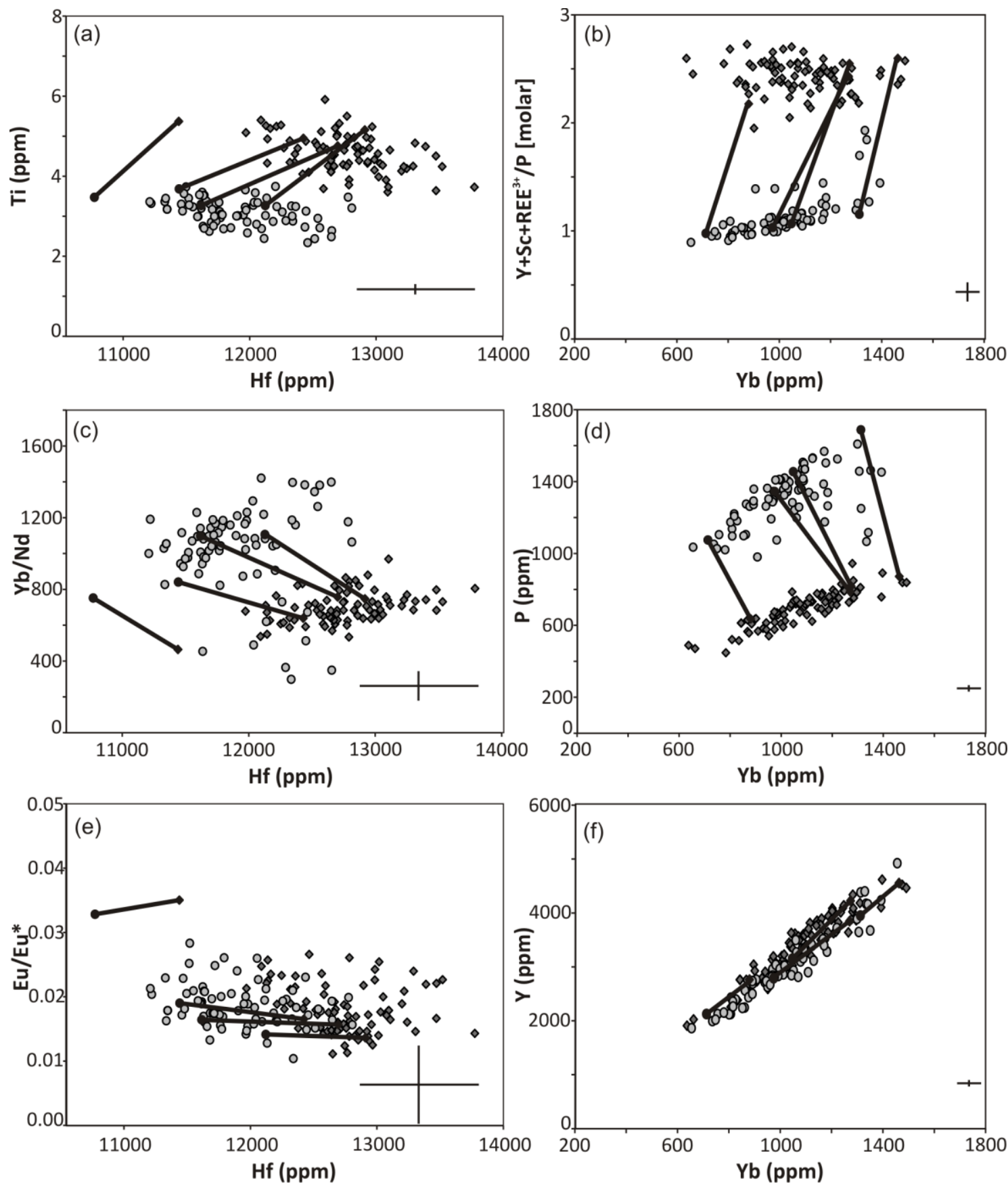

Fig. 3.11. Compositional variations within zircon crystals with textures dominated by sector zoning: dark grey diamonds represent darker tips; light grey circles represent lighter sides. Representative tie-lines connect sides and tips of single crystals. Cross in bottom right of each panel represents $2 \sigma$ uncertainties. (For full data set see Electronic Appendix 3.) 
Table 3.5. Enrichment factors for the dark tips in sector-zoned zircon crystals when compared to the lighter sides, arranged in order from most enriched to least enriched. An enrichment factor of 1.00 shows no enrichment. Factor $<1$ indicates depletion in the dark tips; a factor $>1$ shows enrichment.

\begin{tabular}{cc} 
Element & $\begin{array}{c}\text { Dark Tip Enrichment } \\
\text { Factor }\end{array}$ \\
\hline \hline $\mathrm{Th}$ & 2.61 \\
$\mathrm{Nb}$ & 2 \\
$\mathrm{U}$ & 1.75 \\
$\mathrm{Nd}$ & 1.56 \\
$\mathrm{Sm}$ & 1.42 \\
$\mathrm{Ti}$ & 1.37 \\
$\mathrm{Gd}$ & 1.37 \\
$\mathrm{Eu}$ & 1.32 \\
$\mathrm{Dy}$ & 1.22 \\
$\mathrm{~Tb}$ & 1.21 \\
$\mathrm{Ho}$ & 1.35 \\
$\mathrm{Y}$ & 1 \\
$\mathrm{Yb}$ & 1 \\
$\mathrm{Tm}$ & 1 \\
$\mathrm{Sc}$ & 1 \\
$\mathrm{Lu}$ & 1 \\
$\mathrm{Hf}$ & 1 \\
$\mathrm{Er}$ & 1 \\
$\mathrm{P}$ & 0.75 \\
$\mathrm{Y}+\mathrm{SC}+\mathrm{REE}{ }^{3+}: \mathrm{P}$ & 1.88 \\
\hline
\end{tabular}

\subsubsection{Core-bright-rim contrasts}

In zircons that lack a bright rim, sector zoning dominates the variations in trace-element patterns. However, where bright rims were wide enough to analyse [three samples: from Ig1Eb (BP040), Ig2NWa (BP118) and Ig2Nb (BP170)] it is clear that the normal, sectorzoned Bishop cores (as defined on textural grounds) are enriched (on average) by $\sim 50 \%$ in middle REE (MREE), Th and U relative to the bright rims (Fig. 3.12a,b). Although the absolute enrichment differs when bright rims are compared to dark tips or light sides, the enrichment is nonetheless present, and therefore we use an average of the sides and tips to calculate our enrichment factors. The bright rims crystallised from less evolved melts, displaying higher $\mathrm{Eu} / \mathrm{Eu}^{*}$ ratios $(0.05-0.2)$ than the normal sector-zoned cores $(0.01-$ 0.04; Fig. 3.12c), indicative of a melt that had experienced less feldspar fractionation than the cores they overgrew. However, although the absolute concentrations show variability, several elemental ratios show no variation between cores and bright rims, for example, $\mathrm{Yb} / \mathrm{Gd}$ vs Th/U (Fig. 3.12d). The bright rim analyses do not display as significant an influence of sector zoning on trace-element distributions; only a single trend in trace element patterns is defined, unlike the sub parallel trends seen in 'normal' Bishop grains (see previous section and Fig. 3.11). 

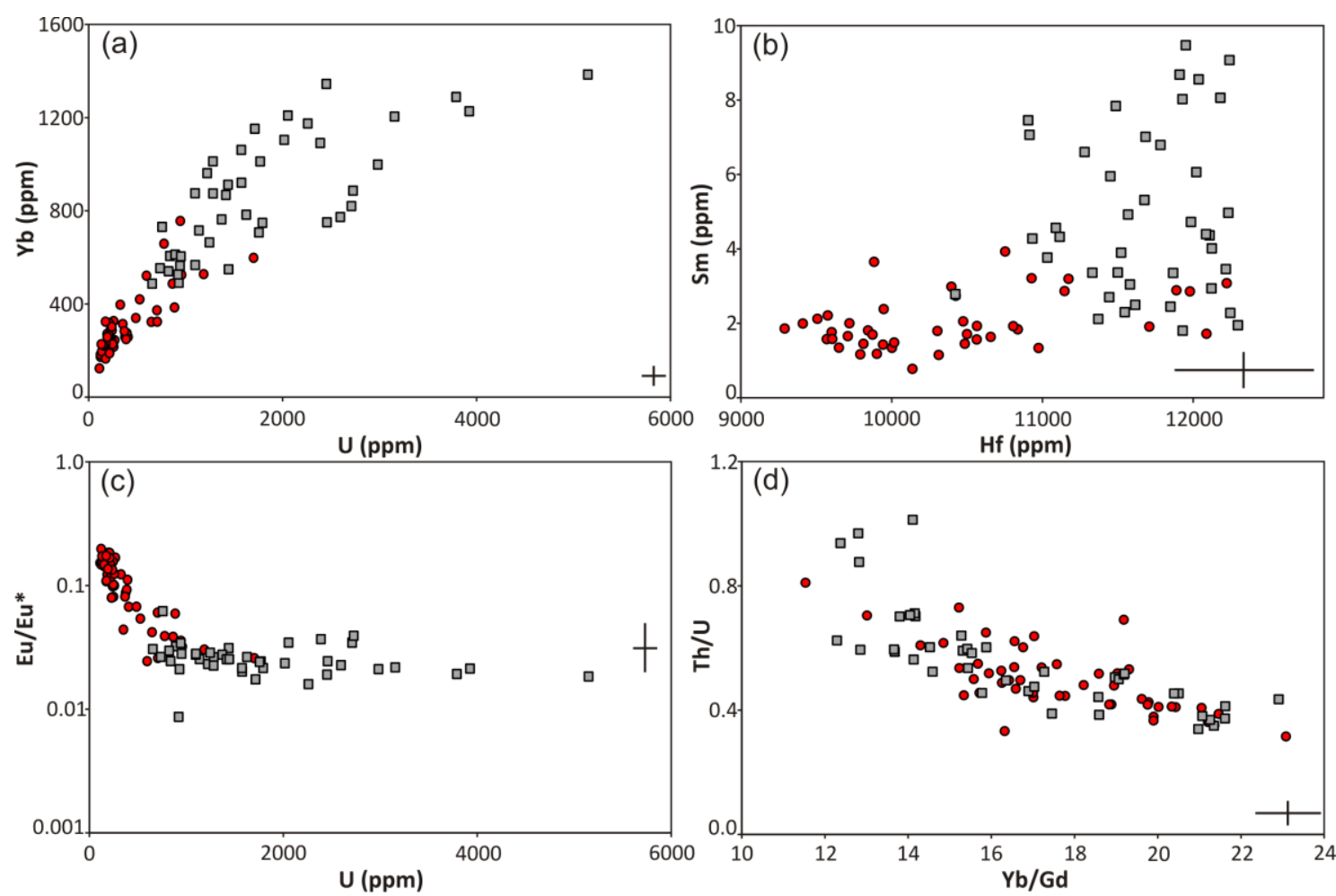

Fig. 3.12. Representative trace element compositional variations in CL-darker cores vs CLbrighter rims within Bishop zircon crystals. Cores are grey squares, rims are filled red circles. Cross in bottom right of each panel represents $2 \sigma$ uncertainties. (For full data set see Electronic Appendix 3.)

\subsection{Discussion}

As emphasised by Hildreth $(1977,1979)$, zircon was among the first crystallising mineral phases in the Bishop magma. Integration of the information available from single zircons is thus relevant to the origins and evolution of the Bishop system across the entirety of its lifespan as a felsic, zircon-saturated entity.

\subsubsection{Zircon chronological information in the Bishop Tuff}

\subsubsection{Eruption age of the Bishop Tuff}

Recent studies on the Bishop Tuff have raised issues regarding the eruption age, primarily from comparisons between ${ }^{40} \mathrm{Ar} /{ }^{39} \mathrm{Ar}$ age determinations on feldspar and ID-TIMS determinations on zircon (e.g. Sarna-Wojcicki et al., 2000; Crowley et al., 2007; Rivera et al., 2011; Singer et al., 2012). This apparent conflict arises from two independent aspects:

(1) controversy over the appropriate values for the ${ }^{40} \mathrm{~K}$ decay constant and consequent ages for the Fish Canyon (FCT) sanidine standard that is a benchmark for most young ${ }^{40} \mathrm{Ar} /{ }^{39} \mathrm{Ar}$ age experiments (e.g. Kuiper et al., 2008; Renne et al., 2010, 2011; Rivera et al. 2011); 
(2) debate over the comparisons between single-crystal ID-TIMS age determinations and those obtained by spot analyses using SIMS techniques (Simon \& Reid, 2005; Crowley et al., 2007). This second debate in turn focuses on three issues: (1) the contrasting precisions obtainable by each technique, (2) the possibility of inheritance of grains with significant residence histories, skewing age determinations and populations towards older values, and (3) the three orders of magnitude contrasts in sample volume between the half- or wholecrystals analysed by ID-TIMS $\left[(\sim 1-3) \times 10^{6} \mu \mathrm{m}^{3}\right]$ versus the small volumes $\left[(\sim 1.5-2) \times 10^{3}\right.$ $\mu^{3}$ ] excavated by SIMS analysis (see Crowley et al., 2007; Simon et al., 2008; Reid et al., 2011; Reid \& Schmitt, 2012).

We obtain a weighted mean age of $766.6 \pm 3.1 \mathrm{ka}$ (95\% confidence) for grains that we have analysed in cross-section as close to the rims as feasible. These grains, which lack CL-bright overgrowths, come from samples in early-erupted material and hence represent the closest approximation we can make to measuring immediately pre-eruptive ages. Our mean value is the same, within uncertainty, as the weighted mean of $767.1 \pm 0.9 \mathrm{ka}(2 \sigma)$ from IDTIMS work on single grains (Crowley et al., 2007), and the published ${ }^{40} \mathrm{Ar} /{ }^{39} \mathrm{Ar}$ age of 767.4 $\pm 2.2 \mathrm{ka}(2 \sigma)$ of Rivera et al. (2011), the latter based on a value for the FCT standard of $28.172 \pm 0.028 \mathrm{Ma}$ modified from Kuiper et al. (2008). Our data are, in turn, not in agreement with the older ages suggested for the Bishop eruption by Renne et al. [(2010, 2011: $778.1 \pm 7.4 \mathrm{ka}(2 \sigma)$, based on re-calculation of the original data of Sarna-Wojcicki et al., 2000)] and Mark et al. (2012: $776.4 \pm 1.8 \mathrm{ka}, 2 \sigma)$. These differences are not bridged in our ${ }^{206} \mathrm{~Pb} /{ }^{238} \mathrm{U}$ age determinations by the $\mathrm{Th} / \mathrm{U}$ melt values adopted (Table 3.1) and its influence on the initial ${ }^{230} \mathrm{Th}$ disequilibrium correction. Comparisons between the range of melt $\mathrm{Th} / \mathrm{U}$ ratios we use versus the uniform 2.81 value used by Crowley et al. (2007) indicate that ${ }^{230} \mathrm{Th}$-corrected age values are $2-3 \mathrm{ka}$ younger for $\mathrm{Th} / \mathrm{U}=2.5$ (typical of early eruptives) and $6-8 \mathrm{ka}$ older for $\mathrm{Th} / \mathrm{U}=4.0$ (the maximum for later eruptive rocks: see Electronic Appendix 1).

Hence, despite the markedly different sampling strategies employed by SIMS and IDTIMS, the results are identical within uncertainties. However, we note that there are some discrepancies in the data sets that could have produced systematic bias. The SIMS data clearly resolve the appropriate common $\mathrm{Pb}$ composition because there is no blank $\mathrm{Pb}$ to consider. As such, we clearly establish that the common $\mathrm{Pb}$ in the zircons (at the attogram- 
femtogram level) is magmatic and not surface related. The common $\mathrm{Pb}$ value that we obtain from the inverse concordia plot of our common-Pb-rich data points is consistent with value from Stacey \& Kramers (1975) used in SQUID 2, and also within uncertainty the same as the published bulk rock value of ${ }^{207} \mathrm{~Pb} /{ }^{206} \mathrm{~Pb}=0.818$ derived by Halliday et al. (1989) and used by Simon \& Reid (2005). Conversely, the ID-TIMS data relies on the common $\mathrm{Pb}$ being from the laboratory blank at the appropriate composition (see Crowley et al., 2007, their supplementary data Table 1). In addition, our SIMS data utilizes Th/U compositions of the glass phase from the respective samples to make sample-specific $\mathrm{Th} / \mathrm{U}$ fractionation corrections to the raw ${ }^{238} \mathrm{U}_{-}{ }^{206} \mathrm{~Pb}$ ages (see Table 3.3 and Electronic Appendix 1, which show the differences in age determinations between sample specific $\mathrm{Th} / \mathrm{U}$ ratios and a constant $\mathrm{Th} / \mathrm{U}$ ratio of 2.81). On the other hand, the ID-TIMS data use an averaged Th/U value from the data of Anderson et al. (2000) with which to calculate the age correction for initial ${ }^{230} \mathrm{Th}$ disequilibrium. The coincidence of the final ages from the two techniques indicates that common $\mathrm{Pb}$ and $\mathrm{Th} / \mathrm{U}$ fractionation is treated appropriately in both data sets.

Although the precisions we obtain are an order of magnitude poorer than those from single-crystal ID-TIMS work, the utility of SIMS instruments to undertake orders of magnitude more analyses in the same time span and to give spatially resolved ages within single crystals, offers a complementary perspective that is, in this case, in agreement. As highlighted by Reid \& Schmitt (2012), bulk ID-TIMS analysis is a whole-grain average, weighted by the $\mathrm{U}$ (and $\mathrm{Pb}$ ) contents of the individual zones which compose the crystal. Volumetrically small core zones could therefore be completely dominated by the large outer growth zones (Charlier \& Zellmer, 2000). Another aspect that arises is comparisons between surface profiling techniques (e.g. Reid et al., 2011; Storm et al., 2011; Reid \& Schmitt, 2012) and the cross-sectional techniques we have employed, with the outermost rims being argued to yield a 'true' $\mathrm{U}-\mathrm{Pb}$ eruption age owing to there being no influence from older cores. Reid \& Schmitt (2012) reported an average of SIMS surface profiling ages from Bishop zircons of $781 \pm 22 \mathrm{ka}$ (uncertainty inferred by us to be $2 \sigma$ ). With crosssectional analysis we can thus replicate as good an approximation to eruption age as the uncertainties on the measurements allow, despite not analysing the outermost parts of any crystal. With both approaches (e.g. Charlier et al., 2005; Storm et al., 2011), however, there are commonly grains within samples that have inherited ages, whether through their recent (re-)introduction into the magma as antecrysts from the underlying mush pile or xenocrysts 
from country rock. In either case, the scatter of ages obtained may reflect subtle issues of inheritance, not just position within the crystal or the uncertainties associated with single age determinations.

\subsubsection{Temporal relationships between Glass Mountain and the Bishop Tuff}

A previous tenet of the magmatic history at Long Valley is the temporal continuity and close compositional relationships between the younger series of eruptions from Glass Mountain and the Bishop Tuff. The YA dome K-Ar age of $790 \pm 20 \mathrm{ka}$ (Metz \& Mahood, 1985) has been accepted by all workers and has been used to consider that there was temporal overlap of the Bishop and Glass Mountain systems. Our data suggest, in contrast, that the two systems are separate in time and distinct, with our estimate of $862 \pm 23 \mathrm{ka}$ for the eruption age of dome YA.

Other data also support an older age for the cessation of Glass Mountain activity (SarnaWojcicki et al., 2005). An averaged single-crystal sanidine ${ }^{40} \mathrm{Ar} /{ }^{39} \mathrm{Ar}$ age of $890 \pm 31 \mathrm{ka}$ [adjusted relative to a Taylor Creek sanidine standard age of $28.485 \pm 0.033 \mathrm{Ma}$ to match Rivera et al. (2011)] was reported by Sarna-Wojcicki et al. for their bed BT-16, underlying the Bishop Tuff at Chalk Bluffs. This sample was reported by them as yielding the youngest reliable (i.e. uncontaminated) age for pre-Bishop fall deposits at this location. The older eruption ages suggested by our zircon ages for domes YA and OD [the latter matched by the ${ }^{40} \mathrm{Ar} /{ }^{39} \mathrm{Ar}$ age determination in Davies et al. (1994)] imply that the entire Glass Mountain system may be significantly older than previously reported. A revision to the age spread for the Glass Mountain complex therefore could suggest the older ${ }^{40} \mathrm{Ar} /{ }^{39} \mathrm{Ar}$ dated tephras of Sarna-Wojcicki et al. (2005) in the Blind Spring Hill area were early products of the Glass Mountain system, rather than from an as-yet unknown older system in Long Valley.

In comparison, a weighted mean estimate for the oldest $10 \%$ of our acceptable Bishop zircon ages (all of which are core analyses) is $844 \pm 6 \mathrm{ka}(n=62, \mathrm{MSWD}=0.78$, probability of 0.89: data points shown in Fig. 3.5). This age is indistinguishable from the older population of cores from the northern units derived by unmixing (838.5 \pm 8.7, Fig. 3.7). We thus infer on the basis of age data, coupled with qualitative observations of the zircon textures, that the Glass Mountain and Bishop systems were not only temporally but also physically separate entities. Such a view is not in conflict with abundant evidence for 
their chemical continuity, on the basis of compositional and isotopic data for the younger Glass Mountain activity, from $\sim 1.1 \mathrm{Ma}$ onwards from published $\mathrm{K}-\mathrm{Ar}$ ages (e.g. Halliday et al., 1984, 1989; Metz \& Mahood, 1991; Bindeman \& Valley, 2002; Simon et al., 2007). We would contend, however, that growth of the Bishop zircon population and assembly of the Bishop melt-dominant body post-dated and were separate from the youngest activity from the Glass Mountain system.

\subsubsection{Assembly of the Bishop magma body}

We interpret our age data to show that crystallisation of Bishop magma began from $844 \pm$ $6 \mathrm{ka}$ (as above) and continued up to the time of eruption, at $766.6 \pm 3.1 \mathrm{ka}$. Previous workers have reported age ranges consistent with a prolonged crystallisation history of zircons in the Bishop Tuff of $\sim 160$ kyr (Reid \& Coath, 2000; Simon \& Reid, 2005). Peak PDF estimates ( $2 \sigma$ uncertainties) of $823 \pm 28 \mathrm{ka}$ (early Bishop Tuff), and $811 \pm 14 \mathrm{ka}$ (late Bishop Tuff) can be calculated from the data of Reid \& Coath (2000) and $841 \pm 16 \mathrm{ka}$ (early Bishop Tuff) from Simon \& Reid (2005). It has been inferred that both the early- and late-erupted Bishop units had a history of zircon crystallisation extending as far back as 900 ka, with average maxima of $917 \pm 27 \mathrm{ka}$ for the early Bishop Tuff and $901 \pm 17 \mathrm{ka}$ for the late Bishop Tuff (Simon \& Reid, 2005), and a value of $892 \pm 26$ ka reported by Reid \& Schmitt (2012). In contrast, we can see evidence for only $\sim 80 \mathrm{kyr}$ of crystallization history in the overwhelming majority of zircons within the tuff.

The older suite of ages we obtain (Fig. 3.8 and Electronic Appendix 1) from zircon cores, particularly from pumices erupted later and from the northern vents, are inferred to represent the onset of zircon crystallisation within the Bishop mush zone: that is, the onset of crystallisation for most of the mineral species represented in Bishop pumices (Hildreth, 1979). What cannot be discerned from our data alone is whether this onset of zircon growth accompanied or pre-dated growth of the melt-dominant, stratified body. Overall growth rates for Bishop zircons implied by our age data are similar to the generalised $10^{-18}$ $-10^{-19} \mathrm{~m} \mathrm{~s}^{-1}$ value for granitic melts by Watson \& Liang (1995), and grains from the $844 \mathrm{ka}$ average-age suite show no differences in texture from those yielding ages within uncertainty of the eruption age. Where possible, zircons with a narrow $(<10 \mu \mathrm{m})$ bright rim were dated at spots within the 'normal' sector-zoned Bishop interior, directly adjacent to the bright rim. These ages give the oldest age for the bright rim (in those thinly rimmed crystals), and thus the difference in the weighted mean of these ages $(777.5 \mathrm{ka})$ from the 
proposed eruption age $(766.6 \mathrm{ka})$ can be used as the maximum time for growth of a $10 \mu \mathrm{m}$ (or less) rim. This age difference yields a maximum growth rate of $\sim 3 \times 10^{-19} \mathrm{~ms}^{-1}$ (up to $1.3 \times 10^{-18} \mathrm{~ms}^{-1}$, and as slow as $1.6 \times 10^{-19} \mathrm{~ms}^{-1}$, with uncertainties), assuming no dissolution or cessation of zircon growth occurred during that time. If the zircons across the age range from 845 to $766 \mathrm{ka}$ grew in contrasting physical environments (i.e. a crystaldominated mush versus a melt-dominant magma body) then these contrasts have left no distinctive textural or compositional signals.

\subsubsection{Zircon compositional information in the Bishop Tuff}

\subsubsection{Implications of sector zoning variations}

The ubiquitous sector zoning observed in zircons from early-erupted samples and in the cores of many crystals in samples from the northern ignimbrite lobes is in contrast to the more homogeneous CL textures generally documented in dated zircons (e.g. Corfu et al., 2003; Munoz et al., 2012). Experimental studies that investigated sector zoning and traceelement uptake in pyroxene, titanite and zircon have found that these minerals have apparent partition coefficients that vary depending on the crystal face (Paterson \& Stephens, 1992; Watson \& Liang, 1995; Lofgren et al., 2006; Schwandt \& McKay, 2006). It has been proposed that if the crystal growth rate is fast enough to 'trap' trace elements at the crystal-melt interface, and diffusivity of elements within the crystal lattice is not rapid enough to eradicate differences in concentration, sector zoning is generated (Watson \& Liang, 1995; Watson, 1996). However, such conditions are almost always met in volcanic zircons regardless of whether or not sector zoning is visible in CL imagery. Sector zoning is not as obvious in the Glass Mountain or the bright-CL Bishop zircons, suggesting that there were differences in the crystal growth regimes when compared with the normal Bishop sector zoned grains.

The differences in trace elements between different sectors in the normal Bishop zircons raise questions about the relevant substitution mechanisms. Although the lighter sides have molar $\left(\mathrm{Y}+\mathrm{Sc}+\mathrm{REE}^{3+}\right) / \mathrm{P}$ values of $\sim 1$ [the 'xenotime substitution' of Hoskin \& Schaltegger (2003)], the darker tips have considerably higher values (Figs. 3.11a; 3.13a), in large part due to a depletion in P. Although it is beyond the scope of this paper to suggest an alternative substitution mechanism, it appears that the xenotime substitution may only be operable on certain crystal faces along the $a$ and $b$-axes (100 and 010 in the tetragonal grains we are dealing with here) (Hoskin \& Schaltegger, 2003). It is therefore possible that 
$\mathrm{P}$ fits better, and $\mathrm{Y}$ and the larger REE somewhat less well, into the lattice configuration along the 100 and 010 faces than the faces intersecting with the c-axis. An alternative charge-balancing scheme for crystallization in the dark sectors may need to be considered.

\subsubsection{Ti concentrations and Ti-in-zircon thermometry}

Our data show that the $\mathrm{Ti}$ concentrations in the same growth zone (as indicated by oscillatory zonation patterns) in sector zoned zircons varies significantly between the sides and tips. This has strong implications for the applicability of Ti-in-zircon thermometry to the Bishop Tuff. As currently formulated, a single value of the activity of $\mathrm{TiO}_{2}$ in the magma $\left(a \mathrm{TiO}_{2}\right)$ is adopted when applying the Ti-in-zircon thermometer (Watson \& Harrison, 2005; Watson et al., 2006; Ferry \& Watson, 2007; Fu et al., 2008). Five estimates for the value(s) of $a \mathrm{TiO}_{2}$ have been proposed for the Bishop magma: 0.6, estimated by Watson et al. (2006) and Wark et al. (2007); 0.53 as calculated from Fe-Ti-oxide equilibrium modelling (Thomas et al., 2010; Reid et al., 2011); 0.15 using MELTS and 0.23 using rhyolite-MELTS (Thomas \& Watson, 2012); and 0.45 - 0.67 calculated from Fe-Ti-oxide compositions by Ghiorso \& Gualda (2013). An additional universal assumption is that the value of $\mathrm{aSiO}_{2}$ is 1.0 , based on the abundance of crystallising quartz in the Bishop Tuff.

Using the calibration of Ferry \& Watson (2007), we calculated apparent temperatures (on 101 side-tip pairs) from measured Ti concentrations in the same growth zone. These calculations yield average apparent temperatures for the darker tips between $712{ }^{\circ} \mathrm{C}$ $\left(a \mathrm{TiO}_{2}=0.67\right)$ and $863{ }^{\circ} \mathrm{C}\left(a \mathrm{TiO}_{2}=0.15\right)$ depending upon which value of $a \mathrm{TiO}_{2}$ is used. $\mathrm{In}$ contrast the lighter sides yield average apparent temperatures of $686{ }^{\circ} \mathrm{C}\left(a \mathrm{TiO}_{2}=0.67\right)$ to $829^{\circ} \mathrm{C}\left(a \mathrm{TiO}_{2}=0.15\right)$ (Electronic Appendix 3). This gives a range of apparent temperature difference of $20-50{ }^{\circ} \mathrm{C}$ for different sectors within the same crystal growth zone (Fig. 3.13a). If a constant $\mathrm{T}$ of $750{ }^{\circ} \mathrm{C}$ is assumed the difference in calculated $a \mathrm{TiO}_{2}$ between the darker tips $\left(a \mathrm{TiO}_{2}=0.44\right)$ and the lighter sides $\left(a \mathrm{TiO}_{2}=0.34\right)$ is on average $\sim 0.1$. This difference in $a \mathrm{TiO}_{2}$ increases at cooler temperatures, but is reduced at temperatures $>750$ ${ }^{\circ} \mathrm{C}$.

Ti concentrations also vary between bright overgrowths and their respective cores (neither of which are visibly sector zoned in order for these variations to be estimated). The bright rims produce average apparent temperatures between $718{ }^{\circ} \mathrm{C}\left(a \mathrm{TiO}_{2}=0.67\right)$ and $871{ }^{\circ} \mathrm{C}$ $\left(a \mathrm{TiO}_{2}=0.15\right)$ with an average range in apparent temperatures of $87^{\circ} \mathrm{C}$ across all bright 
rims. Cores yield apparent temperatures between $697{ }^{\circ} \mathrm{C}\left(a \mathrm{TiO}_{2}=0.67\right)$ and $805^{\circ} \mathrm{C}\left(a \mathrm{TiO}_{2}\right.$ $=0.15)$ with an average range in apparent temperatures of $77^{\circ} \mathrm{C}$ across the cores. The trend in Ti-U space of cores and rims are very different, both apparently evolving to (or from) a similar point (Fig. 3.13b). These calculated apparent temperatures for sectors and core-rim pairs are distinctly lower than those calculated using Fe-Ti-oxide thermometry (Hildreth, 1979; Hildreth \& Wilson, 2007), two-pyroxene thermometry (Hildreth \& Wilson, 2007) and Ti-in-quartz thermometry, when the same values of $a \mathrm{TiO}_{2}$ are used (Wark et al., 2007; Thomas et al., 2010).
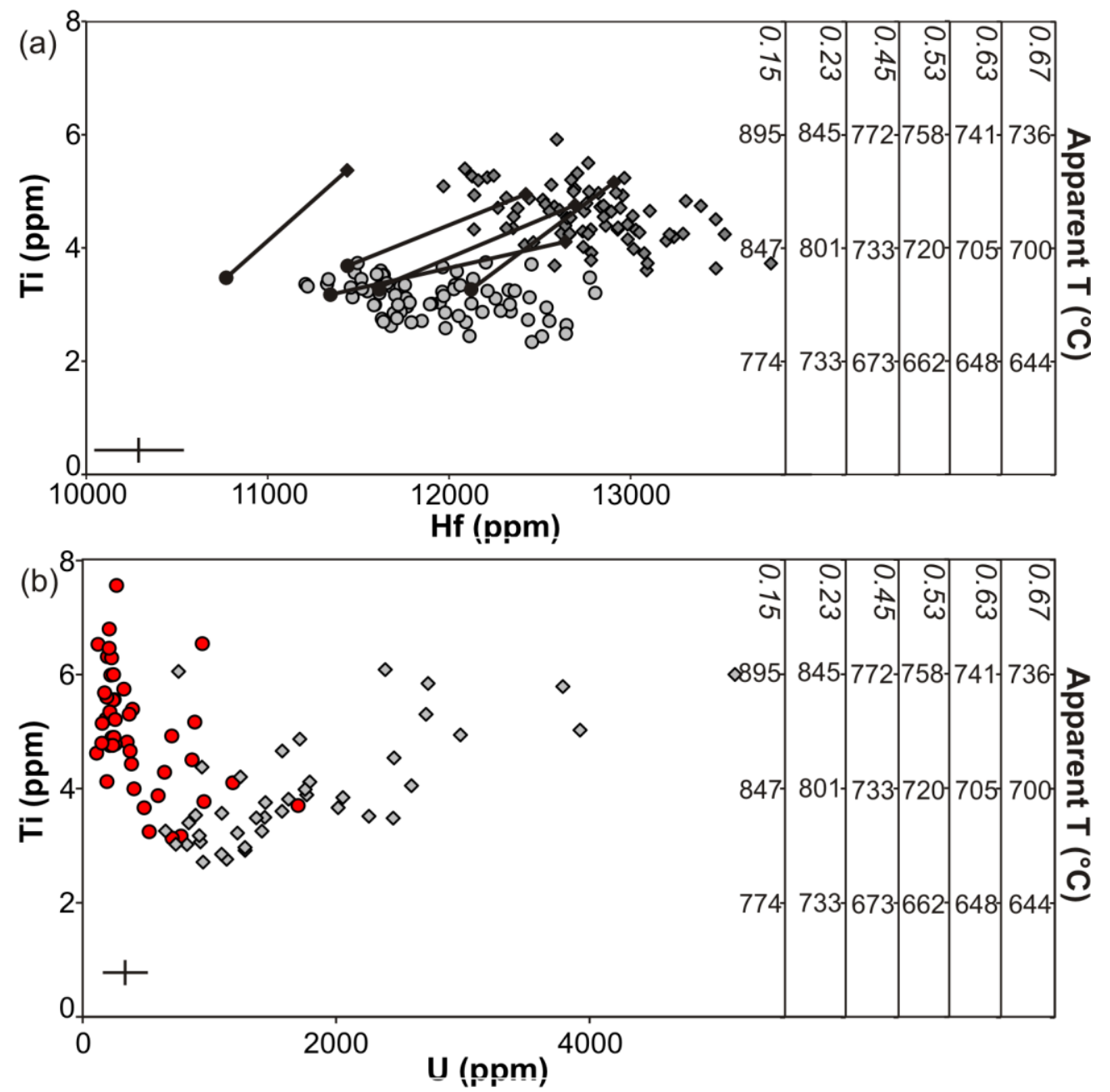

Fig. 3.13. Summary of results from Ti-in-zircon thermometry from Bishop zircons. (a) Comparisons of model temperatures obtained from Ti concentrations between different sectors of the same crystals: light grey circles are lighter sides, dark grey diamonds are darker tips. (b) Differences between CL-darker cores and CL-brighter rims of the same crystals: Red circles represent rims, grey squares represent cores. The $y$-axis is labelled with the measured $\mathrm{Ti}$ concentrations ( $\mathrm{ppm}$ ) on the left, and the resulting model temperature scales on the right based on the multiple published estimates of $a \mathrm{TiO}_{2}$ (given in italics) proposed for the Bishop magma (see text for discussion). Cross represents $2 \sigma$ uncertainty. (For full data set see Electronic Appendix 2.) 
Considering Ti concentration alone, the Bishop zircons display a relatively limited range in Ti concentrations $(2-8 \mathrm{ppm})$ when compared with other large silicic eruptives, such as the Oruanui (2 - 14 ppm), Ongatiti (3 - 18 ppm) and Kidnappers $(2-18$ ppm) examples in New Zealand (C. J. N. Wilson et al., unpublished data). The nano-scale Ti variability reported by Hofmann et al. (2013), if generally present, would raise further issues over the measurement of Ti concentrations in zircon and interpretation of these values in terms of entry of $\mathrm{Ti}$ into the zircon structure (e.g. as nano-inclusions versus as a structural component) and consequent temperature estimates. However the great contrast in the sampling volumes of the NanoSIMS versus ion probe means that the two suites of data are not yet comparable.

\subsubsection{Contributing components to the zircon population in the Bishop Tuff magma}

By combining the textural, age and trace-element data sets it is clear that there are at least four components which have contributed to the zircon assemblages in the Bishop Tuff: (1) the magma that grew the sector-zoned 'normal Bishop' crystals, which are the dominant population in most of the Bishop samples examined (Table 3.2; Fig. 3.4); (2) the magma that caused the growth of bright rims (and sparse whole crystals) in the zircon population; (3) the xenocrystic crustal component, mostly from Triassic granitoids, and present at up to $20 \%$ of the zircon population in two samples (Table 3.2; Fig. 3.4); (4) the Glass Mountain component which dominates the YA dome sample, but forms only a minor component ( $6 \%$ maximum) of grains in the Bishop samples

The top of the magma chamber (sampled with F1 and Ig1Eb) is dominated by the normal Bishop zircons, rapidly grown (reflecting the sector zoning) and with no bright overgrowths. This situation highlights a lack of mixing within the upper parts of the magma chamber, consistent with the limited ranges in corresponding Bishop Tuff phenocryst and whole-rock compositions (Hildreth, 1979; Hildreth \& Wilson, 2007). These early-erupted zircons have trace element variations dominated by sector zoning and ages close to eruption age (cores of F1 and Ig1Eb are dominantly aged from 760 to 820 ka). However, it is apparent from their relatively restricted $\mathrm{Th} / \mathrm{U}$ ratios, only mildly affected by sector zoning (Fig. 3.10), that the source for the 'normal Bishop' zircons involved melting of an arc-sourced lithology (Miller \& Wooden, 2004; Claiborne et al., 2010). The trends evident in U vs Yb (Fig. 3.10) and most other element-element and element-ratio plots in which element concentrations are increasing with fractionation, are 
likely to reflect continuing high-percentage fractionation of quartz and feldspar (up to $90 \%$ of the erupted crystal assemblage: Hildreth, 1979) which makes most of the trace elements common to zircon behave incompatibly in the melt. We cannot find evidence for allanite fractionation influencing zircon trace-element patterns, as there is no decrease in $\mathrm{U}$ and $\mathrm{Th}$ concentrations with increasing Hf (Fig. 3.10). Allanite fractionation has been proposed to explain a coupled decrease in light REE (LREE) and Zr/Hf in zircon (Reid et al., 2011). Allanite is not present, however, in the late Bishop Tuff and the extremely low abundances of LREE in any zircons make monitoring LREE changes challenging.

With progression through the eruption sequence (i.e. deeper in the magma chamber) the zircon textures become more variable, with the magma responsible for the bright zircon rims first becoming present in significant amounts in the latest Ig1Eb deposits (Sherwin subunit). It had previously been thought that the bright rims on quartz and sanidine crystals (Hildreth, 1979; Anderson et al., 2000; Peppard et al., 2001; Wark et al., 2007) were restricted to the northern units. Recent investigations of quartz-hosted melt inclusions have, however, revealed a more complex history (Roberge et al., 2013). This study documented changes in melt inclusion compositions, from less evolved than the host melt, to more evolved than the host melt, taken as evidence of melt mixing occurring at depth within the magma chamber. This pattern of less evolved glass coupled with more evolved melt inclusions is not, however, restricted to the northern-erupted Bishop Tuff, but occurs also in the mid- to late-erupted eastern units (Ig2Ea, Ig2Eb). When coupled with the presence of the bright rims on zircons in late Ig1Eb, these observations imply that the introduction of a new magmatic component into the chamber caused growth of the zircon bright rims.

Samples from the later-erupted Bishop units (Ig2N, Ig2NW) contain a smaller proportion of sector-zoned zircons, with sparse crystals of Glass Mountain type (Table 3.2; Fig. 3.4). These contrasts suggest that zircon suites in the later-erupted units of the Bishop Tuff, inferred to come from deeper in the chamber (Wallace et al., 1999), incorporate some influence from a longer-lived part of the magma system. Some minor inheritance from the Glass Mountain system is also inferred to be present on the basis of textural observations, although this is not reflected in the age spectra. If such grains are from a source common to the Glass Mountain system, then magmatism continued after eruption of the youngest Glass Mountain domes. 
The later-erupted deeper-sourced magma, which contains zircons that began to crystallise at $\sim 845$ ka produced grains which do not show obvious sector zoning in CL, but are similar in trace element composition to those found in the early deposits (including some sectoral zoning in trace-elements such as $\mathrm{P}$ and $\mathrm{Ti}$ ). Our data indicate that the melts from which the sector-zoned and non-sector-zoned zircons grew were broadly similar in composition and had experienced comparable degrees of fractionation. This cogenetic nature of the early versus late-erupted zircons is consistent with a unitary nature for the Bishop Tuff magma body (Hildreth, 1979; Hildreth \& Wilson, 2007) and counts against any notion of two separate magma bodies (Gualda et al., 2012a).

The trace to subordinate component of Triassic zircons, most abundant in the swirly pumice type (Hildreth \& Wilson, 2007) indicates a late-stage incorporation of country-rock components into the magma (see also Hildreth, 1985). The Triassic zircons have a lower range in Th/U compared with the normal Bishop-type zircons (Fig. 3.10), indicating that melts of Triassic crust have not been a source for the main Bishop Tuff magma body. The lack of overgrowths on any of the zircon crystals implies that xenocrystic incorporation was very late-stage, most probably syn-eruptive.

\subsubsection{Origin of the 'bright-rim' magma}

Development of the CL-bright zircon rims is linked to changes in melt inclusion chemistry (Wallace et al., 1999; Anderson et al., 2000; Roberge et al., 2013), and bright overgrowths found on quartz (CL imagery) and sanidine (BSE imagery) in the northern-erupted units (Anderson et al., 2000; Peppard et al., 2001; Morgan \& Blake, 2006; Wark et al., 2007; Gualda et al., 2012b). It has been suggested that varying growth conditions (i.e. changes in $\mathrm{T}, \mathrm{P}, \mathrm{O}_{2}$ ) could have caused crystallisation of these bright rims on quartz, sanidine and zircon (Anderson et al., 2000; Peppard et al., 2001; Wark et al., 2007; Thomas et al., 2010). However, our trace-element data from bright rims show low concentrations of elements such as the HREE, $\mathrm{U}$ and Th compared with those of the sector-zoned zircons, indicating that these species were at lower concentrations within the parental melt. Using the partition coefficients of Sano et al. (2002) on the rims and cores of the same sectors indicates that the melt that crystallised the bright zircon was higher in Eu, but lower in the MREE and HREE than the melt associated with the sector-zoned zircons, assuming constant partition coefficients for both growth regimes. The difference between the bright rims and normal cores is more variable in Ig2Nb when compared with earlier-erupted units. This 'bright- 
rim' melt had Th/U ratios of $0.3-0.6$, similar to the normal Bishop sector zoned cores, which indicates that both the 'bright-rim' melt and the 'normal Bishop' melt involved the melting of a similar, arc-lithology source, consistent with the low U/Yb values of less than 1.0 (Fig. 3.10, Electronic Appendix 3). The lower values of HREE agree with previously published melt-inclusion and glass data (e.g. Anderson et al., 2000; Roberge et al., 2013), showing that these changes in the zircon trace elements match the evolution of host melt compositions. Increases in Ti concentration in the bright overgrowths yields $\sim 20{ }^{\circ} \mathrm{C}$ higher apparent temperatures over the cores (independent of the value of $a \mathrm{TiO}_{2}$ used), possibly showing that the magma was hotter. This is in agreement with Fe-Ti-oxide thermometry, which shows that the eruption temperatures of the melts are higher in the later units $(\sim 815$ ${ }^{\circ} \mathrm{C}$ versus $\sim 715{ }^{\circ} \mathrm{C}$; Hildreth \& Wilson, 2007). However, owing to the highly incompatible nature of many key trace elements into zircon and the obvious overprinting from the sector zoning, more detail about the nature of this 'bright-rim' melt cannot be derived from zircon chemistry alone. Further investigations are currently under way to into the nature of the 'bright-rim' magma and its relationship to the minor less-evolved components in the Bishop Tuff (Hildreth, 1979; Hildreth \& Wilson, 2007).

Introduction of the bright-rim forming magma has previously been considered to be on such a short timescale ( $<100 \mathrm{yrs})$ that it was a possible trigger for the Bishop Tuff eruption (Wark et al., 2007). By calculating the weighted means of our age determinations from directly inside the bright rim it is apparent that these zones are systematically older than the true rim analyses (whether they are 'bright-rim' or 'normal'; Fig. 3.14). However, there is no linear relationship between the bright rim width and age inside the rim, so we cannot determine absolutely when the bright-rim magma started to invade the magma chamber, apart from that it must be within $10 \mathrm{kyr}$ of eruption age, based on ages within the cores of crystals with wide bright rims (Fig. 3.14). There are therefore two possibilities for the timing of interaction with this 'bright-rim' melt. The first is that the systematic differences in rim width are due to a constant zircon growth rate, and therefore the increase in mean ages with bright-rim width (Fig. 3.14) shows that the 'bright-rim' magma was interacting with the roots of the Bishop system under the northern side of what became Long Valley caldera for a longer period of time. However, this is inconsistent with quartz diffusion timescales that indicate $<100$ years of interaction with the 'bright-rim' magma (Wark et al., 2007; Gualda et al., 2012b). The second possible interpretation of the differences in timescales with rim width is that it reflects a cessation of zircon growth (but no dissolution, 
hence the euhedral core morphologies). Therefore, in the deepest parts of the magma chamber (where rims are typically thicker: see Fig. 3.4) the magma was close to (or just above) zircon saturation, and zircons had ceased growing until interaction with the 'brightrim' magma triggered renewed growth. In the upper parts of the magma system, where bright rims on zircon are rare and thin, the magma remained zircon saturated (and therefore zircon continued to grow) until the shortly pre-eruptive interaction with the 'bright-rim' magma (Wark et al., 2007).

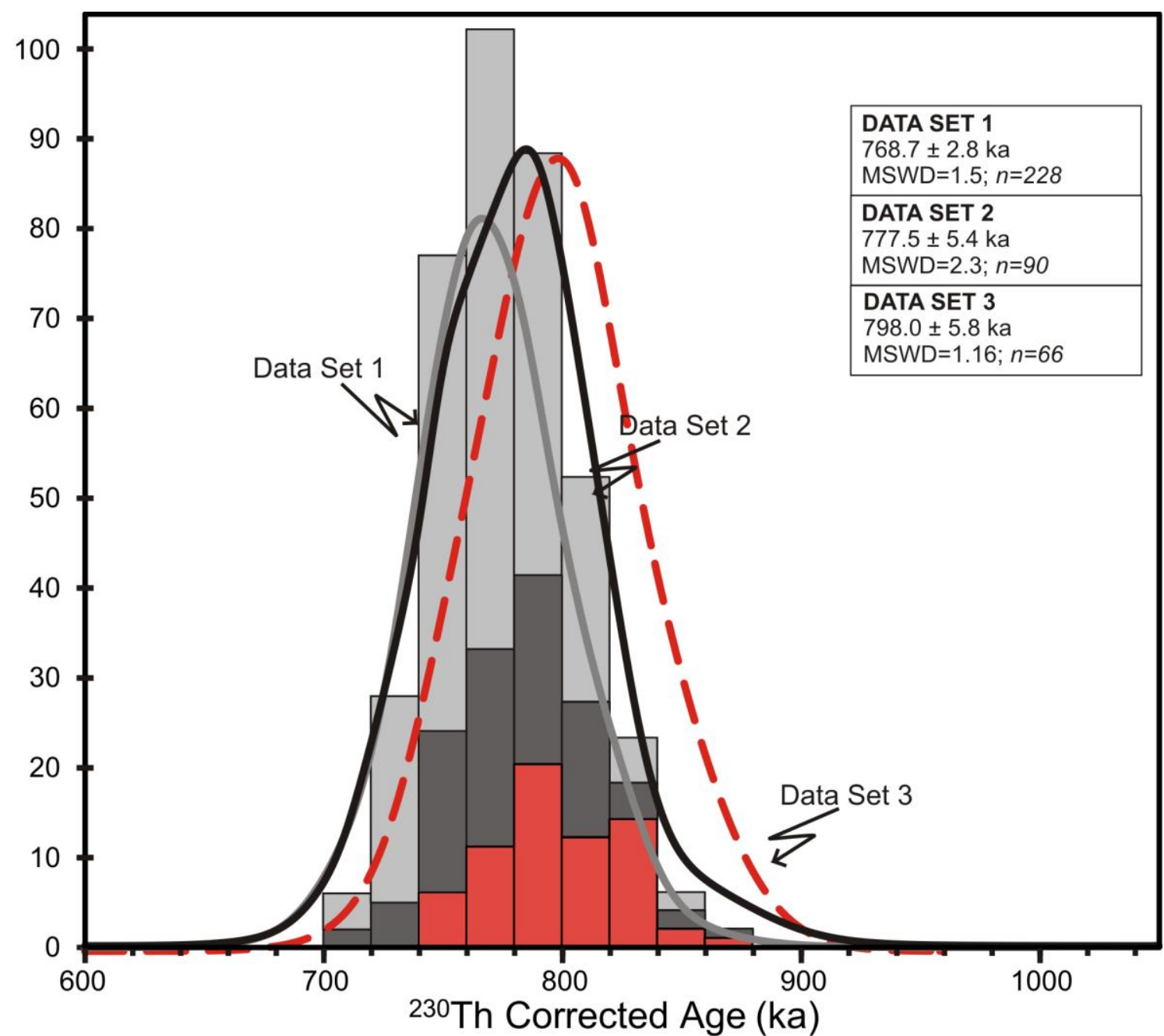

Fig. 3.14. Variation in ${ }^{230} \mathrm{Th}$-corrected ${ }^{206} \mathrm{~Pb} /{ }^{208} \mathrm{U}$ ages measured in 'normal Bishop' zircons (as defined from CL imagery; see text and Fig. 3.3). Data set 1 (light grey) combines all age determinations by us on rims of 'normal Bishop' zircons where there is no development of any CL-bright rim overgrowth. Data set 2 (dark grey) represents measurements on Bishop zircons which have narrow $(<10 \mu \mathrm{m})$ bright rims, where the spots were sited in the darker CL cores just inside the brighter rim. Data set 3 (red, dashed line) represents measurements on Bishop zircons which have wide $(>10 \mu \mathrm{m})$ bright rims, where the spots were sited in the darker CL cores just inside the brighter rim. Probability density function (PDF) curves from Isoplot. Values for the data sets represent the number of spots used $(n)$, and the weighted means, uncertainties at 95\% confidence and MSWD values for the respective populations. (For full data set see Electronic Appendix 1.) 
To assess if introduction of the hotter 'bright-rim' magma would allow crystallisation of the observed bright rims, we calculated the state of zirconium saturation in the melt, using the Watson \& Harrison (1983) calibration. In the samples dominated by 'normal' Bishop zircons the $\mathrm{Zr}$ saturation temperatures are within uncertainty of the published Fe-Ti-oxide and $\Delta^{18} \mathrm{O}(\mathrm{Qz}-\mathrm{Mt})$ temperatures, and therefore the melt was zirconium saturated, at least immediately prior to eruption (Hildreth, 1979; Bindeman \& Valley, 2002). However, in the three samples which display high proportions of bright rims the Zr saturation temperatures are up to $50{ }^{\circ} \mathrm{C}$ lower than the Fe-Ti-oxide thermometry for those units, implying that the 'bright-rim' melt was slightly Zr undersaturated. This result would seem to indicate that the 'bright-rims' must have grown before those modelled in quartz. However, Harrison et al. (2007) propose that zircon can crystallise at up to $80{ }^{\circ} \mathrm{C}$ higher than the zircon saturation temperature calculated from Watson \& Harrison (1983). In addition, it is unlikely that the zircon bright-rims are unrelated to the bright rims observed in quartz and sanidine, given the similar associated trace element changes (Hildreth, 1979; Anderson et al., 2000; Wark et al., 2007; Simakin \& Bindeman, 2008).

\subsection{Conclusions}

This study demonstrates some key findings that are not only relevant to the development and eruption of the Bishop Tuff magma body, but that also raise important considerations for zircon studies on any silicic system.

1. A comprehensive suite of $\mathrm{U}-\mathrm{Pb}$ ages from the earliest to the latest units of the Bishop Tuff reveal no evidence for a long 'tail' to the precursory Glass Mountain system, and we cannot replicate published peaks in age spectra greater than $\sim 845$ ka. Our nearest-rim analyses in samples from early erupted material yield a weighted-mean estimate for the eruption age of $766.6 \pm 3.1 \mathrm{ka}$ (95\% confidence), fully consistent with the ID-TIMS estimate of Crowley et al. (2007) and ${ }^{40} \mathrm{Ar} /{ }^{39} \mathrm{Ar}$ age determinations of Rivera et al. (2011). Our data are not consistent with proposals of older ages for the Fish Canyon standard that would have the Bishop eruption age in the 776-778 ka range (Renne et al., 2010, 2011; Mark et al., 2012). SIMS chronologies on zircons, at least in this key example, can match in overall accuracy and precision those obtained by ID-TIMS, with the advantage of being able to link analytical spot positions to textural features within grains. 
2. Zircon age data from the youngest Glass Mountain dome (YA) are consistent with an eruption age of $862 \pm 23 \mathrm{ka}$, in contrast to the universally used K-Ar value of $790 \pm 20 \mathrm{ka}$ (Metz \& Mahood, 1985). Our data, coupled with zircon ages and ${ }^{40} \mathrm{Ar} /{ }^{39} \mathrm{Ar}$ age determinations from Glass Mountain dome OD (Davies et al., 1994; Simon \& Reid, 2005) imply that the K-Ar chronological framework of Metz \& Mahood (1985) may be significantly inaccurate.

3. Our age data show that the Bishop Tuff magma and mush systems were physically separated from the Glass Mountain system and must have evolved in separate fashion. Textural data imply that there was very little $(<10 \%)$ zircon crystal inheritance from the Glass Mountain roots even in the deepest parts of the magma chamber. Our ages imply that the Bishop magma system began its operations with zircon saturated compositions only to begin crystallising zircon $\sim 80 \mathrm{kyr}$ prior to eruption. This is not necessarily the assembly time for the melt-dominant magma body, but the lack of systematic textural contrasts between zircons spanning this $\sim 80 \mathrm{kyr}$ range suggests that this was the case.

4. The Bishop zircons can be classified into four categories: (a) a numerically dominant suite of sector zoned grains; (b) a subordinate suite of grains with rims of CL-bright material (and cores that may or may not show sector zoning); (c) a sparse suite of grains with oscillatory zoning and shapes that match the dominant population in Glass Mountain dome YA; and (d) oscillatory zoned Mesozoic crustal xenocrysts. We demonstrate that a major control on trace-element variations in the Bishop zircon population is imposed by sector zoning. This sector zoning is most dominant in crystals from the early Bishop Tuff units which are representative of the archetypical and numerically dominant 'normal Bishop' type of zircon. Application of Ti-in-zircon model temperatures in particular is hindered both by the sector zoning (differences of $20-50{ }^{\circ} \mathrm{C}$ between sides and tips in the same growth zone in the same crystals) and by contrasting values proposed for the value of $a \mathrm{TiO}_{2}(0.15-0.67)$.

5. Despite the strong influence of sector zoning, key magmatic features can still be identified. By combining textural observations from CL imagery and trace-element analyses, two major end-member host magmas for the Bishop Tuff are identified, one responsible for the 'normal Bishop' sector-zoned zircons and the other responsible for the CL-bright components. The 'bright-rim' component was a less evolved late-stage 
contributor to the Bishop system, and it also influenced growth of bright rims on sanidine and quartz. However, 'rejuvenation' of the Bishop magma chamber is observed to reach levels as shallow as those tapped by the latest Ig1Eb unit, earlier than has been previously identified. The sources for the Bishop Tuff magmas (whether 'normal' or that responsible for the bright-rims) appear to involve an evolved arc source, which subsequently experienced significant proportions of quartz and feldspar fractionation. 


\section{Chapter 4}

Published as: Chamberlain, K. J., Morgan, D. J. \& Wilson, C. J. N. (2014):

Timescales of magma mixing and mobilisation in the Bishop Tuff magma body: perspectives from diffusion chronometry. Contributions to Mineralogy and Petrology (accepted manuscript). 


\title{
4. Timescales of mixing and mobilisation in the Bishop Tuff magma body: perspectives from diffusion chronometry
}

\begin{abstract}
We present two-feldspar thermometry and diffusion chronometry from sanidine, orthopyroxene and quartz from multiple samples of the Bishop Tuff, California, to constrain the temperature stratification within the pre-eruptive magma body and the timescales of magma mixing prior to its evacuation. Two-feldspar thermometry yields estimates that agree well with previous Fe-Ti oxide thermometry and gives a $\sim 80{ }^{\circ} \mathrm{C}$ temperature difference between the earlier- and later-erupted regions of the magma chamber. Using the thermometry results, we model diffusion of Ti in quartz, and $\mathrm{Ba}$ and $\mathrm{Sr}$ in sanidine as well as $\mathrm{Fe}-\mathrm{Mg}$ interdiffusion in orthopyroxene to yield timescales for the formation of overgrowth rims on these crystal phases. Diffusion profiles of Ti in quartz and $\mathrm{Fe}-\mathrm{Mg}$ in orthopyroxene both yield timescales of $<150$ years for the formation of overgrowth rims. In contrast, both $\mathrm{Ba}$ and $\mathrm{Sr}$ diffusion in sanidine yield nominal timescales 1-2 orders of magnitude longer than these two methods. The main cause for this discrepancy is inferred to be an incorrect assumption for the initial profile shape for $\mathrm{Ba}$ and Sr diffusion modelling (i.e., growth zoning exists). Utilising the divergent diffusion behaviour of $\mathrm{Ba}$ and $\mathrm{Sr}$, we place constraints on the initial width of the interface and can refine our initial conditions considerably, bringing $\mathrm{Ba}$ and $\mathrm{Sr}$ data into alignment, and yielding timescales closer to 500 years, the majority of which are then within uncertainty of timescales modelled from Ti diffusion in quartz. Care must be thus taken when using Bain-sanidine geospeedometry in evolved magmatic systems where no other phases or elements are available for comparative diffusion profiling. Our diffusion modelling reveals piecemeal rejuvenation of the lower parts of the Bishop Tuff magma chamber at least 500 years prior to eruption. Timescales from our mineral profiling imply either that diffusion coefficients currently used are uncertain by 1-2 orders of magnitude, or that the minerals concerned did not experience a common history, despite being extracted from the same single pumice clasts. Introduction of the magma initiating crystallization of the contrasting rims on sanidine, quartz, orthopyroxene and zircon was prolonged, and may be a marker of other processes that initiated the Bishop Tuff eruption rather than the trigger itself.
\end{abstract}




\subsection{Introduction}

Understanding the role of recharge in the assembly, stratification and evacuation of magma chambers has been a long standing question in the study of large-scale silicic magma systems, particularly those generating supereruptions. These eruptions, of $>10^{15} \mathrm{~kg}(\sim 450$ $\mathrm{km}^{3}$ ) magma (Self, 2006; Miller \& Wark, 2008), have the potential to cause massive destruction, as well as having catastrophic effects on global climate (Self \& Blake, 2008). In terms of mitigating potential hazards, the more that can be determined regarding the timescales of the processes occurring in the parental magma systems (regardless of size), the more information that can be fed into monitoring programs at currently-active silicic volcanoes.

Recharge of volcanic systems has often been cited as a trigger for eruptions (e.g. Sparks et al., 1977; Jellinek \& DePaolo, 2003; Wark et al., 2007; Arienzo et al., 2011; Matthews et al., 2012a; Saunders et al., 2012) whether due to direct increase in volume causing failure of the magma chamber wall rocks (e.g. Jellinek \& DePaolo, 2003), the buoyancy-driven effects of accumulating magma (e.g. Carrichi et al., 2014; Malfait et al., 2014), or by indirectly causing changes in volume of saturated gases and crystal cargo (e.g. Snyder, 2000; Wark et al., 2007). Evidence of magmatic recharge or mixing is commonly preserved as zonations within crystal phases already present in the magma chamber (e.g. Morgan et al., 2004; Ginibre et al., 2007; Wark et al., 2007; Martin et al., 2008; Humphreys et al., 2009; Allan et al., 2013). However, two factors make interpretation complex. The first is whether the crystal phases are recording consistently the same event, resolution of which is hampered (in general) by use of single mineral phases for study (e.g. Wark et al., 2007; Gualda et al., 2012a). The second is whether evidence for recharge or magma mixing is automatically evidence for an eruption trigger (e.g. Wark et al., 2007), when other, external factors may be important in causing both the recharge and the eruption (e.g. Allan et al., 2012; 2013).

Diffusional geochronometry aims to model the evolution of compositional profiles within zoned crystals to determine the time elapsed since compositional variations were introduced. Typically, an initial starting profile shape is assumed - usually a sharp, stepchange - and this is modelled forwards in time until it matches the observed profile. The timescale determined via this method can be regarded as a maximum, as the exact initial condition is not known. We will return to the validity of this initial assumption later in this paper. Although diffusion modelling of single or multiple elements has been frequently 
utilised to explore timescales of crystal residence in magma chambers (e.g. Zellmer et al., 1999; Costa et al., 2003; Morgan et al., 2004; Costa \& Dungan, 2005; Morgan et al., 2006; Wark et al., 2007; Gualda et al., 2012a; Saunders et al., 2012; Till et al., 2012; Allan et al., 2013), multiple phases from the same sample have not been routinely investigated.

The Bishop Tuff (eruption age of 767 ka: Rivera et al., 2011) is an iconic example of a supereruption which displays evidence of magma mixing preserved as zonation in quartz, sanidine and orthopyroxene crystals (Hildreth, 1977, 1979; Anderson et al., 2000; Peppard et al., 2001; Morgan \& Blake, 2006; Wark et al., 2007; Gualda et al., 2012a). Whilst the Bishop Tuff has been the subject of many volcanological and geochemical investigations (see Hildreth \& Wilson, 2007, for review), the timescales associated with magma chamber assembly, residence and pre-eruptive mobilisation remain controversial. For example, radiogenic isotopic studies on crystal and glass separates from the Bishop Tuff pointed to a long residence time for the magma (300 - 1300 kyr: Christensen \& Halliday, 1996; Davies \& Halliday, 1998), apparently supported by theoretical models of felsic magma genesis (Fowler \& Spera, 2010). However, more recent studies of zircon U-Pb ages and crystal size distribution (CSD) modelling indicate that this is unrealistic and infer timescales of between $\sim 160 \mathrm{kyr}$ to a few thousand years (e.g. Gualda et al., 2012a; Pamukcu et al., 2012; Reid \& Schmitt 2012; Chamberlain et al., 2014a [Chapter 3]) for crystals residing in the meltdominant magma body. Previous workers have investigated the timescales for magma mobilisation within the Bishop Tuff magma chamber, primarily by modelling Ti diffusion with quartz (Wark et al., 2007; Gualda et al., 2012a), which yields timescales of $<100 \mathrm{yr}$ (for the 'bright-rim' [in CL imagery] overgrowths) to $\sim 2700 \mathrm{yr}$ (for core-interior zonation). However, no comprehensive combined study of the diffusion records of multiple crystal phases within the Bishop Tuff has been undertaken. Here we compare and contrast the timescales inferred from Fe-Mg interdiffusion in orthopyroxene, Ti diffusion in quartz (cf. Wark et al., 2007; Gualda et al., 2012a), Sr diffusion in sanidine and Ba diffusion in sanidine (cf. Morgan \& Blake, 2006) from multiple samples in the Bishop Tuff. We examine how comparable each of these timescales are, whether they are tracing the same magmatic events, and constrain the relatively short-lived injection of magma preceding the eruption. We also compare our data with alternative information on timescales of the processes involved from high-precision $\mathrm{U}-\mathrm{Pb}$ chronometry and textural studies in co-erupted zircon (Chamberlain et al., 2014a [Chapter 3]). 


\subsection{Geological setting}

The Bishop Tuff eruption was the culmination of $\sim 3.8 \mathrm{Myr}$ of magmatic activity in the Long Valley region and is the product of one of the largest eruptions on Earth in the last 1 Myr. Over $600 \mathrm{~km}^{3}$ of magma was erupted to generate fall deposits and ignimbrite, along with voluminous infill from the formation of Long Valley caldera (Fig. 4.1; Bailey et al., 1976; Hildreth, 1979, 2004; Wilson \& Hildreth, 1997; Hildreth \& Wilson, 2007). The volume of rhyolite erupted as the Bishop Tuff is greater than all other felsic eruptions combined in the Long Valley area before or since (Hildreth, 2004), and so questions arise as to how, and over what time period, such a large body of magma was accumulated and what the triggering processes were for the eruption.

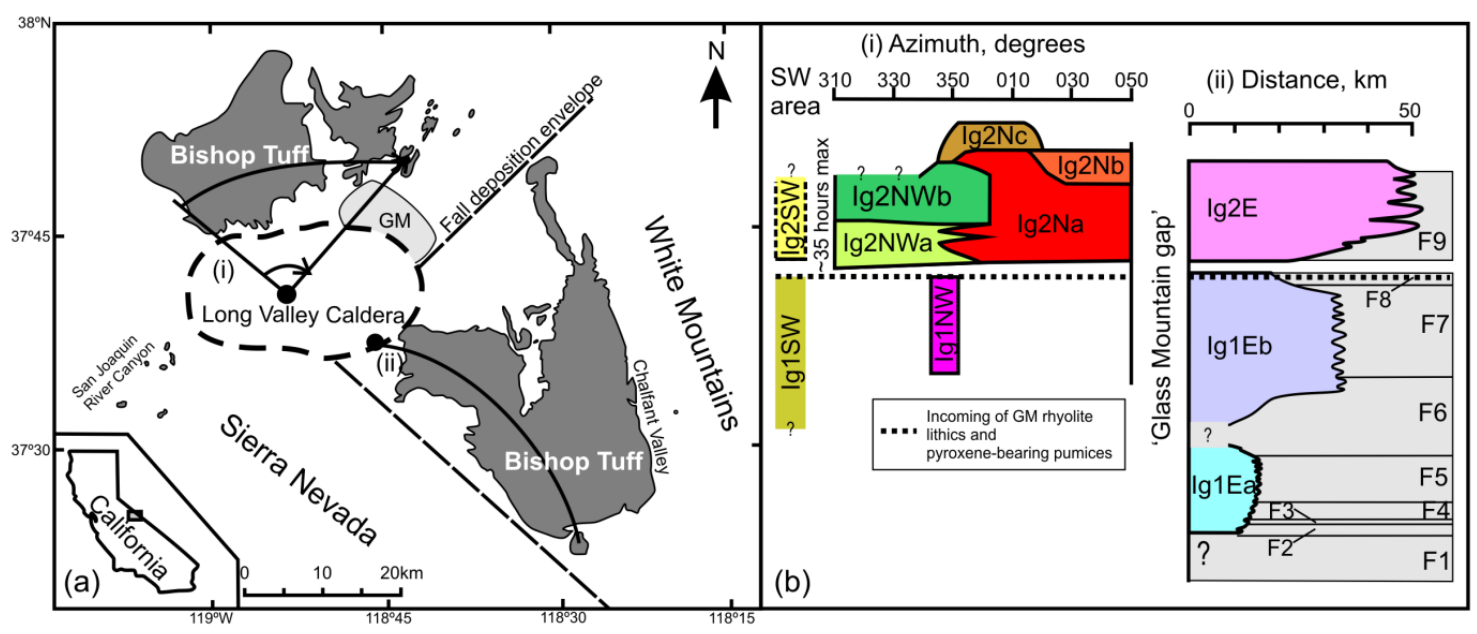

Fig. 4.1. (a) Map of the Long Valley area, eastern California, USA and (b) summary of the Bishop Tuff stratigraphy, after Hildreth \& Wilson (2007). (a) The topographic outline of Long Valley caldera is shown as a dashed line, regions of Bishop ignimbrite are filled in grey. The envelope enclosing mapped vent locations for the precursory Glass Mountain (GM) eruptions is highlighted in light grey. The line marked 'Fall deposition envelope' marks the westerly limits of where Bishop fall deposits are found in this area. The lines marked (i) and (ii) relate to the respective labels in panel (b). Line (i) Shows a hypothetical cross section from NW to NE across the northern ignimbrite lobes as viewed from the centre of Long Valley caldera. Line (ii) is a schematic proximal to distal cross section, approximately along the line of the Owens River gorge. (b) Schematic stratigraphy of the Bishop Tuff in its proximal area based on sections along lines (i) and (ii). Ignimbrite units are coloured; fall units are grey. Samples collected for this paper cover most of the stratigraphic units and are detailed in Electronic Appendix 4. Enlarged stratigraphy figure is also repeated in Appendix 1. 
Proximal deposits of the eruption consist of nine fall units (F1-9) and eleven ignimbrite packages (Wilson \& Hildreth, 1997; Fig.4.1). A systematic change from 'early', crystal poor (<6 wt. \% crystals), more-evolved (78.2 - 74.8 wt. $\% \mathrm{SiO}_{2}$ whole rock) to 'late', crystal rich (12-25 wt.\% crystals), less-evolved (77.8 - 73.4 wt. $\% \mathrm{SiO}_{2}$ whole rock) compositions is observed within the stratigraphy of the Bishop Tuff (see Hildreth \& Wilson, 2007, for details). In the context of this paper, 'early' refers to fall units F1-F8 and their coeval Ig1 ignimbrite packages; 'late' refers to Ig2N and Ig2NW; and 'intermediate' to the $\operatorname{Ig} 2 \mathrm{E}$ ignimbrite packages and fall unit F9. Changes in pumice composition accompany an overall change in volatile contents and species in quartz hosted melt inclusions from water-richer, $\mathrm{CO}_{2}$-poorer to water-poorer, $\mathrm{CO}_{2}$-richer (Dunbar \& Hervig, 1992; Wallace et al., 1999) magma. For this study, single pumice samples were collected from every ignimbrite unit of the Bishop Tuff, and pumices covering the range of crystallinities were sampled (Fig. 4.1; see Electronic Appendix 4 for sample descriptions and localities). Pumice clasts are categorised within two spectra: the 'normal' crystal-poor (xp) to crystal-rich (xr) scale, and the 'variant' types, following Hildreth \& Wilson (2007). The latter are of particular interest because they often show evidence of physical mixing on millimetre to centimetre scales, and so eight samples of the 'swirly' and 'chocolate' variant pumice types of Hildreth \& Wilson (2007) were inspected from packages Ig1Eb through to Ig2Nb.

\subsection{Methods}

\subsubsection{Sample preparation}

Single pumices were selected, washed to remove adhering matrix, and then crushed to chips using a Boyd crusher at Victoria University of Wellington. Crushed material was sieved and the sample was water-panned to separate glass from crystals. Quartz and sanidine crystals were then hand-picked under an optical microscope from the $1-2 \mathrm{~mm}$ size fraction. Orthopyroxene crystals were hand-picked from the $250-500 \mu \mathrm{m}$ size fraction (the sieved fraction in which orthopyroxene crystals were most common). Sanidine and orthopyroxene crystals were orientated with the crystal $b$ - and $c$ - axes in the plane of the section, so that these axes were exposed once the epoxy mount was ground and polished for imaging and analysis.

\subsubsection{BSE imaging}

Zoning patterns in sanidine and orthopyroxene were imaged by back-scattered electron (BSE) methods on a JEOL JXA 8230 Electron Microprobe (EPMA) at Victoria University 
of Wellington. Due to the dependence of BSE brightness on the effective atomic number of the sample per unit volume, changes in BSE brightness correspond to compositional changes within the crystal (Reed, 2005). In sanidine the major element affecting BSE brightness is $\mathrm{Ba}$, and therefore brighter BSE tones relate, in these samples, to areas of higher $\mathrm{Ba}$ concentration. Sanidine compositions vary by less $0.5 \mathrm{~mol} \%$ anorthite, $<3 \mathrm{~mol} \%$ albite and $<3 \mathrm{~mol} \%$ orthoclase, though typically this does not exceed $\sim 0.2, \sim 0.8$ and $\sim 1$ $\mathrm{mol} \%$, respectively. In orthopyroxene, BSE brightness is controlled largely by changing Fe$\mathrm{Mg}$ content. Ca can have an effect, but this can be neglected in this case (see Electronic Appendix 5 and Allan et al., 2013). All crystals were imaged completely and any zoning identified, before high-resolution images of the boundaries in the crystal were acquired to give improved spatial resolution across boundaries of interest. Image acquisition time was $\sim 2$ minutes, with a single integration.

\subsubsection{CL imaging}

Quartz zoning patterns were gathered by cathodoluminescence (CL) imaging, where the brightness of the image directly corresponds to Ti concentration (Wark et al., 2007; Matthews et al., 2012a, b). Initial lower quality whole-crystal images were acquired at Stanford University using a JEOL LV 5600 Scanning Electron Microscope (SEM) so that a large number of crystals could be evaluated for their zoning patterns prior to detailed analysis. High-resolution CL images of Ti boundaries in quartz crystals were obtained on a FEI Quanta 650 FEG-SEM (Field Emission Gun- Scanning Electron Microscope) with a KE Centaurus panchromatic CL detector at the University of Leeds, with a dwell time of $100 \mu$ s per pixel.

\subsubsection{Quantitative analyses}

Quantitative major, minor and selected trace element analyses were undertaken on a JEOL JXA 8230 SuperProbe at Victoria University of Wellington. For all elements apart from Sr and $\mathrm{Ba}$ an accelerating voltage of $15 \mathrm{kV}$, a beam current of $12 \mathrm{nA}$ and a spot size of $\sim 1 \mu \mathrm{m}$ was used. Elements were analysed with a 30 s count on-peak. For $\mathrm{Sr}$ and $\mathrm{Ba}$ in sanidines a $20 \mathrm{kV}$ accelerating voltage and $40 \mathrm{nA}$ beam current was used (following the method of Ginibre et al., 2002) with a defocused beam diameter of $5 \mu \mathrm{m}$. Spots were placed at a $7 \mu \mathrm{m}$ spacing (between spot centres) so as to avoid significant convolution issues. Sr was analysed with a $240 \mathrm{~s}$ peak count, and background was measured within $2 \mathrm{~mm}$ of the peak location (unlike $5 \mathrm{~mm}$ for other elements) to remove the effect of Si. Ba was analysed with 
a 120 s count time on-peak. Further details regarding standards used are detailed in Chapter 2. Trace element analyses from the EPMA were compared with trace element concentrations measured using laser ablation inductively coupled plasma mass spectrometry (LA-ICPMS) at Victoria University of Wellington. In situ measurements were undertaken using a New Wave deep UV laser (193 nm solid state) coupled to an Agilent 7500cs ICPMS.

\subsubsection{Modelling parameters}

Greyscale profiles of $\mathrm{Ba}$ in sanidine, $\mathrm{Fe}-\mathrm{Mg}$ in orthopyroxene and $\mathrm{Ti}$ in quartz were extracted from BSE or CL images using ImageJ ${ }^{\circledR}$ software. Sr profiles in sanidine were taken directly from EPMA measurements at $7 \mu \mathrm{m}$ spacing. For all profiles an initial condition of a step-function was assumed. Sanidine and quartz modelling was carried out using a simple 1D model (e.g. Morgan et al., 2006). This assumption can hold due to the relatively small extent of diffusion relative to grain size, and follows the method of Morgan et al. (2006) and Morgan \& Blake (2006). Diffusion anisotropy was considered small for Ti in quartz, and $\mathrm{Ba}$ and $\mathrm{Sr}$ in sanidine, consistent with results from previous studies (Cherniak \& Watson, 1992; Cherniak, 2002, 2010; Cherniak et al., 2007). The modelling parameters used for each species are presented in Table 4.1. Given the high temperature dependence of elemental diffusion, the uncertainty on every timescale was calculated using $\pm 30{ }^{\circ} \mathrm{C}$ in the temperature input, based on common uncertainties in $\mathrm{Fe}$ - $\mathrm{Ti}$ oxide thermometry (e.g. Hildreth \& Wilson, 2007), and that associated with the two-feldspar thermometry (see Results section).

In order to model diffusion for $\mathrm{Ti}$ in quartz, $\mathrm{Sr}$ in sanidine and $\mathrm{Ba}$ in sanidine, the diffusivity of the element $\left(\mathrm{D}_{\mathrm{i}}\right)$ being considered must be calculated. In many systems (including those listed above) where there is no compositional or oxygen fugacity dependence, these diffusivities are expressed in the form:

$D_{i}=D_{i, 0} e^{\left(\frac{-E}{R T}\right)}$ (Equation 4.1; see e.g. Crank, 1975; Zhang, 2010),

where $D_{i, 0}$ is the $D_{0}$ for species $i$ given in Table 4.1, $E$ is the activation energy given in Table 4.1, $R$ is the gas constant, and $T$ is temperature in Kelvins. Having calculated the 
Table 4.1. Listing of diffusion constants used for all species modelled

\begin{tabular}{lccccc} 
Phase & $\begin{array}{c}\text { Diffusing } \\
\text { Species }\end{array}$ & $\begin{array}{c}\mathbf{D}_{\mathbf{0}} \\
\left(\mathbf{m s}^{-2}\right)\end{array}$ & $\begin{array}{c}\mathrm{E}_{\text {act }} \\
(\mathrm{J} / \mathbf{m o l})\end{array}$ & $\begin{array}{c}\mathbf{f O}_{\mathbf{2}} \\
(\boldsymbol{\Delta} \text { NNO; range) }\end{array}$ & $\begin{array}{c}\mathbf{T} \\
\left({ }^{\circ} \mathbf{C} ; \text { range) }\right.\end{array}$ \\
\hline \hline Orthopyroxene & $\mathrm{Fe}-\mathrm{Mg}$ & $0.00000288^{\mathrm{A}}$ & $\mathrm{NA}$ & $0.483-1.111^{\mathrm{B}}$ & $790-815$ \\
Quartz & $\mathrm{Ti}$ & $0.00000007^{\mathrm{C}}$ & $273000^{\mathrm{C}}$ & $\mathrm{NA}$ & $753-815$ \\
Sanidine & $\mathrm{Ba}$ & $0.29^{\mathrm{D}}$ & $455000^{\mathrm{D}}$ & $\mathrm{NA}$ & $753-815$ \\
Sanidine & $\mathrm{Sr}$ & $8.4^{\mathrm{E}}$ & $450000^{\mathrm{E}}$ & $\mathrm{NA}$ & $770-815$ \\
\hline
\end{tabular}

Sources of values used. A: Ganguly \& Tazzoli, 1994; B: Hildreth \& Wilson, 2007; C:

Cherniak et al., 2007; D: Cherniak, 2002; E: Cherniak, 1996. NA = Not applicable.

appropriate values of $D$ for each elemental system at the appropriate temperature, the following equation was solved for time:

$\mathrm{C}=\mathrm{C}_{0}+\frac{\left(\mathrm{C}_{1}-\mathrm{C}_{0}\right)}{2}\left[\operatorname{erfc}\left(\frac{\mathrm{x}}{2 \sqrt{\overline{\mathrm{D}_{\mathrm{i}} \mathrm{t}}}}\right)\right]$

(Equation 4.2; Crank, 1975; Morgan et al., 2004),

where $C$ is the normalised concentration of $\mathrm{Ti}$, $\mathrm{Sr}$ or $\mathrm{Ba}, C_{0}$ and $C_{1}$ refer to the initial amounts of the element on each side of an initial interface, $D_{i}$ is the calculated diffusivity in $\mathrm{m}^{2} \mathrm{~s}^{-1}, t$ is the diffusion time, and $x$ is the position measured in metres along the profile and centred on the interface (the midpoint of the profile). The best-fit profiles were then determined by using a macro to goalseek the difference between modelled profile shape and the input profile to zero, yielding a timescale for the best-fit profile.

For modelling in orthopyroxene, Fe-Mg profiles were obtained along the crystallographic $a$ - or $b$-axis, to be internally consistent and to avoid anisotropy effects. This is comparable with other $\mathrm{Fe}-\mathrm{Mg}$ orthopyroxene interdiffusion chronometry where growth effects along the c-axis could be demonstrated to have occurred (e.g. Allan et al., 2013). Due to an expected $\mathrm{fO}_{2}$ dependence of $D_{\mathrm{Fe}-\mathrm{Mg}}$ in orthopyroxene (Ganguly \& Tazzoli, 1994), the formula of Ganguly \& Tazzoli (1994) modified as in Allan et al. (2013) is used to calculate $D_{\mathrm{Fe} M g^{\mathrm{B}}}$

$$
\log _{10} \mathrm{D}_{\mathrm{Fe}-\mathrm{Mg}}=\left(-5.54+2.6 \mathrm{X}_{\mathrm{Fe}}-\frac{12530}{\mathrm{~T}}\right)+\frac{1}{6} \log _{10}\left(\frac{\mathrm{fO}_{2}(\text { sample, } \mathrm{T})}{\mathrm{fO}_{2}(\mathrm{IW} \text { buffer, } \mathrm{T})}\right)
$$

(Equation 4.3), 
where $X_{F e}$ is the molar proportion of the Fe end member (ferrosilite), $T$ is temperature in Kelvins, and $\mathrm{fO}_{2}$ is oxygen fugacity. In order to then model a timescale, finite difference methods were used, as detailed in Allan et al. (2013). We revisit the potential accuracy of this expression in the discussion.

In order to test that all profiles extracted were statistically significant, and to what degree variation on either end of the profile is significant, statistical analyses were conducted across every profile extracted from images. The uncertainty on the greyscale profile, being

essentially random thermal noise in the BSE or CL detector, scales as $\frac{1}{\sqrt{n}}$ where $n$ is the number of pixels being averaged together; yielding a standard error (s.e.). If diffusion is the cause of the sigmoidal concentration profile, the plateaux at either end of the profile should be flat. Profiles which had variation in the plateaux that exceeded the calculated 2 s.e. were rejected.

\subsection{Results}

\subsubsection{Two-feldspar thermometry}

Where present, major element analyses of sanidine inclusions in plagioclase crystals (and vice versa) were used in combination with the Elkins \& Grove (1990) calibration of the twofeldspar thermometer to iteratively calculate the temperatures at which these feldspars crystallised. We present 26 new temperature calculations from the early Bishop Tuff (Ig1Eb- Fig. 4.1) through to the latest Bishop Tuff (Ig2Nc- Fig. 4.1). The full results are presented in Table 4.2. All inclusions measured are within BSE-'dark' cores of crystals, showing that the temperature stratification of $\sim 80{ }^{\circ} \mathrm{C}$ calculated by two-feldspar thermometry (Fig. 4.2) was present prior to any mixing with the contrasting magma composition that gave rise to the BSE-bright crystal rims. The 'bright-rim' forming magma is inferred to have been of slightly higher temperature than the 'normal' Bishop Tuff magma due to its less-evolved melt composition (from increased $\mathrm{Ba}, \mathrm{Sr}$ and $\mathrm{Ti}$ in overgrowth rims) and as indicated by increases in Fe-Ti oxide and oxygen-isotope model temperatures with inferred depth in the system (Hildreth, 1979; Wallace et al., 1999; Bindeman \& Valley, 2002; Hildreth \& Wilson, 2007). 


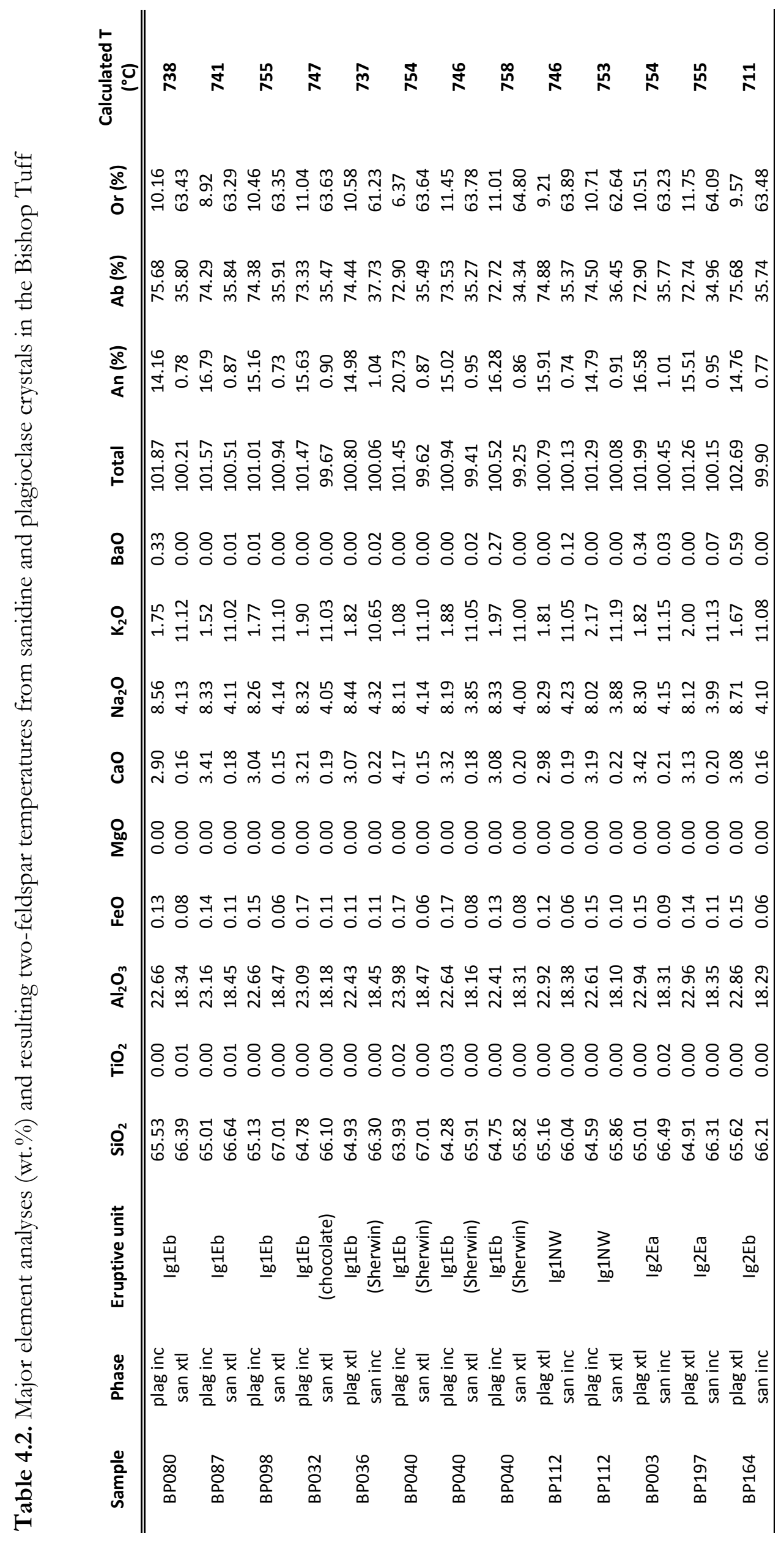




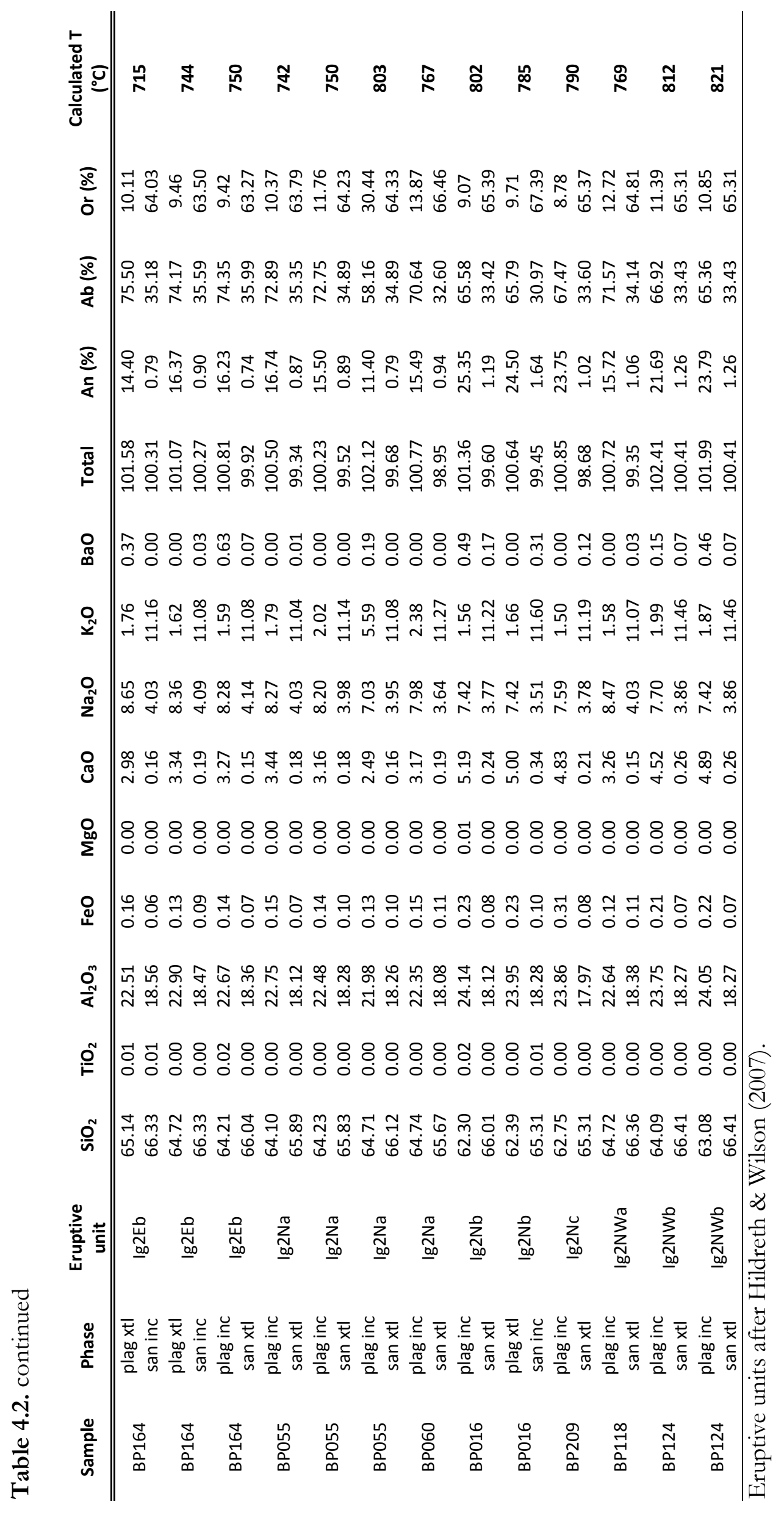




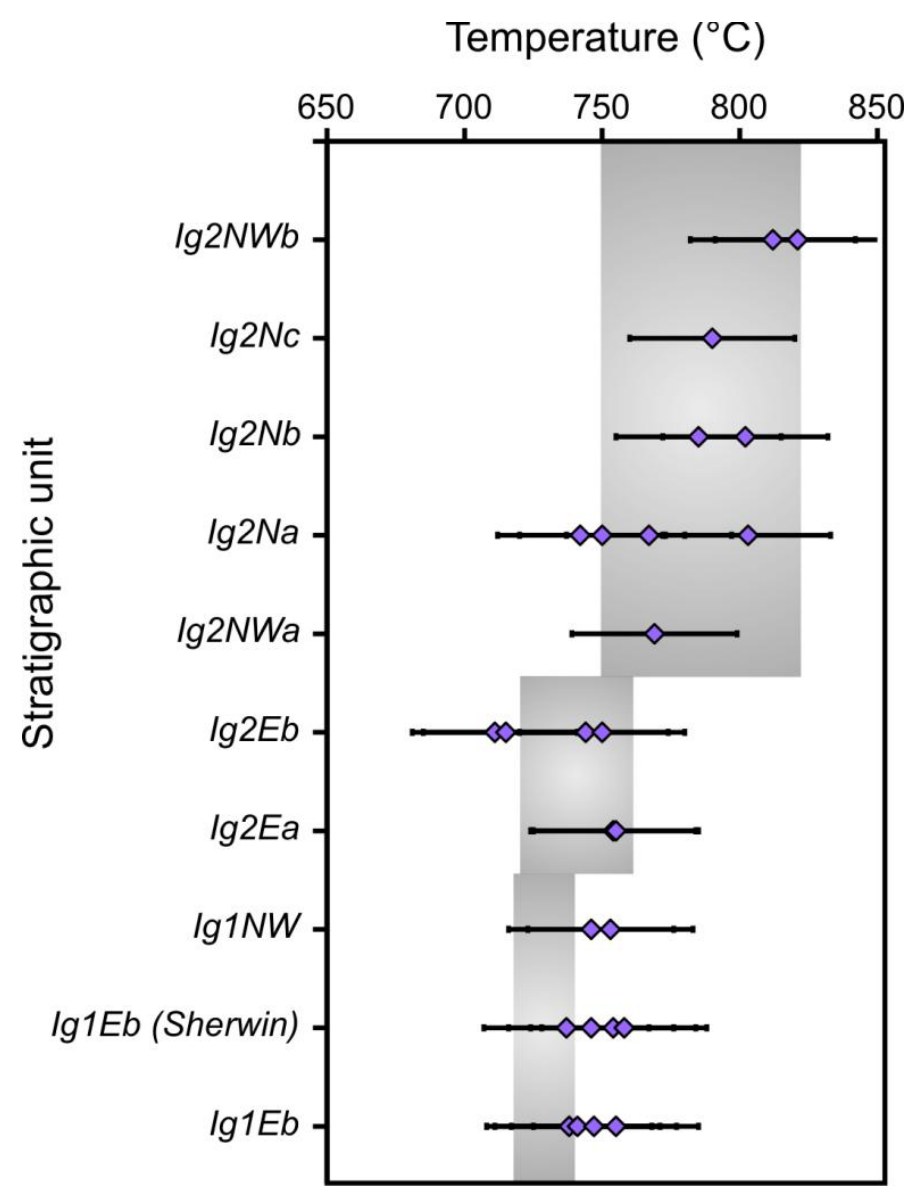

Fig. 4.2. Temperature variation with stratigraphic unit of the Bishop Tuff from early (Ig1Eb) to late (Ig2N/Ig2NW). Results presented (diamonds) are from two-feldspar thermometry with an associated $\pm 30{ }^{\circ} \mathrm{C}$ uncertainty. The grey fields represent the range in FeTi-oxide temperatures calculated by Hildreth $(1977,1979)$ and Hildreth \& Wilson (2007). Stratigraphic units used are those of Fig. 4.1 and follow the nomenclature of Wilson \& Hildreth (1997).

We then use these temperature results, in combination with previously published Fe-Ti oxide thermometry (Hildreth \& Wilson, 2007), to estimate temperatures at which diffusion occurred (Table 4.3). Samples from units Ig2Na yield cooler temperatures than those of the overlying Ig2Nb and Ig2Nc packages (Fig. 4.1; Table 4.2), and are thus modelled at 770 ${ }^{\circ} \mathrm{C}$, representing a rounded average of the calculated model temperatures. Samples from $\operatorname{Ig} 2 \mathrm{Nb}$ and $\mathrm{Ig} 2 \mathrm{Nc}$ appear indistinguishable based on the feldspar thermometry and thus are modelled at $790{ }^{\circ} \mathrm{C}$, representing again a rounded average of the results. Samples from Ig2NWa and Ig2NWb are modelled at $815^{\circ} \mathrm{C}$ due to their higher model temperatures than Ig2N packages. Where zoning is present, crystals from the F9 sample are modelled using an average of $780{ }^{\circ} \mathrm{C}$ represented by the results from Ig2N. Some quartz crystals from $\operatorname{Ig} 2 \mathrm{SW}$ preserved $\mathrm{Ti}$ zonation, and this diffusion was modelled at $753{ }^{\circ} \mathrm{C}$, that is, an average of $\operatorname{Ig} 2 \mathrm{E}$ and $\operatorname{Ig} 2 \mathrm{Na}$ modelled temperatures. In all cases a $\pm 30{ }^{\circ} \mathrm{C}(1 \sigma)$ uncertainty on 
thermometry is assumed which is then propagated through to uncertainties on the diffusive timescales. The actual temperature controlling diffusion is, however, likely to have been slightly hotter than those modelled here from the cores of crystals given that the brighter rims grew from a less-evolved melt (Hildreth, 1979; Hildreth \& Wilson, 2007; Chamberlain et al., 2014a [Chapter 3]: see Table 4.3 for temperatures used).

\subsubsection{Ti-in-quartr.}

Quartz from 16 samples from F1 (earliest erupted) to Ig2Nc (latest erupted: Fig. 4.1) were imaged, of which 11 samples showed bright rim overgrowths on quartz crystals suitable for modelling (Fig. 4.3; Electronic Appendix 4). The 11 samples came from units Ig2Na, Ig2Nb, Ig2Nc, Ig2NWa, Ig2NWb, F9 as well as 3 boundaries from a sample of Ig2SW (Fig. 4.1). As previously shown, only quartz crystals from 'late' in the Bishop Tuff eruption sequence (and therefore from deeper in the magma chamber: Wallace et al., 1999) have high-Ti rims. 'Early' samples (which constitute $\sim 2 / 3$ of the eruptive volume, Hildreth \& Wilson, 2007) still retain some complex oscillatory zoning (Peppard et al., 2001; Wark et al., 2007; Gualda et al., 2012a), but this is not investigated further here.

One hundred and seventy four timescales were modelled, with temperatures constrained using the results of the two-feldspar thermometry detailed above. Of these timescales, fifteen were rejected for not having a statistically significant contrast along the profile (see Methods). The boundaries between higher and lower Ti-bearing quartz range in width from $\sim 5 \mu \mathrm{m}$ to $\sim 30 \mu \mathrm{m}$, yielding maximum timescales which range from as little as 15 days $(+37 /-8$ days uncertainty) to 226 years $(+556 /-97$ yrs uncertainty) with a mean value of 24 years which is skewed by the dominance of shorter timescales. The best timescale

Table 4.3. Temperatures used for diffusion modelling in various units of the Bishop Tuff

\begin{tabular}{|c|c|c|}
\hline Eruptive unit & $\begin{array}{c}\text { T modelled } \\
\text { at }\left({ }^{\circ} \mathrm{C}\right)\end{array}$ & Rationale \\
\hline $\lg 2 \mathrm{SW}$ & 753 & Weighted Average of all Eastern and Ig2Na feldspar temperatures \\
\hline F9 & 780 & Average of $\lg 2 \mathrm{Na}$, Ig2 $\mathrm{Nb}$ and $\lg 2 \mathrm{Nc}$ feldspar temperatures \\
\hline $\lg 2 \mathrm{Na}$ & 770 & Average of Ig2Na feldspar temperatures \\
\hline $\lg 2 \mathrm{Nb}+\mathrm{c}$ & 790 & Average of Ig2 $\mathrm{Nb}$ and Ig2Nc feldspar temperatures \\
\hline $\lg 2 \mathrm{NWa}+\mathrm{b}$ & 815 & $\begin{array}{l}\text { Average of Ig2NWb temperature only, due to "eastern" appearance of sanidine, } \\
\text { zircon, and glass chemistry in sample BP118 }\end{array}$ \\
\hline
\end{tabular}

Eruptive units after Hildreth \& Wilson (2007). 


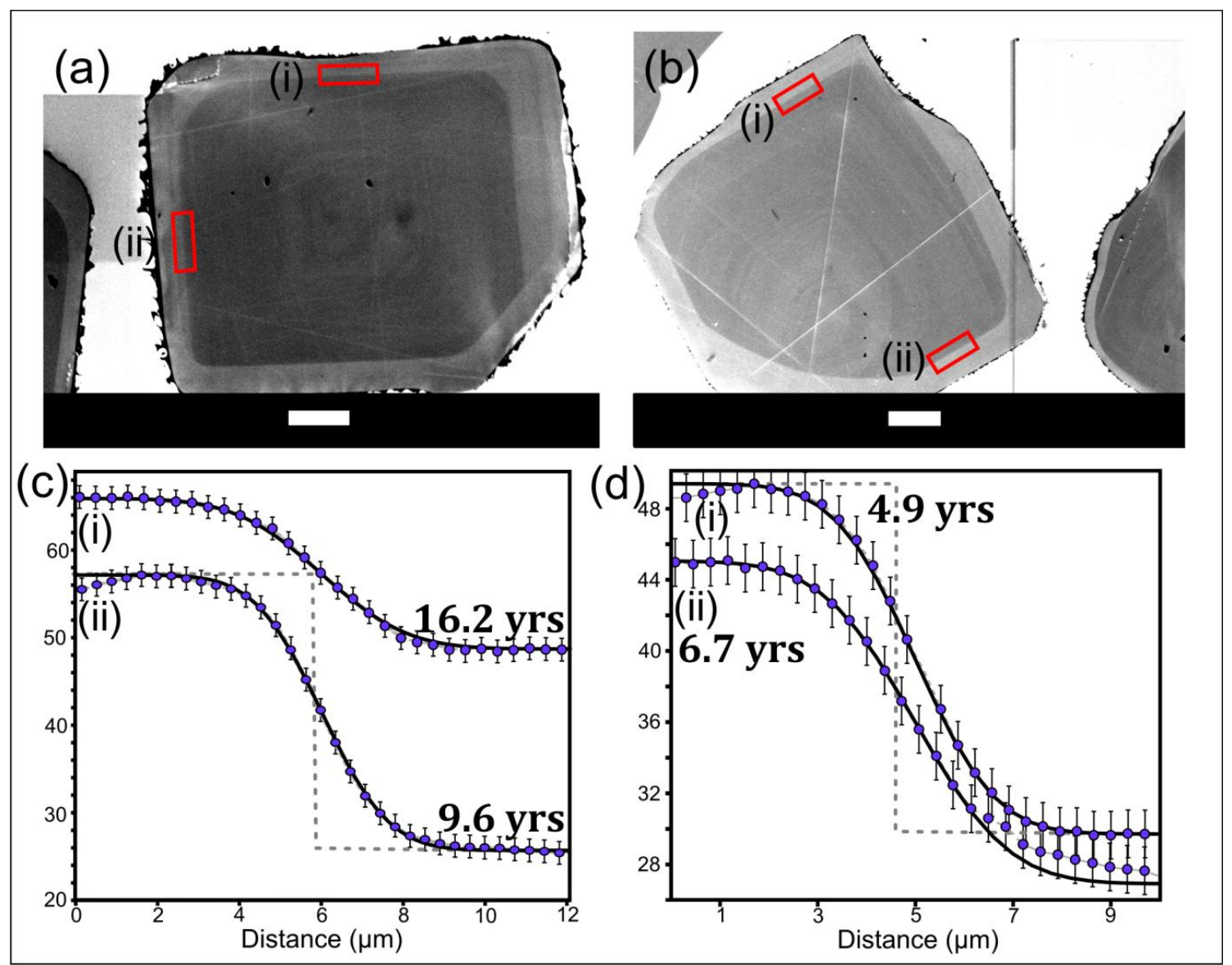

Fig. 4.3. CL images of representative quartz crystals from ignimbrite packages (a) Ig2NWb and (b) Ig2Nb. Areas across which greyscale profiles were extracted are highlighted as red boxes, and their corresponding profiles shown below the images. The modelled profile (age given next to the associated profiles) is shown as a black line, overlying the data (circles, connected by grey dashed line). The y axis for both graphs is relative greyscale values, with $2 \sigma$ uncertainty on greyscale value shown as the error bars. It is apparent that no matter which axis the greyscale profile is extracted from, timescales are comparable. White scale bars are $100 \mu \mathrm{m}$.

resolution achievable from CL images was calculated by modelling the fictive apparent timescale across a known sharp contact, in this case, a crack within a quartz crystal. This yielded a "timescale" of 0.56 years (at $815^{\circ} \mathrm{C}$ ), and therefore any timescales shorter than this are effectively unresolvable via CL imaging and are discounted. The shortest resolvable timescale from our data is thus 1.0 years (+2.4/-0.45 yrs) (Fig. 4.4). All timescales are referred to as "maximum" due to the assumption that the initial boundary between the horizontal concentration profiles was both sharp and oriented perpendicular to the sample surface (see Fig. 4.3 dotted lines), as no angular correction has been applied (Matthews et al., 2012b; Costa \& Morgan, 2010). Changing these assumptions would serve only to shorten the modelled timescales further. 


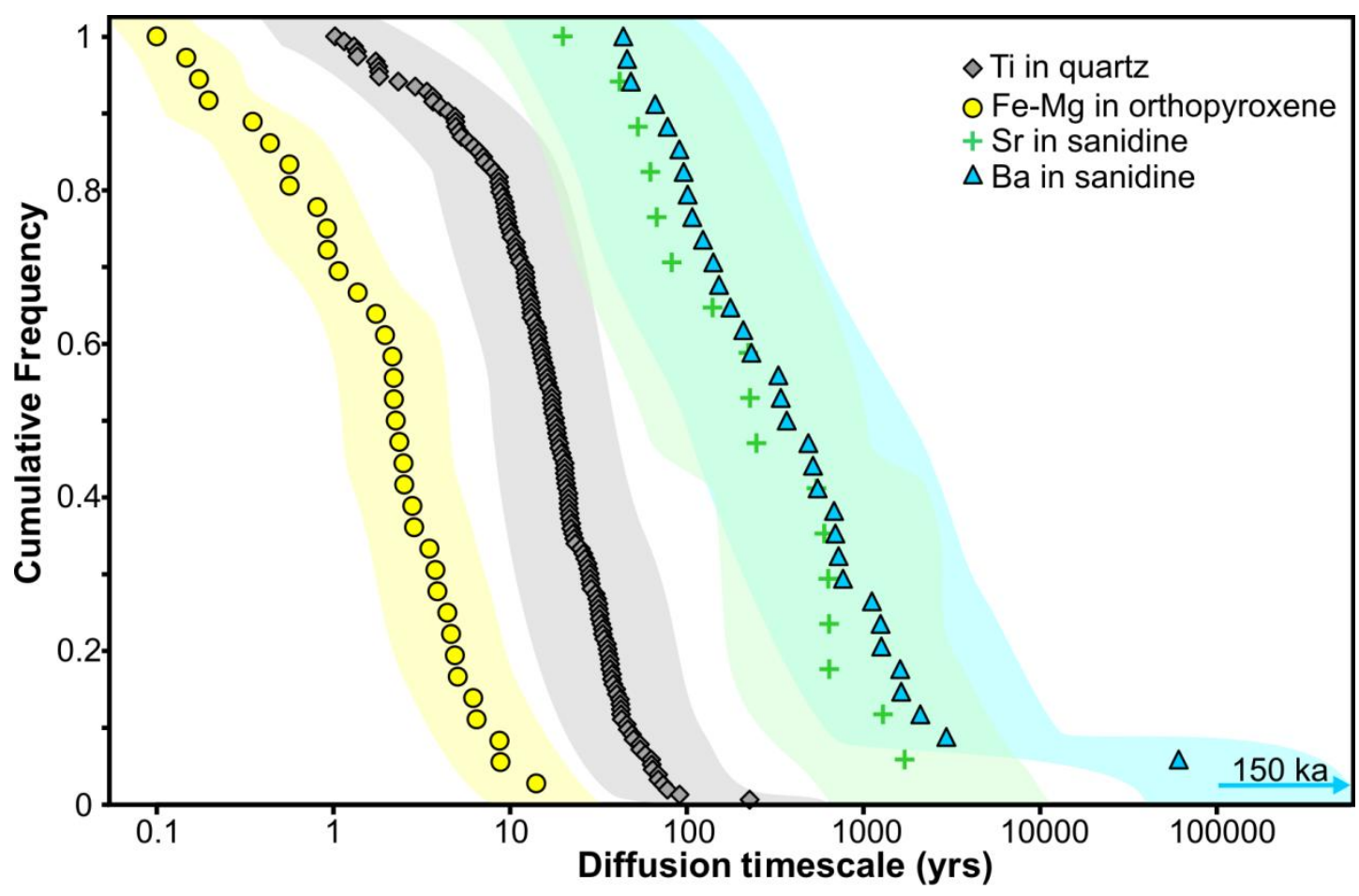

Fig. 4.4. Compiled cumulative frequency plot of modelled timescales from Ti diffusion in quartz (grey diamonds), Fe-Mg interdiffusion in orthopyroxene (yellow circles), Sr in sanidine (green crosses), and $\mathrm{Ba}$ in sanidine (blue triangles). The 1 s.d. uncertainty on each timescale modelled is shown as corresponding fields for each technique: yellow for $\mathrm{Fe}-\mathrm{Mg}$ in orthopyroxene, grey for $\mathrm{Ti}$ in quartz, green for $\mathrm{Sr}$ in sanidine and blue for $\mathrm{Ba}$ in sanidine.

There is no systematic difference in timescales obtained from individual samples or packages, although note that of the eighteen quartz crystals imaged from Ig2SW only two showed a bright overgrowth. In all other late-erupted packages the bright rim development was far more common (see Electronic Appendix 6 for compiled, low resolution images of representative samples; Electronic Appendix 7 for all modelled boundaries in quartz). This pattern is matched in Bishop zircons (Chamberlain et al., 2014a [Chapter 3]) where samples from Ig2SW show only sparsely developed bright rim overgrowths when compared with other late-erupted material from the northern and north-western vents.

\subsubsection{Fe-Mg in orthopyroxene}

There were twelve samples from which orthopyroxene could be extracted (from packages Ig2Nb, Ig2Nc, Ig2NWa and Ig2NWb; note that there was a lack of significant orthopyroxene in $\operatorname{Ig} 2 \mathrm{Na}$ ). Of these, nine produced zoned crystals suitable for modelling for diffusive timescales. The zoning textures in orthopyroxene are not as systematic as those in quartz, but can be split into three groups: unzoned (Fig. 4.5a); darker (i.e. Mg-richer) rims (Fig. 4.5b); and brighter (i.e. Fe-richer) rims (Fig. 4.5c). A direct correlation exists between BSE brightness and Fe-Mg content (e.g. Allan et al., 2013) and is demonstrated for 


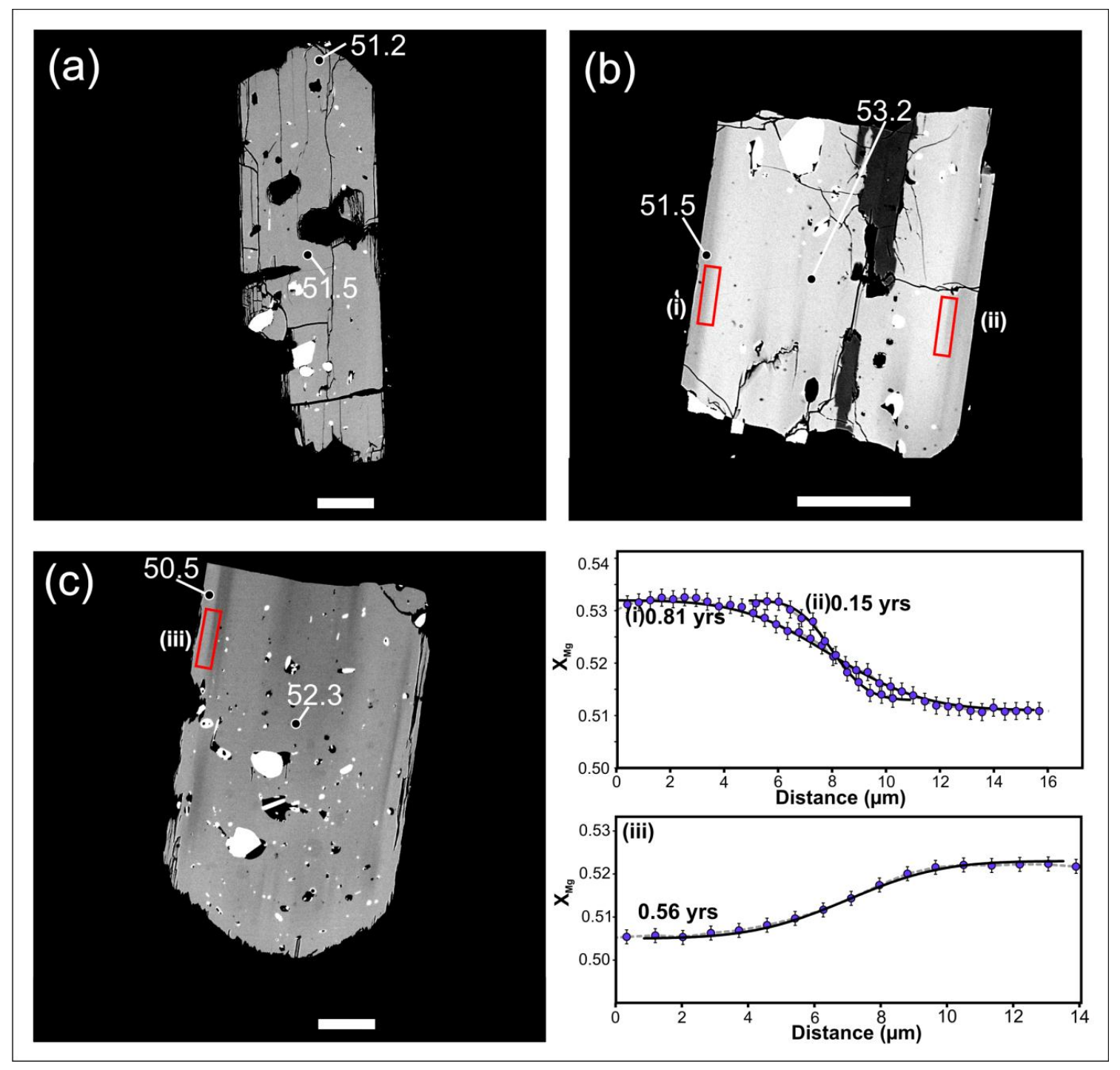

Fig. 4.5. BSE images of orthopyroxene showing the three observed zoning categories, with $\mathrm{Mg} \#$ labelled in white. (a) unzoned; (b) those with a dark rim (more Mg-rich rim); (c) those with a light (more Fe-rich rim). Areas across which greyscale profiles were extracted are shown by red boxes, with the corresponding profiles labelled with (i), (ii) or (iii). The profiles have been corrected to $\mathrm{X}_{\mathrm{Mg}}$ and the modelled timescale is given next to the associated profile. Extracted profiles are shown as circles (connected with a grey line), and the modelled profiles are the black lines. $2 \sigma$ uncertainty on greyscale value (corrected to $\left.\mathrm{X}_{\mathrm{Mg}}\right)$ is shown as the error bars. White scale bar on all images is $100 \mu \mathrm{m}$.

the Bishop samples in Electronic Appendix 5. The variation in $\mathrm{Mg}$ content across the zones is relatively small, only up to $5.4 \mathrm{~mol} \%$ enstatite, with the minimum resolvable change for diffusive modelling in this way being $0.5 \mathrm{~mol} \%$ enstatite

Thirty-six timescales were obtained from diffusive modelling within orthopyroxene crystals following the method of Allan et al. (2013), where different oxygen fugacities $(+0.48 \mathrm{log}$ units to $+1.11 \log$ units, relative to $\mathrm{Ni}-\mathrm{NiO}$ buffer $[\mathrm{NNO}]$ ) were used in combination 
with the range in temperatures $\left(790^{\circ} \mathrm{C}\right.$ or $\left.815^{\circ} \mathrm{C}\right)$. Oxygen fugacity data was taken from Hildreth \& Wilson (2007) and calculated relative to NNO using the formulation from Huebner \& Sato (1970). The maximum resolution for orthopyroxene boundaries was calculated in the same way as for quartz crystals using a crystal edge as the known sharp boundary. The shortest time resolvable by this technique is equivalent to $\sim 0.04$ years, shorter than that from CL images of $\mathrm{Ti}$ in quartz due to the better spatial resolution of BSE imaging and the different values of $\mathrm{D}$ calculated for different diffusion regimes. Boundaries between lower Fe and higher Fe vary in full width from $\sim 4 \mu \mathrm{m}$ to $\sim 30 \mu \mathrm{m}$, giving ranges in maximum timescales of 0.1 year $(+0.1 /-0.05 \mathrm{yrs})$ to 14 years $(+13 /-6.7 \mathrm{yrs}$ :

Fig. 4.4). The mean value of Fe-Mg interdiffusion timescales is 2.8 years, an order of magnitude shorter than that of Ti in quartz, and again shows a dominance of very short timescales ( $<4$ years). Although different textural groups are observed, the timescales do not vary systematically with absolute rim compositions, relative changes in $\mathrm{Mg}$ content (i.e. lighter versus darker rims), or eruptive package. This observation implies that although the resulting rims have slightly different compositions, the process(es) causing the overgrowths occurred over similar timescales (Electronic Appendix 5).

\subsubsection{Ba-in-sanidine}

A total of 52 samples of sanidine crystals were imaged, spanning the entire eruptive sequence from F1 to Ig2Nc (Fig. 4.1). Of these, 15 samples showed sanidine crystals with a bright (higher Ba, Sr) overgrowth (Fig. 4.6). These crystals were found dominantly in samples from the Ig2N and Ig2NW packages (plus single samples from F9 and Ig2SW). As with quartz CL images (see above) the Ig2SW sanidines generally lack bright rims, with only two of twelve crystals having a bright overgrowth. All other early-erupted samples show no zonation (Fig. 4.6a). We cannot replicate the observations by Gualda (2007) and Pamukcu et al. (2012) that some feldspars from Ig2E have bright rims in our ten sample suite from Ig2E pumices (representing a range in crystallinities from vxp to xr- Hildreth \& Wilson, 2007). The minimum resolvable timescale for $\mathrm{Ba}$ in sanidine was calculated using the same method as for orthopyroxene, yielding a value of $\sim 30$ years.

Fifty-four timescales were modelled from the statistically significant profiles (see Methods section) between higher- and lower-Ba zones in sanidine crystals. The width of these boundaries varied from $\sim 4 \mu \mathrm{m}$ to $\sim 40 \mu \mathrm{m}$, yielding maximum timescales that range from 44 years $(+138 /-33$ yrs $)$ to 150,000 years $(+540,000 /-114,000$ yrs $)$, although most are 
commonly on the order of 100s to 10,000s of years (Fig. 4.4; Electronic Appendix 5 for all modelled timescales). The mean value of timescales for Ba diffusion in sanidine is 6770 years, but if the two longest values are removed this is reduced to 600 years. The median value of timescales for $\mathrm{Ba}$ diffusion in sanidine is 350 years. Even though these timescales are considered maxima there remain substantial differences from the modelled timescales of $\mathrm{Ti}$ diffusion in quartz and $\mathrm{Fe}-\mathrm{Mg}$ interdiffusion in orthopyroxene. $\mathrm{Ba}$ diffusion timescales in sanidine appear to be between one and three orders of magnitude longer than those from other two phases (Fig. 4.4).

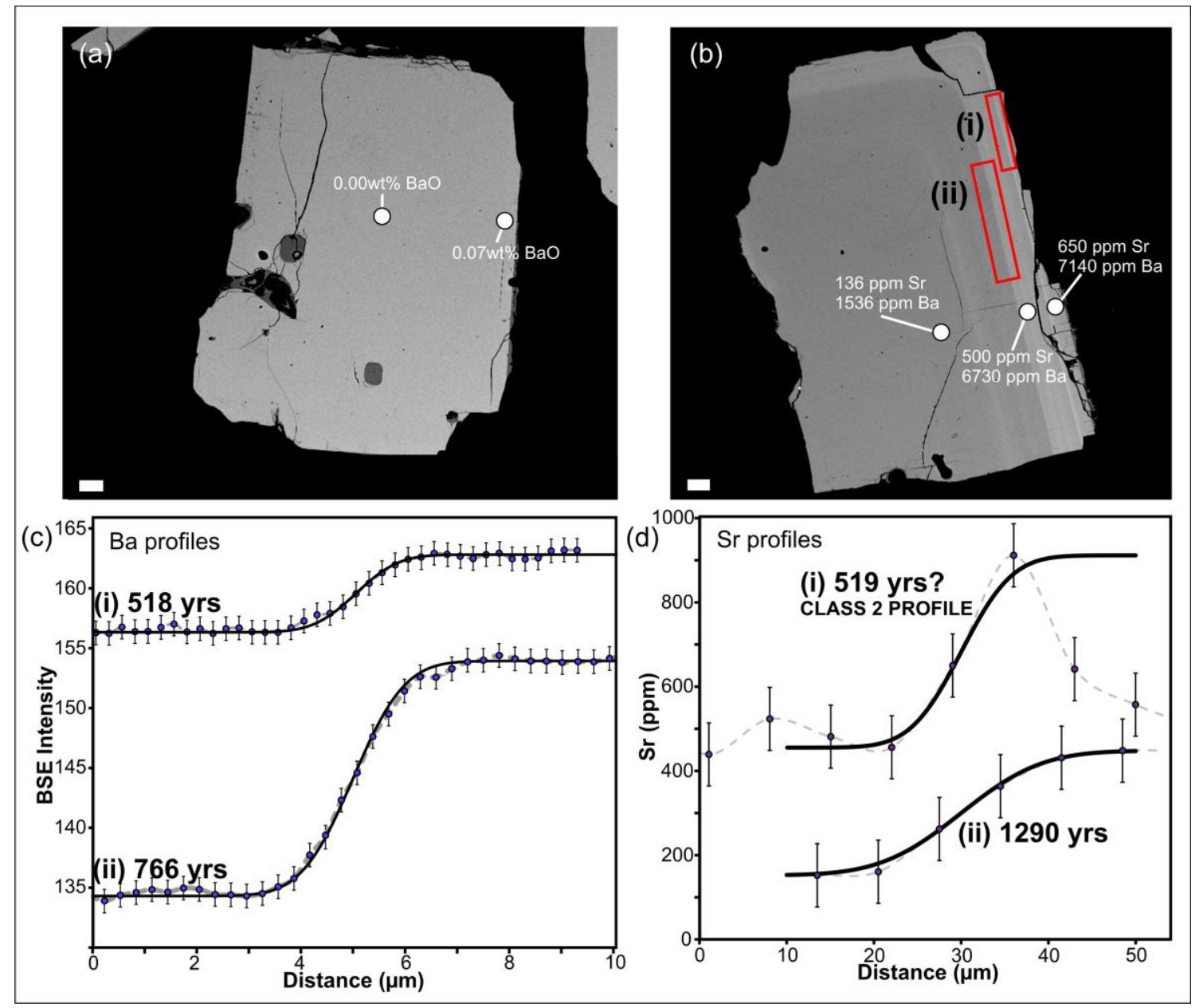

Fig. 4.6. BSE images of sanidine crystals showing representative examples of (a) those which are unzoned and (b) those which have a bright, Ba- and Sr-rich rim. Sr and $\mathrm{Ba}$ contents are labelled in white, from EPMA analyses. Areas over which greyscale profiles were extracted are shown as red boxes, which are labelled to correspond to the profiles shown below. All profiles are plotted as circles, connected with a grey dashed line; the modelled profiles are plotted as black curves. Ba profiles from (b) are shown in c with the $y$ axis being relative grey-scale values, $2 \sigma$ uncertainty on greyscale value plotted as error bars. The associated Sr profiles from EPMA are plotted in d, with 2 s.d. EPMA analytical uncertainties shown. Note the lack of a stable Sr plateau in $(d, i)$ which means that this timescale is not included in our results (see text for discussion of profile classes and Fig. 4.8, below). White scale bars in images (a) and (b) are $100 \mu \mathrm{m}$. 


\subsubsection{Sr-in-sanidine}

In order to assess whether the contrast in $\mathrm{Ba}$-in-sanidine model ages is due to sanidine having a different crystallisation history to quartz and orthopyroxene, or reflects an issue related to the modelling of $\mathrm{Ba}$ behaviour, we undertook comparative modelling of $\mathrm{Sr}$ diffusion in sanidine. Strontium distribution in these sanidines is known to mimic that of Ba (Hildreth, 1977, 1979; Lu, 1991; Lu et al., 1992; Anderson et al., 2000; Hildreth \& Wilson, 2007). With the more rapid diffusion rates of Sr in alkali feldspar (Cherniak \& Watson, 1992), it would be expected that Sr profiles would be over a length scale that could be measured via EPMA or LA-ICPMS. Ten of the 15 examples of Ba-zoned sanidine were selected for investigation. Initial LA-ICPMS measurements were conducted to confirm that the correlations of $\mathrm{Sr}$ and $\mathrm{Ba}$ in zoned sanidines noted by earlier authors ( $\mathrm{Lu}, 1991$; Anderson et al., 2000) were widespread throughout the Bishop Tuff (Fig. 4.7: $\mathrm{R}^{2}$ values of 0.87 for LA-ICPMS and 0.74 for EPMA). Given these positive correlations, a range of diffusion boundaries previously analysed for $\mathrm{Ba}$ were selected for $\mathrm{Sr}$ analysis. Due to the relatively narrow width of the diffusion boundaries $(<50 \mu \mathrm{m})$, LA-ICPMS lacked the spatial resolution to definitively measure $\mathrm{Sr}$ changes across the boundary without serious convolution problems. Although use of NanoSIMS (Saunders et al., 2014) would have been preferable in terms of spatial precision, the short time required to measure a Sr profile

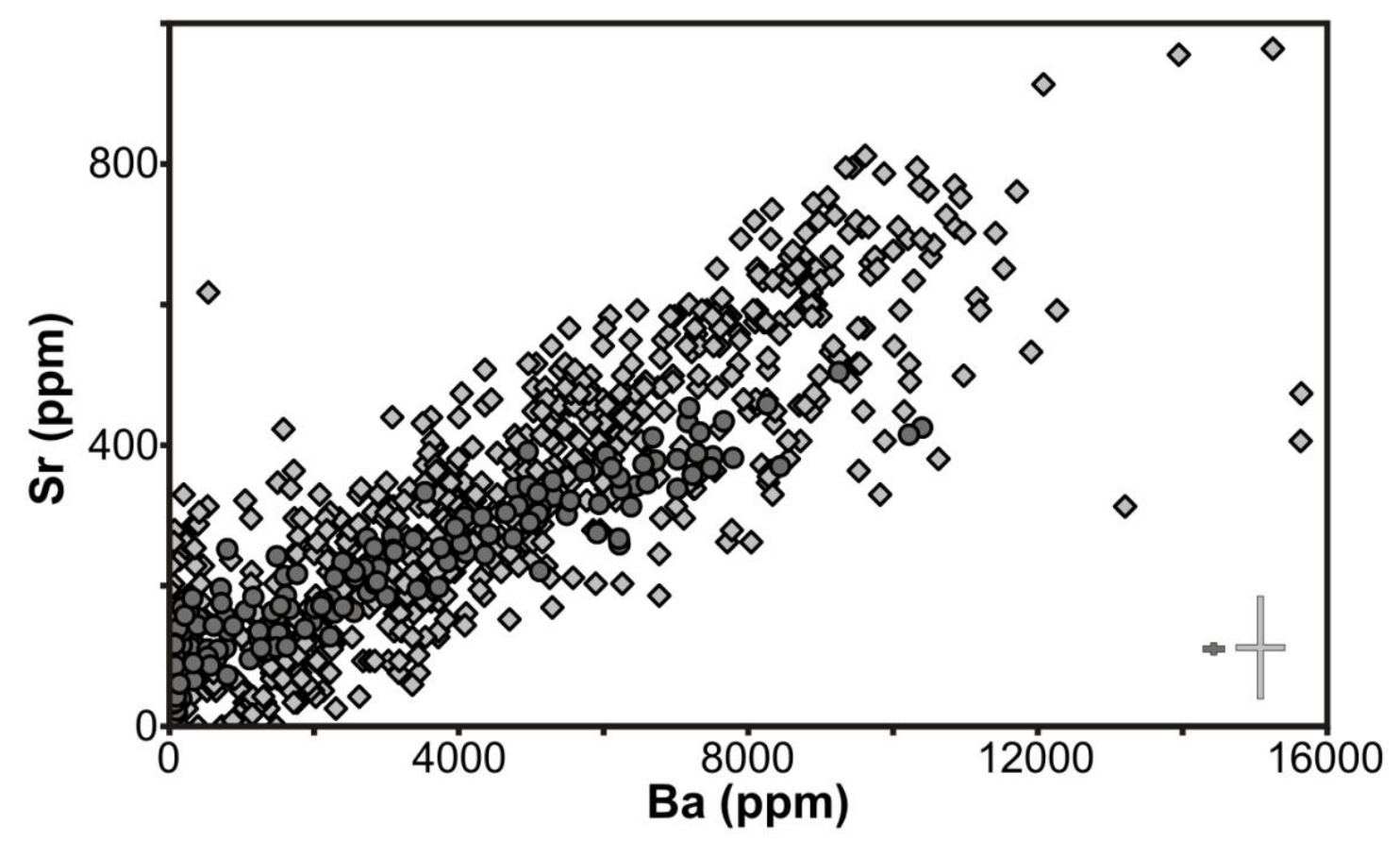

Fig. 4.7. Plot of Ba vs. Sr from LA-ICPMS (dark circles) and EPMA (light diamonds) analyses of sanidine crystals from samples investigated in this study. Error crosses show 2 s.d. uncertainties: the dark grey cross corresponds to LA-ICPMS analyses, the larger light grey cross to EPMA analyses. 
by EPMA $(\sim 1.5 \mathrm{hrs})$ meant that modelling of maximum timescales (reflecting the spatial resolution) across multiple boundaries was relatively straightforward. By using a $40 \mathrm{nA}$ current and long (240 s) count time, our measurement uncertainties were improved to \pm 75 ppm (2 sd), with a detection limit of $150 \mathrm{ppm}(4 \mathrm{sd})$, sufficient to define profiles in 19 grains.

Boundaries for Sr were located using the BSE images, as Sr and Ba were directly correlated (Figs. 4.6, 4.7). Although many boundaries were analysed, only seventeen yielded Sr profiles which were deemed appropriate for diffusion modelling with acceptable definition, and lower degrees of analytical noise (e.g. Fig. 4.6d [i]). Only Sr profiles that were matched by changes in $\mathrm{Ba}$ concentration (from EPMA analyses) were used for modelling, to ensure that the change in $\mathrm{Sr}$ concentration was not an artifact of sub-optimal analytical procedures. The maximum width of these profiles varied between $\sim 5 \mu \mathrm{m}$ and $\sim 50 \mu \mathrm{m}$ which yielded maximum timescales of 19 years $(+65 /-14$ yrs) to 1710 years $(+5790 /-1290$ yrs: Fig. 4.4), with a mean timescale of 430 years. With analysis by EPMA and a defocused beam, these results will necessarily include some convolution, and so these timescales are effectively overestimates but at least provide upper limits for comparative purposes. However, given that the shortest resolvable time is 20 years (across a 2 point jump from plateau to plateau), the maximum convolution introduced will not be greater than 20 years for all modelled timescales.

\subsection{Discussion}

\subsubsection{Temperature stratification within the Bishop magma body}

Many estimates have been presented of magmatic temperatures of the Bishop Tuff. These thermometry calculations have utilised Fe-Ti oxides (Hildreth, 1977, 1979; Hildreth \& Wilson, 2007; Evans \& Bachmann, 2013), Ti concentrations in quartz (Wark et al., 2007; Thomas et al., 2010; Thomas \& Watson, 2012; Wilson et al., 2012), Ti concentrations in zircon (Reid et al., 2011; Chamberlain et al., 2014a [Chapter 3]), $\Delta^{18} \mathrm{O}$ fractionation between crystal phases (Bindeman \& Valley, 2002), and 2-pyroxene compositions (Hildreth, 1979; Frost \& Lindsley, 1992). All of these approaches yield $\sim 100{ }^{\circ} \mathrm{C}$ temperature difference between upper and lower regions in the magma chamber. In contrast, thermodynamic modelling of the Bishop Tuff system has been used to propose a very uniform temperature range (Gualda et al., 2012b). Calculations for thermometry can be somewhat limited as they often involve assumptions about the uniformity of pre-eruptive melt conditions (e.g. $a \mathrm{TiO}_{2}$ 
for Ti-in-quartz and Ti-in-zircon), or reveal only the most recent thermal stratification within the magma chamber [e.g. Fe-Ti oxides re-equilibrate rapidly and so cannot preserve evidence of any longer-term history (Buddington \& Lindsley, 1964; Hammond \& Taylor, 1982; Ghiorso \& Sack, 1991)]. By utilising two-feldspar thermometry we avoid entering into ongoing debates over the use of Fe-Ti oxide and $\mathrm{Ti}$ in quartz thermometry (cf. Thomas et al., 2010; Wilson et al., 2012; Evans \& Bachmann, 2013; Ghiorso \& Gualda, 2013), although our conclusions are similar to those previously proposed regarding thermal gradients within the Bishop magma body (Bindeman \& Valley, 2002; Hildreth \& Wilson, 2007). Our two-feldspar thermometry does not make any assumptions other than that the two feldspars were in equilibrium with each other at the time of inclusion. The feldspar thermometer is not reset quickly due to the relatively slow diffusion timescales for $\mathrm{Ca}, \mathrm{Na}$ and $\mathrm{K}$ within feldspar crystals and the need for coupled substitution of $\mathrm{Al}$ and $\mathrm{Si}$ for charge balance (Cherniak, 2010). We therefore infer that our temperatures accurately record the magmatic temperatures at the point of crystallisation. All inclusion pairs analysed were within the cores of crystals, and have therefore been unaffected by the late-stage mixing with the 'bright-rim' magma (Wark et al., 2007; Chamberlain et al., 2014a [Chapter 3]). As such we can thus investigate any temperature stratification within the Bishop Tuff magma body prior to formation of the bright-rim overgrowths seen on quartz, sanidine and zircon.

Our results show that the 'early' units from Ig1Eb through to Ig2Eb (Fig. 4.1) have relatively uniform model temperatures of $740-760{ }^{\circ} \mathrm{C}$ (except for two analyses from Ig2Eb, Fig. 4.2; Table 4.2). This is up to $30^{\circ} \mathrm{C}$ hotter than the reported Fe-Ti oxide and $\Delta^{18} \mathrm{O}$ (qtz-mt) temperatures of $714{ }^{\circ} \mathrm{C}$ (Bindeman \& Valley, 2002; Hildreth \& Wilson, 2007), but is more comparable (when the $\pm 30{ }^{\circ} \mathrm{C}$ uncertainty is considered) with Ti-inquartz analyses which yield temperatures of $720-750{ }^{\circ} \mathrm{C}$ (Wark et al., 2007; Kularatne \& Audetat, 2014). Temperatures then start to increase in samples from Ig2Na, an ignimbrite package which appears to play a transitional role between the cooler, upper and hotter, lower regions of the magma chamber. We observe a general progression within the northern and north-western units to the hottest model temperature of $821{ }^{\circ} \mathrm{C}$ (Fig. 4.2; Table 4.2). The temperatures calculated for cores of late-erupted northern and northwestern units are broadly similar to temperatures calculated from FeTi oxide, $\Delta^{18} \mathrm{O}$ (qtz-mt) and Ti-in-quartz thermometry (Hildreth, 1977, 1979; Bindeman \& Valley, 2002; Hildreth \& Wilson, 2007; Wark et al., 2007), all of which are subject to late stage reequilibration due to mixing with the less-evolved 'bright-rim' magma (for example, in the 
case of Ti-in-quartz the analyses are from within the bright, Ti rich rims). These similarities in model temperatures imply that the 'bright-rim' magma was not in fact significantly hotter than the pre-existing 'normal' Bishop magma. Our data thus support the notion that a general temperature and compositional stratification (Hildreth \& Wilson, 2007, and references therein) existed within the unitary magma chamber prior to introduction of the 'bright-rim’ magma.

In contrast, recent thermodynamic modelling (Gualda et al., 2012b) has led to the assertion that there was no significant thermal gradient through the Bishop Tuff magma chamber (and that in fact there existed two separate magma chambers: Gualda \& Ghiorso, 2013). This modelling suggests that the 'late' Bishop Tuff magma was held at $\sim 760{ }^{\circ} \mathrm{C}$ and that there was a $<30{ }^{\circ} \mathrm{C}$ gradient across the 'late' north and north-western units. We do not find evidence of crystallisation at $760{ }^{\circ} \mathrm{C}$ for any of our 'late' ternary feldspar pairs, apart from those in $\mathrm{Ig} 2 \mathrm{Na}$ (which fills a transitional role with respect to model temperatures), and in turn see evidence for $\sim 80{ }^{\circ} \mathrm{C}$ variation across the erupted Bishop compositions.

\subsubsection{Uncertainties in diffusion chronometry}

The single most important factor in calculating the uncertainties associated with diffusion chronometry is temperature, which has an exponential effect (see equations 4.1 and 4.2) on the timescales modelled via the Arrhenius relationship in equation 4.1 (e.g. Morgan et al., 2006; Allan et al., 2013). Given uncertainties of $\pm 30^{\circ} \mathrm{C}$ in our thermometry estimates, this leads to an asymmetric uncertainty which, for the longer $(+)$ timescale uncertainty, can be numerically more than double the calculated timescale (from modelling at the low temperature from uncertainties: see Electronic Appendix 10 for all timescales and relative uncertainties). Uncertainties in $D_{0}$ and $\mathrm{OO}_{2}$ are second order, but still play a considerable role. Uncertainty in $\mathrm{fO}_{2}$ is only considered in relation to $\mathrm{Fe}-\mathrm{Mg}$ interdiffusion modelling, and a value of $\pm 0.3 \log$ units is assumed (following Allan et al., 2013). In the case of Ti in quartz, $\mathrm{Ba}$ in sanidine and $\mathrm{Sr}$ in sanidine we calculate uncertainties of $\pm 0.06,0.12$ and 0.03 $\log$ units (for $\mathrm{Ti}, \mathrm{Ba}$ and $\mathrm{Sr}$, respectively) for $D_{0}$ and $E$ (Electronic Appendix 10). For further discussion on the effects of $\mathrm{T}$ and $\mathrm{fO}_{2}$ variation on orthopyroxene $\mathrm{Fe}-\mathrm{Mg}$ interdiffusion modelling see Allan et al. (2013).

Timescales in this paper are referred to as maximum timescales due to the spatial limitations of constraining the maximum profile width of the zone across which diffusion 
has occurred. Due to either pixel size (a more limited effect) or spot size and spacing (for Sr) the maximum distance across which diffusion has occurred is always likely to be slightly over-estimated. Similarly, by assuming an initial step-change concentration profile, the full width of the profile is assumed to be caused by diffusion, yielding the maximum timescale (see Equation 4.2). These assumptions will be discussed later in relation to sanidine diffusion modelling.

\subsubsection{Trends in diffusion profiles}

Three distinct categories of profile shape are evident on visual inspection of all modelled profiles from all four modelled systems (Fig. 4.8). They can be defined as class 1: ideal diffusion shape, good sigmoid and close fit to modelled profile shape; class 2: profiles with a spike on the side of one boundary, which sets an initially high/low condition on half of the profile; class 3: slightly asymmetric profiles, where one side of the measured profile deviates away from the modelled profile.

We interpret that the class 2 and class 3 profiles generally represent some relict growth zoning which has been overprinted by diffusion and are not ideal for modelling. By their shape they indicate that our initial assumption of the starting profile shape was not correct, and the profile must have started with a width somewhat greater than zero, i.e., less sharp than the modelled step-change. Whilst this is problematic in terms of absolute timescale determination, the true timescale of such a profile cannot exceed the timescale from a simple step profile diffused to the same width. Again, therefore, our choice of model starting condition leads us to an overestimate in timescale, and we can confidently regard the class 2 and class 3 profiles as maxima in the light of this knowledge. Whilst class 2 profiles seem to be quite reproducible in terms of their end results, giving answers close to the more ideal class 1 profiles, we are less confident about class 3, and there is no a priori method to determine how much growth versus diffusion these represent. Whilst they do represent a maximum time constraint, we regard this as very loose, and so the class 3 profiles have been excluded from our accumulated data (but can be found in Electronic Appendices 8 and 10 due to the significant proportion of sanidine crystals which have these class 3 profiles).

The recognition of all three boundary types in $\mathrm{Sr}, \mathrm{Ba}$, $\mathrm{Ti}$ and $\mathrm{Fe}-\mathrm{Mg}$ profiles raises the question as to what processes have caused the preservation of the class 2 and 3 profiles, 


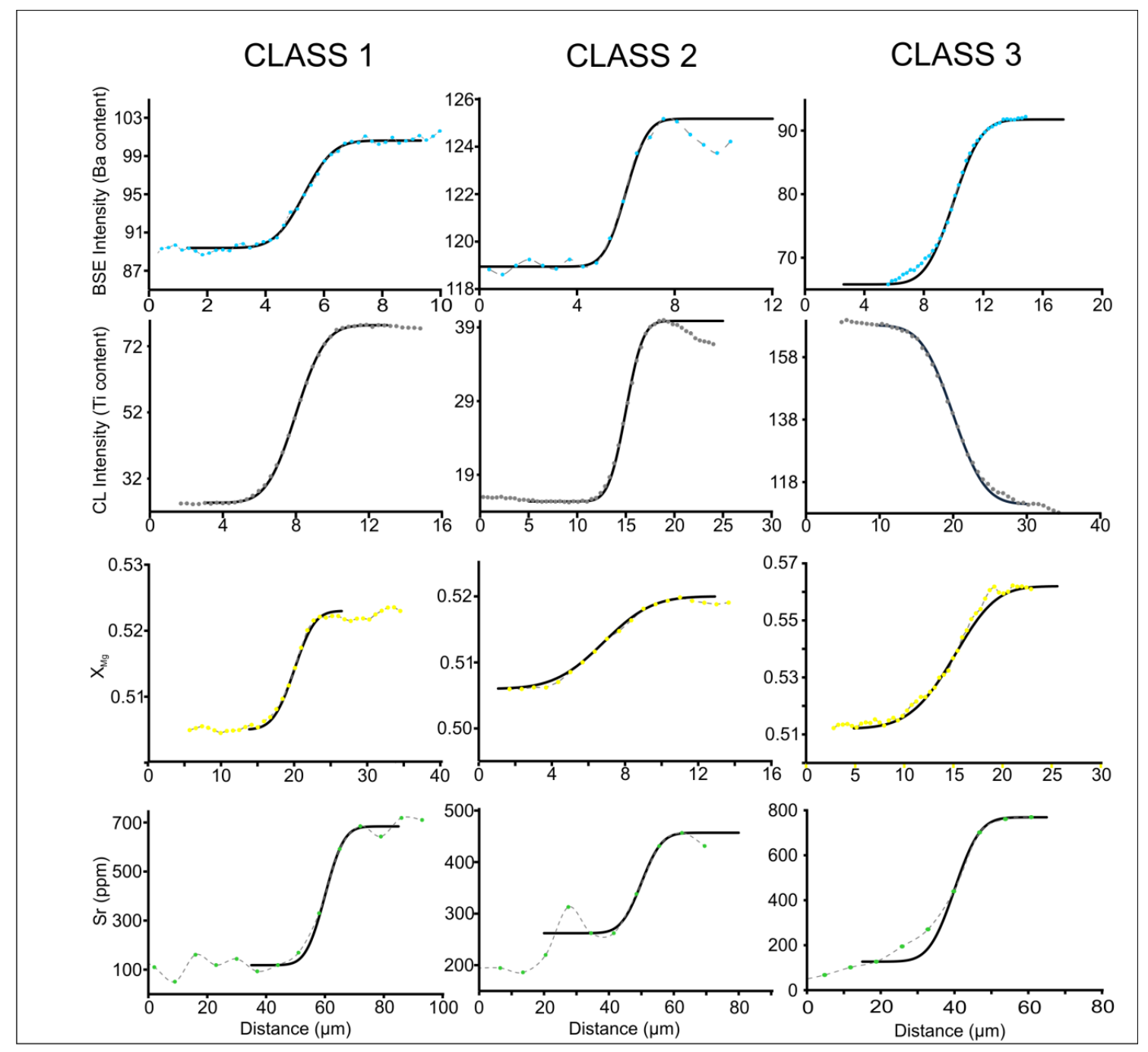

Fig. 4.8. The three classes of diffusion profiles demonstrated in $\mathrm{Ba}$ profiles in sanidine (blue), Ti profiles in quartz (grey), Mg\# number profiles in orthopyroxene (yellow) and $\mathrm{Sr}$ profiles in sanidine (green) (see text for details). All $\mathrm{x}$ axes are distance (in $\mu \mathrm{m}$ ), y axes are concentrations (absolute or inferred) of the element in question. Class 1 is the ideal diffusion profile, being symmetrical and fitting the model (black line) well. Class 2 profiles reveal a false high/low on one side of the profile, where the "plateau" is not horizontal as assumed in the modelling (black line). Class 3 shows the asymmetric boundaries which deviate away from the model (black line) within the concentration gradient. This relict of growth zoning would cause timescales to be over-estimated.

and may yield insights into the precursory processes occurring in the Bishop Tuff magma chamber. Class 2 profiles, with their distinctive peak prior to the diffusion sigmoid, could represent evidence of relict growth zoning due to slow diffusion of cations to the crystalmelt interface (Magaritz \& Hofmann, 1978) or due to depletion in $\mathrm{Ba} / \mathrm{Ti} / \mathrm{Sr} / \mathrm{Fe} / \mathrm{Mg}$ in the boundary layer of melt at the crystal face. They are typically most extreme in Ba profiles, which would suggest the involvement of zone-refining and boundary depletion effects due to the extreme partition coefficient of $\mathrm{Ba}$ in sanidine ( 28.4: Lu, 1991). Class 3 profiles 
raise more challenging issues but, again, are most evident in Ba profiles from sanidine, and thus are likely to preserve evidence of an initial profile which had some component of growth zoning, possibly even caused by Ba retention during dissolution of the core prior to rim growth. Although these three classes of profiles have significantly different appearances, there is no systematic difference in the range of timescales modelled from each mineral-element pair. The identification of all three boundary types in all phases investigated here strongly suggests that the zoning reflects common origins, and that the timescales modelled should be roughly comparable across all phases.

\subsubsection{Contrasts in modelled timescales between crystal phases}

\subsubsection{Modelling diffusion in sanidine}

It is apparent that diffusion modelling of both $\mathrm{Ba}$ and $\mathrm{Sr}$ in sanidine yields much longer timescales, by up to 3 orders of magnitude, than modelling of Ti in quartz and $\mathrm{Fe}-\mathrm{Mg}$ in orthopyroxene. This result matches other studies, for example from profiles obtained from NanoSIMS analyses (Till et al., 2012). One interpretation could be that timescales from modelling of $\mathrm{Ba}$ and $\mathrm{Sr}$ diffusion in sanidine are overestimates (Figs. 4.4 and 4.6). Based on consideration of the applicable diffusivities, the width of Sr boundaries should be $\sim 10$ times wider than those of $\mathrm{Ba}$ (Cherniak, 2002), had these elements been diffusing for similar amounts of time (Table 4.1). This is not always the case (Fig. 4.6; Electronic Appendices 8 and 9) and the widths of the boundaries can be similar. Given the variable nature of the relationship between $\mathrm{Ba}$ and Sr profile widths, and the longer timescales from $\mathrm{Ba}$ and $\mathrm{Sr}$ in sanidine diffusion modelling, there are several possible factors that could cause this discrepancy.

(1). Ba and $\mathrm{Sr}$ are not always being affected in the same way, sometimes not being correlated during crystal growth across the boundary between darker core and brighter rim, and their behaviour may not be related to the change in Ti content in quartz crystals.

(2). The very high activation energy and $D_{0}$ of $\mathrm{Ba}$ and $\mathrm{Sr}$ diffusion in sanidine (Table 4.1) is sensitive to small thermal perturbations (although variably sensitive, due to differences in their diffusion coefficients: Table 1). Short periods of time at elevated temperatures could thus allow $\mathrm{Ba}$ and $\mathrm{Sr}$ to diffuse rapidly, making their timescales appear unusually long.

(3). The initial $\mathrm{Ba}$ and $\mathrm{Sr}$ profiles were not step-like as assumed, and modelling requires a different initial condition with some gradient across the boundary as an initial state from which to model. 
All three of these factors could contribute towards yielding longer timescales, but in practice we can rule out some of these possibilities. If $\mathrm{Ba}$ and $\mathrm{Sr}$ were unrelated in their behaviour, then the overall trends seen in graphs of Ba versus Sr in ICPMS and EPMA data would not be so clear (Fig. 4.7). Glass trace element data shows coupled increases in Ti, Ba and Sr (Hildreth \& Wilson, 2007; Electronic Appendix 12) implying that the high-Ti rims on quartz are related to the high $\mathrm{Ba}$ and $\mathrm{Sr}$ rims on sanidine. These lines of evidence suggests that option (1) is unlikely.

The second option, that the high activation energy of $\mathrm{Ba}$ and $\mathrm{Sr}$ could allow the diffusion behaviours to decorrelate, is also demonstrably unlikely. The high resolution EPMA data shows that the steps are correlated in space, occurring across the same regions. The difference in timescales between sanidine, quartz and orthopyroxene is more reflective of differences in diffusion speed than discrepancies in profile width. For $\mathrm{Ba}$ diffusion to overtake $\mathrm{Ti}$ diffusion would require temperatures around $1100{ }^{\circ} \mathrm{C}$, which is wholly implausible for a rhyolitic magma in which plagioclase-sanidine pairs survived (and lacking any other mineral textural evidence for such high temperatures).

Ti-in-quartz profiles are comparable in width to $\mathrm{Ba}$-in-sanidine profiles, again showing that these $\mathrm{Ba}$ profiles are artificially wide (Ti diffuses faster in quartz than $\mathrm{Ba}$ in sanidine at these conditions: Cherniak, 2002; Cherniak et al., 2007). Given the wide profile of Ba in sanidine it would thus seem likely that the initial assumption of a sharp step function is incorrect for the case of $\mathrm{Ba}$ and $\mathrm{Sr}$ diffusion in sanidine. The timescales modelled are therefore a combination of $\mathrm{Ba}$ and $\mathrm{Sr}$ diffusion, superposed on initially curved $\mathrm{Ba}$ and $\mathrm{Sr}$ starting profiles. This raises questions as to how initially curved $\mathrm{Ba}$ and Sr profiles can be generated in sanidine, but not in other phases, with the effect much more noticeable in $\mathrm{Ba}$ concentration profiles than those of Sr.

The highly compatible nature of $\mathrm{Ba}$ in Bishop Tuff sanidine $\left(\mathrm{K}_{\mathrm{d}} \sim 22\right.$ : Electronic Appendix 12; 28.4: Lu, 1991) means that any partial dissolution of sanidine will lead to an interfacial layer of melt that is enriched in $\mathrm{Ba}$. This interfacial layer will have $\mathrm{Ba}$ concentrations similar to those in the crystal, rather than the lower levels found in the ambient melt, and as a consequence the sanidine crystal cannot be in equilibrium. In response to this situation, the remaining sanidine crystal will, by diffusion, scavenge the $\mathrm{Ba}$ from the melt interface, leading to an enriched zone in the sanidine crystal prior to growth of the Ba-rich bright rim 
on sanidine, that is, a zone-refining process. Sr, with a $\mathrm{K}_{\mathrm{d}}$ of $\sim 9$ (Electronic Appendix 12); $\sim 11.4$ (Lu, 1991) will be similarly affected. The more rapid diffusion of $\mathrm{Sr}$ in sanidine means, however, that this initially curved Sr profile will be broader and less well preserved than for $\mathrm{Ba}$ by the time of eruption. The curvature of the initial starting profile will also have less effect on timescales from diffusion modelling of $\mathrm{Sr}$, as the initial curvature represents less equivalent diffusion time for $\mathrm{Sr}$ than for Ba. From this inference we conclude that both $\mathrm{Ba}$ and $\mathrm{Sr}$ in sanidine will yield over-estimates of time for diffusion, but that for $\mathrm{Ba}$ the timescales recovered will be dominated by the growth curvature, while the Sr profile would contain appreciable components of both diffusion and growth. This conclusion agrees with the trends seen in timescales from $\mathrm{Ba}$ and $\mathrm{Sr}$ diffusion compared with those timescales from Fe-Mg interdiffusion in orthopyroxene and Ti in quartz (Fig. 4.4). Evidence for dissolution of quartz is preserved in CL imagery, where interior zones are truncated against the bright rim overgrowth (Electronic Appendix 6; Peppard et al., 2001; Wark et al., 2007). This texture is replicated in sanidine BSE images, which commonly reveal rounded corners on grains, inferring a similar resorptive process.

In systems where partial dissolution of sanidine could have occurred prior to rim overgrowth, and until its effects on the initial profile of $\mathrm{Ba}$ (and to a lesser extent $\mathrm{Sr}$ ) can be constrained, $\mathrm{Ba}$ and $\mathrm{Sr}$ geospeedometry in low temperature rhyolitic systems (i.e. $<900{ }^{\circ} \mathrm{C}$ : Till et al., 2012) yields discrepancies at $\sim 800-840{ }^{\circ} \mathrm{C}$ and should be treated with caution. It is necessary to bear in mind that a step change in composition is a model assumption, and that at one extreme, diffusion and growth are comparable processes at sub-micron lengthscales, placing a limit on how sharp a profile junction can be. This limit in turn controls how far spatial resolution can reasonably be pushed before the assumptions of diffusion modelling have to be considered for their reliability.

\subsubsection{Removing the "growth" effect}

In order to derive a viable timescale from $\mathrm{Ba}$ and $\mathrm{Sr}$ diffusion in Bishop sanidines, a model to remove the effect of growth on compositional profiles was developed. The profile widths of both $\mathrm{Ba}$ and $\mathrm{Sr}$ in sanidine are interpreted to comprise both a true diffusion component (active for the same times and temperatures whether $\mathrm{Ba}$ or $\mathrm{Sr}$ is considered) and a "growth" component due to partial dissolution prior to overgrowth of the bright rim. Given that for individual profiles of $\mathrm{Ba}$ and Sr across the same boundary within the same crystal, the modelled timescale due to diffusion alone should be the same, and thus by 
Table 4.4. Differences in modelled timescales in sanidine between using combined $\mathrm{Ba}$ and Sr diffusion versus Sr or Ba diffusion alone

\begin{tabular}{|c|c|c|c|c|c|}
\hline Sample & $\begin{array}{l}\text { T used } \\
\text { (K) }\end{array}$ & Boundary & $\begin{array}{c}\text { Combined Timescale } \\
\text { (yrs) }\end{array}$ & $\begin{array}{c}\text { Sr timescale } \\
\text { (yrs) }\end{array}$ & $\begin{array}{c}\text { Ba timescale } \\
\text { (yrs) }\end{array}$ \\
\hline BP124-Ig2NWb & 1088 & k10 outer & 24 & 30 & 78 \\
\hline BP126-Ig2NWb & 1088 & k13-outer & 30 & 39 & 124 \\
\hline BP170- Ig2Nb & 1063 & k16-inner & 64 & 140 & 1250 \\
\hline BP209-Ig2Nc & 1063 & k12 & 77 & 125 & 682 \\
\hline BP124-Ig2NWb & 1088 & k6 & 128 & 223 & 1370 \\
\hline BP115-Ig2NWa & 1088 & k4 & 253 & 268 & 368 \\
\hline BP124-Ig2NWb & 1088 & k10-inner & 367 & 639 & 3940 \\
\hline BP061-lg2Na & 1043 & k4-rhs & 407 & 527 & 1610 \\
\hline BP016-Ig2Nb & 1063 & k12 & 438 & 640 & 2730 \\
\hline BP015-Ig2Nb & 1063 & k18-outer & 484 & 519 & 766 \\
\hline BP060-Ig2Na & 1043 & k16 & 1490 & 1570 & 2100 \\
\hline $\mathrm{BP} 015-\lg 2 \mathrm{Nb}$ & 1063 & k10 & 1540 & 1710 & 2950 \\
\hline
\end{tabular}

Sample numbers and boundaries relate to those used in Electronic Appendix 10.

exploiting differential diffusion speeds, the combined modelling of both $\mathrm{Ba}$ and $\mathrm{Sr}$ diffusion simultaneously should allow for removal of the variable growth component. Twelve paired profiles of $\mathrm{Ba}$ and $\mathrm{Sr}$ were used to test this model, with all the modelled timescales being significantly reduced when compared to the timescales for either $\mathrm{Ba}$ or $\mathrm{Sr}$ alone (Table 4.4). Modelled timescales range from 24 years to 1540 years, with ten of the twelve modelled boundaries yielding timescales of $<500$ years. These values are within an order of magnitude of those from Ti-in-quartz modelling (Figs. 4.9, 4.10). Prior to the combined modelling the average model timescales in these crystals were 1500 (Ba) and 540 years $(\mathrm{Sr}), \sim 63$ times and $\sim 23$ times longer (respectively) than the average Ti-in-quartz model timescales, respectively. The average from combined modelling is now 440 years ( $\sim 19$ times longer than the Ti-in-quartz average), but with the two longest timescales removed this is shortened to only 230 years ( $\sim 10$ times longer than the Ti-in-quartz average).

Given the very high activation energy of both $\mathrm{Ba}$ and $\mathrm{Sr}$ diffusion in sanidine when compared with Ti diffusion in quartz, small temperature changes from those at which diffusion is modelled could allow for closer agreement between the combined $\mathrm{Ba}$ and $\mathrm{Sr}$ timescales and those modelled from Ti in quartz. As temperature is increased, the $\mathrm{Ba}$ and Sr in sanidine combined timescales will decrease faster than, and thus approach those of 


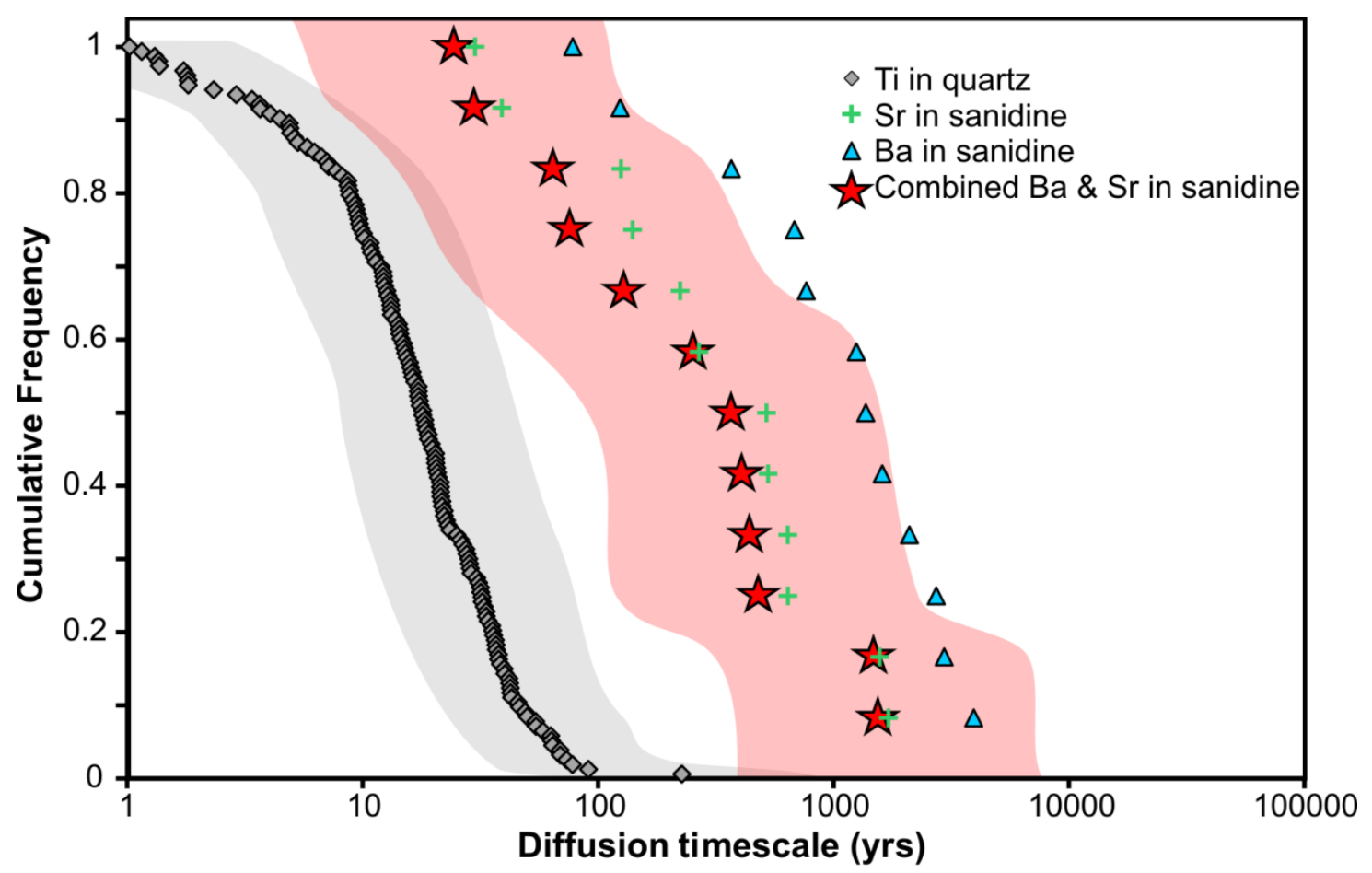

Fig. 4.9. Cumulative frequency plot comparing the timescales modelled from Ti diffusion in quartz (diamonds), and the combined modelling of $\mathrm{Ba}$ and $\mathrm{Sr}$ in sanidine (red stars). The 1 s.d. error window is shown as grey ( $\mathrm{Ti}$ in quartz) or red ( $\mathrm{Ba}$ and $\mathrm{Sr}$ in sanidine) fields. The original timescales from $\mathrm{Sr}$ diffusion in sanidine (crosses) and $\mathrm{Ba}$ diffusion in sanidine (triangles) from the crystals used in the combined modelling are also plotted to show the significant reduction in $\mathrm{Ba}$ timescales once combined modelling is used.

the Ti diffusion in quartz data. It is not, however, possible to completely close the gap with reasonable temperature estimates. The ratio in the timescales falls to a factor of 6 at $\sim 827$ ${ }^{\circ} \mathrm{C}$, an uppermost temperature limit taken from the work of Hildreth \& Wilson (2007) and one that would likely not represent the entire magma body. In order to properly constrain the role of growth zoning, the thermal effect on diffusion in sanidine, and to properly quantify how closely sanidine and quartz timescales agree, further investigation using techniques such as NanoSIMS is needed.

\subsubsection{Comparisons of modelled timescales between crystal phases}

Using the current calibration of the Fe-Mg interdiffusion coefficient within orthopyroxene, diffusion timescales for the Bishop Tuff are extremely short ( $<20$ years: Fig. 4.4). Given the comparable profile groups observed in orthopyroxene, quartz and sanidine (Fig. 4.8), and the phase stability relationships of Naney (1983) it seems valid to infer that the orthopyroxene timescales should be comparable with those from sanidine and quartz. In order for this to be the case, the value of the diffusion coefficients for Fe-Mg interdiffusion would have to be over-estimated by about an order of magnitude (Fig. 4.10). This 
(a) Combined Ti in quartz, $\mathrm{Fe}-\mathrm{Mg}$ in opx and $\mathrm{Ba}+\mathrm{Sr}$ in sanidine

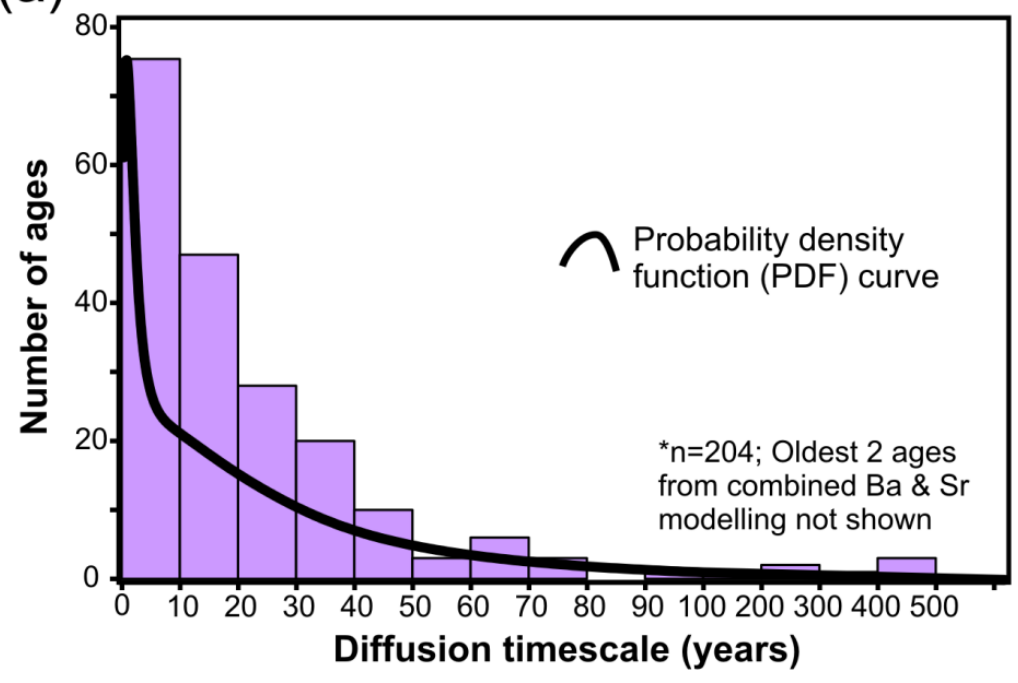

(b) Combined Ti in quartz, Fe-Mg in opx and $\mathrm{Ba}+\mathrm{Sr}$ in sanidine

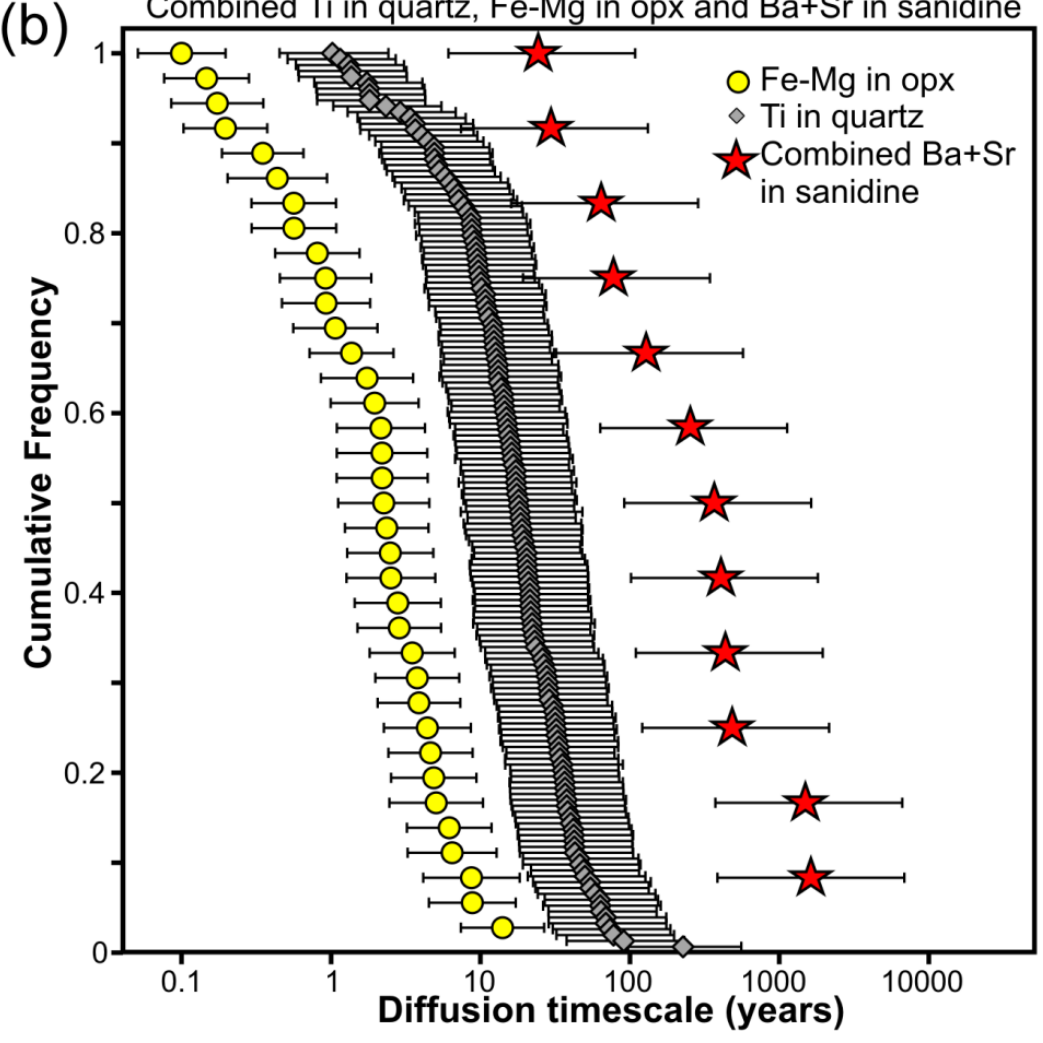

Fig. 4.10. (a) Histogram of all combined diffusion timescales including those from Fe-Mg interdiffusion in orthopyroxene, Ti diffusion in quartz, and combined $\mathrm{Ba}-\mathrm{Sr}$ diffusion in sanidine with (b) cumulative frequency chart showing the timescales and their uncertainties for each method. All uncertainty bars are \pm 1 s.d.

possibility is not surprising in the light of the large range in orthopyroxene diffusion coefficients and calibrations used in the literature (Ganguly \& Tazzoli, 1994; Schwandt et al., 1998). Using the Ganguly \& Tazzoli (1994) calibrations, $D$ values used here are $\sim 1 \mathrm{x}$ $10^{-19} \mathrm{~m}^{2} \mathrm{~s}^{-1}$ to $\sim 1 \times 10^{-20} \mathrm{~m}^{2} \mathrm{~s}^{-1}$. In contrast, using the calibration of Schwandt et al. (1998) $\mathrm{D}$ values at the temperatures used here range from $\sim 1 \times 10^{-22} \mathrm{~m}^{2} \mathrm{~s}^{-1}$ to $\sim 6 \times 10^{-22} \mathrm{~m}^{2} \mathrm{~s}^{-1}$, two to 
three orders of magnitude smaller. Use of the latter figures would result in timescales which are two to three orders of magnitude longer than that calculated in this paper, i.e. up to 14000 years, and which are comparable with the un-corrected $\mathrm{Ba}$-in-sanidine diffusion timescales we derive.

In order to bring the orthopyroxene timescales into alignment with those obtained from $\mathrm{Ti}$ diffusion in quartz, the value of $D$ would need to be $\sim 1 / 5$ of that currently used: $\sim 1-2 \mathrm{x}$ $10^{-20} \mathrm{~m}^{2} \mathrm{~s}^{-1}$ depending on the model temperature $\left(790\right.$ or $\left.815^{\circ} \mathrm{C}\right)$. Following discussion with those conducting experimental research, preliminary findings suggest that the Ganguly \& Tazzoli (1994) formulation with added oxygen dependence we have used may well yield an overestimate of diffusion speed (S. Chakraborty and R. Dohmen, pers. Comm..). Our work suggests that regarding orthopyroxene, the quantification of $D_{0}$ and $E$ for $\mathrm{Fe}-\mathrm{Mg}$ interdiffusion in rhyolitic systems warrants further investigation, as it has significant impacts on the compatibility of timescales modelled from different phases in the Bishop Tuff.

\subsubsection{Pyroxenes and their textural implications}

The diversity of textures observed in orthopyroxene (normal-zoned, bright rim grains, to reversely-zoned, dark rim grains, to those which are unzoned) is not matched by a diversity in timescales. In addition, the rim compositions do not converge towards a single value, unlike that seen in the Oruanui example (Allan et al., 2013). These features raise the issue as to how the process that caused the growth of Fe-richer rims was occurring over the same timescales as that which caused growth of $\mathrm{Mg}$-richer rims. Orthopyroxene with contrasting rim compositions revealing similar timescales has been previously noted at Mt St. Helens (Saunders et al., 2012) where compositional differences were larger than those recorded here ( 8 to $15 \mathrm{~mol} \%$ enstatite variation from cores to rims compared with 0.5 to $5.4 \mathrm{~mol} \%$ enstatite variation in the Bishop orthopyroxenes: Electronic Appendix 5). Saunders et al. (2012) cited intrusion of a more mafic component to cause growth of both reversely-zoned and normally-zoned orthopyroxene, due to changes not only in melt composition, but also volatile contents and $\mathrm{fO}_{2}$. For the Bishop Tuff, there appears to be multiple options for the formation of both Fe-rich and Mg-rich rims (Fig. 4.11), as follows.

Option (1). Mg-richer cores grew at depth within the Bishop magma reservoir, possibly within a crystal-rich mush zone (e.g. Hildreth \& Wilson, 2007) and consequently are slightly 
more enstatite-rich. Concurrently, a Fe-richer population of crystals were growing within the shallower melt-dominant magma chamber from the slightly more evolved melt (Fig. 4.11). When the 'bright-rim' magma intruded the Bishop melt-dominant magma body, it either originated in, or entrained crystals from, the underlying mush zone, bringing the $\mathrm{Mg}$ richer cores into the melt-dominant body. Chaotic, piecemeal mixing within the lower parts of this body (Figs. 4.4 and 4.11) with this 'bright-rim' magma could produce rims of marginally higher or lower $\mathrm{Mg}$ content to crystallise simultaneously, depending on the sense of entrainment from Mg-richer to Mg-poorer melt, or vice versa.

Option (2). The 'bright-rim' magma was not compositionally different in $\mathrm{Fe}$ or $\mathrm{Mg}$ concentrations, but had higher $\mathrm{fO}_{2}$ values and $\mathrm{CO}_{2}$ contents (Wallace et al., 1999). In this scenario, there would be interplay between induced rapid crystallisation of Fe-rich orthopyroxene rims from melts with higher $\mathrm{CO}_{2}$ (Fig. 4.11) and the increased $\mathrm{fO}_{2}$ resulting in crystallisation of more Mg-rich rims (Blundy et al., 2010; Saunders et al., 2012). The interplay between these two factors and the degree of mixing would produce magma which has orthopyroxene with both Fe- and Mg-rich rims.

Option (3). The orthopyroxene crystallised as a result of mixing between the dominant 'normal' Bishop Tuff magma and the 'bright-rim' magma (Fig. 4.11). This would, however, appear to be a less likely explanation, as this would require extremely rapid crystallisation of orthopyroxene (and associated clinopyroxene). Although the timescales for $\mathrm{Fe}-\mathrm{Mg}$ interdiffusion in orthopyroxene are relatively short (using the Ganguly \& Tazzoli [1994] calibration), current investigation suggests that the inaccuracies in constraining the diffusion coefficients could be the cause of these apparently short timescales (S. Chakraborty, pers. comm.). In order to distinguish between options (1) and (2), more detailed investigation into the composition (major and trace elements) of orthopyroxene and other phases in the Bishop Tuff is required.

A major question has been raised in previous studies over the occurrence of pyroxene (both ortho- and clino-) in the Bishop Tuff, with some suggesting that the pyroxenes are not in equilibrium with other crystal phases (e.g. Ghiorso \& Sack, 1991; Frost \& Lindsley, 1992; Evans \& Bachmann, 2013). The euhedral appearance of orthopyroxene (and clinopyroxene) crystals (Fig. 4.5), the similar compositions of inclusions within the orthopyroxenes when compared with free crystals (Hildreth, 1977, 1979) and phase 


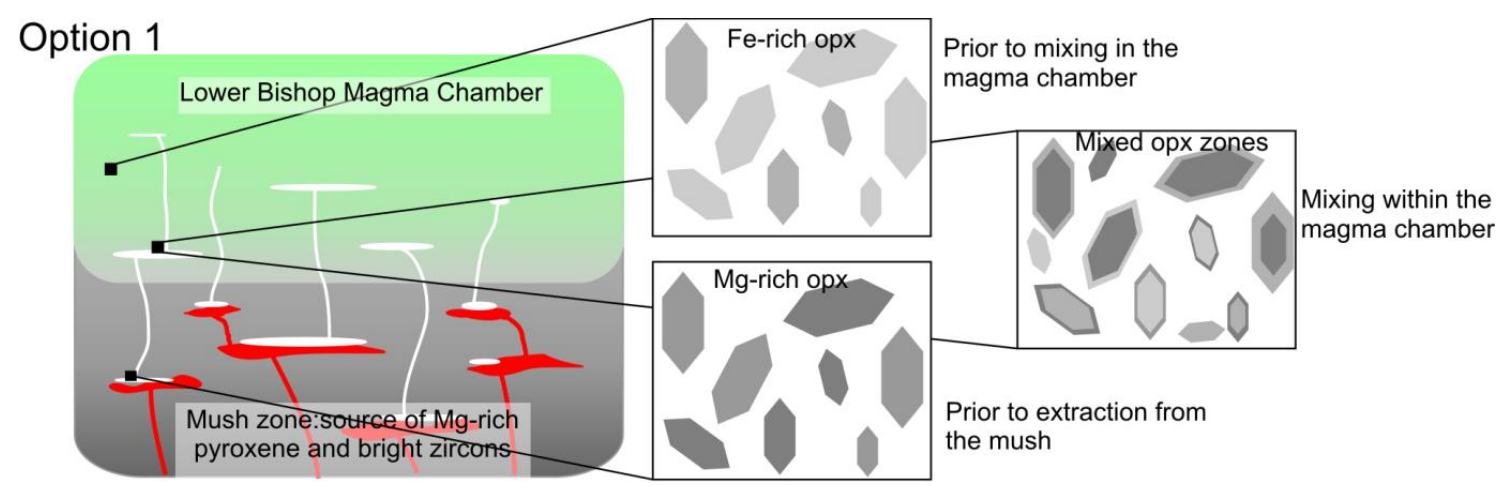

Option 2

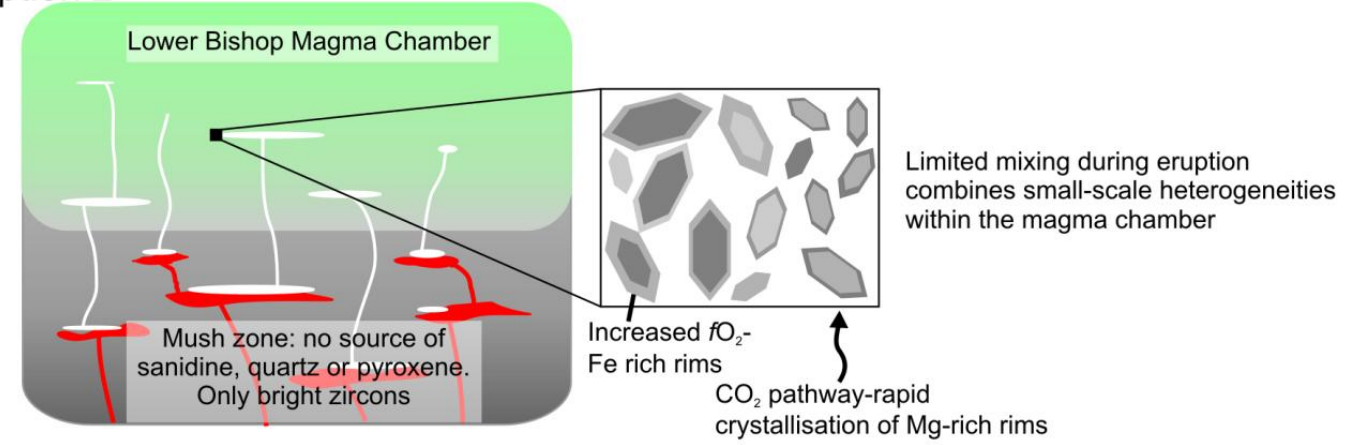

\section{Option 3}

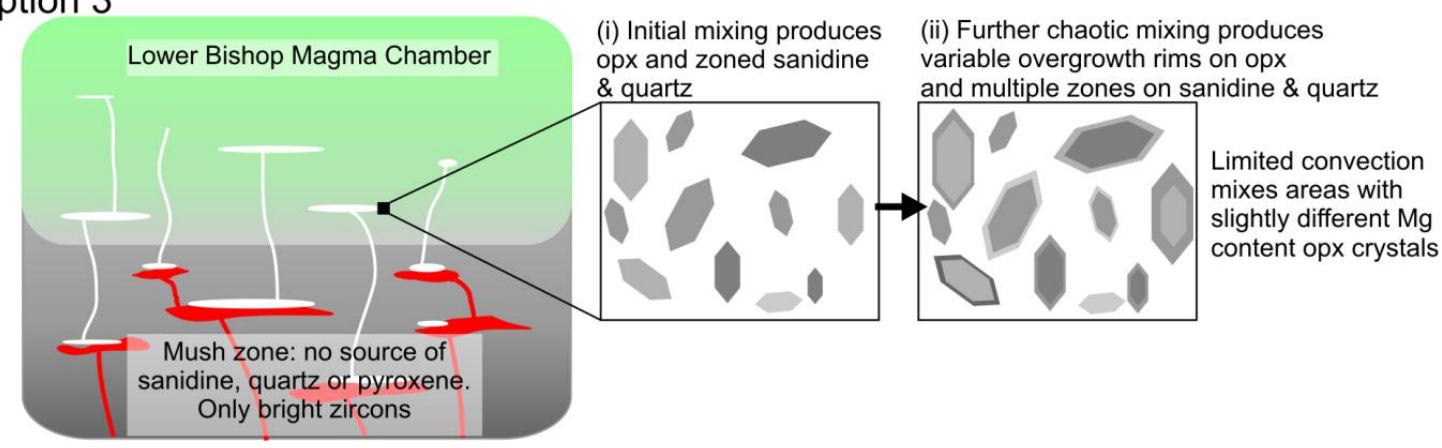

Fig. 4.11. Cartoons illustrating three possible model options (not to scale) for the origin of orthopyroxene and its associated zoning in the Bishop Tuff. Only a segment of the lower part of the magma chamber is depicted (in green) which is intruded by the 'bright rim' forming magma (white) from remelting of the underlying crystal mush (grey) by a more mafic magma (red). In all three models the end result is variably zoned orthopyroxene crystals, but the possible origins for these crystals is changeable. Note that in options 2 and 3 there must be limited convection within the melt-dominant magma body [consistent with the views of Hildreth (1979) and Hildreth \& Wilson (2007)] in order to preserve small-scale heterogeneities within the melt-dominant magma body prior to late-stage mingling upon eruption.

stability relations (Naney, 1983) based on the two-feldspar thermometry presented here counts against them being 'foreign'. In addition, the similarity in groups of diffusion profiles (Fig. 4.8) from all three crystal phases modelled here could be used to suggest that Bishop pyroxene, sanidine and quartz crystals experienced similar controls on growth and diffusion. 


\subsubsection{Rejuvenation of the Bishop magma body}

Many explanations have been put forward for the bright rim overgrowths on quartz and sanidine. Initially it was proposed that these rims grew from sinking of the crystals into less evolved, Ba-, Sr- and Ti-richer magma within the magma chamber (Anderson et al., 2000; Peppard et al., 2001). Studies on melt inclusion entrapment pressures and compositions have however, shown that core and rim inclusions crystallised at comparable pressures, but within varying melt compositions (Wallace et al., 1999; Roberge et al., 2013). These observations imply that introduction of a melt with a slightly different composition underlies the growth of bright rims on quartz and sanidine (Wark et al., 2007; Roberge et al., 2013). The short timescales presented here support this hypothesis of shortly pre-eruptive rejuvenation of lower parts of the Bishop magma chamber by interaction with a melt enriched in Ti, Ba, Sr and $\mathrm{CO}_{2}$ (Wallace et al., 1999; Hildreth \& Wilson, 2007; Wark et al., 2007; Roberge et al., 2013).

Our timescales from quartz, sanidine and orthopyroxene diffusion profiles do not provide any evidence for long-lived (>1000 year) interactions between the 'bright-rim' magma and the resident melt-dominant body. However, zircons from the same samples or eruptive units as those studied in this paper have parallel records of the presence or absence of bright-rim overgrowths, plus sparse numbers of grains wholly crystallised from the 'brightrim' magma (Chamberlain et al., 2014a [Chapter 3]). Age data from sectors of the crystal cores just inside the bright rims suggest that growth of these rims could have commenced up to $\sim 10 \mathrm{kyr}$ before eruption. It is plausible that the longer history of zircon interaction with the 'bright-rim' magma may be tracing crystal growth within the 'bright-rim' magma prior to its later interaction with the main Bishop magma body, and thus provides a maximum time constraint for interaction of the 'bright-rim' magma in the Bishop magma system. In addition, the contrasting timescales recorded of interaction between the zircon, sanidine, quartz and orthopyroxene and the 'bright-rim' magma may reflect a more gradual sequence of events than any immediately pre-eruptive triggering event.

In the sanidine, quartz and orthopyroxene records, intrusion of the 'bright-rim' magma into the main Bishop melt-dominant magma body seems to have consisted of multiple events (at least three, from preserved crystal zonation: Electronic Appendices 5 - 9) which began $\sim 500$ years prior to eruption, as shown by the fairly continuous distribution of timescales that can be calculated from sequentially higher $\mathrm{Ba} / \mathrm{Sr} / \mathrm{Ti}$ profiles within sanidine and 
quartz crystals (e.g. Fig. 4.4; Electronic Appendices 7 and 8). The modelled timescales appear to cluster towards eruption age (Figs. 4.4, 4.10), with $50 \%$ of the timescales being $<18$ years (Ti-in-quartz), $<250$ years (combined $\mathrm{Ba}$ and $\mathrm{Sr}$ in sanidine) and $<2.5$ years (Fe$\mathrm{Mg}$ in orthopyroxene). Although the three suites of model ages have varying absolute values, their cumulative frequency distributions and textural boundary features are closely comparable.

The apparent clustering of timescales closer to eruption could be due to exponential increases in the volume and frequency of magmatic intrusion into the lower magma chamber immediately prior to eruption, which would favour the concept of mixing as an eruptive trigger (Wark et al., 2007). Another possibility, however, is that although rates of ingress of the external 'bright-rim' magma stayed relatively constant, magmatic overturn and increased thermal contrasts between the less-evolved magma and the 'normal' Bishop magma caused increases in mixing within the lower regions of the magma chamber. This would then expose increasing numbers of crystals to a less-evolved (and slightly hotter) melt than that which they initially resided in, generating the shorter timescales and apparent increases in mixing intensity, even if there was not an increasing rate of intrusion into the magma body. Whatever the cause, it is still apparent that rejuvenation (recorded from diffusion modelling in the major mineral phases) and mixing with a melt that was marginally hotter, but enriched in Ti, Sr and Ba occurred over a short timescale $(<500 \mathrm{yrs})$ and continued to cause compositional variation within the Bishop magma chamber until quenched by eruption.

\subsection{Implications and conclusions}

We show that timescales calculated from first order diffusion modelling of $\mathrm{Sr}$ and $\mathrm{Ba}$ in sanidine are 1-3 orders of magnitude longer than Ti diffusion in quartz, which are in turn an order of magnitude longer than timescale from $\mathrm{Fe}-\mathrm{Mg}$ interdiffusion in orthopyroxene. There are no a priori reasons as such for supposing which of the three systems yields the 'correct' result. Recognition of the role of growth zoning in sanidine highlights an incorrect initial assumption of an initially sharp step in $\mathrm{Ba}$ and $\mathrm{Sr}$ contents in this mineral. We have used combined $\mathrm{Ba}$ and $\mathrm{Sr}$ diffusion modelling to remove this growth effect, and the resulting timescales are shortened to become more comparable (to within roughly an order of magnitude) of those modelled from Ti diffusion in quartz. Given the similar nature of diffusion profiles extracted from orthopyroxene images to those from quartz and sanidine 
images we suggest that modelling of $\mathrm{Fe}-\mathrm{Mg}$ interdiffusion in orthopyroxene may produce artificially short timescales. In order for orthopyroxene timescales to align with those in modelled from Ti diffusion in quartz, for example, the calculated values of $D$ would have to be approximately an order of magnitude smaller than those using the Ganguly \& Tazzoli (1994) calibration with $f \mathrm{O}_{2}$ dependence at $\mathrm{T}=\sim 800{ }^{\circ} \mathrm{C}$, but $1-2$ orders of magnitude larger than that of the Schwandt et al. (1998) calibration. Adoption of the latter values would then align the orthopyroxene timescales more closely with those derived from the growthcorrected profiles for $\mathrm{Ba}$ and $\mathrm{Sr}$ in sanidine. These gross disparities highlight the very pressing need in particular for calibration of $\mathrm{Fe}-\mathrm{Mg}$ interdiffusion at temperatures and pressures representative of evolved (particularly rhyolitic) compositions, in order to extract viable and consistent timescales.

Two-feldspar thermometry shows that a temperature stratification of $\sim 80{ }^{\circ} \mathrm{C}$ existed between the upper and lower reaches of the Bishop Tuff magma chamber, and that this stratification was not simply a result of the late-stage intrusion at the base of the magma chamber. This temperature range is similar to that suggested by Fe-Ti oxide and oxygenisotopic thermometry, and supports the model of Hildreth \& Wilson (2007) for a unitary zoned magma chamber for the Bishop Tuff. An important implication arising from the similarity of the temperature estimates is that the intruding 'bright-rim' magma was not significantly hotter than the basal parts of the Bishop magma chamber. Instead it would appear that the intruding magma was enriched in $\mathrm{Ba}$, Ti, $\mathrm{Sr}$ and $\mathrm{CO}_{2}$ (e.g. Wallace et al., 1999; Wark et al., 2007) which has affected crystallisation conditions to cause growth of the bright rims on orthopyroxene, quartz and sanidine (and zircon: Chamberlain et al., 2014a [Chapter 3]).

The similarity of diffusion profile shapes between quartz, orthopyroxene and sanidine and the order of magnitude agreement between sanidine and quartz geospeedometry, indicates that for at least $\sim 500$ years prior to eruption, these phases shared a common history and experienced magmatic intrusion causing the overgrowth of compositionally contrasting rims. It remains an open question as to whether the three major phases are actually recording events with closely similar timings, and that the diversity in model-age ranges reflects systematic errors in the diffusion parameters available at present. An important conclusion of our work is that application of diffusion modelling over multiple co-erupted mineral species is restricted by uncertainties over values for diffusion coefficients in such 
evolved, relatively low-temperature magmatic systems. The alternative end-member inference to explain the diverse zoning patterns and contrasting diffusive timescales is that the crystals are recording different timescales because gradational interaction with the 'bright-rim' magma affected different mineral species now found together within single pumices over different timescales. The great ranges in proportions of zircon crystals with bright rims, and the diversity of development of zircon overgrowths from the 'bright-rim' magma (Chamberlain et al., 2014a [Chapter 3]) support this alternative inference to some extent. These observations would imply that the zircons found within single pumices are mixtures that did not all grow in situ from the host melt represented in that pumice (cf. Hildreth, 1979), and such inferences may also apply to the major mineral phases, at least in the lower portion of the magma chamber which is pyroxene-bearing and has other crystal species with bright rims.

We show from textural proportions that rejuvenation of the Bishop magma chamber had noticeable effects on mineral phases only found in the northern and north-western ignimbrite packages, inferred to represent the deeper, less-evolved parts of the magma body. Rejuvenation by the 'bright-rim' magma was not a single event and, from the timescales measured here in the common mineral phases, occurred over a period of $\sim 500$ years prior to eruption. The longer timescale for interaction of the 'bright-rim' magma (up to $\sim 10$ k.y.) indicated by zircon age spectra from cores to bright-rimmed crystals would imply that the intruding magma was in itself probably not the trigger for the eruption. Instead, its rise into and interaction with the Bishop magma chamber may have reflected other processes, such as changes in the regional stress conditions (cf. Allan et al., 2013) or disturbance of the mush zone by extraction of large volumes of melt. As such the brightrim' magma could be regarded as the marker for processes leading to eruption, rather than the trigger. Our study has important implications not only for models of the Bishop Tuff magma chamber, but also raises significant issues regarding the application of systematic diffusion chronometry to other rhyolitic systems. 
Chapter 5 


\title{
5. New perspectives on the Bishop Tuff magma chamber from crystal and glass chemistries
}

\begin{abstract}
In situ major and trace element analyses of crystals (sanidine, plagioclase, biotite, orthopyroxene, clinopyroxene, where present) and matrix glass are presented from pumice and tephra samples in the Bishop Tuff and two representative Glass Mountain lavas. These data are used to investigate the nature and zonation of the Bishop pre-eruptive magma chamber and its chemical relationship to the Glass Mountain system. Bishop Tuff samples cover the full eruptive sequence from the earliest fall unit (F1) to the latest ignimbrite package (Ig2Nc). Analyses of samples through the Bishop stratigraphy confirm that the magma chamber was thermally and compositionally zoned prior to growth of crystals and before the late-stage intrusion of the 'bright-rim'-forming magma. Rare mixed swirly and dacitic pumices show enrichments in $\mathrm{Ba}$, Sr and $\mathrm{Ti}$, the elements involved in bright-rim overgrowths in crystal phases, and identifies these pumices as possible representatives of the 'bright-rim' magma. Integrated study of crystals and glass from the Bishop Tuff leads to the development of a revised model for the pre-eruptive magma chamber. This model highlights the compositionally and thermally zoned nature of the unitary magma body, which consists of three main parts: the upper, only slightly zoned magma body- the source of units $\operatorname{Ig} 1 \mathrm{E}$ and $\operatorname{Ig} 2 \mathrm{E}$, the middle transition zone which has variable degrees of mixing and sourced $\operatorname{Ig} 2 \mathrm{Na}$ and the Sherwin subunit of Ig1Eb, and the lower, mixed region which is affected by mixing with the 'bright-rim' magma in the lead-up to the eruption, and sourced units Ig2Nb/c and Ig2NW. Ingress of the 'bright-rim' magma introduced high-Ca plagioclase, clinopyroxene and dominantly-bright-rimmed zircon crystals and caused overgrowth of bright rims enriched in $\mathrm{Ti}, \mathrm{Sr}, \mathrm{Ba}$ on sanidine and quartz phenocrysts, and the development of zoning in orthopyroxene crystals. Chemical compositions of Glass Mountain and Bishop Tuff materials show a consanguinity, implying common modes of magma generation. Chronological information obtained from zircon study, however, demonstrates that the generation of Glass Mountain and Bishop eruptible magma bodies were physically and temporally separate events. This research reinforces previous concepts of a single compositionally and thermally zoned magma chamber prior to eruption of the Bishop Tuff.
\end{abstract}




\subsection{Introduction}

The Bishop Tuff in eastern California, is an iconic example of a deposit formed from the eruption of a large ('super-sized') volume $\left(>600 \mathrm{~km}^{3}\right.$; Hildreth \& Wilson, 1997) silicic magma chamber. The deposit has been a focal point for $>35$ years of reconstructions of compositionally and thermally zoned magma chambers. The wealth of analytical investigation that has been undertaken on the Bishop Tuff (including, but not limited to: Hildreth, 1977, 1979; Dunbar \& Hervig, 1992a; Hervig \& Dunbar, 1992; Christensen \& Halliday, 1996; Davies \& Halliday 1998; Wallace et al., 1999; Anderson et al., 2000; Reid \& Coath, 2000; Simon \& Reid, 2005; Hildreth \& Wilson, 2007; Wark et al., 2007; Reid et al., 2011; Gualda et al., 2012a; Pamukcu et al., 2012; Roberge et al., 2013) has led to the Bishop Tuff being used as a case study to build and refine models applied to the origins of largevolume, high-silica rhyolitic volcanism. The tuff was used to both establish and refine the 'mush model' for mechanisms of generation of large volumes of rhyolite melt (Bachmann \& Bergantz, 2004; Hildreth, 2004; Hildreth \& Wilson, 2007; Bachmann \& Bergantz, 2008c) and has been a case study for theoretical models about the origins and state of large, evolved rhyolitic magma bodies (e.g. Fowler \& Spera, 2010; Gualda et al., 2012a). The Bishop Tuff has also been used as a focal point for discussions about the application of the Ti-in-quartz and Fe-Ti-oxide thermometers (e.g. Wark et al., 2007; Thomas et al., 2010; Wilson et al., 2012; Evans \& Bachmann, 2013; Ghiorso \& Gualda, 2013). The dependence of many models for silicic magmatism on data from the Bishop Tuff means that developing an accurate understanding of the timescales of assembly and evacuation of the magma chamber, and the nature and stratification (both thermal and compositional) of the pre-eruptive Bishop magma body is vital. Such an understanding is not only significant in terms of our understanding of Bishop (and surrounding Long Valley) magmatism, but also has major implications for the comparative interpretation of magmatic systems for all highsilica, large-scale volcanism worldwide (see also section 6.3).

Although many authors have investigated the Bishop Tuff, debate still remains regarding various aspects of the Bishop magma system and its relationship to the precursory Glass Mountain activity. This debate has centred around the mineral (rather than glass and melt inclusion) records, which are in turn used to reconstruct intensive variables within the magma chamber. This debate has two main aspects which I address in this chapter. The first of these is the genetic relationship between the precursory Glass Mountain magma system (active from at least 2.2 (possibly 2.8) Ma to $862 \pm 23$ ka: Metz \& Mahood, 1985; 
Sarna-Wojcicki et al., 2005; Chamberlain et al., 2014a [Chapter 3]) and the Bishop magma system. Previously it was thought that the Younger Glass Mountain magma system (1.3 Ma - 862 ka: Metz \& Mahood, 1991; Chamberlain et al., 2014a [Chapter 3]) had evolved seamlessly into the Bishop magma system from three pieces of evidence:

(a) The apparent lack of a significant time gap between the youngest Glass Mountain eruption (previously dated to $790 \pm 20 \mathrm{ka}$ : Metz \& Mahood, 1985) and the Bishop Tuff eruption;

(b) the apparent longevity of the Bishop magma system from studies of Rb-Sr systematics (Christensen \& Halliday, 1996; Davies \& Halliday, 1998), and

(c) the similarity in whole rock compositions between Young Glass Mountain lavas and early-erupted Bishop Tuff pumices (Metz \& Mahood, 1985, 1991).

Investigation into the zircon record for this thesis from both the youngest dated Glass Mountain lava and the Bishop Tuff has revealed systematically different zircon textures, and a greater time gap (from U-Pb dating) between the two eruptions (Chamberlain et al., 2014a [Chapter 3]). By presenting glass and crystal chemistries from the youngest dated Glass Mountain lava along with those of the Bishop Tuff, this comparison is further investigated here.

Separate from the longevity of the Bishop Tuff magma system is the debate surrounding the nature and origins of pressure, temperature and compositional variations within the Bishop Tuff magma body. These variations have been investigated using either compositional variation in crystal phases (and melt inclusions), or thermodynamic models to yield competing (and sometimes contradictory) models for the Bishop magma chamber. Comprehensive petrography and analysis of all crystal phases in the Bishop Tuff was undertaken by Hildreth $(1977,1979)$, and the compositional variations in crystal chemistry were interpreted to reflect growth of crystals in the melt in which they were found. The variations in crystal composition thus were taken to reflect compositional stratification of the Bishop magma chamber, prior to crystallisation, from upper, most-evolved, waterricher, $\mathrm{CO}_{2}$-poorer magma to lower, less-evolved, water-poorer, $\mathrm{CO}_{2}$-richer magma (Hildreth, 1977, 1979; Dunbar \& Hervig, 1992a; Wallace et al., 1999; Hildreth \& Wilson, 2007). This compositional gradient was inferred to be mirrored by a thermal gradient of $\sim 100{ }^{\circ} \mathrm{C}$, with coolest temperatures being at the top of the magma chamber. These temperature estimates have been derived from Fe-Ti-oxide thermometry $\left(714-818{ }^{\circ} \mathrm{C}\right.$ : Hildreth 1977, 1979; Hildreth \& Wilson, 2007; Ghiorso \& Evans, 2008), $\Delta^{18} \mathrm{O}$ (Qtz-mt) 
thermometry $\left(715-815^{\circ} \mathrm{C}\right.$ : Bindeman \& Valley, 2002) and two-feldspar thermometry $(711$ - $821^{\circ} \mathrm{C}$ : Hildreth \& Wilson, 2007; Chamberlain et al., 2014b [Chapter 4]). An interesting facet of the debate arising from crystal-specific studies of the Bishop Tuff is over the presence of orthopyroxene and clinopyroxene in the later-erupted Bishop Tuff units. Some authors infer the pyroxenes to not be in equilibrium with the melt that they are found in or with the other crystal phases, contrary to Hildreth's $(1977,1979)$ conclusions (Andersen \& Lindsley, 1988; Evans \& Bachmann, 2013).

Distinctly different perspectives on the Bishop Tuff magma chamber have arisen also from thermodynamic modelling of samples of the Bishop Tuff. At one extreme, some authors infer that the pyroxenes are in equilibrium with the surrounding melt, but that that Fe-Tioxides are not and that the inferences on pre-eruptive temperatures are flawed (Ghiorso \& Gualda, 2013). Associated Rhyolite-MELTS modelling of the Bishop Tuff is used to assert that there was no thermal gradient within the Bishop magma chamber, with temperatures of $\sim 740{ }^{\circ} \mathrm{C}$ modelled for all investigated samples of the Bishop Tuff, using the analyses of Hildreth (1977) (Gualda et al., 2012a). Furthermore, Rhyolite-MELTS and silica-in-glass barometry have been used to infer that there was no pressure gradient either (contrary to what has been inferred from melt inclusion barometry: Wallace et al., 1999; Anderson et al., 2000; Roberge et al., 2013), and that all Bishop magma resided at $175 \mathrm{MPa}$ (Gualda et al., 2012a; Gualda \& Ghiorso 2013a,b). In the extreme these concepts have been used, in association with perceived bimodality of crystal compositions, to suggest that the Bishop Tuff is the product of the eruption of two chemically distinct and physically separated magma chambers (Gualda \& Ghiorso, 2013a), with analogues drawn from the multiple magma bodies of the Kidnappers (Cooper et al., 2012) and Mamaku/Ohakuri (Gravley et al., 2007) eruptions in New Zealand.

An aspect that is often overlooked, however, in the debates about the nature of the Bishop Tuff magma chamber(s) is that much of the original compositional data for pumices and crystals used dates back to the seminal work of Hildreth (1977, 1979)(e.g. Evans \& Bachmann, 2013). Only Fe-Ti-oxide compositional analyses, and bulk rock XRF analyses have been carried out since (Hildreth \& Wilson, 2007), even though substantial debate, centred on crystal compositions still continues. To address the issues around the nature of the Bishop Tuff magma chamber and its relationship to precursory Glass Mountain activity, I have undertaken detailed analyses of both glass and crystal phases from samples 
which span the entire stratigraphic range of the Bishop Tuff. I also compare my crystal and glass data with detailed age and trace element work from zircons (Chamberlain et al., 2014a [Chapter 3]) and diffusion modelling in sanidine, quartz and orthopyroxene (Chamberlain et al., 2014b, [Chapter 4]). Given the wealth of melt inclusion data already obtained from Bishop Tuff samples (Dunbar \& Hervig, 1992a; Hervig \& Dunbar, 1992; Wallace et al., 1999; Anderson et al., 2000; Roberge et al., 2013) I did not analyse melt inclusions as part of this study. Instead, my phenocryst and glass data are used in consideration with published melt inclusion data by these authors to reveal insights into the composition and stratification within the Bishop Tuff magma body, and to decipher the nature and role of the magma which gave rise to the bright overgrowth rims on sanidine, quartz and zircon.

\subsection{The Bishop Tuff}

The Bishop Tuff was erupted at $767.4 \pm 2.2 \mathrm{ka}$ (Rivera et al., 2011), accompanying the formation of Long Valley caldera in eastern California (Fig. 5.1: Bailey et al., 1976; Hildreth, 1979, 2004; Bailey, 1989; Wilson \& Hildreth, 1997; Hildreth \& Wilson, 2007; Chamberlain et al., 2014a [Chapter 3]). The $>600 \mathrm{~km}^{3}$ of high-silica rhyolite magma is inferred to have been erupted, with possibly one short hiatus, over a period of $\sim 6$ days (Wilson \& Hildreth, 1997). The Bishop Tuff represents the culmination of 3.8 Myr of magmatism in general and $>\sim 1.4 \mathrm{Myr}$ of rhyolitic volcanism in particular in the Long Valley region (Bailey et al., 1976; Metz \& Mahood, 1985, 1991; Metz \& Bailey, 1993; Bailey, 2004; Hildreth, 2004; Sarna-Wojcicki et al., 2005). In its proximal outcrop area between the Sierra Nevada and the White Mountains (Fig. 5.1) the tuff consists of multiple fall units (F1-F9, Fig. 5.2), now preserved within a $90^{\circ}$ sector east of the caldera, and ignimbrite packages $(\operatorname{Ig} 1 \mathrm{Ea}-\operatorname{Ig} 2 \mathrm{Nc}$, Fig. 5.2) which were mostly deposited in two sectors to the north and east of the caldera margin (Fig. 5.1). Lithic assemblages in the tuff link the earliest erupted units to a vent area in the south-eastern part of what became the caldera, and reflect in their changes the subsequent concurrent development of venting along the northern and eastern portions of the caldera ring fracture (Figs. 5.1, 5.2: Hildreth \& Mahood, 1986; Wilson \& Hildreth, 1997).

Through the Bishop Tuff, the types and proportions of pumice change systematically (Hildreth \& Wilson, 2007), in general from the dominance of crystal-poor (xp) pumice in the earlier erupted units (F1-F8; Ig 1 ignimbrite packages deposited to the east of source) to crystal-rich (xr) pumice in the later erupted ignimbrite, deposited mostly north of the 


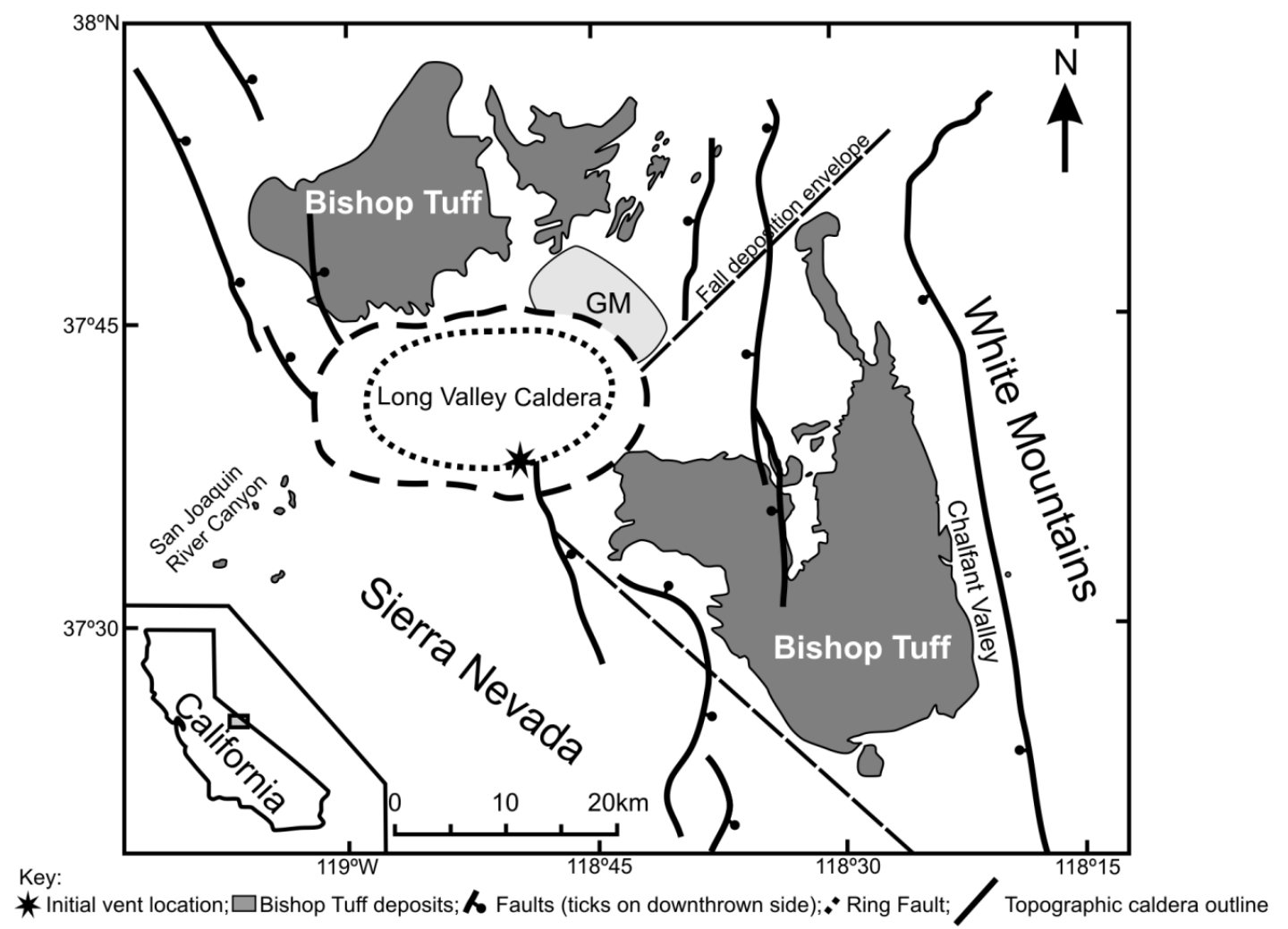

Fig. 5.1. Map of the Long Valley area, eastern California, USA, after Hildreth \& Wilson (2007). The topographic outline of the caldera is shown as a dashed line, with the ring-fault zone shown as a dotted ellipse inside this margin. The approximate initial vent location is shown as a star after Hildreth \& Mahood (1986). Regions of present-day outcrops of Bishop ignimbrite are highlighted in dark grey. The envelope enclosing precursory Glass Mountain (GM) lava domes is shown in light grey. The line marked 'Fall deposition envelope' marks the westerly limits of Bishop fall deposits found in the proximal area shown in this map.

contemporaneous caldera rim. Studies of volatiles in quartz-hosted melt inclusions show a general decrease in $\mathrm{H}_{2} \mathrm{O}$ contents, an increase in $\mathrm{CO}_{2}$ contents and inferred melt inclusion entrapment pressures from earlier, eastern eruptives into later, northern units (Dunbar \& Hervig, 1992a; Wallace et al., 1999). The earlier eastern deposited ignimbrite units, together with their coeval fall deposits, are consequently inferred to represent the top of the magma body (at $\sim 6 \mathrm{~km}$ : Wallace et al., 1999), whereas the later, northern ignimbrite packages are thought to represent magma erupted from deeper (up to $\sim 12 \mathrm{~km}$ : Wallace et al., 1999) in the magma chamber.

Prior to eruption of the Bishop Tuff the rhyolitic Glass Mountain system was in operation from $\sim 2.2 \mathrm{Ma}$ (although possibly earlier - see Chamberlain et al., 2014a [Chapter 3]) to 862 \pm 23 ka producing more than 60 effusive and explosive eruptions (Metz \& Mahood, 1985, 1991; Halliday et al., 1989; Metz \& Bailey, 1993; Hildreth, 2004; Chamberlain et al., 2014a 
(a) Azimuth, degrees
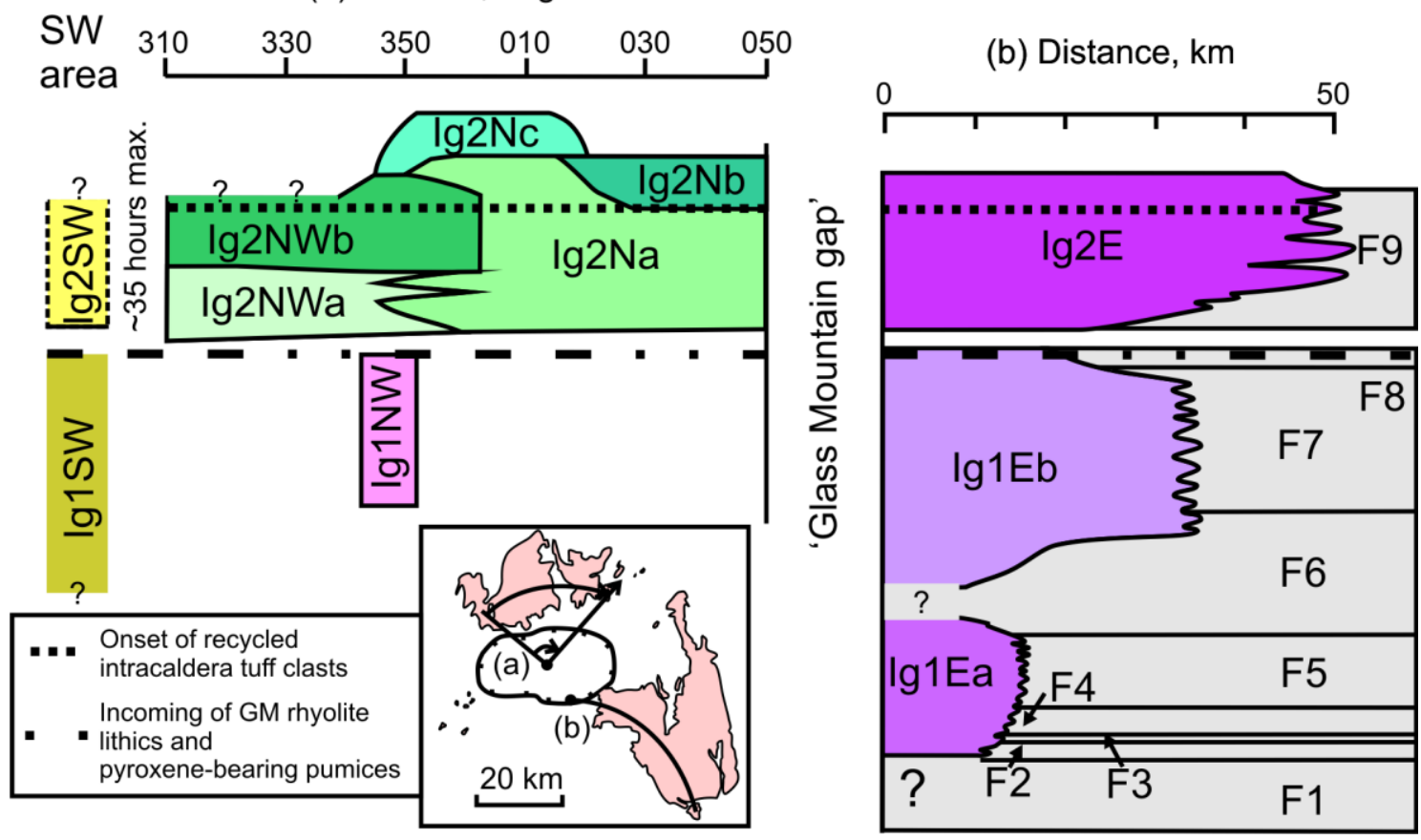

Fig. 5.2. Summary of the stratigraphy of the Bishop Tuff, after Hildreth \& Wilson (2007). Ignimbrite units are coloured: purple for the interpreted 'early' units; green for the interpreted 'late' units. Fall units are in grey. Panel (a) shows a hypothetical cross section from NW to NE across the northern ignimbrite lobes as viewed from the centre of Long Valley caldera. Panel (b) is a schematic proximal to distal cross-section approximately along the line of Owens River Gorge, where the horizontal axis represents distance from the initial vent site of Hildreth \& Mahood (1986). Enlarged stratigraphy figure is also repeated in Appendix 1.

[Chapter 3]). These eruptions built an edifice of domes and associated pyroclastic fans which were partly truncated by the Bishop caldera collapse, but the remaining part of which served to provide a topographic high which divided the northerly and easterlydirected Bishop pyroclastic flows. Glass Mountain activity is separated into two distinct sequences. The Older Glass Mountain $(>2.2 \mathrm{Ma}-1.3 \mathrm{Ma})$ activity produced chemically variable, very highly evolved high-silica $\left(\sim 77\right.$ wt. $\left.\% \mathrm{SiO}_{2}\right)$ rhyolites. The Younger Glass Mountain $(1.2 \mathrm{Ma}-860 \mathrm{ka})$ activity generated larger volumes of more homogenous, and slightly less-evolved high-silica rhyolite, in general with a bulk composition similar to that of the early-erupted Bishop Tuff (Metz \& Mahood, 1985, 1991; Davies et al., 1994; Davies \& Halliday, 1998; Hildreth, 2004). The time gap between eruption of the youngest dated Glass Mountain lava (dome YA) and the Bishop Tuff was long held to be about 30-50 kyr, based on an age (790 $\pm 20 \mathrm{ka})$ obtained by whole K-Ar methods for the lava (Metz \& Mahood, 1985) and eruption age estimates yielded by ${ }^{40} \mathrm{Ar} /{ }^{39} \mathrm{Ar}$ experiments on samples from the Bishop Tuff (e.g. Davies et al., 1994; Sarna-Wojcicki et al., 2000). Interestingly, further investigation into the Bishop Tuff eruption age has yielded estimates of $\sim 767 \mathrm{ka}$ 
(Rivera et al., 2011). Subsequent Ar-Ar ages, and inferences from zircon U-Pb age determinations, has led to suggestions of eruptions ages for the youngest Glass Mountain dome (YA) which are between $875 \mathrm{ka}$ (Simon et al., 2014) and $862 \pm 23 \mathrm{ka}$ (Chamberlain et al., 2014a [Chapter 3]). This has led to the suggestion that development of the Bishop magma body represented a physically separate event from formation of the earlier Glass Mountain magma chamber(s) (Chamberlain et al., 2014a [Chapter 3]).

\subsection{Sampling and analytical techniques}

Sixty samples of the Bishop Tuff and two of precursory Glass Mountain lavas (domes YA and OD) were selected for investigation of glass and phenocryst compositions (Table 5.1). Samples were selected so as to represent all ignimbrite units, as well as fall units 1, 2, 4, 7 and 9 (Fig. 5.2). Pumice samples were chosen to span the range of 'normal' crystal poor (xp) to crystal-rich ( $\mathrm{xr}$ ) clasts, as well as investigating the 'variant' pumice types including those defined as chocolate (dark), swirly and dacitic by Hildreth \& Wilson (2007). Where possible, single pumice clasts were collected for analysis; however, if this was not possible, multiple lapilli-sized pumice clasts were collected. All clasts were cleaned of any adhering matrix prior to sample preparation. Full details of all samples collected and analyses undertaken are in Table 5.1.

Pumice clasts were rough crushed using a Boyd crusher, and then sieved to various size fractions. Crystals were then hand-picked from the 1-2 $\mathrm{mm}$ (feldspars), 0.5-1 mm (biotite, glass) or 250-500 $\mu \mathrm{m}$ (pyroxenes) sieve fractions, before being mounted into epoxy discs and polished to expose the cores of the crystals. Epoxy discs were then carbon coated for imaging and major element analyses. Major element analyses were obtained on a JEOL JXA 8230 electron probe microanalyser (EPMA) at Victoria University of Wellington (VUW) using wavelength-dispersive spectrometry (for individual operating conditions see Chapter 2). Prior to analysis, back-scattered electron (BSE) images were taken of all crystal phases so as to identify zoning patterns and locate analyses accurately. Precision of standard analyses of major elements ( $>5 \mathrm{wt} . \%$ concentration) is nearly always within $5 \%$ (relative percent, $2 \sigma$ ), and accurate to within 1 wt.\% (absolute) for minor elements (1-5 wt.\%). For biotite, analyses with totals less than 95 wt.\% were deleted. Similarly, glass analyses with totals of less than 93 wt.\% were set aside and not used; values for acceptable analyses were then normalised to $100 \mathrm{wt} . \%$. 
Table 5.1: Samples studied for this thesis

\begin{tabular}{|c|c|c|c|c|c|c|c|c|}
\hline $\begin{array}{l}\text { Sample } \\
\text { Number }\end{array}$ & Unit & Type & $\begin{array}{l}\text { Sanidine } \\
\text { (\% zoned) }\end{array}$ & Plagioclase & Glass & Biotite & Orthopyroxene & Clinopyroxene \\
\hline BP003 & $\lg 2 \mathrm{~Eb}$ & $\mathrm{xm}$ & $x(0)$ & $x$ & $x$ & $x$ & N/A & $\mathrm{N} / \mathrm{A}$ \\
\hline BP004 & $\lg 2 \mathrm{~Eb}$ & $\mathrm{xm}$ & $x(0)$ & $x$ & $x$ & $x$ & N/A & N/A \\
\hline BP015 & $\lg 2 \mathrm{Nb}$ & $\mathrm{xr}$ & $x(78)$ & $x$ & $x$ & $x$ & $x$ & $x$ \\
\hline BP016 & $\lg 2 \mathrm{Nb}$ & $\mathrm{xr}$ & $x(45)$ & $x$ & $x$ & $x$ & $x$ & $x$ \\
\hline BP019 & Ig1Eb (Watt.) & sw-xp & $x(0)$ & $x$ & $x$ & & N/A & $N / A$ \\
\hline ВР030 & $\lg 1 \mathrm{~Eb}$ & vxr & $x(0)$ & $x$ & & & N/A & N/A \\
\hline ВР032 & $\lg 1 \mathrm{~Eb}$ & $d k-x p$ & $x(10)$ & $x$ & $x$ & & N/A & N/A \\
\hline BP036 & Ig1Eb (Sher.) & $\mathrm{xr}$ & $x(0)$ & $x$ & $x$ & & N/A & N/A \\
\hline ВР039 & Ig1Eb (Sher.) & $\mathrm{xr}$ & & & $x$ & & N/A & N/A \\
\hline ВР040 & Ig1Eb (Sher.) & $\mathrm{xr}$ & $x(0)$ & $x$ & $x$ & $x$ & N/A & N/A \\
\hline BP053 & $\lg 2 \mathrm{Na}$ & $\mathrm{xr}$ & $x(44)$ & $x$ & $x$ & $x$ & N/A & N/A \\
\hline BP055 & $\lg 2 \mathrm{Na}$ & $\mathrm{xr}$ & $x(0)$ & $x$ & $x$ & & N/A & N/A \\
\hline BP059 & $\lg 2 \mathrm{Na}$ & vxr & x (19) & $x$ & $x$ & & N/A & N/A \\
\hline BP060 & $\lg 2 \mathrm{Na}$ & $\mathrm{xr}$ & $x(27)$ & $x$ & $x$ & $x$ & N/A & N/A \\
\hline BP061 & $\lg 2 \mathrm{Na}$ & $x p$ & $x(67)$ & & $x$ & $x$ & N/A & N/A \\
\hline BP068 & F7 & $\mathrm{xp}$ & $x(0)$ & $x$ & $x$ & $x$ & N/A & N/A \\
\hline BP075 & $\lg 2 \mathrm{Ea}$ & $x r$ & $x(0)$ & $x$ & $x$ & $x$ & N/A & N/A \\
\hline BP080 & Ig1Eb & vxp & $x(0)$ & $x$ & $x$ & & N/A & N/A \\
\hline BP087 & $\lg 1 \mathrm{~Eb}$ & $x p$ & $x(0)$ & $x$ & $x$ & & N/A & $\mathrm{N} / \mathrm{A}$ \\
\hline BP092 & $\lg 1 \mathrm{~Eb}$ & $\mathrm{xm}$ & & & $x$ & & N/A & N/A \\
\hline BP098 & $\lg 1 \mathrm{~Eb}$ & vxp & $x(0)$ & $x$ & $x$ & & N/A & N/A \\
\hline BP107 & F4 & multi-xp & $x(0)$ & $x$ & $x$ & & N/A & N/A \\
\hline BP108 & $\mathrm{F} 2$ & multi-xp & $x(0)$ & $x$ & $x$ & & N/A & $\mathrm{N} / \mathrm{A}$ \\
\hline BP109 & $\mathrm{F} 1$ & multi-xp & $x(0)$ & $x$ & $x$ & & N/A & N/A \\
\hline BP112 & Ig1NW & multi-xm & $x(0)$ & $x$ & $x$ & $x$ & N/A & N/A \\
\hline BP115 & $\lg 2 \mathrm{NWa}$ & vxr & $x(15)$ & $x$ & $x$ & $x$ & $x$ & $x$ \\
\hline BP118 & $\lg 2 \mathrm{NWa}$ & vxr & $x(17)$ & $x$ & $x$ & $x$ & N/A & N/A \\
\hline BP120 & Ig2NWa & vxp & $x(100)$ & $x$ & $x$ & $x$ & & \\
\hline BP122 & Ig2NWb & sw-vxp & & & $x$ & & $x$ & $x$ \\
\hline BP124 & Ig $2 N W b$ & $\mathrm{xr}$ & $x(67)$ & $x$ & $x$ & $x$ & $x$ & $x$ \\
\hline BP126 & Ig2NWb & sw & $x(79)$ & $x$ & & $x$ & $x$ & $x$ \\
\hline BP129 & $\lg 2 \mathrm{NWb}$ & $\mathrm{xr}$ & & & $x$ & & $x$ & $x$ \\
\hline BP130 & Ig1SW & multi-xp & $x(0)$ & $x$ & $x$ & $x$ & N/A & N/A \\
\hline BP132 & $\lg 1 \mathrm{Ea}$ & $\mathrm{xp}$ & $x(0)$ & $x$ & $x$ & $x$ & N/A & N/A \\
\hline BP148 & F9 & multi-range & & & $x$ & & N/A & N/A \\
\hline BP149 & F7 & $\mathrm{xp}$ & $x(0)$ & $x$ & $x$ & $x$ & N/A & N/A \\
\hline BP151 & F7 & $\mathrm{xp}$ & & & $x$ & & N/A & $N / A$ \\
\hline BP158 & F7 & $x p$ & $x(0)$ & $x$ & & & N/A & N/A \\
\hline BP160 & F9 & multi-xm & $x(40)$ & $x$ & $x$ & & N/A & $\mathrm{N} / \mathrm{A}$ \\
\hline BP164 & $\lg 2 \mathrm{~Eb}$ & $\mathrm{xm}$ & $x(0)$ & $x$ & $x$ & $x$ & N/A & N/A \\
\hline BP167 & $\lg 2 \mathrm{Nb}$ & $\mathrm{xr}$ & & & $x$ & $x$ & & $x$ \\
\hline BP169 & $\lg 2 \mathrm{Nb}$ & $\mathrm{xm}$ & $x(56)$ & $x$ & $x$ & $x$ & & \\
\hline BP170 & $\lg 2 \mathrm{Nb}$ & $\mathrm{xr}$ & $x(87)$ & $x$ & $x$ & $x$ & $x$ & $x$ \\
\hline BP172 & $\lg 2 \mathrm{Nb}$ & sw-vxp & $x(17)$ & $x$ & $x$ & & N/A & N/A \\
\hline BP197 & $\lg 2 \mathrm{Ea}$ & sw-vxp & $x(0)$ & $x$ & $x$ & & N/A & $N / A$ \\
\hline BP198 & $\lg 2 \mathrm{Ea}$ & sw-vxp & $x(0)$ & $x$ & $x$ & & N/A & N/A \\
\hline BP209 & $\lg 2 \mathrm{Nc}$ & $\mathrm{xr}$ & $x(80)$ & & $x$ & $x$ & $x$ & $x$ \\
\hline BP211 & $\lg 2 \mathrm{NWb}$ & dc-xr & $\times(54)$ & & $x$ & & N/A & N/A \\
\hline BP214 & Ig2NWb & dc-xp & $x(67)$ & & $x$ & & N/A & N/A \\
\hline BP216 & $\lg 2 \mathrm{SW}$ & multi-xm & $x(0)$ & $x$ & $x$ & $x$ & N/A & N/A \\
\hline BP218 & Ig2NWb & $d k-x p$ & & & $x$ & & N/A & N/A \\
\hline BP220 & $\lg 2 \mathrm{NWb}$ & $d k-x p$ & $x(87)$ & $x$ & $x$ & & $x$ & $x$ \\
\hline BP222 & Ig2NWb & $\mathrm{dk}-\mathrm{xr}$ & $x(94)$ & $x$ & $x$ & & N/A & N/A \\
\hline BP225 & $\lg 2 \mathrm{Nb}$ & sw-xp & $x(50)$ & $x$ & $x$ & & $x$ & $x$ \\
\hline BP230 & $\lg 2 \mathrm{Nb}$ & $d k-v x p$ & $x(0)$ & $x$ & $x$ & & N/A & N/A \\
\hline BP232 & $\lg 2 \mathrm{Nb}$ & sw-vxp & $x(14)$ & $x$ & $x$ & & N/A & N/A \\
\hline BP242 & $\lg 2 \mathrm{~Eb}$ & $\mathrm{xm}$ & $x(0)$ & $x$ & $x$ & & N/A & N/A \\
\hline BP243 & $\lg 2 \mathrm{~Eb}$ & $\mathrm{xr}$ & $x(0)$ & $x$ & $x$ & & N/A & N/A \\
\hline BP244 & $\lg 2 \mathrm{~Eb}$ & $\mathrm{xr}$ & $x(25)$ & $x$ & $x$ & & N/A & N/A \\
\hline BP248 & $\lg 2 \mathrm{~Eb}$ & vxp & $x(0)$ & $x$ & $x$ & & N/A & N/A \\
\hline BR226 & Dome OD & $\mathrm{xr}$ & $x(0)$ & & $x$ & & N/A & N/A \\
\hline BR228 & Dome YA & $x p$ & & & $x$ & & N/A & N/A \\
\hline
\end{tabular}

Unit and type abbreviations after Hildreth \& Wilson (2007). $x$ marks where analyses of the fraction have been made of specific samples. In some cases no plagioclase was present in the hand-picked feldspar fraction, and hence no analyses were made. Watt. = Watterson subunit; Sher. $=$ Sherwin subunit, both in Ig1Eb. 
Trace element analyses were measured in situ using a New Wave deep UV laser (193 nm solid state) coupled to an Agilent $7500 \mathrm{cs}$ inductively coupled plasma mass spectrometer (ICPMS). The laser ablation (LA) - ICPMS data was internally normalized to ${ }^{29} \mathrm{Si}$ or ${ }^{43} \mathrm{Ca}$ from EPMA analyses. Abundances of single trace elements were calculated relative to a bracketing standard (NIST 612 or BCR-2G) which was analysed throughout the run under identical conditions. Precision and accuracies varied depending on the analytical conditions but generally have $<5 \%(2 \sigma)$ uncertainty on elements with abundances of $>20 \mathrm{ppm}$ (see Chapter 2 for full estimates of analytical precision and accuracy).

\subsection{Results}

Results from both EPMA and LA-ICPMS analyses of crystals and glass separates from multiple units of the Bishop Tuff (Table 5.1) are detailed here. For clarity, I refer to 'normal' pumice (or glass) as being from samples which fall into the normal xp-xr suite defined by Hildreth \& Wilson (2007). 'Variant' pumice samples, which can be swirly, dark or dacitic in character, are again based on the classification of Hildreth \& Wilson (2007).

\subsubsection{Sanidine}

Sanidine is one of the two most abundant crystal species in the Bishop Tuff, making up $\sim 40 \%$ of the crystal population (Hildreth, 1977, 1979; Hildreth \& Wilson, 2007). Sanidine crystals from eastern units are dominantly unzoned under BSE (Fig. 5.3) and the lack of compositional variation was confirmed in representative grains by EPMA analyses (Fig. 5.4). Of 28 samples of all eastern and most fall (units F1 - F8) material, only two (BP032 and BP244) contained any sanidine grains with bright rims in BSE imagery (see Table 5.1) where the bright rims reflect increased concentrations of $\mathrm{Ba}$ and $\mathrm{Sr}$ (Chamberlain et al., 2014b [Chapter 4]). Within these two samples, the bright-rimmed sanidine crystals constituted $10-25 \%$ of the population imaged.

Fig. 5.3. (Opposite) Representative images to show the range of textural variation in the common mineral phases in Bishop pumices (see Chamberlain et al., 2014a [Chapter 3], for zircon zonation patterns). Panel (a) shows the four different types of sanidine zoning identified from BSE imagery, and panel (b) shows the normally unzoned plagioclase, and the subordinate oscillatory zoned plagioclase (BSE images). Panel (c) shows the bright CL overgrowths on late quartz crystals and the normal oscillatory zoning in quartz lacking a bright overgrowth. Panels (d) and (e) shows the variations observed in BSE images of pyroxenes ranging from unzoned through to complexly zoned, where a bright in BSE rim represents higher $\mathrm{Fe}$ (and lower $\mathrm{Mg}$ ) content, and a dark in BSE rim represent lower $\mathrm{Fe}$ (and higher $\mathrm{Mg}$ ) content compared with the core. In all images the scale bar is $100 \mu \mathrm{m}$ in length. 


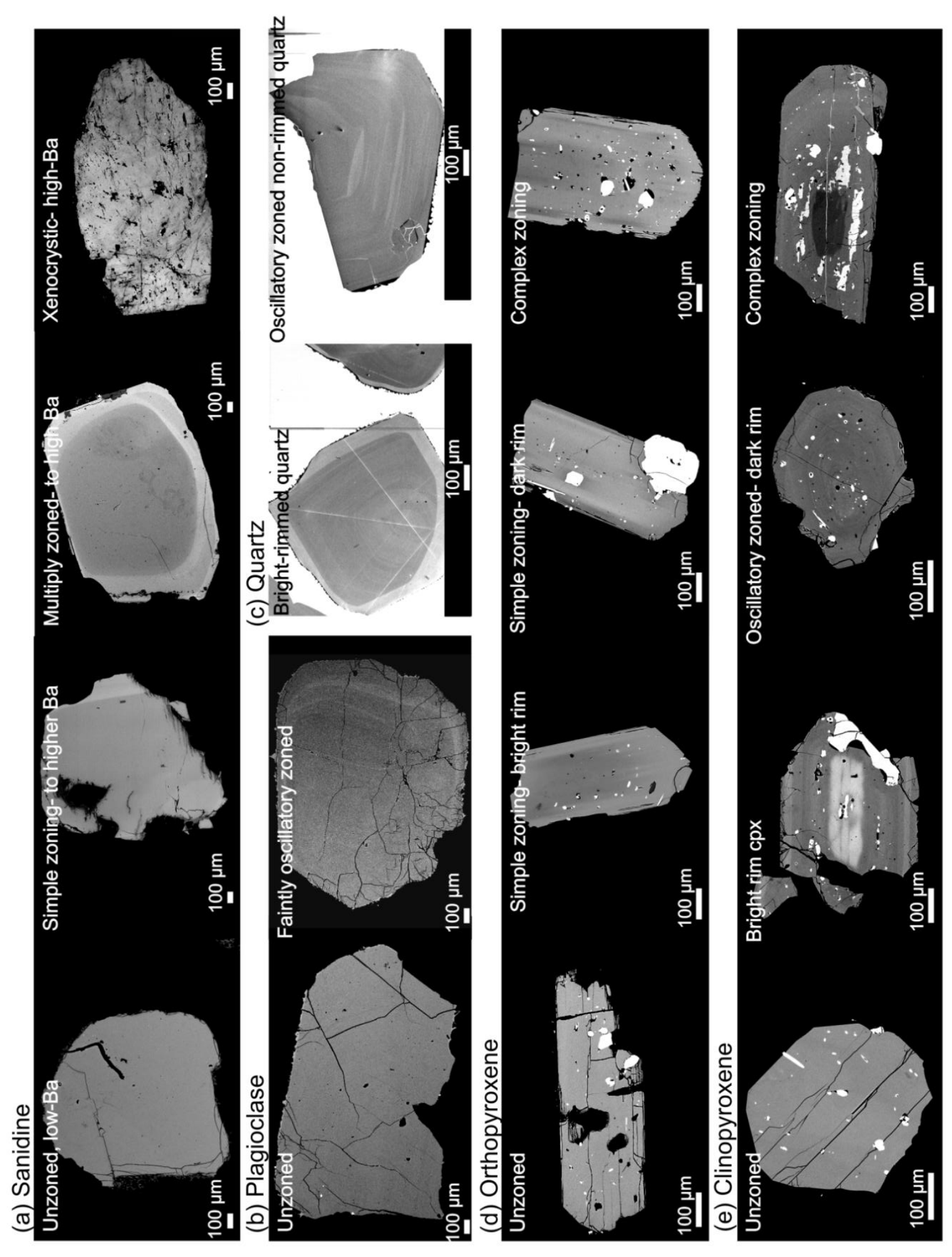



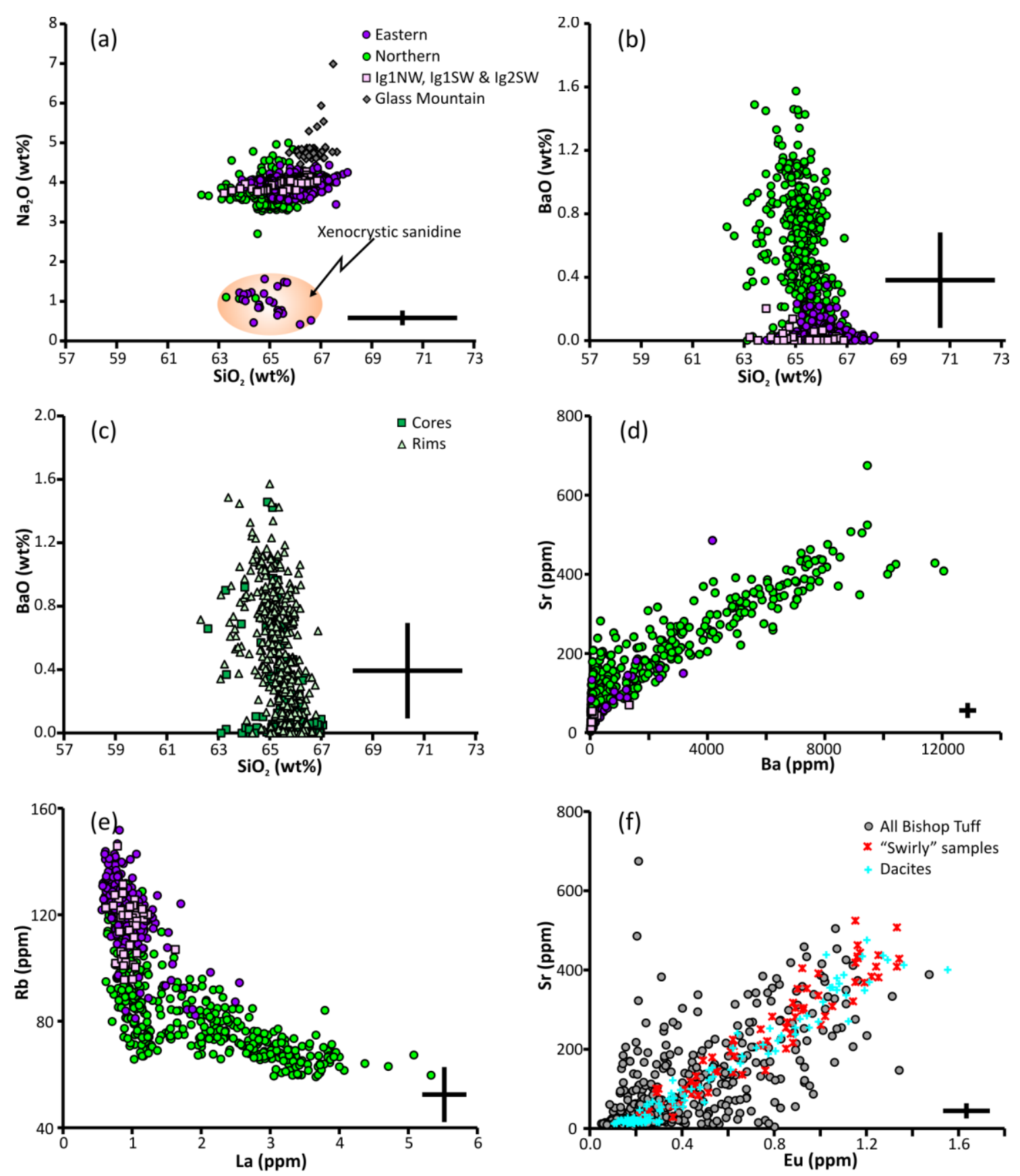

Fig. 5.4. Major ( $a, b)$ and trace ( $c$ to $f$ ) element variations in sanidines. Purple filled circles represent eastern material; green filled circles northern material; grey filled diamonds are Glass Mountain (Dome OD) and pink filled squares are analyses from pumices in Ig1NW, Ig1SW and Ig2SW. Xenocrystic sanidines are outlined in orange on panel (a). All error crosses represent 2 s.d. uncertainties from standard analyses. The full data set is available in Electronic Appendices 11 and 12.

All nine samples from F9, Ig2NWa and Ig2Na have $14-45 \%$ of their sanidine crystals with bright rims, while all eleven late northern (Ig2NWb, Ig2Nb, and Ig2Nc) samples have $45 \%$ to $100 \%$ of their sanidine crystals showing bright rims (Figs. 5.2 and 5.3; Table 5.1). Sanidines extracted from some swirly or dacitic samples additionally sometimes show clearly xenocrystic grains, commonly fractured and completely bright under BSE (Fig. 5.3). 
These grains are not included in the percent bright rim figures listed in Table 5.1. Sanidines from Glass Mountain (GM) dome OD were also imaged, and no bright rim overgrowths were evident under BSE (contrasting as such with the zircons from the same sample: Chamberlain et al., 2014a [Chapter 3]).

Major element $(\mathrm{n}=1403)$ and trace element $(\mathrm{n}=834)$ analyses of sanidine crystals show relatively restricted ranges in major element composition, with most major element variations being within the 2 s.d. analytical uncertainty (Table 5.2; Fig. 5.4a; for full data set see Electronic Appendices 11 and 12). 97\% of sanidine compositions range from $\mathrm{Or}_{60}$ to $\mathrm{Or}_{68}$ with variations outside of this only found in xenocrystic or rare overgrowth rims found only in sanidine crystals from northern-vented samples. When the data are considered as a whole two groups of sanidine composition are identified using $\mathrm{BaO}$ content. However on grouping data by cores and rims, it is clear that the higher $\mathrm{BaO}$ group $(>0.32$ wt. $\% \mathrm{BaO})$ are defined dominantly by the bright rim overgrowths identified in northern sanidine crystals. Sanidine crystals from eastern units (both fall deposits and ignimbrite) are solely low-Ba sanidine irrespective of whether the analysis is from cores or rims of crystals. Sanidine crystals from northern ignimbrite units are much more variable, with a range in zoning patterns seen, from low-Ba cores and rims $43 \%$ of sanidine from northern vents pumices), to low-Ba cores and higher $\mathrm{Ba}$ rims (47\% of sanidine from northern vented pumices), to moderate $\mathrm{Ba}$ cores, with higher $\mathrm{Ba}$ rims (10\% of sanidine from northern vented pumices)(Fig. 5.4c). Whether eastern or northern units are considered, rims of sanidine crystals commonly contain higher $\mathrm{BaO}$ content than their associated cores (Fig. 5.4c), however the difference between cores and rims in eastern sanidine crystals is always $<0.3 \mathrm{wt} . \% \mathrm{BaO}$, whereas this core-rim difference can be as great as 1.2 wt. $\% \mathrm{BaO}$ in northern sanidine crystals. Sanidines from northern units are also slightly enriched in $\mathrm{CaO}$ when compared with sanidines from the eastern units. Glass Mountain dome OD sanidines are distinctly different in composition from Bishop Tuff sanidines, with lower $\mathrm{CaO}$ and $\mathrm{K}_{2} \mathrm{O}$, and higher $\mathrm{SiO}_{2}$ and $\mathrm{Na}_{2} \mathrm{O}$ (Fig. 5.4a).

The separation between high-Ba (dominantly defined by northern-sourced rims) and low$\mathrm{Ba}$ (eastern-sourced cores and rims) sanidine zones is further defined in trace element variations, where the high-Ba group is enriched in $\mathrm{Mg}$, $\mathrm{Sr}$, light rare earth elements (LREE), and depleted in $\mathrm{Rb}$ (Table 5.2; Fig. 5.4) relative to the low-Ba group. Evidence for slight enrichment of $\mathrm{Ba}$ (although still classified as low-Ba) in non-rimmed sanidine crystals 


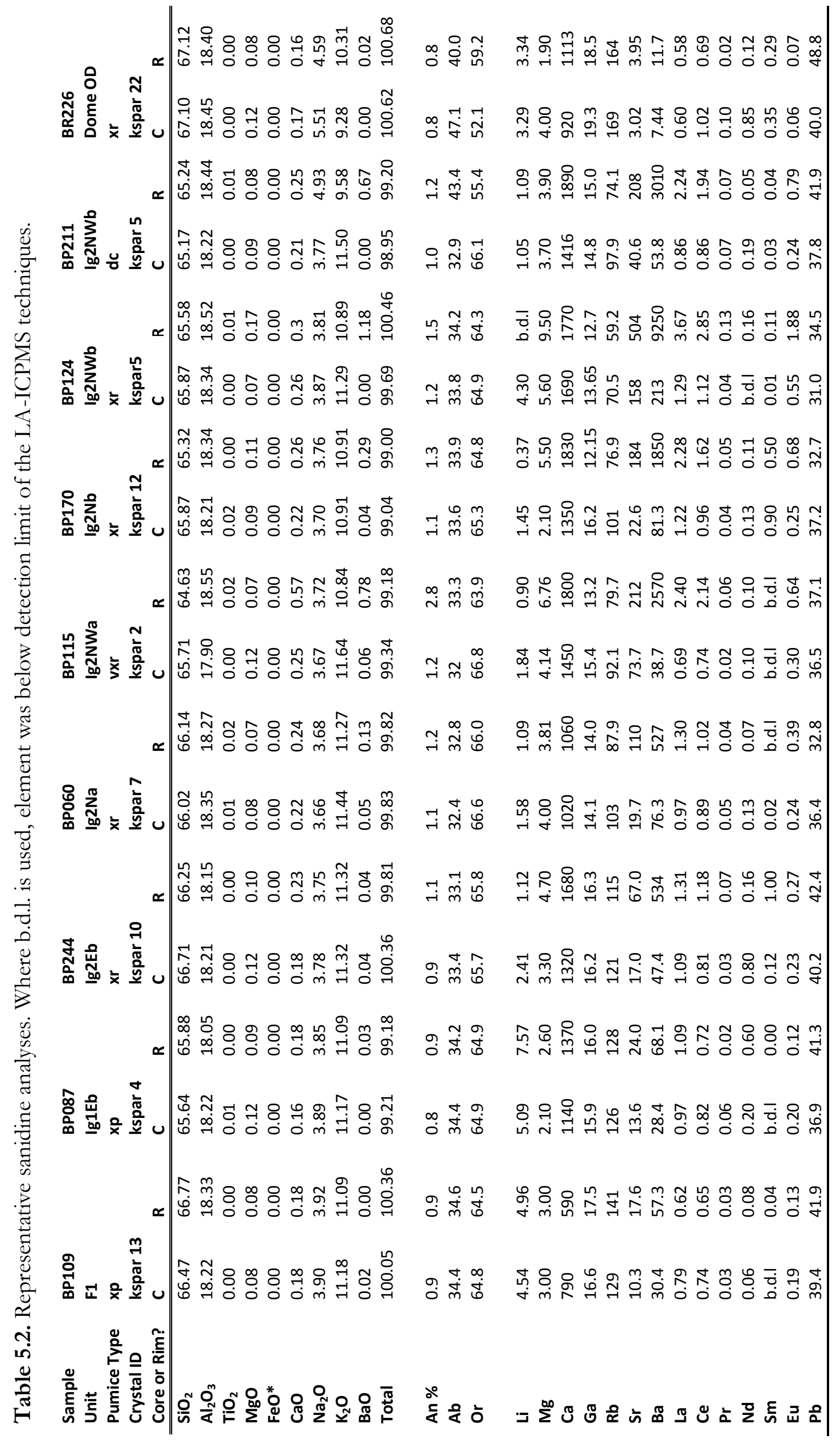


from eastern ignimbrite packages is also apparent with $\mathrm{Ba}$ concentrations reaching $\sim 800$ ppm ( 0.09 wt. \% BaO). Ig2Na sanidines show the most evolved compositions of crystals in all samples from northern ignimbrite packages, with compositions which overlap most closely with sanidine from eastern ignimbrite packages. Sanidines from swirly, chocolate and dacite pumice clasts have trace element characteristics that are indistinguishable from each other, as well as those sanidines from 'normal' pumice samples, apart from xenocrystic sanidines, identified by BSE images, which have much higher $\mathrm{Ba}$, Sr and Ca concentrations. Dome OD sanidines display much more limited trace element ranges than Bishop sanidines, with very low Sr and Ba contents that are comparable to sanidines in the very earliest, most evolved, samples of the Bishop Tuff.

\subsubsection{Plagioclase}

Plagioclase is the third most abundant mineral species in the Bishop Tuff, making up $\sim 10 \%$ of the crystal population (Hildreth, 1977, 1979; Hildreth \& Wilson, 2007). Two groups of plagioclase crystals have been identified using BSE images and confirmed with EPMA data. The first group is completely unzoned, and contrastingly the second group has faint oscillatory zoning (Fig. 5.3). These oscillatory-zoned plagioclase are generally only found in the late, northern pumice samples, and there constitute varying proportions (17 $100 \%)$ of the total plagioclase population.

Major $(\mathrm{n}=379)$ and trace element $(\mathrm{n}=310)$ analyses were carried out on plagioclase crystals from multiple samples of the Bishop Tuff (Tables 5.1, 5.3). In tune with observations from the BSE imagery, two populations of plagioclase are identified based on $\mathrm{CaO}$ content, similar to those reported in Gualda et al. (2012b). A high-Ca group (where $\mathrm{CaO}$ is $>4.4$ wt. $\%$, or $\left.>\mathrm{An}_{22}\right)$ are dominated by the oscillatory-zoned plagioclase $(82 \%$ of the high-Ca group are oscillatory zoned), whereas a low-Ca group (with $\mathrm{CaO}<4.4$ wt.\%, or $\left.<\mathrm{An}_{22}\right)$ are dominantly $(>65 \%)$ unzoned under BSE. The high-Ca plagioclase crystals are enriched in Fe with respect to the low-Ca plagioclase (Fig. 5.5). Unlike in sanidine, there are no systematic differences between cores and rims of crystals, with only $\sim 5 \%$ of crystals showing an overgrowth of a low/high-Ca rim over a high/low-Ca core. High-Ca plagioclase is almost solely restricted to samples from the northern ignimbrite packages. The only eastern sample containing high-Ca plagioclase is a swirly pumice from unit Ig2Ea, which preserves evidence for mixing in hand sample. Low-Ca plagioclase is ubiquitous throughout all Bishop Tuff samples examined, and there are no identifiable differences in 
Table 5.3. Representative raw analyses of plagioclase Where b.d.l. is used, element was below detection limit of the LA-ICPMS techniques. For full data set see Electronic Appendices 11 and 12.

\begin{tabular}{|c|c|c|c|c|c|c|c|c|}
\hline \multirow{5}{*}{$\begin{array}{l}\text { Sample } \\
\text { Unit } \\
\text { Pumice Type } \\
\text { Crystal ID } \\
\text { Core or Rim? }\end{array}$} & \multicolumn{2}{|l|}{ BP109 } & \multicolumn{2}{|l|}{ ВР030 } & \multicolumn{2}{|l|}{ BP244 } & \multicolumn{2}{|l|}{ BP060 } \\
\hline & \multicolumn{2}{|l|}{ F1 } & \multicolumn{2}{|l|}{ Ig1Eb } & \multicolumn{2}{|l|}{$\lg 2 \mathrm{~Eb}$} & \multicolumn{2}{|l|}{$\lg 2 \mathrm{Na}$} \\
\hline & & \multirow{2}{*}{\multicolumn{2}{|c|}{$\begin{array}{l}\text { xr } \\
\text { plag } 6\end{array}$}} & \multirow{2}{*}{\multicolumn{2}{|c|}{$\begin{array}{l}\text { xr } \\
\text { plag } 2\end{array}$}} & \multirow{2}{*}{\multicolumn{2}{|c|}{$\begin{array}{l}\text { xr } \\
\text { plag } 9\end{array}$}} \\
\hline & plag 1 & & & & & & & \\
\hline & C & $\mathbf{R}$ & C & $\mathbf{R}$ & C & $\mathbf{R}$ & C & $\mathbf{R}$ \\
\hline $\mathrm{SiO}_{2}$ & 66.67 & 666.47 & 64.19 & 63.92 & 65.93 & 65.30 & "63.83 & 63.33 \\
\hline $\mathrm{Al}_{2} \mathrm{O}_{3}$ & 23.75 & 23.75 & 22.42 & 22.45 & 22.21 & 22.40 & 22.37 & 22.05 \\
\hline $\mathrm{TiO}_{2}$ & 0.00 & 0.01 & 0.00 & 0.00 & 0.01 & 0.00 & 0.00 & 0.00 \\
\hline FeO* & 0.09 & 0.14 & 0.16 & 0.17 & 0.13 & 0.15 & 0.15 & 0.16 \\
\hline MgO & 0.00 & 0.00 & 0.00 & 0.00 & 0.00 & 0.00 & 0.00 & 0.01 \\
\hline $\mathrm{CaO}$ & 2.95 & 3.14 & 3.30 & 3.32 & 3.06 & 3.25 & 3.37 & 3.4 \\
\hline $\mathrm{Na}_{2} \mathrm{O}$ & 7.69 & 7.75 & 8.21 & 8.34 & 7.71 & 7.61 & 7.88 & 7.74 \\
\hline $\mathrm{K}_{2} \mathrm{O}$ & 1.20 & 1.14 & 1.54 & 1.49 & 1.79 & 1.96 & 1.39 & 1.49 \\
\hline $\mathrm{BaO}$ & 0.00 & 0.05 & 0.02 & 0.02 & 0.00 & 0.04 & 0.00 & 0.00 \\
\hline Total & 102.35 & 102.45 & 99.83 & 99.70 & 100.83 & 100.71 & 98.98 & 98.17 \\
\hline An \% & 16.1 & 17.0 & 16.5 & 16.5 & 16.0 & 16.8 & 17.5 & 17.7 \\
\hline$A b \%$ & 76.1 & 75.7 & 74.3 & 74.8 & 72.9 & 71.2 & 74.0 & 73.0 \\
\hline Or \% & 7.8 & 7.3 & 9.2 & 8.8 & 11.1 & 12.0 & 8.6 & 9.2 \\
\hline Li & 12.2 & 13.0 & 9.46 & 4.72 & 10.6 & 4.42 & 6.69 & 5.00 \\
\hline Mg & 14.9 & 13.3 & 14.8 & 9.10 & 14.2 & 14.0 & 24.2 & 21.1 \\
\hline $\mathrm{Ca}$ & 16650 & 17340 & 21390 & 21970 & 21840 & 20260 & 17510 & 18250 \\
\hline Sc & 3.81 & 4.09 & 5.19 & 4.74 & 6.17 & 6.09 & 4.94 & 4.69 \\
\hline $\mathrm{Ti}$ & 31.0 & 24.2 & 30.2 & 26.1 & 37.9 & 26.9 & 29.7 & 43.3 \\
\hline$M n$ & 6.32 & 6.70 & 6.70 & 8.40 & 6.88 & 6.12 & 6.20 & 5.90 \\
\hline Ga & 20.5 & 22.8 & 22.4 & 24.0 & 23.7 & 23.1 & 21.7 & 20.8 \\
\hline $\mathbf{R b}$ & 2.09 & 2.10 & 1.97 & 1.41 & 2.12 & 2.4 & 2.17 & 2.19 \\
\hline $\mathrm{Sr}$ & 20.4 & 25.7 & 30.40 & 23.0 & 23.7 & 32.2 & 18.3 & 66.8 \\
\hline $\mathrm{Nb}$ & 0.02 & 0.04 & 0.00 & 0.07 & 0.03 & b.d.I & 0.03 & 0.03 \\
\hline $\mathrm{Ba}$ & 2.77 & 4.90 & 6.95 & 2.25 & 4.04 & 4.52 & 3.19 & 24.6 \\
\hline La & 4.76 & 4.26 & 7.13 & 4.00 & 5.83 & 4.18 & 6.08 & 8.90 \\
\hline $\mathrm{Ce}$ & 6.15 & 6.11 & 8.95 & 5.83 & 8.42 & 5.84 & 7.95 & 10.7 \\
\hline $\mathrm{Pr}$ & 0.38 & 0.43 & 0.57 & 0.44 & 0.52 & 0.37 & 0.53 & 0.71 \\
\hline Nd & 1.14 & 1.17 & 1.56 & 0.82 & 1.54 & 1.03 & 1.5 & 1.44 \\
\hline Sm & 0.21 & 0.18 & 0.70 & 0.70 & 0.20 & 0.80 & 0.18 & 0.22 \\
\hline $\mathrm{Eu}$ & 0.20 & 0.20 & 0.23 & 0.30 & 0.26 & 0.19 & 0.20 & 0.34 \\
\hline Gd & 0.26 & b.d.I & 0.50 & 0.31 & 0.14 & 0.00 & b.d.I & b.d.I \\
\hline Lu & 0.06 & 0.03 & b.d.I & 0.03 & 0.00 & b.d.I & b.d.I & 0.01 \\
\hline $\mathrm{Pb}$ & 19.0 & 19.3 & 18.0 & 17.6 & 21.1 & 18.7 & 20.6 & 17.3 \\
\hline Th & 0.01 & b.d.I & 0.03 & 0.02 & 0.05 & b.d.I & b.d.I & 0.08 \\
\hline U & 0.03 & 0.08 & 0.00 & 0.03 & 0.02 & b.d.I & b.d.I & b.d.I \\
\hline
\end{tabular}

its composition between eastern-sourced (earlier erupted) versus northern-sourced (later erupted) samples. The enrichment in $\mathrm{CaO}$ in high-Ca plagioclase crystals is mirrored by enrichments in $\mathrm{Eu}, \mathrm{Sr}, \mathrm{Ba}, \mathrm{Ti}, \mathrm{Mg}$ and LREE (Fig. 5.5) when compared with the low-Ca plagioclase, consistent with crystallisation from a less-evolved source for the former. When examined alone, the low-Ca plagioclase crystals show a weak positive correlation between $\mathrm{Sr}$ and $\mathrm{Ba}$ and LREE, which does not vary based on eruptive timing, or on core-to-rim variations, in contrast to the changes observed in sanidine. 
Table 5.3. cont.

\begin{tabular}{|c|c|c|c|c|c|c|c|c|}
\hline \multirow{5}{*}{$\begin{array}{l}\text { Sample } \\
\text { Unit } \\
\text { Pumice Type } \\
\text { Crystal ID } \\
\text { Core or Rim? }\end{array}$} & \multicolumn{2}{|l|}{ BP115 } & \multicolumn{2}{|l|}{ BP170 } & \multicolumn{2}{|l|}{ BP124 } & \multicolumn{2}{|l|}{ BP211 } \\
\hline & \multicolumn{2}{|l|}{ Ig2Nwa } & \multicolumn{2}{|l|}{$\lg 2 \mathrm{Nb}$} & \multicolumn{2}{|l|}{ Ig2NWb } & \multicolumn{2}{|l|}{ Ig2NWb } \\
\hline & \multirow{2}{*}{\multicolumn{2}{|c|}{$\begin{array}{l}\text { vxr } \\
\text { plag } 9\end{array}$}} & \multicolumn{2}{|l|}{$x r$} & & \\
\hline & & & plag 13 & & plag 14 & & plag 9 & \\
\hline & C & $\mathbf{R}$ & C & $\mathbf{R}$ & C & $\mathbf{R}$ & C & $\mathbf{R}$ \\
\hline $\mathrm{SiO}_{2}$ & 61.02 & 62.54 & 62.61 & 63.32 & 61.93 & 62.04 & 66.45 & 65.16 \\
\hline $\mathrm{Al}_{2} \mathrm{O}_{3}$ & 23.58 & 25.10 & 23.49 & 22.54 & 23.23 & 23.24 & 21.71 & 21.67 \\
\hline $\mathrm{TiO}_{2}$ & 0.00 & 0.00 & 0.02 & 0.00 & 0.00 & 0.00 & 0.00 & 0.00 \\
\hline $\mathrm{FeO}^{*}$ & 0.25 & 0.22 & 0.23 & 0.17 & 0.19 & 0.20 & 0.15 & 0.17 \\
\hline MgO & 0.00 & 0.00 & 0.00 & 0.00 & 0.00 & 0.01 & 0.00 & 0.00 \\
\hline $\mathrm{CaO}$ & 5.49 & 4.64 & 4.71 & 3.67 & 4.64 & 4.64 & 3.41 & 3.57 \\
\hline $\mathrm{Na}_{2} \mathrm{O}$ & 6.90 & 6.71 & 7.18 & 7.43 & 7.39 & 7.36 & 7.67 & 7.62 \\
\hline $\mathrm{K}_{2} \mathrm{O}$ & 1.05 & 1.34 & 1.19 & 1.61 & 1.24 & 1.26 & 1.34 & 1.25 \\
\hline $\mathrm{BaO}$ & 0.09 & 0.00 & 0.03 & 0.08 & 0.01 & 0.01 & 0.03 & 0.00 \\
\hline Total & 98.36 & 100.55 & 99.47 & 98.81 & 98.63 & 98.74 & 100.76 & 99.44 \\
\hline An \% & 28.6 & 25.2 & 24.6 & 19.3 & 23.8 & 23.9 & 18.1 & 18.9 \\
\hline$A b \%$ & 65.0 & 66.1 & 68.0 & 70.7 & 68.6 & 68.5 & 73.5 & 73.2 \\
\hline Or \% & 6.5 & 8.7 & 7.4 & 10.1 & 7.6 & 7.7 & 8.5 & 7.9 \\
\hline Li & 6.17 & 3.63 & 8.01 & 2.51 & 21.1 & 3.28 & 6.71 & 3.07 \\
\hline Mg & 59.0 & 49.6 & 45.1 & 37.9 & 41.0 & 48.9 & 60.0 & 69.9 \\
\hline $\mathrm{Ca}$ & 42500 & 30760 & 24800 & 22610 & 25140 & 26560 & 30120 & 31250 \\
\hline Sc & 13.6 & 12.6 & 6.45 & 6.36 & 4.99 & 5.35 & 6.95 & 7.15 \\
\hline $\mathrm{Ti}$ & 91.0 & 50.8 & 54.1 & 44.0 & 49.2 & 56.1 & 45.7 & 67.4 \\
\hline Mn & 11.3 & 8.30 & 8.00 & 7.70 & 6.58 & 7.50 & 7.29 & 7.21 \\
\hline Ga & 25.1 & 20.0 & 19.7 & 20.5 & 21.0 & 20.0 & 20.7 & 22.4 \\
\hline $\mathbf{R b}$ & 0.97 & 1.45 & 1.44 & 1.74 & 1.24 & 1.30 & 1.57 & 1.33 \\
\hline $\mathrm{Sr}$ & 610 & 376 & 300 & 202 & 189 & 477 & 332 & 608 \\
\hline $\mathrm{Nb}$ & 0.03 & 0.02 & 0.05 & 0.01 & 0.02 & 0.00 & b.d.l & 0.04 \\
\hline $\mathrm{Ba}$ & 850 & 360 & 242 & 99.3 & 87.7 & 346 & 233 & 497 \\
\hline La & 17.6 & 17.5 & 17.2 & 12.93 & 14.9 & 17.4 & 17.8 & 19.4 \\
\hline $\mathrm{Ce}$ & 21.2 & 23.3 & 19.3 & 14.7 & 18.1 & 19.9 & 20.4 & 22.5 \\
\hline $\mathrm{Pr}$ & 1.21 & 1.30 & 1.18 & 0.87 & 1.17 & 1.30 & 1.11 & 1.32 \\
\hline Nd & 3.24 & 3.47 & 2.68 & 2.35 & 3.08 & 2.70 & 2.29 & 2.75 \\
\hline Sm & 0.20 & 0.34 & 0.14 & 0.17 & 0.11 & 0.25 & 0.22 & 0.28 \\
\hline Eu & 1.45 & 1.20 & 1.13 & 0.78 & 0.85 & 1.15 & 1.09 & 1.30 \\
\hline Gd & 0.20 & 0.24 & 0.28 & 0.04 & 0.21 & 0.34 & 0.18 & 0.60 \\
\hline Lu & 0.01 & b.d.l & 0.00 & 0.02 & 0.1 & b.d.l & b.d.l & b.d.I \\
\hline $\mathrm{Pb}$ & 16.6 & 15.8 & 15.5 & 15.4 & 15.1 & 14.9 & 16.8 & 16.5 \\
\hline Th & 0.08 & b.d.l & 0.02 & b.d.I & b.d.l & 0.00 & 0.02 & 0.01 \\
\hline $\mathbf{U}$ & b.d.l & b.d.l & 0.02 & 0.02 & 0.00 & b.d.l & 0.02 & 0.02 \\
\hline
\end{tabular}

\subsubsection{Biotite}

Biotite is the most common ferromagnesian phase in the Bishop Tuff, increasing in abundance from $<0.005 \%$ in early fall units to $\sim 0.05 \%$ in late northern ignimbrite units (Hildreth, 1977, 1979; Hildreth \& Wilson, 2007). Biotite was extracted from 25 pumice samples from early fall units to late ignimbrite deposits (Table 5.1). Although commonly found as golden brown weathered crystals, every effort to select the freshest looking black biotites was made. Where preserved, biotite occurs as euhedral crystals which display no evidence for dissolution. When imaged under BSE, no zoning was evident in any biotite crystals. 

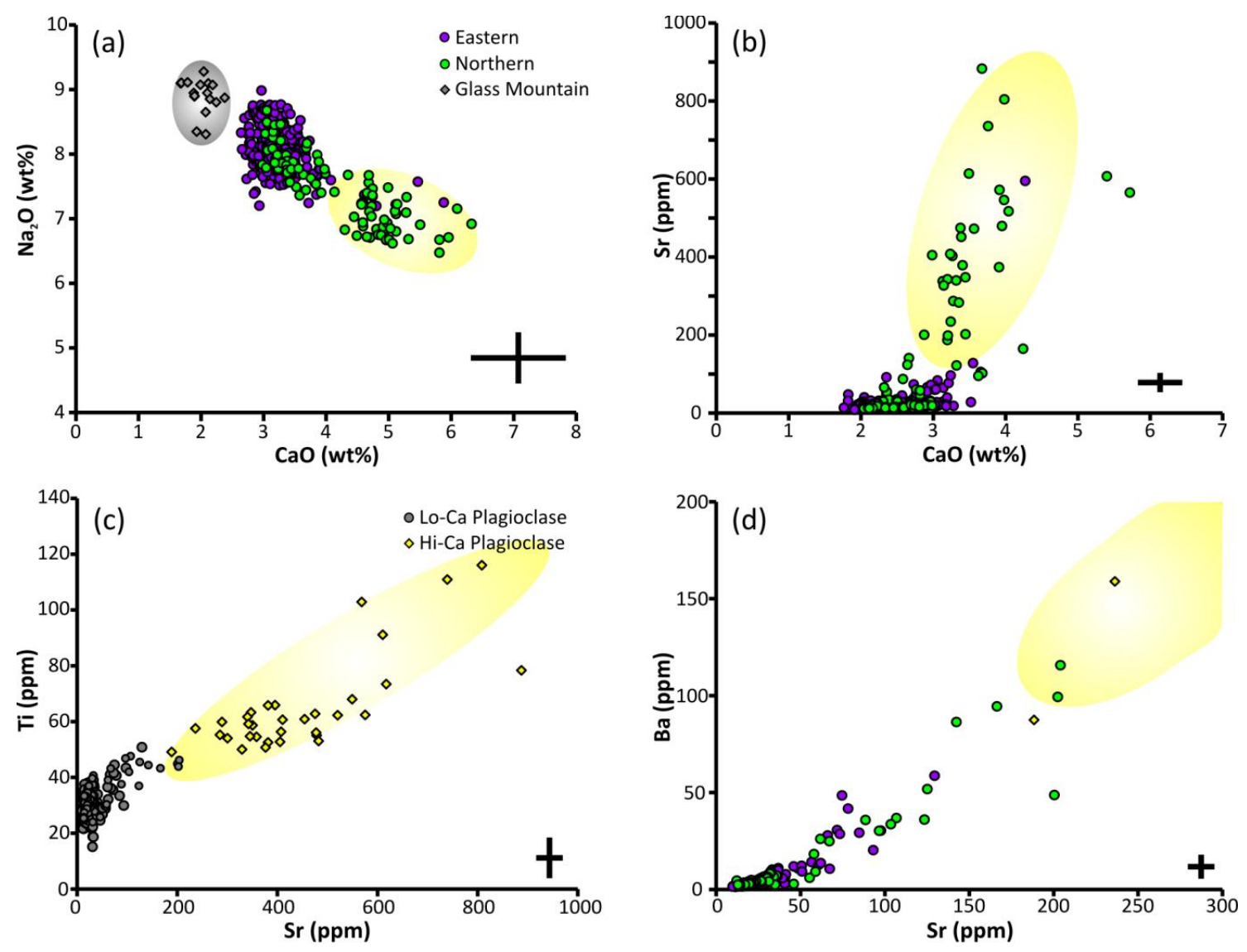

Fig. 5.5. Major $(\mathrm{a}, \mathrm{b})$ and trace $(\mathrm{c}, \mathrm{d})$ element variations in plagioclase from Bishop and Glass Mountain samples. Purple filled circles represent eastern material; green filled circles northern material; grey filled diamonds are Glass Mountain (Dome OD). The high-Ca plagioclase group is outlined by the yellow field. All error crosses represent 2 s.d. uncertainties from standard analyses. The full data set is available in Electronic Appendices 11 and 12 .

Major element compositions were determined from 438 grains from all samples where fresh crystals could be found, however once all totals less than 95 wt. \% were removed, 236 valid major element measurements remained. Interestingly, early eastern biotite (Ig1E, fall units 1-8) systematically produced low totals (see Table 5.4) due to strong interlayer deficiencies in $\mathrm{K}_{2} \mathrm{O}$, and so cannot be used for accurate comparison of eastern and northern biotite. This is not the first time this has been noticed, and has been attributed to syn-eruptive destabilisation of biotite in the upper (more water-rich, Wallace et al., 1999) Bishop magma chamber (Hildreth, 1977). Although limited by the varying degrees of alteration which biotite has undergone, northern-erupted biotites are enriched in $\mathrm{TiO}_{2}$ and extend to lower $\mathrm{K}_{2} \mathrm{O}$ values than eastern-erupted biotite. No other differences in major element chemistry can be discerned from the EPMA data (Fig. 5.6). The compositions of biotites from Ig $2 \mathrm{Na}$ fall in a compositional field (in Ti-K space) that lies between the majority of grains from earlier, eastern-erupted material and all the other grains analysed 
Table 5.4. Representative raw analyses of biotite. For full data set see Electronic Appendix 11.

\begin{tabular}{|c|c|c|c|c|c|c|c|c|c|c|}
\hline \multirow{4}{*}{$\begin{array}{l}\text { Sample } \\
\text { Unit } \\
\text { Pumice Type } \\
\text { Crystal ID }\end{array}$} & \multicolumn{2}{|l|}{ BP132 } & \multicolumn{2}{|l|}{ BP004 } & \multicolumn{2}{|l|}{ BP164 } & \multicolumn{2}{|l|}{ BP216 } & \multicolumn{2}{|l|}{ ВP060 } \\
\hline & Ig1Ea & & Ig2Ea & & Ig2Eb & & Ig2SW & & $\lg 2 \mathrm{Na}$ & \\
\hline & & & & & & & & & & \\
\hline & bio-4 & & bio-2 & & bio-4 & & bio-9 & & bio-5 & \\
\hline Core or Rim? & $\mathrm{C}$ & $\mathbf{R}$ & $\mathrm{C}$ & $\mathbf{R}$ & C & $\mathbf{R}$ & $\mathrm{C}$ & $\mathbf{R}$ & C & $\mathbf{R}$ \\
\hline $\mathrm{SiO}_{2}$ & 41.28 & 41.09 & 41.73 & 41.87 & 36.74 & 35.65 & 41.87 & 37.52 & 37.48 & 37.71 \\
\hline $\mathrm{Al}_{2} \mathrm{O}_{3}$ & 12.16 & 12.18 & 11.57 & 11.72 & 13.14 & 12.21 & 18.85 & 14.81 & 12.96 & 13.37 \\
\hline $\mathrm{FeO}^{*}$ & 20.12 & 20.46 & 20.81 & 20.18 & 24.73 & 28.4 & 15.66 & 20.91 & 21.9 & 21.25 \\
\hline MgO & 6.68 & 6.76 & 6.91 & 7.58 & 8.73 & 7.70 & 6.76 & 8.78 & 11.13 & 10.96 \\
\hline $\mathrm{CaO}$ & 0.67 & 0.69 & 0.69 & 0.83 & 0.04 & 0.07 & 0.20 & 0.01 & 0.00 & 0.03 \\
\hline $\mathrm{Na}_{2} \mathrm{O}$ & 0.16 & 0.14 & 0.19 & 0.46 & 0.40 & 0.48 & 0.16 & 0.51 & 0.58 & 0.48 \\
\hline $\mathrm{K}_{2} \mathrm{O}$ & 6.02 & 5.9 & 5.83 & 5.87 & 9.49 & 7.83 & 5.05 & 8.56 & 9.35 & 9.07 \\
\hline
\end{tabular}

Table 5.4. cont.

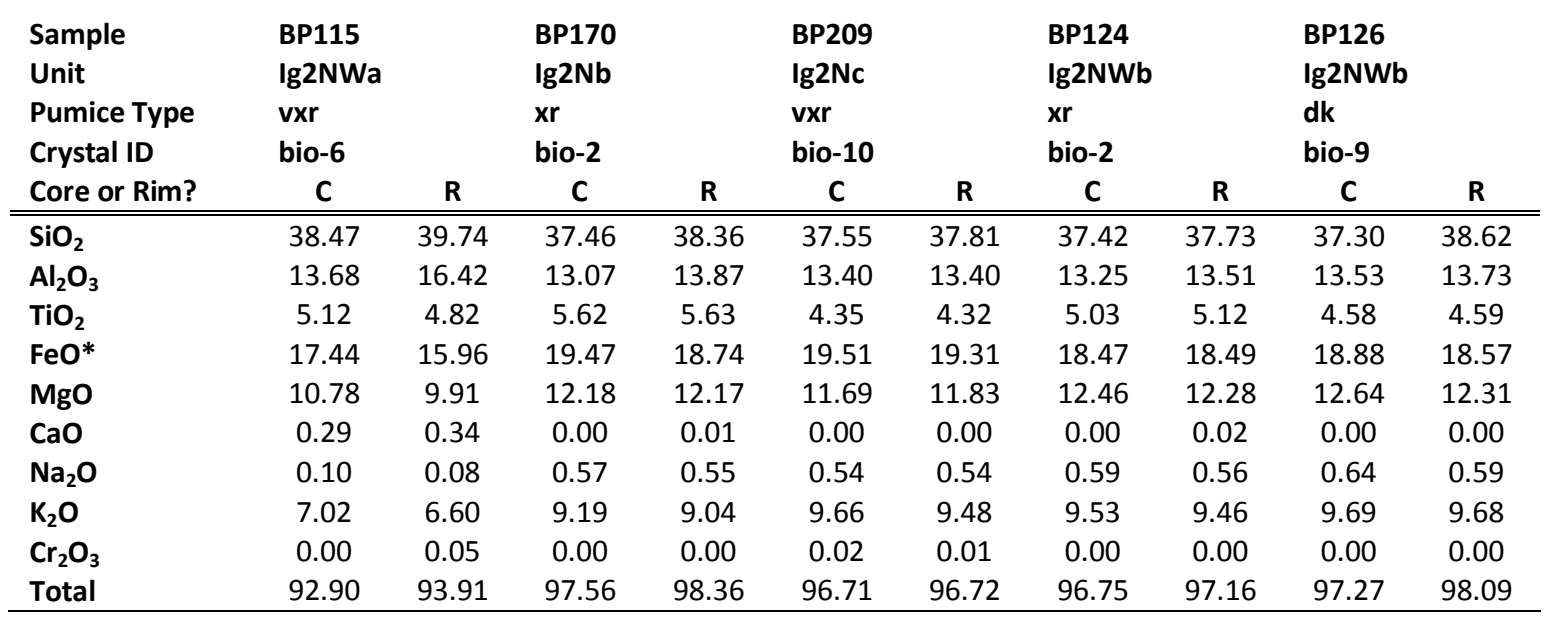

from later, northern-erupted material. A similar relationship was also observed in sanidine crystals from $\operatorname{Ig} 2 \mathrm{Na}$ (see section 5.4.1.1.) Variable degrees of alteration of biotite are noted to have occurred in all erupted samples, reflected in the biotite-glass and biotite-sanidine thermometry yielding temperatures generally $<400{ }^{\circ} \mathrm{C}$ (Hildreth, 1977) with no systematic temperature variation as shown by other thermometers (Hildreth, 1979; Hildreth \& Wilson, 2007; Chamberlain et al., 2014b [Chapter 4]). Due to this varying degree of alteration evident in biotites, further investigation using trace element analyses was not undertaken, and the use of biotite in investigating or constraining the nature of the pre-eruptive magma body may be somewhat limited.

\subsubsection{Orthopyroxene}

Pyroxenes, both ortho- and clino-, have only been reported from the later-erupted northern material, and some Sherwin subunit (latest Ig1Eb) and later eastern (Ig2Eb,c) 

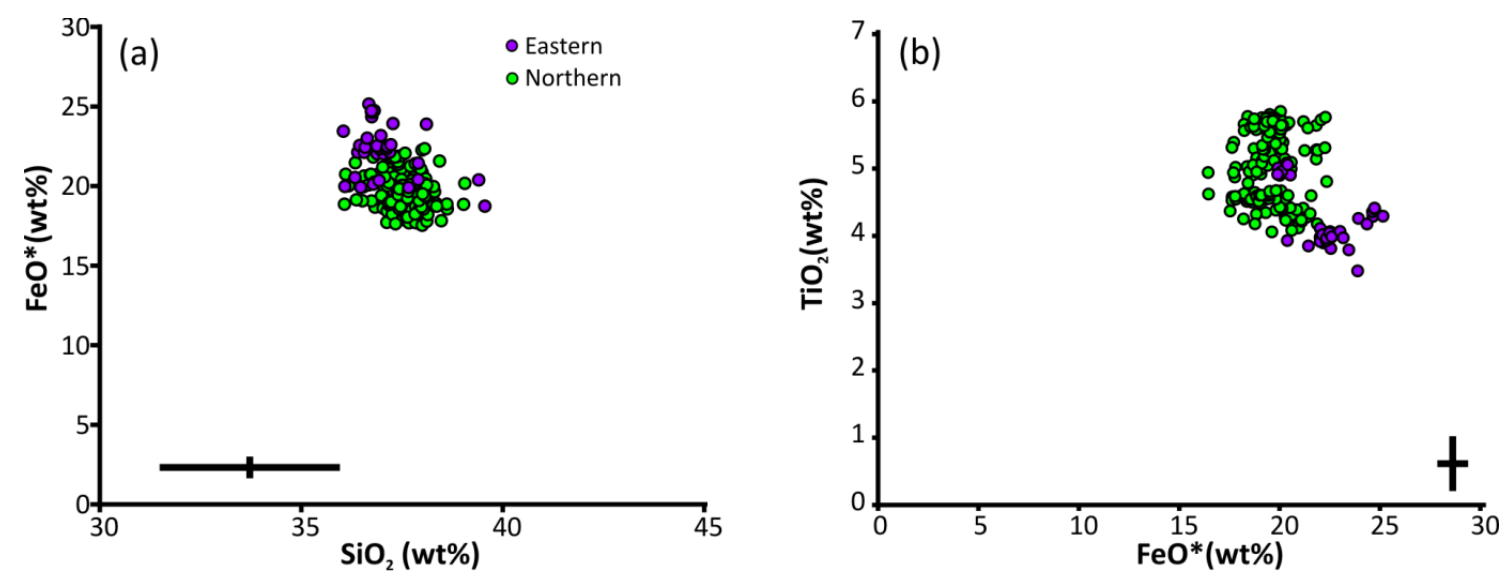

Fig. 5.6. Biotite major element variations from Bishop Tuff samples. (a) and (b) highlight the influence of alteration within the Bishop samples, especially those from the eastern Bishop Tuff. All error crosses represent 2 s.d. uncertainties from standard analyses. The full data set is available in Electronic Appendices 11 and 12.

pumices (Hildreth, 1977, 1979; Hildreth \& Wilson, 2007). In this study, however, pyroxenes could only be hand-picked from the Ig2NWa, Ig2NWb, Ig2Nb and Ig2Nc samples, with no appropriately large $(\geq 250 \mu \mathrm{m})$ pyroxenes present in the samples of Ig2Na or the Sherwin subunit of Ig1Eb. All orthopyroxene crystals are euhedral, and under BSE show no evidence for any late-stage or syn-eruptive dissolution to suggest that they had moved out of equilibrium with the host melt. Using high contrast BSE imagery, some zoning is discernible in the orthopyroxene, with $\mathrm{Mg} \#$ obtained from subsequent EPMA analyses varying from 48.2 to 56.3 (Fig. 5.7; Chamberlain et al., 2014b [Chapter 4]). Orthopyroxene crystals display a range in zoning textures which can be split into 4 groups: 1) completely unzoned, 2) simple zoned with a brighter (Fe-richer) rim, 3) simple zoned with a darker (Mg-richer) rim, and 4) complexly zoned crystals (Fig. 5.3). The zoning style is not systematically related to any particular sample or eruptive unit (Electronic Appendices 11, 12).

Major element analyses $(\mathrm{n}=379)$ of orthopyroxene show slight variation in $\mathrm{SiO}_{2}, \mathrm{MgO}$, $\mathrm{FeO}$ and $\mathrm{CaO}$, with a negative correlation between $\mathrm{MgO}$ and $\mathrm{FeO}$ indicative of expected evolutionary trends within orthopyroxene (Table 5.5; Fig. 5.7). Trace element analyses ( $\mathrm{n}=$ 269) show that $\mathrm{Mn}$ and $\mathrm{Zn}$ are positively correlated (Fig. 5.7c), and that $\mathrm{Zn}$ is slightly negatively correlated with $\mathrm{Co}, \mathrm{Ni}$ and $\mathrm{Mg}$ (Fig. 5.7e). There are, however, no systematic differences in orthopyroxene composition between cores and rims of crystals, crystallinity of pumice clast, location of pumice clast within the eruptive stratigraphy or between different pumice textural groups (e.g. swirly vs. 'normal'; Fig. 5.7). 

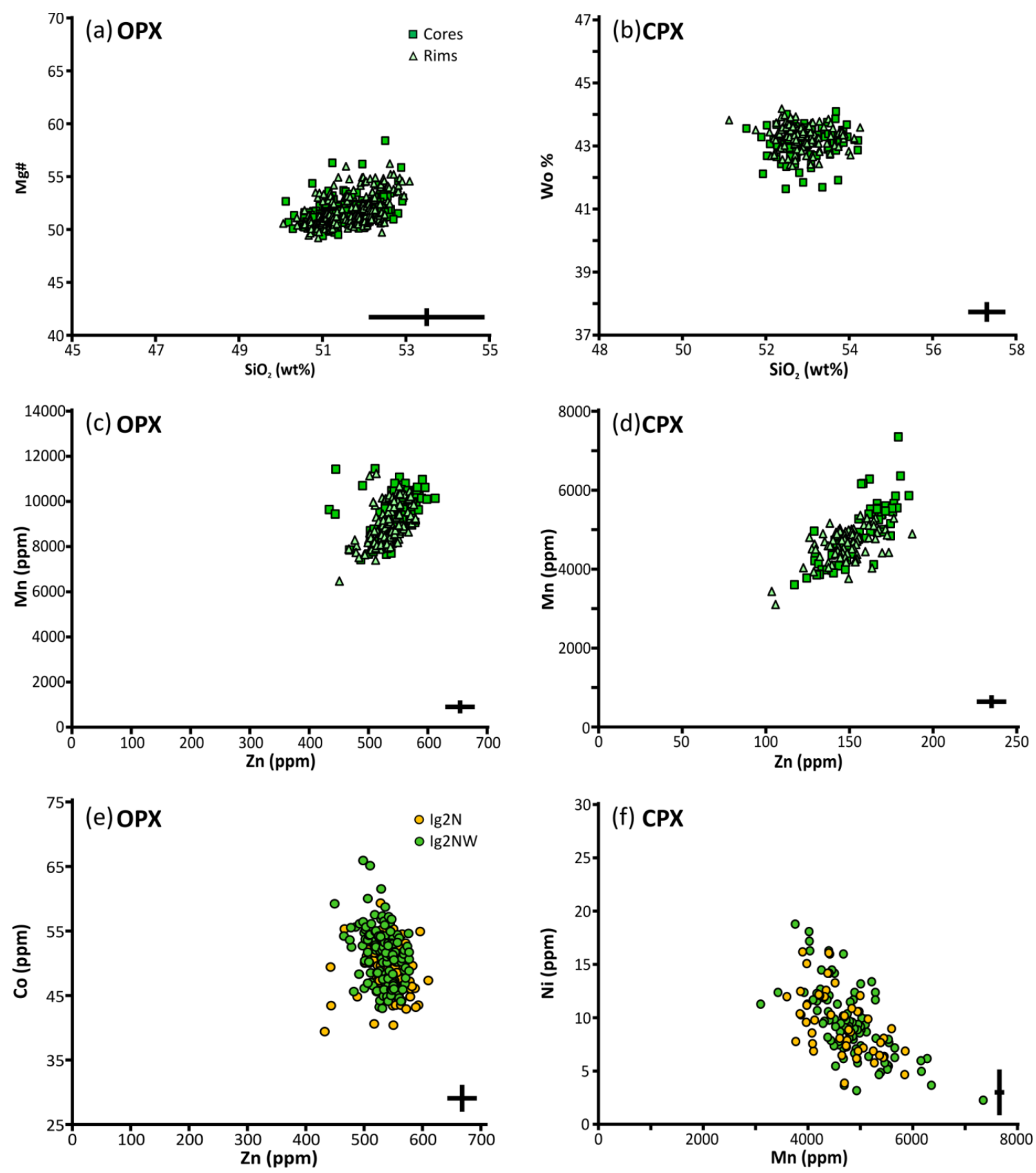

Fig. 5.7. Major ( $a, b)$ and trace (c to $\mathrm{f}$ ) element compositions in pyroxene from northern units of the Bishop Tuff. Orthopyroxene analyses are presented in the left column (a, c, e); clinopyroxene are presented in the right column $(\mathrm{b}, \mathrm{d}, \mathrm{f})$. Cores are plotted as filled squares, rims as filled triangles. Samples from Ig2N and Ig2NW are compared in (e) and (f): note the lack of clear differences in pyroxene compositions between the two ignimbrite packages. All error crosses represent 2 s.d. uncertainties from standard analyses. The full data set is available in Electronic Appendices 11 and 12. 
Table 5.5. Representative raw analyses of clinopyroxene (CPX) and orthopyroxene (OPX). Where b.d.l. is used, element was below detection limit of the LA-ICPMS techniques. For full data set see Electronic Appendices 11 and 12.

\begin{tabular}{|c|c|c|c|c|c|c|c|c|c|c|}
\hline \multirow{2}{*}{$\begin{array}{l}\text { Sample } \\
\text { Unit } \\
\text { Pumice Type } \\
\text { Type \& ID? } \\
\text { Core or Rim? }\end{array}$} & $\begin{array}{l}\text { BP115 } \\
\text { Ig2NWa } \\
\text { vxr } \\
\text { OPX-20 }\end{array}$ & & CPX-2 & & $\begin{array}{l}\text { BP170 } \\
\text { Ig2Nb } \\
x r \\
\text { OPX-9 }\end{array}$ & & CPX-24 & & $\begin{array}{l}\text { BP209 } \\
\text { Ig2Nc } \\
\text { vxr } \\
\text { OPX-33 }\end{array}$ & \\
\hline & $\mathrm{C}$ & $\mathbf{R}$ & C & $\mathbf{R}$ & $\mathrm{C}$ & $\mathbf{R}$ & C & $\mathbf{R}$ & $\mathrm{C}$ & $\mathbf{R}$ \\
\hline $\mathrm{SiO}_{2}$ & 51.13 & 51.27 & 53.09 & 52.58 & 52.65 & 51.31 & 52.51 & 52.72 & 50.98 & 52.72 \\
\hline $\mathrm{Al}_{2} \mathrm{O}_{3}$ & 0.89 & 0.34 & 0.65 & 0.63 & 0.31 & 0.32 & 0.79 & 0.56 & 0.37 & 0.35 \\
\hline $\mathrm{TiO}_{2}$ & 0.30 & 0.15 & 0.09 & 0.08 & 0.16 & 0.13 & 0.15 & 0.09 & 0.16 & 0.13 \\
\hline $\mathrm{FeO}^{*}$ & 28.58 & 28.79 & 11.72 & 12.63 & 27.58 & 27.46 & 11.72 & 12.49 & 29.67 & 27.03 \\
\hline MnO & 0.95 & 1.30 & 0.58 & 0.61 & 1.21 & 1.03 & 0.52 & 0.62 & 1.14 & 1.31 \\
\hline MgO & 17.78 & 17.38 & 12.92 & 12.29 & 18.22 & 18.48 & 13.07 & 12.35 & 17.32 & 17.34 \\
\hline $\mathrm{CaO}$ & 1.65 & 1.23 & 21.32 & 21.12 & 0.95 & 0.91 & 21.04 & 21.19 & 1.24 & 1.28 \\
\hline $\mathrm{Na}_{2} \mathrm{O}$ & 0.02 & 0.00 & 0.33 & 0.36 & 0.01 & 0.04 & 0.37 & 0.36 & 0.02 & 0.02 \\
\hline $\mathrm{Cr}_{2} \mathrm{O}_{3}$ & 0.04 & 0.02 & 0.00 & 0.01 & 0.00 & 0.05 & 0.04 & 0.00 & 0.00 & 0.05 \\
\hline Total & 101.31 & 100.48 & 100.71 & 100.31 & 100.69 & 100.63 & 100.21 & 100.39 & 101.20 & 98.99 \\
\hline En\% & 50.0 & 49.4 & 43.6 & 43.5 & 52.0 & 52.6 & 43.1 & 43.6 & 48.8 & 50.7 \\
\hline Fs $\%$ & 46.6 & 48.0 & 19.6 & 21.3 & 46.1 & 45.5 & 19.6 & 21.1 & 48.7 & 46.6 \\
\hline Wo \% & 3.3 & 2.5 & 36.8 & 35.2 & 1.9 & 1.9 & 37.3 & 35.3 & 2.5 & 2.7 \\
\hline Li & 7.30 & 6.53 & 7.65 & 8.59 & 6.28 & 6.21 & 8.25 & 8.37 & 7.01 & 7.17 \\
\hline Sc & 30.5 & 25.99 & 129 & 159 & 28.0 & 28.8 & 138 & 152 & 29.9 & 28.43 \\
\hline $\mathrm{Ti}$ & 685 & 402 & 643 & 516 & 528 & 522 & 805 & 563 & 500 & 443 \\
\hline v & 47.0 & 9.01 & 85.4 & 30.4 & 13.7 & 15.0 & 67.6 & 39.2 & 11.4 & 9.64 \\
\hline $\mathrm{Cr}$ & 12.8 & 1.50 & 2.50 & 4.20 & b.d.I & b.d.I & 6.70 & 3.10 & b.d.I & 2.60 \\
\hline Co & 60.0 & 47.3 & 27.4 & 18.5 & 50.7 & 49.7 & 30.2 & 24.0 & 48.6 & 45.8 \\
\hline $\mathrm{Ni}$ & 19.5 & 13.1 & 13.4 & 5.60 & 20.3 & 17.1 & 16.2 & 8.10 & 11.9 & 12.5 \\
\hline $\mathrm{Zn}$ & 507 & 553 & 164 & 162 & 550 & 558 & 140 & 142 & 557 & 560 \\
\hline Ga & 3.38 & 2.05 & 1.28 & 1.09 & 2.53 & 3.28 & 1.58 & 1.19 & 2.33 & 2.58 \\
\hline $\mathbf{R b}$ & 0.17 & 0.07 & b.d.I & 0.15 & 0.80 & 0.4 & 0.02 & 0.05 & 0.57 & 1.82 \\
\hline $\mathrm{Sr}$ & 0.22 & 0.08 & 16.1 & 9.1 & b.d.I & b.d.I & 16.4 & 10.4 & 0.23 & 0.55 \\
\hline$Y$ & 8.99 & 6.38 & 59.1 & 58.1 & 6.73 & 6.94 & 55.3 & 52.8 & 8.14 & 7.69 \\
\hline $\mathrm{Zr}$ & 1.93 & 0.70 & 18.7 & 14.3 & 1.33 & 0.82 & 22.3 & 14.1 & 1.58 & 1.48 \\
\hline $\mathrm{Ba}$ & 0.67 & 0.03 & 1.00 & 0.61 & b.d.I & 0.11 & 0.03 & 0.00 & 0.17 & 0.22 \\
\hline La & 0.42 & 0.14 & 20.5 & 27.0 & b.d.I & 0.00 & 25.0 & 18.1 & 0.10 & 0.16 \\
\hline $\mathrm{Ce}$ & 1.45 & 0.54 & 92.0 & 101 & 0.38 & 0.41 & 104 & 82.6 & 0.39 & 0.57 \\
\hline $\mathbf{N d}$ & 1.15 & 0.59 & 68.3 & 80.0 & 0.40 & 1.20 & 81.3 & 67.4 & 0.48 & 0.53 \\
\hline Sm & 0.49 & 0.25 & 17.8 & 18.2 & 0.90 & 0.80 & 15.6 & 14.7 & 0.31 & 0.29 \\
\hline $\mathrm{Eu}$ & 0.04 & 0.01 & 0.95 & 0.65 & b.d.I & b.d.I & 1.30 & 0.75 & b.d.I & b.d.I \\
\hline Gd & 0.69 & 0.60 & 15.7 & 15.8 & b.d.I & 2.40 & 13.1 & 13.4 & 0.29 & 0.60 \\
\hline $\mathrm{Yb}$ & 2.13 & 1.61 & 5.39 & 5.53 & 1.02 & 1.05 & 5.63 & 4.99 & 1.69 & 1.48 \\
\hline Lu & 0.35 & 0.28 & 0.88 & 0.93 & b.d.I & 0.37 & 0.82 & 0.78 & 0.33 & 0.30 \\
\hline $\mathrm{Pb}$ & 0.07 & 0.00 & 0.81 & 0.94 & b.d.I & 0.71 & 0.74 & 0.95 & 0.76 & 1.29 \\
\hline
\end{tabular}

\subsubsection{Clinopyroxene}

Clinopyroxene occurs in similar proportions as orthopyroxene (Hildreth, 1977; Hildreth \& Wilson, 2007), and is only found in samples which also contain orthopyroxene. Similar to orthopyroxene, large $(\geq 250 \mu \mathrm{m})$ clinopyroxenes are extremely euhedral, with no evidence for late-stage dissolution that might reflect disequilibrium. Clinopyroxene BSE images 
Table 5.5. cont.

\begin{tabular}{|c|c|c|c|c|c|c|c|c|c|c|}
\hline \multirow{5}{*}{$\begin{array}{l}\text { Sample } \\
\text { Unit } \\
\text { Pumice Type } \\
\text { Type \& ID? } \\
\text { Core or Rim? }\end{array}$} & \multirow{3}{*}{\multicolumn{2}{|c|}{$\begin{array}{l}\text { BP209 } \\
\text { Ig2Nc }\end{array}$}} & \multicolumn{4}{|l|}{ BP124 } & \multicolumn{4}{|l|}{ BP126 } \\
\hline & & & \multicolumn{4}{|l|}{ Ig2NWb } & \multicolumn{4}{|c|}{$\lg 2 \mathrm{NWb}$} \\
\hline & & & $\mathbf{x r}$ & & & & dk & & & \\
\hline & \multicolumn{2}{|l|}{ CPX-10 } & \multicolumn{2}{|l|}{ OPX-15 } & \multicolumn{2}{|l|}{ CPX-12 } & \multicolumn{2}{|l|}{ OPX-17 } & \multicolumn{2}{|l|}{ CPX-24 } \\
\hline & C & $\mathbf{R}$ & C & $\mathbf{R}$ & C & $\mathbf{R}$ & C & $\mathbf{R}$ & C & $\mathbf{R}$ \\
\hline $\mathrm{SiO}_{2}$ & 52.99 & 52.99 & 50.77 & 51.18 & 53.96 & 53.86 & 50.67 & 51.26 & 52.49 & 52.28 \\
\hline $\mathrm{Al}_{2} \mathrm{O}_{3}$ & 0.68 & 0.67 & 0.45 & 0.44 & 0.62 & 0.60 & 0.51 & 0.36 & 0.54 & 0.58 \\
\hline $\mathrm{TiO}_{2}$ & 0.13 & 0.11 & 0.07 & 0.09 & 0.07 & 0.11 & 0.24 & 0.18 & 0.08 & 0.07 \\
\hline $\mathrm{FeO}^{*}$ & 11.56 & 12.1 & 28.67 & 27.86 & 12.15 & 12.28 & 28.43 & 28.53 & 12.87 & 12.29 \\
\hline MnO & 0.45 & 0.57 & 1.23 & 1.08 & 0.54 & 0.58 & 1.15 & 1.30 & 0.68 & 0.60 \\
\hline MgO & 13.28 & 12.86 & 18.21 & 18.73 & 13.03 & 13.05 & 17.67 & 17.19 & 12.63 & 12.56 \\
\hline $\mathrm{CaO}$ & 21.22 & 21.17 & 1.13 & 1.10 & 21.42 & 21.48 & 1.33 & 1.19 & 20.69 & 21.1 \\
\hline $\mathrm{Na}_{2} \mathrm{O}$ & 0.37 & 0.39 & 0.01 & 0.02 & 0.36 & 0.36 & 0.03 & 0.02 & 0.35 & 0.35 \\
\hline $\mathrm{Cr}_{2} \mathrm{O}_{3}$ & 0.00 & 0.01 & 0.05 & 0.02 & 0.06 & 0.03 & 0.00 & 0.01 & 0.00 & 0.00 \\
\hline Total & 100.71 & 100.9 & 101.89 & 101.35 & 102.2 & 102.36 & 100.16 & 99.37 & 100.33 & 99.84 \\
\hline En\% & 43.2 & 43.2 & 50.9 & 52.4 & 43.3 & 43.2 & 50.2 & 49.4 & 42.4 & 43.4 \\
\hline Fs \% & 19.1 & 20.2 & 46.9 & 45.4 & 20.0 & 20.2 & 47.1 & 48.1 & 21.7 & 20.7 \\
\hline Wo \% & 37.7 & 36.6 & 2.3 & 2.2 & 36.7 & 36.6 & 2.7 & 2.5 & 36.0 & 35.9 \\
\hline Li & 7.35 & 7.57 & 6.43 & 6.33 & 7.51 & 7.27 & 6.15 & 5.93 & 8.43 & 7.65 \\
\hline Sc & 133 & 177 & 29.3 & 29.1 & 110 & 114 & 30.5 & 27.4 & 128 & 153 \\
\hline $\mathrm{Ti}$ & 763 & 594 & 544 & 545 & 591 & 604 & 576 & 468 & 587 & 574 \\
\hline $\mathbf{V}$ & 59.4 & 45.5 & 16.6 & 15.8 & 41.0 & 42.2 & 17.1 & 9.90 & 32.1 & 40.2 \\
\hline $\mathrm{Cr}$ & 1.80 & 2.50 & 13.4 & 9.10 & 8.60 & 2.00 & 6.10 & 5.70 & 2.10 & 3.90 \\
\hline Co & 28.5 & 22.3 & 52.5 & 54.1 & 23.6 & 22.4 & 54.7 & 47.5 & 20.0 & 23.0 \\
\hline $\mathrm{Ni}$ & 12.0 & 7.30 & 24.3 & 23.1 & 11.9 & 11.5 & 21.3 & 15.9 & 5.80 & 8.90 \\
\hline $\mathrm{Zn}$ & 117 & 143 & 534 & 529 & 147 & 156 & 501 & 533 & 151 & 152 \\
\hline Ga & 1.33 & 1.38 & 3.97 & 2.63 & 0.80 & 0.84 & 3.85 & 2.04 & 1.07 & 0.98 \\
\hline $\mathbf{R b}$ & 0.08 & 0.14 & b.d.I & 0.97 & b.d.I & b.d.I & 0.50 & 0.50 & 0.06 & 0.06 \\
\hline $\mathrm{Sr}$ & 15.9 & 12.7 & 0.57 & 1.27 & 9.40 & 9.14 & 0.47 & 0.09 & 9.50 & 11.5 \\
\hline$Y$ & 58.0 & 70.7 & 9.40 & 7.75 & 51.3 & 58.7 & 9.96 & 7.21 & 66.6 & 57.2 \\
\hline $\mathrm{Zr}$ & 21.5 & 19.3 & 0.86 & 1.11 & 11.4 & 14.1 & 1.21 & 0.60 & 17.2 & 13.8 \\
\hline $\mathrm{Ba}$ & 0.11 & 0.11 & 0.23 & 1.72 & 1.5 & 1.80 & 0.22 & 0.70 & 0.12 & 0.10 \\
\hline La & 26.4 & 22.0 & 5.50 & 2.41 & 17.2 & 18.5 & 4.59 & b.d.l & 18.9 & 19.0 \\
\hline $\mathrm{Ce}$ & 94.7 & 90.0 & 12.7 & 4.70 & 72.0 & 77.7 & 11.2 & 0.25 & 81.7 & 83.8 \\
\hline Nd & 74.6 & 78.4 & 8.00 & 2.02 & 63.5 & 70.3 & 5.23 & 0.72 & 68.0 & 70.9 \\
\hline Sm & 16.2 & 17.6 & 1.12 & 1.22 & 12.9 & 14.7 & 0.92 & 0.82 & 17.2 & 16.8 \\
\hline Eu & 1.25 & 0.92 & 0.13 & 0.50 & 0.96 & 0.91 & b.d.l & 0.15 & 0.71 & 0.74 \\
\hline Gd & 13.9 & 18.0 & 1.90 & 0.42 & 12.5 & 14.2 & 1.33 & 0.8 & 15.6 & 16.4 \\
\hline $\mathbf{Y b}$ & 5.26 & 6.45 & 1.89 & 1.27 & 4.00 & 4.01 & 1.75 & 1.58 & 5.97 & 5.44 \\
\hline Lu & 0.91 & 1.09 & 0.34 & 0.26 & 0.65 & 0.55 & 0.55 & 0.13 & 0.97 & 0.84 \\
\hline $\mathrm{Pb}$ & 0.77 & 0.83 & 0.12 & 0.67 & 0.77 & 0.73 & b.d.I & b.d.I & 0.82 & 0.90 \\
\hline
\end{tabular}

commonly show more well-developed zoning patterns than orthopyroxene crystals, but again can be divided into 4 groups: unzoned crystals, those with a bright rim, those with a dark rim and those with a more complex zoning pattern (Fig. 5.3).

Major element analyses $(n=248)$ and trace element analyses $(n=143)$ of clinopyroxene were carried out and clinopyroxene compositions vary between $41.7 \%$ Wo and $44.2 \%$ Wo. Major element concentrations are uniform apart from slight variations in $\mathrm{SiO}_{2}, \mathrm{CaO}$ and $\mathrm{MgO}$ (Table 5.5; Fig. 5.7b). Trace elements are more variable than in the orthopyroxene: 
Zn correlates negatively against $\mathrm{Eu}, \mathrm{Zr}, \mathrm{Ni}$ and $\mathrm{Co}$, but correlates positively with $\mathrm{Mn}$ and Y. However, these observed variations are not distinguishable by core/rims, pumice type (swirly vs. normal, xp vs. xr) or by north vs. northwestern ignimbrite packages (Fig. 5.7d,f). In the last case, both cores and rims show the same ranges in trace element concentrations. Zoning type is also not a control on the observed trace element variations.

\subsubsection{Glass host material}

Fifty-six samples of separated glass fractions from the Bishop Tuff were analysed, as well as two samples of precursory Glass Mountain material. The data set comprises both major element $(n=1571)$ and trace element $(n=697)$ analyses. Elements with concentrations close to the detection limit using EPMA were also analysed using LA-ICPMS to improve precision and accuracy. Bishop Tuff samples from which the glass was separated ranged from crystal poor (xp) typical eastern-type pumice to crystal rich (xr) northern-type pumice, and also included samples of variant 'swirly' pumice and porphyritic dacite (Table 5.1).

\subsubsection{Glass chemistry from 'normal' early- and intermediate-erupted pumices}

Eastern pumice clasts (representative of earliest- to intermediate-erupted magma) are typically crystal-poor to crystal-medium, although some of the rare crystal-rich pumices of eastern units also had their matrix glass analysed for comparison (see Table 5.1). Major element glass chemistry is very restricted in eastern samples, all having $\mathrm{SiO}_{2}$ contents (calculated volatile free) of $75.9-78.4$ wt. $\%$ ( \pm 2 wt. $\%, 2$ s.d. for $\mathrm{SiO}_{2}$ analyses from EPMA analysis) with no measurable variations beyond analytical uncertainties in $\mathrm{TiO}_{2}, \mathrm{FeO}, \mathrm{MnO}$, $\mathrm{MgO}$ and $\mathrm{BaO}$ (Table 5.6). Slight variations in $\mathrm{K}_{2} \mathrm{O}, \mathrm{Al}_{2} \mathrm{O}_{3}, \mathrm{CaO}$ and $\mathrm{Na}_{2} \mathrm{O}$ are observed, but these are hard to resolve beyond analytical uncertainty on EPMA analyses (Fig. 5.8). Trace element analyses of eastern glass reveal much more distinctive chemical variations and highlight systematic trends in eastern units. The most evolved glass compositions, with the lowest Sr, Ba, LREE, Ca, Ti, Zr and Mg contents, and the highest incompatible element ( $\mathrm{Rb}, \mathrm{Nb}, \mathrm{Cs})$ contents are found in the very earliest fall material (F1, F2) and some Ig1E samples (Table 5.6; Fig. 5.8c). The measured variations within a given pumice increase with progression through the eruption, with some eastern pumices displaying a fivefold increase in the ranges of $\mathrm{Ba}$ and $\mathrm{Sr}$ concentrations from different glass shards yielded by crushing of a single pumice (Fig. 5.8). By comparing the compositional data of eastern glass samples with data from glass matrices from pumices in the Ig1NW, Ig1SW 
and Ig2SW ignimbrite packages, it is clear that samples from these units all share trace element characteristics similar to the 'normal' eastern type samples (Fig. 5.8).
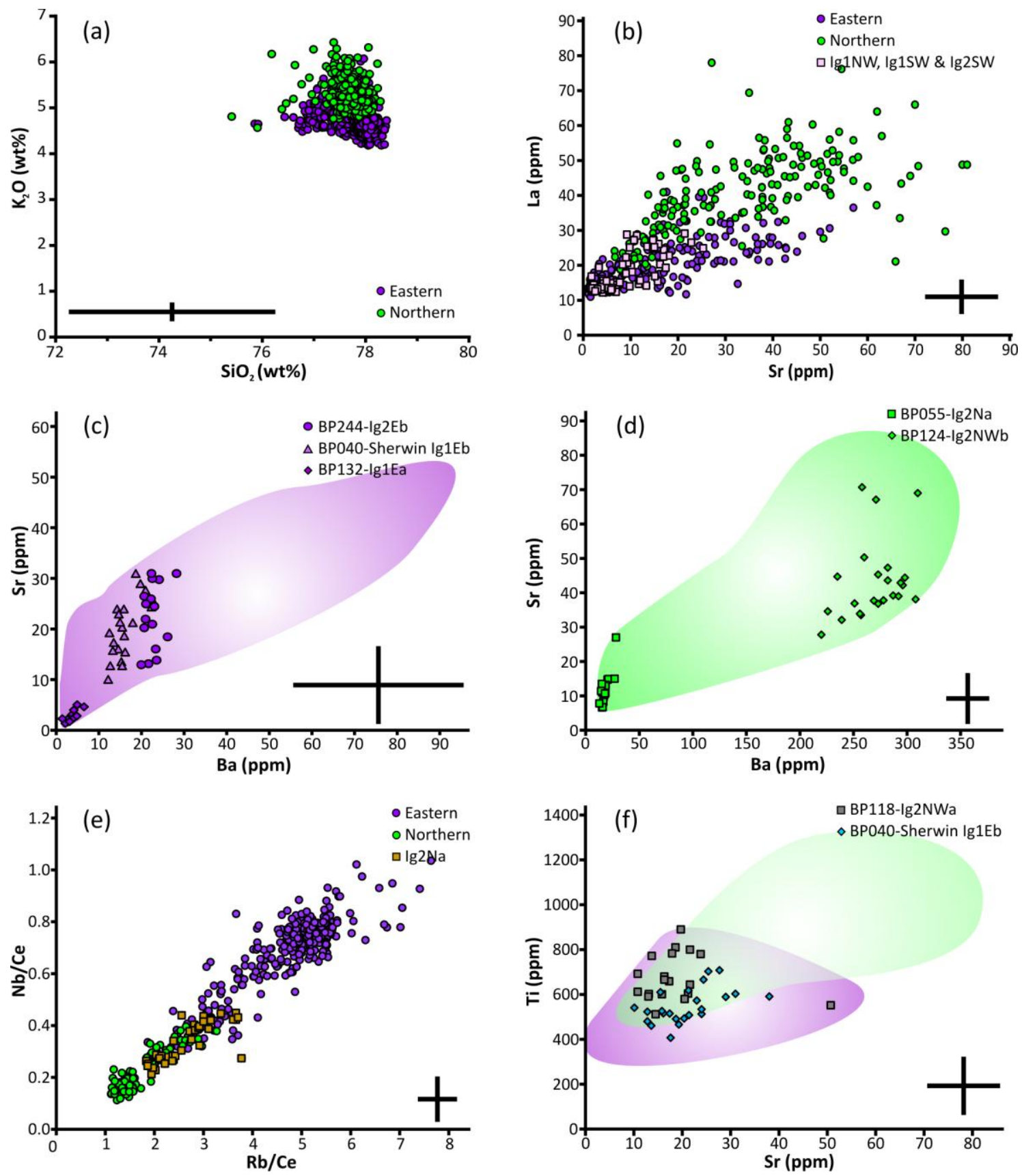

Fig. 5.8. Major (a) and trace (b to f) element variations in glass from samples in the crystalpoor to crystal-rich range of 'normal' pumices (as defined by Hildreth \& Wilson, 2007) of the Bishop Tuff. Eastern samples are plotted as purple filled circles and shaded fields; northern samples as green filled circles and shaded fields. Ig1NW, Ig1SW and Ig2SW data are plotted as pink filled squares in panel (b); Ig2Na data as gold filled squares in panel (e). Illustrative single sample variations are shown in panels (c) and (d). All error crosses represent 2 s.d. uncertainties from standard analyses. The full data set is available in Electronic Appendices 11 and 12. 
Table 5.6. Representative normalised analyses of glass host materials. Where b.d.l. is used, element was below detection limit of the LA-ICPMS techniques. The least evolved 'normal' Bishop glass is shown here as BP124 10_7 and BP209 6_1. For raw data see Electronic Appendix 11. For full data set see Electronic Appendices 11 and 12.

\begin{tabular}{|c|c|c|c|c|c|c|c|c|}
\hline $\begin{array}{l}\text { Sample } \\
\text { Unit } \\
\text { Pumice Type } \\
\text { Shard ID } \\
\end{array}$ & $\begin{array}{l}\text { BP109 } \\
\text { F1 } \\
\times 1 \\
2 \_1\end{array}$ & $\begin{array}{l}\text { BP080 } \\
\text { Ig1Eb } \\
\text { vxp } \\
1 \_4 \\
\end{array}$ & $\begin{array}{l}\text { BP244 } \\
\text { Ig2Eb } \\
x r \\
10 \_3 \\
\end{array}$ & $\begin{array}{l}\mathrm{BP} 060 \\
\text { Ig2Na } \\
\mathrm{xr} \\
4 \_1\end{array}$ & $\begin{array}{l}\text { BP115 } \\
\text { Ig2Nwa } \\
\text { vxr } \\
11 \_1 \\
\end{array}$ & $\begin{array}{l}\text { BP170 } \\
\text { Ig2Nb } \\
x r \\
4 \_4 \\
\end{array}$ & $\begin{array}{l}\text { BP209 } \\
\text { Ig2Nc } \\
\text { vxr } \\
5 \_3\end{array}$ & $\begin{array}{l}\text { BP124 } \\
\text { Ig2NWb } \\
x r \\
10 \_7\end{array}$ \\
\hline $\mathrm{SiO}_{2}$ & 77.59 & 77.83 & 78.04 & 77.83 & 77.84 & 77.65 & 78.06 & 76.96 \\
\hline $\mathrm{Al}_{2} \mathrm{O}_{3}$ & 12.56 & 12.78 & 12.67 & 12.67 & 12.47 & 12.57 & 12.33 & 12.87 \\
\hline $\mathrm{TiO}_{2}$ & 0.03 & 0.05 & 0.07 & 0.11 & 0.11 & 0.15 & 0.16 & 0.16 \\
\hline FeO* & 0.60 & 0.65 & 0.36 & 0.30 & 0.70 & 0.40 & 0.33 & 0.75 \\
\hline MnO & 0.00 & 0.03 & 0.01 & 0.02 & 0.03 & 0.04 & 0.00 & 0.01 \\
\hline MgO & 0.04 & 0.02 & 0.04 & 0.04 & 0.08 & 0.06 & 0.02 & 0.09 \\
\hline $\mathrm{CaO}$ & 0.40 & 0.44 & 0.44 & 0.51 & 0.51 & 0.47 & 0.55 & 0.58 \\
\hline $\mathrm{Na}_{2} \mathrm{O}$ & 4.11 & 3.77 & 3.68 & 3.21 & 3.17 & 3.42 & 3.16 & 3.22 \\
\hline $\mathrm{K}_{2} \mathrm{O}$ & 4.67 & 4.43 & 4.69 & 5.28 & 5.06 & 5.20 & 5.34 & 5.29 \\
\hline $\mathrm{BaO}$ & 0.00 & 0.00 & 0.00 & 0.04 & 0.04 & 0.04 & 0.05 & 0.55 \\
\hline Total & 100 & 100 & 100 & 100 & 100 & 100 & 100 & 100 \\
\hline Li & 49.3 & 57.6 & 33.0 & 37.9 & 32.0 & 28.1 & 38.2 & 25.9 \\
\hline $\mathrm{Mg}$ & 197 & 221 & 660 & 343 & 702 & 546 & 380 & 540 \\
\hline $\mathrm{Ca}$ & 4400 & 3130 & 3370 & 2800 & 4370 & 3980 & 5380 & 5300 \\
\hline Sc & 6.60 & 13.9 & 6.70 & 5.70 & 7.80 & 8.59 & 9.30 & 6.90 \\
\hline $\mathrm{Ti}$ & 347 & 434 & 526 & 630 & 970 & 791 & 935 & 796 \\
\hline V & 0.10 & 0.16 & 0.75 & 0.83 & 1.48 & 0.93 & 2.22 & 1.17 \\
\hline $\mathrm{Cr}$ & 1.30 & 2.30 & 0.40 & 7.00 & b.d.I & b.d.I & 5.00 & 13.3 \\
\hline Mn & 226 & 263 & 210 & 201 & 180 & 153 & 67.0 & 159 \\
\hline $\mathrm{Cu}$ & 2.60 & 2.10 & b.d.I & 0.80 & b.d.I & b.d.l & 5.60 & 1.80 \\
\hline $\mathrm{Zn}$ & 30.6 & 30.5 & 24.4 & 14.9 & 13.6 & 14.3 & 4.70 & 36.0 \\
\hline Ga & 15.1 & 16.2 & 18.4 & 15.7 & 15.2 & 14.2 & 15.4 & 15.1 \\
\hline $\mathbf{R b}$ & 180 & 197 & 153 & 140 & 121 & 166.7 & 115 & 113 \\
\hline $\mathrm{Sr}$ & 1.54 & 6.50 & 30.0 & 12.5 & 54.0 & 53.7 & 54.0 & 42.9 \\
\hline$Y$ & 17.2 & 22.0 & 13.8 & 9.90 & 17.1 & 12.1 & 13.5 & 8.60 \\
\hline $\mathrm{Zr}$ & 49.2 & 72.5 & 85.2 & 73.0 & 166 & 124 & 149 & 102 \\
\hline $\mathrm{Nb}$ & 22.6 & 26.8 & 20.2 & 16.7 & 18.0 & 12.6 & 13.7 & 12.4 \\
\hline Cs & 4.12 & 5.83 & 4.70 & 3.26 & 3.08 & 2.85 & 2.65 & 2.20 \\
\hline $\mathrm{Ba}$ & 1.91 & 2.01 & 22.8 & 68.2 & 262 & 232 & 316 & 294 \\
\hline La & 11.0 & 14.2 & 28.3 & 28.2 & 51.5 & 49.7 & 58.2 & 38.7 \\
\hline $\mathrm{Ce}$ & 29.9 & 39.4 & 52.6 & 59.0 & 87.0 & 81.6 & 85.4 & 83.0 \\
\hline $\mathrm{Pr}$ & 3.14 & 3.92 & 5.37 & 5.89 & 10.0 & 7.80 & 7.45 & 6.20 \\
\hline Nd & 10.3 & 13.8 & 17.4 & 13.7 & 28.3 & 25.8 & 26.6 & 16.2 \\
\hline Sm & 2.62 & 3.90 & 1.97 & 1.79 & 4.30 & 3.94 & 4.00 & 1.97 \\
\hline Eu & 0.01 & 0.09 & 0.10 & 0.30 & 0.20 & 0.29 & 0.07 & 0.33 \\
\hline Gd & 2.04 & 3.39 & 2.70 & 2.35 & 3.90 & 2.82 & 3.20 & 1.61 \\
\hline $\mathrm{Yb}$ & 1.65 & 1.86 & 2.27 & 1.91 & 2.08 & 0.88 & 1.58 & 1.49 \\
\hline Lu & 0.27 & 0.40 & 0.19 & 0.46 & 0.37 & 0.18 & 0.31 & 0.20 \\
\hline Hf & 2.66 & 3.64 & 2.90 & 2.12 & 4.80 & 3.37 & 4.50 & 2.49 \\
\hline $\mathrm{Pb}$ & 27.2 & 34.2 & 36.3 & 26.9 & 31.6 & 35.9 & 44.3 & 23.9 \\
\hline Th & 16.9 & 19.4 & 15.9 & 14.8 & 18.2 & 14.4 & 15.9 & 11.2 \\
\hline $\mathbf{U}$ & 7.30 & 8.26 & 5.62 & 4.74 & 4.46 & 3.47 & 3.35 & 3.85 \\
\hline
\end{tabular}

\subsubsection{Glass chemistry from 'normal' late-erupted pumices}

Glass matrix samples from pumices in northern ignimbrite lobes (representative of lateerupted material) and fall unit 9 (F9) of the Bishop Tuff have more variable chemistries than earlier, eastern samples, although $\mathrm{SiO}_{2}$ values cover a similar range (75.4 to 78.3 wt.\%, 
Table 5.6. cont.

\begin{tabular}{|c|c|c|c|c|c|}
\hline Sample & BP209 & BP211-rhyolite & BP211-dacite & BR228 & BR226 \\
\hline Unit & $\lg 2 \mathrm{Nc}$ & $\lg 2 N W b$ & Ig2NWb & Dome YA & Dome OD \\
\hline Pumice Type & vxr & $\mathbf{x r}$ & dc & $x p$ & $\mathbf{x r}$ \\
\hline Shard ID & 6_1 & 9_2 & 23_2 & 12_1 & 1_2 \\
\hline $\mathrm{SiO}_{2}$ & 77.71 & 77.38 & 68.31 & 77.78 & 77.71 \\
\hline $\mathrm{Al}_{2} \mathrm{O}_{3}$ & 12.59 & 12.84 & 15.40 & 12.41 & 12.59 \\
\hline $\mathrm{TiO}_{2}$ & 0.15 & 0.06 & 0.71 & 0.10 & 0.03 \\
\hline $\mathrm{FeO}^{*}$ & 0.36 & 0.21 & 2.56 & 0.62 & 0.55 \\
\hline MnO & 0.00 & 0.00 & 0.00 & 0.03 & 0.03 \\
\hline MgO & 0.03 & 0.06 & 2.04 & 0.03 & 0.00 \\
\hline $\mathrm{CaO}$ & 0.54 & 0.63 & 2.75 & 0.46 & 0.36 \\
\hline $\mathrm{Na}_{2} \mathrm{O}$ & 3.15 & 2.86 & 3.41 & 3.59 & 3.97 \\
\hline $\mathrm{K}_{2} \mathrm{O}$ & 5.41 & 5.93 & 4.73 & 4.97 & 4.76 \\
\hline $\mathrm{BaO}$ & 0.06 & 0.02 & 0.09 & 0.00 & 0.01 \\
\hline Total & 100 & 100 & 100 & 100 & 100 \\
\hline Li & 29.6 & 18.7 & 48.7 & 52.5 & 113 \\
\hline $\mathrm{Mg}$ & 1060 & 655 & 16940 & 276 & 125 \\
\hline $\mathrm{Ca}$ & 4640 & 5030 & 23900 & 2890 & 2110 \\
\hline Sc & 8.80 & 5.60 & 11.7 & 8.50 & 16.8 \\
\hline $\mathrm{Ti}$ & 951 & 628 & 4080 & 488 & 243 \\
\hline V & 2.16 & 1.70 & 63.0 & 0.20 & 0.50 \\
\hline $\mathrm{Cr}$ & 2.00 & 7.00 & 13.0 & 0.80 & 1.20 \\
\hline Mn & 246 & 55.0 & 451 & 217 & 487 \\
\hline $\mathrm{Cu}$ & 15.1 & 19.5 & 9.40 & b.d.I & b.d.I \\
\hline $\mathrm{Zn}$ & 13.3 & 9.10 & 38.7 & 26.3 & 45.5 \\
\hline Ga & 21.0 & 14.0 & 15.9 & 14.5 & 19.5 \\
\hline $\mathbf{R b}$ & 119 & 116 & 78.7 & 172 & 290 \\
\hline $\mathrm{Sr}$ & 54.5 & 84.1 & 344 & 1.74 & 0.20 \\
\hline $\mathbf{Y}$ & 16.5 & 10.8 & 13.8 & 15.8 & 29.1 \\
\hline $\mathrm{Zr}$ & 143 & 88.5 & 147 & 69.6 & 63.1 \\
\hline $\mathrm{Nb}$ & 14.5 & 12.9 & 17.2 & 21.5 & 52.7 \\
\hline Cs & 2.75 & 2.75 & 1.98 & 5.12 & 10.2 \\
\hline $\mathrm{Ba}$ & 338 & 262 & 811 & 5.35 & 0.51 \\
\hline La & 76.2 & 42.6 & 46.0 & 25.0 & 7.64 \\
\hline $\mathrm{Ce}$ & 106 & 79.3 & 83.7 & 36.4 & 28.0 \\
\hline $\mathrm{Pr}$ & 10.0 & 8.54 & 7.70 & 5.61 & 3.48 \\
\hline Nd & 39.8 & 25.1 & 29.2 & 20.4 & 13.7 \\
\hline Sm & 6.50 & 2.90 & 4.50 & 3.87 & 4.81 \\
\hline Eu & 0.30 & 0.42 & 0.77 & 0.02 & 0.06 \\
\hline Gd & 4.30 & 2.10 & 3.30 & 2.58 & 4.53 \\
\hline Yb & 2.14 & 0.25 & 1.03 & 1.76 & 3.15 \\
\hline Lu & 0.37 & 0.20 & 0.31 & 0.26 & 0.48 \\
\hline Hf & 4.75 & 2.64 & 3.68 & 2.45 & 3.88 \\
\hline $\mathrm{Pb}$ & 52.6 & 39.1 & 29.1 & 29.7 & 41.1 \\
\hline Th & 15.8 & 11.7 & 8.80 & 15.0 & 26.2 \\
\hline $\mathbf{U}$ & 4.09 & 3.92 & 2.23 & 6.57 & 13.5 \\
\hline
\end{tabular}

volatile free). Samples of northern glass are all more enriched in Ba, Sr, LREE, Ti and Zr when compared with eastern glass, and similarly are depleted in $\mathrm{Mn}, \mathrm{Rb}, \mathrm{Nb}, \mathrm{Cs}$, Th and $\mathrm{U}$ (Table 5.6; Fig. 5.8). Ig2Na and F9 have the most evolved compositions of all later-erupted material, apparently delineating an overlap in composition between earlier, eastern, moreevolved glass, and later, northern less-evolved glass (Fig. 5.8). Single-pumice variation in 
glass compositions is also much greater in later, northern-sourced pumices than in those from earlier, eastern units, with $\mathrm{Ba}$ varying by up to $\sim 100 \mathrm{ppm}$ within a single sample (Fig. 5.8). Interestingly, one xr pumice collected in the suite from Ig2NWa (BP118) has glass chemistry which completely overlaps the 'eastern' field of measured glass compositions, which, coupled with the poorly zoned nature of its sanidine, quartz and zircon, and no identifiable pyroxene, suggests an 'eastern' origin for the magma. Other samples from the same location (loc. 208: Crestview cut on Highway US395) do not overlap with the earlier, eastern field (Fig. 5.8f) and display the expected zonation within crystals.

\subsubsection{Glass chemistry from variant (swirly, dark) pumices}

Swirly pumices are typically very finely vesicular and thus it is challenging to locate laser spots on the glass shards created by crushing. Of the samples identified as 'swirly' or 'dark' in hand specimen (Table 5.1) only five clasts showed any distinct differences from the 'normal' suite of Bishop Tuff pumice glass. Samples BP032, BP197, BP198, BP230 and BP232 all show enrichments in $\mathrm{Ca}, \mathrm{Fe}, \mathrm{Ti}$ and $\mathrm{Mg}$ compared with 'normal' Bishop glass (eastern and northern sampled; Fig. 5.9a,b), coupled with enrichments in Ca, Ba, Ti, V, Mn, Sr and $\mathrm{Mg}$ (Fig. 5.9). There is, however, no variation in any REE, or highly incompatible elements such as $\mathrm{Rb}, \mathrm{Nb}$ or $\mathrm{Cs}$. Variations within single pumices are very large within these swirly pumices, greatly exceeding those observed in northern normal pumice clasts.

\subsubsection{Glass from dacitic juvenile clasts}

Three dacite samples were examined for this study and all have glass compositions which are distinctly different from all other glass analysed from the Bishop Tuff. The dacite samples were from unit Ig2NWb, from pumices where black (or red, where oxidised) dacite is comingled with a white rhyolite. Instead of seeing a continuum in glass chemistry, as evidenced from variable degrees of mixing in swirly samples, distinctly bimodal behaviour is observed. The white rhyolite 'normal' glass component mingled in the pumices overlaps with the northern Bishop glass field. In contrast, the darker dacite (glass $\mathrm{SiO}_{2}$ of $64.6-69.9$ wt. $\%$, volatile free) is very significantly enriched (by factors of up to $4-$ 5 times: Table 5.6) in $\mathrm{Ba}, \mathrm{Sr}, \mathrm{Mg}, \mathrm{Ti}, \mathrm{V}, \mathrm{Ca}, \mathrm{Zr}, \mathrm{Eu}$ and $\mathrm{Ni}$, with accompanying depletion in $\mathrm{Rb}$ when compared with Bishop glass (see Table 5.6; Fig. 5.9). The lack of intervening glass compositions shows that very little chemical mixing occurred between these two glass types prior to or during eruption. 

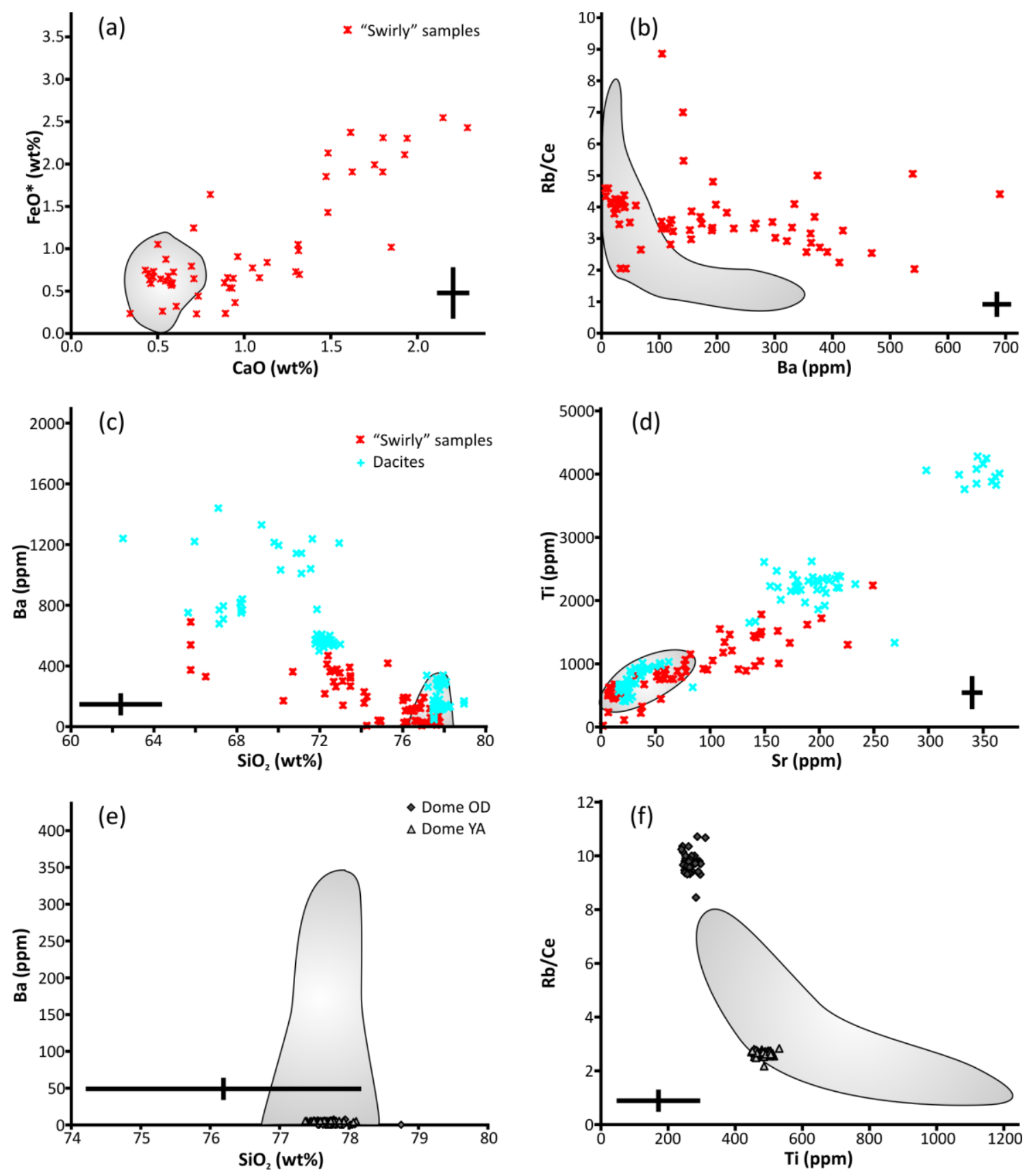

Fig. 5.9. Major (a) and trace (b to d) element variations in glass from samples in the range of 'variant' pumices (as defined by Hildreth \& Wilson, 2007) in the Bishop Tuff: swirly pumices are red crosses, dacitic pumices are blue crosses. Glass Mountain glass compositions from Dome OD (diamonds) and Dome YA (triangles) are shown in panels (e) and (f). The grey field outlines the total range of glass compositions from 'normal' Bishop pumices. All error crosses represent 2 s.d. uncertainties from standard analyses. The full data set is available in Electronic Appendices 11 and 12.

\subsubsection{Glasses from Glass Mountain domes YA and OD}

The glass groundmass in the youngest dated Glass Mountain dome (YA) is chemically indistiguishable from glass in the eastern Bishop Tuff, overlapping in all major and trace element characteristics. Contrastingly, glass from Glass Mountain dome OD (older, 1.702 
\pm 0.011 Ma, revised from Davies et al., 1994, using the calibration of Renne et al., 2011 for the Hb3gr standard) is more chemically distinct from the Bishop Tuff with higher $\mathrm{SiO}_{2}$ concentrations (77.5 and 78.8 wt.\%) mirrored by higher concentrations of $\mathrm{Li}, \mathrm{Mn}, \mathrm{Rb}, \mathrm{Nb}$, Cs, U and lower Ca, Ti, Mg, Sr, Ba and LREE than eastern Bishop glass, (Table 5.6; Fig. 5.9).

\subsection{Discussion}

Here I use the major and trace element analyses of glass and phenocrysts from samples spanning the entire eruptive spectrum of the Bishop Tuff, to address five key issues which remain unsolved with regards to the Bishop Tuff.

1) Did all the crystals grow in the melt in which they are now found (as proposed by Hildreth, 1977, 1979)? If not, then which crystals were sourced from what magmas (see Chamberlain et al., 2014a [Chapter 3]).

2) What was the nature of zonation within the pre-eruptive Bishop magma chamber, and what role did the intrusion of the 'bright-rim' magma have in establishing this zonation (Chamberlain et al., 2014 a,b [Chapters 3 and 4])?

3) Where did the minor ignimbrite packages of Ig1SW and Ig2SW (Fig. 5.2; Wilson \& Hildreth, 1997) originate? How do they relate to zoning within the Bishop magma chamber?

4) What was the chemical relationship between the precursory Glass Mountain activity and the Bishop Tuff, given that recent zircon studies reveal a $\sim 100 \mathrm{kyr}$ time break between the last Glass Mountain eruption and the Bishop Tuff eruption (Chamberlain $e t$ al., 2014a [Chapter 3])?

5) What information about the morphology of the Bishop magma chamber can be gleaned from crystal and glass chemistry, and how does this compare with proposed models for two distinct magma chambers feeding the Bishop Tuff eruption (Gualda et al., 2012a; Gualda \& Ghiorso, 2013a)?

\subsubsection{Origin of Bishop crystals}

Compositional zonation within pumice samples in the Bishop Tuff is clearly highlighted by whole-rock major and trace element compositional data of other authors which show a 
change from, for example, $\sim 30 \mathrm{ppm} \mathrm{Ba}$ in early fall units through to $\sim 500 \mathrm{ppm} \mathrm{Ba}$ in late (Ig2Nb/c and Ig2NWb- Fig. 5.2) ignimbrite units (Hildreth, 1979; Hildreth \& Wilson, 2007). Initially it was suggested that all phenocryst phases grew within the melt composition in which they were immersed on eruption (Hildreth, 1979) with no evidence of what would now be called 'antecrystic' major phases that grew in an underlying mushy zone (e.g. Bacon \& Lowenstern, 2005; Charlier et al., 2005, 2008; Allan et al., 2013; Cooper, 2014). If all Bishop crystals are true phenocrysts, changes in crystal chemistry must reflect the already established changes in magma chemistry in the magma chamber (Hildreth, 1979; Halliday et al., 1984; Hildreth \& Wilson, 2007). However, identification of zoning within sanidine, quartz, zircon and orthopyroxene in later-erupted units of the Bishop Tuff has highlighted that this cannot be the case at least for certain regions of the Bishop magma chamber (Wallace et al., 1999; Anderson et al., 2000; Peppard et al., 2001; Simon \& Reid, 2005; Wark et al., 2007; Chamberlain et al., 2014a,b [Chapters 3 and 4]). This zoning is interpreted to reflect the presence of a rejuvenating, less-evolved magma which affects the deeper parts of the Bishop Tuff magma chamber, and caused the overgrowth rims richer in $\mathrm{Ba}$ and $\mathrm{Sr}$ in sanidine, richer in Ti in quartz, and poorer in U, Th and REE in zircon crystals (Anderson et al., 2000; Peppard et al., 2001; Gualda, 2007; Hildreth \& Wilson, 2007; Wark et al., 2007; Gualda et al., 2012b; Roberge et al., 2013; Chamberlain et al., 2014a,b [Chapters 3 and 4]), and may in turn bring in zircons (and potentially other crystals, investigated here) (Wark et al., 2007; Roberge et al., 2013; Chamberlain et al., 2014a,b [Chapters 3 and 4]). By examining the systematic changes in crystal chemistry from the earliest to the latest units of the Bishop Tuff, including the difference between cores and rims, insights into any compositional variations within the melt-dominant magma body, both before and after the late-stage mixing event, can be gained.

\subsubsection{Phenocrysts in the Bishop magma}

The late-stage mixing event(s) in the deeper parts of the Bishop magma chamber affected the overall stratification of the Bishop magma chamber. In order to trace any compositional stratification in the melt-dominant magma body prior to this mixing event, I consider only the cores of crystals, to eliminate the role of the late-stage overgrowths. Twofeldspar thermometry on plagioclase inclusions within sanidine cores, or sanidine inclusions within plagioclase cores, reveals a distinct variation in model temperatures of $\sim 80{ }^{\circ} \mathrm{C}$ from early eastern units to late northern units (Chamberlain et al., 2014b [Chapter 4]). This variation correlates well with the $\mathrm{Ba}$, Sr and LREE contents of the matrix glass of 
the samples from which the crystals are taken (Fig. 5.10a). This trend in turn is matched when all trace element data from sanidine are considered (Fig. 5.10b), whereby sanidine cores in earlier eastern deposits have much more-evolved values, with much less variability (Fig. 5.4). The sanidine data presented here show that the Bishop Tuff magma chamber was zoned prior to any late-stage mixing with the 'bright-rim' magma, and that sanidine crystals are true 'Bishop' phenocrysts. This is consistent with the notion that the Bishop magma body assembled by piecemeal release of nearly aphyric melts from a common mush zone, which then rose to their respective levels of neutral buoyancy based on slight compositional differences and underwent some crystallisation (Hildreth \& Wilson, 2007).
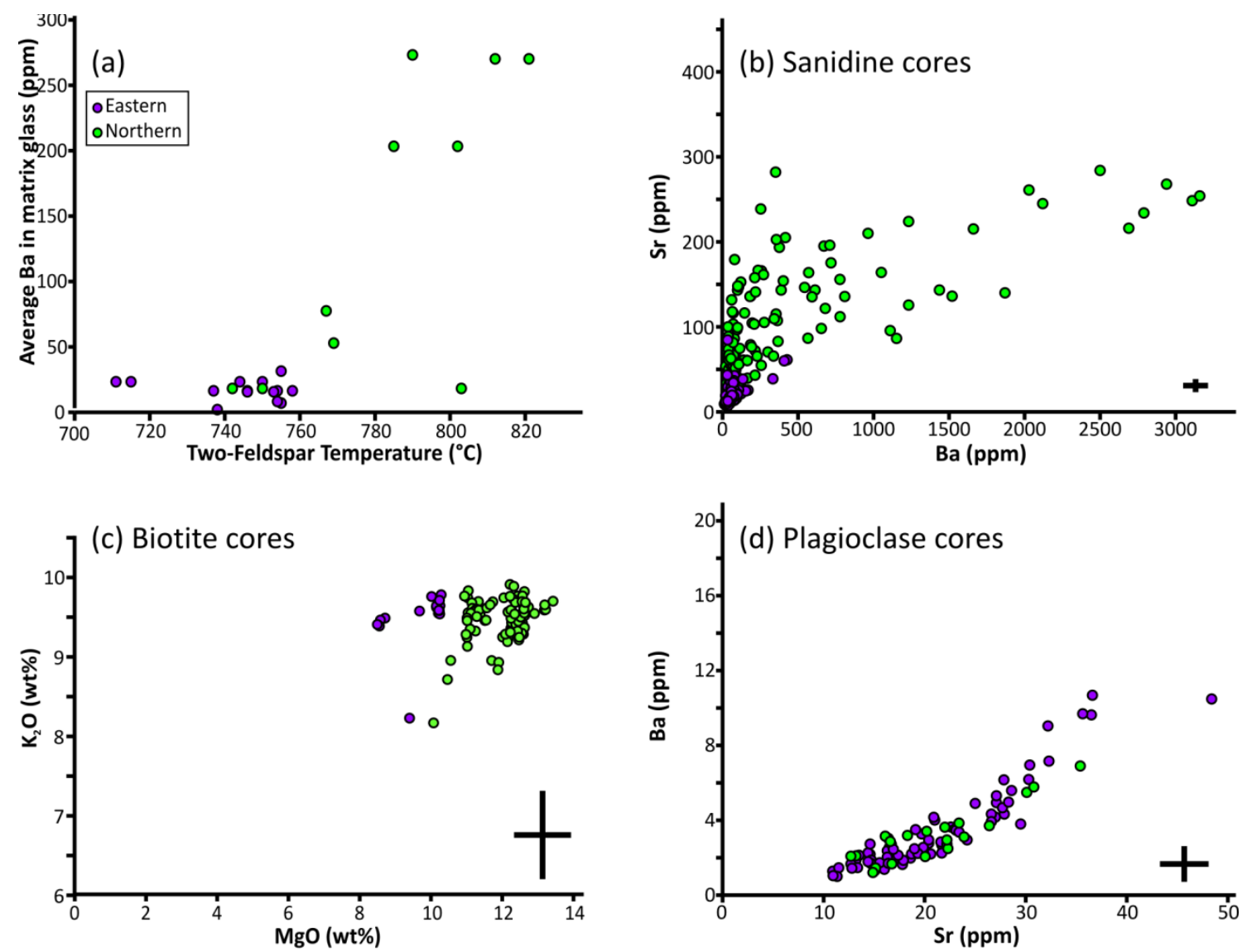

Fig.5.10. Summary of crystal compositional data providing evidence for thermal and compositional stratification within the Bishop Tuff prior to intrusion of the 'bright-rim' magma. (a) Two-feldspar temperatures from Chamberlain et al. (2014b [Chapter 4]) plotted against the average $\mathrm{Ba}$ content of glass from the same sample. Trace element variations in sanidine (b), biotite (c) and plagioclase (d) cores plotted by eruptive timing. Eastern samples are purple filled circles; northern samples are green filled circles. All error crosses represent 2 s.d. uncertainties from standard analyses. 
Although there is no systematic difference in the core composition of low-Ca plagioclase crystals from eastern and northern units of the Bishop Tuff (Fig. 5.10d) their euhedral appearance, and occurrence as inclusions within sanidine crystals, points to the fact that the low-Ca plagioclase are also true Bishop phenocrysts, and grew in the melt dominant magma chamber. Similarly, biotite crystal chemistries do not vary significantly between eastern-sourced pumice clasts and northern-source pumice clasts, and any variations are outweighed in some samples by syn- to post-eruptive alteration (section 5.4.3; Hildreth, 1977). However, the rapid re-equilibration of biotite chemistry at magmatic temperatures (Lasaga, 1983), and the occurrence of biotite throughout the Bishop Tuff eruptive sequence (Hildreth, 1977, 1979), would suggest that the biotite crystals were in equilibrium with the melt with which it was erupted.

Pyroxene, although only present in northern units, shows no variability between different northern units, both in cores and rim (Fig. 5.7). My data imply that any variations within or between the northern units is too small to be traced in pyroxenes, and that the pyroxenes are a late-stage component (possibly entering the magma chamber with the 'bright rim' forming magma - see below). The latter situation would explain why the pyroxenes show such small variations and diverse changes from core to rims. The cores do not reflect any pre-existing compositional stratification within the melt-dominant body, and could be interpreted to reflect mixing of diverse melts (see below section 5.5.1.3; Chamberlain et al., 2014b [Chapter 4]).

\subsubsection{2. 'Bright-rim' crystals}

The intrusion of the 'bright-rim' magma caused overgrowth of rims on sanidine zircon and quartz (Chamberlain et al., 2014b [Chapter 4]), yet the presence of an aphyric contaminant melt seems implausible, given the small contrasts in temperature inferred from comparisons of two-pyroxene and Fe-Ti-oxide temperature gradients (see section 5.5.1.3). Therefore it is likely that some of the crystals did not grow in the melt in which they are found (cf. Hildreth, 1977, 1979), at least in the lower regions of the Bishop magma chamber. The identification of zircons composed of $80-100 \%$ CL-bright material in pumices from the late-erupted units of the Bishop Tuff implies that these zircons grew largely or wholly within the 'bright-rim' magma and demonstrates this inference. U-Pb ages of cores to bright-rim zircons, and the collective (but lower-precision) ages from the CLbright portions of grains themselves imply that the interaction between the 'bright-rim' 


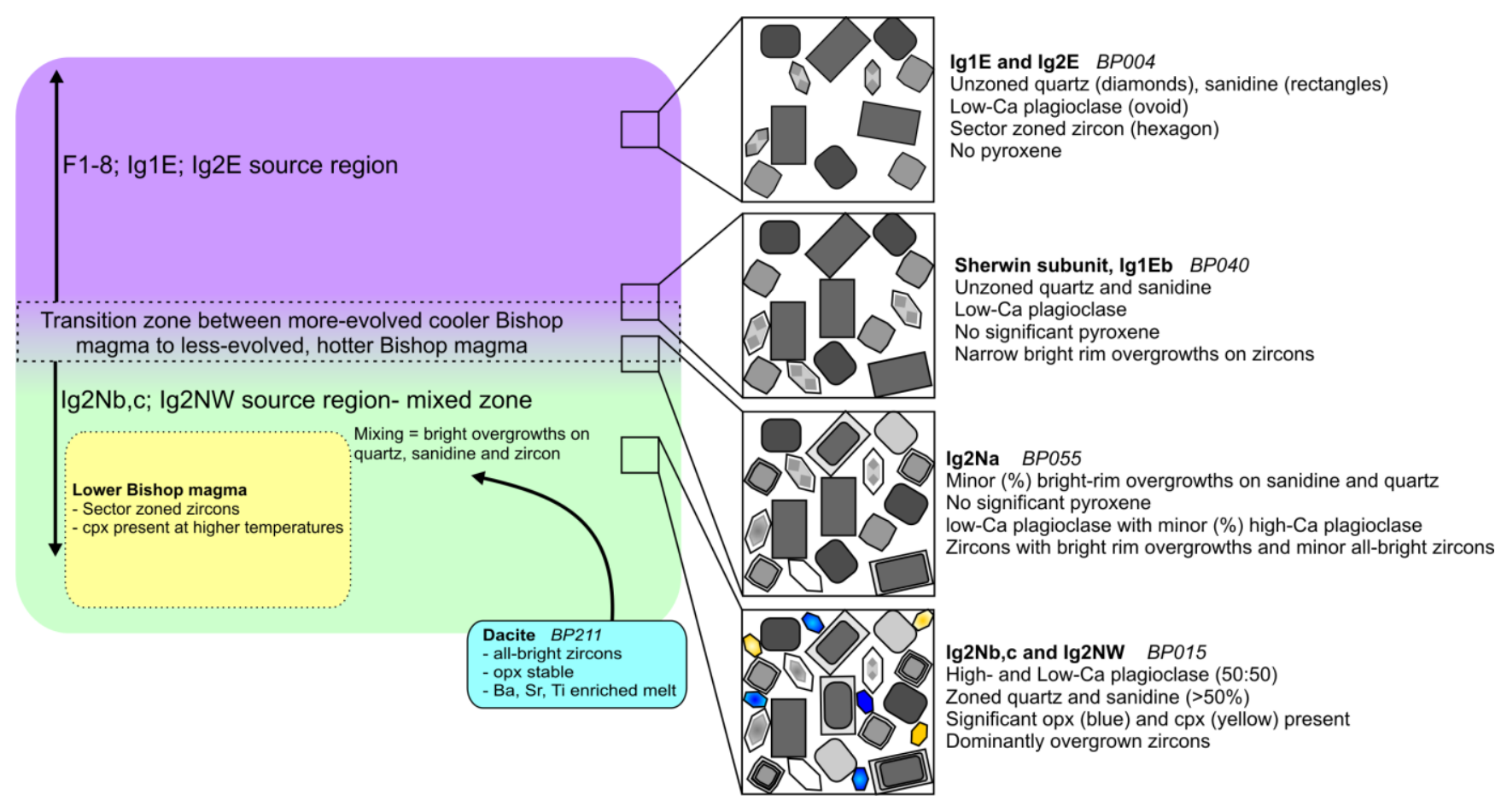

Fig. 5.11. Cartoon of the Bishop magma chamber showing the inferred origins for the crystal species and their compositional variations found in different eruptive units of the Bishop Tuff. Examples of eruptive units (from Hildreth \& Wilson, 2007) are detailed in bold, with specific sample numbers from this study (listed in Table 5.1) in italics. There is a change from unzoned crystals and pyroxene-free magma for the dominant volume of early eruptives, through a transition zone (a source region for the Sherwin subunit of Ig1Eb and $\operatorname{Ig} 2 \mathrm{Na}$ ), to zoned quartz, sanidine and zircon crystals and pyroxene-bearing magma in the later eruptives. An enlarged copy of this figure is also repeated in Appendix 1.

magma and the sampled roots to the Bishop chamber began at roughly $10^{4}$ years before eruption (Chamberlain et al., 2014a [Chapter 3]). If the timescale of interaction of the 'bright-rim' magma with the lower part of the Bishop chamber is taken as the $<500$ years yielded by the sanidine crystals (Chamberlain et al., 2014b [Chapter 4]), then it seems likely that these zircon crystals were carried into the Bishop magma chamber during a later-stage mixing event or events (Fig. 5.11). Interestingly, sanidine crystals do not appear to have been resident in the 'bright-rim' melt, possibly due to its slightly higher temperature (Wark et al., 2007; Chamberlain et al., 2014a [Chapter 3]) and less-evolved composition, which may have made sanidine not a stable phase (cf. Naney, 1983). This could also explain the partial dissolution observed in sanidines with bright overgrowths (Chamberlain et al., 2014b [Chapter 4]), which show that after the interaction of the 'bright-rim' magma with the Bishop magma some cooling and mixing was required to allow resumption of sanidine crystallisation with growth of bright rims from the mixed magma. 


\subsubsection{Pyroxenes and Fe-Ti-oxides - disequilibrium or not?}

A key question remaining regarding the origins of crystals in the Bishop Tuff is whether the pyroxenes found in the later-erupted units of the Bishop Tuff are in equilibrium with the surrounding melt (see Hildreth \& Wilson, 2007 for discussion) and therefore whether they fit with the model of Hildreth $(1977,1979)$ that all Bishop crystals are in equilibrium with the melt in which they were erupted. An alternative suggestion is that in fact it is the Fe-Ti-oxides which are not in equilibrium with the surrounding magma (Ghiorso \& Gualda, 2013), and hence this has very significant implications for the application of FeTi-oxide thermometry to the Bishop Tuff. In order to determine the true origin of pyroxene and Fe-Ti-oxides, I consider the compatibility of various thermometry techniques, and the results of previous experimentally derived phase relationships in the Bishop Tuff.

Thermal stratification of the Bishop Tuff magma chamber was originally inferred by Hildreth (1979) from the analysis of coexisting Fe-Ti-oxide pairs, using the thermometric calibration of Buddington \& Lindsley (1964). Later recalibration of these results using the Andersen \& Lindsley (1988) calibration as well as the addition of new data, again shows a range in temperatures from $703{ }^{\circ} \mathrm{C}$ in early fall units, to $816^{\circ} \mathrm{C}$ in late-erupted ignimbrite samples (Hildreth \& Wilson, 2007). Closely similar results were reported by Ghiorso \& Evans (2008) using their modified calibration, and these were reiterated by Evans \& Bachmann (2013). The general values and $\sim 100{ }^{\circ} \mathrm{C}$ range in Fe-Ti-oxide model temperatures from top to bottom of the Bishop Tuff are consistent with those derived from $\Delta^{18} \mathrm{O}$ thermometry utilising the fractionation of ${ }^{18} \mathrm{O}$ between quartz and magnetite (Bindeman \& Valley, 2002). Application of Ti-in-quartz and Ti-in-zircon thermometry also reveal a reported $\sim 100{ }^{\circ} \mathrm{C}$ gradient in temperature (Wark et al., 2007; Reid et al., 2011) but use of these models is made problematic by the assumptions associated with the appropriate value for $a \mathrm{TiO}_{2}$ (for discussion see Thomas \& Watson, 2012; Wilson et al., 2012) and sector zoning variations of Ti concentrations in zircon (Chamberlain et al., 2014a [Chapter 3]). The two-feldspar thermometry carried out for this thesis (Chamberlain et al., 2014b [Chapter 4]) yields a $\sim 80{ }^{\circ} \mathrm{C}$ range in model temperatures from Ig1Eb to Ig2Nc for the cores of crystals, somewhat less that the $\sim 100{ }^{\circ} \mathrm{C}$ ranges from other phases. The significance of the two-feldspar estimates is, however, that they reflect a substantial temperature zonation within the Bishop magma chamber prior to any changes associated with influx of the magma of contrasting composition (the 'bright-rim' magma) and growth 
of the $\mathrm{Ba}$ richer rims. The bright-rim magma, on this basis, had only a second-order effect on intensifying the thermal gradient already present in the Bishop magma chamber.

In sharp contrast to these mineral-based models, use of rhyolite-MELTS modelling on Bishop Tuff samples has been used to propose that the temperature range of crystallisation for Bishop Tuff crystals lies within a $10{ }^{\circ} \mathrm{C}$ range (Gualda et al., 2012a). These contrasting estimates of temperature values and ranges in the Bishop Tuff represent an important aspect of contention that currently remains with regards to the Bishop Tuff magma chamber. The assertion from Rhyolite-MELTS modelling that the Fe-Ti-oxides from the Bishop Tuff are not in equilibrium (Ghiorso \& Gualda, 2013) is based on the relationship between calculated model temperatures and modelled $a \mathrm{TiO}_{2}$, which does not fall within a plausible pressure range as considered by them for the Bishop Tuff. Therefore it was proposed (following Lindsley et al., 1990, 1991; Frost \& Lindsley, 1992) that the ilmenite in the Bishop Tuff is very late stage in origin and has not had a chance to equilibrate with magnetite (Ghiorso \& Gualda, 2013). Three points suggest strongly that such an argument, however, is not soundly based. First, Rhyolite-MELTS was initially calibrated using an early Bishop Tuff composition, and yet does not correctly replicate the ferromagnesian phases within the Bishop Tuff (cf. Gualda et al., 2012a), suggesting limitations in its application. Second, given the good agreement between two-feldspar thermometry, $\Delta^{18} \mathrm{O}$ thermometry and Fe-Ti-oxide thermometry, and the demonstrably rapid timescales for equilibration of Fe-Ti-oxides with their host melt (Buddington \& Lindsley, 1964; Hammond \& Taylor, 1982; Ghiorso \& Sack, 1991) it would seem most improbable that the ilmenite is not in equilibrium (e.g. Evans \& Bachmann, 2013). Third, there is an issue in Ghiorso \& Gualda (2013) in that temperature estimates for oxide pairs are derived using the (equilibrium) model of Ghiorso \& Evans (2008), yet the resulting derived values of $a \mathrm{TiO}_{2}$ are taken as indicating that the oxide pairs are not in equilibrium. Therefore the balance of evidence is that the Fe-Ti-oxides are in equilibrium with the melt in which they were erupted, and so the origin of the pyroxenes, and their relationship to the Bishop magma chamber, must be considered (cf. Ghiorso \& Sack, 1991; Evans \& Bachmann, 2013).

Pyroxenes (both clinopyroxene and orthopyroxene) first appear sparsely in the Sherwin subunit of Ig1Eb (W. Hildreth, pers. comm. to Colin Wilson) and in Ig2SW, Ig2Na and Ig2Ea and Ig2Eb (Hildreth, 1997, 1979). Pyroxenes $>250 \mu \mathrm{m}$ across, as studied for this thesis, are only found in units Ig2NWa, Ig2NWb, Ig2Nb and Ig2Nc which have modelled 
two-feldspar temperatures between 769 and $821{ }^{\circ} \mathrm{C}$ (from cores, inside any bright overgrowth zones; Chamberlain et al., 2014b [Chapter 4]). Both clinopyroxene and orthopyroxene appear at the same time in the stratigraphy of the Bishop Tuff, and are in apparent equilibrium with each other (Frost \& Lindsley, 1992 [using the major element data of Hildreth, 1977]; Bindeman \& Valley, 2002), suggesting that they are genetically linked. BSE imaging reveals that both clinopyroxene and orthopyroxene are zoned in composition (Fig. 5.3), which has until now, been unnoticed. There is no systematic difference, however, in pyroxene composition based on either zoning type, or location of analysis (e.g. core or rim; see Fig. 5.7).

Experimental studies on synthetic granitic and granodiorite samples (Naney, 1983) contribute to the debate over stability of pyroxenes. Given the relatively high temperature for these units, and a water content of $\sim 4.1 \mathrm{wt} . \%$ (from melt inclusions within late Bishop Tuff quartz: Wallace et al., 1999) experimental studies on synthetic granite at $200 \mathrm{MPa}$ shows that the stable phase assemblage is orthopyroxene + clinopyroxene + biotite + plagioclase + alkali feldspar + liquid + volatiles (Naney, 1983). Given the higher water contents, and lower temperatures of the early and middle Bishop Tuff (5.3 wt.\% $\mathrm{H}_{2} \mathrm{O}$ : Wallace et al., 1999; 711-758 ${ }^{\circ} \mathrm{C}$ : Chamberlain et al., 2014b [Chapter 4]) the predicted phase assemblage is biotite + plagioclase + alkali feldspar + liquid + volatiles \pm clinopyroxene (Naney, 1983). Both of these phase assemblages are modelled at $200 \mathrm{MPa}$. However melt inclusion entrapment pressures predict a range of $\sim 100 \mathrm{MPa}$ between earliest and latest Bishop Tuff (Wallace et al., 1999), which could be the reason for absence of significant clinopyroxene in the early or middle Bishop Tuff. In addition to this, the experimental studies of Scaillet \& Hildreth (2001) on samples of the Bishop Tuff itself reported that clinopyroxene (but not orthopyroxene) was stable in $200 \mathrm{MPa}$ experiments using starting composition of Ig2NWb rhyolite, and orthopyroxene (but not clinopyroxene) was stable in a dark variant pumice of 'trachytic' (67 wt. $\% \mathrm{SiO}_{2}$ ) composition from Ig1Eb in experiments run at similar P,T conditions to the rhyolites. Equilibrium fractionation of pyroxenes is further supported by the euhedral appearance of pyroxenes in the later Bishop Tuff units (Fig. 5.3), by $\Delta^{18} \mathrm{O}$ kinetics which show equilibrium between both pyroxenes and quartz, magnetite, zircon and titanomagnetite (Bindeman \& Valley, 2002), and by the composition of all crystal inclusions within pyroxenes being the same as that of free crystals (Hildreth, 1977; Hildreth \& Wilson, 2007). 
A possibility raised by the study of Scaillet \& Hildreth (2001) is that clinopyroxene is a true phenocryst in the sense used by Hildreth (1977, 1979), whereas the orthopyroxene is another crystal phase which was stable in the 'bright-rim' magma, and only entered the Bishop magma chamber when mixing commenced, along with the dominantly bright zircon crystals. It has been considered that short timescales modelled from interdiffusion of Fe-Mg in orthopyroxene could reflect the late-stage crystallisation of orthopyroxene on mixing between the lower Bishop magma and the 'bright-rim' magma (Chamberlain et al., 2014b [Chapter 4]). The phase stability experiments of Scaillet \& Hildreth (2001) seem to preclude this crystallisation upon mixing option, and instead support the proposed alternative that poorly constrained diffusion coefficients have caused the extremely short (<20 year) timescales for zoning seen in orthopyroxene (Chamberlain et al., 2014b [Chapter 4]).

My results, along with results from experimental studies therefore suggest that clinopyroxene is in equilibrium with the lower, hotter, mixed (between the lower Bishop magma and the 'bright-rim' magma) Bishop magma which produced the northern units of the Bishop Tuff (Fig. 5.11). This is in agreement with the modelled melt-compositions from cores of clinopyroxene crystals (Fig. 5.12a) using the partition coefficients of Olin \& Wolff (2010), which overlap well with the Bishop Tuff field, and not that of the dacites. Given the similarities in modelled temperatures from various techniques in the Bishop Tuff, it would also seem that the Fe-Ti-oxides are also in equilibrium in the Bishop magma. A possibility that the identified high-Ca plagioclase is also 'native' to the 'brightrim' magma warrants investigation, yet attempts to model the melt from which the high-Ca plagioclase crystallised (using the partition coefficients of Brophy et al., 2011) has yielded glass compositions which cannot match the high Sr content of the dacites (Fig. 5.12b). Also, the compositions of plagioclase inclusions within the cores of "non-bright" sanidine are also of high-Ca composition. These pieces of evidence suggest that the high-Ca plagioclase are not incoming with the 'bright-rim' magma. Orthopyroxene and dominant 'bright' zircon, appears to be native to the incoming 'bright-rim' magma (Fig. 5.11), which has mixed with the lower regions of the Bishop magma chamber. Yet, the field for modelled melt compositions from orthopyroxene overlaps with both the "normal" Bishop field and the measured dacitic glass. Complexity of unravelling melt compositions from crystals arises due to the assumption that the dacites represent exactly the melt from which the orthopyroxene crystallised. This may not in fact be the case, and the 'bright-rim' 

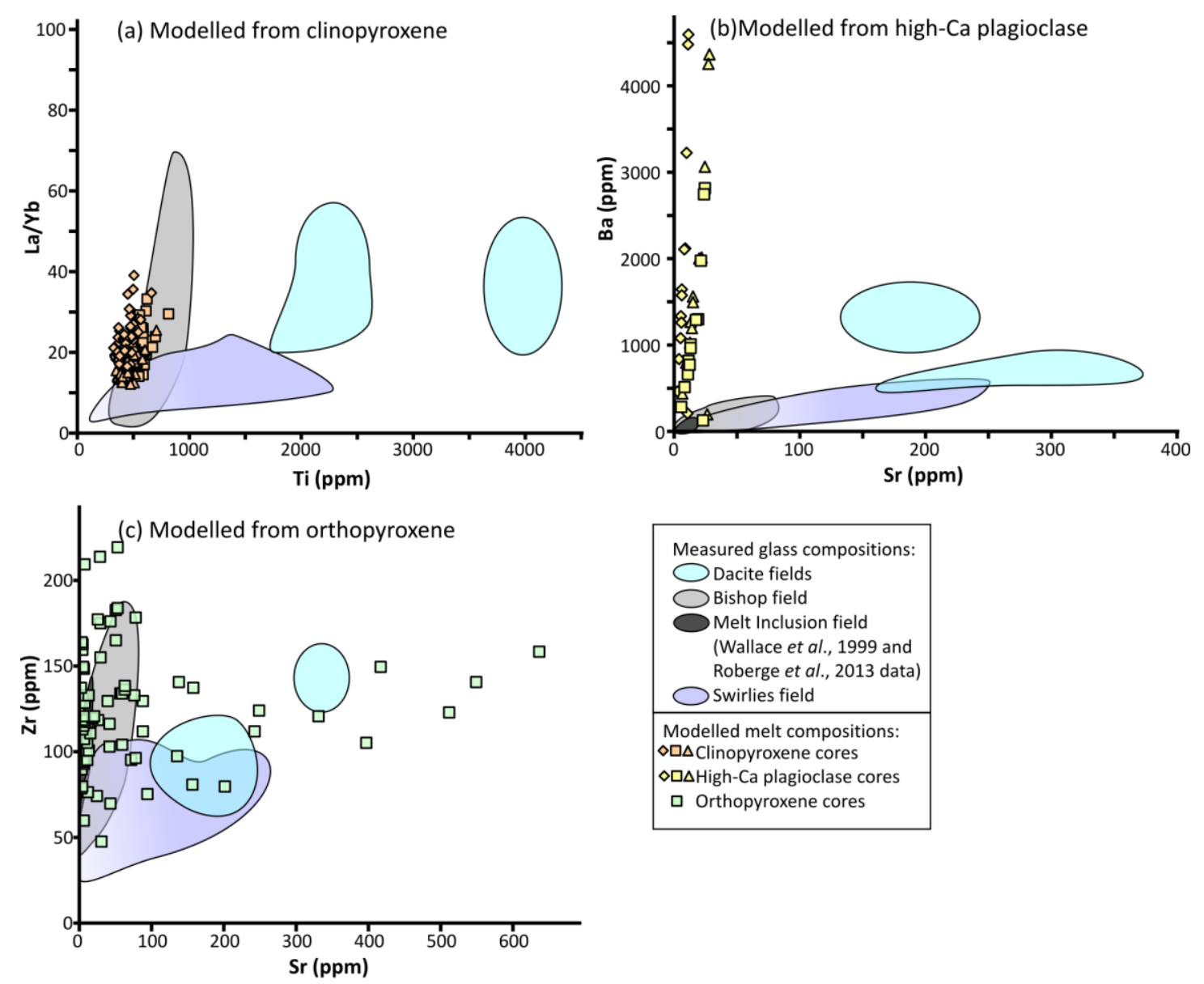

Fig. 5.12. Modelling of inferred melt compositions from (a) clinopyroxene (b) high-Ca plagioclase and (c) orthopyroxene. The field of all Bishop glass data is shown in light grey, the range in melt inclusion compositions from Roberge et al., 2013 in dark grey, and the field for glass compositions of swirly pumices in purple. Dacite glass fields are shown in blue. Modelled glass compositions from clinopyroxene cores are shown as orange points from the partition coefficients of Olin \& Wolff, 2010. Modelled glass compositions from high-Ca plagioclase cores (yellow points) and from orthopyroxene cores (green points) calculated from the partition coefficients of Brophy et al., 2011. Different shaped symbols indicate modelled melt compositions from different partition coefficients calculated in the respective papers.

magma may not be able to be defined by one single melt composition, as is suggested by the heterogeneity in dacitic and swirly glass compositions. Although the two pyroxenes in the Bishop Tuff may have different origins, they still remain in apparent equilibrium, and are lacking any evidence for wide-scale dissolution, due to the similar pressure and temperatures of the two melts, and the lack of a major compositional contrast between the resident Bishop magma and the 'bright-rim' magma. 


\subsubsection{Zonation within the Bishop magma chamber}

The Bishop Tuff is widely cited as a classic product of the sequential eruption of a compositionally stratified magma chamber (Figs. 5.2, 5.8) which did not experience catastrophic chamber-wide mixing prior to, or during, eruption (cf. Oruanui eruption; Wilson et al., 2006). Therefore the chemical variations both laterally and vertically within the magma chamber(s) can be investigated and are discussed here.

\subsubsection{Vertical zonation}

It is evident from investigation of cores of sanidine crystals that the Bishop Tuff magma chamber was stratified prior to growth of these crystals, in agreement with previous studies which suggested that stratification within the melt-dominant magma chamber was established prior to growth of phenocrysts (Hildreth, 1979; Hildreth \& Wilson 2007; Roberge et al., 2013). Therefore, although the 'bright-rim' magma played a clear role in accentuating the vertical zonation, it was not the sole cause for this zonation as has been previously suggested (Dunbar \& Hervig, 1992a; Bindeman \& Valley, 2002). By examining the compositions of glass from all units of the Bishop Tuff the nature of any zonation within the magma chamber immediately prior to eruption (and after mixing with the 'bright-rim' magma) can be investigated.

On the large scale, when considering only pumices which fall into the 'normal' spectrum of xp to xr of Hildreth \& Wilson (2007), a simple progression is evident in the glass data, from most-evolved, $\mathrm{Ba}, \mathrm{Sr}$, Ti poor magma in the very earliest fall units, transitioning systematically through to less-evolved, $\mathrm{Ba}$, Sr and Ti enriched magma in the order of: early fall (F1- F6) - early eastern ignimbrites (Ig1E) and F7 - F8 - late eastern units (Ig2E and $\mathrm{Ig} 2 \mathrm{SW}$ ) - Sherwin lobe (geographically confined lobe of latest Ig1Eb) - Ig2Na (and F8/9) - Late northern units (Ig2Nb/c; Ig2NW) (Table 5.6; Fig. 5.8; Electronic Appendices 11, 12). Although the Sherwin lobe is known to underlie Ig2E material (Wilson \& Hildreth, 1997), it appears that in the geographically constrained segment of the magma chamber tapped by the Sherwin unit the magma was less-evolved than the magma sourcing Ig2E. The least-evolved glass compositions (77.8 wt.\% $\mathrm{SiO}_{2} ; 0.50$ wt.\% $\mathrm{CaO} ; 950$ ppm Ti; 55 ppm Sr; 340 ppm Ba: Table 5.6) of normal pumices are found in samples of $\mathrm{Ig} 2 \mathrm{Nb} / \mathrm{c}$ and $\operatorname{Ig} 2 \mathrm{NWa} / \mathrm{b}$, with no systematic difference between any of these units. However, given the already highlighted role of the 'bright-rim' magma in these units, this glass composition is likely a mixture of the less-evolved Bishop magma and the 'bright-rim' magma (Fig. 5.10). 
The general progression in glass chemistry matches that reported from previous matrix glass, melt inclusion studies, and whole rock analyses (Hildreth, 1979; Lu et al., 1992; Wallace et al., 1999; Anderson et al., 2000; Hildreth \& Wilson, 2007; Roberge et al., 2013). Glass chemistry highlights the role of the $\operatorname{Ig} 2 \mathrm{Na}$ unit in transitioning from the eastern, more-evolved material to northern, less-evolved material (Figs. 5.6, 5.8, 5.11). Ig2Na glass chemistry overlaps both northern and eastern glass compositions (Fig. 5.8e) with melt inclusions from this unit having $\mathrm{Rb} / \mathrm{Ce}$ and $\mathrm{Nb} / \mathrm{Ce}$ ratios which define almost the entire range of matrix glass from the Bishop Tuff (Roberge et al., 2013). Similarly, no pyroxene crystals $>250 \mu \mathrm{m}$ were obtained from any Ig2Na samples (Chamberlain et al., 2014b [Chapter 4]), sanidine crystals are less systematically zoned when compared with other northern samples (Table 5.1) and bright rims in zircon crystals are less prevalent when compared with later erupted units (Fig. 4 in Chamberlain et al., 2014a [Fig. 3.4: Chapter 3]). All of these lines of evidence point towards the intermediate status of Ig2 $\mathrm{Na}$ in providing a link between the more-evolved and less-evolved units of the Bishop Tuff, and again highlight the single stratified nature of the Bishop Tuff magma body.

In addition to the general trend from more-evolved to less-evolved glass compositions with eruptive timing, increased variation within stratigraphic units (and in fact single pumice clasts) is identified (Fig. 5.13). Northern sourced units (Ig2NW and $\operatorname{Ig} 2 \mathrm{~N}$ ) have the biggest variation in glass chemistries reflecting an important role of magma mixing evidenced by the overgrowth rims on sanidine, quartz and zircons in these samples (Figs. 5.3, 5.8d). Yet, some eastern -sourced pumice clasts show variation of up to $20 \mathrm{ppm} \mathrm{Sr}$ within single clasts (Fig. 5.8c). The range in trace elements seen in eastern glass samples could be a relic of slightly variable crystal fractionation within the magma body. By using the equation $x \sim 2 \sqrt{D} t$ (Humphreys et al., 2010), we can estimate a timescale for diffusive reequilibration within the rhyolite magma (as viscosities will be similar, due to no major element differences, Fig. 5.8; Sparks \& Marshall, 1986). At $750{ }^{\circ} \mathrm{C}$ (a generous estimate of temperature) diffusivities are $\mathrm{D}_{\mathrm{Sr}} \sim 6 \times 10^{-10} \mathrm{~cm}^{2} / \mathrm{s} ; \mathrm{D}_{\mathrm{Ba}} \sim 8.8 \times 10^{-12} \mathrm{~cm}^{2} / \mathrm{s}$ (Magaritz \& Hofmann, 1978). For equilibration across $10 \mathrm{~cm}$ of magma, this gives timescales of $\sim 19$ $\mathrm{kyr}(\mathrm{Sr})$ and $\sim 90 \mathrm{kyr}(\mathrm{Ba})$, reaching the limits of time in the history of the Bishop magma chamber, which only has evidence for $\sim 80 \mathrm{kyr}$ of history in zircons (Chamberlain et al., 2014a [Chapter 3]). Convectional mixing within the whole Bishop Tuff chamber is not thought to be a dominant process (Christensen \& Halliday, 1996; Davies \& Halliday, 1998; Wallace et al., 1999; Hildreth \& Wilson, 2007), therefore the small-scale heterogeneity seen 


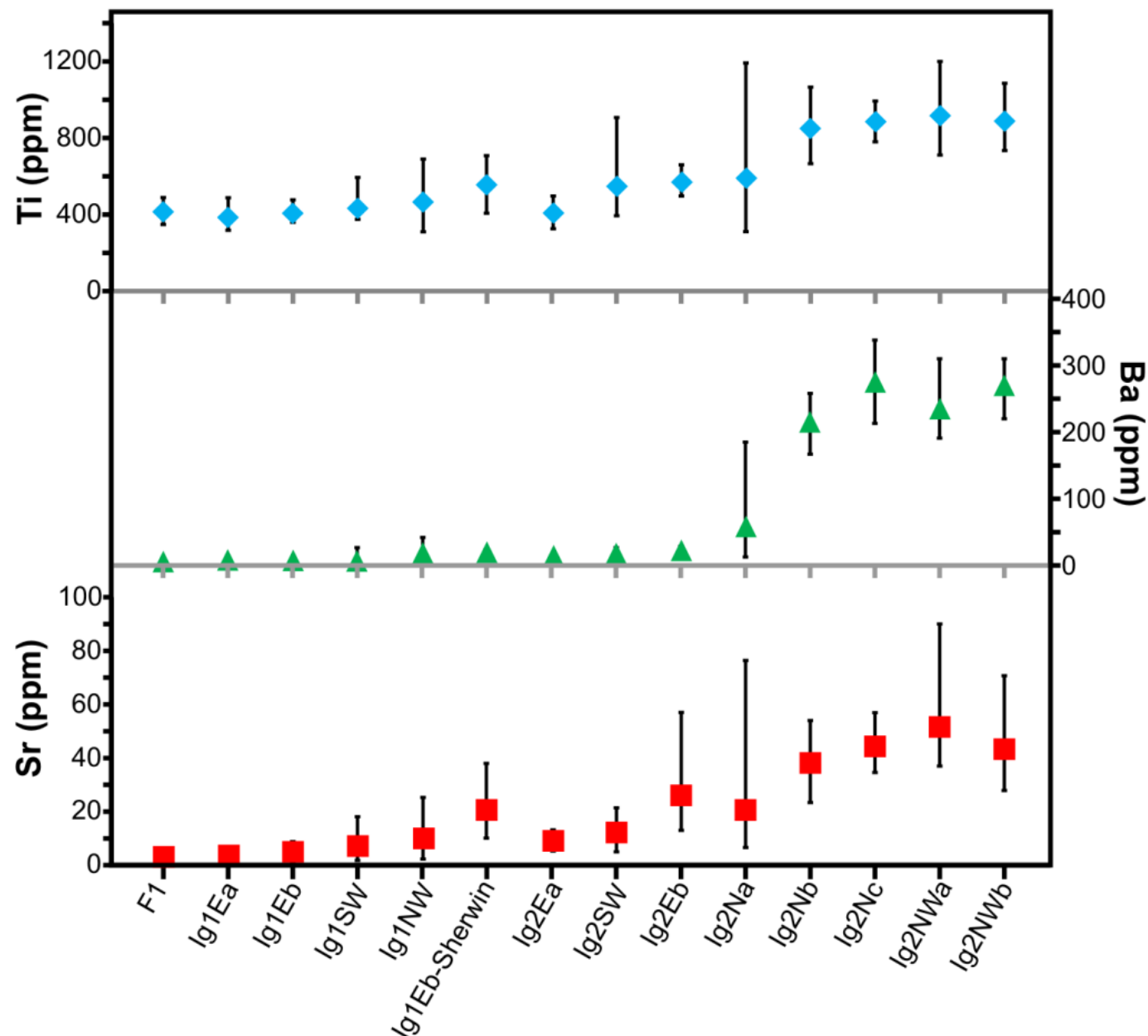

Stratigraphic Unit

Fig. 5.13. Plot of concentrations and variations of key elements in glass of the Bishop Tuff by eruptive timing. The change from more restricted values, and generally lower concentrations of compatible elements in earlier-erupted units to greater variation and higher concentrations of compatible elements in later-erupted units is highlighted.

within single pumice clasts of the eastern Bishop Tuff may purely reflect slight heterogeneity generated by crystal fractionation within the melt dominant magma chamber. In the northern units, where compositional variation within stratigraphic units is greatest and mixing is known to have occurred, vertically limited convection is likely to have occurred with the intrusion of the 'bright-rim' magma, partially evidenced by the range of timescales modelled from diffusion (Chamberlain et al., 2014b [Chapter 4]). At the higher temperatures of $820{ }^{\circ} \mathrm{C}$ for the lower northern units, timescales for diffusive reequilibration of $\mathrm{Ba}$ and $\mathrm{Sr}$ within $10 \mathrm{~cm}$ of mixed rhyolite glass are on the order of 5 to 25 kyr, significantly longer than the timescale inferred for interaction with the 'bright-rim' forming magma (Wark et al., 2007; Chamberlain et al., 2014b [Chapter 4]), hence the wide range of glass chemistry preserved in pumices from these units. 


\subsubsection{Lateral heterogeneity}

The question about any lateral, or geographic, heterogeneity within the Bishop Tuff magma chamber has not been previously systematically investigated, even though units with distinctive pumice suites have been identified in the physical volcanological study, such as the Sherwin and Watterson subunits of Ig1Eb (Wilson \& Hildreth, 1997). We collected samples from multiple locations within single defined units of the stratigraphy to test if much lateral variability existed (or was preserved during eruption) within the Bishop magma chamber (Table 5.1). Lateral variability is here investigated by comparing synchronously erupted units, which have variable areas of deposition, and therefore lateral heterogeneity identified is not due to geographic variation in ignimbrite preservation, and instead directly traces variation within the pre-eruptive magma chamber. In most units of the Bishop Tuff, no identifiable lateral variability can be identified, in fact the sample from the Watterson subunit of $\operatorname{Ig} 1 \mathrm{~Eb}$ (BP019) is indistinguishable from other Ig1Eb samples (see Electronic Appendices 11, 12). The relatively high abundance of swirly appearance pumice clasts in this subunit does not seem to reflect injection of the 'bright-rim' magma, as no crystals within this unit have any bright overgrowths (Table 5.1). Therefore the high occurrence of swirly pumices may in fact reflect localised vent withdrawal dynamics causing mixing with variably oxidised material, creating the swirly appearance. Conversely, the Sherwin subunit, rich in crystal-rich pumice clasts and also part of Ig1Eb, has been shown to have thin bright overgrowths on zircon crystals distinct from that of 'normal' Ig1Eb zircons (Chamberlain et al., 2014a [Chapter 3]). It has also been noted to contain some pyroxene-bearing pumice (Hildreth, 1977; Hildreth \& Wilson, 2007). However, in all 3 samples collected from this unit, no pyroxene $>250 \mu \mathrm{m}$ was recovered, as is the case in Ig2Na samples. Glass compositions from the Sherwin subunit plot in comparable fields to those from the later Ig2E, and extend the less-evolved compositions reached by eastern material, but do not match the high $\mathrm{Ba}$, Sr, LREE levels of northern material. Similarly, no zoned sanidine phenocrysts or all-bright zircons are found in these samples, suggesting that although some 'bright-rim' magma may have reached this sector or level within the magma chamber, it was not a significant constituent of the Sherwin subunit, and likely only interacted very shortly prior to eruption. The interaction with a less-evolved magma in the Sherwin subunit shows that rejuvenation within the Bishop magma body was heterogeneous, and only affected a hybrid zone between the 'pure' earliest-erupted, moreevolved magma and the mixed, less-evolved, later-erupted magma (Fig. 5.11). 
Lateral variability is also evident in the earlier northern units, where study of the outflow sheets shows that units Ig2NWa and Ig2Na were erupted largely coevally (albeit from different vents; Wilson \& Hildreth, 1997). However, Ig2NWa is much more similar to the late northern units with prevalent zoning in sanidine, quartz and zircon, the high proportions of high-Ca plagioclase, the presence of large $(>250 \mu \mathrm{m})$ pyroxenes and the much less-evolved nature of matrix glass. It would seem that the 'bright-rim' magma was able to mix more with the source regions of package Ig2NWa than $\operatorname{Ig} 2 \mathrm{Na}$, even though melt inclusion entrapment pressures would imply similar depths of origin for both of these units within the magma chamber (Wallace et al., 1999; Anderson et al., 2000). Again this highlights that at least some lateral heterogeneity within the melt-dominant Bishop magma chamber has been preserved, showing greater complexity was present in the pre-eruptive magma body than previously modelled.

\subsubsection{Role of mixing and the 'bright-rim' magma}

Recognition of 'bright', under BSE or CL, overgrowth rims on sanidine, quartz and zircon in late erupted samples (Hildreth 1977, 1979; Anderson et al., 2000; Peppard et al., 2001; Gualda, 2007; Wark et al., 2007; Gualda et al., 2012a; Chamberlain et al., 2014a,b [Chapters 3 and 4]) led to the hypothesis that late-stage introduction of a less-evolved magma affected the lower regions of the Bishop magma chamber (Hildreth \& Wilson, 2007; Wark et al., 2007; Chamberlain et al., 2014a [Chapter 3]). With this hypothesis the least-evolved compositions within the normal pumice spectrum are a mix of both less-evolved (evidenced by less-evolved sanidine core compositions) Bishop magma residing in the lower regions of the magma chamber, and the even less-evolved 'bright-rim' magma which caused overgrowth of rims on sanidine, quartz, pyroxene and zircon. Caldera-forming eruptions often preserve evidence for late-stage mixing (e.g. Shane et al., 2005; Wilson et al., 2006; Wilcock et al., 2013), which is sometimes cited as an eruptive trigger (Sparks et al., 1977). However, timescale estimates from diffusion studies across core-rim boundaries in the Bishop sanidine, quartz and orthopyroxene reveal that this mixing occurred with the major mineral phases over a period of up to 500 years prior to eruption, and was not related to a single ingress of less-evolved magma of a uniform composition (Chamberlain et al., 2014b [Chapter 4]).

The origin of this intruding magma is, however, not well constrained with different theories arising for its origin. There are suggestions that a late deep mafic melt is related to 
the overgrowth of the high-Ti rims on quartz and the high-Ba and Sr rims on sanidine crystals (Hildreth \& Wilson, 2007; Roberge et al., 2013) although how this directly relates to the intruding magma is unspecified. Wark et al. (2007) hypothesise that a deep intruding mafic magma provided a heat source for dissolution of quartz and sanidine crystals, and also caused melting of an intermediate crystal mush zone between the melt-dominant magma body and the intruded mafic magma. This melted mushy material then itself intruded the melt-dominant magma body and caused overgrowth of the rims on sanidine and quartz, and may be evidenced by the rare dacitic/trachytic juvenile clasts found in the late Bishop Tuff (Hildreth \& Wilson, 2007; Wark et al., 2007). The identification of bright rim overgrowths on some Glass Mountain dome OD zircons (Chamberlain et al., 2014a [Chapter 3]), and the presence of pre-and post-caldera dacites of similar compositions to those erupted with the Bishop Tuff (Bailey, 1989; Hildreth, 2004) implies that this 'brightrim' magma is not necessarily unique to the Bishop Tuff, and in fact may represent a more long-lived but sparsely erupted magma source in the Long Valley region.

Rare dacitic dense juvenile clasts are found in unit Ig2NWb (Hildreth \& Wilson, 2007), which are mixed with 'normal' Bishop rhyolite in hand sample [see Hildreth \& Wilson (2007) for more detailed description]. These dacite samples obviously represent a very latestage ingress into the lower parts of the Bishop magma chamber due to the clear bimodality in glass chemistry, with no apparent exchange of any elements between the dacite and rhyolite portions of the samples (Fig. 5.9). The dacite samples are among the most primitive juvenile material found in the Bishop Tuff with the least-evolved (BP211) having 65.65 wt. \% $\mathrm{SiO}_{2}$, 4.29 wt. \% CaO, 3830 ppm Ti, 360 ppm Sr and 750 ppm Ba (Table 5.6). The dacites also plot as end-members for the less-evolved (clearly mixed) swirly, and dark pumices (such as that investigated by Scaillet \& Hildreth, 2001, with a whole rock composition of 67 wt. $\% \mathrm{SiO}_{2}, 3.85$ wt. \% CaO, 460 ppm Sr and 1350 ppm Ba: Hildreth \& Wilson, 2007) (Fig. 5.9) which are present in variably small proportions throughout the Bishop Tuff. The possibility therefore is that these dacites, as well as the swirly and dark pumice, represent different degrees of interaction with the 'bright-rim' magma which mixed with the deeper parts of the Bishop magma chamber to produce enrichments in $\mathrm{Ti}$, $\mathrm{Ba}$, Sr and LREE. It is of note that no one sample of dacite, swirly or dark pumice plots in the same field. Instead they all represent a continuum of less-evolved compositions (Fig. 5.9), suggesting that either: 1) varying degrees of mixing with the melts in the main Bishop magma body have occurred or 2) these samples represent heterogeneity within the source 
region and in fact the 'bright-rim' magma cannot be defined as such by a single composition.

The dacitic end member has a couple of potential origins within the Long Valley region. 1) Re-melting of the underlying crystal mush zone, where sanidine and quartz are melted to produce a less-evolved magma (Hildreth \& Wilson, 2007; Wark et al., 2007). However, this will not explain the increased concentrations of both $\mathrm{Ti}$ and $\mathrm{Zr}$ in the dacites (see Electronic Appendix 12). 2) A separate magma type, possibly similar to that of the precaldera dacites, or the post-caldera dacite of Dome 7403 (Hildreth, 2004), which could have had limited physical interaction with the magma chambers feeding the Glass Mountain eruptions, as evidenced by bright-rim overgrowths on zircon crystals from Dome OD (Chamberlain et al., 2014a [Chapter 3]). Dacites have been present in the Long Valley region for significant portions of the eruptive history of the region, both preceding $(3.5-2.5 \mathrm{Ma})$ and postdating (Dome 7403 on the NE caldera rim) the rhyolitic volcanism (Bailey et al., 1976; Bailey, 2004; Hildreth, 2004). It is therefore plausible that the dacite was as part of the fractionating sequence of magmas present during rhyolitic activity, but that it could not be erupted due to the existence of a rhyolitic density trap in the upper mush zones of the Glass Mountain and Bishop Tuff systems (cf. Hildreth, 2004, Fig. 7). Instead it was only able to be erupted at the surface, or mixed with an existing rhyolitic magma chamber, when some other control, possibly tectonic, permitted its progression through the density trap. This sustained presence in the Long Valley region could explain the evidence for relatively long timescales of interaction of the 'bright-rim' magma with zircon crystals (Chamberlain et al., 2014a [Chapter 3]).

\subsubsection{Origin of minor ignimbrite packages}

Many geochemical studies of the Bishop Tuff have neglected the less voluminous (or less completely preserved) ignimbrite packages of Ig1SW, Ig1NW and Ig2SW (Fig. 5.2). Studies of lithic assemblages and pumice crystal contents and proportions have linked Ig1SW and Ig1NW to Ig1Eb (Wilson \& Hildreth, 1997; Hildreth \& Wilson, 2007). This linkage is also supported by the similarity of $\mathrm{Fe}$-Ti-oxide model temperatures and $\mathrm{Rb} / \mathrm{Sr}$ systematics between these three units (Hildreth, 1979; Christensen \& DePaolo, 1993; Hildreth \& Wilson, 2007). Ig2SW was interpreted to originate from a similar source region to Ig1SW, albeit with slightly higher Fe-Ti-oxide model temperatures, the presence of zircons with bright over-growth rims $(57 \%)$ and the presence of minor pyroxene, indicating similar 
magmatic conditions to the pumices examined from Ig2E (Hildreth, 1979; Hildreth \& Wilson, 2007; Chamberlain et al., 2014a [Chapter 3]). Based on these interpretations, all three of these minor ignimbrite units should be closely related to those of the easternerupted material, i.e. more-evolved with less variability. Such similarities between Ig1NW, Ig1SW, Ig2SW and all other eastern samples are particularly evident when feldspar and glass chemistries are considered (Figs. 5.4, 5.8; Electronic Appendices 11, 12). My data are thus consistent with Ig1SW and Ig1NW tapping the same magma source as the other earlier-emplaced, eastern deposits (Wilson \& Hildreth, 1997). The presence of minor pyroxene (Hildreth, 1979, but not observed in the crystal grain size fractions used in this study) and overgrowth rims on zircons raises the possibility that Ig2SW tapped a magma similar to that of the Sherwin subunit of Ig1Eb (see above section 5.5.2.2), which may have been also present beneath the ring fracture along the SW caldera rim.

\subsubsection{Compositional relationships between Glass Mountain and the Bishop Tuff}

Glass Mountain activity is divided into two separate periods, Older $(\geq 2.2 \mathrm{Ma}-1.2 \mathrm{Ma})$ and Younger (1.1 Ma - 0.86 Ma; Metz \& Mahood, 1991; Metz \& Bailey, 1993; Chamberlain et al., 2014a [Chapter 3]). Eruptives from the Older Glass Mountain period are highly evolved but geochemically heterogeneous (Halliday et al., 1984; Metz \& Mahood, 1991; Christensen \& Halliday, 1996; Davies \& Halliday, 1998), and glass and phenocrysts analysed here from dome OD appropriately extend to compositions more evolved than those of the Bishop Tuff (Tables 5.2 and 5.6; Figs. 5.4, 5.5 and 5.9). The Older Glass Mountain eruptive units are thought to originate from small ephemeral magma chambers, chemically distinct from that of the Younger Glass Mountain and the Bishop Tuff (Metz \& Mahood, 1991; Christensen \& Halliday, 1996; Davies \& Halliday, 1998; Hildreth, 2004; Simon et al., 2014). Given the spatial overlap between the Glass Mountain edifice and the Long Valley caldera, and the somewhat less-evolved compositions of the Younger Glass Mountain eruptives, it has long been inferred that the Younger Glass Mountain magma chamber is genetically related to the Bishop Tuff magma chamber (Fig. 5.1; Metz \& Mahood, 1991; Christensen \& Halliday, 1996; Davies \& Halliday, 1998; Hildreth, 2004). It has been proposed on the basis of geochemical similarities that the integrated system that produced the Younger Glass Mountain eruptives evolved directly into the super-sized Bishop Tuff magma chamber (Metz \& Mahood, 1991). The glass data presented here from dome YA shows a large degree of compositional overlap with glasses from the earlier-erupted pumices in the Bishop Tuff, consistent with the two systems sharing common root systems with similar 
degrees of evolution and crystal fractionation (as emphasised by previous workers). However, textural characteristics and age data from zircons in the youngest dated Glass Mountain dome YA are distinctly different to those of the Bishop Tuff (Chamberlain et al., 2014a [Chapter 3]), implying that the two systems were physically separate in time, and that the melt-dominant bodies for the two eruptions developed independently. To illustrate the contrast, textural studies indicate that the Bishop Tuff samples with the largest proportion (up to $6 \%$ ) of zircons with textures similar to those dominant (97\% of all grains) in dome YA are from the very latest northern units, i.e. those erupted from deepest within the magma chamber (Chamberlain et al., 2014a [Chapter 3]). Glass from pumices in these late northern Bishop units in contrast is distinctly less-evolved than the compositions measured in Dome YA (Fig. 5.9). The evolved nature of Dome YA glass indicates that it was not involved in the overgrowth of bright rims on quartz, sanidine and zircon in the lessevolved northern units of the Bishop Tuff (Hildreth, 1979; Anderson et al., 2000; Peppard et al., 2001; Wark et al., 2007; Chamberlain et al., 2014a [Chapter 3]). The zircon age data in Chamberlain et al. (2014a [Chapter 3]) would imply that the Bishop Tuff magma chamber was entirely developed as a physical entity in the $\sim 95 \mathrm{kyr}$ time gap following the eruption of dome YA, similar to the model of Simon et al. (2014)

\subsubsection{The Bishop magma chamber}

By combining the data acquired in this study with melt-inclusion entrapment pressures from Wallace et al. (1999), I address the possibility of multiple magma chambers sourcing the Bishop Tuff, and then draw a new model for the Bishop magma chamber.

\subsubsection{One chamber or two?}

Given the systematic change in chemistry between the earliest and latest erupted products of the Bishop Tuff eruption (see sections above), current debate centres around whether the change in magma composition was gradational or abrupt, and therefore whether the Bishop Tuff represents tapping of a single zoned magma chamber (e.g. Hildreth, 1979; Wallace et al., 1999; Anderson et al., 2000; Hildreth \& Wilson, 2007), or the eruption of two separate magma chambers (Gualda et al., 2012b; Gualda \& Ghiorso, 2013a). Apparent support for the multiple magma chamber model is marshalled in the form of new thermobarometry models, and reconsideration of the mineral data from Hildreth (1977, 1979). These observations have led to the suggestion that in fact two spatially separate magma chambers existed in the Long Valley caldera region, with the early, eastern material 
representing tapping of one of these magma chambers, and the late northern material representing tapping of another distinct magma chamber with higher-Ba sanidine and higher-Ca plagioclase, but with comparable temperatures and pressures (Gualda \& Ghiorso, 2013a). In addition, recent consideration of the temporal evolution of Long Valley has led Simon et al. (2014) to suggest that the 'early' Bishop Tuff is sourced from remelting of most-fusible granitoids in the crust, and the 'late' Bishop Tuff is sourced from later re-melting of less-fusible granitoids. These granitoids are suggested to range in age from $\sim 2500 \mathrm{ka}$ to as young as the Younger Glass Mountain [ 875 ka from Simon et al.'s (2014) ${ }^{39} \mathrm{Ar}^{40} \mathrm{Ar}$ dates]. However, this is incomparable with zircon U-Pb ages and textures presented in this thesis in two ways. First, Glass Mountain (or older) zircons are clearly identifiable in both textures and ages. Had the Bishop magma accumulated from re-melting of granitoids, it would be expected that some zircons would remain, and therefore $\mathrm{U}-\mathrm{Pb}$ ages (and zircon textures) would retain these features. Instead none of the samples dated have any evidence for more than $80 \mathrm{kyr}$ of zircon growth, showing the temporally separate nature of the precursory Glass Mountain and the Bishop Tuff systems. Second, had the 'late' Bishop Tuff resulted from later stage melting of less-fusible granitoids, it could be reasonably expected that the 'late' Bishop Tuff would have a shorter zircon record in U-Pb ages when compared with the 'early' eastern Bishop Tuff. In fact, the 'late' Bishop Tuff has the longest zircon residence times (up to $\sim 80 \mathrm{kyr}$ ) whereas the 'early' Bishop Tuff has considerably shorter zircon residence times (no more than $30 \mathrm{kyr}$ ) (Chamberlain et al., 2014a [Chapter 3]), contrary to the model of Simon et al. (2014).

A central pillar for the two magma chamber theory for the Bishop Tuff, is the apparent lack of a thermal gradient in the pre-eruptive Bishop magma chamber(s), with all modelled units having temperatures of $740-750{ }^{\circ} \mathrm{C}$ according to Rhyolite-MELTS thermometry (Gualda et al., 2012a; Gualda \& Ghiorso, 2013a). These results conflict with all previous thermometry work on the Bishop Tuff, and also are contradictory to the two-feldspar thermometry carried out in the course of this study (Chamberlain et al., 2014 [Chapter 4]). My two-feldspar thermometry reveals an $\sim 80{ }^{\circ} \mathrm{C}$ variation from early-erupted to latererupted units, prior to intrusion of the 'bright-rim' magma. This result is in agreement with Fe-Ti-oxide, $\Delta^{18} \mathrm{O}$, two-pyroxene and Ti-in quartz thermometry previously utilised in the Bishop Tuff (Hildreth, 1977, 1979; Bindeman \& Valley, 2002; Hildreth \& Wilson, 2007; Wark et al., 2007). This then raises questions about the applicability of Rhyolite-MELTS modelling in the Bishop Tuff, and why these temperature estimates are so in contrast to 
other thermometry methods. Although there is current debate about the use of Fe-Tioxides in the Bishop Tuff (Ghiorso \& Gualda, 2013), the fact Fe-Ti-oxide thermometry agrees with modelled temperatures from all other methods, apart from Rhyolite-MELTS again brings up issues with $a \mathrm{TiO}_{2}$ and using inferred, single, values for the duration of crystallisation when it can be seen in phenocryst phases that the intensive variables change during this time (see Thomas et al., 2012, Wilson et al., 2012 and Allan, 2013, for detailed debates). Aside from this debate, another controversial factor regarding the application of Rhyolite-MELTS to the Bishop Tuff, is the fact that the model was calibrated from MELTS (Ghiorso \& Sack, 1995; Asimow \& Ghiorso, 1998) using the 'average earlyerupted bulk-pumice composition of Hildreth (1979)' of the Bishop Tuff (Gualda et al., 2012a). It seems therefore circular to apply Rhyolite-MELTS to the Bishop Tuff system in any form other than to refine the model. The Rhyolite-MELTS modelling only takes account of the felsic phases, and although these are dominant in the Bishop Tuff (up to 90\% of the phenocrysts: Hildreth, 1977; 1979), biotite, clinopyroxene, orthopyroxene and the oxide phases remain unaccounted for. Given the phase stability experiments of Naney (1983) and Scaillet \& Hildreth (2001) where pyroxene and biotite are found to be stable in granitic melts (and those specifically related to Bishop Tuff samples), this seems to oversimplify the Bishop system. Rhyolite-MELTS modelling is also only valid for samples which are not mixed. Given the abundant evidence for mixing with the 'bright-rim' magma evident in late Bishop Tuff samples, this seems to be an assumption which is not valid in the case of the later-erupted Bishop Tuff.

Gualda \& Ghiorso (2013a) also infer there to be no difference in the pressures at which the Bishop magma body(s) resided, giving a pressure of $175-200 \mathrm{MPa}$ for all units of the Bishop Tuff. This is again based on the application of Rhyolite-MELTS modelling and Si in glass barometry (Gualda \& Ghiorso, 2012a, 2013b). There is an apparent correlation between $\mathrm{SiO}_{2}$ (wt.\%) content of matrix glass or melt inclusions and pressure from independent calculations such as $\mathrm{H}_{2} \mathrm{O}-\mathrm{CO}_{2}$ systematics in melt inclusions or application of hornblende barometry (Ridolfi et al., 2010) from various high-silica eruptions. This correlation is interpreted to show that pressure has a control on silica content of glass (and the location of the quartz-sanidine cotectic) and is calibrated to develop $\mathrm{SiO}_{2}$ in glass barometry, which has a significant issue. The uncertainties of $\mathrm{SiO}_{2}$ measurements from glass or melt inclusions are limited by the precision of the data obtained from EPMA measurements. In this study 532 analyses of glass standard VG-568 over 2.5 years leads to 
a $2 \sigma$ uncertainty of \pm 2.0 wt. $\% \mathrm{SiO}_{2}$ (Chapter 2). This is significantly reduced when analyses over shorter periods of time are considered, for example a 24-hour run of 123 standards (with intervening unknowns) leads to a $2 \sigma$ uncertainty of \pm 0.74 wt. $\% \mathrm{SiO}_{2}$. This is comparable with other studies (where uncertainties are published) with $2 \sigma$ uncertainties varying from \pm 0.6 wt. $\% \mathrm{SiO}_{2}$ (Wallace et al., 1999; Bachmann et al., 2002; Allan, 2013) to \pm 2.0 wt. \% $\mathrm{SiO}_{2}$ (Liu et al., 2006; Cooper, 2014). The silica in glass barometer predicts a change in pressure of $\sim 200 \mathrm{MPa}$ (from $500 \mathrm{MPa}$ to $300 \mathrm{MPa}$ ) with a change of 2 wt.\% silica (from 74 wt. $\% \mathrm{SiO}_{2}$ to 76 wt. $\% \mathrm{SiO}_{2}$; Gualda \& Ghiorso, 2013b). Given the above uncertainties this large apparent pressure change is actually irresolvable given the current uncertainties associated with glass and melt inclusion analyses by EPMA.

Even ignoring the inherent issues with the proposed thermobarometry of Gualda \& Ghiorso $(2013 \mathrm{a}, \mathrm{b})$ the two magma chamber model is incompatible with the data presented in this study and many, still valid, observations made by earlier workers. Melt inclusion studies show a sequential change in inferred entrapment pressures, from $\sim 160 \mathrm{MPa}$ in the early Bishop Tuff, to $\sim 270 \mathrm{MPa}$ in the late Bishop Tuff (Wallace et al., 1999). The change from shallower entrapment depths to deeper entrapment depths is not abrupt and instead the intermediate entrapment pressures of later, middle eastern (Ig2Ea) units are identified. These inferences are in agreement with other thermometry such as $\Delta^{18} \mathrm{O}$ (qtz-mt) and twofeldspar which both show a systematic change from upper, cooler temperatures, to deeper, hotter temperatures (Bindeman \& Valley, 2002; Chamberlain et al., 2014b [Chapter 4]). Field evidence also supports a single zoned magma chamber, where a systematic change occurs from the eruption of dominantly crystal-poor pumice present in early units, to dominantly crystal rich pumice in late units (Wilson \& Hildreth, 1997; Hildreth \& Wilson, 2007). Again this change is gradual and not abrupt. The apparent 'bimodality' of crystal compositions in fact represents the influence of the 'bright-rim' magma in the deeper regions of the Bishop Tuff, and can be accurately replicated by core and rim analyses from single crystals from single pumices in the northern-erupted units. The evidence is overwhelmingly indicative therefore that the Bishop Tuff eruption systematically tapped a single, gradationally zoned, magma body.

\subsubsection{A model for the Bishop magma chamber}

By systematically sampling through the entire eruptive sequence of the Bishop Tuff a revised model can be drawn for the pre-eruptive melt dominant magma body. Similar to 
the wealth of previous work (e.g. Hildreth, 1977, 1979; Wallace et al., 1999; Anderson et al., 2000; Hildreth \& Wilson, 2007) this study provides evidence for a melt-dominant magma chamber which was zoned in composition and temperature (Chamberlain et al., 2014b [Chapter 4]) prior to growth of any phenocryst phases (see section 5.5.1.1).

Crystal poor (xp) pumice is rare in northern-erupted units, making up less than $20 \%$ of each stratigraphic unit, with the dominant pumice type being crystal rich (xr) (Wilson \& Hildreth, 1997). An outstanding question remains as to whether this paucity of xp material found in northern units represents an original lack of xp, 'eastern-type' material under the northern vents, or if the xp material was present there, but was drained laterally and erupted from the earlier eastern-vents (Hildreth \& Wilson, 2007). This has important implications for the morphology of the magma chamber, (cf. Fig. 13 of Wallace et al., 1999 versus Fig. 18 of Hildreth \& Wilson, 2007). In order to investigate this I measured glass compositions from xp pumices that were erupted from the northern vents, to determine whether they have 'eastern' type glass chemistry, and were more evolved than the dominant crystal rich pumices found in northern units. This is in fact not the case (Fig. 5.14): xp pumices erupted from the northern vents have similar glass and sanidine chemistries to the crystal rich pumices from the northern side, with no clear distinctions across the range in crystallinity. This situation is repeated when crystal textures and compositions are considered (Table 5.1; Fig. 5.14) which show similar levels of zoning and enrichment
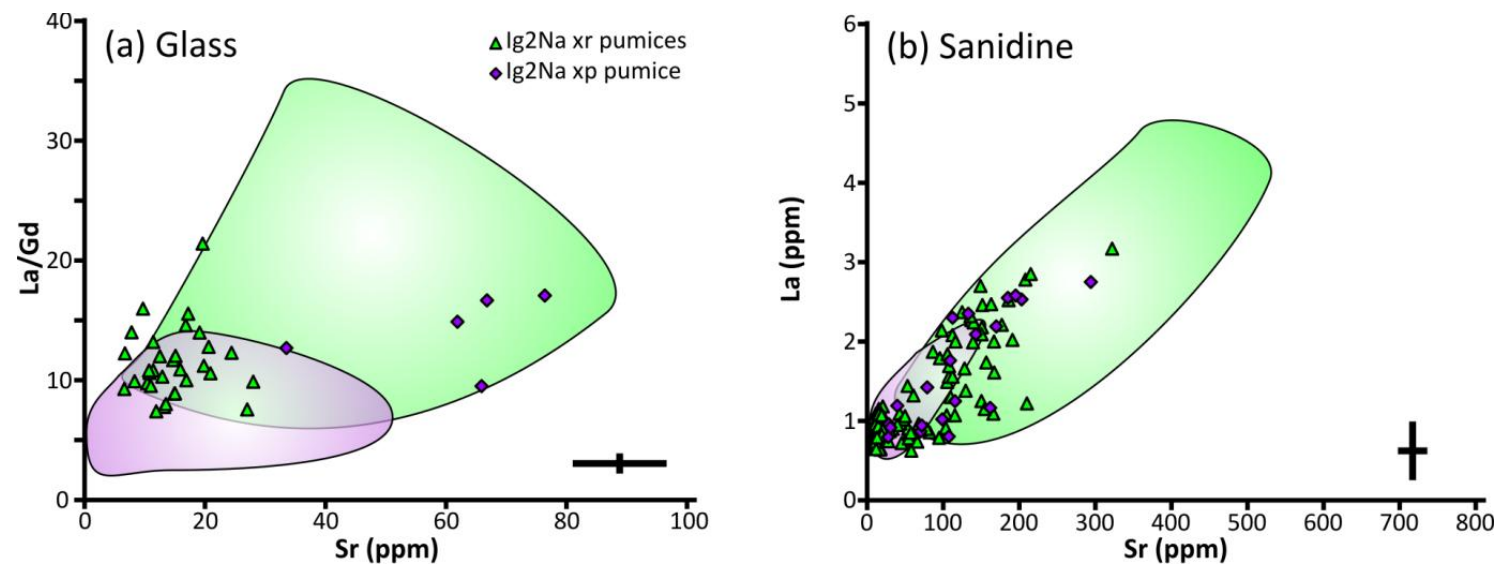

Fig. 5.14. Comparison of crystal-poor (xp) and crystal-rich (xr) samples from package Ig2Na, showing (a) glass and (b) sanidine trace element concentrations compared with the ranges of concentrations from all eastern (purple shaded area) and northern (green shaded area) samples. Analyses from the xp sample (purple filled diamonds) of $\operatorname{Ig} 2 \mathrm{Na}$ should overlap with the purple eastern field if it represented 'eastern-type' magma that was present in the part of the chamber tapped by the northern vents. Analyses from crystal rich samples are plotted as green triangles. All error crosses represent 2 s.d. uncertainty from standard analyses. The full data set is available in Electronic Appendices 11, 12. 
degree of crystal-liquid separation. This observation implies that the 'eastern-type' magma within crystals from xp northern pumices as are found in $\mathrm{xr}$ pumices. Therefore the occurrence of rare xp pumices in northern units simply reflects a mechanical process which caused some pumices to be erupted with less crystals than others, possibly due to smallscale heterogeneities with respect to number of crystal nuclei sites locally available. Therefore it is apparent that the 'eastern-type' more-evolved magma was not resident under the northern vents (cf. Hildreth \& Wilson, 2007) and is in agreement with melt inclusion entrapment pressures supporting the suggestion of a stepped, or asymmetric, roof to the magma chamber (Wallace et al., 1999). In addition to an asymmetric roof, the model of the Bishop magma chamber (Fig. 5.15) incorporates the following key aspects:

1) Crystal and matrix glass chemistries define a compositional continuum, and not a bimodal assemblage (Gualda \& Ghiorso, 2013a). The role of Ig2Na (and to a lesser degree the Sherwin unit of Ig1Eb) in providing a transition from the eastern, more-evolved, crystal poor, unzoned phenocrysts, pyroxene-free material to northern, less-evolved, crystal rich, zoned phenocrysts, pyroxenebearing material is highlighted from my data. In addition, this transitional role is consistent with the melt inclusion compositional data of Roberge et al. (2013) is compared with other northern and eastern samples. Therefore, there is no evidence for the presence of two distinct magma chambers in the Long Valley region during the Bishop Tuff eruption.

2) Similar to the presence of a stepped-roof for the Bishop magma chamber, is the inference of a stepped lower margin of the magma chamber (Fig. 5.15). The distinctive 'Adobe-type' (Hildreth \& Wilson, 2007) xr pumices are rare in the eastern units, and therefore it seems unlikely that the enriched, less-evolved 'northern'-type magma ever underlay the southern and eastern sectors of the caldera in quantity. Even the xr pumices investigated from eastern-deposited units (with the exception of samples from the Sherwin subunit) have moreevolved, restricted compositions when compared with northern deposited samples (see Electronic Appendices 11, 12).

3) By examining the chemical characteristics of the rare mixed dacitic pumices from Ig2NWb I suggest that these are similar in origin to the 'bright-rim' magma. However, it may not be possibly to typify the 'bright-rim' magma by one single composition, and in fact it may be itself heterogeneous. (Fig. 5.15). 


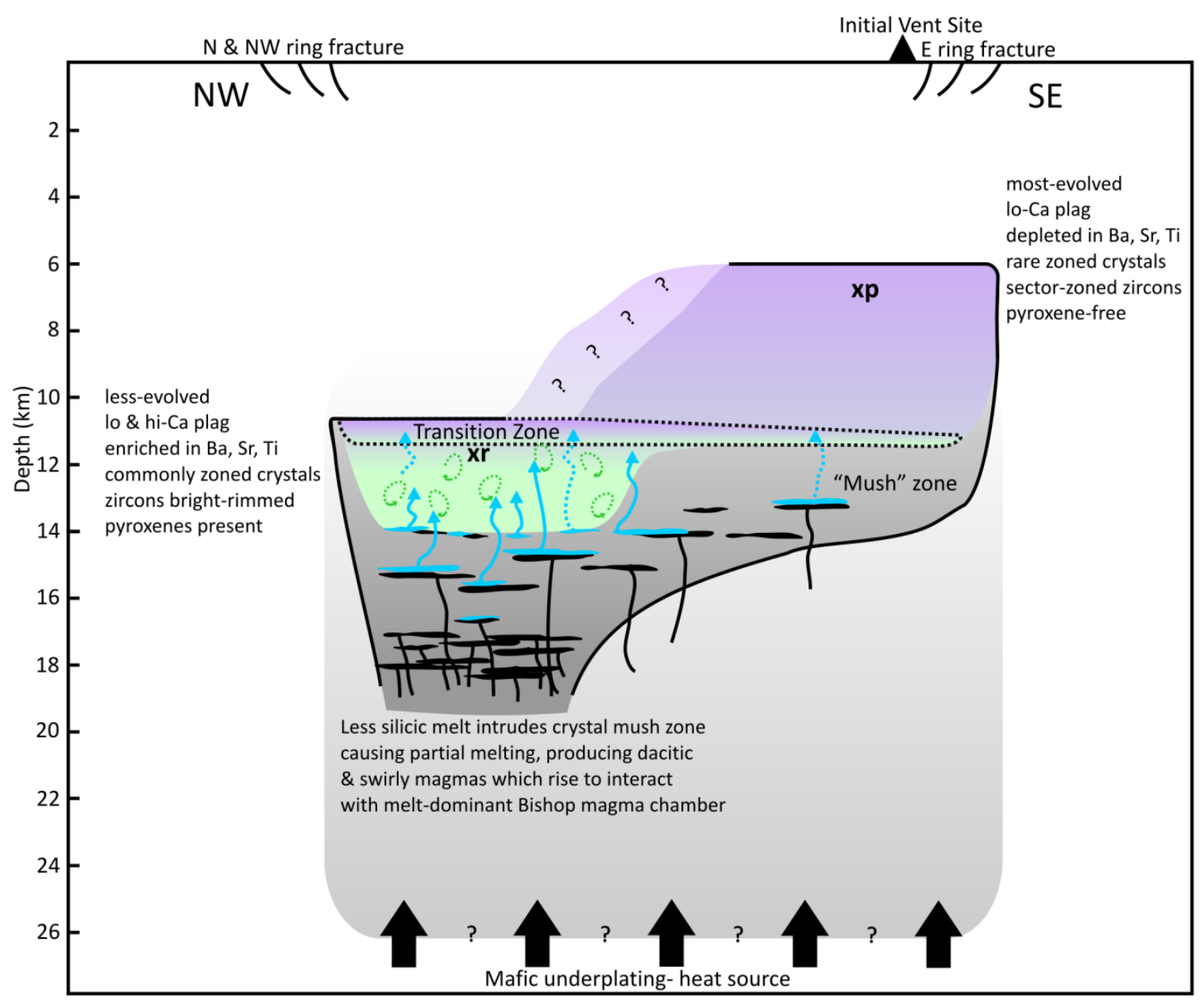

Fig. 5.15. A revised model for the immediately pre-eruptive Bishop magma chamber derived from my work and utilising the depth estimates of Wallace et al. (1999). The magma chamber is systematically zoned from upper, crystal poor, more-evolved through the transition zone to lower, crystal rich, less-evolved. The blue region represent the 'brightrim' magma being generated and having variable interaction with the underlying mush region. The lack of interaction with a Glass Mountain root is the cause for asymmetry of the underlying mush region. See text and Fig. 5.11 for discussion of various crystal origins. The step in the roof from southeast to northwest is poorly constrained as to whether it is sharp or gradual, hence the question-marked region. The surrounding geology in this region consists of Palaeozoic metasediments and Mesozoic igneous rocks.

The model I present (Fig. 5.15) draws on the melt inclusion compositional data and entrapment pressure estimates of Wallace et al. (1999), Anderson et al. (2000) and Roberge et al. (2013) to constrain the depth of the magma chamber. It is established that the earlyerupted units largely, but not entirely sourced from vents along the southern and eastern sides of the caldera ring fracture (F1-F7; Ig1E; Ig2E; Ig1SW; Ig2SW; Ig1NW), are volumetrically dominant (roughly two-thirds) when compared with the later northern units 
(Hildreth \& Wilson, 2007). For these reasons, and from the apparent lack of significant volumes of xp magma ejected from the northern ring fracture vents, I draw in the large step in the magma chamber roof between the southern/eastern and northern vents.

A key feature of this study has been to highlight the role of $\operatorname{Ig} 2 \mathrm{Na}$ and the Sherwin subunit of Ig1Eb in the transition from the upper, most-evolved, slightly stratified regions of the magma chamber, where crystals grew in the melt in which they were erupted (and sourced units $\mathrm{Ig} 1 \mathrm{E}$ and $\mathrm{Ig} 2 \mathrm{E}$ ), to the lower, mixed, less-evolved regions of the magma chamber which sourced Ig2Nb,c and Ig2NW. In the lower regions of the magma chamber not all crystals grew in the melt with which they were erupted, contrary to the model of Hildreth (1979), and instead the pure bright zircons are sourced from the 'bright-rim' magma. The mixing between the 'normal' lower Bishop magma body and the 'bright-rim' magma also caused overgrowths on sanidine, quartz, zircon and pyroxene. The transition zone highlighted on Fig 5.15 is a region which had more limited interaction with the 'bright-rim' magma, has sparse overgrowths on sanidine, quartz and zircon, and has only rare pyroxenes present.

Variations in the composition of the 'bright-rim' magma are schematically illustrated by the various stalling levels within the underlying mush pile, with accompanying diversity in the range of assimilation of mush and crystallisation, producing slightly different chemical compositions of the rejuvenating magma that eventually reaches levels where it forms part of the ejecta. Although challenging to clearly demonstrate on a $2 \mathrm{D}$ diagram, lateral variability on location of ingress of the 'bright-rim' magma is shown by localised intrusion into the melt-dominant magma body (Fig. 5.15).

\subsection{Conclusions}

This study has reached five main conclusions relating to the pre-eruptive Bishop Tuff magma chamber and its relationship to precursory and rejuvenating magmatism.

1. Studies of glass and phenocrysts from dome OD of Glass Mountain confirm the highlyevolved nature of the Older Glass Mountain sequence, with Rb/Sr values up to 150 (Fig. 5.9). Dome YA (the youngest dated unit erupted from Glass Mountain, Metz \& Mahood, 1985; Chamberlain et al., 2014a [Chapter 3]; Simon et al., 2014) has a glass chemistry similar to that of the eastern Bishop Tuff units (Fig. 5.9). Zircon studies show that the young 
Glass Mountain and Bishop Tuff, however, share almost no similarities in zircon textures or overlap in ages (Chamberlain et al., 2014a [Chapter 3]). These results demonstrate that the melt-dominant magma bodies responsible for the young Glass Mountain sequence, and the Bishop Tuff were spatially and temporally distinct. The overlap in glass chemistry confirms similar compositional sources for both the young Glass Mountain eruptives and the early-erupted units of the Bishop Tuff, highlighting the long duration of production of 'eastern'-type magma in the Long Valley region ( $400 \mathrm{kyr})$.

2. The Bishop Tuff magma chamber was not only stratified in temperature prior to intrusion of the 'bright-rim' magma (Chamberlain et al., 2014b [Chapter 4]), but was also stratified in composition. This is shown by the variation in cores of sanidine crystals which can be demonstrated to have grown within the melt-dominant magma body prior to any significant ingress of and interaction with the 'bright-rim' magma (Fig. 5.10; Hildreth \& Wilson, 2007; Roberge et al., 2013).

3. The stratification of the Bishop magma chamber was gradational from the upper units with the most evolved glass compositions, unzoned phenocrysts, pyroxene-free and lower temperature magma through to lower units with less-evolved glass compositions, systematically zoned sanidine and quartz phenocrysts, pyroxene-bearing and higher temperature magma (Figs. 5.4 - 5.8). The transition from more-evolved to less-evolved compositions is revealed in unit Ig2Na which shows both eastern and northern sanidine and glass (and melt inclusion: Roberge et al., 2013) compositions. The identification of the role of $\mathrm{Ig} 2 \mathrm{Na}$ and the Sherwin subunit of $\mathrm{Ig} 1 \mathrm{~Eb}$ in preserving the gradient in composition within the Bishop Tuff magma chamber exemplifies the singular nature of the Bishop magma chamber. I find no evidence to support the presence of two physically separate magma chambers feeding the Bishop Tuff (cf. Gualda et al., 2012a; Gualda \& Ghiorso, 2013a).

4. I find no evidence for eastern-type magma underlying the northern vents of the Bishop magma chamber (Fig. 5.15) and thus infer an asymmetric roof for the pre-eruptive Bishop magma chamber (Fig. 5.15) similar to that suggested from melt inclusion studies (Wallace et al., 1999). 
5. Rare dacitic and dark pumices are identified as possible analogues for the 'bright-rim' magma known to intrude the lower regions of the Bishop magma chamber (Anderson et al., 2000; Wark et al., 2007; Chamberlain et al., 2014a,b [Chapters 3 and 4]) given their significant enrichment in Ba, Sr, LREE and Ti (Fig. 5.9). The 'bright-rim' magma cannot be typified by a single composition, and instead likely represents varied tapping of a chemically heterogeneous source. The source of the 'bright-rim' magma could have been enriched in $\mathrm{Ba}, \mathrm{Sr}$, Ti and LREE due to heterogeneous re-melting of an underlying mushy region, or could have been heterogeneous itself and represent various different dacitic or trachytic magmas present in Long Valley. The occurrence of bright-rims on zircons from Dome OD (Chamberlain et al., 2014a [Chapter 3]) and the presence of a postcaldera rhyodacite dome (Dome 7043) enriched in Ba and Sr (Hildreth, 2004) implies that various 'bright-rim' dacite magmas may be the recurrent products of a long-lived source within the Long Valley area. 
Chapter 6 


\section{Synthesis and Conclusions}

\subsection{Key findings}

This study is the first whole-deposit investigation into the chemistry of Bishop Tuff crystals and glass since the seminal work of Hildreth $(1977,1979)$, and contributes to the ongoing discussion of the state of the pre-eruptive Bishop magma system. Although many different analytical investigations into the nature of the Bishop Tuff magma system have been carried out since Hildreth's Ph.D. thesis (1977; see section 1.5.2), these have been somewhat constrained by limited sampling campaigns, and the ongoing debate surrounding key issues. In this thesis the lateral and vertical variation within the pre-eruptive Bishop Tuff magma chamber have been systematically investigated, and the timescales associated with assembly and mixing established. As well as yielding a revised magma chamber model for the Bishop Tuff this study also reveals insights into the comparability of ID-TIMS and SIMS dating techniques on zircon crystals, and has highlighted possible issues with diffusion modelling in multiple phases in lower temperature rhyolitic magmas. The key results of this study are synthesised here.

\subsubsection{Can eruption age estimates from ID-TIMS be replicated using SIMS techniques in the Bishop Tuff?} Application of SIMS techniques to U-Pb date zircon crystals provides a method for determining crystallisation ages in relatively short analytical times when compared with IDTIMS methods, which require considerably more sample preparation. A distinct advantage of using SIMS to date zircon crystals is that the same crystal imaged under CL can also be analysed, and the analysis spot can be located accurately within any zonation identified from the imagery. In this thesis we have utilised these in situ SIMS methods to date zircons from the Bishop Tuff, the earliest crystallising phase (Hildreth, 1977, 1979) and therefore date the beginning of crystallisation within the Bishop magma system (Chapter 3). Although SIMS has a distinct spatial advantage when compared with ID-TIMS analyses, the precision of individual measurements is significantly lower than that of ID-TIMS, which commonly have precisions of $\sim 1 \%$ or lower (e.g. Crowley et al., 2007; Keeley et al., 2013). In contrast, single measurements on Bishop zircons in this study have uncertainties of up to $10 \%$ (Chapter 3). When combined, however, the precision of SIMS analyses can begin to equal that of ID-TIMS, as well as yielding comparable ages. An ID-TIMS study on 19 whole Bishop zircons (of which 17 were considered 'acceptable') from a single sample of unit Ig1Eb (Fig. 1.7) yield a weighted mean of $767.1 \pm 0.9$ ka (Crowley et al., 2007), 
which is within uncertainty of the weighted mean of early-erupted rims of Bishop zircons from this study at $766.6 \pm 3.1$ ka obtained using SIMS techniques $(n=173$; Chapter 3$)$.

A clear advantage of using SIMS analyses of zircons is the ability to date single internal regions of zircon crystals and to therefore trace the longevity of magma systems, as in whole crystal dissolution for ID-TIMS, previously employed for Bishop zircons (Crowley et al., 2007), the volumetrically large rims will mask any small inherited or older core regions of a zircon crystal (Reid \& Schmitt, 2012). In this case the $\sim 80 \mathrm{kyr}$ history of zircon crystallisation revealed in late northern zircons of the Bishop Tuff would be concealed (or at least diluted; Chapter 3). The rim U-Pb age presented in this study of $766.6 \pm 3.1 \mathrm{ka}$ is the best-estimate of eruption age from SIMS U-Pb dating of Bishop zircon rims, and is within uncertainty the same as the eruption age yielded by ${ }^{40} \mathrm{Ar} /{ }^{39} \mathrm{Ar}$ dating of Bishop sanidines: $767.4 \pm 2.2 \mathrm{ka}$ (Rivera et al., 2011). Therefore, not only can eruption age measurements obtained using ID-TIMS be replicated using SIMS techniques, the latter can also yield a spatial constraint on ages, not preserved in bulk ID-TIMS measurements, that allows comparison with ${ }^{40} \mathrm{Ar} /{ }^{39} \mathrm{Ar}$ eruption age determinations.

\subsubsection{What are the timescales for assembly of the Bishop Tuff magma chamber?}

A range of U-Pb dates have been measured using both ID-TIMS and SIMS techniques, which (respectively) suggest between $\sim 0 \mathrm{kyr}$ to $\sim 220 \mathrm{kyr}$ of zircon growth in the Bishop Tuff magma chamber prior to eruption (Reid \& Coath, 2000; Simon \& Reid, 2005; Crowley et al., 2007; Reid \& Schmitt, 2012). As discussed above, one possibility for why ID-TIMS ages replicate eruption ages of Rivera et al. (2011) could be due to the volumetrically dominant eruption-age rims (Crowley et al., 2007; Reid \& Schmitt, 2012). In this study no evidence was found for more than $80 \mathrm{kyr}$ of zircon growth recorded even in the cores of the latest erupted material, and suggests that the Bishop magma system was only in operation for that period prior to eruption. This estimate is shorter than previously proposed from other studies where zircon cores have been dated using SIMS techniques (Reid \& Coath, 2000; Simon \& Reid, 2005; Reid \& Schmitt, 2012).

An important question in terms of the growth of the melt-dominant Bishop magma body is whether this $80 \mathrm{kyr}$ represents growth of zircons within this body, or growth within an underlying mush zone (and are therefore antecrystic: Bacon \& Lowenstern, 2005; Charlier et al., 2005). In many supereruptive systems around the world evidence can be seen for 
antecrystic vs. phenocrystic zircons, with significant inheritance from precursory systems. A compiled PDF curve of all Bishop zircon U-Pb ages is distinctly unimodal (Fig. 3.6), and only once core ages from late-erupted northern zircons are considered alone are two peaks identified (whereas U-Pb ages of cores of earlier-erupted eastern zircons are markedly unimodal). These two peaks are inferred here to represent growth within the underlying mush zone (with a weighted mean of these ages of $838.5 \pm 8.7 \mathrm{ka}$; Section 3.4.2.2.1), whereas the younger age group (with a weighted mean of $784.1 \pm 8.7$ ) is likely to represent growth within the melt-dominant magma chamber, however, this study has been unable to confirm this inference. Therefore the mush system (and possibly the melt dominant magma body) responsible for the Bishop Tuff only experienced zircon growth for $\sim 80 \mathrm{kyr}$ prior to eruption, with less than 10\% inheritance of any precursory Glass Mountain zircons, from zircon textures, even in the latest erupted samples.

\subsubsection{The Bishop Tuff and Glass Mountain: two separate entities?}

Another significant aspect of this study was the comparison of U-Pb ages and textures of zircons from two precursory Glass Mountain domes (YA and OD) with ages and textures of zircons from the Bishop Tuff (Chapter 3). Previous investigations into the relationship between the Glass Mountain and Bishop Tuff systems using Rb/Sr or Sm/Nd systematics and geochemical analyses of whole rock samples, has inferred that the Younger Glass Mountain magma system (0.79 - 1.2 Ma; Metz \& Mahood, 1985) evolved into the Bishop Tuff due to chemical overlap in glass and whole rock compositions, and the apparent lack of a significant time break between the two periods of activity (Metz \& Mahood, 1985; Metz \& Mahood, 1991; Christensen \& Halliday, 1996; Davies \& Halliday, 1998; Hildreth \& Wilson, 2007). The chemical similarity between youngest Glass Mountain (Dome YA) and eastern Bishop Tuff glass is again highlighted in this study (Chapter 5), which would seem to support the evolution of a long-lived magma system in the Long Valley caldera. However, U-Pb age determinations on zircons in this study in fact suggest that the eruption age of Dome YA was $862 \pm 23 \mathrm{ka}$ (Chapter 3) much older than from K-Ar dating (Metz \& Mahood, 1985). The long gap ( 100 kyr) between the youngest Glass Mountain and the climactic Bishop Tuff eruption coupled with the identification of distinctively different zircon textures in Glass Mountain and Bishop Tuff zircons (from CL imagery) suggests that although there is a chemical link between Glass Mountain and the Bishop Tuff (likely due to their geographic overlap; Fig. 1.6) the two magma systems were temporally and spatially separate, supported by recent work of Simon et al. (2014). 


\subsubsection{Bishop: One magma chamber or two?}

A key debate which has arisen during the course of this project is the hypothesis that the Bishop Tuff is the product of two separate magma chambers erupting coevally (Gualda et al., 2012a; Gualda \& Ghiorso, 2013a). This is apparently supported by 'bimodality' of crystal populations, and similar temperatures and pressures of the magma across all units. However, upon closer examination, the 'bimodality' in fact represents compositional variation within crystals from the later-erupted, mixed units and the assumptions used to determine temperatures and pressures using Rhyolite-MELTS (Gualda et al., 2012a) and silica in glass barometry (Gualda \& Ghiorso, 2013b) appear flawed (Chapter 5). Detailed stratigraphic sampling, modelled two-feldspar thermometry and measured phenocryst chemistries in this thesis study decisively point to the existence of only a single, compositionally and thermally zoned magma chamber as a source for the Bishop Tuff, in agreement with the dominant volume of previous work (Chapter 5; e.g. Hildreth, 1977, 1979; Wallace et al., 1999; Anderson et al., 2000; Hildreth \& Wilson, 2007; Wark et al., 2007).

\subsubsection{What was the nature of the Bishop magma body?}

By integrating zircon studies (Chapter 3), diffusion modelling (Chapter 4) and microanalytical investigation into crystal and glass chemistry (Chapter 5) with previously published melt inclusion compositions and pressures (e.g. Lu, 1991; Wallace et al., 1999; Anderson et al., 2001; Roberge et al., 2013) the following insights into the nature of the Bishop magma body have been gained:

1) The dominant volume of the Bishop Tuff, represented by the earlier, easterndeposited units (Wilson \& Hildreth, 1997) was only slightly stratified in composition and temperature, and no evidence for mixing is found in these units (Chapter 5). These findings support the theory, for the eastern-deposited units, that all crystals grew in the melt in which they are found (as proposed by Hildreth, 1977, 1979).

2) The whole Bishop magma chamber was both compositionally (Chapters 3, 5) and thermally (Chapter 4) stratified prior to eruption, and prior to mixing with the 'bright-rim' forming magma, similar to that proposed by Hildreth $(1977,1979)$ and Hildreth \& Wilson (2007). 
3) Late northern-erupted units are systematically enriched in Ba, Sr, LREE, Ti in their matrix glass compositions, and show the presence of significant clino- and orthopyroxene, high-Ca plagioclase and bright overgrowths on quartz, sanidine and zircon crystals when compared with earlier-erupted (shallower: Wallace et al., 1999) eastern units, due to significant mixing with the 'bright-rim' magma in the lower regions of the Bishop Tuff magma chamber (Chapter 5; Fig. 6.1). Therefore crystals in the later, northern deposited units do not comply with the model of Hildreth $(1977,1979)$ that all crystals grew in the melt in which they were erupted.

4) The key transitional role is identified for unit Ig2Na (Fig. 1.8; Chapter 5), where large $(>250 \mu \mathrm{m})$ pyroxene phenocrysts are not found, 'bright-rim' overgrowths of sanidine, quartz and zircon are less prominent and two-feldspar temperatures are lower when compared with other northern-erupted units (Chapter 3, 4, 5). Therefore Ig2Na and, to a lesser degree, the Sherwin subunit of Ig1Eb (as based on zircon textures and the sporadic presence of pyroxene) seems to be intermediate between the more-evolved, eastern-erupted units of the Bishop Tuff which lack bright rim overgrowths and pyroxene phenocrysts, and the less-evolved, northernerupted units of the Bishop Tuff which have pervasive bright-rim overgrowths on sanidine, quartz and zircon, and where pyroxene (clino and ortho) are present, and pickable by hand (Fig. 6.1; Chapter 5).

5) Geographic variation in magma chemistry is evidenced when coevally erupted units $\operatorname{Ig} 2 \mathrm{Na}$ and $\mathrm{Ig} 2 \mathrm{NWa}$ and 'normal' Ig1Eb and the Sherwin subunit of Ig1Eb are compared (Chapter 5). Variations are highlighted in the presence (or absence) of zonation within quartz, sanidine and zircon, as well as the presence (or absence) of pyroxenes.

6) The asymmetric nature of the pre-eruptive Bishop magma body is highlighted in this study by comparing crystal poor and crystal rich material from the same units (Fig. 6.1; Chapter 5). The model for the Bishop Tuff magma chamber of Hildreth \& Wilson (2007: Fig. 18) implies that eastern-type, crystal poor material resided under the northern vents prior to eruption, but this was drained and erupted at eastern deposited units, and therefore the rare crystal-poor pumices found in northern-erupted units are a relic of this eastern-type, more-evolved magma. 


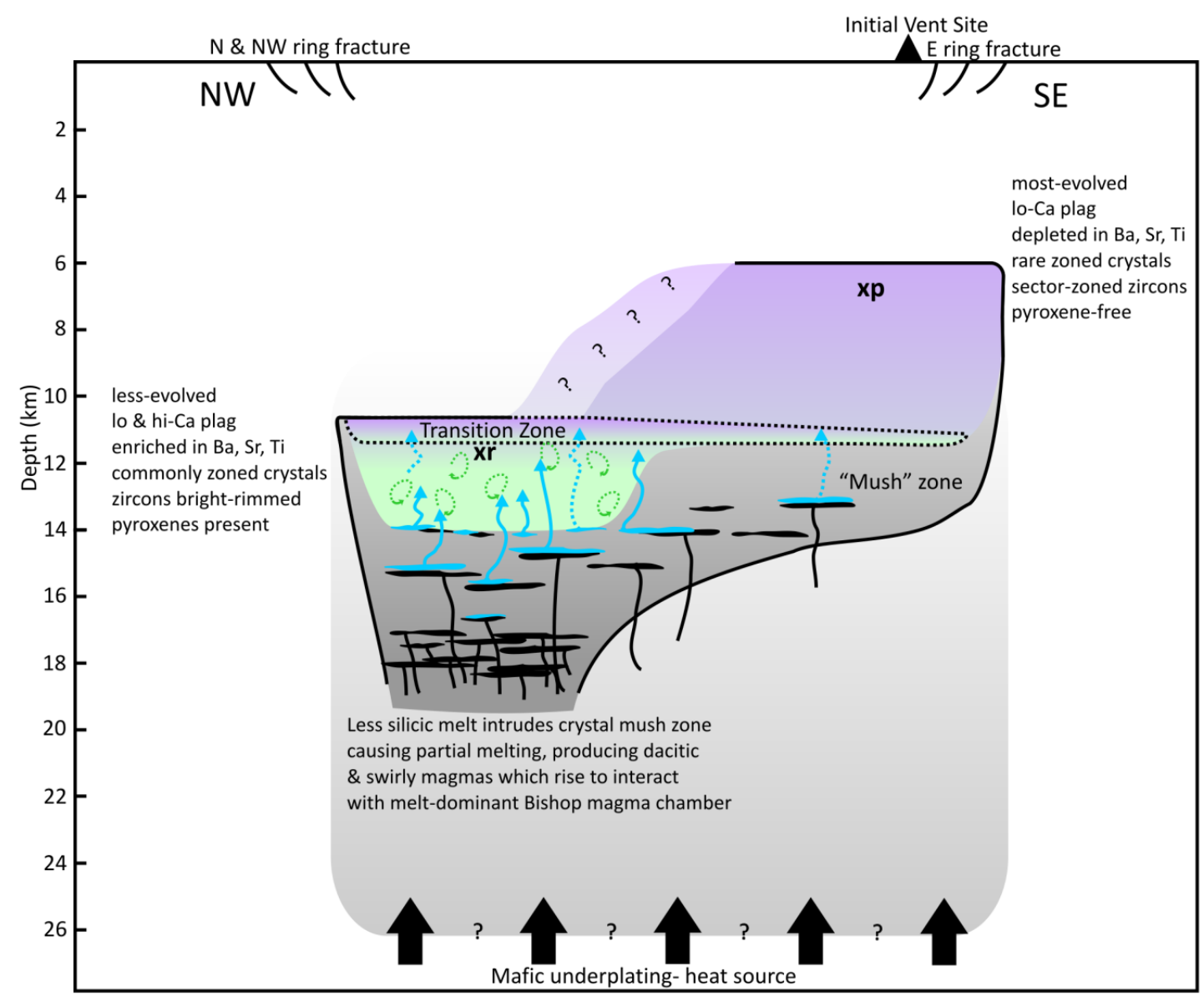

Fig. 6.1. [Repeated Fig. 5.15 included for reference in this chapter.] A revised model for the immediately pre-eruptive Bishop magma chamber derived from my work and utilising the depth estimates of Wallace et al. (1999). See text and Fig. 5.11 for discussion of various crystal origins.

Comparison of crystals and glass from crystal poor (but still 'normal') pumice from $\operatorname{Ig} 2 \mathrm{Na}$ with crystals and glass from the dominant crystal rich pumice of $\operatorname{Ig} 2 \mathrm{Na}$ reveals that the crystal poor material is, if anything, less-evolved than the crystal rich samples, and therefore is not the product of relic crystal poor 'eastern-type' magma (Chapter 5).

In conclusion, phenocryst and glass chemistries measured in this study support previous models (e.g. Hildreth \& Wilson, 2007) where a compositional and thermal stratification existed in the melt-dominant magma body of the Bishop Tuff, prior to any phenocryst growth. The magma chamber model of Hildreth \& Wilson (2007) is refined with no evidence for eastern material being found in any northern units, inferring that an asymmetric magma chamber existed in Long Valley prior to the Bishop Tuff eruption, similar to Wallace et al. (1999) (Fig. 6.1). Lateral heterogeneity within the Bishop magma 
chamber is identified when $\operatorname{Ig} 2 \mathrm{Na}$ is compared with Ig2NWa, and the Sherwin subunit of Ig1Eb with 'normal' Ig1Eb, which was only possible due to the thorough sampling strategy initially undertaken as part of this study.

\subsubsection{What was the role of the 'bright-rim' magma in establishing the stratification of the Bishop Tuff?}

Late-stage mixing with a less-evolved magma has long been known to occur at the base of the Bishop magma chamber (e.g. Wark et al., 2007; Roberge et al., 2013) but what role this less-evolved magma had in establishing the observed change in glass chemistry and thermometry from upper, cooler, more-evolved magma to lower, hotter, less-evolved magma had not yet been investigated.

Two-feldspar thermometry reveals an $\sim 80{ }^{\circ} \mathrm{C}$ thermal stratification between the upper and lower units of the Bishop Tuff prior to intrusion of the bright rim magma, and yet Fe-Tioxide thermometry (which is reset on a weeks-months timescale: Buddington \& Lindsley, 1965) shows a $\sim 100{ }^{\circ} \mathrm{C}$ thermal gradient (Hildreth 1977, 1979; Hildreth \& Wilson, 2007). This apparent difference in the established thermal gradient of $\sim 20{ }^{\circ} \mathrm{C}$ before and after intrusion of the 'bright-rim' magma suggests that the 'bright-rim' magma was not significantly hotter, supported by Ti-in-zircon thermometry (Chapter 3). Although the temperature difference between the lower Bishop magma chamber and 'bright-rim' magma may be somewhat masked due to the volumetric dominance of the 'normal' Bishop magma, it is clear that a thermal gradient existed in the Bishop magma chamber prior to introduction of the 'bright-rim' magma, and that the temperature difference between the 'normal' Bishop magma and the 'bright-rim' magma was not extreme (Chapters 4, 5).

Examination of elemental variation in cores of phenocrysts reveals a chemical stratification in the Bishop Tuff magma chamber prior to intrusion of the 'bright-rim' melt, which is only slightly enhanced when the rims are considered (Chapter 5). In general, rims of crystals are enriched in $\mathrm{Ba}, \mathrm{Sr}, \mathrm{Ti}, \mathrm{LREE}$ with a less-evolved Eu anomaly, which shows that the 'bright-rim' magma was chemically less-evolved than even the 'normal' latest-erupted Bishop Tuff magma. It is inferred that the dominantly bright zircon are native to the 'bright-rim' magma crystals, which show a much more extended interaction with the 'bright-rim' magma (Chapter 3, 5). The identification of bright (in CL) overgrowths in Glass Mountain Dome OD zircons suggests that this 'bright-rim' magma could be a longlived source in Long Valley, but to constrain this further is beyond the scope of this project. 
The origin of this 'bright-rim' magma is somewhat unclear, with previous workers suggesting that it is remelted crystal mush (Wark et al., 2007) or a separate magma source, possibly linked to post-caldera eruptives (Hildreth, 2004). 'Variant' pumice samples of the Bishop Tuff are identified as possible 'bright-rim' magma representatives. Dark, swirly and dacitic samples are enriched in $\mathrm{Ti}, \mathrm{Sr}, \mathrm{Ba}$ and LREE, as is found in the high-Ca plagioclase and overgrowth rims on sanidine and quartz. Significantly, even in samples which show no chemical evidence of mixing between the rhyolite and less-evolved dacite, no single endmember composition can be identified, suggesting that the 'bright-rim' magma cannot be constrained by this work to one single composition, and instead represents a continuum in composition between the deeper, less-evolved Bishop magma and the source for the 'bright-rim' magma (Chapter 5).

\subsubsection{For how long did the 'bright-rim' magma interact with the Bishop Tuff?}

Diffusion modelling within sanidine, quartz and orthopyroxene phenocrysts reveals timescales of generally less than 500 years for diffusion between the overgrowth rims and 'normal' cores of crystals (Chapter 4). Although there appears to be some complexities involved in this modelling (see below) the similarities in diffusion profiles shapes implies that the zoning in quartz, sanidine and orthopyroxene could be tracing similar processes occurring within the magma chamber, rather than tracing different processes (e.g. Millet et al., 2014). Although major phases record a relatively short-lived ( $<500$ years) interaction with the 'bright-rim' magma, zircon crystals seem to have as much as $10 \mathrm{kyr}$ of history with the 'bright-rim' magma (with some completely bright zircons present in late erupted material, highlighting this) (Chapter 3). This long-lived interaction with the 'bright-rim' magma evidenced by thick bright rims in zircon crystals (and rare pure bright zircon crystals) is likely due to extended growth within the 'bright-rim' magma at depth within the underlying mush system (Fig. 1.2). These crystals are then incorporated into the meltdominant magma body during the mixing in the lower regions of the Bishop magma chamber that occurs within 500 years of eruption.

Previous studies have suggested that the previously modelled timescales (of $<100$ years) show that the mixing with the 'bright-rim' magma could have been an eruptive trigger for the destabilisation of the melt-dominant Bishop magma body (Wark et al., 2007). Although mixing with a less-evolved magma is often cited as an eruptive trigger (Sparks et al., 1977; 
Jellinek \& DePaolo, 2003; Wark et al., 2007; Arienzo et al., 2011; Matthews et al., 2012a; Saunders et al., 2012a), in this case the longer timescales revealed from diffusion modelling in multiple phases (Chapter 4) somewhat limits this possibility. In fact, the late-stage mixing with the 'bright-rim' magma may reflect changes to underlying mush systems, or tectonic processes which allow this 'bright-rim' magma to progress to progressively shallower levels in the melt-dominant magma body, and therefore it was changes within these processes, and their resultant effects which caused the eruption of the Bishop Tuff, and not in fact the initial mixing itself which triggered eruption. Due to the dominantly $(>99 \%$, Hildreth \& Wilson, 2007) high-silica rhyolite nature of the Bishop Tuff, it is nigh on impossible to demonstrate cause and effect for eruption triggering, and instead only speculations can be made about possible triggering factors.

\subsubsection{Diffusion modelling in the Bishop Tuff: limitations and implications}

Adding complexity to the debate about when the 'bright-rim' magma invaded the Bishop Tuff magma chamber is the observation that orders of magnitude different timescales are modelled from $\mathrm{Fe}-\mathrm{Mg}$ interdiffusion in orthopyroxene, Ti diffusion in quartz, and $\mathrm{Ba}+\mathrm{Sr}$ combined diffusion modelling in sanidine (Chapter 4). Fe-Mg interdiffusion timescales are all less than 20 years, Ti diffusion in quartz timescales are less than 100 years and $\mathrm{Ba}$-Sr diffusion in sanidine timescales are less than 500 years. As discussed, the similarity between the extracted profiles (and their apparent class 1, 2, 3 types: Chapter 4: Fig 4.7) from all three phases could infer that these timescales should be at least comparable orders of magnitude, as apparently similar processes have generated the range in profiles observed. Further complications are added to the timescales debate by the identification of bright (in $\mathrm{CL}$ ) overgrowth rims on zircon phenocrysts in the late-erupted samples from the Bishop Tuff (Chapter 3).

Two end-member possibilities exist for the cause of the discrepancy in modelled timescales from the 3 different phases in the Bishop Tuff:

1) The value of the diffusion coefficients for $\mathrm{Fe}-\mathrm{Mg}$ interdiffusion in orthopyroxene are still poorly defined. In this study I used the modified formulation of Ganguly \& Tazzoli (1994), but this yielded timescales which were approximately an order of magnitude shorter than Ti diffusion in quartz. Alternatively, had the calibration of Schwandt et al. (1997) been used, the modelled timescales would be 2-3 orders of magnitude longer than that of $\mathrm{Ti}$ in quartz, comparable with $\mathrm{Ba}$ in sanidine 
timescales prior to removal of the growth effect. By inferring that the modelled timescales from orthopyroxene should agree with timescales from $\mathrm{Ti}$ in quartz diffusion, we suggest that $D_{0}$ needs to be 1-2 orders of magnitude greater than that suggested in Ganguly \& Tazzoli (1994) in alignment with that suggested by those authors who are currently investigating this issue (S. Chakraborty, R. Dohmen, pers. comm.).

2) Alternatively, the remains possibility that the timescales modelled from Fe-Mg interdiffusion within orthopyroxene are correct and the differences between modelled timescales (from sanidine, quartz and orthopyroxene) represents differing areas of interaction within the melt-dominant magma body. Pyroxenes in particular could have crystallised only once mixing between the 'bright-rim' magma and the lower Bishop magma had occurred, and the zoning preserved in fact developed due to later-stage convective mixing. The overgrowth rims on orthopyroxene could therefore be triggered by increasing $\mathrm{CO}_{2}$ flux and increasing convective mixing within the lower regions of the main melt-dominant magma body (Chapter 4).

Another important observation resulting from the comparison of diffusion modelling in multiple crystal phases of the Bishop Tuff is the identification of the role of growth zoning in altering modelled timescales, in this case in sanidine crystals. Growth zoning can negate the initial assumption in diffusion modelling that the initial contact between the high- and low-concentration zones was sharp (with a full width of zero). If growth zoning is not removed, timescales modelled from these extracted profiles will be excessively long (Chapter 4). This is the case in the Bishop Tuff, where both $\mathrm{Ba}$ and $\mathrm{Sr}$ are highly compatible in sanidine phenocrysts (Lu, 1991). Partial dissolution, evidence by rounded cores, occurred prior to overgrowth of the bright rim, and this led to zone refining around the crystal, and an initial profile, prior to any diffusion occurring, which had a curved appearance. This effect is more significant when modelling $\mathrm{Ba}$ diffusion in sanidine than $\mathrm{Sr}$ diffusion in sanidine, due to more compatible nature of $\mathrm{Ba}$ in sanidine, and the slower diffusion of $\mathrm{Ba}$ in sanidine, so growth effects take longer to eradicate through diffusion. This observation is of particular importance when modelling diffusion in rhyolitic systems, as diffusion speeds will be much slower than in, for example, basaltic systems where these growth effects may not be preserved due to greater full widths of diffusion profiles masking any lingering growth profiles. 
In conclusion, although diffusion modelling is a valuable tool to extract pre-eruptive timescales, the added complexities of low temperatures in rhyolitic systems, and variablysaturated magma bodies means that timescales extracted from diffusion modelling in rhyolitic systems need to be carefully considered to ensure that the modelled timescales represent diffusive relaxation alone.

\subsection{Addressing the controversies of the Bishop Tuff}

Many controversies regarding the nature and timing of the Bishop Tuff remained at the initiation of this thesis study, and are addressed here.

1) A key question that is still debated is how long-lived the Bishop Tuff magma system was. Estimates have ranged from as long as 1 Myr (see Chapter 3; Christensen \& Halliday, 1996; Davies \& Halliday, 1998) to as short as thousands of years (Pamukcu et al., 2012; Gualda et al., 2012b). Zircon U-Pb dating carried out for this thesis reveals only $\sim 80 \mathrm{kyr}$ of zircon growth for the Bishop Tuff (Chapter 3).

2) Also of interest is how much temporal overlap there was between the Bishop and Glass Mountain magmatic systems. A time break of $<30 \mathrm{kyr}$ was accepted with an apparent eruption age of $0.79 \mathrm{Ma}$ for the youngest Glass Mountain dome (Metz \& Mahood, 1985). This project (since corroborated by the studies of Simon et al., 2014) has shown a significantly longer time gap between the youngest Glass Mountain dome (YA) and the Bishop Tuff, and has revealed distinctly different zircon textural characteristics between Bishop and Glass Mountain zircons (Chapter 3). Although the glass chemistry of dome YA is comparable with that of early Bishop material (Chapter 5), the zircon study has highlighted the physically and temporally discrete nature of the Glass Mountain and Bishop magma systems.

3) Another debatable issue which has arisen during this thesis study is the possibility that the Bishop Tuff is the product of the eruption of not one but two separate magma chambers, similar to that proposed for the Kidnappers eruption (Cooper et al., 2012; Gualda \& Ghiorso, 2013a,b). By examining glass and phenocrysts from all stratigraphic levels of the Bishop Tuff I have shown that the Bishop Tuff was the 
product of the eruption of a single compositionally (Chapter 5) and thermally (Chapter 4) zoned magma body, where apparent bimodality of crystal compositions is in fact due to late-stage mixing with a less-evolved magma in the lower regions of the Bishop magma chamber.

4) A final controversy associated with the Bishop Tuff is the role of an apparently less-evolved magma in stratifying the Bishop Tuff magma body and possibly causing eruption (Anderson et al., 2000; Peppard et al., 2001; Hildreth \& Wilson, 2007; Wark et al., 2007). Some authors have suggested that high-Ti rims on quartz record decompression during eruption (Thomas et al., 2010; Gualda et al., 2012b; Pamukcu et al., 2012), rather than mixing with the 'bright-rim' magma. Diffusion modelling of $\mathrm{Ti}$ in quartz and $\mathrm{Ba}$ and $\mathrm{Sr}$ within sanidine phenocrysts reveals longer timescales than that required for decompression, and so are instead interpreted to reflect mixing with the identified 'bright-rim' magma. Being able to clearly determine if the intrusion of the 'bright-rim' magma into the Bishop magma body began a chain of events which eventually led to eruption is not yet possible due to many other factors which may also have affected the stability of the magma body.

\subsection{Comparison and contrasts}

The Bishop Tuff is an iconic example of a large (super-eruptive) silicic deposit, and has been widely used as a key exemplar for building and refining models for silicic magmatism. The work presented in this thesis has refined our understanding of the Bishop magmatic system, and allows for more detailed comparisons and contrasts with other large-scale silicic eruptions.

1) The underlying crystal mush regions (see section 1.3.1.2) is known to play varying roles in sourcing both melt and crystals into the melt-dominant magma body. These crystal mush systems can in some cases be long-lived regions in the crust (Table 6.1), yet in the Bishop Tuff there are very limited proportions of Glass Mountain zircons (Chapter 3), highlighting either almost complete resetting of the underlying crystal mush or that a completely new crystal mush system was established in the $\sim 95$ kyr time break between the youngest Glass Mountain and the climactic Bishop Tuff eruption (Chapter 3). The Bishop Tuff also has no clear 


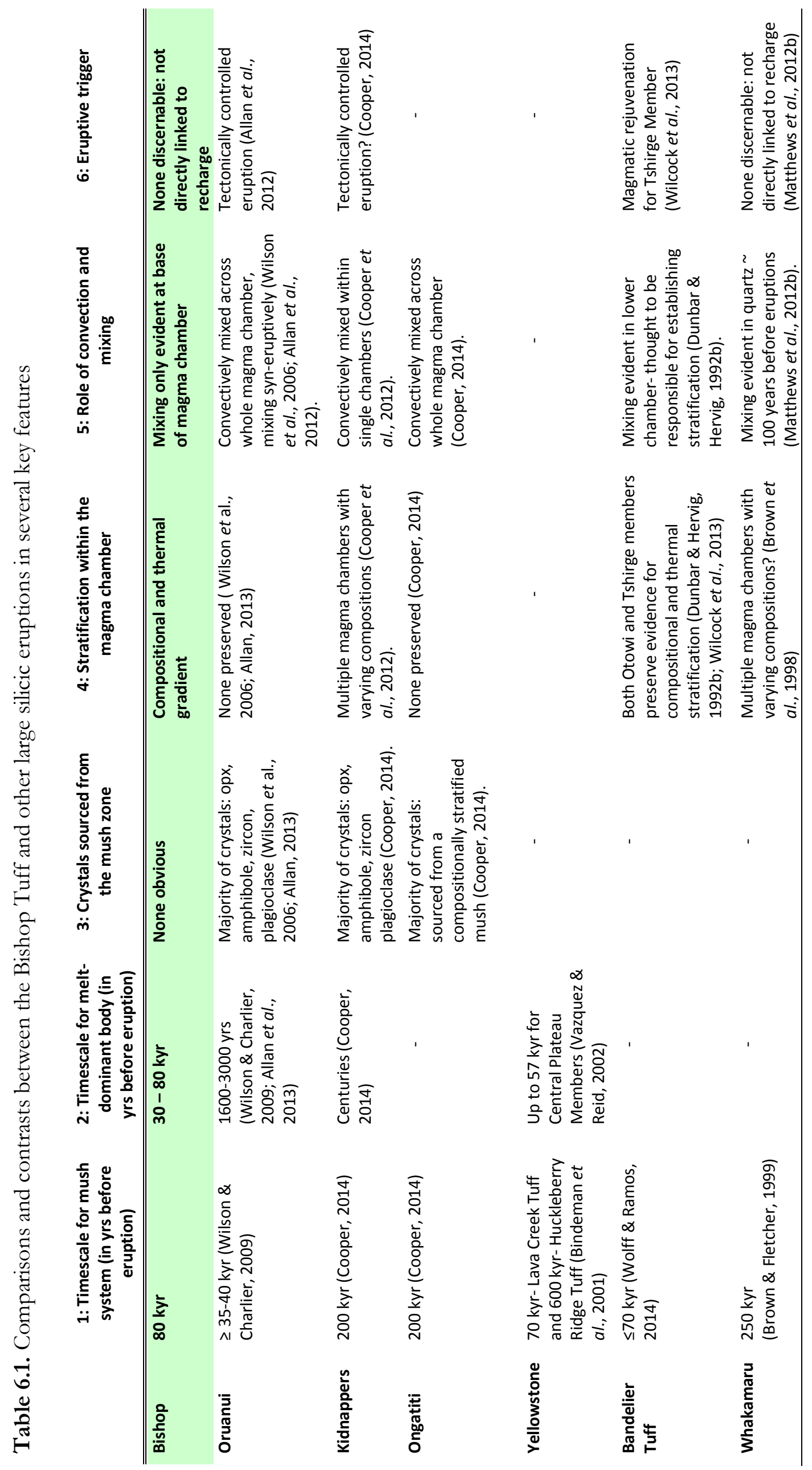


evidence for crystals originating in the mushy region, unlike other systems (Table 6.1).

2) Zircon $\mathrm{U}-\mathrm{Pb}$ dating for this thesis has revealed that it took $\sim 80 \mathrm{kyr}$ (Chapter 3) to assemble the $>600 \mathrm{~km}^{3}$ (Wilson \& Hildreth, 1997) melt-dominant magma body. This inferred steady accumulation of the Bishop magma chamber is likely due to its proposed piecemeal assembly from melts rising to their level of neutral buoyancy, without significant crystal components (Hildreth \& Wilson, 2007). In other regions, the TVZ especially, this process is much more rapid, possibly due to the very high heat flux in the region, intense tectonic activity and high heat loss of crystallisation during rapid magma chamber assembly (Table 6.1).

3) This study has refined the model for the Bishop magma body and highlights the thermal and compositional gradient (established in the Bishop chamber prior to mixing with the 'bright-rim' magma) (Chapter 5). The preservation of this zoning shows that convection and mixing was not a significant chamber-wide process in the Bishop, even though it is a dominant feature of many other large silicic systems (Table 6.1).

4) An important feature when considering silicic systems is whether the magma chambers reflect open or closed-system processes. The Bishop Tuff used to be considered a classic 'closed-system', and yet the role of mixing in the late Bishop Tuff has been clearly shown in this thesis (Chapter 4, 5). However, other large events have very open system processes occurring (Table 6.1) and deciphering whether a magma chamber can ever be truly 'closed' warrants further investigation.

5) A final feature of interest is the various triggering factors which have been proposed for different supervolcanic systems. Although intrusion of a more mafic magma or buoyancy-driven overpressure of such a large volume of magma are often suggested as triggers for eruption (e.g. Sparks et al., 1977; Malfait et al., 2014), recent studies have highlighted the role of tectonics in both triggering and halting super-eruptions (e.g. Allan et al., 2012; Cooper et al., 2012). Although this study lacks the crystal-specific evidence to support or disprove this hypothesis for the Bishop Tuff, it would appear that the longer timescales of mixing with the 'bright- 
rim' magma are too long to be a direct trigger as has been previously suggested (Wark et al., 2007). Instead, given the identification of active faulting controlling recent eruptions in Long Valley (e.g. Bursik et al., 2003), it could seem plausible that tectonic processes may have also played a significant role in allowing the rise of the 'bright-rim' magma and possibly in triggering the Bishop Tuff eruption. Whether the paleotectonic record could be probed in enough detail to investigate this hypothesis is unknown, but it appears a valuable avenue for further exploration in the Long Valley region.

\subsection{Suggestions for Further Work}

In the process of addressing the questions described above, new avenues for further investigation have been illuminated, not only with respect to the Long Valley magmatic centre, but also for other magmatic systems and analytical techniques.

\subsubsection{Within the Long Valley region}

$\mathrm{U}-\mathrm{Pb}$ dating of zircons from precursory two Glass Mountain domes (specifically Dome $\mathrm{YA}$ ) has highlighted a major discrepancy between the earliest 30\% of U-Pb ages (an eruption age estimate) and the published K-Ar ages of Metz \& Mahood (1985). The difference in proposed ages is $\sim 70 \mathrm{kyr}$ for Dome YA and $\sim 40 \mathrm{kyr}$ for Dome OD (Chapter 3). All the proposed eruption ages from U-Pb dating of zircon crystals give older ages than the $\mathrm{K}-\mathrm{Ar}$ eruption ages, and therefore the possibility exists that the Glass Mountain activity began earlier than the accepted 2.2 Ma (Metz \& Mahood, 1985, 1991; Metz and Bailey, 1993), and could in fact be the source for the lapilli-bearing rhyolitic deposits dated to c. $2.2-2.8 \mathrm{Ma}$ (Sarna-Wojcicki et al., 2005). Some ${ }^{40} \mathrm{Ar} /{ }^{39} \mathrm{Ar}$ and U-Pb dating has been carried out on both pre- and post-Bishop units, which reveals older than previously considered eruption ages for the units sampled (Davies et al., 1994; Simon et al., 2014). However, not all units were sampled, and debate about the calibration of ${ }^{40} \mathrm{Ar} /{ }^{39} \mathrm{Ar}$ dates remains. An eruption age of 780 ka was given for the Bishop Tuff in Simon et al. (2014), which would result in $\sim 75 \%$ of my zircon $\mathrm{U}-\mathrm{Pb}$ ages being younger than the proposed eruption age. Suggestions for why the ID-TIMS ages of Crowley et al. (2007) are younger than the 780 ka eruption age (Simon et al., 2014) have been addressed in my study (Chamberlain et al., 2014a [Chapter 3]), and therefore do not explain the discrepancy between the old eruption age and zircon $\mathrm{U}-\mathrm{Pb}$ ages. Therefore, an intensive sampling campaign to ${ }^{40} \mathrm{Ar} /{ }^{39} \mathrm{Ar}$ (or zircon $\mathrm{U}-\mathrm{Pb}$ ) date all the

Glass Mountain units is vital in order to truly understand the temporal relationships 
between all Glass Mountain activity as well as the time break between Glass Mountain and the Bishop Tuff eruption. It is also imperative for agreement to be reached upon the age of the widely used Fish Canyon Tuff sanidine and the value of the ${ }^{40} \mathrm{~K}$ decay constant (see Phillips \& Matchan, 2013; Chamberlain et al., 2014a [Chapter 3]). The comparison between new eruption ages and zircon $\mathrm{U}-\mathrm{Pb}$ ages will have interesting implications for overlap of the young and old Glass Mountain activity, and yield insights into how connected the magma sources for each Glass Mountain eruption were.

In this study the 'bright-rim' magma has been identified as a late-stage entrant in the Bishop Tuff magma system. However, identification of bright rim overgrowths on zircon crystals from Dome OD (but, interestingly, not Dome YA) and the similarity between the nature of the 'bright-rim' magma and a single resurgent dome composition (Dome 7043; Hildreth, 2004) raises the possibility that this 'bright-rim' magma was a long-lived magma type in the Long Valley region. In order to fully assess if the 'bright-rim' magma was present in the Long Valley systems prior to and after the Bishop Tuff eruption, petrographic investigation of sanidine and quartz phenocrysts, as well as glass compositions should be undertaken. The resurgent domes in Long Valley caldera are interpreted to represent later tapping of the Bishop magma system, and therefore comparison of these chemistries with the dacites of the Bishop Tuff should reveal how dominant the 'bright-rim' magma was in these units.

The origin of the 'bright-rim' magma could be further investigated using both micro-Sr and $\mathrm{Pb}$ measurements from sanidine crystals which have bright rim overgrowths. By measuring $\mathrm{Sr}$ and $\mathrm{Pb}$ isotopes in small volumes of the dark (in BSE imaging) core and small volume samples of the overgrowth rims, comparative source origins could be inferred (e.g. Charlier et al., 2006; Davidson et al., 2007, 2008). Pb isotopes from the Bishop Tuff and Glass Mountain have been carried out previously and used to infer increasing mantle inputs closer to the Bishop Tuff eruption, so this could again be tested for the 'bright-rim' component compared with the 'normal' Bishop components of sanidine and glass (Simon et al., 2007). By comparing the isotopic characteristics of the overgrowth rim and the core of the sanidines the relationship between the origins of the 'bright-rim' magma and the main Bishop magma (and underlying mush) could be resolved (e.g. Davidson et al., 2007; Simon et al., 2007; Font et al., 2008; Deegan et al., 2010). 
In addition to characterising the 'bright-rim' magma using Sr isotopes, reinvestigation of the $\mathrm{Rb} / \mathrm{Sr}$ systematic could be carried out in the light of recent observations that the ${ }^{88} \mathrm{Sr} /{ }^{86} \mathrm{Sr}$ ratio is not uniform in K-feldspars from the Huckleberry Ridge Tuff (Charlier et al., 2013). By carrying out double-spike TIMS measurements in sanidine and glass of the Bishop Tuff of not only the ${ }^{88} \mathrm{Sr} /{ }^{86} \mathrm{Sr}$ ratio but also ${ }^{87} \mathrm{Sr} /{ }^{86} \mathrm{Sr}$ ratio, the role of stable-Sr fractionation could be assessed in light of previous $\mathrm{Rb} / \mathrm{Sr}$ studies which give up to 1300 kyr of 'magma residence' in the Bishop Tuff (e.g. Christensen \& Halliday, 1996; Davies \& Halliday, 1998). Stable Sr fractionation could be the cause of discrepancies between $\mathrm{Rb} / \mathrm{Sr}$ estimates of magma residence time in the Bishop Tuff when compared with the relatively short ( $<80 \mathrm{kyr}$ ) shown from U-Pb dating of zircon phenocrysts (Chamberlain et al., 2014a [Chapter 3]). Intra-crystalline $\mathrm{Sr}$ and $\mathrm{Pb}$ isotopes could also be used to further investigate the open- versus closed-system nature of the Bishop magma body (e.g. Wolff \& Ramos, 2014). This research has shown that the dominantly bright zircon crystals and orthopyroxene crystals were native to the 'bright-rim' magma. However, the possibility remains that some feldspar and clinopyroxene could also be indigenous to the 'bright-rim' magma, but lack systematic chemical differences to identify them as growing in this lessevolved magma. A way to identify which crystals grew in the 'bright-rim' magma would be to analyse melt inclusions within sanidine and pyroxenes (as well as high-Ca plagioclase) and compare these measurements with those of quartz crystals, which are known to have grown in the melt-dominant magma body (e.g. Wallace et al., 1999; Anderson et al., 2000; Roberge et al., 2013).

Finally, to confirm that $\mathrm{Fe}-\mathrm{Mg}$ in orthopyroxene interdiffusion timescales should be comparable orders of magnitude to $\mathrm{Ti}$ in quartz diffusion timescales, interdiffusion modelling of $\mathrm{Fe}-\mathrm{Mg}-\mathrm{Ca}$ in clinopyroxene could be undertaken. If the timescales are also considerably shorter than that modelled from Ti diffusion in quartz, it would in fact imply that the pyroxenes crystallised as a result of mixing of the 'normal' Bishop magma with the 'bright-rim' magma. In order to carry out this modelling the role of anisotropy of Fe-Mg$\mathrm{Ca}$ interdiffusion in clinopyroxene needs to be better understood and the diffusion coefficients calibrated for rhyolitic temperatures and compositions (Morgan et al., 2004; Cherniak \& Dimanov, 2010; Costa et al., 2013). 


\subsubsection{Possibilities for wider study}

Highlighted in this study is the huge range in possible diffusion coefficients for modelling $\mathrm{Fe}-\mathrm{Mg}$ interdiffusion in orthopyroxenes, which yields timescales up to 3 orders of magnitude different, depending on which calibration is used (e.g. Ganguly \& Tazzoli, 1994; Schwandt et al., 1998). The lack of experimental calibration of Fe-Mg interdiffusion in orthopyroxene at rhyolitic temperatures and compositions limits the application of experimentally derived diffusion coefficients as significant extrapolations are required to give a $D_{0}$ and $E$ to model diffusion. Therefore, imperative for further interdiffusion modelling of $\mathrm{Fe}-\mathrm{Mg}$ in orthopyroxene are experiments to properly constrain these coefficients at conditions suitable for rhyolitic systems and to quantitatively understand the role that oxygen fugacity has on this diffusion (e.g. Saunders et al., 2012b; Allan et al., 2013).

Another avenue for further investigation would be to use Nano-SIMS techniques to precisely measure both $\mathrm{Ba}$ and $\mathrm{Sr}$ concentration profiles in sanidine crystals to more accurately constrain the growth effect in sanidine phenocrysts from zone-refining in lower temperature rhyolitic systems. By comparing diffusion profiles from samples of eruptions of differing intensive variables, the conditions when this zone-refining is most prominent could be determined. The high-precision nature of Nano-SIMS analyses and high spatial resolution would allow for boundaries $<7 \mu \mathrm{m}$ to be constrained, and allow more comparison between $\mathrm{Ba}$ and $\mathrm{Sr}$, as well as using the newly developed combined modelling of $\mathrm{Ba}$ and $\mathrm{Sr}$ in sanidine, to allow better comparison with other modelled timescales. CL images of quartz zoning reveals some crystals where the bright-rim overgrowth is discontinuous, and in some cases not as simple as those modelled in this thesis (Chamberlain et al., 2014b [Chapter 4]; Electronic Appendix 5). The use of Nano-SIMS to extract Ti profiles in quartz would allow further investigation into these more complex zones to better constrain small-scale variation. By extracting more diffusion profiles from Nano-SIMS measurements, a much more accurate comparison of diffusion timescales can be made, and although it is time consuming, would allow for more robust corrections for any relict growth zoning in any rhyolitic system.

This study has highlighted the ability to distinguish lateral variation within a giant $(>600$ $\mathrm{km}^{3}$ ) stratified magma body by systematically sampling from all ignimbrite units in various geographic sectors of the Bishop Tuff. This approach could be used to investigate other rhyolitic systems. In order for these lateral heterogeneities to be revealed significant syn- 
eruptive mixing cannot have occurred (for example, as in the Oruanui: Charlier et al., 2008; Allan et al., 2012; Allan, 2013). Other places where a vertical gradation has been preserved, and therefore have the potential for identification of lateral heterogeneity, include the Valles Caldera (Dunbar \& Hervig, 1992b; Wolff et al., 1999; Wolff \& Ramos, 2003), the Young Toba Tuff (Chesner, 1998) the Huckleberry Ridge Tuff (Hildreth et al., 1984, 1991), and the Campanian Ignimbrite (Civetta et al., 1997). By carefully sampling from a wellestablished stratigraphy this study has revealed significant insights into the nature of the pre-eruptive Bishop Tuff magma body, and this approach could be applied to many caldera-forming eruptions globally to reveal information that is currently overlooked due to more limited sampling campaigns. 


\section{References}

Allan, A. S. R. (2013). The Oruanui eruption: insights into the generation and dynamics of the world's youngest supereruption. [Ph.D. Thesis] Victoria University of Wellington. URI: http://hdl.handle.net/10063/2975

Allan, A. S. R., Wilson, C. J. N., Millet, M. -A. \& Wysoczanski, R. J. (2012). The invisible hand: Tectonic triggering and modulation of a rhyolitic supereruption. Geology 40, 563-566.

Allan, A. S. R., Morgan, D. J., Wilson, C. J. N. \& Millet, M. -A. (2013). From mush to eruption in centuries: assembly of the super-sized Oruanui magma body. Contributions to Mineralogy and Petrology 166, 143-164.

Andersen, D. J. \& Lindsley, D. H. (1988). Internally consistent solution models for Fe-MgMn-Ti oxides: Fe-Ti oxides. American Mineralogist 73, 714-726.

Anderson, A. T., Davis, A. M. \& Lu, F. (2000). Evolution of Bishop Tuff rhyolitic magma based on melt and magnetite inclusions and zoned phenocrysts. Journal of Petrology 41, 449-473.

Arienzo, I., Heumann, A., Wörner, G., Civetta, L. \& Orsi, G. (2011). Processes and timescales of magma evolution prior to the Campanian Ignimbrite eruption (Campi Flegrei, Italy). Earth and Planetary Science Letters 306, 217-228.

Asimow, P. D., \& Ghiorso, M. S. (1998). Algorithmic modifications extending MELTS to calculate subsolidus phase relations. American Mineralogist 83, 1127-1132.

Bachmann, O. \& Bergantz, G. W. (2004). On the origin of crystal-poor rhyolites: extracted from batholithic crystal mushes. Journal of Petrology 45, 1565-1582.

Bachmann, O. \& Bergantz, G.W. (2008a). The magma reservoirs that feed supereruptions. Elements 4, 17-21.

Bachmann, O. \& Bergantz, G. W. (2008b). Rhyolites and their source mushes across tectonic settings. Journal of Petrology 49, 2277-2285.

Bachmann, O. \& Bergantz, G. W. (2008c). Deciphering magma chamber dynamics from styles of compositional zoning in large silicic ash flow sheets.In: Putirka, K. \& Tepley III, F. J. (eds) Minerals, inclusions and volcanic processes. Mineralogical Society of America and Geochemical Society, Reviews in Mineralogy and Geochemistry 69, 651-674.

Bachmann, O., Dungan, M. A. \& Lipman, P. W. (2002). The Fish Canyon magma body, San Juan Volcanic Field, Colorado: Rejuvenation and eruption of an upper-crustal batholith. Journal of Petrology 43, 1469-1503.

Bachmann, O., Miller, C. F. \& de Silva, S. L. (2007). The volcanic-plutonic connection as a stage for understanding crustal magmatism. Journal of Volcanology and Geothermal Research 167, 1-23. 
Bacon, C. R. \& Druitt, T. H. (1988). Compositional evolution of the zoned calcalkaline magma chamber of Mount Mazama, Crater Lake, Oregon. Contributions to Mineralogy and Petrology 98, 224-256.

Bacon, C. R. \& Lowenstern, J. B. (2005). Late Pleistocene granodiorite source for recycled zircon and phenocrysts in rhyodacite lava at Crater Lake, Oregon. Earth and Planetary Science Letters 233, 277-293.

Bailey, R. A. (1989). Geologic map of Long Valley caldera, Mono Inyo Craters volcanic chain and vicinity, eastern California. US Geological Survey Miscellaneous Investigations Series Map I-1933, scale 1:62 500.

Bailey, R. A. (2004). Eruptive history and chemical evolution of the precaldera and postcaldera basalt-dacite sequences, Long Valley, California: Implications for magma sources, current seismic unrest, and future volcanism. U.S. Geological Survey, Professional Papers 1692, 1-75.

Bailey, R. A., Dalrymple, G. B. \& Lamphere, M. A. (1976). Volcanism, structure, and geochronology of Long Valley Caldera, Mono County, California. Journal of Geophysical Research 81, 725-744.

Barth, A. P. \& Wooden, J. L. (2010). Coupled elemental and isotopic analyses of polygenetic zircons from granitic rocks by ion microprobe, with implications for melt evolution and the sources of granitic magmas. Chemical Geology 277, 149-159.

Barth, A. P., Walker, J. D., Wooden, J. L., Riggs, N. R. \& Schweickert, R. A. (2011). Birth of the Sierra Nevada magmatic arc: early Mesozoic plutonism and volcanism in the east-central Sierra Nevada of California. Geosphere 7, 877-897.

Barth, A. P., Feilen, A. D. G., Yager, S. L., Douglas, S. R., Wooden, J. L., Riggs, N. R. \& Walker, J. D. (2012). Petrogenetic connections between ash-flow tuffs and a granodioritic to granitic intrusive suite in the Sierra Nevada arc, California. Geosphere $\mathbf{8}, 250-264$.

Bateman, P. C. (1965). Geology and tungsten mineralization of the Bishop district, California. U.S. Geological Survey, Professional Papers 470, 1-208.

Belousova, E. A., Griffin, W. L., O’Reilly, S. Y. \& Fisher, N. I. (2002). Igneous zircon: trace element composition as an indicator of source rock type. Contributions to Mineralogy and Petrology 143, 602-622.

Bennett, R., Davis, J. \& Wernicke, B. (1999). Present-day pattern of Cordilleran deformation in the western United States. Geology 27, 371-374.

Bindeman, I. N. \& Valley, J. W. (2002). Oxygen isotope study of the Long Valley magmatic system, California: isotope thermometry and convection in large silicic magma bodies. Contributions to Mineralogy and Petrology 144, 185-205.

Bindeman, I. N., Valley, J. W., Wooden, J. L. \& Persing, H. M. (2001). Post-caldera volcanism: in situ measurement of $\mathrm{U}-\mathrm{Pb}$ age and oxygen isotope ratio in Pleistocene zircons from Yellowstone caldera. Earth and Planetary Science Letters 189, 197-206. 
Bindeman, I. N., Schmitt, A. K. \& Valley, J. W. (2006). U-Pb zircon geochronology of silicic tuffs from the Timber Mountain/Oasis Valley caldera complex, Nevada: rapid generation of large volume magmas by shallow-level remelting. Contributions to Mineralogy and Petrology 152, 649-665.

Blundy, J., Cashman, K. V., Rust, A. \& Witham, F. (2010). A case for $\mathrm{CO}_{2}$-rich arc magmas. Earth and Planetary Science Letters 290, 289-301.

Brophy, J. G., Ota, T., Kunihro, T., Tsujimori, T. \& Nakamaru, E. (2011). In situ ionmicroprobe determination of trace element partition coefficients for hornblende, plagioclase, orthopyroxene, and apatite in equilibrium with natural rhyolitic glass, Little Glass Mountain Rhyolite, California. American Mineralogist 96, 1838-1850.

Brown, S. J. A., \& Fletcher, I. R. (1999). SHRIMP U-Pb dating of the preeruption growth history of zircons from the $340 \mathrm{ka}$ Whakamaru Ignimbrite, New Zealand: Evidence for> 250 ky magma residence times. Geology 27, 1035-1038.

Brown, S. J. A., Wilson, C. J. N., Cole, J. W. \& Wooden, J. (1998). The Whakamaru group ignimbrites, Taupo Volcanic Zone, New Zealand: evidence for reverse tapping of a zoned silicic magmatic system. Journal of Volcanology and Geothermal Research 84, 1-37.

Browne, B., Bursik, M., Deming, J., Louros, M., Martos, A. \& Stine, S. (2010). Eruption chronology and petrologic reconstruction of the ca. $8500 \mathrm{yr}$ BP eruption of Red Cones, southern Inyo chain, California. Geological Society of America Bulletin 122, 14011422.

Buddington, A. F. \& Lindsley, D. H. (1964): Iron-titanium oxide minerals and synthetic equivalents. Journal of Petrology 5, 310-357.

Burov, E., Jaupart, C. \& Guillou-Frottier, L. (2003). Ascent and emplacement of buoyant magma bodies in brittle-ductile upper crust. Journal of Geophysical Research 108, 2177.

Bursik, M. \& Sieh, K. (1989). Range front faulting and volcanism in the Mono Basin, eastern California. Journal of Geophysical Research 94, 15587-15609.

Bursik, M., Renshaw, C., McCalpin, J. \& Berry, M. (2003). A volcanotectonic cascade: Activation of range front faulting and eruptions by dike intrusion, Mono Basin-Long Valley Caldera, California. Journal of Geophysical Research 108, 2393.

Cameron, K. L. (1984). Bishop Tuff revisited: new rare earth element data consistent with crystal fractionation. Science 224, 1339-1340.

Carley, T. L., Miller, C. F., Wooden, J. L., Bindeman, I. N. \& Barth, A. P. (2011). Zircon from historic eruptions in Iceland: reconstructing storage and evolution of silicic magmas. Mineralogy and Petrology 102, 135-161.

Chamberlain, K. J., Wilson, C. J. N., Wooden, J. L., Charlier, B. L. A. \& Ireland, T. R. (2014a). New perspectives on the Bishop Tuff from zircon textures, ages and trace elements. Journal of Petrology 55, 395-426.

Chamberlain, K. J., Morgan, D. J. \& Wilson, C. J. N. (2014b). Timescales of magma mixing and mobilisation in the Bishop Tuff magma body: perspectives from diffusion chronometry. Contributions to Mineralogy and Petrology (accepted). 
Charlier, B. L. A. \& Zellmer, G. (2000). Some remarks on U-Th mineral ages from igneous rocks with prolonged crystallisation histories. Earth and Planetary Science Letters 183, 457-469.

Charlier, B. L. A., Wilson, C. J. N., Lowenstern, J. B., Blake, S., van Calsteren, P. W. \& Davidson, J. P. (2005). Magma generation at a large, hyperactive silicic volcano (Taupo, New Zealand) revealed by U-Th and U-Pb systematics in zircons. Journal of Petrology 46, 3-32.

Charlier, B. L. A., Ginibre, C., Morgan, D., Nowell, G. M., Pearson, D. G., Davidson, J. P. \& Ottley, C. J. (2006). Methods for the microsampling and high-precision analysis of strontium and rubidium isotopes at single crystal scale for petrological and geochronological applications. Chemical Geology 232, 114-133.

Charlier, B. L. A., Bachmann, O., Davidson, J. P., Dungan, M. A. \& Morgan, D. J. (2007). The upper crustal evolution of a large silicic magma body: Evidence from crystalscale $\mathrm{Rb}-\mathrm{Sr}$ isotopic heterogeneities in the Fish Canyon magmatic system, Colorado. Journal of Petrology 48, 1875-1894.

Charlier, B. L. A., Wilson, C. J. N. \& Davidson, J. P. (2008). Rapid open-system assembly of a large silicic magma body: time-resolved evidence from cored plagioclase crystals in the Oruanui eruption deposits, New Zealand. Contributions to Mineralogy and Petrology 156, 799-813.

Charlier, B. L. A., Wilson, C. J. N. \& Mortimer, N. (2010). Evidence from zircon U-Pb age spectra for crustal structure and felsic magma genesis at Taupo volcano, New Zealand. Geology 38, 915-918.

Charlier, B. L. A., Wilson, C. J. N., Parkinson, I. \& Mueller, W. (2013). Sr stable isotope variations in an evolved rhyolitic volcanic system investigated using an ${ }^{84} \mathrm{Sr}-{ }^{87} \mathrm{Sr}$ double spike. Abstract V51A-2636, presented at the 2013 Fall Meeting of the American Geophysical Union, San Francisco, California, 9-13 December.

Chen, Y., Smith, P. E., Evensen, N. M., York, D. \& Lajoie, K. R. (1996). The edge of time: Dating young volcanic ash layers with the ${ }^{40} \mathrm{Ar} /{ }^{39} \mathrm{Ar}$ laser probe. Science 274, 11761178.

Cherniak, D. J. (1996). Strontium diffusion in sanidine and albite, and general comments on strontium diffusion in alkali feldspars. Geochimica et Cosmochimica Acta 60, 50375043.

Cherniak, D. J. (2002). Ba diffusion in feldspar. Geochimica et Cosmochimica Acta 66, 1641 1650.

Cherniak, D. J. (2010). Cation diffusion in feldspars. In Zhang, Y. \& Cherniak, D. J. (eds) Diffusion in mineral and melts. Mineralogical Society of America and Geochemical Society, Reviews in Mineralogy and Geochemistry 72, 691-733.

Cherniak, D. J. \& Dimanov, A. (2010). Diffusion in pyroxene, mica and amphibole. In Zhang, Y. \& Cherniak, D. J. (eds) Diffusion in mineral and melts. Mineralogical Society of America and Geochemical Society, Reviews in Mineralogy and Geochemistry 72, 641-690. 
Cherniak, D. J. \& Watson, E. B. (1992). A study of strontium diffusion in K-feldspar, Na$\mathrm{K}$ feldspar and anorthite using Rutherford backscattering spectroscopy. Earth and Planetary Science Letters 113, 411-425.

Cherniak, D. J., Watson, E. B. \& Wark, D. A. (2007). Ti diffusion in quartz. Chemical Geology 236, 65-74.

Chesner, C. A. (1998). Petrogenesis of the Toba Tuffs, Sumatra, Indonesia. Journal of Petrology 39, 397-438.

Christensen, J. N. \& DePaolo, D. J. (1993). Time scales of large volume silicic magma systems- Sr isotopic systematics of phenocrysts and glass from the Bishop Tuff, Long Valley, California. Contributions to Mineralogy and Petrology 113, 100-114.

Christensen, J. N. \& Halliday, A. N. (1996). Rb-Sr ages and Nd isotopic compositions of melt inclusions from the Bishop Tuff and the generation of silicic magma. Earth and Planetary Science Letters 144, 547-561.

Christiansen, R. L. (2001). The Quaternary and Pliocene Yellowstone Plateau Volcanic Field of Wyoming, Idaho, and Montana. United States Geological Survey, Professional Papers 729-G, 1-143.

Christiansen, R. L. \& Blank, H. R. (1972). Volcanic stratigraphy of the Quaternary rhyolite plateau in Yellowstone National Park. United States Geological Survey, Professional Papers 729-B, 1-18.

Civetta, L., Orsi, G., Pappalardo, L., Fisher, R. V., Heiken, G. \& Ort, M. (1997). Geochemical zoning, mingling, eruptive dynamics and depositional processes- the Campanian Ignimbrite, Campi Flegrei caldera, Italy. Journal of Volcanology and Geothermal Research 75, 183-219.

Claiborne, L. L., Miller, C. F., Walker, B. A., Wooden, J. L., Mazdab, F. K. \& Bea, F. (2006). Tracking magmatic processes through $\mathrm{Zr} / \mathrm{Hf}$ ratios in rocks and $\mathrm{Hf}$ and $\mathrm{Ti}$ zoning in zircons: An example from the Spirit Mountain batholith, Nevada. Mineralogical Magazine 70, 517-543.

Claiborne, L. L., Miller, C. F. \& Wooden, J. L. (2010). Trace element composition of igneous zircons: a thermal and compositional record of the accumulation and evolutions of a large silicic batholith, Spirit Mountain, Nevada. Contributions to Mineralogy and Petrology 160, 511-531.

Cooper, G. F. (2014). The dynamics of large-scale silicic magmatic systems: case studies from Mangakino Volcanic Centre, Taupo Volcanic Zone, New Zealand. [Ph. D. Thesis] Victoria University of Wellington. URI: http://hdl.handle.net/10063/3153

Cooper, G. F., Wilson, C. J. N., Millet, M.-A., Baker, J. A. \& Smith, E. G. C. (2012). Systematic tapping of independent magma chambers during the 1 Ma Kidnappers supereruption. Earth and Planetary Science Letters 313, 23-33.

Corfu, F., Hanchar, J. M., Hoskin, P. W. O. \& Kinny, P. (2003). Atlas of zircon textures. In: Hanchar, J. M. \& Hoskin, P. W. O. (eds) Zircon. Mineralogical Society of America and Geochemical Society, Reviews in Mineralogy and Geochemistry 53, 469-500. 
Costa, F. \& Dungan, M. (2005). Short time scales of magmatic assimilation from diffusion modeling of multiple elements in olivine. Geology 33, 837-840.

Costa, F. \& Morgan, D. (2010). Time constraints from chemical equilibration in magmatic crystals. In: Dosseto, A., Turner, S. P. \& Van Orman, J. A. (eds) Timescales of magmatic processes: from core to atmosphere. John Wiley \& Sons, Chichester, UK, pp 125-159.

Costa, F., Chakraborty, S. \& Dohmen, R. (2003). Diffusion coupling between trace and major elements and a model for calculation of magma residence times using plagioclase. Geochimica et Cosmochimica Acta 67, 2189-2200.

Costa, F., Dohmen, R., \& Chakraborty, S. (2008). Time scales of magmatic processes from modeling the zoning patterns of crystals. In: Putirka, K. \& Tepley III, F. J. (eds) Minerals, inclusions and volcanic processes. Mineralogical Society of America and Geochemical Society, Reviews in Mineralogy and Geochemistry 69, 545-594.

Crank, J. (1975). The Mathematics of Diffusion ( $2^{\text {nd }}$ edition), Oxford University Press, Oxford, $\mathrm{UK}, 414 \mathrm{pp}$.

Crowley, J. L., Schoene, B. \& Bowring, S. A. (2007). U-Pb dating of zircon in the Bishop Tuff at the millennial scale. Geology 35, 1123-1126.

Dalrymple, G. B., Cox, A., \& Doell, R. R. (1965). Potassium-argon age and paleomagnetism of the Bishop Tuff, California. Geological Society of America Bulletin 76, 665-674.

Davidson, J. P., Morgan, D. J. \& Charlier, B. L. A. (2007). Isotopic microsampling of magmatic rocks. Elements 3, 253-259.

Davidson, J. P., Font, F., Charlier, B. L. A. \& Tepley, F. J. (2008). Mineral-scale Sr isotope variation in plutonic rocks - a tool for unravelling the evolution of magma systems. Transactions of the Royal Society of Edinburgh: Earth Sciences 97, 357-367.

Davies, G. R. \& Halliday, A. N. (1998). Development of the Long Valley rhyolitic magma system: strontium and neodymium isotope evidence from glasses and individual phenocrysts. Geochimica et Cosmochimica Acta 62, 3561-3574.

Davies, G. R., Halliday, A. N., Mahood, G. A. \& Hall, C. M. (1994). Isotopic constraints on the production rates, crystallization histories and residence times of precaldera silicic magmas, Long Valley, California. Earth and Planetary Science Letters 125, 17-37.

Deegan, F. M., Troll, V. R., Freda, C., Misiti, V., Chadwick, J. P., McLeod, C. L. \& Davidson, J. P. (2010). Magma-carbonate interaction processes and associated $\mathrm{CO}_{2}$ release at Merapi volcano, Indonesia: Insights from experimental petrology. Journal of Petrology 51, 1027-1050.

Dreher, S. T., Eichelberger, J. C. \& Larsen, J. F. (2005). The petrology and geochemistry of the Aniakchak caldera-forming ignimbrite, Aleutian arc, Alaska. Journal of Petrology 46, 1747-1768.

Druitt, T. H. \& Bacon, C. R. (1989). Petrology of the zoned calcalkaline magma chamber of Mount Mazama, Crater Lake, Oregon. Contributions to Mineralogy and Petrology 101, 245-259. 
Dunbar, N. W. \& Hervig, R. L. (1992a). Petrogenesis and volatile stratigraphy of the Bishop Tuff: evidence from melt inclusion analysis. Journal of Geophysical Research 97, 15129-15150.

Dunbar, N. W. \& Hervig, R. L. (1992b). Volatile and trace element compositions of melt inclusions from the Lower Bandelier Tuff: Implications for magma chamber processes and eruptive style. Journal of Geophysical Research 97, 15151-15170.

Dixon, T. H., Miller, M., Farina, F., Wang, H. Z. \& Johnson, D. (2000). Present-day motion of the Sierra Nevada block and some tectonic implications for the Basin and Range province, North American Cordillera. Tectonics 19, 1-24.

Elkins, L. T. \& Grove, T. L. (1990). Ternary feldspar experiments and thermodynamic models. American Mineralogist 75, 544-559.

Evans, B. W. \& Bachmann, O. (2013). Implications of equilibrium and disequilibrium among crystal phases in the Bishop Tuff. American Mineralogist 98, 271-274.

Ferry, J. M. \& Watson, E. B. (2007). New thermodynamic models and revised calibrations for the Ti-in-zircon and Zr-in-rutile thermometers. Contributions to Mineralogy and Petrology 154, 429-437.

Font, I., Davidson, J. P., Pearson, D. G., Nowell, G. M., Jerram., D. A. \& Ottley, C. J. (2008). Sr and $\mathrm{Pb}$ isotope micro-analysis of plagioclase crystals from Skye lavas: an insight into open-system processes in a flood basalt province. Journal of Petrology 49, 1449-1471.

Fowler, S. J. \& Spera, F. J. (2010). A metamodel for crustal magmatism: phase equilibria of giant ignimbrites. Journal of Petrology 51, 1783-1830.

Fowler, S. J. \& Spera, F. J. (2011). Reply to Gualda \& Ghiorso comment on: 'A metamodel for crustal magmatism: phase equilibria of giant ignimbrites'. Journal of Petrology 52, 435-438.

Freer, R. \& Hauptman, Z. (1978). An experimental study of magnetite-titanomagnetite interdiffusion. Physics of the Earth and Planetary Interiors 16, 223-231.

Frost, B. R. \& Lindsley, D. H. (1992). Equilibria among Fe-Ti oxides, pyroxenes, olivine, and quartz. Part II. Application. American Mineralogist 77, 1004-1020.

Fu, B., Page, F. Z., Cavosie, A. J., Fournelle, J., Kita, N. T., Lackey, J. S., Wilde, S. A. \& Valley, J. W. (2008). Ti-in-zircon thermometry: applications and limitations. Contributions to Mineralogy and Petrology 156, 197-215.

Gagnevin, D., Daly, J. S., Horstwood, M. S. A. \& Whitehouse, M. J. (2011). In-situ zircon $\mathrm{U}-\mathrm{Pb}$, oxygen and hafnium isotopic evidence for magma mixing and mantle metasomatism in the Tuscan Magmatic Province, Italy. Earth and Planetary Science Letters 305, 45-56.

Ganguly, J. \& Tazzoli, V. (1994). $\mathrm{Fe}^{2+}-\mathrm{Mg}$ interdiffusion in orthopyroxene: retrieval from the data on intracrystalline exchange reaction. American Mineralogist 79, 930-937. 
Ghiorso, M. S. \& Evans, B. W. (2008). Thermodynamics of rhombohedral oxide solid solutions and a revision of the Fe-Ti two-oxide geothermometer and oxygenbarometer. American Journal of Science 308, 957-1039.

Ghiorso, M. S. \& Gualda, G. A. R. (2013). A method for estimating the activity of titania in magmatic liquids from the compositions of coexisting rhombohedral and cubic irontitanium oxides. Contributions to Mineralogy and Petrology 165, 73-81.

Ghiorso, M. S. \& Sack, R. O. (1991): Fe-Ti oxide geothermometry: thermodynamic formulation and the estimation of intensive variable in silici magmas. Contributions to Mineralogy and Petrology 108, 485-510.

Ghiorso, M. S., \& Sack, R. O. (1995). Chemical mass transfer in magmatic processes IV. A revised and internally consistent thermodynamic model for the interpolation and extrapolation of liquid-solid equilibria in magmatic systems at elevated temperatures and pressures. Contributions to Mineralogy and Petrology 119, 197-212.

Gilbert, C. M. (1938). Welded tuff in eastern California. Geological Society of America Bulletin 49, 1829-1862.

Ginibre, C., Wörner, G. \& Kronz, A. (2002). Minor- and trace-element zoning in plagioclase: implications for magma chamber processes in Parinacota volcano, northern Chile. Contributions to Mineralogy and Petrology 143, 300-315.

Ginibre, C., Wörner, G. \& Kronz, A. (2007). Crystal zoning as an archive for magma evolution. Elements 3, 261-266.

Goldich, S. S., Ingamells, C. O., Suhr, N. H. \& Anderson, D. H. (1967). Analyses of silicate rock and mineral standards. Canadian Journal of Earth Sciences 4, 747-755.

Gravley, D. M., Wilson, C. J. N., Leonard, G. S. \& Cole, J. W. (2007). Double trouble: paired ignimbrite eruptions and collateral subsidence in the Taupo Volcanic Zone, New Zealand. Geological Society of America Bulletin 119, 18-30.

Grimes, C. B., John, B. E., Cheadle, M. J., Mazdab, F. K., Wooden, J. L., Swapp, S. \& Schwartz, J. J. (2009). On the occurrence, trace element geochemistry, and crystallization history of zircon from in situ ocean lithosphere. Contributions to Mineralogy and Petrology 158, 757-783.

Gualda, G. A. R. (2007). Crystal and bubble populations in the early-erupted Bishop rhyolitic magma: Microscopy, x-ray tomography and microanalysis of pumice clasts. [Ph.D. Thesis]: The University of Chicago, Chicago, Illinois.

Gualda, G. A. R. \& Ghiorso, M. S. (2011). Comment on: 'A metamodel for crustal magmatism: phase equilibria of giant ignimbrites' by S.J. Fowler and F.J. Spera. Journal of Petrology 52, 431-434.

Gualda, G. A. R. \& Ghiorso, M. S. (2013a). The Bishop Tuff giant magma body: an alternative to the Standard Model. Contributions to Mineralogy and Petrology 166, 755-775.

Gualda, G. A. R. \& Ghiorso, M. S. (2013b). Low-pressure origin of high-silica rhyolites and granites. Journal of Geology 121, 537-545. 
Gualda, G. A. R., Ghiorso, M. S., Lemons, R. V. \& Carley, T. L. (2012a). Rhyolite-MELTS: a modified calibration of MELTS optimized for silica-rich, fluid-bearing magmatic systems. Journal of Petrology 53, 875-890.

Gualda, G. A. R., Pamukcu, A. S., Ghiorso, M. S., Anderson, A. T., Sutton, S. R. \& Rivers, M. L. (2012b). Timescales of quartz crystallization and the longevity of the Bishop giant magma body. PLOS ONE 7, e37492.

Halliday, A. N., Fallick, A. E., Hutchinson, J. \& Hildreth, W. (1984). A Nd, Sr and O isotopic investigation into the causes of chemical and isotopic zonation in the Bishop Tuff, California. Earth and Planetary Science Letters 68, 379-391.

Halliday, A. N., Mahood, G. A., Holden, P., Metz, J. M., Dempster, T. J. \& Davidson, J. P. (1989). Evidence for long residence times of rhyolitic magma in the Long Valley magmatic system: the isotopic record in precaldera lavas of Glass Mountain. Earth and Planetary Science Letters 94, 274-290.

Hammond, P. A. \& Taylor, L. A. (1982). The ilmenite/titano-magnetite assemblage: kinetics of re-equilibration. Earth and Planetary Science Letters 61, 143-150.

Harrison, T. M., Watson, E. B. \& Aikman, A. B. (2007). Temperature spectra of zircon crystallisation in plutonic rocks. Geology 35, 635-638.

Hawkesworth, C. J., Blake, S., Evans, P., Hughes, R., MacDonald, R., Thomas, L. E. \& Turner, S. P. (2000). Time scales of crystal fractionation in magma chambers Integrating physical, isotopic and geochemical perspectives. Journal of Petrology 41, 991 1006.

Hawkesworth, C., George, R., Turner, S. \& Zellmer, G. (2004). Time scales of magmatic processes. Earth and Planetary Science Letters 218, 1-16.

Hervig, R. L. \& Dunbar, N. (1992). Causes of chemical zoning in the Bishop (California) and Bandelier (New Mexico) magma chambers. Earth and Planetary Science Letters 111, 97-108.

Hildreth, E. W. (1977). The magma chamber of the Bishop Tuff: Gradients in temperature, pressure, and composition [Ph. D. Thesis]: University of California, Berkeley.

Hildreth, W. (1979). The Bishop Tuff: evidence for the origin of compositional zonation in silicic magma chambers. In: Chapin, C. E. \& Elston, W. E. (eds.) Ash-flow tuffs. Geological Society of America, Special Paper 180, 43-75.

Hildreth, W. (1981). Gradients in silicic magma chambers: implications for lithospheric magmatism. Journal of Geophysical Research 86, 10153-10192.

Hildreth, W. (1983). The compositionally zoned eruption of 1912 in the Valley of Ten Thousand Smokes, Katmai National Park, Alaska. Journal of Volcanology and Geothermal Research 18, 1-56.

Hildreth, W. (1985). The Bishop Tuff: trace contents of dark pumice. Geological Society of America Abstracts with Programs 17, 361. 
Hildreth, W. (2004). Volcanological perspectives on Long Valley, Mammoth Mountain, and Mono Craters: several contiguous but discrete systems. Journal of Volcanology and Geothermal Research 136, 169-198.

Hildreth, W. \& Mahood, G. A. (1986). Ring-fracture eruption of the Bishop Tuff. Geological Society of America Bulletin 97, 396-403.

Hildreth, W. \& Wilson, C. J. N. (2007). Compositional zoning of the Bishop Tuff. Journal of Petrology 48, 951-999.

Hildreth, W., Christiansen, R. L. \& O’Neil, J. R. (1984). Catastrophic isotopic modification of rhyolite magma at times of caldera subsidence, Yellowstone Plateau Volcanic Field. Journal of Geophysical Research 89, 8339-8369.

Hildreth, W., Halliday, A. N. \& Christiansen, R. L. (1991). Isotopic and chemical evidence concerning the genesis and contamination of basaltic and rhyolitic magma beneath the Yellowstone Plateau volcanic field. Journal of Petrology 32, 63-138.

Hill, D. P. \& Prejean, S. (2005). Magmatic unrest beneath Mammoth Mountain, California. Journal of Volcanology and Geothermal Research 146, 257-283.

Hill, D. P., Bailey, R. A. \& Ryall, A. S. (1985). Active tectonic and magmatic processes beneath Long Valley caldera, eastern California: an overview. Journal of Geophysical Research 90, 11111-11120.

Hill, D. P., Langbein, J. O. \& Prejean., S. (2003). Relations between seismicity and deformation during unrest in Long Valley Caldera, California, from 1995 through 1999. Journal of Volcanology and Geothermal Research 127, 175-193.

Hofmann, A. E., Baker, M. B. \& Eiler, J. M. (2013). An experimental study of Ti and Zr partitioning among zircon, rutile, and granitic melt. Contributions to Mineralogy and Petrology 166, 235-253.

Hoskin, P. W. O. \& Schaltegger, U. (2003). The composition of zircon and igneous and metamorphic petrogenesis. In: Hanchar, J. M. \& Hoskin, P. W. O. (eds) Zircon. Mineralogical Society of America and Geochemical Society, Reviews in Mineralogy and Geochemistry 53, 27-62.

Huebner, J. S. \& Sato, M. (1970). The oxygen fugacity-temperature relationships of manganese oxide and nickel oxide buffers. American Mineralogist 55, 934-952.

Humphreys, M. C. S., Christopher, T. \& Hards, V. (2009). Microlite transfer by disaggregation of mafic inclusions following magma mixing at Soufriere Hills volcano, Montserrat. Contributions to Mineralogy and Petrology 157, 609-624.

Humphreys, M. C. S., Edmonds, M., Christopher, T., \& Hards, V. (2010). Magma hybridisation and diffusive exchange recorded in heterogeneous glasses from Soufrière Hills Volcano, Montserrat. Geophysical Research Letters 37, L00E06.

Ingamells, C. O. (1979). Microprobe column. Geostandards and Geoanalytical Research 3, 207.

Ingamells, C. O. (1980). Analysed minerals for electron microprobe standards. Geostandards Newsletter 2, 115. 
Izett, G. A., Wilcox, R. E., Powers, H. A., \& Desborough, G. A. (1970). The Bishop ash bed, a Pleistocene marker bed in the western United States. Quaternary Research 1, 121132.

Izett, G. A., Obradovich, J. D. \& Mehnert, H. H. (1988). The Bishop Ash Bed (middle Pleistocene) and some older (Pliocene and Pleistocene) chemically and mineralogically similar ash beds in California, Nevada, and Utah. US Geological Survey Bulletin 1675, 1-37.

Jarosewich, E., Nelen, J. A. \& Norberg, J. A. (1980). Reference samples for electron microprobe analysis. Geostandards Newsletter 4, 43-47.

Jellinek, A. M. \& DePaolo, D. J. (2003). A model for the origin of large silicic magma chambers: precursors of caldera-forming eruptions. Bulletin of Volcanology 65, 363-381.

Jochum, K. P., Nohl, U., Herwig, K., Lammel, E., Stoll, B. \& Hofmann, A. W. (2005). GeoReM: A new geochemical database for reference materials and isotopic standards. Geostandards and Geoanalytical Research 29, 333-338.

Kahl, M., Chakraborty, S., Costa, F., Pompilio, M., Liuzzo, M. \& Viccaro, M. (2013). Compositionally zoned crystals and real-time degassing data reveal changes in magma transfer dynamics during the 2006 summit eruptive episodes of Mt. Etna. Bulletin of Volcanology 75, 692.

Keeley, J. A., Link, P. K., Fanning, C. M., \& Schmitz, M. D. (2013). Pre-to synglacial riftrelated volcanism in the Neoproterozoic (Cryogenian) Pocatello Formation, SE Idaho: New SHRIMP and CA-ID-TIMS constraints. Lithosphere 5, 128-150.

Kelleher, P. C. \& Cameron, K. L. (1990). The geochemistry of the Mono Craters-Mono Lake Islands Volcanic Complex, eastern California. Journal of Geophysical Research 95, 17643-17659.

Kent, D. V., Hemming, S. R. \& Turrin, B. D. (2002). Laschamp Excursion at Mono Lake?. Earth and Planetary Science Letters 197, 151-164.

Kissling, E. (1988). Geotomography with local earthquake data. Reviews of Geophysics 26, 659-698.

Klügel, A. Hansteen, T. H. \& Galipp, K. (2005). Magma storage and underplating beneath Cumbre Vieja volcano, La Palma (Canary Islands). Earth and Planetary Science Letters 236, 211-226.

Kuiper, K. F., Deino, A., Hilgen, F. J., Krijgsman, W., Renne, P. R. \& Wijbrans, J. R. (2008). Synchronising rock clocks of Earth history. Science 320, 500-504.

Kularatne, K. \& Audétat, A. (2014). Rutile solubility in hydrous rhyolite melts at $750-900$ ${ }^{\circ} \mathrm{C}$ and $2 \mathrm{kbar}$, with application to titanium-in-quartz (TitaniQ) thermobarometry. Geochimica et Cosmochimica Acta 125, 196-209

Lange, R. A. \& Carmichael, I. S. E. (1996). The Aurora volcanic field, California-Nevada: oxygen fugacity constraints on the development of andesitic magma. Contributions to Mineralogy and Petrology 125, 167-185. 
Lange, R. A., Carmichael, I. S. E. \& Renne, P. R. (1993). Potassic volcanism near Mono basin, California: evidence for high water and oxygen fugacities inherited from subduction. Geology 21, 949-952.

Lasaga, A. C. (1983). Geospeedometry: an extension of geothermometry. In: Saxena, S. K. (ed.) Kinetics and equilibrium in mineral reactions. Springer, New York, 81-114.

Lesher, C. E. (1986). Effects of silicate liquid composition on mineral-liquid element partitioning from Soret diffusion studies. Journal of Geophysical Research 91, 6123-6141.

Lindsley, D. H., Frost, B. R., Andersen, D. J. \& Davidson, P. J. (1990). Fe-Ti oxide-silicate equilibria: Assemblages with orthopyroxene. In R. Spencer, I. Chou, I., Eds., Fluidmineral interactions: A tribute to H.P. Eugster. Geochemical Society: Special Publication 2, 103119.

Lindsley, D. H., Frost, B. R., Ghiorso, M. S. \& Sack, R. O. (1991) Oxides lie: The Bishop Tuff did not erupt from a thermally zoned magma body. EOS, Transactions of the American Geophysical Union 72, 313.

Lipman, P. W. (1984). The roots of ash flow calderas in western North America: windows into the tops of granitic batholiths. Journal of Geophysical Research 89, 8801-8841.

Lipman, P. W. (1997). Subsidence of ash-flow calderas: relation to caldera size and magmachamber geometry. Bulletin of Volcanology 59, 198-218.

Lipman, P. W. (2007). Incremental assembly and prolonged consolidation of Cordilleran magma chambers: evidence from the Southern Rocky Mountain volcanic field. Geosphere 3, 42-70.

Lipman, P., Dungan, M., \& Bachmann, O. (1997). Comagmatic granophyric granite in the Fish Canyon Tuff, Colorado: implications for magma-chamber processes during a large ash-flow eruption. Geology 25, 915-918.

Liu, Y., Anderson, A. T., Wilson, C. J. N., Davis, A. M., \& Steele, I. M. (2006). Mixing and differentiation in the Oruanui rhyolitic magma, Taupo, New Zealand: evidence from volatiles and trace elements in melt inclusions. Contributions to Mineralogy and Petrology 151, 71-87.

Lofgren, G. E., Huss, G. R. \& Wasserburg, G. J. (2006). An experimental study of traceelement partitioning between Ti-Al-clinopyroxene and melt: equilibrium and kinetic effects, including sector zoning. American Mineralogist 91, 1596-1606.

Lu, F. (1991). The Bishop Tuff: origins of the high-silica rhyolite and its thermal and chemical zonations. [PhD Thesis]: The University of Chicago, Chicago.

Lu, F., Anderson, A. T. \& Davis, A. M. (1992). Melt inclusions and crystal-liquid separation in rhyolitic magma of the Bishop Tuff. Contributions to Mineralogy and Petrology 110, 113120.

Ludwig, K. R. (2008). Isoplot/Ex version 3.70, A geochronological toolkit for Microsoft Excel, revision of August 26, 2008. Berkeley Geochronology Center Special Publication 4. 
Ludwig, K. (2009). SQUID 2: A User's Manual, revision of 12 April, 2009. Berkeley Geochronology Center Special Publication 5.

Magaritz, M. \& Hofmann, A. W. (1978). Diffusion of Sr, Ba and Na in obsidian. Geochimica et Cosmochimica Acta, 42, 595-605.

Mahood, G. A. \& Hildreth, W. (1983). Large partition coefficients for trace elements in high-silica rhyolites. Geochimica et Cosmochimica Acta 47, 11-30.

Mahood, G. A., Ring, J. H., Manganelli, S. \& McWilliams, M. O. (2010). New ${ }^{40} \mathrm{Ar} /{ }^{39} \mathrm{Ar}$ ages reveal contemporaneous mafic and silicic eruptions during the past 160,000 years at Mammoth Mountain and Long Valley caldera, California. Geological Society of America Bulletin 122, 396-407.

Malfait, W. J., Seifert, R., Petitgirard, S., Perrillar, J.-P., Mezouar, M., Ota, T., Nakamura, E., Lerch, P. \& Sanchez-Valle, C. (2014). Supervolcano eruptions driven by melt buoyancy in large silicic magma chambers. Nature Geoscience, doi: 10.1038/NGEO2042.

Mandeville, C. W., Carey, S. \& Sigurdsson, H. (1996). Magma mixing, fractional crystallization and volatile degassing during the 1883 eruption of Krakatau volcano, Indonesia. Journal of Volcanology and Geothermal Research 74, 243-274.

Mark, D. F., Renne, P. R., Morgan, L. E., Deino, A., Smith, V.C., Ellis, B. S. \& Pearce, N. J. (2012). ${ }^{40} \mathrm{Ar} /{ }^{39} \mathrm{Ar}$ dating of Pleistocene tuffs: an accurate age for the MatuyamaBrunhes geomagnetic reversal (MBGR). Abstract V21E-07, presented at the 2012 Fall Meeting of the American Geophysical Union, San Francisco, California, 3-7 December.

Marsh, B. D. (1989). Magma chambers. Annual Review of Earth and Planetary Sciences 17, 439474.

Marsh, B. D. (2000). Magma chambers. In: Sigurdsson, H., Houghton, B. F., McNutt, S. R., Rymer, H. \& Stix, J. (eds.) Encycopedia of volcanoes. London, UK: Academic Press, 191206.

Marshall, D. J. (1988). Cathodoluminescence of geological materials. Unwin Hyman, London.

Martin, V. M., Morgan, D. J, Jerram, D. A., Caddick, M. J., Prior, D. J. \& Davidson J. P. (2008). Bang! Month-scale eruption triggering at Santorini volcano. Science 321, 1178.

Mastin, L. G. (1991). The roles of magma and groundwater in the phreatic eruptions at Inyo Craters, Long Valley caldera, California. Bulletin of Volcanology 53, 579-596.

Matthews, N. E., Huber, C., Pyle, D. M. \& Smith, V. C. (2012a). Timescales of magma recharge and reactivation of large silicic systems from Ti diffusion in quartz. Journal of Petrology 53, 1385-1416.

Matthews, N. E., Pyle, D. M., Smith, V. C., Wilson, C. J. N., Huber, C. \& Van Hinsberg, V. (2012b). Quartz zoning and the pre-eruptive evolution of the $\sim 340$-ka Whakamaru magma systems, New Zealand. Contributions to Mineralogy and Petrology 163, 87-107. 
McConnell, V. S., Shearer, C. K., Eichelberger, J. C., Keskinen, M. J., Layer, P. W. \& Papike, J. J. (1995). Rhyolite intrusions in the intracaldera Bishop Tuff, Long Valley caldera, California. Journal of Volcanology and Geothermal Research 67, 41-60.

McKenzie, D. (1985). The extraction of magma from the crust and mantle. Earth and Planetary Science Letters 74, 81-91.

Metz, J. M. \& Mahood, G. A. (1985). Precursors to the Bishop Tuff eruption: Glass Mountain, Long Valley, California. Journal of Geophysical Research 90, 11121-11126.

Metz, J. M. \& Mahood, G. A. (1991). Development of the Long Valley, California, magma chamber recorded in precaldera rhyolite lavas of Glass Mountain. Contributions to Mineralogy and Petrology 106, 379-397.

Metz, J. M. \& Bailey, R. A. (1993). Geologic map of Glass Mountain, Mono County, California. U.S. Geological Survey Miscellaneous Investigation Series Map I-1995, scale 1:24 000 .

Michael, P. J. (1983). Chemical differentiation of the Bishop Tuff and other high-silica magmas through crystallization processes. Geology 11, 31-34.

Milicich, S. D., Wilson, C. J. N., Bignall, G., Pezaro, B., Charlier, B. L. A., Wooden, J. L. \& Ireland, T. R. (2013). U-Pb dating of zircon in hydrothermally altered rocks of the Kawerau Geothermal Field, Taupo Volcanic Zone, New Zealand. Journal of Volcanology and Geothermal Research 253, 97-113.

Miller, C. D. (1985). Holocene eruptions at the Inyo volcanic chain, California implications for possible eruptions in Long Valley caldera. Geology 13, 14-17.

Miller, C. F. \& Wark, D. A. (2008). Supervolcanoes and their explosive supereruptions. Elements 4, 11-15.

Miller, J. S. \& Wooden, J. L. (2004). Residence, resorption and recycling of zircons in the Devils Kitchen rhyolite, Coso Volcanic field, California. Journal of Petrology 45, 21552170.

Millet, M.-A., Tutt, C. M., Handler, M. R. \& Baker, J. A. (2014) Processes and timescales of dacite magma assembly and eruption at Tauhara volcano, Taupo Volcanic Zone, New Zealand. Geochemistry, Geophysics, Geosystems 15, 213-237.

Morgan, D. J. \& Blake, S. (2006). Magmatic residence times of zoned phenocrysts: introduction and application of the binary element diffusion modelling (BEDM) technique. Contributions to Mineralogy and Petrology 151, 58-70.

Morgan, D. J., Blake, S., Rogers, N. W., De Vivo, B., Rolandi, G., MacDonald, R. \& Hawkesworth, C. J. (2004). Time scales of crystal residence and magma chamber volumes from modelling of diffusion profiles in phenocrysts: Vesuvius 1944. Earth and Planetary Science Letters 222, 933-946.

Morgan, D. J., Blake, S., Rogers, N. W., De Vivo, B., Rolandi, G. \& Davidson, J. P. (2006). Magma chamber recharge at Vesuvius in the century prior to A.D. 79. Geology 34, 845-848. 
Morse, S. A. \& Allaz, J. (2013). Experimental partitioning of Sr and Ba in Kiglapait feldspars. American Mineralogist 98, 2197-2200.

Munoz, M., Charrier, R., Fanning, C. M., Maksaev, V. \& Deckart, K. (2012). Zircon trace element and O-Hf isotope analysis of mineralized intrusions from El Teniente ore deposit, Chilean Andes: Constraints on the source and magmatic evolution of porphyry Cu-Mo related magmas. Journal of Petrology 53, 1091-1122.

Murphy, M. D., Sparks, R. S. J., Barclay, J., Carroll, M. R. \& Brewer, T. S. (2000). Remobilization of andesite magma by intrusion of mafic magma at the Soufriere Hills Volcano, Montserrat, West Indies. Journal of Petrology 41, 21-42.

Naney, M. T. (1983). Phase equilibria of rock-forming ferromagnesian silicates in granitic systems. American Journal of Science 283, 993-1033.

Nasdala, L., Zhang, M., Kempe, U., Panczer, G., Gaft, M., Andrut, M. \& Plotze, M. (2003). Spectroscopic methods applied to zircon. In: Hanchar, J. M. \& Hoskin, P. W. O. (eds) Zircon. Mineralogical Society of America and Geochemical Society, Reviens in Mineralogy and Geochemistry 53, 427-467.

Oldow, J., Aiken, C., Hare, J., Ferguson, J. \& Hardyman, R. (2001). Active displacement transfer and differential block motion within the central Walker Lane, western Great Basin. Geology 29, 19-22.

Olin, P. H. \& Wolff, J. A. (2010). Rare earth and high field strength element partitioning between iron-rich clinopyroxenes and felsic liquids. Contributions to Mineralogy and Petrology 160, 761-775.

Pamukcu, A. S., Gualda, G. A. R. \& Anderson, A. T. (2012). Crystallization stages of the Bishop Tuff magma body recorded in crystal textures in pumice clasts. Journal of Petrology 53, 589-609.

Paterson, B. A. \& Stephens, W. E. (1992). Kinetically-induced compositional zoning in titanite: implications for accessory-phase/melt partitioning of trace elements. Contributions to Mineralogy and Petrology 109, 373-385.

Peppard, B. T., Steele, I. M., Davis, A. M., Wallace, P. J. \& Anderson, A. T. (2001). Zoned quartz phenocrysts from the rhyolitic Bishop Tuff. American Mineralogist 86, 10341052.

Phillips, D. \& Matchan, E. M. (2013). Ultra-high precision ${ }^{40} \mathrm{Ar} /{ }^{39} \mathrm{Ar}$ ages for Fish Canyon Tuff and Alder Creek Rhyolite sanidine: New dating standards required? Geochimica et Cosmochimica Acta 121, 229-239.

Putirka, K. D. (2008). Thermometers and barometers for volcanic systems. In: Putirka, K. \& Tepley III, F. J. (eds) Minerals, inclusions and volcanic processes. Mineralogical Society of America and Geochemical Society, Reviews in Mineralogy and Geochemistry 69, 61-120.

Quick, J. E., Sinigoi, S., Peressini, G., Demarchi, G., Wooden, J. L. \& Sbisa, A. (2009). Magmatic plumbing of a large Permian caldera exposed to a depth of $25 \mathrm{~km}$. Geology 37, 603-606. 
Rampino, M. R., \& Self, S. (1993). Climate-volcanism feedback and the Toba eruption of $\sim 74,000$ years ago. Quaternary Research 40, 269-280.

Reed, S. J. B. (2005). Electron microprobe analysis and scanning electron microscopy in geology. Cambridge: Cambridge University Press.

Reid, M. R. \& Coath, C. D. (2000). In situ U-Pb ages of zircons from the Bishop Tuff: no evidence for long crystal residence times. Geology 28, 443-446.

Reid, M. R. \& Schmitt, A. K. (2012). Implications of Bishop Tuff zircon U-Pb ages for rates of zircon growth and magma accumulation. Abstract V13F-07 presented at the 2012 Fall Meeting of the American Geophysical Union, San Francisco, California, 37 December.

Reid, M. R., Coath, C. D., Harrison, T. M. \& McKeegan, K. D. (1997). Prolonged residence times for the youngest rhyolites associated with Long Valley Caldera: ${ }^{230} \mathrm{Th}-{ }^{238} \mathrm{U}$ ion microprobe dating of young zircons. Earth and Planetary Science Letters 150, 27-39.

Reid, M. R., Vazquez, J. A. \& Schmitt, A. K. (2011). Zircon-scale insights into the history of a supervolcano, Bishop Tuff, Long Valley, California, with implications for the Tiin-zircon geothermometer. Contributions to Mineralogy and Petrology 161, 293-311.

Renne, P. R., Mundil, R., Balco, G., Min, K. \& Ludwig, K. R. (2010). Joint determination of ${ }^{40} \mathrm{~K}$ decay constants and ${ }^{40} \mathrm{Ar} * /{ }^{40} \mathrm{~K}$ for the Fish Canyon sanidine standard, and improved accuracy for ${ }^{40} \mathrm{Ar} /{ }^{39} \mathrm{Ar}$ geochronology. Geochimica et Cosmochimica Acta 74, 5349-5367.

Renne, P. R., Balco, G., Ludwig, K. R., Mundil, R. \& Min, K. (2011). Response to the comment by W.H. Schwarz et al. on 'Joint determination of ${ }^{40} \mathrm{~K}$ decay constants and ${ }^{40} \mathrm{Ar} * /{ }^{40} \mathrm{~K}$ for the Fish Canyon sanidine standard, and improved accuracy for ${ }^{40} \mathrm{Ar} /{ }^{39} \mathrm{Ar}$ geochronology' by P. R. Renne et al. (2010). Geochimica et Cosmochimica Acta 75, 5097-5100.

Ridolfi, F., Renzulli, A. \& Puerini, M. (2010). Stability and chemical equilibrium of amphibole in calc-alkaline magmas: an overview, new thermobarometric formulations and application to subduction-related volcanoes. Contributions to Mineralogy and Petrology 160, 45-66.

Rivera, T. A., Storey, M., Zeeden, C., Hilgen, F. J. \& Kuiper, K. (2011). A refined astronomically calibrated ${ }^{40} \mathrm{Ar} /{ }^{39} \mathrm{Ar}$ age for Fish Canyon sanidine. Earth and Planetary Science Letters 311, 420-426.

Roberge, J., Wallace, P. J. \& Kent, A. J. R. (2013). Magmatic processes in the Bishop Tuff rhyolitic magma based on trace elements in melt inclusions and pumice matrix glass. Contributions to Mineralogy and Petrology 165, 237-257.

Rundle, J. B. \& Hill, D. P. (1988). The geophysics of a restless caldera: Long Valley, California. Annual Review of Earth and Planetary Sciences 16, 251-271.

Sampson, D. E., \& Cameron, K. L. (1987). The geochemistry of the Inyo volcanic chain: Multiple magma systems in the Long Valley region, eastern California. Journal of Geophysical Research 92, 10403-10421. 
Sano, Y., Terada, K. \& Fukuoka, T. (2002). High mass resolution ion microprobe analysis of rare earth elements in silicate glass, apatite and zircon: lack of matrix dependency. Chemical Geology 184, 217-230.

Sarna-Wojcicki, A. M., Pringle, M. S. \& Wijbrans, J. (2000). New ${ }^{40} \mathrm{Ar} /{ }^{39} \mathrm{Ar}$ age of the Bishop Tuff from multiple sites and sediment rate calibration for the MatuyamaBrunhes boundary. Journal of Geophysical Research 105, 21431-21443.

Sarna-Wojcicki, A. M., Reheis, M. C., Pringle, M. S., Fleck, R. J., Burbank, D. W., Meyer, C. E., Slate, J. L., Wan, E., Budahn, J. R., Troxel, B. \& Walker, J. P. (2005). Tephra layers of Blind Spring Valley and related upper Pliocene and Pleistocene tephra layers, California, Nevada, and Utah: isotopic ages, correlation, and magnetostratigraphy. United States Geological Survey, Professional Papers 1701, 1-63.

Saunders, K., Blundy, J., Dohmen, R., \& Cashman, K. (2012a). Linking petrology and seismology at an active volcano. Science 336, 1023-1027.

Saunders, K., Rinnen, S., Blundy, J., Dohmen, R., Klemme, S. \& Arlinghaus, H. F. (2012b). TOF-SIMS and electron microprobe investigations of zoned magmatic orthopyroxenes: First results of trace and minor element analysis with implications for diffusion modeling. American Mineralogist 97, 532-542.

Saunders, K., Buse, B., Kilburn, M. R., Kearns, S. \& Blundy, J. (2014). Nanoscale characterisation of crystal zoning. Chemical Geology 364, 20-32.

Scaillet, B. \& Hildreth, W. (2001). Experimental constraints on the origin and evolution of the Bishop Tuff. Abstract for presentation at the Penrose conference. URL: http://hal.archives-ouvertes.fr/docs/00/10/26/16/PDF/Abstract_Penrose-1.pdf

Schärer, U. (1984). The effect of initial ${ }^{230}$ Th disequilibrium on young U-Pb ages: the Makalu case, Himalaya. Earth and Planetary Science Letters 67, 191-204.

Schwandt, C. S. \& McKay, G. A. (2006). Minor- and trace-element sector zoning in synthetic enstatite. American Mineralogist 91, 1607-1615.

Schwandt, C. S., Cygan, R. T. \& Westrich, H. R. (1998). Magnesium self-diffusion in orthoenstatite. Contributions to Mineralogy and Petrology 130, 390-396.

Seccia, D., Chiarabba, C., De Gori, P., Bianchi, I. \& Hill, D. P. (2011), Evidence for the contemporary magmatic system beneath Long Valley caldera from local earthquake tomography and receiver function analysis. Journal of Geophysical Research 116, B12314.

Self, S. (2006). The effects and consequences of very large explosive volcanic eruptions. Philosophical Transactions of the Royal Society, London A364, 2073-2097.

Self, S. \& Blake, S. (2007). Consequences of explosive supereruptions. Elements 4, 41-46.

Shane, P., Nairn, I. A., \& Smith, V. C. (2005). Magma mingling in the 50 ka Rotoiti eruption from Okataina Volcanic Centre: implications for geochemical diversity and chronology of large volume rhyolites. Journal of Volcanology and Geothermal Research 139, 295-313. 
Sheridan, M. F. (1965). The mineralogy and petrology of the Bishop Tuff: [Ph. D. Thesis], Stanford University, Stanford, California.

Sheridan, M. F. (1968). Double cooling-unit nature of the Bishop Tuff in Owens Gorge, California. Geology Society of America Special Papers 115, 351.

Sheridan, M. F. (1970). Fuarmolic [sic.] mounds and ridges of the Bishop Tuff, California. Geological Society of America Bulletin 81, 851-868.

Simakin, A. G. \& Bindeman, I. N. (2008). Evolution of crystal sizes in the series of dissolution and precipitation events in open magma systems. Journal of Volcanology and Geothermal Research 177, 997-1010.

Simon, J. I. \& Reid, M. R. (2005). The pace of rhyolite differentiation and storage in an 'archetypical' silicic magma system, Long Valley, California. Earth and Planetary Science Letters 235, 123-140.

Simon, J. I., Reid, M. R. \& Young, E. D. (2007). Lead isotopes by LA-MC-ICPMS: tracking the emergence of mantle signatures in an evolving silicic magma system. Geochimica et Cosmochimica Acta 71, 2014-2035.

Simon, J. I., Renne, P. R. \& Mundil, R. (2008). Implications of pre-eruptive magmatic histories of zircons for $\mathrm{U}-\mathrm{Pb}$ geochronology of silicic extrusions. Earth and Planetary Science Letters 266, 182-194.

Simon, J. I., Weis, D., DePaolo, D. J., Renne., P. J., Mundil, R. \& Schmitt, A. K. (2014). Assimilation of preexisting Pleistocene intrusions at Long Valley by periodic magma recharge accelerates rhyolite generation: rethinking the remelting model. Contributions to Mineralogy and Petrology 167, 955.

Singer, B. S., Jicha, B. R., Coe, R. S. \& Mochizuki, N. (2012). An Earthtime chronology for the Matuyama-Brunhes geomagnetic field reversal. Abstract V21E-06 presented at the 2012 Fall Meeting of the American Geophysical Union, San Francisco, California, 3-7 December.

Smith, R. L. (1979). Ash-flow magmatism. In: Chapin, C. E. \& Elston, W. E. (eds.) Ash-flow tuffs. Geological Society of America, Special Paper 180, 5-25.

Snyder, D. (2000). Thermal effects of the intrusion of basaltic magma into a more silicic magma chamber and implications for eruption triggering. Earth and Planetary Science Letters 175, 257-273.

Sparks, R. S. J. \& Marshall, L. A. (1986). Thermal and mechanical constraints on mixing between mafic and silicic magmas. Journal of Volcanology and Geothermal Research 29, 99124.

Sparks, R. S. J., Sigurdsson, H. \& Wilson, L. (1977). Magma mixing: a mechanism for triggering acid explosive eruptions. Nature 267, 315-318.

Sparks, R. S. J., Self, S., Grattan, J. P., Oppenheimer, C., Pyle, D. M. \& Rymer, H. (2005). Super-eruptions: global effects and future threats. Report of a Geological Society of London working group. London, UK: The Geological Society, 24 p. 
Stacey, J. S. \& Kramers, J. D. (1975). Approximation of terrestrial lead isotope evolution by a 2-stage model. Earth and Planetary Science Letters 26, 207-221.

Storm, S., Shane, P., Schmitt, A. K. \& Lindsay, J. M. (2011). Contrasting punctuated zircon growth in two syn-erupted rhyolite magmas from Tarawera volcano: Insights to crystal diversity in magmatic systems. Earth and Planetary Science Letters 301, 511-520.

Strand, R. G. (1967). Geologic Map of California, Mariposa Sheet; California Division of Mines and Geology: Sacramento, CA, USA; Scale 1:250 000.

Streck, M. J. (2008). Mineral textures and zoning as evidence for open system processes. In: Putirka, K. \& Tepley III, F. J. (eds) Minerals, inclusions and volcanic processes. Mineralogical Society of America and Geochemical Society, Reviews in Mineralogy and Geochemistry 69, 595622.

Sutton, A. N., Blake, S., Wilson, C. J. N. \& Charlier, B. L. A. (2000). Late Quaternary evolution of a hyperactive rhyolite magmatic system: Taupo volcanic centre, New Zealand. Journal of the Geological Society, London 157, 537-552.

Tanguy, J. C., Ribiere, C., Scarth, A. \& Tjetjep, W. S. (1998). Victims from volcanic eruptions: a revised database. Bulletin of Volcanology 60, 137-144.

Taylor, T. R. \& Dewey, J. F. (2009). Transtensional analyses of fault patterns and strain provinces of the Eastern California shear zone-Walker Lane on the eastern margin of the Sierra Nevada microplate, California and Nevada. International Geology Review 51, 843-872.

Thomas, J. B. \& Watson, E. B. (2012). Application of the Ti-in-quartz thermobarometer to rutile-free systems. Reply to: a comment on: 'TitaniQ under pressure: the effect of pressure and temperature on the solubility of 'Ti in quartz' by 'Thomas et al. Contributions to Mineralogy and Petrology 164, 369-374.

Thomas, J. B., Watson, E. B., Spear, F. S., Shemella, P. T., Nayak, S. K. \& Lanzirotti, A. (2010). TitaniQ under pressure: the effect of pressure and temperature on the solubility of Ti in quartz. Contributions to Mineralogy and Petrology 160, 743-759.

Till, C. B., Vazquez, J. A., Boyce, J. W. \& Hitzman, C. (2012). Quantifying the interval between rejuvenation and eruption of rhyolite at Yellowstone caldera using highresolution NanoSIMS geospeedometry. Abstract V43E-01 presented at the 2012 Fall Meeting of the American Geophysical Union, San Francisco, California, 3-7 December.

Turner, S. \& Costa, F. (2007). Measuring timescales of magmatic evolution. Elements 3, $267-$ 272.

Unruh, J., Humphrey, J. \& Barron, A. (2003). Transtensional model for the Sierra Nevada frontal fault system, eastern California. Geology 31, 327-330.

van den Bogaard, P. \& Schirnick, C. (1995). ${ }^{40} \mathrm{Ar} /{ }^{39} \mathrm{Ar}$ laser probe ages of Bishop Tuff quartz phenocrysts substantiate long-lived silicic magma chamber at Long Valley, United States. Geology 23, 759-762. 
Vandergoes, M. J., Hogg, A. G., Lowe, D. J., Newnham, R. M., Denton, G. H., Southon, J., Barrell, D. J. A., Wilson, C. J. N., McGlone, M. S., Allan, A. S. R., Almond, P. C., Petchey, F., Dabell, K., Dieffenbacher-Krall, A.C. \& Blaauw, M. (2013). A revised age for the Kawakawa/Oruanui tephra, a key marker for the Last Glacial Maximum in New Zealand. Quaternary Science Reviews 74, 195-201.

Van Kooten, G. K. (1980). Mineralogy, petrology, and geochemistry of an ultrapotassic basaltic suite, central Sierra Nevada, California, USA. Journal of Petrology 21, 651-684.

Van Kooten, G. K. (1981). Pb and Sr systematics of ultrapotassic and basaltic rocks from the central Sierra Nevada, California. Contributions to Mineralogy and Petrology 76, 378385.

Vazquez, J. A. \& Reid, M. R. (2002). Time scales of magma storage and differentiation of voluminous high-silica rhyolites at Yellowstone caldera, Wyoming. Contributions to Mineralogy and Petrology 144, 274-285.

Venezky, D. Y. \& Rutherford, M. J. (1999). Petrology and Fe-Ti oxide reequilibration of the 1991 Mount Unzen mixed magma. Journal of Volcanology and Geothermal Research 89, 213-230.

Vigneresse, J. L. \& Clemens, J. D. (2000). Granitic magma ascent and emplacement: neither diapirism nor neutral buoyancy. In Vendeville, B. C., Mart, Y. \& Vigneresse, J. L. (eds) Salt Shale and Igneous Diapirs in and around Europe, Geological Society Special Publications 174, 1-19.

Vogel, T. A., Eichelberger, J. C., Younker, L. W., Schuraytz, B. C., Horkowitz, J. P., Stockman, H. W. \& Westrich, H. R. (1989). Petrology and emplacement dynamics of intrusive and extrusive rhyolites of Obsidian Dome, Inyo Craters volcanic chain, eastern California. Journal of Geophysical Research 94, 17937-17956.

Wakabayashi, J. \& Sawyer, T. L. (2001). Stream incision, tectonics, uplift, and evolutions of topography of the Sierra Nevada, California. Journal of Geology 109, 539-562.

Wallace, P. J., Anderson, A. T. \& Davis, A. M. (1999). Gradients in $\mathrm{H}_{2} \mathrm{O}, \mathrm{CO}_{2}$, and exsolved gas in a large-volume silicic magma system: Interpreting the record preserved in melt inclusions from the Bishop Tuff. Journal of Geophysical Research 104, 20097-20122.

Wark, D. A., Hildreth, W., Spear, F. S., Cherniak, D. J. \& Watson, E. B. (2007). Preeruption recharge of the Bishop magma system. Geology 35, 235-238.

Watson, E. B. (1996). Surface enrichment and trace-element uptake during crystal growth. Geochimica et Cosmochimica Acta 60, 5013-5020.

Watson, E. B. \& Harrison, T. M. (1983). Zircon saturation revisited: temperature and composition effects in a variety of crustal magma types. Earth and Planetary Science Letters 64, 295-304.

Watson, E. B. \& Harrison, T. M. (2005). Zircon thermometer reveals minimum melting conditions on earliest Earth. Science 308, 841-844. 
Watson, E. B. \& Liang, Y. (1995). A simple model for sector zoning in slowly grown crystals: implications for growth rate and lattice diffusion, with emphasis on accessory minerals in crustal rocks. American Mineralogist 80, 1179-1187.

Watson, E. B., Wark, D. A. \& Thomas, J. B. (2006). Crystallization thermometers for zircon and rutile. Contributions to Mineralogy and Petrology 151, 413-433.

White, L. T. \& Ireland, T. R. (2012). High-uranium matrix effect in zircon and its implications for SHRIMP U-Pb age determinations. Chemical Geology 306-307, 78-91.

Wickham, S. M. (1987). The segregation and emplacement of granitic magmas. Journal of the Geological Society, London 144, 281-297.

Wilcock, J., Goff, F., Minarik, W. G., \& Stix, J. (2013). Magmatic recharge during the formation and resurgence of the Valles caldera, New Mexico, USA: evidence from quartz compositional zoning and geothermometry. Journal of Petrology 54, 635-664.

Wilson, C. J. N. (1993). Stratigraphy, chronology, styles and dynamics of late Quaternary eruptions from Taupo volcano, New Zealand. Philosophical Transactions of the Royal Society, London A343, 205-306.

Wilson, C. J. N. (2001). The 26.5ka Oruanui eruption, New Zealand: an introduction and overview. Journal of Volcanology and Geothermal Research 112, 133-174.

Wilson, C. J. N. \& Charlier, B. L. A. (2009). Rapid rates of magma generation at contemporaneous magma systems, Taupo volcano, New Zealand: insights from UTh model-age spectra in zircons. Journal of Petrology 50, 875-907.

Wilson, C. J. N. \& Hildreth, W. (1997). The Bishop Tuff: New insights from eruptive stratigraphy. Journal of Geology 105, 407-439.

Wilson, C. J. N. \& Hildreth, W. (2003). Assembling an ignimbrite: mechanical and thermal building blocks in the Bishop Tuff, California. Journal of Geology 111, 653-670.

Wilson, C. J. N., Blake, S., Charlier, B. L. A. \& Sutton, A. N. (2006). The 26. 5 ka Oruanui eruption, Taupo volcano, New Zealand: development, characteristics and evacuation of a large rhyolitic magma body. Journal of Petrology 47, 35-69.

Wilson, C. J. N., Seward, T. M., Charlier, B. L. A., Allan, A. S. R. \& Bello, L. (2012). A comment on: 'TitaniQ under pressure: the effect of pressure and temperature on the solubility of Ti in quartz', by Jay B. Thoms, E. Bruce Watson, Frank S. Spear, Philip T. Shemella, Saroj K. Nayak and Antonio Lanzirotti. Contributions to Mineralogy and Petrology 164, 359-368.

Winick, J. A., McIntosh, W. C. \& Dunbar, N. W. (2001). Melt-inclusion-hosted excess ${ }^{40}$ Ar in quartz crystals of the Bishop and Bandelier magma systems. Geology 29, 275-278.

Wolff, J. A. \& Ramos, F. C. (2003). Pb isotope variations among Bandelier Tuff feldspars: No evidence for a long-lived silicic magma chamber. Geology 31, 533-536.

Wolff, J. A. \& Ramos, F. C. (2014). Processes in caldera-forming high-silica rhyolite magma: $\mathrm{Rb}-\mathrm{Sr}$ and $\mathrm{Pb}$ isotope systematics of the Otowi Member of the Bandelier Tuff, Valles Caldera, New Mexico, USA. Journal of Petrology 55, 345-375. 
Wolff, J. A., Ramos, F. C. \& Davidson, J. P. (1999). Sr isotope disequilibrium during differentiation of the Bandelier Tuff: Constraints on the crystallisation of a large rhyolitic magma chamber. Geology 27, 469-498.

Wood, S. H. (1983). Chronology of late Pleistocene and Holocene volcanics, Long Valley and Mono Basin geothermal areas, eastern California. US Geological Survey Open-File Report 83-747 1-84.

Zandt, G., Gilbert, H., Owens, T. J., Ducea, M., Saleeby, J. \& Jones, C. H. (2004). Active foundering of a continental arc root beneath the southern Sierra Nevada in California. Nature 431, 41-46.

Zellmer, G. F., Blake, S., Vance, D., Hawkesworth, C., \& Turner, S. (1999). Plagioclase residence times at two island arc volcanoes (Kameni Islands, Santorini, and Soufriere, St. Vincent) determined by Sr diffusion systematics. Contributions to Mineralogy and Petrology 136, 345-357.

Zhang, Y. (2010). Diffusion in minerals and melts: theoretical background. In Zhang, Y. \& Cherniak, D. J. (eds) Diffusion in mineral and melts. Mineralogical Society of America and Geochemical Society, Reviews in Mineralogy and Geochemistry 72, 5-59. 


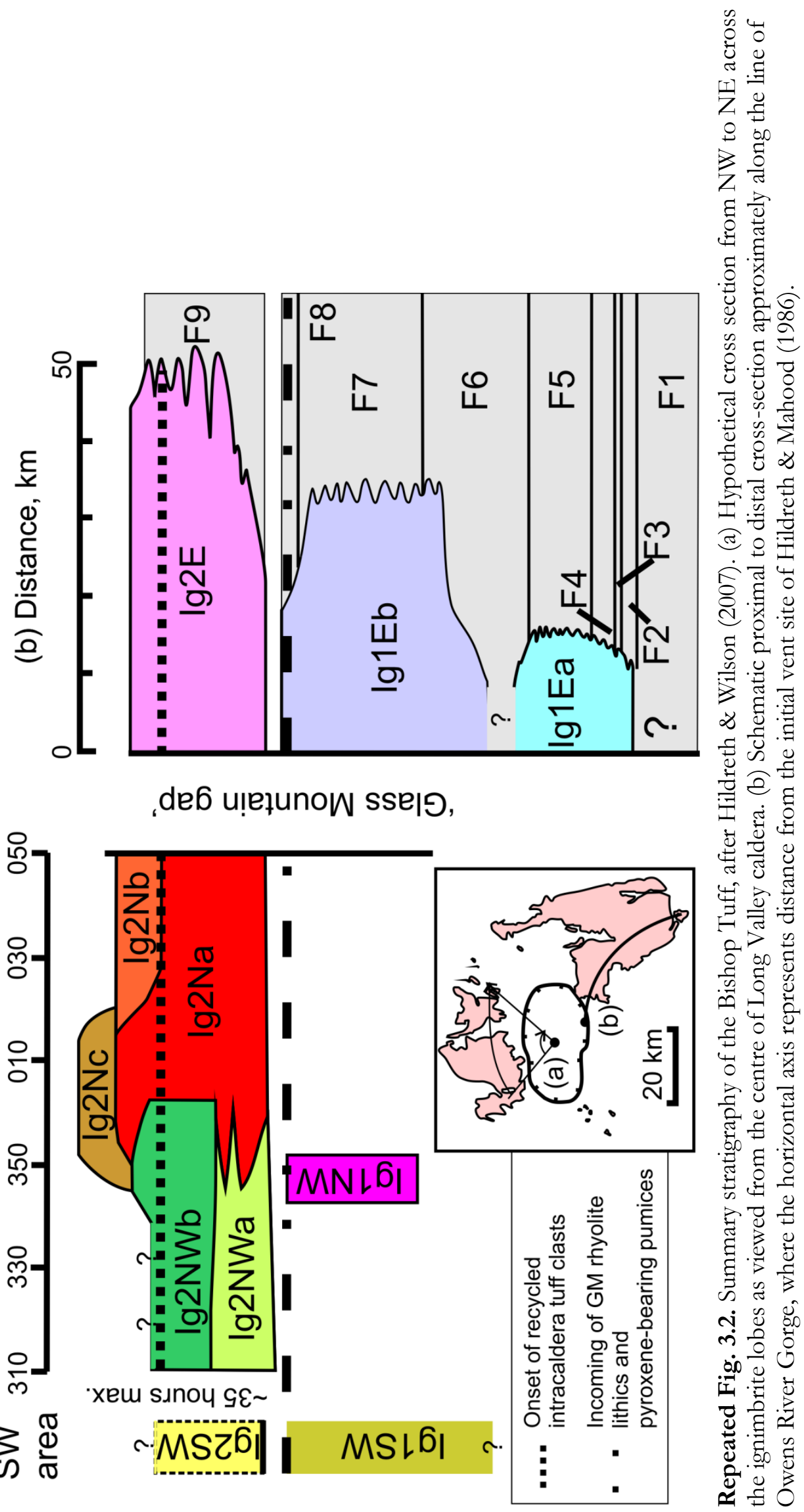




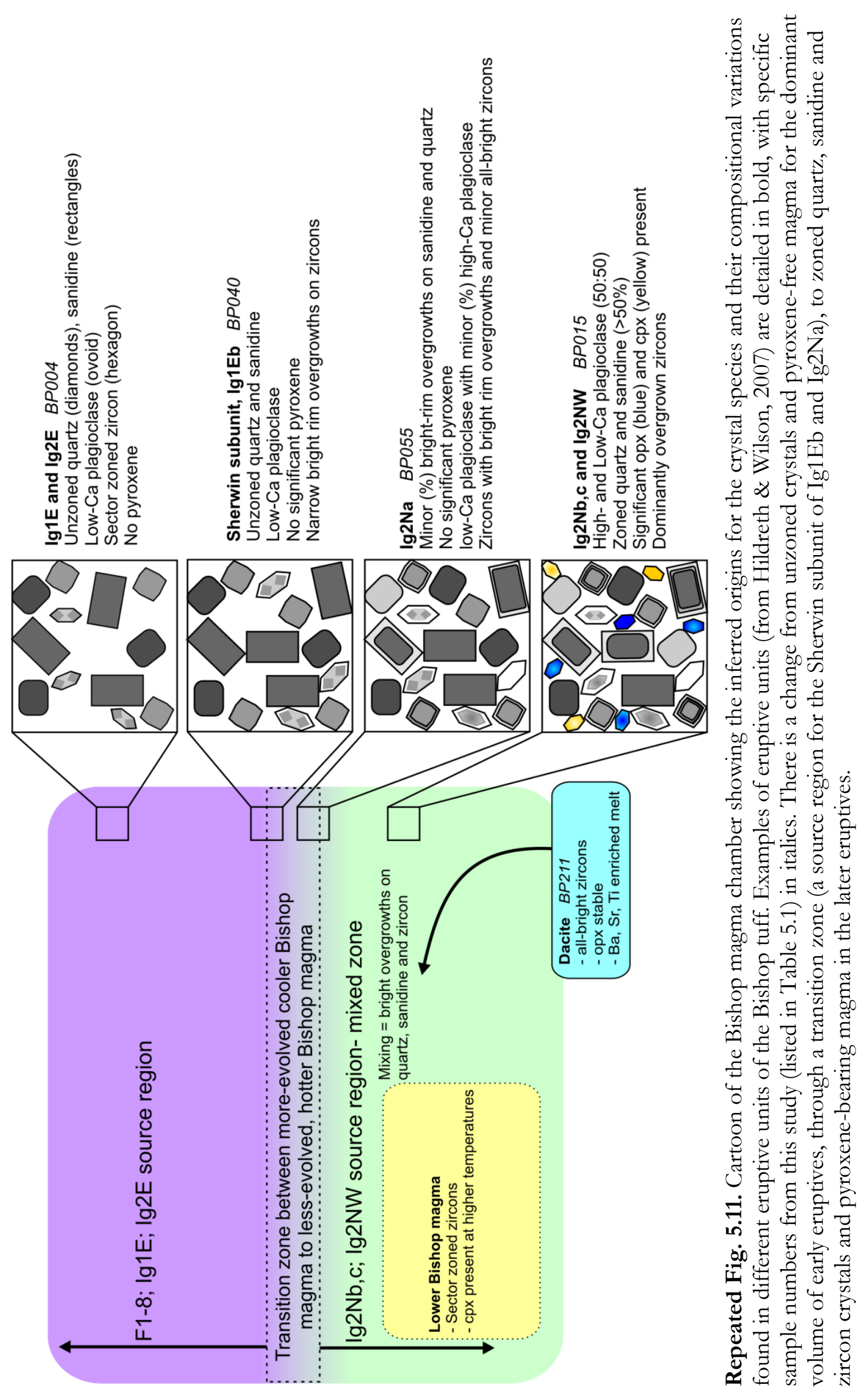




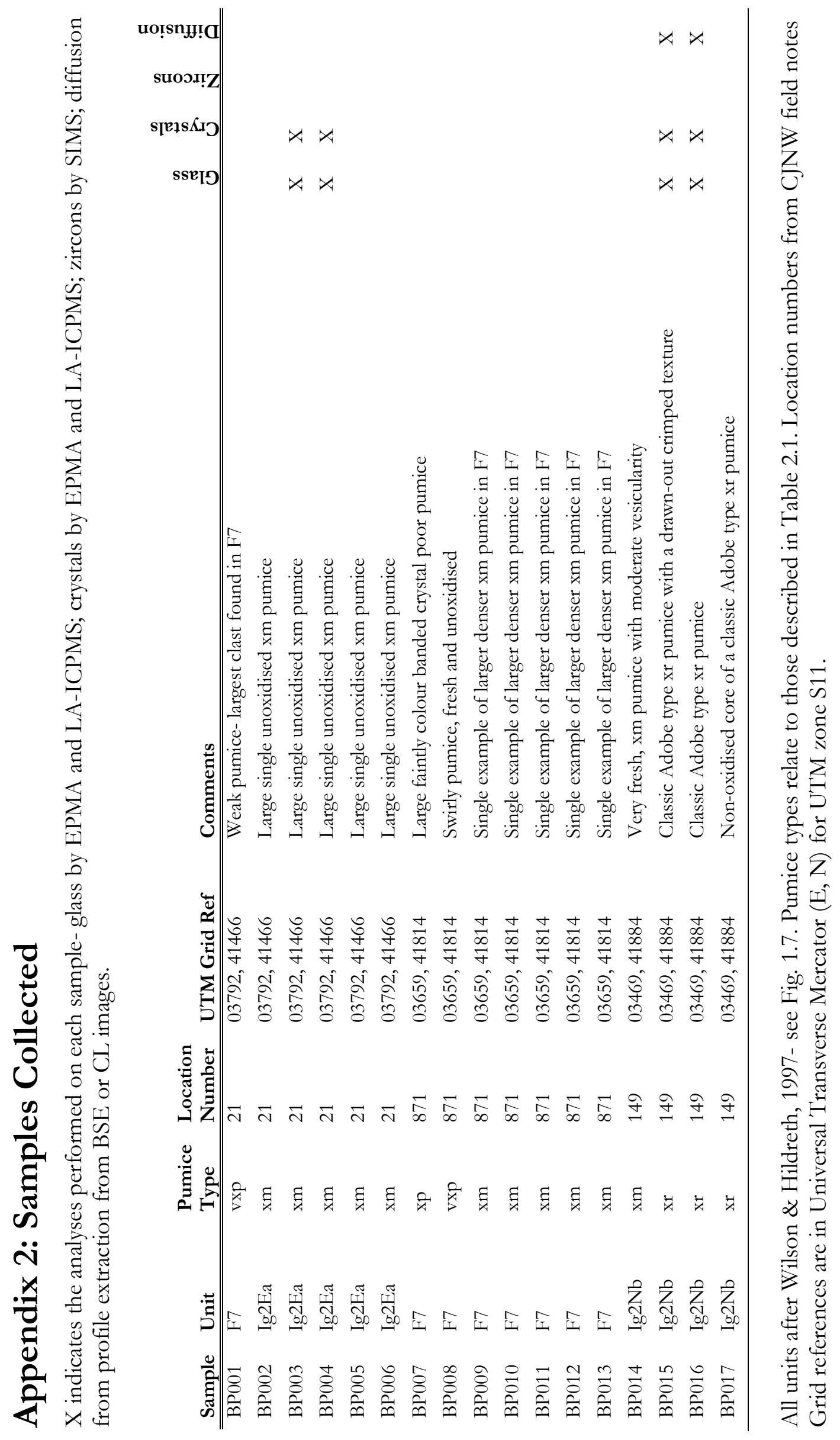




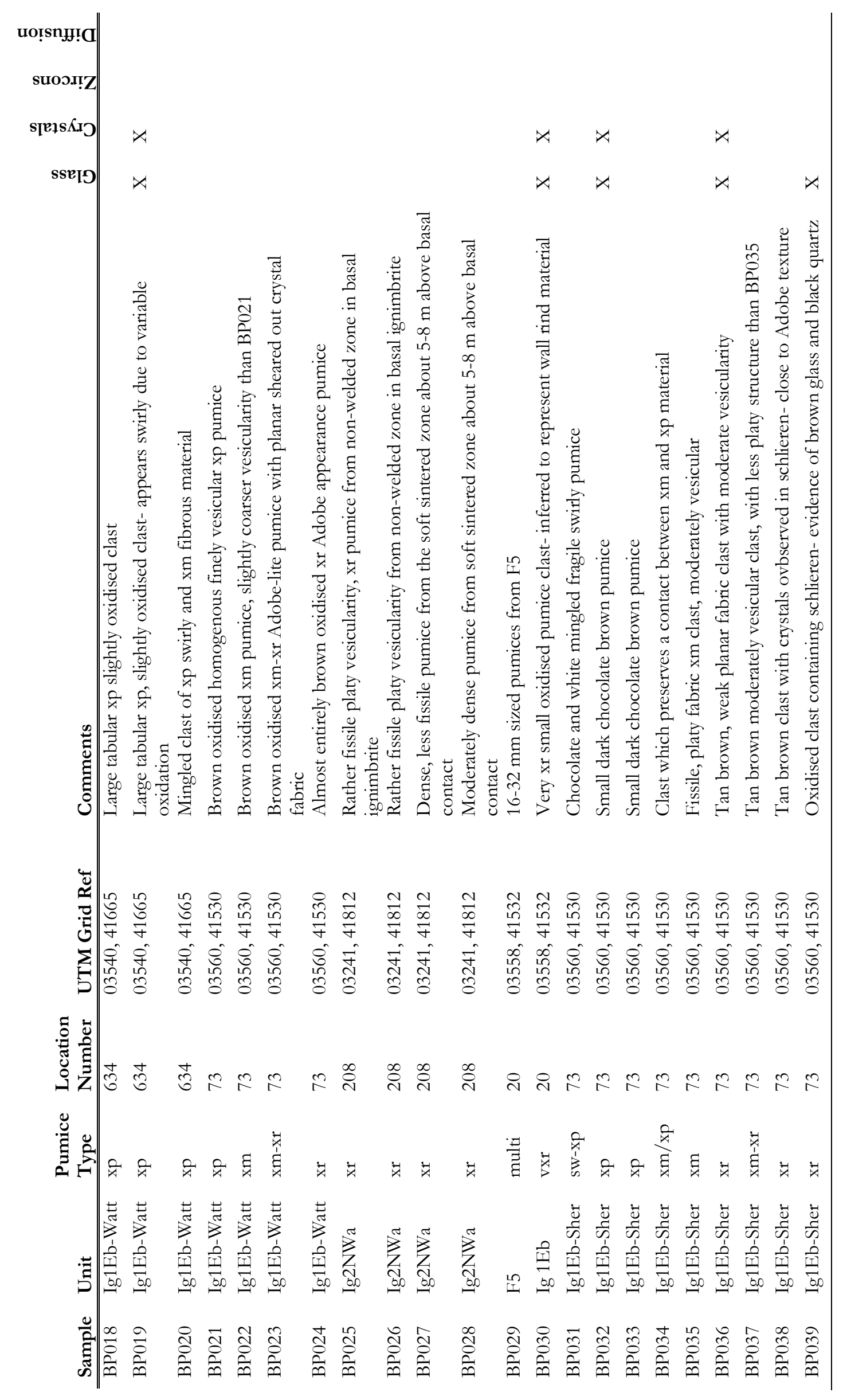




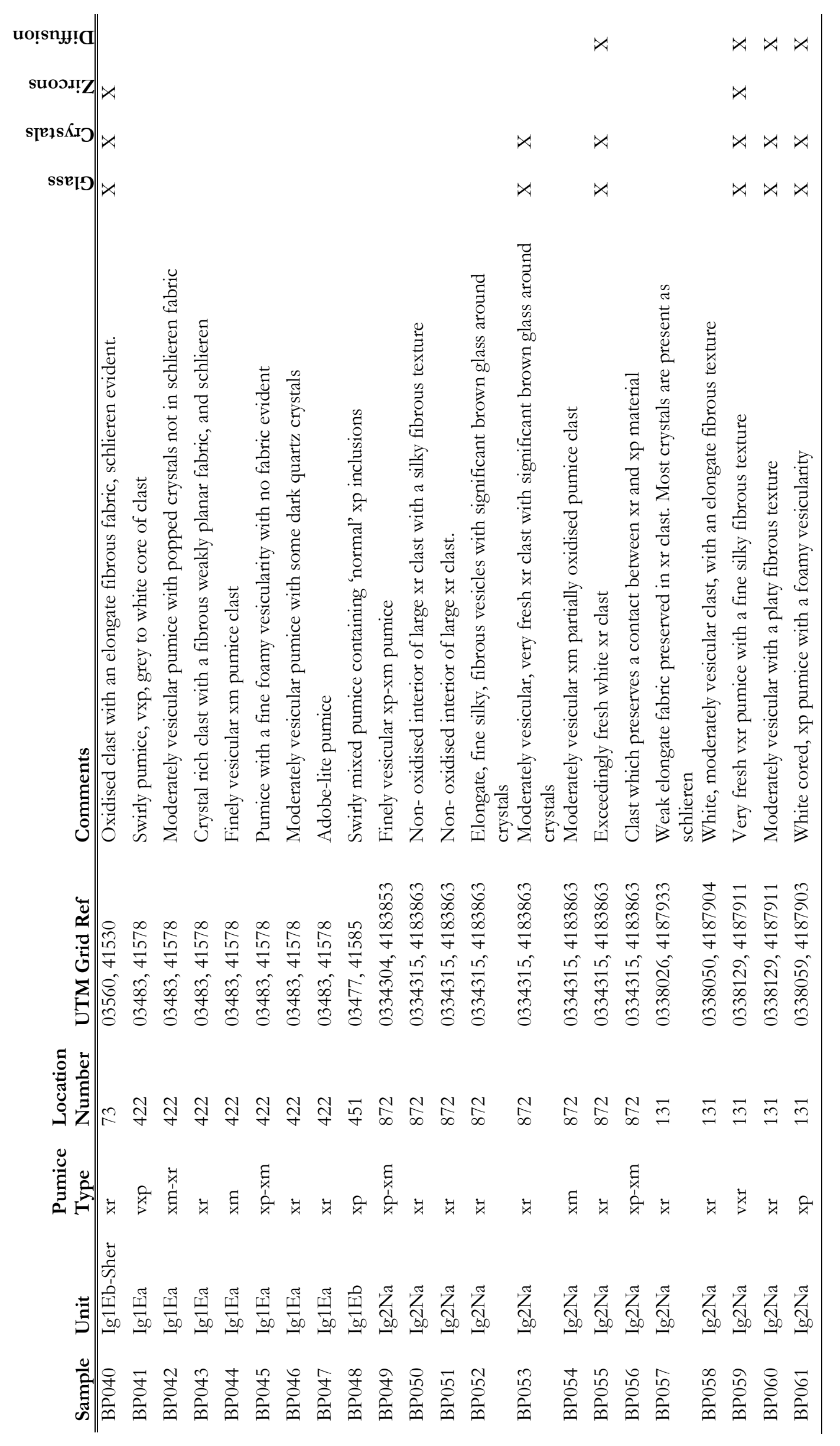




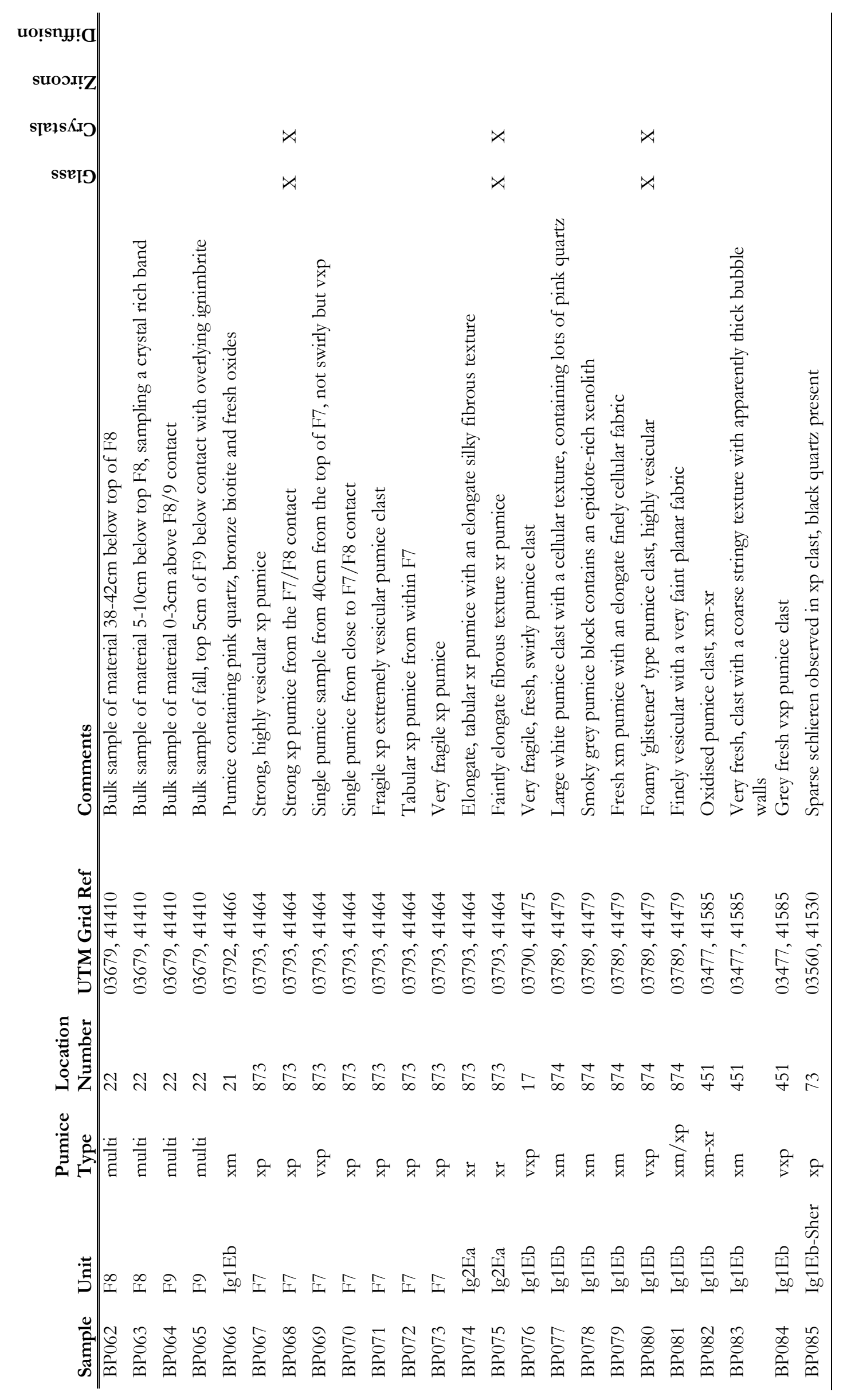




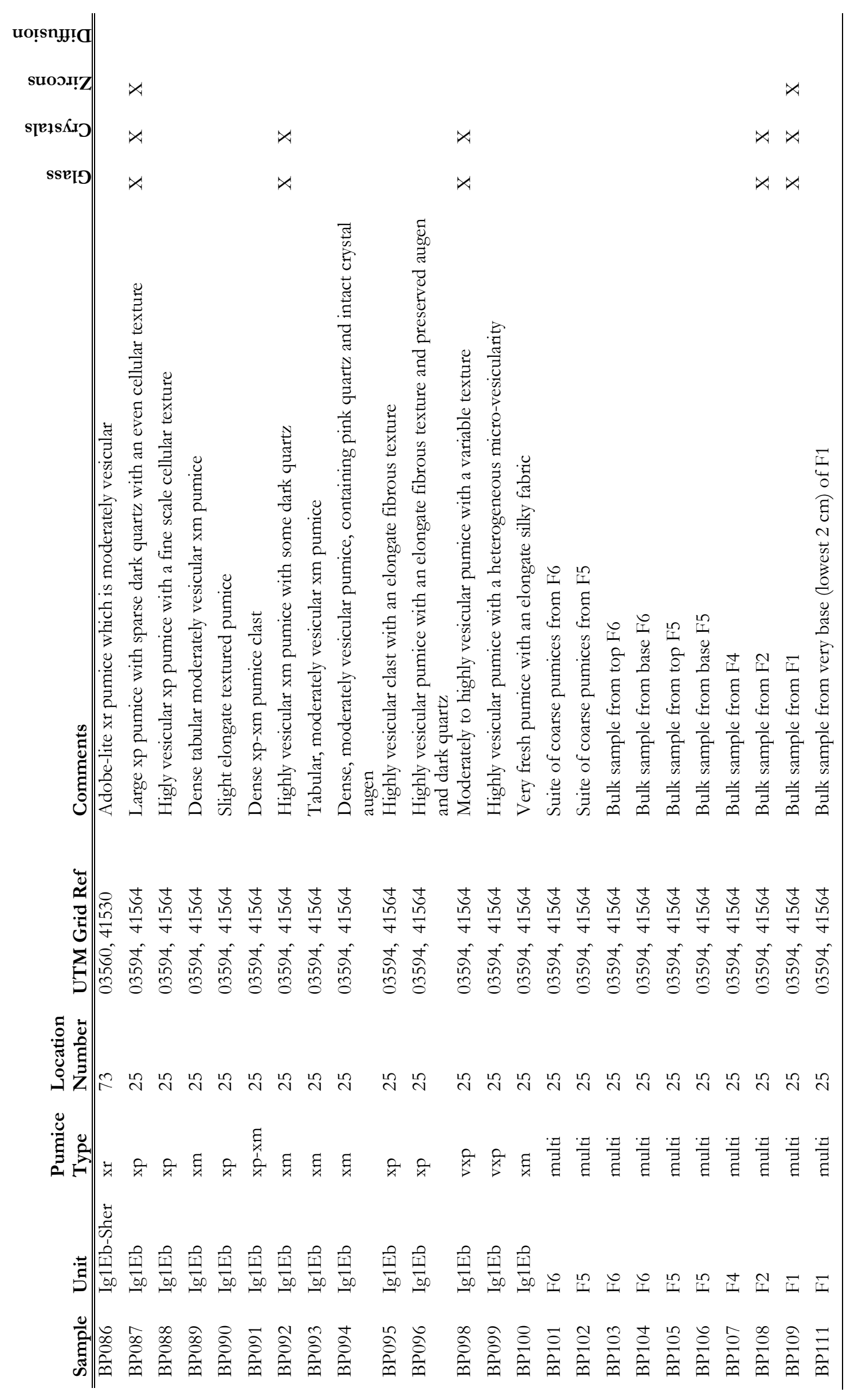




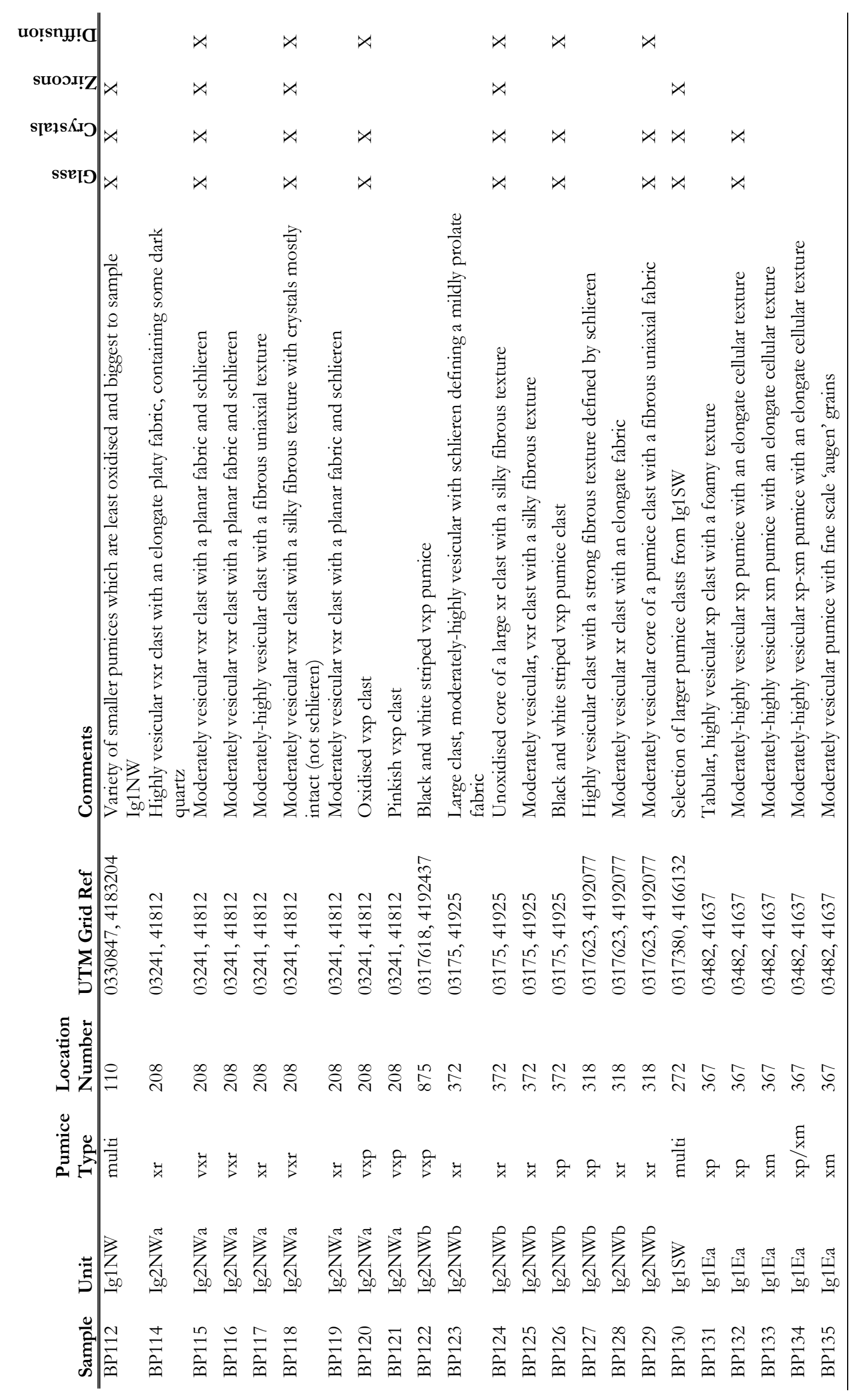




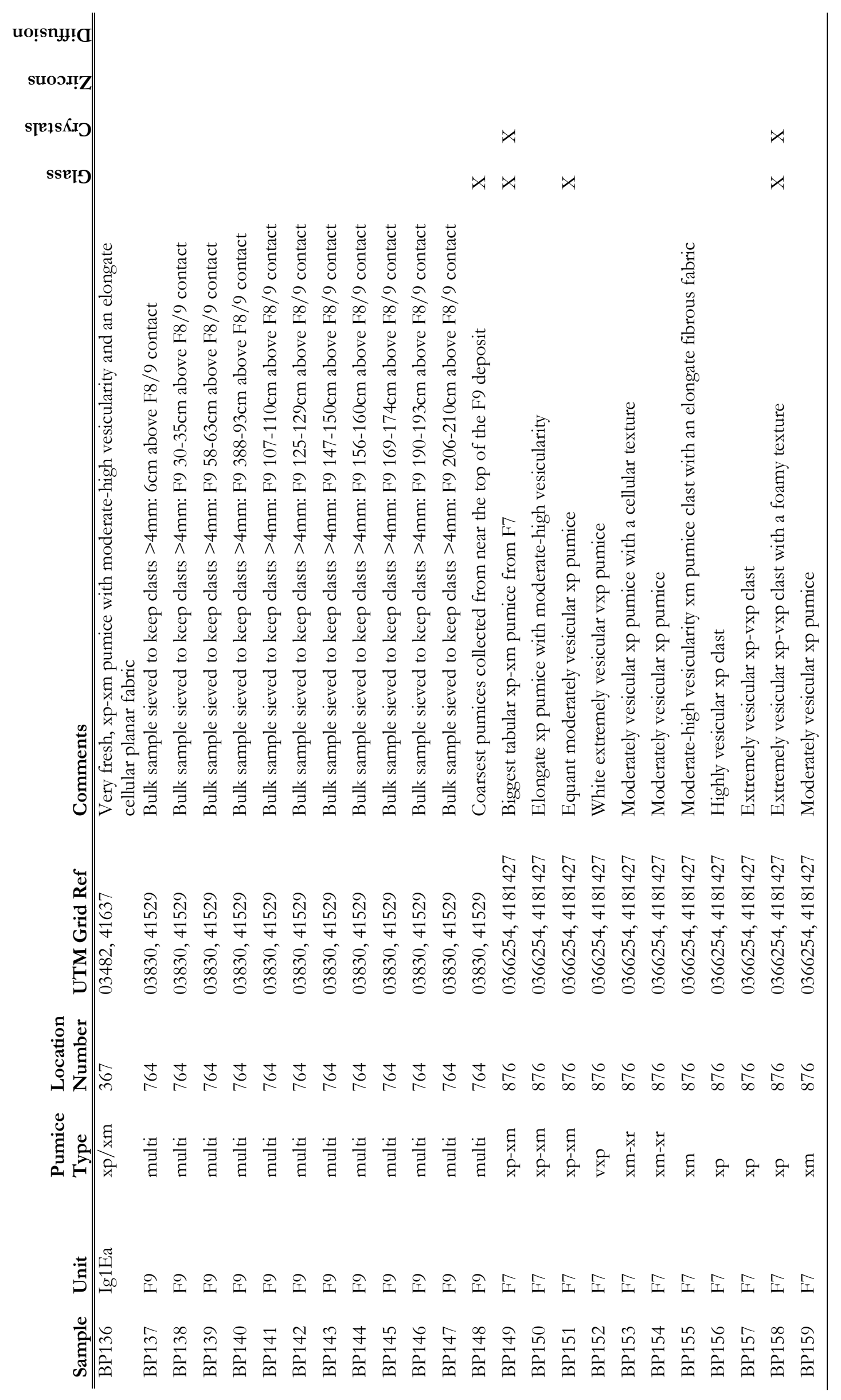




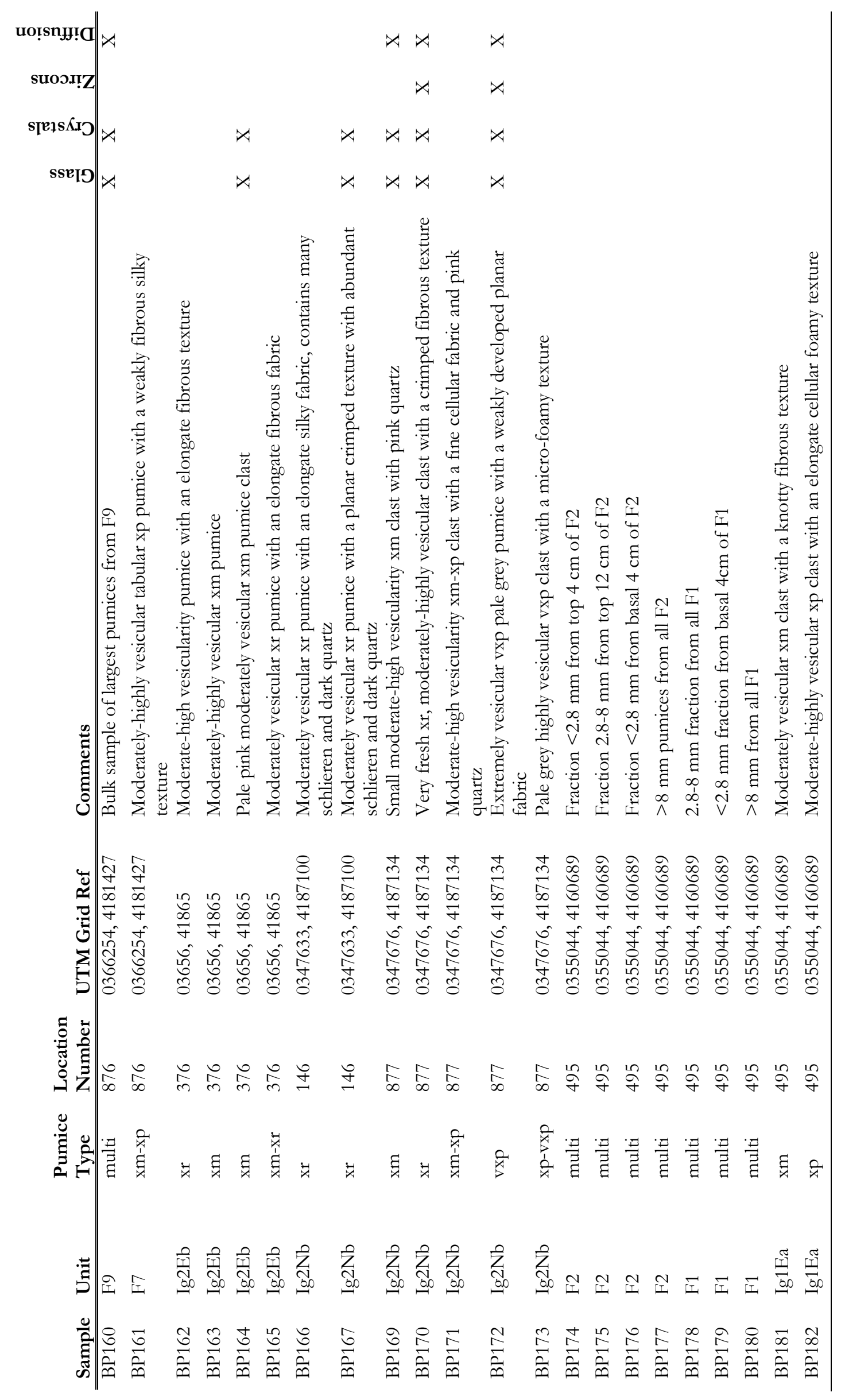




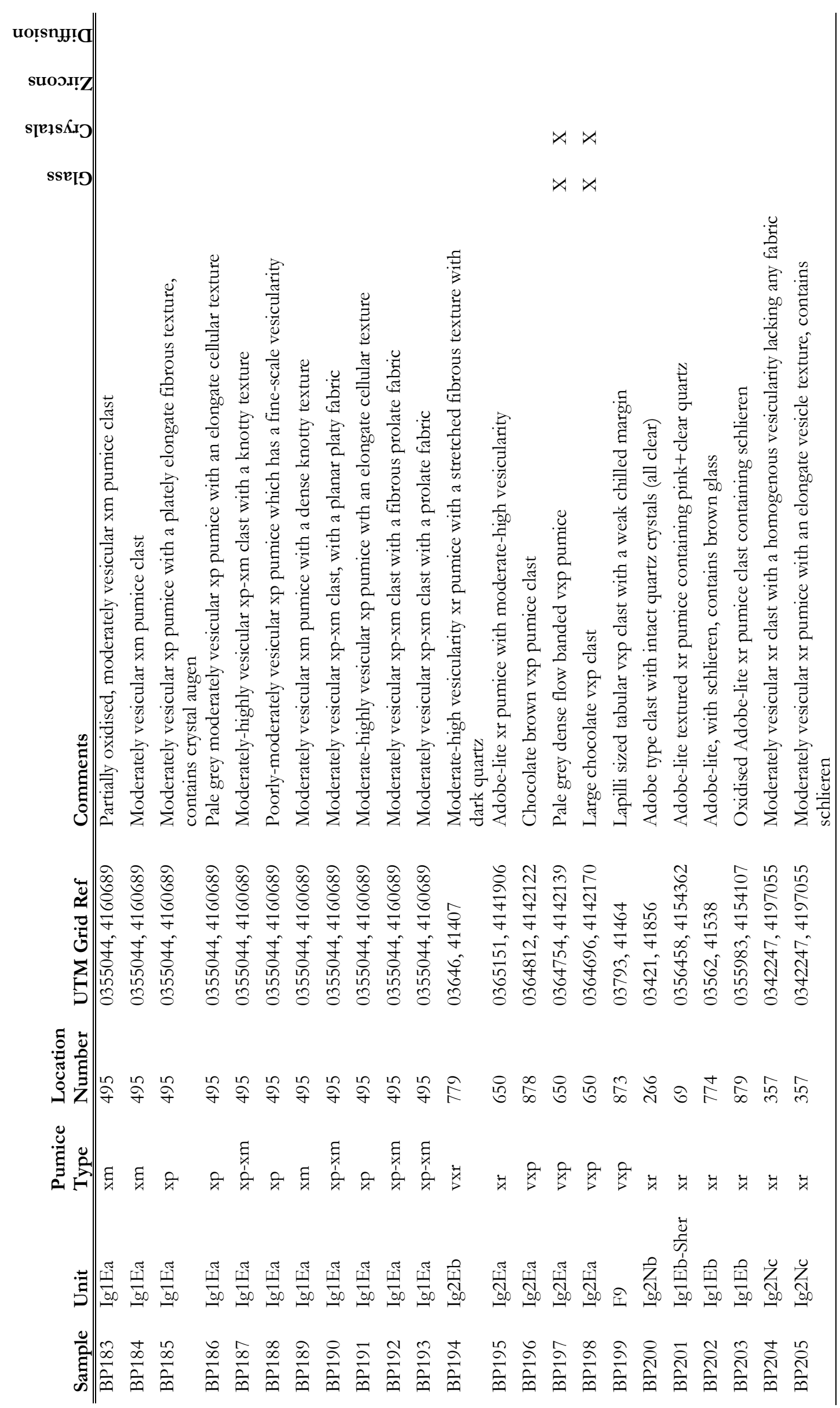




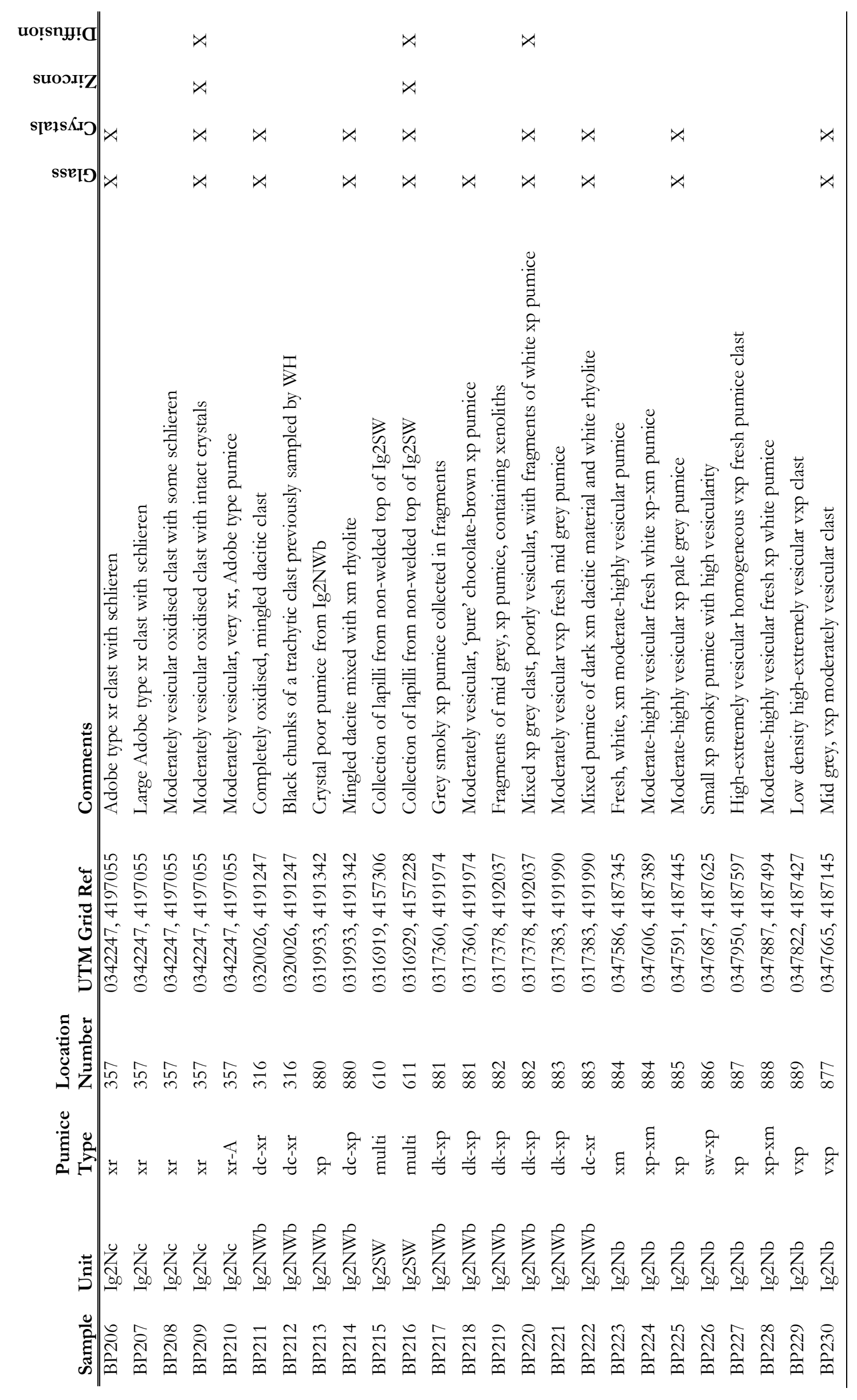




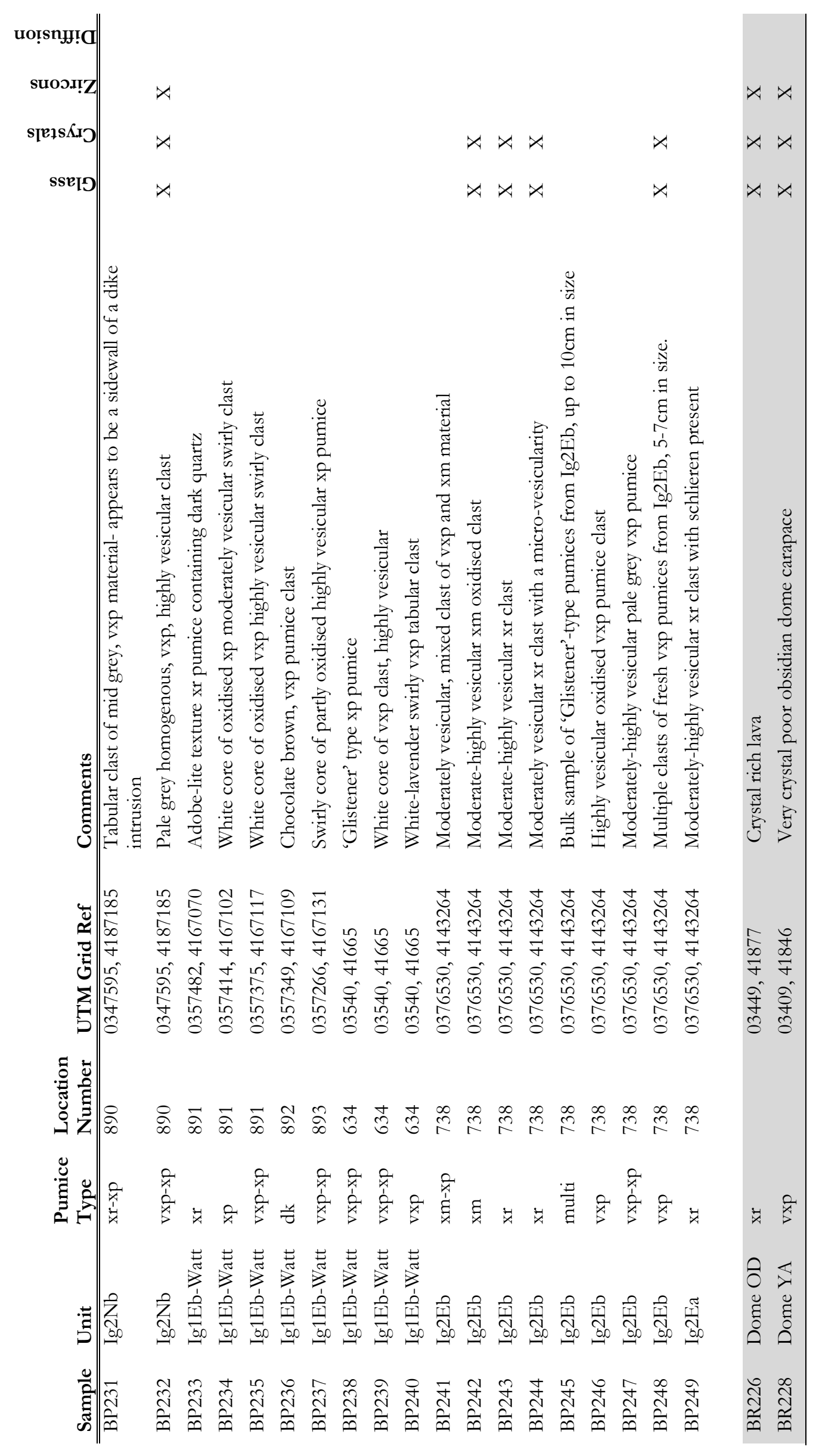




\section{Appendix 3: Conference abstracts}

\section{A3.1 GeoNZ 2011- Oral Presentation}

The Bishop Tuff, California: Deposit of a Horizontally Variable Super-sized Magma Chamber?

K.J. Chamberlain ${ }^{1}$, C.J.N. Wilson ${ }^{1}$ and J.A. Baker ${ }^{1}$

1: SGEES, Victoria University of Wellington, New Zealand

The $\sim 0.76 \mathrm{Ma}$ Bishop Tuff eruption in eastern California is one of the great eruptions on Earth in the last 2 million years. As an archetypal example of the products of a compositionally stratified magma chamber, the Bishop Tuff provides an excellent opportunity to study processes which operate on this 'super-eruptive' scale. These processes are being compared with those inferred for New Zealand supereruption deposits such as the Oruanui, where growth of a non-stratified melt dominant body was extraordinarily rapid. Crystal specific studies of multiple pumice clasts from all units from the Bishop Tuff are being used to quantify not only the vertical stratification of the magma body, but also identify any lateral (geographic) variations which existed prior to eruption.

Re-examination of published XRF data (Hildreth and Wilson 2007, Journal of Petrology 49, 951) reveals variations in trace element concentrations within single ignimbrite packages, which are not dependent on crystal content, suggesting that there was some geographic change in availability of different magma types across the chamber. Laser ablation inductively coupled mass spectrometry (LA-ICPMS) analyses of sanidine has confirmed that some of the late-erupted crystals have a $\mathrm{Ba}$ - rich rim, which is accompanied by increases in strontium and light rare earth elements. This Ba- rich rim is not seen in the eastern units of the Bishop Tuff, and is not present in all crystals from the northern units. Microprobe analyses of plagioclase show no differences between core and rim major elements, but distinct differences within the northern units, again suggesting varying availability of small scale magma batches. Study of these sector-confined eruptive compositions will allow a more detailed model of the magma body to be constructed, and to be comparison to be made with models for caldera eruptions in New Zealand and around the world. 


\section{A3.2 AGU 2012- Poster Presentation}

Fifty Shades of Grey: Zircon Perspectives on the Timing and Chemistry of Magma Interactions in the Bishop Tuff

K.J. Chamberlain ; C.J.N. Wilson ${ }^{1}$; J.L. Wooden ${ }^{2}$; J.A. Baker ${ }^{1}$; B.L.A. Charlier ${ }^{3}$

1: SGEES, Victoria University of Wellington, New Zealand

2: SUMAC, Stanford University, California, USA

3: CEPSAR, The Open University, Milton Keynes, UK.

The $\sim 0.76 \mathrm{Ma}$ Bishop Tuff eruption in eastern California is an archetypal example of the products of a compositionally stratified magma chamber. Key issues regarding the meltdominant magma body that have arisen from recent studies include the role of horizontal variability versus vertical stratification, and the nature and timing of a late-stage ingress of compositionally contrasting melt. The latter is reflected in, for example, CL-bright rims on quartz, and Sr- and Ba-rich rims on sanidines, both of which are reported in samples from ignimbrite erupted from vents along the northern caldera rim. Various studies have placed contrasting temporal constraints on assembly and evacuation of the Bishop Tuff magma body and the processes occurring within it from one or two mineral phases. Although the overall crystal specific record is more complex, it has the potential to distinguish between mixing, in-situ crystallisation and other magmatic processes, and resolve the associated timings of these events.

Zircon has been widely utilised in the Bishop Tuff and other silicic systems because of its unique records of information about the ages and P-T-X environments of growth. Here we present SHRIMP-RG ion probe data from Bishop Tuff zircons, collected from samples spanning the full eruptive sequence. A combination of age data, textural analysis and trace element analysis is used to yield insights into magma chamber development and the preeruptive state of the melt-dominant magma body, as evidenced in material erupted from different vent areas around what became the Long Valley caldera. U-Pb dating of 307 spots from all zones in crystals from all samples yields a strongly unimodal age spectrum, with a mean age of $794+/-3 \mathrm{ka}(10$ spots rejected, MSWD $=2.0)$. CL images of the dated zircon suites show the appearance of bright-rimmed zircons in later-erupted ignimbrite packages (accompanied generally by bright-rimmed sanidine and quartz crystals), but with diversity in the proportions of the bright-rimmed zircons and the thicknesses of the rims. Diverse zircon CL patterns between the Ig2N and Ig2NW units implies that zircon growth 
regimes varied along the northern caldera rim, and indicate the presence of geographic variation in crystals across the Bishop Tuff magma body. Trace element analyses of the 'standard' Bishop non-rimmed sector-zoned zircons show strong variations in contents of elements including $\mathrm{U}, \mathrm{Th}, \mathrm{P}$ and Ti between dark and light sectors in growth zones of the same age (as indicated by subordinate oscillatory zoning). This study highlights the importance of examining samples which span the entire eruptive sequence, and illustrates lateral variations in the magma body which add complexity to the pre-existing 'early' versus 'late' contrasts emphasized by many workers. 


\section{A3.3 Goldschmidt 2013- Poster Presentation}

Combined diffusion studies in sanidine, quartz and orthopyroxene: Timescales of magma mixing in the Bishop Tuff

K. J. Chamberlain ${ }^{1}$; D. J. Morgan ${ }^{2}$; C. J. N. Wilson ${ }^{1}$

1:SGEES, Victoria University of Wellington, New Zealand

2: SEES, University of Leeds, UK

The $\sim 0.76 \mathrm{Ma}$ Bishop Tuff (eastern California) is an archetypal product of a compositionally stratified magma chamber. A key issue regarding the evolution of the meltdominant magma body that has arisen from recent studies involves understanding the nature and timing of late-stage mixing with a compositionally contrasting melt. This melt is reflected, for example, in the CL-bright rims on quartz and Sr- and Ba-rich rims on sanidine reported in ignimbrite samples erupted from vents along the northern caldera rim $[1,2,3]$.

We use ternary feldspar thermometry combined with 1D diffusion models to calculate timescales for diffusion of key elements in three crystal phases of the Bishop Tuff. We show that $\mathrm{Sr}$ in sanidine, $\mathrm{Fe}-\mathrm{Mg}$ in orthopyroxene and $\mathrm{Ti}$ in quartz all indicate mixing timescales of $<150 \mathrm{yrs}$, in contrast to the $\sim 2000 \mathrm{yr}$ timescale from $\mathrm{Ba}$ in sanidine. The anomalously long timescales obtained from $\mathrm{Ba}$ diffusion in sanidine have implications for the application of this chronometer to low- $\mathrm{T}\left(\sim 800^{\circ} \mathrm{C}\right)$ rhyolitic systems. The short timescales modelled indicate that the "contaminant" magma causing the growth of these rims was a relatively transient feature in the $\sim 70 \mathrm{kyr}$ history of the melt-dominant magma chamber [4].

[1] Anderson et al. (2000) J. Pet. 41 449; [2] Peppard et al. (2001) Am. Min. 86 1034; [3] Wark et al. (2007) Geology 35 235; [4] Chamberlain et al. (2014) J. Pet. 55395. 


\author{
A3.4 GeoNZ 2013: Oral Presentation \\ Diffusion profiles in sanidine, orthopyroxene and quartz: timescales for priming of the Bishop Tuff \\ eruption, California \\ K.J. Chamberlain ${ }^{1}$, D.J. Morgan $^{2} \&$ C.J.N. Wilson ${ }^{1}$ \\ 1:SGEES, Victoria University of Wellington, New Zealand \\ 2: SEES, University of Leeds, UK
}

The $0.76 \mathrm{Ma}$ Bishop Tuff (Long Valley, eastern California) is an archetypal product of a compositionally and thermally stratified silicic magma chamber. The presence of a latestage compositionally distinct melt in Bishop deposits is recognised in, for example, CLbright rims on quartz and $\mathrm{Sr}$ - and $\mathrm{Ba}$-rich rims on sanidine in material erupted from vents along the northern caldera rim [1,2,3]. Two key questions in understanding the evolution and evacuation of the Bishop magma chamber are: to what extent did mixing with the compositionally distinct magma contribute to the compositional and thermal zoning, and what effect did the mixing have on magma chamber stability?

Here we present two-feldspar thermometry from samples throughout the Bishop Tuff to test against previous Fe-Ti oxide and oxygen-isotopic thermometry [4,5]. We use our new thermometry estimates to conduct 1D diffusion modelling of $\mathrm{Ba}$ and $\mathrm{Sr}$ in sanidine, Ti in quartz and Fe-Mg interdiffusion in orthopyroxene from all samples where zoning resulting from the mixing event was preserved. Timescales from diffusion modelling of Ti in quartz, $\mathrm{Fe}-\mathrm{Mg}$ in orthopyroxene and $\mathrm{Sr}$ in sanidine all yield results of $<150$ years between magma mixing and eruption, contrasting markedly with the longer-lived history delineated from U$\mathrm{Pb}$ dating of zircons [5,6]. Notably, however, timescales from $\mathrm{Ba}$ diffusion in sanidine are 1-2 orders of magnitude longer than the other element/mineral combinations. These anomalously long timescales raise questions about applicability of this geospeedometer in low $\mathrm{T}\left(<900{ }^{\circ} \mathrm{C}\right)$ silicic systems.

[1] Anderson et al., 2000 J. Pet. 41 449; [2] Peppard et al., 2001 Am. Min. 86 1034; [3] Wark et al., 2007 Geology 35 235; [4] Bindeman \& Valley, 2002, CMP 144 185; [5] Hildreth \& Wilson, 2007, J. Pet. 48 951; [6] Simon \& Reid, 2005, EPSL 235 123; [6] Chamberlain et al., 2014, J. Pet. 55395. 


\section{A3.5 GeoNZ 2013: Poster Presentation}

The Bishop Tuff: product of one or two magma chambers?

K.J. Chamberlain ${ }^{1} \&$ C.J.N. Wilson ${ }^{1}$

1:SGEES, Victoria University of Wellington, New Zealand

The 0.767 Ma Bishop Tuff (Long Valley, California) is an archetypal supereruption, and has been extensively studied as a case study of the products of a single compositionally and thermally zoned magma chamber. However, recent work using Rhyolite-MELTS modelling and silica-in-melt-inclusion barometry has proposed that the Bishop Tuff compositions do not show a systematic range in pressures [1]. This work is combined with the notion that Bishop phenocryst chemistry is bimodal and used to suggest that there were two Bishop magma chambers, erupted consecutively [1] as with the Kidnappers fall deposit, (Mangakino, TVZ) [2].

Here we present major and trace element analyses from all major crystal phases and associated glass in the Bishop Tuff, inferred to be the inverted products of the magma chamber [3]. These samples reflect our systematic collections throughout the Bishop Tuff deposits, from the earliest fall unit (F1) to the latest ignimbrite units $(\operatorname{Ig} 2 \mathrm{NWb}, \operatorname{Ig} 2 \mathrm{Nc})$ and including the less widely studied units (e.g. Sherwin Grade \& Ig2Na). We show that glass chemistries represent a continuum, and highlight the transitionary role of ignimbrite unit Ig2 $\mathrm{Na}$ in chemical and textural changes from earlier-erupted ("eastern-type") deposits to later erupted ("northern-type") deposits. The apparently bimodal nature of phenocryst chemistry reflects core-rim relationships in single crystals, and represents late stage introduction of a less-evolved rhyolite, which causes overgrowth of compositionally distinct rims. With careful sampling of the full eruption sequence, it is apparent that the Bishop Tuff does indeed represent a continuum in compositions, derived from a single magma chamber, zoned in composition, temperature and pressure, as previously suggested $[3,4,5]$.

[1] Gualda \& Ghiorso 2013, CMP 166 755; [2] Cooper et al. 2012, EPSL, 313-314 23; [3] Hildreth 1979, GSA Spec. Pap. 180 43; [4] Wallace et al. 1999, JGR 104 20097; [5] Hildreth \& Wilson 2007, J. Pet. 48951. 